SELECTA

\title{
FUNGORUM CARPOLOGIA.
}

III. 
" Le champ est grand et ouvert à ceux qui voudront y faire gerbe; il y en reste plus "que l'on n'en a moissonné."

(Guy de la Brosse, De la Nature, Vertu et Utilité des Plantes [1628], p. 2.) 


\section{SELECTA}

Folio
Qk623
A1
T84
1865
vol. 3

\section{FUNGORUM CARPOLOGIA,}

EA DOCUMENTA ET ICONES POTISSIMUM EXHIBENS

QUE VARIA FRUCTUUM ET SEMINUM GENERA IN EODEM FUNGO

SIMUL AUT VICISSIM ADESSE DEMONSTRENT.

JUNCTIS STUDIIS EDIDERUNT

\section{LUDOVICUS-RENATUS TULASNE,}

academia scientiarum parisine, monacensis, taurinensis et Cesafee leopoldino-garoline nature curiosorum sodalis;

probotanicus in mUse parisiensi historie NatURalis, C.ET.

ET

CAROLUS TULASNE,

MEdicine doctor in Fagultate parisiensi;

TURONES FRATRES.

\section{TOMUS TERTIUS.}

NECTRIEI. - PHACIDIEI. - PEZIZEI.

ACCEDUNT TABULE XXII ERE INCISA.

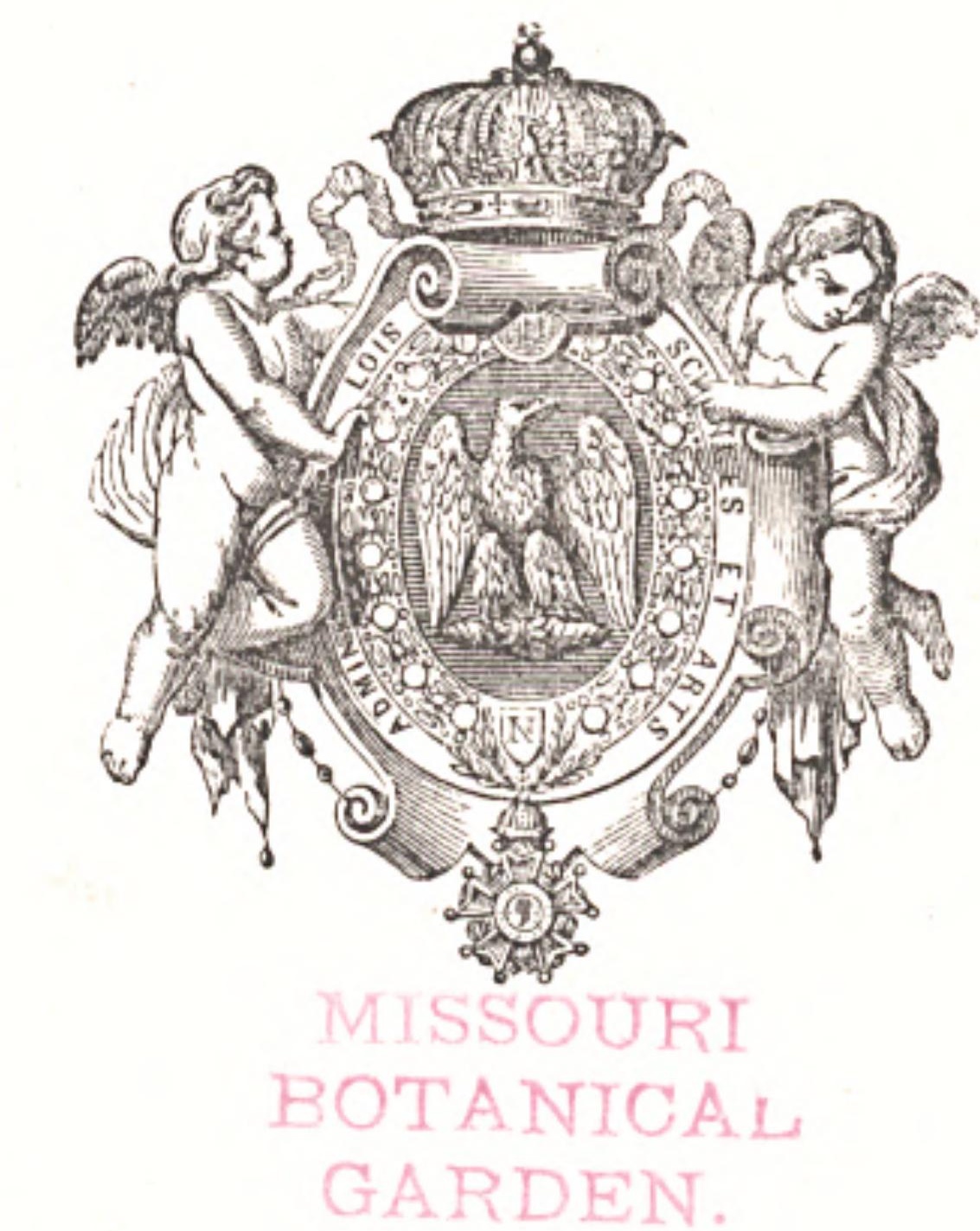

PARISIIS,

IMPERATORIS JUSSU,

IN IMPERIALI TYPOGRAPHEO EXGUDEBATUR.

M DGGG LXV. 
"De omni re el in omni scientia, utilitatis fructum atque DEI laudem et honorem quærere.

(De Imit. Chr. III, LIv, 17.)

"Iัm $\mathfrak{B a l d}$ unt Felo, auf Bergen und in Brintoen,

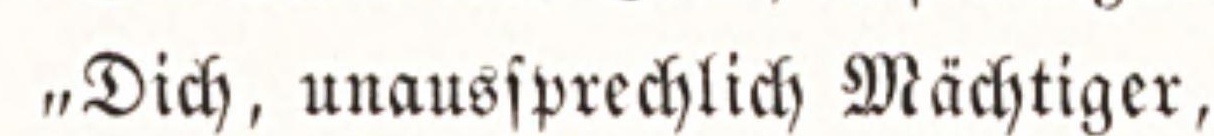

"Itnenolich guter, Gerrlicher,

"Bott, aller $\mathfrak{S e l t e n}$ (bott, Didf futchen und Did) finden!"

(Tode, F. Meckl. sel. 1.) 


\title{
VIRO DOCTISSIMO
}

ET ILLUSTRISSIMO,

\section{ADOLPHO THEODORO BRONGNIART,}

\author{
AGADEMIE SGIENT. PARISINA SOCIO, \\ REI BOTANICE IN MUSEO HISTORIE NATURALIS PROFESSORI, CET. \\ QUI VEL IN MINIMIS MYCOLOGICAM SCIENTIAM
}

SUIS PROMOVERE DISQUISITIONIBUS OLIM NON DEDIGNATUS,

IPSORUM IN EADEM ARTE

STUDIORUM PRIMITIAS BENIGNISSIMUS ACGEPIT,

ULTIMAM HANC OPERIS PARTEM,

EO AUSPICE SUSGEPTI, EO FAUTORE ABSOLUTI,

IN GRATI PIIQUE SEMPER ANIMI HUMILLIMUM TESTIMONIUM,

DICATAM VOLUNT

AUCTORES. 
"Fungorum notitia hominibus summe est necessaria."

$$
\text { (Linn. Cui Bono? [1752], \$ vII.) }
$$

- Studium... Fungorum ad usum æque ac oblectamentum accommodatum esse nobis suaviter blandimur. "Ut œeconomiæ insigne incrementum dedere fungi alibiles sapidique, ita artis medicæ armarium augere "valent alii, quo nemine fungi quidem alias noxii, modo rite adhibiti, spernendi sunt; animi vero oblecta-tionem cupientibus eandem fere quam coronamenta omne genus, præstant fungorum non pauci jucundi"tatem, utpote qui curiosius inspecti formarum diversitate, colorisque fulgore et lusu, multifariam oculis "offerunt voluptatem." 


\section{PROOE M I I.}

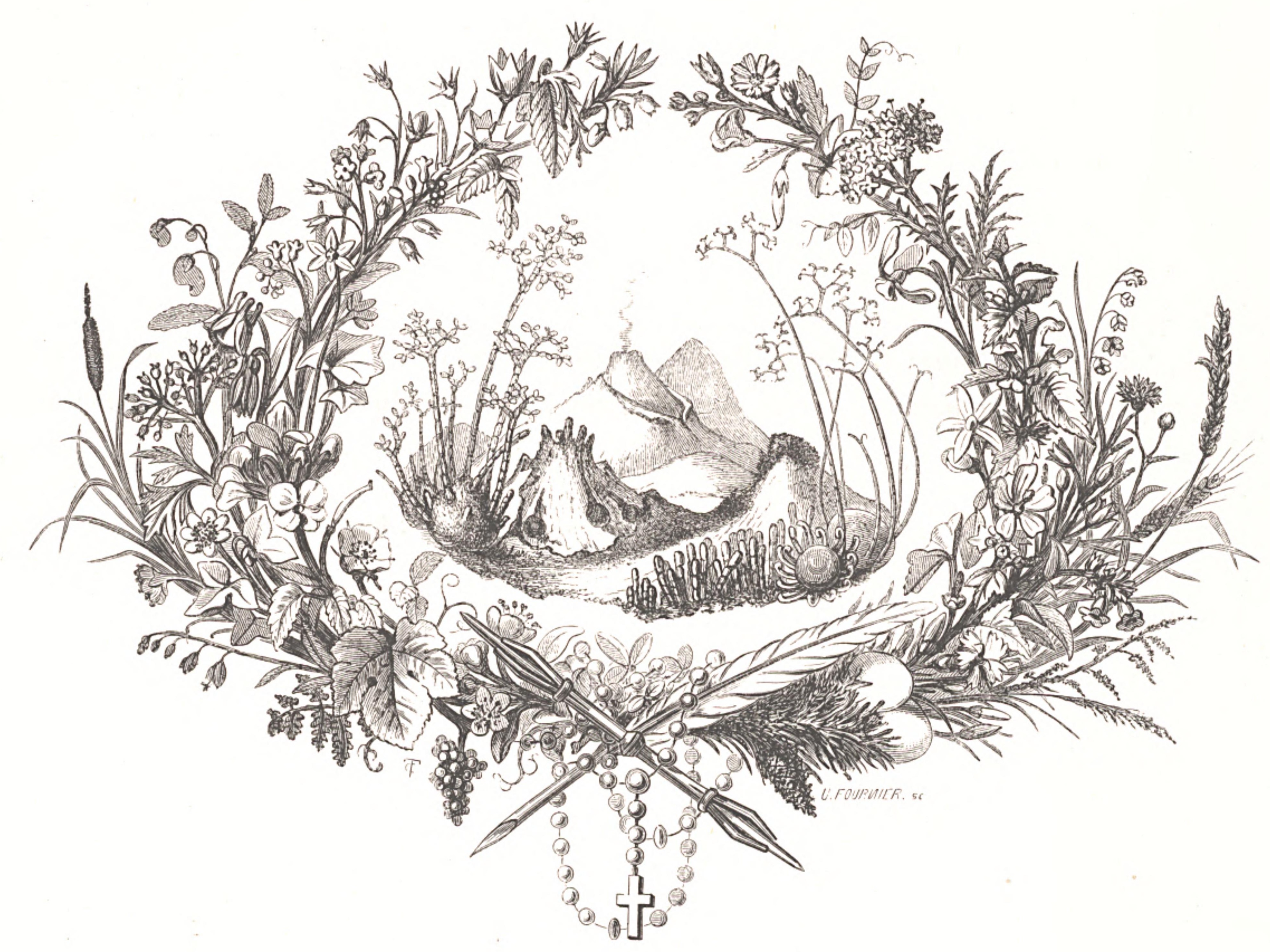

"Benedicite omnia opera Domini Domino, laudate et superexaltate eum in sæcula."

(DAN. III, 57 .) 
"Nihil... in tota rerum natura levidense despiciendumve, sed omnia quæ potentia divina condidit et «conservat contemplatione dignissima . . . cum rerum creatarum nostro judicio minimæ perinde ac maximæ "sua habeant miracula."

(Носмsк. Coryph. [ed. Pers.], p. 3.) 


\section{LECTORI BENEVOLO}

S. P.

Qui libros texere non veretur, etiamsi jam plurimis non habeatur novus, æore in opusculi sui limine continetur quin salutem optato lectori dicat. Assuetam scriptorum humanitatem hodie libenter iterum imitamur, quamvis id minime necessarium arbitremur compendiosam libri nostri rationem, præter ejus elenchum, proponere. Satis enim, ut opinamur, seipsum explicat. Causa ideo alia movemur cur lectoris favorem præoccupemus; et ea ipsa est quæ auctorem habet sollicitum ne suorum opinione minus effecerit. Anxios enim nos tenet nimia tomi hujus, præ antecedentibus, tenuitas, et hoc duntaxat inopiæ nostræ solatium est quod ne unicam quidem pagellam præmissis addere, ni DEO optimo placuisset, valebamus. Quum autem vereremur ne deficerent vires si longius progredi tentaremus, iter susceptum quodammodo nos exegisse, nec diutius esse cunctandum quin imprudenter promissa solveremus, nobis visum est; itaque librum nostrum integrum et qualemcunque, nec per partes, quod facere primum cogitabamus, proferendum decrevimus. Selectam igitur nostram Fungorum Carpologiam, egregia arte fratrum Picart magnifice, 
hodie etiam, illustratam, nunc absolvisse, et circa doctrinam de multiplici fungorum foecunditate satis justam documentorum copiam attulisse, nobis concessum iri confidimus. Olim profecto bene multi venient quibus nactam scientiam confirmare et amplius explanare curæ erit; imo jam nunc sunt qui mirum in modum connituntur ut vera rerum notitia in dies magis ac magis augeatur. Porro, Libelle, velis, nolis, nunc lucis periculum adeas, tempus instat, saltim propter molem non segnis eris, at quid quæris? Modica tua tibi modesto placeant; quidquid nobis in schedis superest, confiteri nobis dolet, magis mancum restimamus quam ut exiguitati tuæ digne succurrere valeat; nec dicas tamen auctores reliquam vitam otio languere secum constituisse, testare potius nil ipsis semper antiquius fore quam ut residuam oculorum aciem, pro posse, ad majorem DEI gloriam impendant, in contemplandis et humiliter interpretandis prodiöis illis vivis, quanquam funginis, quibus nos his in terris exules recreare Ille misericors dionatus est.

Tu autem, Lector amice, iis quæ nunc præstamus, quamlibet paucissima sint, nobiscum indulgenter utere, plura rero et meliora nobis olim referas. Vale.

Dabamus Cavillæ ad Versalias, vг idus septembris, a. S. MDCCCLXV. 


\section{ELENCHUS.}

PROOEMIUM . . . . . . . . . . . ELENCHUS CORRIGENDA et ADDENDA

V. NECTRIEI.

Sect. I. Nectrici caulescentes, conidiis seu protosporis modo (scilicet apud Torrubias) in monilia verticillata aut capitula digestis, tandemque solutis et pulvereis, modo contra (ap. Clavicipites) in apparatu carnosulo, gyroso-cerebrino generatis et cum latice viscoso diffluentibus. - Principes.

I. TORRUBIA Lev. (tab. I et iI ).... . . 1. Entomogence seu Torrobia sinceriores. a. Clavatie aut spiciformes.

1. Torrubia militaris $\left(V_{\text {alll. }}\right)-($ tab. 1 , fig. $19-31) \ldots \ldots \ldots \ldots \ldots \ldots$

Obiter mentio fit (p. 10 ) Melanosporce nostræ parasiticae (tab. III, fig. 11-14).

2. T. sobolifera (Hill. et Wats.) (tab. I, fig. 32 et 33$) \ldots \ldots \ldots \ldots$

Paucis etiam agitur (p. 11 et 12 ) de Torrubia nostra cespitosa, Isaria Cicada Miguelio et Torrubia Melolonthe nob.

3. T. Sphingum (Schw.) - (tab. i, fig. 1 et 2$) \ldots \ldots \ldots \ldots \ldots \ldots$ b. Capilate.

4. Torrubia entomorrhiza (Dicks.) (tab. I, fig. 12-18) .......... 14

5. T. cinerea Tul. (lab. I, fig. 11)... $\quad 16$

6. T. sphecocephala (Klotz.) - (tab. I, fig. $5-9) \ldots \ldots \ldots \ldots \ldots \ldots$

7. T. unilateralis $\dagger$ (tab. I, fig. 3 et 4). 18

8. T. coccigena $†($ tab. I, fig. 10$) \ldots . .19$

2. Mycogenas s. Cordylie vera nobis.

a. Claviformes.

9. Torrubia ophioglossoides (Енrh.) (tab. II, fig. 1-9)............ b. Capitalce.

10. Torrubia capitata (Pers.) - (tab. il, fig. $10-15) \ldots \ldots \ldots \ldots \ldots \ldots$

Sect. II. Nectriei modo carnosi tuncque pulvinati aut tenuiter stratiformes, nunc contra sed rarius byssini et effusi; conidïs unius vel duplicis generis, minoribus solitarie acrogenis aut verticillatis. - . HYPOCREACEI.

II. EPICHLOE Fr. ......... 24

Epichloe typhina Fr........... 24

Data occasione proponitur Hydnopsis nostra (p. 26), ejusque typi duo describuntur, nempe Hydnopsis Eugenice (p. 26 ) et H. graminicola (p. 28); Spheria perispheria $\dagger$, ibidem, pancis nota fit.

6 , 
III. HYPOCREA Fr. (tab. III et Iv)... . a. Pulvinatex.

1. Hypocrea rufa (Pers.) Fr. (tab. ili, fig. $1-10) \ldots \ldots \ldots \ldots \ldots \ldots$

b. Effusa, byssince s. membranacece.

2. Hypocrea deligatula Tul. (tab. iv, fig. $\left.7_{-1} 3\right) \ldots \ldots \ldots \ldots \ldots \ldots$

c. Parasitice, gregatim subiculo vivo immersa.

3. Hypogrea alutacea (Pers.) Tul. (tab. Iv, fig. $1-6) \ldots \ldots \ldots \ldots \ldots \ldots$

IV. HYPOMYGES (Fr.) Tul. (tab. v-Ix). .

1. Macroconidia simplicia vel polymera, semper autem ex utriculis globosis ac scepius verrucosis facta, hisce insuper in seriem linearem aut globum coalitis.

* Macroconidiorum articulis in seriem ordinatis.

1. Hyfomyces ochraceus (Pers.) Tul. (tab. vi, fig. 19 et 20 , et tab. vir) . . . .

.. H. Linkit Tul . . . . . . . . . . .

3. Н. rosellus (Alb. et Schw.) Tul. (tab. $v$ et tab. vi, fig. 1-18) .... .

4. H. chrysospermus (Bule.) Tul. (tab. viII, fig. $1-13) \ldots \ldots \ldots \ldots \ldots$

5. H. cervinus (Ditu.) Tul. . . . . . .

* Macroconidiorum articulis in globum coalitis.

6. Hyponyces Pezize (Corde) Tul....

2. Macroconidia ovata v. oblonga, simplicia, solitaria vel in series catenata.

* Macroconidiis verrucoso-asperatis.

7. Hypomyges asterophores (Fr.) Tul.

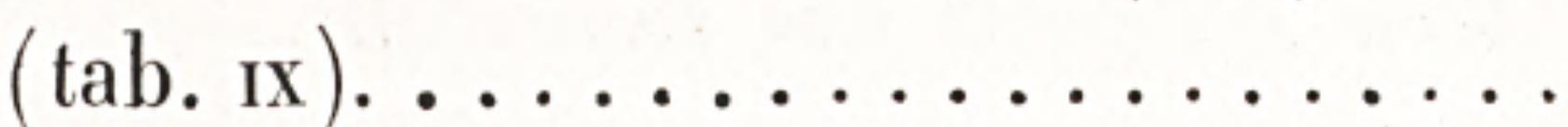

** Macroconidiis levibus.

8. Hypomyces luteo-virens (Fr.) Tul. (tab. viII, fig. 14-16) . . . . . .

9. H. Baryanus Tul. . . . . . . . .

10. H. chlorinus Tul. (tab. vili, fig. 17 ).

1 1. H. violaceus (Schim.) Tul........

12. H. Decipiens †...........

3. Macroconidia nulla vel ionota.
13. Hyponyces lateritius (Fr.) Tul .... 14. H. aUREo-nitens $† \ldots \ldots \ldots \ldots$ 62 64

Sect. III. Nectriei pulvinati vel columelliformes, quandoque etiam sine stromatis vestigio sparsi; conidiis nudis, unius modi aut genere diversis, vulgo ex ramusculis solutis aut articulis dissociatis, pycnidiis microspermis seu spermogonïs longe rarioribus. - EunectrieI s. NeCtrieI GENUINI.

V. NECTRIA Fr. (tab. x-xiII) . . . . . .

1. Corticicola vel lignicolat.

a. Conidiis modo unius modi, lunulatis aut rarissime prosthemieis, nunc contra bifariis et incequalibus, majoribus in arcum curvatis; spermatiis, curvis et exilissimis, interdum accedentibus; peritheciis sxpius caspitosis, quandoque tamen sparsis. - FusarieLLE.

* Conceptaculis caspitosis, atro-caruleis.

7. Negtria cinnabarina (Tode) Fr. (tab.xil).

Obiter etiam describitur, p. 82, Spheria cupularis Pers. (tab. XIII, fig. 14-21).

8. N. miltina Mntgn.............

c. Conidiis vulgo deficientibus, conceptaculis autem bifariis et in utroque genere ascophoris. - Cugurbitule.

9. Nectria Cugurbitula (Tode) Fr..... 10. N. Aquifolit (Fr.) Tul. (tab. x, fig. $13-19) \ldots \ldots \ldots \ldots \ldots$ 
d. Conidiis sinceris ut videtur nullis ; fructibus caspitosis et disparibus, aliis nempe spermogonieis et multiloculatis, aliis simplicibus et ascophoris. - SINOFEE.

1 1. Negtria sinopica Fr. (tab. xi, fig. 1 $10) \ldots \ldots \ldots \ldots \ldots \ldots$

2. Fungicola ; conidiis variis aut nullis; peritheciis crespitosis vel sparsis. - CosMarie seu Cosmospore.

12. Nectrita epispheria Fr..........

13. N. cosmariospora DN $\mathrm{DN}_{\mathrm{Tr}}$. et Cies.....

3. Foliicole, conidiorum apparatu vario, peritheciis sparsis, nudis vel setigeris.

* Stromate subrullo vel inconspicuo, peritheciis autem glabris vel tomentellis. NEGTRIELLE.

14. Nectria pyrochroa Maz. ........ 15. N. carnea Desm. ............ 96

** Stromate conceptaculisque setigeris. Chetostroma Corde.

16. Negtria Russeliana Mntgn.........

VI. SPHAROSTILBE Tul.(tab. xiII et xiv).

1. Conidiis ovatis, brevibus et rectis. StILba proprie dicta.

1. Spherostilbe aurantiaca (Babingt.) Tul. (tab. xiv, fig. 1-13) . . . . .

2. S. gracilipes Tul. (tab. xiv, fig. 14-19)

3. S. cinnabarina (Mntgn.) Tul........

2. Conidiis lineari-lanceolatis et arcuatis. Atractia Linkit.

4. Spherostilbe flammea (Berk. et Rav.)

Tul. (tab. XIII, fig. 10-13) . . . . .

5. S. coccophila (Desur.) Tul........

Hic etiam traditur (p. 107) character Valsa nostræ chrysoidis ( tab. III, fig. 15 et 16$)$.

NOTE

VI. PHACIDIEI

l. HYSTERIUM Tod. (tab. xvi) ......

Hysterium Pinastri Schrad. (tab. xvi, fig. $1-3) \ldots \ldots \ldots \ldots \ldots \ldots \ldots$
II. RHYTISMA Fr. (tab. xv et xvi) . . . . 115

* Endosporis filiformibus seu linearibus. EURHYTISMATA.

1. Rhytisma acerinum Fr. (tab. xv, fig. 9-

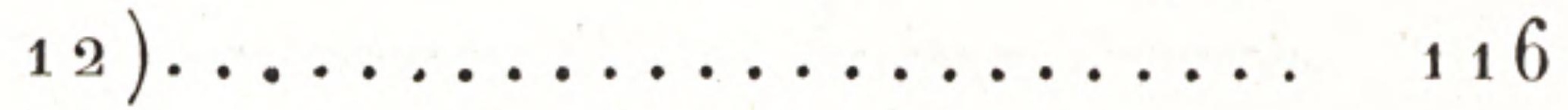

2. R. salicinum Fr. (tab. xv, fig. 13-22). 119

** Endosporis late ovatis. - CRYptomycetes Grev.

3. Rhytisma maximum Fr. (tab. xvi, fig.

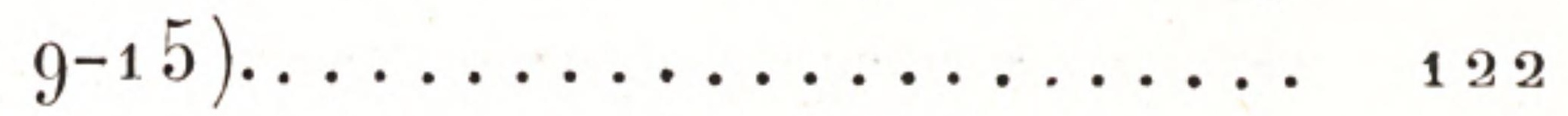

III. STICTIS Pers. (tab. xvi et xviII) . . $\quad 125$

* Endosporis cylindricis et curvulis. Propolis Fr.

1. Stictis cineracea s. cinerascens Pers.

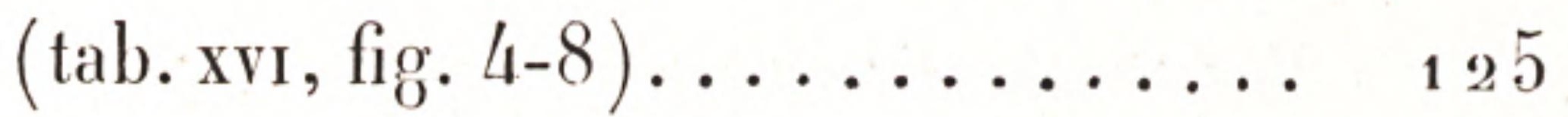

** Endosporis ovatis, incequilateris, crassioribus. - Ocellaria nob.

2. Stictis ogellata (Pers.) Fr. Tul. (tab. xviri, fig. $1-10) \ldots \ldots \ldots \ldots \ldots \ldots{ }_{12} 8$

IV. PHACIDIUM Fr. (tab. xv) ..... $131_{1}$

* Endosporis linearibus. - Lophodermia DNTrs. partim.

1. Phacidium dentatum Schm. et Kze.... 132

2. P. coronatum Fr.......... 134

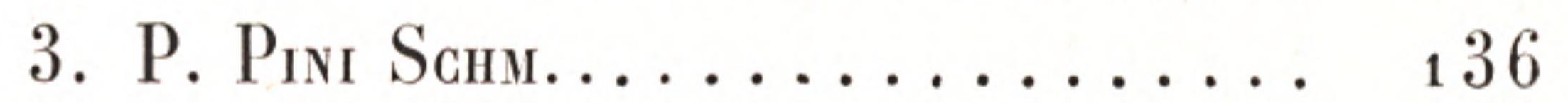

** Endosporis ovatis. - Phacidia sincera DNTrs.

4. Phacidium Ilicis Lib. Maz. (tab. xv, fig. $1-8) \ldots \ldots \ldots \ldots \ldots \ldots \ldots \ldots$

VII. PEZIZEI.

Sect. I. Conidia, si qua sunt, e stromate nata. Fructus saltem biformes; omnes, cujuscunque sint generis, initio clausi et conceptaculiformes. - - HETEROPEZIZE.

I. SCHIZOXYLUM Pers........... $1 / 48$

Schizoxylum sepincola Pers......... 148

II. TYMPANIS (Fr.) DNtrs. (tab. xix). . 150

1. Tympanis Pinastri (Pers.) nob. (tab. xix, fig. $10-12) \ldots \ldots \ldots \ldots \ldots \ldots 151$ 
2. T. Ligustri nob............ . 154

III. DERMATEA Fr. (tab. xix) . . . . . 155

* Dermatece sinceriores, stylosporis linearilanceolatis, arcuatis aut flexuosis, endosporis continuis. - EUDERMATEE.

1. Dermatea Cerasi Fr. (tab. xix, fig. 13 $17) \ldots \ldots \ldots \ldots \ldots \ldots$

2. D. seriata (Fr.) Tul..........

** Typi recedentes, seminibus longe crassioribus et utrinque obtusis, stylosporis scilicet rectis curvatisve, endosporis rectis et quandoque septiferis. - Dermatelle.

3. Dermatea Frangule (Pers.) Tul.... 161

IV. CEnangiUM Fr. (lab. xix et xx) . . 163

* Endosporis linearibus et septiferis. SGLeroderris (Fr.) DNtrs.

1. Cenangium Ribis Fr. (tab. xix, fig. 1-9).

2. C. fuliginosum Fr. (tab. xx, fig. 1-4).

** Endosporis ovatis et continuis. - CLIthris Fr.

3. Cenangium ferruginosum Fr. . . . . .

4. C. ligni Desmaz. (tab. xx, fig. 5-7).

*** Cupulis amplis, membranaceis, late repandis et undulato-rugatis; endosporis breviter lineari-cylindricis, curvulis. Pezize seu Dermatee Encoelie Fr.

5. Cenangium Ulmi $†$ (tab. xix, fig. 18 $22) \ldots \ldots \ldots \ldots \ldots \ldots$

V. HETEROSPHERIA Grev. (tab. xviII).

Heterospheria Patella Grev. (tab. xvili, fig. $16-22) \ldots \ldots \ldots \ldots \ldots \ldots \ldots$

VI. DURELLA (Fr.) Tuı. (tab. $x x$ ) . . . .

Durella compressa (Pers.) Tul. (tab. xx,

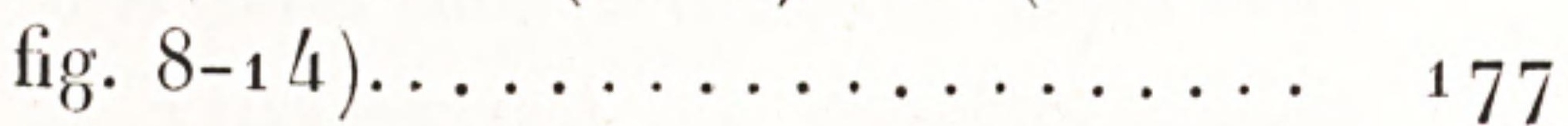

VII. TROCHILA Fr.
1. Trochila Craterium Fr........ 180

2. T. S S

VIII. PEZICULA $\dagger($ tab. xv $) \ldots \ldots \ldots \ldots \quad 18_{2}$

1. Pezicula Coryli Tul........... 183

2. P. amoena Tul. (tab. xv, fig. 1-9)... 184

3. P. dissepta Tul. (tab. xv, fig. 10-14). 186

IX. ChlorospleniUM Fr. (tab. xx) . ${ }_{1} 8_{7}$ Chlorosplenium aruginosum (OEd.) Fr. (tab. xx, fig. 15-19)........ 187

X. CORYNE (Nees) nob. (tab. xvir et xviII). $\quad 190$

1. Coryne sarcoides (Pers.) nob. (tab. xvII, fig. $1-8) \ldots \ldots \ldots \ldots \ldots \ldots$

De Bulgaria inquinante $\mathrm{F}_{\mathrm{R}}$. (tab. nostra xvir, fig. 9 et 10 ) obiter tractatur, p. $19^{2}$ et 193 .

2. Coryne virescens nob. (tab. xuin, fig. $12-15) \ldots \ldots \ldots \ldots \ldots \ldots \ldots \ldots$

XI. CALloria Fr.............. . 195

Calloria fusarioides (Berk.) Fr...... 195

Calloria Erythrostigma (Mntgn.) Fr. ad Nectrias potiori jure, ut videtur, trahitur (p. 196).

XII. PYRONEMA Caro, Neesio cæt. (tab. xvir $) \ldots \ldots \ldots \ldots \ldots$

Pyronema confluens (Pers.) nob. (tab. xvit, fig. 11 et 12$) \ldots \ldots \ldots \ldots \ldots$

XIII. PEZIZA Pers. Fr. (tab. xvi et xxiI).

Agitur in primis de Pezizis sclerotiogenis ut tuberosa Bullardo, Duriceana nostra et Curreiana Berkelei ; P. diplocarpa Curr. describitur et pauca super Geo${ }_{\sigma}^{g}$ lossis, Spathularia et Morchellis afferuntur (p. 198-201).

INDEX fungorum omnium qui in tomo tertio citantur vel describuntur..... 207 TABUL $E \ldots \ldots \ldots \ldots \ldots \ldots 2_{2} 3$ 


\section{GORRIGENDA ET ADDENDA.}

Pag. 56, lin. 2, ab ima pağ. lege Sphceroncema nec Sphceronema.

Pag. 203, lin. 17, lege Batsch, nec Bolt.

Cætera menda quæ nec tollendi, nec quidem indigitandi nobis suppetit facultas, lectori attento et benevolo corrigere curæ sit.

Quum jam prope esset ut librum hunc absolveremus, clariss. H. Lucas, quo viro insectorum scientiæ peritissimo jampridem grati utimur, a D. Carolo Coquerel, medicinam in metropoli insulæ Borboniæ excolenti, quoddam Sphingis genus , scil. Deilephilam Esonem Craneri, tum crusta fungina partim illitum, tum spinulis gracilibus paris naturæ, i. e. torrubieis, undique horrens, accepit. Crusta et setæ vel spinulæ insitæ quæ colore dilute citrino similiter fucantur. perithecia ascophora nondum genuerunt; easdem vero gemmis minimis seu conidiis globosis obrutas viderit C. Coqurres, cujus enim cura et opere concinna suppetit icon quæ fungillum Penicilliorum more seminiferum exprimit. Nunc ideo compertum habemus Torrubiam Sphingum Schw. (infra, p. 12, descriptam) in terris Mascarenis etiam vigere, nosque flagella ejus sterilia quorum mentionem fecimus, non præter naturam fuisse interpretatos.

Quæ sequuntur ad Hypocream (pag. 29) spectant. Symbolum generis hujus præcipue ex peculiari endosporarum natura ductum, minime præ se fert Hypocrea Vitalba BЕrк. et Br. (in Ann. and Mag. of nat. Hist. ser. III [1859], tomo III, p. 363 , n. 829 , tab. Ix, fig. 8); licet enim quidquam gelatinosæ indolis ea ostendat, a sinceris tamen Hypocreis nostris ob endosporas lineari-lanceolatas, vulgo tetrameras, appendiculatas, curvulas nec, ut videtur, rite partiles, longe recedit. Id fungilli præterea pycnidiis insigniri admodum legitimis, sæpius emersis et stylosporas conspiratas foventibus quæ endosporas fabrica prorsus mentiantur, nuper cognovit plantulæ sagacissimus inventor, C. E. BroonE, qui nos rei autoptas fieri benignus permisit. Pycnidia solitas quæ dicuntur Hendersonias imitantur.

lis quæ pag. 190-1 $9^{3}$ circa Corynes nostræ prototypum, sarcoidem scilicet, afferuntur, addere juvat ill. Friesium nunc (nimirum in sua Monographia Hymenomycetum Suecice, t. alt. [1863], p. ${ }_{2} 67$ et 268) minime dubitare Corynem sarcoidem Corde statum esse sterilem Peziza sarcoidis Persooni, quam necessitatem, Sch zfrero olim vix prætervisam, pro certa ille nondum habuerat; ita ut, judice eodem magistro upsaliensi, fungillus noster Ombrophila sarcoides meritissime diceretur. (Cfr. enim illius Summ. Veget. Scand. p. 341, nota 3, de Tremella sarcoide, et p. 358, nota 1, de Bulgaria? 
sarcoide.) Iterum etiam Dacryomycetes plurimos e Callorïs recentibus, imperfectis, originem suam trahere contendit (Monogr. Hymenomycetum Suec. prælaudatæ l. citatis).

Super Peziza diplocarpa Currai de qua verba fecimus p. 199, adnotetur reverend. Berkeleum et Broomeum nuper non dubitasse quin paraphysium apices sporomorphos pro stylosporis solitariis habuerint; item stylosporas origine pares, minime vero solitarias, in Ascobolo vinoso Вевк. iidem magistri observasse declarant, conidia autem amorpha in summis paraphysibus Patellarice olivacece Batsch. (Cfr. Ann. and Mag. of nat. History, ser. III, t. XV [1865], p. 445, 447 et 448 , tab. xv, fig. $22, b$, et tab. xvi, fig. $25, c, d$.) 
V.

NECTRIEI. 


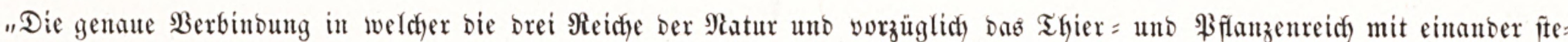

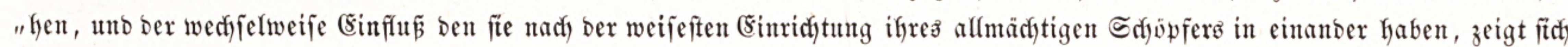

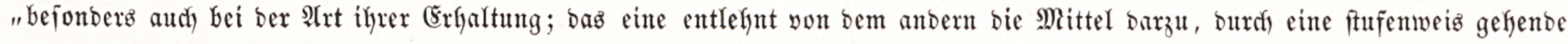
"Beränderung werben bie Beftandtheile ber \$ffanzen wahre Beftanbtheile bes thierifichen Rörders, uno von ben zeriturten uno ver

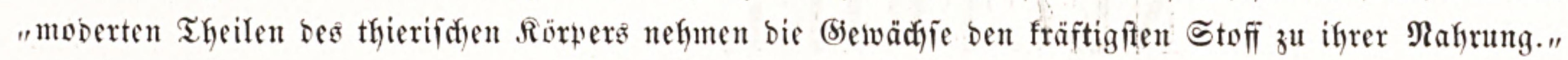

(J. F. GmeLin, Betrachtung der pflanzenartigen Fliegen [1774], \$ 1.) 


\section{NECTRIEI.}

Nectriei conidiophori, imperfecti, a b. Persoonio dispertiuntur per varia NAMATOTHECIORUM (fungorum scilicet byssinorum) suorum, GYMNOSPERMORUM et SCLEROCARPORUM genera; a Friesio autem et innumeris ejus discipulis inter DISCOMYCETES, GASTEROMYCETES, et maxime quum GYMNOMYCETES, tum etiam HAPLOMYCETES; - fungi contra iidem perfectiores seu ascigeri, apud priorem magistrum inter SPherias-XYLarias, SPHerias compositas et caspitosas (Syn. Fung.), aut inter Monostichas et Epistromata (F. Edul.p. 54) computantur; Hypocreas Cordicipitum et $S_{\text {Pheriardm }}$ pulvinatarum, simulque typos nonnullos ex $S_{P H}$ eris caspitosis et bysisedis olim Friesio (Syst. Mycol. t. II) sistebant, nunc eidem (S. Veget. Scand.) et asseclis Cordicipites, Hy pocreas et Nectrias; denique sub HYPOCREACEORUM titulo a clar. Notarisio congregantur, tum ap. Parlaтов Is Ephem. Bot. Italam, anno I, tomo alt. $(1844)$, p. 47 et seq. tum etiam recentiori tempore in Comment. Soc. Cryptog. Itala, fasc. IV, p. 191-196, et suis Sphariaceis Italicis, cent. I (1863), p. 1 et seq.

Nectriei pyrenonycetes, quales saltem in præsenti eos intelligimus et infra exponendos constituimus, prope e solo Hypocrearum grege Friesiano constant. Etenim, volente magistro Upsaliensi, cujus conferas Systema Orbis Vegetabilis, parte I, p. 104 et 105, Hypocrea in Cordicipites, plerasque parasiticas, Hypocreas veras s. genuinas, terrestres vel lignicolas, Hypomycetes fungicolas et Nectrias, quadrifario ordine dividuntur. His autem Hypocreis Friesianis characteres admodum vagi tribuuntur, ita ut præter perithecium membranaceum, carnosam indolem et colorem lætum, reliquæ notæ aut mendaces, aut cæteris pyrenomycetibus communes dici queant. Nectrieorum nostrorum criterium princeps in natura molli, carnosa et læte picta qua pollere solent, etiam versari existimamus; genuini typi inter Spherias pulvinatas et cespitosas vulgo computantur. Equidem unum nosse olim arbitrabamur qui ob conceptacula in stromate circinatim demersa Valseorum habitum imitaretur; id autem fungilli hanc propter notam Nectrieis sinceris magis repugnare nunc nobis videtur quam ut merito iis annumeretur ${ }^{1}$. Cæterum de memoria minime nobis excidit Polystigmata et Melogrammata nonnulla nectrieam indolem inter hypoxyleos nigrosque pyrenomycetes præ se ferre; exinde tantummodo ansam trahimus huc adducendi sequentia Notarisi verba, quibus admodum assentimus : « a tutt' oggi, inquit eruditus auctor, è assai difficile il presentare asso-

${ }^{1}$ Eumdem descriptum infra videsis, ad calcem Nectrieorum, sub Valsa chrysoidis titulo. 
"ciazioni pienamente soddisfacenti dei diversi elementi di questa coorte di myceti..." (Sferiac. Ital. fasc. I [1863], p. 4.)

Quum de his exponendis pyrenomycetibus ageretur qui indole coloreque ad carbonis naturam plerique accedunt, hunc secuti sumus ordinem qui ab omnium nobilissimis, ut saltem videbatur, ad viliores descenderet; quamobrem attendimus primum ad Spharias caulescentes s. claviformes et Spharias pulvinatas, Xylarias scilicet et Hypoxyla, subinde ad Sphorias sociatas et circinatas ut Valsas et analogas stirpes, ac denique ad Sphcrias discretas, sine lege sparsas, quibus plebem et vulgus totius gentis constare æstimabamus. Porro, ni fallimur, seriem vix diversam servare licet, ubi super pyrenomycetibus læte pictis verba facienda sunt; quippe Torrubias et Clavicipites, duce Friesio, si primum animadverteris, nectrieis fruticulosis, majoribus seu primatibus, superiorem concesseris locum; reliqua autem genera typos pulviniformes alios, effusos vel discretos alteros, quasi promiscuos admittunt. Neglecto contra vel postposito stromatis habitu, majorem si rationem habueris endosporarum, Torrubice et Hypocrece simul incedunt propter semina dissilientia, prioribus vero longe filiformia primum, aliis contra mere didyma s. dimera. Pone sequuntur Clavicipites et Epichloe endosporis filiformibus et continuis pariter instructæ, seriemque claudunt Hypomyceles, Nectrice et analogæ Spharostilba quibus, paucissimos ac recedentes typos si excipias, sporæ dimeræ aut rarius multipartitæ impertiuntur.

Sectio I. Nectriei caulescentes, conidiis seu protosporis modo (scil. apud Torrubias) in monilia verticillata aut capitula digestis, tandemque solutis et pulvereis, modo contra (ap. CLAvicipites) in apparatu carnosulo, gyroso-cerebrino generatis, et cum latice viscoso diffluentibus. - Principes.

\section{TORRUBIA .}

(Tab. I et II.)

Fungus conidiophorus CLAVARIE species est Sowerbeo, RAMARIE Holmskioldo, ISARIE autem Persoonio, Friesio, Linkio et recentioribus; nec non verisimillime VERTICILLII forma et ACANTHOMYCETIS typus Leberto; - ascophorus contra CORALLOIDES dicitur Buxbaumio; CLAVARIA Vaillantio, Linnao, Schmidelio, Bulliardo et aliis; SPHerIa Ehrhartio, Persoonio, Friesio et discipulis; CORDYLIA et CORDICEPS Friesio olim scribenti; CORDICEPS Linkio, Berkele et aliis; KENTROSPORIUM Wallrothio; TORRUBIA Leveilleo nobisque (in Ann. Sc. nat. ser. III, t. XX [1853], p. 43, nota 1, et tomo primo hujus Carpologia, p. 61); ACROPHYTON et POLISTOPHTHORA Leberto (1858), ac denique RACEMELLA Cesatio in Comment. Soc. Crypt. Italce, fasc. II (1861), p. 65.

Mrceliun ex filamentis tenuissimis contextum, byssino-stupeum aut radici-

1 Torrubia a clar. LÉveILlé dicta est in honorem Joseph Torrubie, monachi hispani, qui de historia naturali His- paniæ tropicæ olim bene meritus est, licet fabulas de muscis s. vespis gemmantibus incaute probaverit. 
forme, intestinum hypogæumve, album vel pictum deprehenditur. Stroma (sporidochium Lікко) carnosum nunc in brachia sparsa aut cæspitosa, simplicia vel divaricato-ramosa discedit, nunc contra in columellas crassiores, sæpius simplices, erectas, sursum claviformes aut capitatas informatur, semper autem e matrice, quæcunque sit, emergit. Pars summa stromatis gracilioris et ramosi in conidia minima, globosa aut breviter linearia, pallida et pulverea fatiscit; columnæ validiores ascophoræ evadunt. Perithecia exigua, ovata, obtusa acutave, modo in stromate effigurato denso ordine tota nidulantur, modo in eo libera sedent, tuncque stipata laxiorave spicas mentiuntur et parietes crassiores obtinent. THEce longissime lineares, obtusissimæ, imo quasi capitatæ, initioque octosporæ paraphyses vulgo non admittunt. Spors longe et exilissime filiformes, septis plerumque stipatissimis dividuntur tandemque in tot fragmenta solvuntur.

Torrubie sinceriores in insectis varii generis semivivis demortuisve parasitantur; pauciores ex fungis tuberiformibus oriuntur; priores in orbe utroque, temperato vel calidiori, repertce sunt et ob originem sibi privam in numero prodigiorum naturce merito habite sunt.

De fungis qui in insectis vigent et maxime de Torrubiis et Isariis, varia sub variis titulis, nec pauca quidem, scripta sunt. Accurate observata inter primos præstitit HoLmiss (Coryph. ed. Pers. p. 55-75 et 99-102). Persoonio autem jam monente (op. modo laud. p. 126 et 12 7), nihil esse nos ipsi arbitramur, ad Torrubic militaris affiniumque sationem et ortum probe intelligenda, quod eruca olim fungipara ex Torrubia seminifera, limacium more, primum vescatur '; id enim satis esse videtur, si conidiolum quoddam aut endosporam vel minimam suo cum cibo solito bestiola absorpserit; præterea nonne fungina illa semina in ipsa insecti cute fortuito delapsa pariter germinare valent? De regerminatione Torrubice Melolonthe (nob.) non prorsus inepta fingebat Jacob Cist, quum diceret : «I am inclined to believe that the " seed is taken internally by the worm and causes its death; and that in the following spring "it vegetates, finding a suitable bed or soil in the decayed worm." (Cfr. Benj. Silum. Am. Journ. of Sc. and Arts, t. VIII [1824], p. 271.)

\footnotetext{
"Fungorum ortus, ait Holmius, incrementum et tota "reliqua structura tantam produnt artem, ut potentiam reisdem agnoscamus summi Artificis qui eos produxit et " tam provide cauteque conservat, ut certarum specierum "propagationem quorumdam insectorum, esum funginæ
}

«carnis nimis cupide ingestæ vita, ut videtur, redimen"tium, ruinæ superstruxerit, quod luculentis exemplis "nos docent Clavarice militaris et Ramarice farinosce hisetoriæ.» (Cfr. Holmi Coryph. p. 4, 62 et seq.) 
1. Entomogence s. Torrubie sinceriores.

a. Clavatie aut spiciformes.

\section{Torrubia militaris.}

* Conidiophora :

Clavaria farinosa Sowerbeo, Engl. Fungi, t. III (1803), tab. cccvili.

Ramaria farinosa Th. Holmio, in Novis Act. Acad. Sc. Hafniensis, t. I (1781), p. 299, fig. vi; Ot. Bot. t. I, p. 94-97, tab. vir; Coryph. ed. Pers. (1797), p. 99, n. viI.

Isaria farinosa Friesio, Syst. Mycol. t. III, p. 271, n. 3. - Klotzsch, Herb. Myc. ed. princ. fasc. XVIII (1853), n. 1749. - Berk. Outl. of Brit. Fung. p. 338.

Isaria crassa, truncata et velutipes Persoonio, Comment. de Fung. clavaf. p. 231 , n. 1 et 2 ; Syn. Fung. p. 687 , n. 1 et $2 ;$ Mycol. Europ.t. I, p. 45, n. 1,2 et 3.

Isaria crassa Alb. et Schw. Consp. Fung. Nisk. p. 360. - Linkio, in Willd. Sp. Pl. Linnaci, t. VI, parte alt. p. 112 , et in libro inscripto Handb. z. Erkenn. d. Gew. parte III (1833), p. 431.

Isaria velutipes Linkio, Obs. in Ord. pl. nat. Dissert. I (1809), p. 20, tab. I, fig. 32. - Ditmario in Sturmil Fl. Germanica, parte III, t. I, fasc. Iv $(1817)$, p. 109, tab. LIV (fungillum recentem ex Linkı sententia, sed potius gracilipedem exprimente). - Neesio, Syst. Fung. p. 86 , n. 3, tab. vII, fig. 85 .

Fungus conidiophorus habitu mire variat; Isariam velutipedem Lk. pro forma peculiari Is. crassce Pers. jam habebat Ditmarius (loco sup. cit.); imo veremur et nos ne Verticillium corymbosum, quod clar. Lebert in chrysallidibus Fidonice piniarice Tr. vidit et descripsit, nil sit nisi conditio vix abnormis Torrubice nostræ conidiophoræ. (Cfr. Sieboldi et Koellikeri Ephem. Zoolog. t. IX [1858], p. 444 et 445, tab. xvi, fig. 1-5.) ${ }^{1}$

** Fungus ascophorus :

Clataria militaris ${ }^{2}$, crocea, Valllantio, Bot. Par. (1727), p. 39, tab. vil, fig. 4. - Frid. Müller in Nov. Act. Nat. Cur. t. IV (1770), p. 215-219 (Obs. xuv, de Musca vegetante europcea), tab. viI, fig. 5, quam dissertationem gallico sermone traditam etiam videas in Rozeri Ephem. Phys. t. I (1777), p. 150-153, tab. II, fig. v, Clavariam militarem croceam VAILL. (mouche végétale d'Europe), et fig. vi, Clavariam soboliferam (mouche végétale d'Amérique) exprimentibus.

Lichen-Agarigus ex ordine principi Michelio, Nov. Pl. Gen. (1729), p. 104 et 209, utrinque in adnotatione. Coralloides clavata, lutea, minor, Buxbaumio, Plant. minus cogn. cent. IV (1733), p. 39 , tab. LXvi, fig. 2.

Clavaria militaris, clavata, integerrima, capite squamoso, Linneo, Spec. Plant. ed. III (1764), t. alt. p. 1652 ; Syst. Veget. ed. xiv (1784), p. 980, n. 4. - Frid. MüLLER in Beschäflig. der Berl. Gesellsch. naturf. Freunde, t. I (1775), p. 156 et seq. nec non eodem anno in Florce Danica tomo IV, fasc. xi, p. 8, tab. Dcuvir, fig. 1. - Th. Holmsk. in Nov. Comment. Acad. Sc. Hafniensis, t. I (1781), p. 289 et seq. fig. viII, Ix et x; Ot. Bot. t. I (1799), p. 42-63, tab. xv; Coryph. (edente Pers.), p. 55.

Clataria granulosa Bull. Fungis Gallicis, t. I, p. 199, tab. ccccxcvi, fig. 1.

Spheria militaris Ehrhartio, Beitr. z. Nalurkunde, t. III (1788), p. 86, n. 58, et t. VI (1791), p. 47 ,

${ }^{1}$ Isaria Hypoxyli Kalkbrennero apud Rabenhorstium, Fung. Europ. exsicc. fasc. VII (1864), n. 670 (ex Hungaria boreali), et in Ephem. Bot. Berol. t. XXII, p. 174 , n. 70, est Isaria umbrina Persoonir, stirps antiqua incertæque naturæ de qua verba fecimus in tomo II hujus libri, p. 34,36 et 37 .

${ }^{2}$ "Bellicum istud nomen, $n$ ait nobilis HoLmus (Coryph. [ed. Pers.], p. 57), efungillo imposuit Vaillantius, ratione, rut videtur, superficiei ejusdem acuminatis tuberculis ob"sitæ; qua de re autem tacente Botanico Parisiensi, id quoque fingere licet, nimirum quod fungilli coccinei nostri cum apicibus illis quibus militum galeæ frequenter ornantur, quamdam deprehendere similitudinem VaiLLantius sibi visus fuerit. 
n. 192. - Boltoni, F. Halif. (ed. Willden.). parte III, p. 58, n. 161, tab. cxxviII. - Persoonio, Obs. Myc. parte alt. p. 66 , n. 100 , tab. II, fig. 3; Comment. de F. clavaf. (1797), p. 143, n. 1 ; Syn. Fung. p. 1, n. 1. - Pico, Melethem. Inaug. p. 69-71. - Sсним. Enum. Pl. Sellandice, parte post. $(1803)$, p. ${ }_{17} 5$, n. $1342 .-$ Friesio, Syst. Mycol. t. alt. p. $3{ }_{2} 3$, n. 1 , inter Hypocreas Cordicipitum. Tur. in Ann. Sc. nat. ser. iv, t. VIII (1857), p. 36 et seq. - Fr. Gurreio in Act. Soc. Linn. Londin. t. XXII, parte 1 II (1858), p. ${ }_{2} 62$, n. 2 , tab. xuv, fig. 3. - Durıeo, Comment. de Sphæria militari in Bombyce pityocampa parasitante (in libro inscripto Annuaire de l'Institut des Provinces pour l'année 1859). = Minime vero Spharia militaris Кцотzsснг in suo Herb. vivo mycol. ed. princ. fasc. I (1832), n. 47, quæ enim nil est nisi Spharia ophioglossoides Енгн. saltem in exemplo quod præ manibus habuimus in Musæo Bot. par.

Cordiceps militaris Linkio, Handb. z. Erkenn. der Gewächse, t. III (1833), p. 347, n. 1. - Berkeleo apud Hookerum, Fl. Brit. t. V, parte alt. (1836), p. $2_{2} 32$, n. 1, et in suis Outl. of Brit. Fung. p. 382, n. 1, tab. xxiII, fig. 4. - Friesio, Sum. Veget. Scand. p. 381. - Cessatio, in Actis Soc. Cryptog. Itale, fasc. II (1861), p. 69 , et fasc. IV (1863), p. 191.

Kentrosporivm militare et K. clavatum Wallrothio in suis Beitr. z. Botanik, fasc. II, p. 166 et 167 , tab. III, fig. 18-22.

Historiunculam Torrubic militaris (Vaill.) olim præstitimus, simulque extra dubium posuisse nobis videmur qua necessitudine id fungi et Isaria farinosa Fr. connectantur; non ideo cunctati sumus quin eandem doctrinam (nec propterea stomachari velint, quæsumus, mycologi illi qui nobis hactenus contradixerunt ${ }^{1}$ ) hic etiam sequeremur. Apparatus fungi conidiophorus fit ex monilibus gracillimis, 10-20-meris, quæ tenuissimis mycelii albi filamentis extrema simpliciaque sustentantur, aut subsessilia et sociata, III-IV insimul, in verticillos interrupte superpositos digeruntur; idem præterea semper sibi constat quum in bysso effusa seu pulviniformi, tum in clavulis ipsis quæ varias Isaria farinosce formas constituunt. Redit etiam sæpissime in radicibus aut imis partibus columellæ ascophoræ quæ Sphceria militaris potissimum audit. Conidia globosa $0^{\mathrm{mm}}$, oo2 diametro vix æquant; quum seruntur, germina ex iis nata cito brachiata et conidiophora evadunt, ut quidem byssum adultam et gemmiferam plane mentiantur. STIPEs, in utroque fungilli modo, parenchymate solido formatur, colore flavo, aureo, imo rubenti inficitur, rigidus est aut flexuosus, longitudineque centim. II-III et quod superest nanciscitur. Clavula conidiophora tandem in pulverem niveum pro maxima parte fatiscit, detersaque sursum attenuatur. Ascophora contra longe crassior est et colore nitidiore, maxime in parte fertili et validiore, scil. millim. III-v crassa et centim. I-Iv longa, insignitur. Perithecia ovato-conica, $o^{\mathrm{mm}}, 2-3$ et quod excedit longa, $0^{\mathrm{mm}}, 13-20$ crassa, sub vertice nonnihil obtuso et pallescente quadantenus coangustantur, in clavula denso ordine sedent, superneque rubent; singula ex membrana tenui et prope undique glabra fabricantur, ac thecis scatent. Тнес autem ex imo eorum

\footnotetext{
'Quam tuemur opinionem de multiplici forma fertili ejusdem typi fungini, clar. Bonondeni dictis (in suis Commentariis Mycologicis nuper editis) minutam fuisse vix arbitramur; nos equidem nunquam erravisse minime contenderimus, at bene multorum assensus inter rei herbariæ peritos, analogiaque ex revelatis moribus cujusvis fere
}

viventium ordinis ducta, nos quotidie certiores faciunt nostras funginæ naturæ interpretationes a vero non omnino discedere, neque nos monstra polycephala ex entibus sibi invicem alienis imprudenter fingere, potius e contrario membra fungorum disjecta ancipiti labore conferre, ut instaurati illi ordine legitimo jam nunc digerantur. 
pariete fasciculatæ nascuntur, nullis ut videtur intermistis paraphysibus; longissime lineares et angustissimæ sunt singulæque solito modo sporas innumeras, tenuissimas, rectas, vix $o^{\mathrm{mm}}$, oo3 longas, initioque catenatas dimittunt. Endospor $x$ exclusæ, locus si faverit, brevi mire augentur, subovatæ fiunt et ex utroque polo in germen lineare abeunt, ut primum in tot fusos exiles mutatæ videantur; e germinibus vero longius protractis et repentibus brachia intra paucos dies assurgunt quæ monilia ex conidiis, imo verticillos e monilibus istiusmodi sustinent. Conidia hæcce endosporis progenita, seminibus Isarice farinose $\mathrm{F}_{\mathrm{r}}$. adultæ minime dissimilia sunt, quare æorre discernas utrum conidium Torrubice nostræ germinans, an ejusdem endosporam prospere satam præ oculis habeas.

Vere et æstate conidiophora potissimum reperitur, ascophora autem brumali hiemalique tempore; perfecta nascitur ex erucis quas enecat et sæpius apud nos ex larvis Bombycis Rubi L. antequam in pupas convertantur; ex pupis ipsis plurimarum camparum varii generis etiam ascophora oritur, testibus Hozmio ${ }^{1}$, Durie cæt. Conidiophora tamen frequentius quam thecigera in qualibet sede occurrit, nisi ad Isariam farinosam Fr. plus formarum diversarum trahamus quam quis licitum existimet.

Adumbratio præmissa fungum ex erucis tum Bombycis Rubi modo dictæ, tum B. Pytiocampa $\mathrm{F}_{\mathrm{ABR}}$. natum præsertim tradit ${ }^{2}$. Peritheciorum juxta parietes genus quoddam paraphysium interdum offenditur, quæ ex articulis lineari-oblongis, inæqualibus et catenatis integræ constant.

Fungillus in America boreali sibi etiam constare videtur; Schwernitzio obvius factus est quum in Carolina superiori, tum in Pensylvania, « sæpe bipollicaris et polycephalus, semper autem in larvis 》 natus. (Cfr. Act. Soc. nat. scrut. Lips. ser. alt. t. I, p. 28 , et Comment. Soc. phil. Amer. ser. alt. t. IV [1834], p. 188, n. 1147.) Specimina austro-carolinensia Berkelezo quoque innotuerunt. (Vid. Acta trimenstr. Soc. Linn. Lond. t. I [1856], p. 157.)

Formam quamdam Torrubia militaris (L.) sphærocephalam referre videtur Cordiceps Wallaysii WEsTEND. (in Act. menstr. Acad. regice Belgarum, ser. alt. t. VII [1859], p. 81, n. 21, fig. 21), stirps eximia quæ ex pupa bestiolæ articulatæ graminicolæ oriebatur.

Inter Torrubias nostrates, sæpius, ut videtur, mere conidiophoras seu isariformes, quæ a T. militari item gemmifera (Isaria farinosa $\mathrm{F}_{\mathrm{r} .}$ ) manifestius recedunt quam ut ad typum alienum non spectent, autopsi novimus tum Isarice Eleutheratorum NeEsio (Syst. d. Pilze, p. 86, n. 2, tab. vII, fig. 84) formam peculiarem Vercellis in Rhynchite conica Iluig. s. Apio elegantulo Payk. nobili Cesatio obviam ${ }^{3}$, tum etiam Isariam arachnophilam Ditmarir (in Sturmir Fl. Germ. parte iII, t. I, p. 111, tab. uv) quæ præter Linkir sententiam ${ }^{4}$, ab Isaria Aranearum Schw. (in sua Syn. Fung. Carol. sup. p. 126 , n. 1299 )

${ }^{1}$ Cfr. illius Corypharos, ed. Persoonio, p. 62.

${ }^{2}$ Auctor est nobilis Cesstius (in Actis Soc. crypt. Itala, fasc. alt. p. 70) fungillum ex larvata Bombyce Caja in terra Brixiana potissimum oriri, seipsumque in bestiolam semel incidisse adhuc semivivam quæ fungillo gravida clavulas duodecim, nisi plures quidem, insitas jam sustentaret.
${ }^{3}$ Cfr. RabenhorstiI Herb. Mycol. ed. princ. fasc. XVI, n. 1543 (docente Cesatio ipso in schedis nobiscum benevole communicatis).

${ }^{4}$ Videsis Linki Sp. Plunt. Linn. t. VI, part. alt. p. 114 , n. 6, ubi plantula Schweinitziana dicitur Isaria phalangiophila Lx. 
fortassis non discrepat. Uterque fungillus in stipites seu columellas graciles et propter conidia inspersa pulverosas, ex omni parte mire protrahitur, horrescit et Isariam Sphingum Scrw. qua de causa imitatur, unde merito dixit Linkius (loco modo cit.) eorum thallum in stroma abire. Flagella autem Isaria Rhynchitum longa et gracillima evadunt, ac conidiis exiliter linearibus, $0^{\mathrm{mm}}, 006$ et quod excedit longis albisque obruuntur. In araneis contra columellæ gemmiferæ colore sulphureo insigniuntur et conidia violacea gignunt. Hæcce anguste ovata et prioribus duplo breviora, in capitulis globosis et brevissime pedicellatis terminalia nascuntur; capitula autem agmine densissimo columellas vestiunt, et ex hyphis intricatis fabricantur quorum articuli extremi seu exteriores peculiari modo turgent ac quasi in sterigmata brevia et fasciculata desinunt. Id structuræ clar. BввкеLжuм vix sane fugerat, quippe quo judice, ad solitam Aspergillorum s. Penicilliorum fabricam fungillus accederet. (Cf. Ann. of nat. History, ser. I, tomo I [1838], p. 259 , n. 117.) Isaria arachnophila Diтru. in araneis foliicolis, exiguæ crassitudinis, semel atque iterum nobis occurrit, primum scilicet Boloniæ agri parisiensis, et nuperiori tempore Cavillæ ad Versalias, media æstate. Fungillum ascophorum nondum reperimus.

Descripsit etiam Montanius fungum araneivorum, miræ autem præ modo dictis magnitudinis, eumque propterea titulo Isarice givgantere designavit. Conferas laudati auctoris mycographiam cubensem apud Ramonem de $\mathrm{S}_{\mathrm{agRa}}$, Hist. ins. Cubce, Bot. Pl. cell. (1842), p. 309 et 310 edit. gallicæ.

\section{INTERPRETATIO ICONUM.}

(Tab. I, fig. 19-31.)

19 et 20. Erucas duas Bombycis Rubi L. vides ex his quarum historiunculam olim conscripsimus in Annalib. Sc. nat. ser. iv, t. VIII, p. 36 et seq. Cadavera rigida duraque facta, sylvam ex Isaria farinosa $\mathrm{F}_{\mathrm{R}}$ i. e. Torrubia militari conidiophora, vere MDCCCLVII singula enixa sunt; fungilli stipites quandoque dichotomi evadunt, clavulæ farinosæ item forma et crassitudine variant.

21. Conidium, dato loco opportuno, in germen filiforme simplexque protrahitur.

22 et 23. Conidia alia $c, c, c$, pariter germinant; edita autem germina in ramos solitarios aut verticillatos abundeque fertiles jam discesserunt; modo germen unicum, nunc duo opposita e conidio pullulante prodeunt.

24 et 25. Erucæ quæ Torrubiam ascophoram libentius genuerunt; fungi autem clavulæ perfectum suum incrementum nondum (julio medio) nactæ sunt.

26. Torrubice ascophoræ, pleræque maturæ, quarum una clavam bifurcam obtinuit; autumno vigebant.

27. Byssus conidiophora quæ imis stipitibus fungi thecigeri interdum hæret; conidia seminibus isarieis paulo crassiora videntur.

28. Summa pars stili seu columellæ qua se excipit clava fungi fertilis et perfecti; perithecia denso agmine in communi suffulcro sedent; quæ altius in clavula nascuntur, sæpius in eadem uteri sui partem recondunt.

29. Endosporæ proponuntur, aliæ in series adhuc ordinatæ, aliæ solutæ liberæque; paucæ germinarunt.

30. Endosporæ alteræ quæ germina longa jam exseruerunt.

31. Endosporæ $s, s$ quarum germina ætate provectiora, brachia conidiophora facta ostendunt; conidia nova minime differunt tum ab Isarice farinosce seminibus, tum a conidiis quæ figuræ 22 et 23 in monilia catenata monstrant; nec exigui momenti inde oritur argumentum ad thesis nostræ comprobationem.

Figuræ $19,20,24,25$ et 26 nativas rerum demensiones exprimunt, figuræ autem 21-2 3,27 et 29-31 easdem valde auctas, nempe vices circa ccclxxx et amplius quidem; fig. 28 nota bis decuplo major est.

Quum super indole duplici Torrubice nostræ militaris, modo scilicet isarieæ, pulvereæ, nunc e contrario clavatæ et ascophoræ, prima verba faceremus, jam suadebat locus ut etiam de fungillo non sile- 
remus qui in eadem parasitari solet ${ }^{1}$. Porro a temporibus illis id Sphcroncematis iterum iterumque nobis occurrit, equidem, ni fallit memoria, non in Torrubia perfectiore, sed in omni Isarice genere; imo fungi subiculum isarieum ita se habere comperimus, formam scilicet pulvinatam et effusam affectare a fruticosa seu clavata apud Torrubiam militarem solita adeo recedentem, ut sæpius non dubitaverimus quin hoc tapetum legitima Sphoroncmatis ipsius pars foret. Cæterum Isaria ista deminuta de conidiorum forma sphærica, exiguitate et copia innumera, ab Isaria vulgari s. genuina, farinosa dicta, minime differt. Data occasione, iconem hic præstamus Splceronamatis nostri parasitici quod nunc, adhibito Cordæano titulo ${ }^{2}$, Melanosporam potius nuncupamus. Fungillum prorsus analogum, sed endosporis duplo brevioribus et nonnihil crassioribus, vidimus in Lactariis agri versaliensis hospitantem, sclerotio minimo comite.

\section{EXPLICATIO ICONUM.}

(Tab. III, fig. 11-14.)

11. Melolontha vulgaris nostratis mutilum conspicis cadaver quod in querceto Cavillano, æstate pluvia currente, inter muscos humi jacuit, ita ut Melanosporce nostræ parasitica et isariei ejus stromatis sedes factum fuerit.

12. Fungi particula amplificata uteros nigros, longe rostratos, ex floccis niveis assurgentes monstrat.

13. Flocci conidiophori vices circiter CGcLxxx præter nativas demensiones aucti proponuntur.

14. Cæspes, simili modo amplificatus, ex thecis, plerisque gravidis; endosporæ liberæ nonnullæ circumjacent.

\section{Torrubia SObOLIFEra.}

Clataria sobolifera Hillio et Watsoni in Comment. Soc. Philos. Londinensis, t. LIII (1763), p. 271-273, tab. xxiII (quod ad tettigometram spectat non fida); dissertatione inscripta: An account of the insect called the vegetable Fly. - CLavaria sobolifera e pupa nata sive Musca vegetans americana Frid. MülL. in Nov. Act. Acad. nat. Cur. t. IV (1770), p. 219 , tab. viI, fig. 6 (bona), et ap. Rozeri Ephem. Phys. t. I (1777), p. 153 , tab. II, fig. vi.

FUNGI species Georgio EDwards in suis collect. inscriptis Gleanings of nat. History, parte III (1764), cap. cxxv, p. 263 , tab. cccxxxv, fig. hinc et hinc Alcedinis imagini accedentibus. - Andreæ Eliæ Buchnero in Nov. Act. phys.-med. Acad. nat. Cur. t. III (1767), Obs. cxxxviI, p. 437-442, tab. viI, fig. 12 (ex Edwardsio sumpta et de insecto natali partim commentitia), scil. in disputatione cui titulus est : Falso credita metamorphosis summe miracul. insecti cujusd. americani. - J. Fr. Guelin in Ephemeride Halensi inscripta der Naturforscher, t. IV (1774), p. 67 et seq. ubi etiam de Clavaria militari Vallu. prius tractatur.

Fungi s. CLavarie species Fougeroux de Bondaroy in Hist. Acad. Sc. par. ad ann. MDCCLXIX (1772), p. 467 et sequentibus, tab. iv.

Modche véGÉtante seu Vegetable fly Th. Holmio in Novis Act. Acad. Sc. Hafniensis, t. I (1781), p. 302, fig. XI et XII.

Mouche végÉtante des Caraibes ou Moughe-Plante, Clataria species, Boscio in libro inscripto : Nouv. Dict. d'Hist. nat. (ed. Deterville), t. XXI (1818), p. 444 et 445.

Spheria sobolifera Berkeleo in Hookeri Ephem. Bot. Londinensi, t. Il (1843), p. 207 , n. 4.

Hypogrea Buchneriana Leveilleo in Herb. b. Meratil, nunc e thesauris Musæi Bot. par.

Quemadmodum Torrubia militaris (L.) in erucis papilionum crescit, sic T. sobolifera et affines ex Cicadis nondum perfectis, apteris, i. e. Tettigometris veterum, oriuntur.

Cfr. Ann. Sc. nat. ser. iv, t. VIII (1857), p. $40 .-{ }^{2}$ Melanosporce characteres expositos videsis in Corde Iconibus Fung. t. 1, p. 24 , tab. viI, fig. 297. 
Fungi nostri antillani substantia albida, cavernosa, maxime partem nymphæ demortuæ anticam quasi spongia floccosa investit. Clavula fertilis, ovato-oblonga seu linguiformis, stipite pallidiori, crasso, tereti, rigide erecto, glabro, nudo et simplici se excipit, diametro eundum excedit, et conceptaculorum ostiolis minimis nec, ut videtur, conspicue prominentibus, velut tot punctis notatur. Quandoque vero stilus brachiis paucis, brevibus, modo submediis et congestis, nunc remote alternis, quasi prole abnormi augetur. In speciminibus, ex insula Martinica oriundis, quæ nobis suppetunt, hic cauliculus $15-20^{\mathrm{mm}}$ et quod excedit longus, simplex et nudus, clavam 5-8 $8^{\mathrm{mm}}$ longam sustentat.

Provenit in Antillis Americæ æquinoctialis, et Mouche végétante de la Martinique dicitur in mycotheca b. Mérat, medici et botanographi parisiensis. (Cfr. Herb. Mus. par.)

Exempla plurima fungi nostri etiam vidimus, in Nova Hispania nuper collecta, quorum stipites singuli non modo ramusculis brevibus ut dentibus absque ordine secus totam prope longitudinem augentur, sed præterea clavulæ loco paniculam contractam seu cæspitem densum ex innumeris aliis brachiis deformibus apice gerunt; imo brachia ista aliquando in stupam fibrillosam et totam hypogæam multipartita, protracta attenuataque solvuntur et relaxantur, ac simul in apiculos niveos, lanuginosos et abundanter conidiophoros desinunt, ut mycelium illud imitentur quo Torrubia entomorrhiza (Drскs.) et T. ophioglossoides (Енгн.) item utuntur. Conidia lineari-oblonga, utrinque obtusissima, recta, continua, alba, $0^{\mathrm{mm}}, 0065-01$ longa, et $0^{\mathrm{mm}}, 0035$ circiter crassa, primum in capitula digeruntur. Tettigometra fungipara vernacule apud Mexicanos Chicharra nuncupari dicitur.

Multiformis Torrubice soboliferce habitus accurate depingitur in tabula priore quæ accedit dissertationi supra laudatæ nostri Fougeroux super Insectis phytophoris.

Torrubic præcedenti soboliferce omni affinitate proxima est Torrubia altera quam si certo diversam olim cognoscas, caspitosam merito dicas; cicadis defossis in Novæ Zeelandiæ desertis pariter infesta et tota luteo-pallida, anticis matricis partibus item insidet, sed ex stipitibus vI-x aut pluribus quidem, partim coalitis, contorto-flexuosis, $15-25$ millim. et quod excedit longis, tandemque clavato-capitatis, cæspitem efficit totum primitus hypogæum, debito autem tempore verticibus emersum.

Id fungilli in oris Novo-Zeelandicis quas Poverty-Bay nuncupant, Leonardo Williass abhinc paucis annis obvium fuisse declarat schedula msc. quæ plantulis suppetentibus (in Musæo entomolog. par.) accedit.

Tertium Torrubice genus in Cicada larvata epicephalum viget, nempe Torrubia Miquelii (nob.), fungillus brasiliensis, ex omni parte fuscus, subligneus (aridus saltem) et glaberrimus, quem Isariam Cicada appellarunt tum clar. Mrquer, batavus, in Collectaneis inscriptis Bull. des Sc. physiq. et naturelles en Néerlande, t. I (1838), pag. 85 et 86 , tab. I, fig. a, a-f (fungi nondum fertilis scapum exprimente), tum etiam clar. MüLDER in suo libro, germanice scripto, de Chimia physiologica generali, parte I (1851), p. 9o, in fine. Stipite utitur valido, simplicissimo, flexuoso, 5-6 centim. et quod superest alto; larva autem, tota etiam infuscata, triplo crassior est quam tettigometra antillana supra descripta. Specimen mancum hujus fungi vidimus in Musæo entomologico parisiensi. Plantula sane minime diversa, itemque sterilis, adumbratur in larva insecti, ut æstimabatur, lamellicornis et austro-americani, apud Commentarios Soc. entomolog. Londin. t. III (1841-1843), p. v, tab. vi, fig. 6. 
Torrubiam Miquelii habitu referre videtur Torrubia illa quæ apud Pensylvanos Americæ borealis, ex larvis infossis Melolontha, May-Bug vernacule dictæ, haud infrequens oritur. Id fungi quod Torrubiam Melolontha dicere licet, juxta imagines ejus quæ nobis præsto sunt, articulo cervicali bestiolæ exanimis inseritur, solitarium geminumve. Interna fabrica ignoratur. (Cfr. Commentatiunculam a Jacobo Cist editam in Sillimanni Ephem. americ. Sc. et Artium, t. VIII [1 $82_{4} 4$ ], art. xiv, p. $269_{-2} 7_{1}$, tab. iv, cum titulo Notice of the Melolontha or May-Bug.) Ejusdem sane fungi jam meminerat Fovgeroux noster in suo commentariolo supra laudato de Insectis phytophoris (Hist. de l'Acad. roy. des Sc. ann. MDCCLXIX, pag. 470 , t. v, fig. $1-9)$.

A præcedentibus contra habitu longe recedit fungillus comosus quem ex abdomine cicadæ cujusdam perfectæ (cayennensis) ortum vidit idem Fougeroux. (Cfr. librum modo cit. p. $47^{0}$ et 476 , tab. v, fig. 12 et 13.$)$

\section{EXPLICATIO ICONUM.}

(Tab. I, fig. 32 et 33.)

32. Figuram hic tradimus, nativa magnitudine expressam, tettigometræ martinicensis fungiparæ de qua modo verba fecimus; fungus, ni fallimur, debitam crassitudinem nondum assecutus est, semina saltem matura non fovet; stilus his non augetur ramusculis propter quos Torrubia nostra HILLIo sobolifera videbatur.

33. Summa pars asci fertilis endosporæque liberæ, ex clava perfecta depromptæ, valde amplificatæ, scilicet vices circa $\mathbf{D}$, simul proponuntur.

\section{Torrubia Sphinguin.}

* Fungus conidiophorus aut saltem nondum perfectus :

BYssus filamentis erectiusculis, distinctis, crassiusculis, albidis, insecto putrescenti innascens Ricardo apud RozeriI et Mongezir Ephemerid. Physicam, t. XV (1780), p. 402.

Chavaria seu Lichenis species Petro Cramers in suis Papilionum Exoticorum (Uitlandsche Kapellen) illusirationibus, t. III (1782), p. 135 , tab. ccLxvir, fig. mediis a et в quæ fungillum in Achmenide (Sphingis specie surinamensi) crescentem repræsentant.

Isaria Sphingum Schweinitzio in sua Syn. Fungor. Carol. sup. (1822), p. 126, n. 1298 ; et in Syn. Fung. Am. bor. media, n. 3055 (ap. Acta Soc. phil. Americ. ser. alt. t. IV [1834], p. 304). - Abrah. Halsey in Ann. of Lyc. of nat. Hist. of New-York, t. I (1824), p. ${ }_{12} 6$, cujus Halsæanæ dissertationis summam in nostri Férussac Tabellis Sc. naturalium, ad m. januarium a. MDCCGXXV, p. 66-68, videre est. - Fr. Syst. Mycol. t. III, p. 275 , n. 10.

Isaria SPhingophila Linkio in Willdenowi Spec. Pl. Linnaei, t. VI (1824), parte II, p. 114 , n. 5.

Hujus loci etiam manifesto est id vegetabilis quod in Sphinge populivora oriri fertur apud Ernst et EngramelLe, opere inscripto Papillons d'Europe, peints d'après nature, tom. III (1782), p. 107 et 108, tab. cxv, fig. 162 м, ac de quo fusiora jam attulerat cl. Ricardus in Ephemeride physica, supra citata, loco dicto. Nec forlassis immerito huc quoque ducas Acanthomycetem aculeatum Leberti (apud Sieb. et Koеllik. Ephem. Zoolog. t. IX [1858], p. 446 et 447, tab. xvi, fig. 6-12), fungillum mucedineum, conidieum, in Noctua quadam (Cerastide Vaccinii) natum.

** Fungus perfectior, ascophorus :

Acrophyton tuberculatum Leberto in Collectaneis zoologicis modo citatis, tomo dicto, p. 448 et 449 , tab. xviI, fig. 13-1 7 (in Sphinge Pinastri e musæo entomologico Genevensi).

FungILl specimina tria (boreali-americana) quæ nobis suppetunt, papilionum noc-

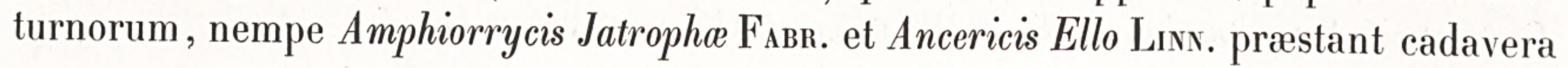


emacerata, partim destructa, crustaque tenui et dilute ochracea undique sed inæquo modo vestita. Hæc crusta tota quanta fungina est, licet glaberrima et quasi ex calce primo obtutu facta; præterea flagella gracillima sed rigidiuscula, $5-40^{\mathrm{mm}}$ et quod excedit longa, undequaque et sparsim, maxime autem ex abdominis articulis, alarum nervis, antennis, cruribusque papilionis exserit, ita ut insectum alieno loricatum tegumento fibris quoque vel setis divaricatis mire horrescat. Simul autem ex crusta ipsa et ex imis mediisve flagellorum partibus conceptacula prodeunt sparsa, parce cæspitosa vel densius in spicam digesta, anguste ovata, vix semimillimetrum longa, teretia, glabra, mutica, carnosa et pallide rubentia, quæ congenerum more thecas longissime et angustissime cylindricas fundunt. Asa enim $0^{\mathrm{mm}}, 004$ crassitudine vix excedunt; sporæ inclusæ exilissime filiformes sunt. (Cfr. collect. entomolog. Musæi parisiensis.)

Modo dicta flagella ramos isarieos, obsoletos et denudatos, omnino referunt, quare non dubitamus quin olim, saltem in apicibus, furfure pallido ex conidiis solennibus obruta fuerint; nunc autem detersa, attenuata et decurtata dantur nobilioreque fructu ditantur; alia fertiliora spicas æmulantur, alia contra parcius fructifera clavularum species gracillimas, valde depauperatas et interruptas fingunt. Perithecia imaginem mentiri videntur conceptaculorum quæ in imis clavis Torrubic militaris (Lins.) a superioribus densatisque capsulis quandoque segregantur; ubi enim adulta facta sunt, quasi libera in columella sua sedent, inde uteros ascophoros Torrubice Robertsï BеRк. (qui autem peculiariter obtusi, multo magis constipati nudique reperiuntur) quodammodo imitantur. Endosporæ adeo exiles sunt ut ægre perspiciantur, sed minime dissimiles sunt seminibus cæterarum Torrubiarum, pariterque in fragmenta brevia tandem solvuntur.

Fungus quem nunc intuemur is ipse manifesto est qui tum in Sphingibus et maxime fagicolis, tum etiam in Phalenis, Schwernitzio apud Carolinenses et Pensylvanos conidiophorus obvius factus est; de eodem narratur, quod profecto miramur, ramulos quibus insideant Sphinges emortuæ, in foliis etiam aridis per longam hiemem læte virescere. (Cfr. Schweinıтzi dicta loco supra cit.)

Merito notat Linkius thallum fungilli nostri indurari et in stroma abire, nec aliter se habere Isariam phalangiophilam suam (in WiLlden. Sp. plant. Limn. t. VI, parte II, p. 114, n. 6) seu Is. Aranearum Schweinitzio in Synopsi jam citata Fungorum Carolince superioris, p. 126 , n. 1299.

\section{INTERPRETATIO ICONUM.}

(Tab. I, fig. 1 et 2.)

1. Figura prior papilionem ex Sphingum ordine, magnitudine nativa descriptum ostendit quem jampridem demortuum occupat Torrubia Sphingum Scнw. (sub Isaria); bestiolæ cadaver deturpatum flagellis funginis ut setis rigidis seu spinis ex omni parte horret.

2. Flagella duo contigua sed valde inæqualia, seorsim et valde aucta proponuntur; Torrubice conceptacula ascophora, quum ex flagellis seu stromate filiformi, tum ex eodem crustæ in modum effuso sparsim emergunt.

Hæc adumbratio juxta specimina facta est quæ in entomotheca Musæi parisini continentur.

In numero Torrubiarum claviformium habendæ sunt pleræque ex his quæ mycologis hactenus innotuerunt, ex. gr. Torrubia sinensis Berk. (sub Spharia in Ноoкеri Ephem. Bot. Lond. t. II [1843], p. 207 
et 208 , n. 5 , tab. viII, fig. I $a-d$, et apud LindLew Regn. Veget. ed. princ. p. 39 cum icone [fig. xxiv]) seu Hia-Tsao-Tom-Tchom Sinensium, auctore rev. P. Parennin (cfr. Realmuri verba, veritati multa ex parte haud consona, in Hist. Acad. Sc. par. ad ann. MDCCXXVI, p. 302 , tab. xvi) ${ }^{1}$; Torrubia Robertsii Ноокеко (Ic. Plant. t. I [1837], tab. хі) et BеккеLето (in Ноокеві Eph. Bot. t. III [1841], p. 77 , tab. I, fig. a, et ejusd. Lond. Journ. of Bot. t. II, p. 209 , n. 6) quæ autem Spharia Hugelii Conde est in suis Iconib. Fung. t. IV (1840), p. 44, tab. Ix, fig. $129^{2}$; Torrubia Tayloris Вевк. in Ноок. Ephem. Bot. Lond. t. II (1843), p. 209 , n. 7, tab. viII, fig. 2, a-c; T. Gunnï ejusdem BевкеLеi aliæque quarum descriptio ab eo evulgata est, sub Cordicipitis titulo, in Actis trim. Soc. Limn. Londinensis, t. I $\left(1_{857}\right)$, p. ${ }_{157}$ et seq. Contra potius racemifera diceretur exigua illa Torrubia memorabilis Cessatio (sub Racemella in Act. Soc. Cryptog. Itala, fasc. alt. p. 65, n. 7 , tab. iv, fig. 1), ex demortuo staphilino nata et cujus brachia conceptaculis sessilibus onusta, flagellorum fertilium Torrubice Sphingum deminutam imaginem prorsus referunt. Remotior est, præter Bonondeni opinionem ${ }^{3}$, hujus Racemellae cum Thamnomycetibus necessitudo.

\section{b. Capitato.}

\section{Torrubia entomorrhiza.}

Spheria entomorrhiza Dicksoni, Pl. Crypt. Brit. fasc. I (1785), p. 22, tab. ili, fig. 3. - Pers. Comment. de Fung. Clavaf. p. 145 , n. 4; Syn. Fung. p. 4, n. 4. - Fr. Syst. Myc. t. II, p. 324 , n. 2. - Berkeleo ap. Ноок. Engl. Fl. t. V, parte alt. p. ${ }_{2} 3_{2}$, n. 2 , cum notis et descriptione congrua.

Kentrosporidm grandlatum Wallr. Beitr. z. Bot. fasc. alt. p. 166, n. 3, tab. iII, fig. 17 , ex Dicksone sumpta. Cordiceps entomorriizus Linkio, Handb. z. Erk. der Gew. t. III, p. 3/47, n. 2.

Cordiceps entomorrhiza Fr. S. Veğ. Scand. p. 381. - Berk. Outl. of Brit. Fung. p. 382, tab. xxili, fig. 5.

Spheria (Cordiceps) entomorrhiza Curreio in Act. Soc. Linn. Londin. t. XXII, parte III (1858), p. 262 , n. 5 , tab. xuv, fig. 6 .

Torrubia entomorrhiza Tul. Sel. Fung. Carp. tomo 1, p. 61, in nota. - Cesatio et Not. in Comment. Soc. Cryptog. Italee, fasc. IV (1863), p. 192.

Hujus loci fortassis est Spharia militaris Pers. $\gamma \gamma$ spharocephala Schmidrı in suis Fasc. Mycolog. parte I, p. 106, quæ capite prorsus globoso et stipite longo gracillimoque a Sphceria militari Енгн. genuina recedere dicitur (cfr. Schmidtir 1. cit. et Fr. Syst. Myc. t. II, p. $3_{2} 3$ ); contra typum nostrum minime repræsentat Sphcria illa entomorrhiza quam accurate descripsit et adumbravit Carolus Roвis in tibro suo de Vegetab. qua in homine et animantibus vivis parasitantur, p. 650 et seq. tab. vIII, fig. 5 et 6 , tab. $x$, fig. 3 et 4 , tab. xI, fig. $4-8$, et tab. xII, fig. 2 et 3 , licet peritheciorum membrana illius oculos fugerit.

Lute0-Fulvus, a vertice autem nitidius aureus assurgit fungillus ex anticis articulis larvæ defossæ et peculiariter induratæ, insecti cujusdam tenthredinei, ut saltem videtur; quem vivum vidimus (semel enim hactenus nobis occurrit) bestiolæ annulis a latere hærebat; pediculo flexuoso, supra basim saturatius fucatam nonnihil inflato,

\footnotetext{
1 Torrubice sinensis etiam mentio est, sub falso titulo Clavarice entomorrhiza, in Actis Societatis Entomol. Londinensis, t. III (1841-1843), p. iv, tab. vi, fig. 5 .

${ }^{2}$ Figuræ citatæ Torrubice Robertsii Berk. redeunt in LindLeI Regno vegetabili, ed. I, p. 40, fig. xxv; idem fungus eximie etiam delineatur in tomo tertio, supra citato,
}

Actorum Soc. Entomol. Londinensis, p. Iv, tab. vi, fig. 4 , et in Caroli Roвı Hist. nat. vegetabilium in animantib. parasitantium, p. 648 , n. 83 , tab. viII, fig. 13 (6).

${ }^{3}$ Quam propositam videas in novissimo citati scriptoris libro qui inscribitur Abhandlungen aus dem Gebiete der $\mathrm{My}_{\text {- }}$ liologie (1864), p. 84, fam. xxI, n. 2 . 
$4^{\mathrm{mm}}$ circiter longo et $2^{\mathrm{mm}}$ crasso, nec non et capitulo ovato-globoso, nitide aureo, millimetra v longo, quatuor autem crasso, solido et propter ostiola fucatiora, obtuse et brevissime exstantia, punctato-tuberculoso utebatur. Conceptacula quæ in isto circum circa nidulantur formam ovato-globosam et parietes tenuissimos pallidosque obtinent. Tнесе longissime lineares $0^{\mathrm{mm}}, 0065$ diametro æquali non excedunt nec apice tument, singulæque intra latera ex membrana cito destructa octuplam sporarum seriem fovent, ita saltem ut undecunque spectentur triplicem exhibeant seminum ordinem; hæcce linearia sed nonnihil ovato-oblonga, utrinque obtusissima, recta, $0^{\mathrm{nm}}, 0065$-008 longa vixque $0^{\mathrm{mm}}, 004$ crassiora, initio alia aliis in series moniliformes hærent; maturo autem tempore ab invicem solvuntur.

Inter gramina fungillum maturum reperimus exeunte mense maio, anno MDCGCLX, in ambulacro quodam hortorum S. Clodoaldi.

Larva matrix millim. xxv in tongitudinem et $\mathrm{III}$ in crassitudinem circiter obtinet. Thecæ cum ex ostiolis conceptaculorum prodeunt, fila rigidula mentiuntur, el membrana qua struuntur maxime extenuata jam partim periit, ita ut sporæ solutæ in plantulæ scapo et omni corpore supposito simul decidant. Hæ cumulatæ nivem candore æmulantur. Disseminatæ germina perquam exilia, loco favente, edunt, nec incrassantur.

Humanissimo Broomeo specimina anglica fungilli nostri plurima et splendida debemus, quæ matricem eandem tenthredineam elegisse videntur atque plantula parisiensis; quædam, præter clavulam ascophoram mediam, cæspites monstrant aureos et conidiophoros, conidiis globosis $0^{\mathrm{mm}}, 005$ circiter crassis; de his exemplis jam verba fecimus in tomo I hujus Carpologice, p. 62 , in nota.

A Torrubia entomorrliza de qua agitur non differt, ni fallimur, Xylaria gracilis Grev. (Fl. Crypt. Scotic, t. II [1824], tab. cxxxvi) quæ Cordiceps est tum Durieo et Montanio (Fl. Alg. t. I, p. 449, tab. xxv, fig. 2), tum etiam Bевкецео (Outl. of Brit. Fung. p. 382, n. 5); nostra autem qua de re sententia potius autopsi nititur fungilli mauretani, Dursæo obvii, quam adumbratione Grevilliana cui, ut opinamur, vix tuto confidas.

Iconem in tabula nostra prima perhibemus tum modo dicti fungi algeriensis (fig. 16), tum quoque Torrubic ipsius quam oculatissimus idem Durisus in Pyrenæis montibus (près l'hospice de Velasque), ucc hexapod. supra Oceani ripas, olim reperit, cujusque mentio fit in Collectaneis quæ inscribuntur Bulletins de la Soc. Entomolog. de France, serie alt. t. VII (1849), p. xxxix et xL; fungillum enim utrumque liberalissimus inventor nobiscum communicavit.

Fungus Dicksonianus, coloris autem solito dilutioris, rarus obvenit Schweinitzio in larvis insectorum Carolinæ superioris. (Cfr. hujus scriptoris Synopsim Fungor. Carol. p. 28 , n. 3.)

\section{EXPLICATIO FIGURARUM.}

(Tab. I, fig. 12-18.)

12. Torrubia illa entomorrhiza quæ in montibus Pyrenæis clar. Durixo olim occurrit ae cujus mentio supra facta est; larva matrix, de sententia b. Caroli Derarovzée, viri adolescentis, amici desideratissimi, in omni insectorum genere, dum viveret, exercitatissimi, elateridea est.

13. Fungillus idem qualem in eruca infossa Clodoalduni obvium habuimus.

13 . Capitulum istius fungi parisiensis a summo dissectum et nota decuplo majus factum conspicis; 
conceptacula endosporas catenatas solutasve ut capillamenta exilissima eructant; juxta adumbrantur hæc seminula, $s$, valde aucta.

14 et 15. Specimina anglica ejusdem fungi in erucis paris naturæ, nemre, ut videtur, tenthredineis vigent, sed singula cæspite ex mycelio aureo, cxiliter ramoso ac quidem conidiophoro basi donantur; a benevolo clar. Broome olim accepta sunt.

16. Mauritanicum fungi nostri exemplum quod Durieus inventor et Montanius pro Sphceria (Xylaria) gracili Grev. una habuerunt.

17. Pars suprema thecæ ex eodem fungo mauretanico depromptæ.

18. Pars altera ejusdem modi, evacuata.

Figuræ 17 et 18 summopere amplificatæ monstrantur; reliquæ, præter decimam tertiam asterisco signatam, naturam non excedunt.

\section{Torrubia cinerea.}

Torrubia cinerea Tul. in tomo primo hujus operis, p. 61 , in nota.

Ex quo fungi hujus descriptiunculam (loco modo cit.) præstitimus, eum denuo reperire nobis non contigit; quare de illo hic omnino siluerimus, ni imaginem juxta vivum fungum expressam tradere voluerimus. Universa ejus suadente fabrica, locus illi pone Torrubiam entomorrhizam meritissime conceditur.

Ad fungillum nostrum propter analogiam accedere æstimatur Torrubia fuliginosa Cesatis (sub Cordicipitis titulo) quam adumbratam videas in Actis Soc. Cryptog. Itales, t. I, p. 67 et 191 , tab. vi, fig. 1.

\section{EXPLICATIO ICONUM.}

(Tab. I, fig. 11.)

11. Torrubia cinerea nostra qualis in silva Compendiensi, junio mense MDCGCLX exeunte, nobis viva maturaque occurrit, simul cum bestiola (Carabo larvato) nutrice, juxta veram suam magnitudinem exprimitur; endosporæ $s$ auctæ apponuntur.

\section{Torrubia SPHEcocephala.}

Planta Gia dicta, saltem quod ad putatam originem spectat, Josepho Torrubie in libro qui inscribitur Apparato para la Historia nat. Españ. $\left({ }_{1} 54\right)$, ad calcem explicat. iconum, scil. pag. penult. et ultima, tab. xIv, quæ figuræ haud mutatæ redeunt tum in Georgii Edwards Gleanures of nat. Hist. parte III, jam supra citata, tab. cccxuxvi, accedentibus Torrubie verbis pag. 265 et 266 (anglice et gallice), tum etiam apud Andr. El. Buchnerum in Nov. Act. phys.-med. nat. Cur. t. III (1767), Obs. LxxxviII, p. 437 , tab. vir, fig. 13 , nec non J. Fr. Gmelinum in Ephemeride Hist. nat. Hallensi, t. IV (1774), tab. Iv $^{1}$.

Spheria entomorrhiza (Dicks.) Ricardo Maddiane, aut saltem Abrah. Halseo in Collectaneis inscriptis Annals of Lyceum of nat. Hist. of New-York, t. I, parte I (1824), p. $1_{2} 5$; cujus scriptoris dissertationem contractam videsis in nostri Férussá Ephemeride Sc. nat. ad m. januar. MDGCGXXV, p. 66-68. - Maddanæ observationes item afferuntur in litteris Samuelis Mitchill ad Gandollium quæ continentur tum in b. Sillimanni Amer. Journ. of Science, t. XII (1827), art. Iv, p. 21-28, tum in D. Brewstert Edinensi scient. Ephem. t. VII

Torrubiæ dicta imprudenter et forsan inscius, viatorum dictis nimium confisus, probavisse videtur P. ENGRAMELLE, monachus cæterum in rebus physicis minime rudis, cujus videsis librum inscriptum Papillons d'Europe, etc. t. I (1779), p. Ix. 
(1827), p. 30-36, cum notis; gallico sermone easdem interpretatus est Henricus de SAussure in sua Monogr, Vesparum socialium, parte gener. (1858), cap. Ix, qui autem Torrubiam sphecocephalam, ut videtur, vix noverat, eamdemque a Torrubia sobolifera cicadarum non differre perperam arbitrabatur (loco cit.).

SPheria SPHecocephala KLotzschio in Herb. Hookeri, auctore Berkela in ejusdem nobilis Hookeri Ephem. Bot. Londinensi, t. II (1843), p. 206 , n. 2. - BERKELEO ipsi, loco modo cit.

Polistophthora Antillarum Leberto in Sieboldiana Ephemeride scientice zoologica, supra laudata, tom. IX (1858), p. 449-452, tab. xvII, fig. $18-26$.

Ex imo thorace vespæ cujusdam americanæ, primum inter pedum par et alterum, tota flavida aureave et glaberrima nascitur, mycelio prorsus latente; cauliculo plerumque simplici, filiformi, 3-6 centim. et quod excedit longo, flexuoso rigidove, continuo et æquali utitur, ac in capitulum fertile, ovato-lanceolatum, $3-5^{\mathrm{mm}}$ longum et ${ }_{2}-3^{\mathrm{mm}}$ crassum, nec non propter conceptaculorum ostiola undique asperatum desinit. PERIтнесі, ex integro immersa, formam ovato-protractam affectant, parietes a substantia stromatica, crassa, vix distinctos obtinent, thecisque longissime filiformibus referciuntur quas sporis innumeris, solito modo brevissime et angustissime ovato-linearibus singulatim foetas vidimus.

Fungillus quem præ oculis habemus in insula Guadalupe Antillarum a clariss. viro BEAUPERTHUIS olim repertus est. (Cfr. Mus. Entomolog. paris.) Vespa matrix flavida est, centimetra duo longitudine circiter æquat et auctore doctissimo H. LuGa, parisiensi, ea ipsa est quæ Polistes Clavaria a b. Boscio olim dicta est in schedis mss. (Videsis Entomoth. Mus. par.) Pro

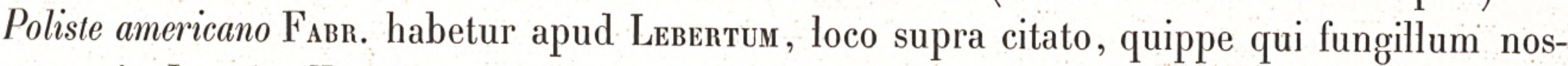
trum, in Jamaica Henrico de SAussure obvium descripsit et delineari curavit.

Vespa vivens, docentibus Maddiana et $\mathrm{H}_{\text {ALSEX}}$, propter insitam plantulam jam fit clavigera; « the most "remarkable particular respecting this fungus, ait Abraham HaLSEY (loc. cit.), is the fact that the wasp $\approx$ is still living with its incumbance attached to it, though apparently in the last stage of existence and "seeming about to perish from the influence of its destructive parasite." Longe minorem meretur fidem Joseph Torrobri qui fruticulum quinque palmarum et spinosum ex vespa demortua nasci contendit (loco sup. cit.).

Fungi columellam quandoque bifurcam fieri, imo stilos duos in ejusdem vespæ thorace interdum offendi, Saussurea s. Lebertiana demonstrant specimina.

Isaria sphecophila Diтn. (apud Sturn, Fl. Germ. parte iII, t. I [1817], p. 115, tab. uviI) quæ Ceratonema Crabronis a Presoonio postea dicta est (in sua Mycolog. Europ. parte I [1822], p. 48, n. 1), fungum præcedenti, saltem propter sedem electam, analogum, sed sterilem seu mere conidiophorum repræsentat; quare minime miramur quod, post Ditmarium ipsum, Linkius etiam quærat (in WilldeNowi Linnæanis Sp. Pl. t. VI, parte alt. p. 114) eane sit sporidochium Spharice cujusdam. Nota illi peculiaris est, quod nimirum stipites in medio quasi articulatos, eosque plurimos e singulis Crabronibus hospitibus exserat. Bene advertit Dirmarius qua analogia devinciri videantur Isaria sua sphecophila et Spharia Hypoxylon L. cujus apices, inquit, corpusculis albis et seminiformibus in prima ætate etiam consperguntur.

Torrubiam sphecocephalam KL. nostris in terris, quoad figuram, refert Torrubia myrmecopliila CEs. (sub Hypocrea) de qua pauca infrä (p. 19) præstamus. 
In vespa etiam, nempe Icaria cincta Lf.Pell. apud Senegalenses oritur Torrubia Humberti Roвını (sub Cordicipitis titulo), cujus fungi meminit H. Saussurius jam laudatus (in sua Monogr. Vespar. social. parte gener. $[1858]$, p. cuxiv, in nota; et parte spec.p. 39 , n. 18 , tab. v, fig. 9). Hujusce Torrubice stili alii breves validique in clavam ovato-oblongam et asperatam subito incrassantur, alii autem graciles et multo tongiores capitulo perexiguo ovatoque terminantur, eodem prope modo atque fungina illa flagella exilia quibus undique horret Vespa crimita ${ }^{1}$ Samuelis Felton in Comment. philos. Londin. ad annum MDCCLXIV (1765), p. 53, tab. vi, fig. dextra; tenuia eadem crura simul observatorem commonent virgularum sterilescentium Torrubia nostræ coccigence (infra, p. 19), et emaciatam quamdam speciem Stilbi Buquctii Rов. (cujus infra meminerimus, ad calcem ordinis Nectrieorum) referunt.

\section{INTERPRETATIO ICONUM.}

(Tab. I, fig. 5-9.)

5. Vespæ duæ supinæ Torrubiam sphecocephalam $\mathrm{K}_{\mathrm{L}}$. in summo thorace insitam monstrant; nativa demensione cum fungillo parasitanti exprimuntur.

6. Pars antica alterius vespæ item fungiferæ, a fronte spectatur.

7. Clavula fungi integra et aucta, nempe præter naturam bis sextuplæ crassitudinis facta.

8. Eadem a summo dissecta, ut conceptacula immersa pateant.

9. Endosporæ, catenatæ aliæ, liberæ alteræ; omnes præter naturam vices circa cccLxxx amplificatæ sunt. Icones omınes juxta fungillos guadalupenses supra descriptos delineatæ sunt.

\section{Torrubia unilateralis $†$.}

E mycelio intestino latenti tum apices seu flocci pauci, exigui et saturate rufi passim oriuntur ac erumpunt, tum etiam stipites pauciores, discreti, graciles, rigiduli, $10-20^{\mathrm{mm}}$ longi, rufo-nigrescentes superneque attenuati et pallidiores. Hæ columellæ articulo bestiolæ matricis secundo s. thoraceo, pone cervicem insistunt, singulique pulvinulum carnosum, hemisphæricum, unilateralem, et circiter crassitudine seminis viciæ dimidiati, i. e. stroma fertile, conceptaculorum immersorum ostiolis dense prominentibus asperatum, supra medium hinc gerunt, ultra autem peculiariter extenuantur et pallescunt, quasi solitum conidiorum pulverem jampridem deposuerint. In specimine fungilli suppetente duo insunt coliculi quorum alter supremo anticoque thoracis lateri inseritur, alter vero ex eodem oblique procedit.

Nascitur ex formica centimetrum et quod superest longa, quæ, docente peritissimo viro H. Luca, Atte cephaloti Fabr. insecto brasiliensi, affinitate proximam se habet, et in Musæo entomologico parisiensi continetur.

Quod ad speciem exteram attinet, Xylariam aristatam Mntgn. (in Ann. Sc. nzt. ser. Iv, t. III [1855], p. 106 , tab. v, fig. 6) quodammodo imitatur; item vix secus setigera est atque Cordiceps stylophora Berк. et Br. aut C. acicularis Ravenelio. (Cfr. Berk. in Actis trim. Soc. Lim. Londin. t. I, p. 158, tab. . .)

Hæc vespa in Jamaica, auctore FeLtone, nascitur, et apud H. Saussurium pro Poliste americano Fabr. habetur; insitus tamen fungus potius ad Torrubiam Humberti Ro-

binio, Icarice cinctce Lepell. infestam, spectare videtur, quam ad Torrubiam sphecocephalam $\mathrm{K}_{\mathrm{L}}$. 
Torrubieo fungo ex formica nato mycologia nostra europæa etiam superbit; etenim Hypocrea (Cordiceps) myrmecophila Ces. (in Schlecht. Ephem. Bot.Berol. t. IV [1846], p. 877 , t. XIII [1855], p. 75 et t. XVI [1858], p. $30_{2}$, n. 19; nec non in Actis Soc. Cryptog. Italex, fasc. II [1861], p. 61-64, tab. Iv, fig. 2, sub titulo Cordicipitis [entomogena] myrmecophila C.es. et fasc. IV [1863], p. 191), stirps insubrica eximia et gracillimi habitus, quam propter quamdam ascorum curvaturam nobilis inventor Campylothecium olim dixisset, optimo jure sub Torrubiarum signo militat. Continetur in Rabenhonsti Herb. mycologico, ed. princ. fasc. XI, n. 1033 , et ed. alt. fasc. VIII (1858), n. $7^{119}$. Non obstante autem analogia ex origine, Torrubia myrmecophila multo minus ad Torrubiam nostram unilateralem similitudine accedit quam ad T. sphecocephalam cujus enim imago deminuta extrinsecus omnino est. Fungillum Cesatianum, in ichneumone quodam britanno stantem, maio reperisse sibi videntur Berkeleus et Broome. (Cfr. Ann. and Mag. of nat. Hist. ser. alt. t. VII [1851], p. 186, n. 591 .)

\section{EXPLICATIO ICONUM.}

(Tab. I, fig. 3 et 4.)

3. Formica fungipara de qua supra agitur a latere hic conspicitur, nativis demensionibus non mutatis.

4. Ejusdem pars antica amplificata a fronte proponitur, simul cum Torrubice unilateralis cauliculis duobus, bestiolæ cervici impositis et valde inæqualibus.

\section{Torrubia cocgigena $†$.}

Coccus fœmina, aptera, turgida, flavida coloreque fusco variata, myc lii intestini causa in stroma solidum mutatur ex quo flagella et columellæ fertiles prodeunt. Apud bestiolam quam præ oculis habemus, columnæ validæ, flexuosæ, $5-7^{\mathrm{mm}}$ altæ, glabræ capiteque globoso crassitudine seminis rapæ singulatim instructæ, e thoracis lateribus contrariæ assurgunt. Præterea vero flagella duo his stilis duplo circiter longiora et multo graciliora, e marginibus excipuli fungini quo Cocci abdomen gravidum subtus augetur, nascuntur, et in clavulæ brevissimæ ac vix incrassatæ speciem desinunt. ConCEPTACULA in suo stromate penitus demerguntur, eorumque ostiola obtusa nonnihil prominent; copiosa stipataque in capitulis modo dictis, paucissima e contrario et valde laxa in clavellis generantur; unde etiam dubitare licet num perithecia unius et ejusdem modi sint in his et illis fructibus; quæstionem solvendi nobis defuit facultas.

Vigebat loco dicto Dory in Nova Guinea et ab illustri navigatore Dumont o'Urvilce reperta est. (Cfr. Mus. entomol. par.)

Fructus fungilli capiliformes Cordicipitem armeniacam Berk. et Curt. imitantur. (Cfr. Act. trim. Soc. Linn. Lond. t. I, p. 158 , tab. I.)

\section{EXPLICATIO FIGURE.}

(Tab. I, fig. 10.)

10. Figura hac exprimitur Torrubia nostra coccigena, nota circiter quadruplo major facta. 
Præter Torrubias entomogenas supra enumeratas, quamdam nondum clavigeram vidimus in variis Curculionum generibus quæ terris nostris aliena sunt, fungillum nempe quam perfectiorem novit Car. Roвin et ad Sphcriam entomorrhizam Dicks. trahendum fore immerito opinatus est. Hæc Torrubia Curculionum in insectis nondum exanimis, ni omni specie decipimur, nascitur et aliquandiu viget. Accuratam ejus descriptionem et iconographiam exhibet Robiniana prælaudata Historia Vegetab. parasit. p. 650 et seq. tab. vIII, x et xII. Torrubiam nondum fertilem insuper videre est, ut arbitramur, in Cordicipite? fuliginosa Cesatio (in Comm. Soc. Cryptog. Itala, fasc. alt. [1861], p. 67, n. 8, tab. vi, fig. 1), ex eruca Bombycis (Orgyce) antiquce Brixiæ ortam, ac propter colorem surdum quo inficitur, inter pyrenomycetes entomogenas vulgo læte pictos, profecto peculiaris indolis. Fungos alios filiformes entomoctonas et miræ structuræ sed steriles, alium glabrum et dichotomum in abdomine Euglossa cujusdam (ex Apidarum tribu), alium contra pilosum, simplicem et fasciculatum, dorso Acanthocephali peculiaris magnitudinis (e grege Coreidarum) insertum tradunt Acta Soc. Entomol. Londinensis, t. III (1841-1843), p. iv. tab. vi, fig. 2 et 7 .

\section{Mycogence s. Cordylie verce nobis.}

a. Claviformes.

\section{Torrubia ophioglossoides.}

Clavaria parasitica Willd. Fl. Berol. Prodr. (1787), p. 405, n. 1178 , tab. vir, fig. 17, cui fungo locum inter Spharias merito impertiendum fore paulo post animadvertit Frid. Енвнатт in suis Beiträge z. Naturkunde, t. VI (1791), p. 47 , n. 193 .

Clataria radicosa Bull. F. Gall. t. I, p. ${ }_{9} 5$, tab. ccccxu, fig. 2. - Minime autem Clavaria ophioglossa Holmsk. Ot. Bot. parte I, p. 18 , tab. I, fig. IV et vI (semina catenata ac basim radiciferam proponentibus), nec non tab. vili, quippe Geoglossum quoddam illa exhibet.

Spheria radicosa Candollio, Fl. Gall. t. II, p. 283 , n. 754.

Spheria ophioglossoides Ehrhartio, Pl. Crypt. exs. dec. XVI, n. 160 (auctore Persoonio). - Pers. Comm. de F. Clavaef. p. 144 , n. 3 ; Syn. Fung. p. 4, n. 5; Myc. Europ. t. I, tab. x, fig. 5-6 (sine descriptione).Moug. et Nestr. Stirp. Vog.-Rhen. fasc. VI (1818), n. 565. - Scнмidtio, Myk. Hefte, parte II, p. 26 et 29 , tab. I, fig. 22. - Friesio, Syst. Myc. t. II, p. 324, n. 4, in Cordicipitum numero, excluso autem fortassis synonymo Schmideliano. - BеккеLеo in НоокеRi Engl. Fl. t. V, parte alt. $(1836)$, p. 233 , n. 4, et in Ann. of nat. Hist. ser. I, t. I, p. 205 , n. $9^{2}$, tab. vi , fig. 4. - Corde apud Sturm, Fl. Germ. t. III (1837), p. 143 , tab. LXIv et ult. clavis æquo brevioribus sporarumque iconibus non fidis. - Mazerio in suis Pl. Crypt. Gallice, serie noviss. fasc. VIII (1856), n. 378 . - Gurreio in Act. Soc. Linn. Londin. t. XXII, parte ilI, p. 263 , n. 6 , tab. xuv, fig. 7 (ascum et sporas liberas præstante). - Tul. in Ann. Sc. nat. ser. Iv, t. XIII $(1860)$, p. 18-19, et in tomo I hujus Carpologice, p. 62 , in nota.

Cordiceps ophioglossoides Linkio, Handb. z. Erk. d. Gew. parte III (1833), p. 347 , n. 4. - Fr. S. Veget. Scand. p. 381. - Rabenh. Herb. Mycol. ed. alt. fasc. V (1857), n. 427, juxta operis indicem, et Fung. Eur. exs. fasc. V (1862), n. 442 (in Elaphomycete granulato agri Lipsiensis). - Berk. Outl. of Brit. Fung. p. 382. - Cesatio et Not. in Act. Soc. Crypt. Itala, fasc. IV (1863), p. 191.

Ut Torrubia sinceræ ex insectis semivivis demortuisve ac sæpissime defossis nascuntur, sic Cordylia ophioglossoides (FR.) in Elaphomycete (El.variegato VITTad. et El. granulato 
NersiI) vivo, maturo hypogæoque parasitatur. Mycelium ejus copiosum ex bysso, fibris et funiculis, læte flavis aureisve ac intricatis totum constat; matricis interanea parcum, laxum et tenuissimum occupat, ita ut nisi oculis armatis æore conspiciatur; extrinsecus contra luxuriat, ramos crassos et brachiatos undique agit et punctis plurimis unicove cervini tuberis cortici inseritur; inde fit ut ima pars seu stilus clavæ fertilis, si eruatur, in radices divaricatas eoque protractiores quo tuber altius in arena demittitur, desinere videatur. Aureus mycelii color in clavula mutatur quæ enim squalide viret et nigro-olivacea, saltem in vertice, emergit. Dum inter muscos assurgit, quidam mycelii hypogæi apices, reliqua bysso pallidiores, conidiophori evadunt et miram Verticilliorum structuram æmulantur. Conıdia sphærica et flavida (quorum mentionem primam habuimus in Annalium nostrorum loco supra cit.) $0^{\mathrm{mm}}, 003$ diametro minora sunt, atque viII- $\mathrm{x}$ aut plura insimul in capitula stipantur quæ spiculis $\mathrm{o}^{\mathrm{mm}}, 015-025$ longis ac sæpius in verticillos superpositos digestis singula sustinentur. Cidava adulta simplex est, rarius bifurca, recta, obtusissima, glaberrima, 1-2-pollicaris et pennæ anserinæ crassitudine, in stipitem macriorem diuque pallidiorem attenuatur, ac punctis minimis, ostiolis nempe conceptaculorum immersorum vix prominentibus, dense et ubique notatur. Perithecia ovato-acuta hinc $o^{\mathrm{mm}}, 4-6$, illinc $0^{\mathrm{mm}}, 2-4$ æquant, membrana tenuissima flavidaque fabricantur et de nido natali integra queunt eximi; maturitatem si nacta fuerint, pulpa primum albida ex endosporis solutis tota replentur. Thеск longissime lineares obtusæque $\mathrm{o}^{\mathrm{mm}}, 008$-01 crassitudine non superant, longitudine vero $o^{\mathrm{mm}}, 3-4$ consequuntur; singulæ sporis virI (nec duabus tantum ut Sснмгртіо quondam videbatur) filiformibus quasi fasciculo subintegræ referciuntur, citoque pereunt et prorsus evanescunt. Paraphyses sinceræ desiderantur. Spore singulæ theca sua vix breviores sunt, crassitudine autem $0^{\mathrm{mm}}, 0015-0025$ non excedere videntur, septisque transversis in articulos innumeros, $0^{\mathrm{mm}}, 002-003$ longos, mox dividuntur; subinde præterea episporio paulatim rupto aut dissoluto, articuli seu sporulæ ab invicem discedunt et cylindros minimos utrinque truncatos referunt. Ex iisdem pulpa fit humida, dilute et squalide flavida, qua exclusa fungus ut glutine illinitur et inquinatur. Sporulæ satæ nonnihil augentur, olobosæ fiunt et germina exilissima hinc aut inde exserunt; tunc etiam a conidiis ægre discernuntur.

Totum per annum hypogæa viget in declivibus silvarum mycelioque aurantio et sede sua assueta adeo insignitur ut primo obtutu agnoscatur; fertilis seu clavigera reperitur quum æstate currente, tum etiam autumno, extremo quidem. Modoni Cavillæque Versaliorum in quercetis et castanetis non infrequens est. Berkelæana (anglica) specimina continentur in mycotheca Mazeriana quæ alia fungillum in Elaphomycete granulato NeEsII, alia in Elaph. variegato VitTad. parasitantem monstrant; nobis autem nonnisi in variegato hactenus occurrit.

Byssus fungi primordialis e filamentis constat vix $0^{\mathrm{mm}}, 0015$ crassioribus et passim in nodos obovatos incrassatis. Id mycelii ubi effoditur arescendo viret aut nigrescit; in ampulla vitrea vivum cum 
matrice integra, æstate ineunte, si concluditur, paulatim crescit, conidiophorum evadit tandemque fertiles edit clavulas. Fungum hoc modo prospere per longos menses domi coluimus.

\section{EXPLICATIO ICONUM.}

(Tab. II, fig. 1-9.)

1. Torrubia seu Cordylia ophioglossoides matura, nativaque magnitudine adumbrata, fibrarum ope Elaphomyceti nutritio adhæret; e fibris exilioribus flocci conidiferi $f$ passim nascuntur; clavularum pars summa inflata propter conceptaculorum ostiola prominula et sporas exeuntes nonnihil asperatur seu punctulis notatur.

2. Clavula altera e duabus coalitis quasi facta, et adhuc levis.

3. Clava extrema a summo dimidiata, nota major exprimitur; sporæ eructantur.

4. Fragmentum maxime auctum clavulæ a vertice dissectæ et nondum maturæ conspicis; perithecịa in parenchymate crasso nidulantur.

5. Thecæ seorsim dantur; aliæ integræ sporis replentur, rupta altera suum tradit farticulum.

6. Sporæ duæ liberæ et longissime lineares septis stipatis dividuntur.

7. Sporarum fragmenta, catenata alia, seorsa liberaque altera.

8. Nonnulla ex his fragmentis quæ postquam medio augusto (a. NDCGGLX, Cavillæ Versaliorum) in aqua sata sunt, crassiora paulatim evaserunt et intra quindecim dies in germen exile singula abierunt.

9. Flocci conidiophori quorum supra (fig. $1, f$ ) mentio agitur, hic valde amplificantur, ut inde appareat conidiorum generatio.

Figuræ 5-9 nativam magnitudinem vices circiter ccclxxx pariter excedunt; eædem et cæteræ, præter primam annis xvII prius adumbratam, anno MDCCCLX Cavillæ delineatæ sunt, omnes autem pariter ex fungis vivis.

\section{b. Capitate.}

\section{Torrubia capitata.}

$F_{U N G U S}$ diffculter ad ullum notorum generum referendus, stipite ex albo livescente, suberoso . . pileo glandis forma, fusco... OEdero in Flore Danica fasc. IX (1770), p. 8, tab. dxu (tubere natali omisso).

Spheria agariciformis Boltoni, F. Halif. (ed. Willden.), t. III, p. 61, n. 163 , tab. cxxx, quam de matrice tuberiformi vix fidam habeas. - Sowеrвао, Fung. Brit. t. III (1803), tab. cccliv, figuris, nonnullis saltem, ut videtur, ex BoLtone sumptis.

Clavaria capitata Holmsk. Ot. Bot. t. I, p. 38, iconibus (tab. xiv) eximiis accedentibus; Coryph. (ed. Pers.), p. $52-55$.

Spheria capitata Pers. Comment. de F. Clavif. p. 145, n. 5; Syn. Fung. p. 3, n. 3; Mycol. Europ. parte 1. tab. x, fig. 1-4, absque descript. - Sснмгртіо, in suis Fasc. Myc. parte I (1817), p. 95-100. - Friesio, Syst. Mycol. t. II, p. 324 , n. 3, inter Cordicipites. - Moug. et Nestr. Stirp. Voğ.-Rhen. fasc. VIII (1823), n. $7^{63}$ (in Elaphomycete granulato Fr.). - Bевкецео apud Ноокевuм, Fl. Brit. t. V, parte alt. p. 233 , n. 3. - Mazerio, Pl. Crypt. Gallice, ser. noviss. fasc. VIII (1856), n. 379 (item in Elaphomycete granulato Fr.). - F. Curreio in Comment. Soc. Linn. Londin. t. XXII, parle III, p. 263 , n. 9 , tab. XLv, fig. 10 , ascum exprimente gravidum et sporas seorsas.

Cordigeps capitatus Linkio, Handb. z. Erkenn. der Gew. parte III (1833), p. 347 , n. 3.

Cordiceps capitata Fr. S. Veget. Scand. p. 381. - Berk. Outl. of Brit. Fung. p. 382. - Cesatio el Not. in Act. Soc. Crypt. Itale, fasc. IV (1863), p. 191.

In hypogæo Elaphomycetis (quum El. variegati VitTad. tum El. granulati NeEsio) tubere, vivo maturoque, fungillus noster parasitatur; sine radicibus mycelioque conspi- 
cuo carnosus ex eodem assurgere solet in columnam rigidam, $2-3$ - pollicarem et quasi digiti minoris crassitudine, atque ubi adolevit, in caput ovato-globosum vel reniforme tumidus desinit. Ex omni parte glaberrimus est ejusque stipilis color aureo-flavus, capituli autem atro-virens. Perithecia ovato-acuta, stipatissima, de more immersa ostioloque vix prominula, stratum tenuissimum struunt quo summum capitulum undique obducitur. Тнесе longissimæ crassæque in vertice obtuso s. umbonato peculiariter tument, deorsum contra in filum perexile singulæ attenuantur, integræque sporis pallidis referciuntur. Spors ex articulis catenatis fabricantur qui demensiones maximas sed inæquales, nimirum $0^{\mathrm{mm}}, 03-06$ in longitudinem ac $0^{\mathrm{mm}}, 003-005$ in crassitudinem, adipiscuntur, formamque variam, scilicet anguste lanceolatam vel ovato-lanceolatam, fusiformem aut rarius lineari-cylindricam, sæpius autem sub utroque apice nonnihil angustatam induunt.

Nascitur æstate recedente autumnoque, in locis pendulis et silvosis, sed longe rarior est apud nos (Modoni Cavillæque Versaliorum) quamTorrubia ophioglossoides supra descripta. Hactenus in solo Elaphomycete variegato Vittad. insitam reperimus; contra apud Movgeotium et Mazerium (herb. sup. citatis) in Elaph. granulato Neesir datur. (Cfr. mycoth. Musæi paris.)

Torrubia capitatce (PERs.) imago a plurimis jam evulgata est, a nemine autem, ante CURreiun, interna illius fabrica. Præ Torrubia ophioglossoide et cæteris pyrenomycetibus qui seminibus partilibus item utuntur, amplis sporarum demensionibus et varia crassaque articulorum s. sporidiorum forma insignitur. Hos articulos quos tamen accurate severamus, germinantes non vidimus nisi in ipsis ostiolorum labris; ubi enim endosporæ ejiciuntur, conuli in modum obtusi et dilute luteoli singula super ostiola adglutinatæ coacervantur. Byssos conidiophoras nunquam deprehendimus.

Fungillus e solita sua matrice hoc modo prodit ut vix miremur quod accuratissimi rerum naturalium scrutatores, quales Holmsкioldus, Bolto, Sowerв zus (locis sup. cit.)aliique, ni fallit memoria, eandem pro legitima illius radice habere non dubitaverint. Errorem veterum primus denuntiavit Sснмгртіus in suis Fasciculis Mycologicis, loco supra cit.

Bene notat Cesatius fungi capitulum in suffulcrum suum, pileoli instar, breviter descendere proptereaque Clavicipites imitari; eodem nobili viro docente, Torrubia capitata et ophioglossoides in Insubria raræ occurrere viderentur. (Cfr. Acta Soc. Cryptog. Itala, fasc. alt. [1861], p. 69 et 7 o.)

\section{EXPLICATIO ICONUM.}

(Tab. II, fig. $10-15$.

10. Spharia capitatce Persoonir, variæ ætatis, stant in Elaphomycete variegato Vittad.

11. Fungus a vertice simul cum tubere natali dissectus exprimitur, unde mira apparet prioris cum altero continuitas; plantula minor integra juxtaponitur.

1؛. Specimen alterum adultum, ex Elaphomycete ita erumpit ut sua basis solulo matricis corticulo brevissime excipiatur.

13. Conceptacula integra de parenchymate in quo informata sunt exempta traduntur.

14. Theca adulta seorsim spectatur. 
15. Endosporæ ex articulis linearibus, lanceolatis ovatisve factæ, integræ aut ruptæ, simulque articuli plurimi soluti, forma et crassitudine mire varii.

Figuræ 10-12 magnitudine nativa proponuntur, reliquæ maxime at pari modo (nempe vices circa CCCLXXx) augentur; cunctæ juxta fungos vivos Cavillæ Versaliorum delineatæ sunt, octobri mense a. MDCCCLIII (præter fig. 12, annum post octavum, mense julio adumbratam).

Sесто II. Nectriei modo carnosi tuncque pulvinati aut tenuiter stratiformes, nunc contra sed rarius byssini et effusi; conidiis unius vel duplicis generis, minoribus solitarie acrogenis aut verticillatis. - Hy POCREACEI.

\section{EPICHLOE.}

TYPHODIUM Linkio, Bonordenio (Disput. Mycol. [1864], p. 84, n. 11, et p. 166, n. 6 ); EPICHLOE Friesio et discipulis.

Genus hactenus, quod sciamus, monotypum, cujus propterea characteres et synonyma ad fungum infra descriptum ex toto spectant.

Epichloe suas propter sporas lineares et continuas, vitamque in graminibus parasiticam, Clavicipites sinceras, sclerotiis instructas, v. gr. Cl. purpuream et microcephalam nostras, pariter graminibus infestas, imitatur, habitu autem Hypocreas effusas et maxime Hypomycetes.

Modo dictæ Clavicipites, ob analogiam ex endosporis ductam, omnino sunt hujus loci; quidquid autem de iis dicendum nobis erat, jam in tomo primo hujus Carpologice proposuimus. Fred. Gurnex iconem præstitit ascorum sporarumque Clavicipitis purpurea (Fr.) in Actis Soc. Linn. Londinensis, t. XXII, parte III (1858), p. 264 , n. 24 , tab. xuv, fig. 25 ; præterea idem fungus eximie adumbratur tum in Julii Küнn libro de plantarum sativarum morbis ex mycetibus (p. 126 et seq. tab. v, fig. 1-23), tum apud Bевкецжuм, Outl. of Brit. Fungology, p. 382 , tab. xxIII, fig. 7. Singula recentiorum KüHNII de Clavicipitibus commentationum nuper persecutus est Arminius Hoffunan in Ephemeride Bot. Berolinensi, t. XXII (1864), p. 26 9-27.1.

\section{EPichloe trphina.}

SPHeria SPICULIFERA Sowerb. Engl. Fung. t. III $(1803)$, tab. cclxxiv, titulo ex endosporis mirum in modum protrusis ducto, fungilloque tamen dubitanter inter Sphcerias admisso.

Spheria typhina Persoonio, Ic. et Descript. Fung. fasc. I, p. 21, tab. vil, fig. 1 et $2 ;$ Syn. meth. Fung. p. 29 , n. 49. - Gandollio, Fl. Gall. t. II, p. 290 , n. 778. - Ant. DE BaRY, in Flora ratisbonensi, ser. alt. t. XXI (1863), n. 26, p. 401-409.

Polystigma ty phinum Candolio, Mém. du Mus. t. III (1817), p. 338. - Modg. et Nestr. Stirp. Vog.-Rhen. fasc. I (1810), n. 79. - Rabenn. Herb. Mycol. ed. alt. fasc. VI (1857), n. 578 (ex agro Dresdensi). 
Dothidea typhina Friesio, Syst. Myc.t. II, p. 553, n. 13 (inter Polystigmata Xylomatum). - Rabenh. Herb. Myc. ed. alt. fasc. VI (1857), n. 578 , et in suis Fung. Europ. exs. fasc. VI (1863), n. 541.

Stromatospheria typhina Grev. Fl. Crypt. Scotice, t. IV $\left(18_{2} 6\right)$, tab. cciv, quod ad endosporas attinet, imprudenter ficta.

Typhodidm graminis Linkio, docentibus Friesio, Syst. Myc. t. III, p. 362 , et Rabenhorstio, tum loco supra citato Fungor. Europ. exsiccatorum suorum, tum etiam in Sснцеснт. Ephem. Bot.t. XXI (1863), p. 229 , infra. - Bonord. 1. supra cit.

HyPocRE species Friesio in Indice sui Syst. Mycol. p. 87.

Cordiceps (E EICHLOE) typhina eidem Friesio, quum in sua Sum. Veget. Scand. p. 381, tum in Ephem. Bot. Berol. t. XXII (1864), p. 189, n. 26.

EpIchloe typhina (Fr.) Tul. in Ann. Sc. nat. ser. iv, t. XIII (186o), p. 18 , et in t. I hujus Carpologice, p. 229 et ${ }_{2} 30$, adnot. xxvi. - Cessatio el Notarisio in Actis Soc. Cryptog. Itale, fasc. IV (1863), p. 192.

CLavigeps typhina Balio in Nov. Act. Acad. nat. Cur. t. XXIX (1862), cum figuris (tab. I, fig. 1-5 et 7-10, et tab. II, fig. 1-10, endosporas abunde septiferas exprimentibus).

Parasitatur fungillus in culmis graminum et præ cæteris, apud nos, in Dactyli glomerata, Holco lanato, Poa bulbosa et nemorali, quapropter sterilibus factis. Hlius mycelium matricis penetralia vix conspicuum occupat, debito autem tempore prodit in lucem et culmum aut imam folii vaginam, imo sæpius gemmam totam strato tenui, byssino primum, niveo levique, mox autem carnoso, minute papilloso ac pedetentim aureo facto induit. Pars graminis sic obducta amplitudine maxime variat, modo enim vix semipollicaris, nunc contra $2-4$ - pollicaris deprehenditur. Donec byssinum se habet, stratum funginum setulas exilissimas $0^{\mathrm{mm}}, 03$ circiter longas erectasque passim at præsertim ex ambitu enititur quibus conidia ovata, $0^{\mathrm{mm}}, 005$ diametro majori vix excedentia, solitarie suffulciuntur. Brevi autem evanescentibus his corpusculis, perithecia ovato-globosa, utrinque obtusissima, e parietibus carnosis, pallidis crassissimisque sibi invicem stipatissima juxtaponuntur et in stratum continuum coalescunt. Conceptacula cum adoleverint, $0^{\mathrm{mm}}$, 4-6 longitudine æquant, colore læte aureo insigniuntur, obtusa consistunt, poroque angusto sporas candidas, anguste lineares, scilicet $\mathrm{o}^{\mathrm{mm}}, 13-$ 16 longas et $\mathrm{o}^{\mathrm{mm}}, 004$ non crassiores, continuas, rectas vel nonnihil flexuosas levesque excludunt. Hæ sporæ singulis in thecis clavato- vel lanceolato-linearibus, inferne breviter attenuatis, $o^{\mathrm{mm}}, 01$ in medio non crassioribus, sub capite brevissime conico seu obtusissimo quasi coangustatis moxque destructis, consumptis, in fasciculos octonæ generantur. Paraphyses sinceræ, ni fallimur, semper desiderantır.

Jampridem quotannis comperimus fungillum haud infrequentem provenire vernali æstivoque tempore in agro parisino, versaliensi, compendiensi, vastinensi cæt. Fungillum aureum factum sporasque maturas foventem junio medio jam reperire licet.

Quum gemmam vel compactissimam occupat, tunc utraque foliorum pagina bysso densa albaque, primum saltem, obducitur, imo fungina substantia gemmam totam infarcire videtur.

Erratne clar. Fred. Curnex, sæpius tamen accuratus et bene oculatus, ubi Epichloem a Spharia militari Eнrн. quoad fructum non discrepare pronuntiat, nisi ascis minoribus? (Cfr. Comment. Soc. Limn. Londin. t. XXII, p. III [1858], p. 265 , n. 26 a.) Nec secus sane sentiebat Balius qui endosporas innu- 
meris septis divisas expressit (loc. cit. Actorum Acad. Cacs. nat. Cur.). Hasce tamen continuas huc usque semper deprehendisse nobis videmur; easdemque efiliformes, hyalinas et simplices " nuper dixit RABENноrstius. (Cfr. Sснцеснт. Ephem. Bot. t. XXI [1863], p. 230 in parte summa.) Friesius e contrario Currer opinionem nuper probavit. (Cfr. eandem Ephem. Bot. Berol. 1. supra cit. tomi XXII.)

Dum in pyrenomycetis vere parasitici consideratione versamur, suadet locus ut pauca etiam verba faciamus de fungillis duobus priori contribulibus qui vitam suam apud plantas vivas, e primatum seu digniorum ordine, item sustentant. Alius in fruticetis Chilenis, alius in terris Columbianis præaltis, uterque ideo sub sole temperato Americæ calidioris viget; præterea colore tandem nigro, forma globosa et tessellato-verrucosa, nec non interna fabrica sibi invicem congruunt, quare eodem titulo his in pagellis salutabuntur.

\section{HYDNOPSIS $\dagger^{1}$.}

Generis characteres qui hactenus innotuerunt in sequentibus adumbrationibus continentur; quos autem majoris momenti æstimamus, hos ministrare nequeunt specimina manca quæ sola suppetunt.

\section{Hydnopsis Eugenia $†$.}

Fungus adultus, globosus ac nucis avellanæ crassitudine, nunc bene compositus seu regularis est, nunc contra foveolis aut cavernulis hinc illinc confoditur et deformis abit; ex omni parte et, ni fallimur, jam a prima ætate, colore atro extrinsecus fucatur simulque tesserulis quasi pyramidatis seu tuberculis tetra- v. pentagonis, Tuberum more (v. gr. Tuberis astivi VITTAD.), mirum in modum ornatur. Verrucæ istæ interdum etiam a vertice scinduntur, rimis exarantur, sed striaturis transversis destituuntur. Quod ad situm et ortum attinet, fungus e gemma arbusculæ hospitis abortiva, id est e ramo maxime contracto in substantiam funginam veluti mutato, aut quidem e pedunculo florifero in basi summopere tumefacto, superne autem emaciato, suam originem ducere solet. Quum gemmæ binæ superpositæ, ut frequenter accidit, in axilla ejusdem folii simul nascuntur, superior in virgam normalem plerumque protrahitur, inferna vero corrupta in fungillum sessilem vertitur; sunt etiam gemmæ solitariæ quæ malam sortern integræ item experiuntur, aut quæ ubi explicantur subito intumescunt proptereaque suffulcrum breve fungillo suppeditant. Fungi præterea nonnulli in axilla nuda ramorum hornorum, adultorum sanorumque, sessiles sæpiusque solitarii gignuntur; multo plures autem e gemmis, pedicellis ramulisque novellis adhuc herbaceis oriuntur. Hi in principio hospita epidermide toti involvuntur, deinde quum increverunt velo rufo ac

${ }^{1}$ Hac voce intelligimus plantas quæ $\check{\Upsilon} \delta \nu \omega \nu$, i. e. Tuberum, habitum quodammodo mentiuntur. 
tomentoso (e pilis v. setis simplicibus, crassis rufoque fartis endochromate), instar rami nascentis, adhuc etiam teguntur; idem vero procedentes ætate pedetentim exuunt, cirris paucis hinc et illine verrucarum in apice diutius persistentibus. Postquam enim nudatus apparuit adolevitque fungus parasiticus, ceræ quoddam genus squalide luteolovirens e rimis externis, angustissimis, exigere incipit, quod totum e seminibus (stylosporis) ovatis, levissimis, hyalinis, utrinque obtusissimis et muticis, $o^{\mathrm{mm}}, 013-015$ longis, $\mathrm{o}^{\mathrm{mm}}, 0056-0064$ crassis, ab invicem liberis sed muco, ut videtur, adglutinatis constare reperies. Semina hæc in parietibus sinuosis cavernulæ angustæ et varie loculatæ quæ sub crasso fungi totius cortice confossa expanditur, singula sterigmate cylindrico, crassiusculo, simplici et $o^{\mathrm{mm}}, 015-02$ longo suffulta generantur. Præter angustias illas seminiferas, fungus solidus est ac parenchymate homogeno, atro-fuligineo, e cellulis globoso-polygonis, $0^{\mathrm{mm}}, 01$ diametro vix æquantibus et arcte consociatis, totus formatur; venis tamen e basi oriundis, albidis angustisque sectus marmoratur, quæ immersas sepultasque ramillorum reliquias, seu materiem hospitis ligneam superstitem, at pro maxima parte commutatam funginamque factam, exhibent. Fungus perfectus, maturus, tandem e ramo materno solvitur integerque aut varie diffractus labitur, relicta in arbore cicatrice variæ amplitudinis formæque, sæpe autem quasi labiosa et basim Visci aut Loranthi minoris quodammodo mentiente.

Viget apud Chilenos in ramis hornis, rarius annotinis, Eugrenic Bridgesii Ноoк. et Ars. (Barn. in GaIr Fl. Chilena, tom. II [1846], p. 394) quæ inter Araucanos aliosque chilensis regionis autochthones Pitra, GAIO auctore (in Herb. Mus. par.), audit. Specimina adumbrata exstant in herbario chileno Musæi parisini et a Claudio GAIo olim lecta sunt.

De fungilli modo descripti aptiore sede in immenso fungorum grege dubia eo magis legitima moventur quod formam illius unicam, nec præstantiorem, ut opinamur, tantummodo novimus. Suadet enim analogia eo inter pyrenomycetes debitum vindicari locum, meram vero pycnidem, propter seminum quibus scatet naturam s. dignitatem, ad præsens constitui. Utrum in hoc sentire erraverimus, necne, futuræ indagationes docebunt.

Stirps nostra crescendi ratione admodum imilatur et habitu quodammodo refert Sphcriam morbosam Schw. in Actis nat. Scrut. Lips. t. I (1822), p. 40, n. 134 , cujus exempla nonnulla, alia Schweinitziana authentica e Carolina superiore, alia e Georgia missa et a cl. BевкеLжо accepta, in mycotheca Musæi Bot. parisini videre nobis licuit. Hæc Spharia in fruticibus vivis instar fungilli nostri chilensis et Sphacrice viroultorum Fr. S. M. t. I, p. 351, n. 64, vere parasitatur, nec impari modo ramos maternos tumefacit et deformat, ita quidem ut Schwersirzı in mentem venerit causam istius deformationis non in fungo insito sed in cynifibus præviis fortassis versari. Quid autem opus est cynifum officium hic invocare, nonne fungus ipse satis est ad matricem deturpandam, testantibus Podisomate, Ustilagine et innumeris paris vitæ consortibus? In exiguis autem Spharice morbosa Scнw. conceptaculis thecas frustra hactenus quæsiimus, nec nisi sporas golobosas, perexiguas, vix enim $0^{\mathrm{mm}}, 003$ crassiores, atras, leves, uniloculatas, innumeras mucoque immersas vidimus.

Neminem quoque fugerit fungillum nostrum eundem vigendi modum affectare qui Cyttarïs, item 
chilenis, solemnis est. (Cfr. inter primos BerкеLеum in Act. Soc. Limn. Londin. t. XIX, parte I [1842], p. $37-43$, tab. iv, et scriptores cit. apud Arm. Horfm. Ind. Fung. [1863], p. 45, vo Cyttaria.)

\section{Hydnopsis graminicola $†$.}

Fungillus ex culmo vivo sterilique graminis cujusdam pennæ corvinæ crassitudine, vix secus nascitur atque cynipum gallæ sphæricæ in ramulis, foliis amentisve quercuum nostratium. Formam sphæricam ipse affectat et pisi crassitudinem nancisci, imo excedere videtur; solidus, carnosus aut suberosus est, ut opinamur, saltem exsiccatus ad cornu duritiem accedit; præterea aculeis polygoniis et stipatissimis instar Elaphomycetis

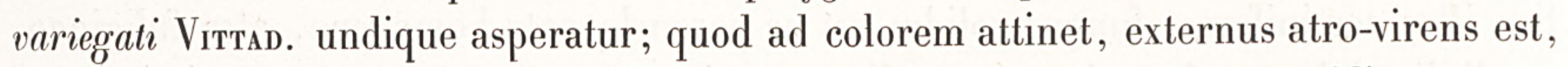
internus autem veluti chlorinus. Seninum genus saltem duplex. Prius conidiorum quæ sphærica, simplicia, lævia, aurei coloris, pulvereæque indolis, $o^{\mathrm{mm}}$, oo 35 diametro singula vix excedunt, et sessilia nascuntur secus filamenta multi-articulata, brevissima et conferta quibus universa plantulæ pagina, maxime in rimis, vix conspicue obsita deprehenditur. Spore digniores in thecis generantur, maturæ autem nobis non suppetunt. Discus enim ater, levis et durus, ex fungillo hinc aut inde oritur, in modum clypei orbiculati extenditur, supposito stromati seu tuberculo aculeato arcte adhæret ejusque anfractus et rimas implet, ut alienæ seu hospitantis plantulæ vices agere omnino videatur. Tum intra supremam hujus disci substantiam constipati informantur uteri oblongi, quare Dothidece fabricam præ oculis habere credas. Plura videre non licuit.

Occurrit abhinc paucis annis, in Nova Granada, oculatissimo viro, Alexandro Lindig, nec locum obtinuit in enumeratione mycetum Columbianorum quam nuper publici juris fecit clar. LÉveillé in Annalib. nostris Sc. naturalium, ser. Iv, t. XX (1863), p. 282-30o. (Cfr. Bot. Musai par.)

Dantur etiam Hydnopseos nostræ specimina quæ propter insitum quoddam Spharice byssisedæ genus (Sph. perisphariam nob.), discum ascigerum edere non valuerunt. Id alieni fungilli, ni fallimur, ad Sphariam mutabilem Pers. (Ic. et Descript. Fung. fasc. I, p. 24 , n. 28 , tab. vII, fig. 6$)^{1}$ affinitate accedit; uteros monstrat globosos, breviter papillatos, ariditate fragiles et cinereo-nigrescentes factos, byssoque cinerea gregatim impositos; ascos autem lineari- v. oblongo-lanceolatos, $0^{\mathrm{mm}}, 08-09$ longos et disticho ordine octosporos; denique endosporas ovato-lanceolatas, rectas, bi- vel tripartitas, $0^{\mathrm{mm}}, 02$ circiter longas et $0^{\mathrm{mm}}, 0065$ vix crassas.

\footnotetext{
Describitur etiam hæc Sphoria a Ditmario apud Sturmium, Fl. Germanica, t. I (1817), p. 129, tab. Lxiv.
} 


\section{HYPOCREA.}

(Tab. III et IV.)

\footnotetext{
* Fungus imperfectus, conidiophorus :
}

PYRENIUM Todei in suis F. Meckl. sel. parte I, p. 33. = TRICHODERMATIS species Persoonio, Syn. Fung. p. ${ }_{2} 31$, inter fungos gymnospermos Angiocarporum. $=$ TRICHODERMATA Friesio, Syst. Myc.t. III, p. 214 , ubi ordinis fungorum Trichodermaceorum quasi centrum constituunt; Sum. Veget. Scand. p. 448, inter Gasteromycetes Trichodermaceos. - BerкeLeno, Outl. of Brit. Fung. p. 357 .

** Fungus ascophorus :

SPHERIARUM species Todeo, Sowerbeo aliisque artis nostræ patribus. = SPHERIE paucæ ex periphericis et compositis Persoonio, Syn. meth. Fung. p. 13, 18 et cæt. = HYPOCREE Sphceriarum pulvinatarum et HYPOCREE quædam connatarum Friesio, Syst. Myc. t. II, p. 335 et seq. = CREOPUS Linkio, Handb. z. Erk. der Gew. parte III (1833), p. 349, n. 56.= SPHERIE hypocreacece ex tribu IV Notarisio apud Parlat. Ephem. Bot. Italam, anno I, t. alt. $(1845)$, p. 50 et 51. = CORDICEPS et HYPOCREA, utrumque genus pro parte, Friesio, S. Veget. Scand. p. 381 et 383.= CORDICIPITES et HYPOCREE Berkeleo, Outl. of Brit. Fung. p. 381 et 383. = HYPOCREARUM maxima pars Cessatio et Not. in Act. Soc. Cryptog. Itala, fasc. IV (1863), p. 192 et $193 .=$ CYTTARIE, HYPOCREE et PYRENODERMIA varia Bonordenio in suis Abhandl. aus d. Geb.d. Mykologie (1864), p. 84, 166 et 167 .

Sтrома varium, modo in pulvinum informatur, nunc in membranam stupeumve stratum extenditur; aliquando etiam prorsus deficit aut saltem a sua matrice non discernitur. Conidia ex bysso verticillata, effusa pulvinatave, aut quasi ex villo insperso, tenuissimo et simplici, in capitula nascuntur, minima, globosa, pallida aut saturatius picta et si abundaverint denique pulverea. Perithecia ovato-golobosa obtusaque in summo stromate stipata nidulantur thecasque anguste cylindricas, breves et octosporas fovent. SP0R a autem monosticho ordine instructæ, ovatooblongæ et didymæ, in partes duas, globosas et æquales, sigillatim tandem scinduntur, indeque sporæ sedecim in singulis ascis generari videntur.

FuNGILLI carnosuli, pallidi pictive, in fungis vivis aut corruptis crescentes, interdum etiam subinde in quisquilias vagantes.

Hypocrea, quales a nobis intelliguntur, habitu variant; typus apud nos vulgatior formam Hypoxylorum pulvinatam usurpat, cæteri autem tum Hypomycetes byssisedas et effusos, tum agaricicolas imitantur; quocumque modo se habeant, endosporis intra singulos ascos primum octonis deinque senis denis, a cæteris contribulibus fungis, sicuti jam sagacissimo Curneio visum est ${ }^{1}$, Hypocrea absque negotio discriminantur. Habita horum seminum ratione, Hypo-

\footnotetext{
${ }^{1}$ Cfr. Acta Soc. Linn. Londinensis, t. XXII, parte III (1858), p. ${ }_{262}$, in nola 1, et p. 266 , n. 36. Fortassis tamen
} 
crece manifeste ad Hypomycetes transeunt quorum enim endosporæ inter germinandum non scinduntur quidem, sed mire didymæ fieri solent. (Videas infra, p. 38 et seq.)

\title{
a. Pulvinater.
}

\section{Hypocrea Rufa.}

\author{
* Fungus totus byssinus, conidiophorus :
}

Pyrenidm lignorum a vulgare Todeo, F. Meckl. sel. parte I, p. 33, n. 1, tab. III, fig. 29 .

Mugor lignifragus Bull. F. Gallice, t. I, p. 103 , n. 6 , tab. div, fig. 6.

Trighoderau viride Pers. Disp. meth. Fung. p. 12 ; Syn. Fung. p. 231 , n. 3. - Albert. et Schw. Consp. F. Nisk. p. 135 , n. 384, descriptione habituali, ut auctoribus mos est, eximie fida. - NeEsio, Syst. d. Pilze, p. 8o, tab. vi, fig. 74. - Grevillio, Fl. Crypt. Scotice, t. V, tab. cclxxi, apud quem scriptorem, duce NeEsio et discipulis, peridium ex floccis intextis et brevi evanidum fungillo perperam tribuitur. - Friesio, Syst. Myc. t. III, p. 215 , n. 1. - Mazerio, Pl. crypt. Gall. ed. I, fasc. II $(1826)$, n. 122 (exemplo pro forma intermedia immerito habito). - Tus. in Ann. Sc. nat. ser. Iv, t. XIII (186o), p. 18 , ubi vera et imperfecta fungilli natura primum ostenditur s. advertitur. - BerкeLEo, Outl. of Brit. Fung. (186o), p. 357, cui auctori fungillus dicitur etiam "probably not autonomous. n - Квомвн. Abbild. der Schw. fasc. I (1831), p. 78 , tab. vi, fig. 28 . - R R ABEnн. F. Europ. exs. fasc. I (1859), n. 67 (in cortice pineo, ex Bohemia).

Botrytis lignifraga Gandolio, Fl. Gall. t. II, p. 70, n. 176. - Linkio, Sp. Pl. Limn. t. VI, parte i, p. 56, n. 10.

Trichoderma erguginosum Persoonio, Champ. Comest. p. 132. - Linkio, Diss. alt. in Ord. pl. nat. p. 23. MAZErio, Herb. modo cit. n. 121.

Huc etiam trahitur Sphceria olivacea Willdenowir in suo Flora Berol. Prodromo (1787), p. 416, n. 1211, quæ non inepte post Sphceriam tremelloidem locum obtinet.

\footnotetext{
** Fungus perfectior, ascophorus :
}

Spharia RUfa Pers. Obs. Myc. t. I, p. 20, n. 38; Syn. F. p. 13 , n. 20. - Alb. et Schw. Consp. F. Lusat. p. 5, n. 16. - Fr. Syst. Myc. t. II, p. 335, n. 26.

Hypocrea rufa Fr. S. Veget. Sc. p. 383. - Tul. in Ann. Sc. nat. ser. iv, t. XIII (1860), p. 18. - Berk. Outl. of Brit. Fung. p. 383, n. 2.

Spheria (Hypocrea) rufa (Pers.) Curreio in Act. Soc. Linn. Lond. t. XXII, parte III (1858), p. 266 , n. 36 , tab. xuv, f. 36 (ascum gravidum exprimente).

Cyttaria rufa Bonordenio, in libro sup. cit. p. 166 , tab. I, fig. 26 .

Pulvinuli perfectiores carnosi, solidi, a grani sinapis ad viciæ molem et quod excedit crassitudine variant, formam globoso-depressam sæpius obtinent nec tota sua basi suffulcro adhærent; præterea discreta manent aut passim coalescunt, inde millim. III-V diametro æquant. Jam a prima ætate colorem dilute stramineum s. luteo-fulvum induunt, senescendo autem saturatiores et rufi quidem veniunt; paucissimi aliquando ab initio virent, imo saturate æruginei fiunt. Donec adoleverint, plerique pilis raris, vix conspicuis, rigide erectis, simplicibus vel basi in cæspitulum parce ramosis, et

non adverterit Curreius endosporas senas denas Hypocrece maturæ primitus geminatim coaluisse. Quin etiam horum seminum series recens nata sæpius continua videtur, et nucleolos xvI, minimis sed paribus distantes intervallis, exhibet. 
$0^{\mathrm{mm}}, 015$-o 3 longis, quasi villo molli, nunc parce, nunc copiosius undique teguntur; hæc autem filamenta exilissima quæ in setæ v. aciculæ modum sursum tenuantur, sertum e conidiis sessilibus, ovatis, $0^{\mathrm{mm}}, 0035-0045$ longis, et $0^{\mathrm{mm}}, 0025$ circiter crassis, singulatim in apice gerunt. Sunt etiam pulvinuli hinc solidi et ascophori, illine autem gossypini et in pulverem æruginei coloris fatiscentes; denique et longe copiosiores offenduntur pulvini toti primum gossypini et subinde in pulverem squalide virentem omnimodo soluti. Hi Trichoderma viride inde a Persoonianis temporibus vulgo audiunt, minime autem, nostro saltem judicio, fungum perfectum ac sui generis constituunt, quippe multo satius æstimamus eosdem pro peculiari conidiorum majorum adparatu, Hypocrece rufa $\mathrm{F}_{\mathrm{r}}$. privo, fore habendos. Trichodermatis enim cæspites in eadem et ipsissima matrice simul cum Hypocrea ascophora nascuntur, licet etiam, eadem utpote multo frequentiores, omnis Hypocrea sociæ expertes sæpissime reperiantur. E filamentis inordinate ramosissimis denseque implexis integri constant, initio candidi sunt deinque Hypocrece instar perfectioris aliquando flavescunt, ac Sepedonia in eo imitantur quod ab intimis suis partibus ordiatur seminum s. conidiorum generatio et maturitas, intusque ideo jam saturate sordideque virescant, quum externum candorem qui e sola byssi sterilitate pendet, nondum deposuerint. Conidia sphærica v. late ovata, levia et æruginei coloris, diametro majori $\mathrm{o}^{\mathrm{mm}}, 0035$ vix excedunt, solitariaque, brevissime moniliformi-catenata, imo fasciculata nascuntur summis in ramis qui breves et contorti, modo alterni, nunc oppositi et maxime divaricati e cruribus crassioribus et assurgentibus prodéunt. Pulvini hemisphærici late sedent, millimetra III-X et quod superest diametro nanciscuntur, et si contigui orti fuerint, sæpe alii cum aliis coalescunt. Conceptacula in stromatis carnosi et solidi peripherico strato laxe distributa nidulantur, poro perexiguo extus denuntiantur nec prominent; illis uterus goboso-ovatus collo subdestitutus, et parietes tenues. THEс exiliter lineari-cylindricæ, sessiles, obtusæ et octosporæ paraphysibus vulgo destituuntur ${ }^{1}$. Spor E monostichæ et didymæ, in globulos s. utriculos duos æquales singulæ mox dividuntur; singuli autem utriculi (sporidiola), quandoque nonnihil ovati, $o^{\mathrm{mm}}, 004$ non excedere solent, et ubi excluduntur pulverem niveum constituunt; sati lente progerminant, salva forma et crassitudine.

Oritur hiemali tempore vereque in corticibus corruptis liognoque putrescente ac fungifero Quercus, Alni, Castaneœ, Salicum, Populorum, Carpini et cæt. ibidemque sæpissime innascitur stromatibus obsoletis diversorum pyrenomycetum, ex. gr. Valse lipheme Fr. et congenerum; reperitur etiam in fungis majoribus exoletis, v. gr. in Agarico adusto PERs. arido, Elaphomycete Leveillei nob. effosso et.cæt. Conidiophora vulgaris occurrit circa Parisios et Versalias,

\footnotetext{
${ }^{1}$ Paraphyses simplices deprehendisse, sporidiola autem in singulis ascis sena dena generari non animadvertisse videtur Bonordensus cujus videsis locum citatum. Quales hic

eas exponimus, Hypocrece nostræ structura et focunditas, quum in pulvinis rufis, tum in æruginosis sibi constant.
} 
ascophora contra minime frequens est. Carpinicolam vidimus Fontebellaqueo, februario medio, anno MDCGCLX. Ubique loca uda, obscura et suffocata quisquiliasque acervatas prædiligit.

Filamenta conidiophora aciculiformia et laxe sparsa, qualia in stromatibus ascophoris deprehenduntur, aqua affusa, præter conidium unicum et centrale, reliqua omnia dimittunt, quapropter monospora incautis oculis haberentur. Byssus ex qua aciculæ illæ assurgunt, tenuissima et vix conspicua, in matrice, circa pulvinos ascophoros, quandoque late serpit et extenditur, ubique etiam læte conidiophora.

Qui specimina illa amphibola, nempe thecaphora simul et trichodermea, quorum supra meminisse decuit, aut ascophora tantum sed æruginei s. trichodermei coloris, et ipse offenderit, is profecto in

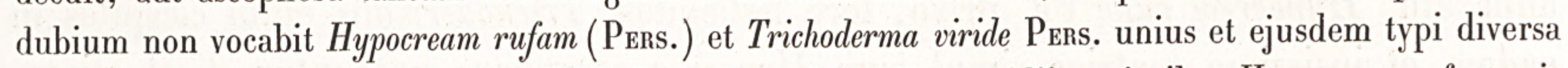
esse membra; atque hujus sic dicti Trichodermatis semina solita conidiis majoribus Hypomycetum fortassis respondere existimabit.

Spharia gelatinosa Toder, Hypocrece rufec $\mathrm{F}_{\mathrm{R}}$. prorsus analoga, duplicis etiam naturæ Todeo ipsi innotuisse videtur; conferas enim hujus accuratissimi mycologi verba de Spharice modo dictæ forma a lutea et $\beta$ viridi, in suis Fungis Meckl. selectis, parte altera, p. 48 et 49, n. 46 , tab. xvi, fig. 123 et 124. Fungillum luteolum solum hactenus vidimus, in agro Gissensi a clar. Arminio Horrmann lectum. (Cfr. Herb. Mus. par.) Ejusdem adumbrationem nuper præstitit Notarisius in suis Sphariaceis Italicis, fasc. I (1863), p. 7 , tab. I, fig. I, $1-4$.

\section{EXPLICATIO ICONUM.}

(Tab. III, fig. 1-10.)

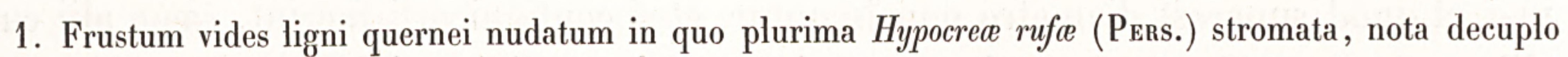
majora expressa, sine lege sparguntur; alia mere conidiophora pro ætate gossypinam vel pulveream meraci Trichodermatis faciem ostendunt; alia, amphibolæ naturæ, conidiorum parciora sunt nec nisi floccis sparsis ornantur, sed uteros hinc inde reconditos fovent; pauciora denique glabra sinceram fungi dignioris et maturi formam affectant.

2 et 3. Stromata amphibola a vertice dissecta proponuntur, aliud in umbilico medio, aliud in latere emaciato ex floccis constat gemmiferis s. trichodermeis; conceptacula autem nondum perfecta in utriusque parenchymate solidiori nidulantur.

4-6. Stromata alia pari modo dimidiata, at mere thecigera; docent fungillum inæquali basi suo adhærere suffulcro, intusque aliquando diversimode fucari.

7. Flocci trichodermei inæqualis, qui iis solennis est, habitus; exteriores graciles spicula conidiophora agunt; interiores autem ex utriculis inflatis struuntur indeque quasi articulati evadunt.

8. Conidia in aqua sata progerminarunt.

9. Pars tenuis et valde aucta conceptaculi a summo dissecti, floccos trichodermeos i. e. conidiophoros, externo supremoque parieti insitos, simul et thecas in utero natas exhibet.

10. Endosporæ paucæ quæ germinare cœperant.

Fig. 2-6 nativas demensiones bis decuplo nota majores faciunt, figuræ autem 7-10 easdem longe magis, nempe vices cccLxxx, superant. Icones omnes a. MDCCCLX, exeunte augusto septembrique, juxta fungos vivos, quercicolas alios, alnicolas alteros, Cavillæ Versaliorum adumbratæ sunt. 
b. Effusa, byssina s. membranacea.

\section{Hypocrea delicatula.}

Hypocrea delicatula Tul. in Ann. Sc. nat. ser. iv, t. XIII (1860), p. 18, cum descriptiuncula in nota.

NulLus sane est qui non miraretur fungilli hujus structuram et vigendi rationem. Mycelium e bysso candida et tenuissima, nunc variis quisquiliis, foliis aridis, late diffusum laxumque hæret, nunc in strata densiora inspissatur et stupeos flocculos tenues, multimodis effiguratos, orbiculares oblongosve, lineas III-XII et quod excedit latos, refert, simulque de suffulcri natura parum curat; quare non solum in corporibus aridis sed etiam in muscis et plantulis vivis effunditur. Ex bysso, utcumque se habeat, assurgunt filamenta duplo vel triplo his exiliora capillamentis quibus implexis stupeum constat stratum; eadem villum rarum constituunt, singulaque ramos breves et gradatos, ipsos sua vice verticilliferos (gradibus distantibus v. pressioribus) induunt; ramuli extremi, fasciculatim verticillati et fusiformes, $0^{\mathrm{mm}}, 01$ longitudine vix excedunt sigillatimque sertulo minimo ex conidiis coronantur. Hæc corpuscula sunt nivea, sphærica, levia et $0^{\mathrm{mm}}, 001$ vix crassiora; disseminatis tempus locusque si faverint, incrassantur, formam globosam in ovatam mutant et utrinque in filum protrahuntur citissime conidiferum. Cum villus conidifer stromati tenuissimo, byssino-araneoso stupeove inspersus, læte aliquandiu effloruit et jam relicta quasi hujusce area, in marginibus nitidissimis densior insidet, tunc etiam conceptacula centralia adparere incipiunt, modo superficialia, modo pene tota immersa, pro byssi substratæ crassitudine; forma gaudent turbinata, utero scilicet $0^{\mathrm{mm}}, 13-16$ crasso, subgloboso et sessili, collo autem brevissimo, nec non vertice obtusissimo atque utriculis exstantibus obsito. Conceptacula illa, e pariete tenui, celluloso semperque glaberrimo, initio dilute flavescunt, maturescendo autem cervina evadunt, et ore vix conspicuo quidquid fovent cum eructaverint, formam et crassitudinem salvas infuscata retinent. THECE rectæ, angustissime lineares, $o^{\mathrm{mm}}, 004$ enim vix crassiores, $o^{\mathrm{mm}}, 1$ longitudine non excedunt, paraphysibus sinceris destitutæ videntur, et sporis xvi in seriem simplicem contiguis geminatimque, ut opinamur, primitus coalitis totæ singulatim replentur. Spor e in principio quasi cubicæ aut saltem e duplici latere truncato-deplanatæ, tandem ab invicem liberæ et perfecte sphæricæ, diametro $\mathrm{o}^{\mathrm{mm}}, 003$ vix æquant; satæ lente incrassantur, salva forma, et in germina filiformia prælonga, exilia parceque ramosa pedetentim abeunt.

Hieme currente bis nobis obvius est fungillus, prope Parisios, nempe Clamarii, ineunte januario, et Cavillæ agri versaliensis, martio recedente, utraque vice in muscis vivis, quisquiliis ligneis, foliis aridis, truncis cæsis humi jacentibus, per sylvarum toca uda et umbrosa. 
Plantulæ hujus cum Hypomycetibus sinceris, v. gr. Hyp. rosello (Aьв. et ScHw.), tanta nobis videtur de habilu et apparatu conidifero affinitas, ut pro verisimili habeamus mycelium ejus ex fungo corrupto primarn quoque trahere originem, indeque in omni corpore circumjacente diffundi et serpere.

Fungus gemmifer mucedinem verticillatam adeo mentitur, ut neutiquam videamus quo modo tute discriminaretur. Conceptacula adeo multiplicantur ut byssum natalem demum fere totam velent, solis illius marginibus angustissime sterilibus. Fungi perfecti aut obsolescentis mycelium maxime tenuatur, proptereaque conceptacula, et illa quidem quæ antea verticem solum, obtusum, emersum efferebant, omnia indiscriminatim nudari videntur.

Hujus loci omnino est Hypocrea citrina Frıesı in sua S. Veg. Scand. p. 383 (Sphacria citrina eidem magistro in suis Scler. Suecia, fasc. I [1819], n. 31, et in Syst. Myc. t. I, p. 337, n. 3o) ${ }^{1}$, præcedentis typi sincera imago, ac cujus stroma citrini coloris late quidem et indeterminato modo expanditur, sed crassum et carnosum fit, tuncque suo suffulcro arcte adhærere videtur. Conceptacula prorsus immersa fovet sporasque vomit innumeras quarum causa veluti pulvere tota stato tempore conspergitur. Fungum hunc nonnisi exsiccatum quum noverimus, de illius conidiis, si qua sunt, nil prorsus comperimus. Ejusdem iconem præstitit Greviluıus (Fl. Crypt. Scotice, t. IV, tab. ccxv) quæ habitum et crescendi modum Hypocrea nostræ delicatula manifesto refert. Hæcce subiculi sui tenuitate et peritheciis subnudis præsertim discriminatur. Adumbratur etiam Hypocrea citrina Fr. apud Notarisiun (Sphacr. Ital. fasc. I, p. 8 , tab. I, fig. 2) qui corpuscula lineari-cylindrica, spermatiformia, in pyreniorum ostiolis animadvertisse sibi videtur.

\section{EXPLICATIO ICONUM.}

(Tab. IV, fig. $7-13$.)

7. Mycelium dense byssinum candidumque Hypocrea delicatula nostræ strata fingit bene definita, quisquiliis, foliis aridis et vivis etiam muscis imposita; qua in sede fructus punctiformes nonnihil exstant; omnia nativæ magnitudinis dantur.

8. Perithecia inæqualis ætatis et crassitudinis simul cum mycelio conidiophoro ex quo emergunt, vices ultra naturam circiter cccixxx pariter amplificata exhibentur.

9-10. Conidia sata et germinantia; adultiora germina progeniem novam, conidiola scilicet acrogena, jam ediderunt.

11. Thecæ et sporæ liberæ seorsim delineantur.

12 et 13. Satæ sunt sporæ, nativam in seriem adhuc ordinatæ, et pleræque creverunt, salva forma; crassiores in germen longe lineare insuper abierunt.

Præter primam, figuræ omnes pari modo auctæ sunt; januario (a. D. MDCGCLX) Parisiis delineatæ sunt, juxta fungos vivos modonenses.

c. Parasitica, gregatim subiculo vivo immerse.

\section{Hypocrea alutacea.}

Fungillus, nisi omni specie decipimur, hactenus a sua matrice viva non distinguitur, quapropter singula synonyma infra allata ens duplex, insciis auctoribus, designant, Hypocream scilicet nostram et Clavariam in qua priorem parasitari præter consuetam opinionem arbitraremur.

${ }^{1}$ Fungillus sub eodem titulo primum a Persoonıo describitur in suis Observationibus Mycologicis, parte I (1796), p. 68, n. 124 , nec inepte cum Poriarum s. Polypororum hymenio et antica Endocarporum pagina æquiparatur. 
CLavaria simplex, oblonga, pulvinata Schmidenio, Icon. el Anal. part. p. 18-26, tab. iv, fig. 2, et tab. v, fig. 1-3; Clavarias autem sanas exprimere videntur figura secunda tabulæ iv et fig. superiores tabulæ v.

Spheria aldtacea Persoonio, Obs. Mycol. t. II, p. 66, n. 99, tab. I, fig. 2 ; Comment. de fung. clavif. (1797), p. 144 , n. 2 ; Syn. Fung. p. 2, n. 2. - Sснumach. Enum. Pl. Sellandice, t. JI (1803), p. 175 , n. $1343 .-$ Friesio, Syst. Mycol. t. II, p. 325 , n. 6, inter Cordicipites Sphariarum compositarum. - Curreio in Comment. Soc. Linn. Lond. t. XXII, parte III (1858), p. 264 , n. 22 , ubi recte animadvertitur fungillum eo ipso uti fructu quo Sphceria rufa Pens. ideoque Cordicipitis habitum, Hypocrece contra fructum præstare.

SPHERIA CLAVATA Sowerbeo, F. Angl. t. II (1799), tab. clix, figuris æquo pallidioribus, saltem apud exemplare quod nobis licuit in Bibliotheca Lessertiana evolvere.

Cordigeps alutaceus Linkio, Handb. z. Erkenn. der Gewächse, parte III (1833), p. 347, n. 5.

Cordiceps alutacea Friesio, Sum. Veget. Scand. (1849), p. 381. - Rabenh. F. Eur. exs. fasc. alt. (1860), n. $1_{2}$, ex silvis abiegnis Britanniæ, et fasc. III $(1860)$, n. 246 , forma albicans dicta Persoonio, ex agro Lipsiensi. - Berk. Outl. of Brit. Fungology, p. 382, n. 9, tab. xxiII, fig. 6.

Hypocrea aldtacea (Pers.) Tul. in tomo I hujus Carpologice, p. 62 , in nota. - Notarisio et Ces. in Act. Soc. Cryptog. Italce, fasc. IV (1863), p. 193.

Claviceps alutacea Balio in N. Act. Acad. nat. Cur. t. XXIX, p. 22, cum iconibus (tab. I, fig. 6 [fungi formam quasi monstrosam exprimente], 11 et 12 ).

Fracidia alutacea Friesio, in Schlechtendalit Ephem. Bot. Berol. t. XXII (1864), p. 189 , n. 22.

Нуромусетим mores fungillus noster prorsus imitari videtur; quemadmodum enim Hypomyces lateritius $\mathrm{F}_{\mathrm{r}}$. et H. Lactifluorum $\mathrm{S}_{\mathrm{cHw}}$. in Agaricis lactariis parasitantur, sic, ut opinamur, Hypocrea alutacea in Clavaria Ligula Schefreno ${ }^{1}$. Inde fit etiam ut Clavaria hæcce alieno prægnans hospite Sphcriam claviformem mentiatur, nec ulla externa nota a Torrubia sincera discrepare videatur. Minime ideo miramur cur usque ad hodiernum tempus Hypocrea alutacea in numero Sphcriarum claviformium habita fuerit. Id fungilli hospitem quidem integram mycelio latente et achroo sane occupat, sæpius vero in sola ejusdem clava, nec in stipite, perithecia gignit; floccis contra conidiophoris pedes matris investit. Hi flocci byssini, parci, albi, conidia globosa, levia, minima, achroa, e summis ramusculis ovato-acutis et sæpius in verticillos digestis enituntur. Conceptacula ascophora globosa et perexigua, scil. $0^{\mathrm{mm}}, 2-225$ diametro crassa, punctulis saturatioris coloris denotantur, tota immersa latent nec nisi papilla obtusissima brevissime prominent, atque poro inconspicuo sporas ut pollen niveum et subtilissimum vomunt. Sровж minimæ, contigue monostichæ, primum octonæ et subcylindricæ, tum didymæ, loculis inæqualibus, posteaque in sporulas duas globoso-disciformes singulatim divisæ et solutæ, thecas exiliter lineares et subsessiles, tandemque solutas et pereuntes, prope integras replent. Pаварнуses, maturo fungo, desiderantur.

Fungilli nostri solita matrix, i. e. Clavaria Ligula Scherfero, provenit autumno in foliis

\footnotetext{
${ }^{1}$ Clavaria tertia seu Clavaria Ligula Scheffero in suis Fungis agri Ratisb. t. II, tab. cLxxI, et tom. IV, Ind. I, p. 116 , n. ccxurx; Clavaria caspitosa Wulfenio apud JaGQUinum, Miscell. Austr. t. II (1781), p. 98 , n. xu, tab. xII, fig. 2 inferioribus; Clavaria Ligula Friesio, Syst. Myc. t. I, p. 477, n. 32; Clavaria Ligula $\beta$ luteola Квомвноцz, $A b$ -
}

bild. der Schwomme, fasc. VII (1841), p. 22 , tab. LIV, fig. 12 .

Datur fungillus in Rabenhorstil Fungis Europ. exs. fasc. II (1860), n. 128 , e pinetis Upsaliensibus, auctore Theodoro Fries. 
acervatis Abietum. Quæ viva vidimus specimina prope Batheaston Britannorum creverant, nobiscumque benevole communicata sunt a clar. viro C. E. Broone, omnis mycetologiæ jampridem studiosissimo.

Clava peritheciis immersis scatens modo in stipitem graciliorem et sterilem continua attenuatur, modo contra formam ovato-oblongam potius affectat et stilo longe tenuiore ac subtereti discreta innititur; priore sub specie fungus hospes Clavariam sanam admodum imitatur. Neque raro tamen accidit ut propter Hypocream insitam Clavaria solitum suum deponat habitum et monstrosa evadat: talem vidit BaLIUs et delineari curavit loco supra laudato. Icones illæ Schmidelianæ quæ Clavarias simplices, oblongas, pulvinatas, ætate provectas et semina sua exigentes tradunt (tab. v libri Schmideliani, fig. 2 et 3), hos fungillos, nimirum Clavariam Ligulam Schefreri, Hypocrea causa plus minus monstrosos factos, ni fallimur, monstrant, immeritoque ad Sphariam militarem vel ophioglossoidem Енгн. duce Sснмnelio ipso, traherentur. Cæterum sententia nostra de vita Hypocrea alutacea ( $\mathrm{P}_{\text {ERs. }}$ ) parasitica plurimorum legitima dubia movebit, donec fortunatus quidam naturæ funginæ scrutator hymenium clavarieum fertile, aut saltem indubium, in illius clava deprehenderit. Jam nunc vero, licet audaciore forsan utamur interpretatione, analogiæ libenter confidimus, ex moribus Hypocrece rufa ( $\mathrm{P}_{\mathrm{ERS}}$.) initio certe fungicolæ consulimus minusque movemur dicto hoc Persooniano, cui tamen, mutato argumento, minime contradixerimus, naturam scilicet in operibus suis esse multiformem, fungosque quoad genus diversissimos nonnunquam eandem prope formam induere. (Cfr. Pers. Obs. Mycol. parte I, p. 68, n. 124 .)

Clavaria Ligula, ubi nostro laborat fungillo, in basi primum tenuissime floccosa est; quum adolevit,

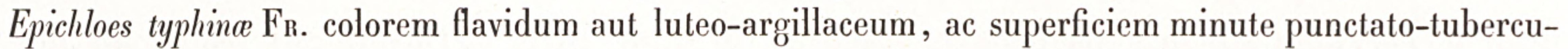
losam prorsus refert, tandemque sordide infuscatur. In foliis abiegnis jampridem aridis, imo corruptis, absque sclerotio prævio, eam nasci autopsi comperimus, quare minime dubitamus quin perperam pro fungo seminicola aut aliquando entomogena habita sit ' . Erroris fons ex eo manifeste emanat quod simul sumpta cum Hypocrea hospita, ens sistere videretur indole et habitu analogum non modo Spharice purpurea $\mathrm{F}_{\mathrm{R}}$. quæ seminibus corruptis graminum insidere olim immerito æstimabatur, sed etiam Spharice militari Енвн. semper entomoctonæ. Qui vero suffulcri sui interpretationem modo propositam probaverit, is profecto Hypocream nostram ex Clavicipitum et Torrubiarum societate rejiciet. Sinceræ enim affinitatis indicia in sui ipsius fructu et interna structura, minime autem in stromatis alieni forma et magnitudine versari palam erit. Qui Persoonir, Schimpti (Myk. Hefte, parte alt. p. 26 ), aliorumque exemplo de fabrica fungorum intima parum curabant, sedem plantulæ nostræ naturalem duplici de causa indigitare non valebant; sagacem tamen Eliam Fries non prorsus latuerat quod propter thecas et endosporas, ad Hypocreas genuinas illa merito accederet. (Cfr. illius Summ. Veget. Scandin. p. 383, nota 1.)

Endosporæ solutæ, quales in pulverem album ejiciuntur, globosæ sunt et hinc atque hinc depressæ, sive propterea nonnihil disciformes; diametro majori $0^{\mathrm{mm}}, 0035$ vix æquant, et antequam dispergantur monile e globulis xv in singulis ascis constipatæ struunt. Thecæ $0^{\mathrm{mm}}, 05-06$ in longitudinem obtinent nec $0^{\mathrm{mm}}, 004$ crassiores sunt; brevi pereunt et semina nudant.

${ }^{1}$ Auctore enim Persoonio (Obs. Mycol. loc. supra cit.), quandoque chrysalidibus, Friesio autem docente (Summ. Veget. Scandin. 1. cit.), sæpius seminibus Abietum innas- ceretur. Crescit apud Anglos non modo in silvis acerosis, sed etiam in ligno corrupto Ulicis, testibus BerкeLeo et G. Broome. 


\section{EXPLICATIO ICONUM.}

(Tab. IV, fig. 1-6.)

1 et 2. Clavarice Ligula Scнғfr. in foliis abiegnis vigent et nativa magnitudine exprimuntur; Hypocream alutaceam nostram singulæ alunt, quare tot punctulis notantur quot suis in clavulis conceptacula hospita fovent.

3. Fungillus recentissimus qui mycelio floccoso donatur, natura quadruplo major proponitur.

4. Flocci conidiophori aucti, quales in summo mycelio generantur.

5. Clavula fungi hospitalis a summo dissecta et valde amplificata.

6 . Thecæ et sporæ liberæ pariter auctæ sunt.

Præmissæ icones specimina tradunt quæ circa Batheaston Angiæiæ medio octobri (a. S. MDCGCLX) lecta, nobis eodem tempore ab amico doctissimo C. E. Broоме, viva missa sunt, statimque examini subjecta et delineata. Fig. 3 et 5 nativas demensiones quadruplas exhibent, figuræ autem 4 et 6 easdem multo magis amplificatas, scilicet vices circa ccclxxx.

Spharia (Poronia) cupularis Friesio in Linnace tomo V (1830), p. 539 , n. 65, carnosa, cupularis, marginata, lutea, extus villosa, disco depresso peritheciis periphericis tecto, in lignis putridis apud Germanos provenit; auctore magistro upsaliensi optima Hypocrece species est et eo inter congeneres præsertim discriminatur quod formam cupularem obtineat proptereaque Poronias Hypoxylorum imitetur. Cæterum Spharia gelatinosa Top. affinem quidem sed specie peculiari semper diversam se præstare existimatur. Asci tamen si tales prorsus fuerint quales in Spharia militari Енвн. et consimilibus deprehenduntur, cum Hypocrearum nota principi minime quadrare poterunt; discus fungilli maturi velut mucedine alba propter sporas ascosve exclusos obductus dicitur. (Cfr. Friesium, loco sup. cit.)

Ad Hypocreas apud Berkeleum (Outl. of Brit. Fung. p. 383) Cesatiumque (in Comment. Soc. Crypt. Itala, fasc. IV, p. ${ }_{9} 3$ ), vix autem jure et merito, trahitur nostratium phœenix Pyrenomycetum, scilicet nobilissima Spharia riccioidea Bour. (in sua Hist. Fung. Halif. t. IV, p. 79 , tab. cLxxxi et ult. [edit. WILLDev.]), quæ illustri Tode in Germania primum obvia, Acrospermum lichenoides in Fungis ejus Mecklenburgensibus selectis (t. I [179o], p. 9, tab. II , fig. 15) audierat, et recentiori tempore Sphcria et Hypocrea parmelioides apud nos salutata est. (Cfr. Montanium in Annalib. Sc. nat. ser. alt. t. VI [1836], p. 333, tab. xviII, fig. 4, et in sua Syllog. gener. specierumq. crypt. [1856], p. 210 .) Clariss. eidem Montanio nostro primam debemus notitiam seminum hujus fungilli, cujus natura ad id usque temporis dubia et lichenosa, opinante Friesio ${ }^{1}$, nonnullis æstimata, exinde certior evasit. Jam enim Acrospermum lichenoides vix congener Acrospermi compressi et cæterorum existimabatur pritzierensi mycologo, quod testantur sequentia ejus verba : «Vereor sane, inquit, ne fungus abnormis (Acrospermum lichenoides) "quibusdam huc magis compactus quam reliquis hujus generis speciebus amice consociatus videa"tur; sed profecto quo me tandem cum eo vergam nescio." (Tode, F. Meck. sel. t. I, p. 10.) Spharice riccioidece BoLt. vidimus quum specimina immatura et conidiophora, in cortice betuligno nata, ex his Laponicis quæ citantur apud Annales Sc. nat. ser. Iv, tom. XV $\left(1861_{\circ}\right)$, p. 23 , in nota, quorum-

${ }^{1}$ Cfr. Friesil Syst. Myc. t. II, p. 527 , et t. III, in Indice, p. 173. 
que mentionem in tomo secundo hujus Carpologice (p. 297, in adnot. 1) jam fecimus, tum etiam, nuperiori tempore, exempla omni parte perfectissima eaque lemovicensia et clar. Lamyo quondam obvia. Hæcce in mycotheca Mazeriana, nunc e thesauris Musæi Bot. parisiensis, continentur, fungillumque monstrant multis notis, præter colorem gilvum, Dothidea ribesice (P Prs.) analogum; ejus enim perithecia golobosa, minima, papillam atram efferunt, at in stromate pallido sepulta latent, parietibus privatis aut saltem discretis in utero destituuntur, nucleumque pallidum et cereum fovent ex thecis lineari-cylindricis, $0^{\mathrm{mm}}, 13-16$ longis, $\mathrm{o}^{\mathrm{mm}}, 01$ circiter crassis et monostiche octosporis, sporis autem ovatis, utrinque obtusissimis, æquo modo biloculatis, rectis, levibus, muticis, $0^{\mathrm{mm}}, 016-022$ longis, $0^{\mathrm{mm}}, 008-01$ crassis, nec hypocreaceo more intersectilibus. Fungus a temporibus Boltonianis in Britannia rarissimus, mycologis anglicis hujus ævi iterum tamen occurrit. (Cfr. Berk. in Amn. of nat. Hist. ser. I, t. I [1838], p. 206 , n. 95 , et Outl. of Brit. Fungology, loc. sup. cit.)

\section{HYPOMYCES.}

(Tab. V-IX.)

* Fungus gemmifer, simul cum matrice fungina sumptus, ELVELLA, MERULIUS, BOLETUS, ONYGENA, AGARICUS, NYCTALIS et STEPHANOMA passim salulatur.

** Fungus conidiophorus solus BOTRYTIDES, ASPERGILLOS, VERTICILLIA, SPOROTRICHA, FUSISPORIA, UREDINES, PUCCINIAS, RACODIA, MYCOBANCHAS, SEPEDONIA, MYCOGENAS, ASTEROPHORAS, ARTOTROGOS, ASTEROTRICHA, CLADOTRICHA, MUCORES, RETICULARIAS, TRICHODERMATA, MONOSPORIA, DIPLOCLADIA, aliorumque etiam, quæ sane omittimus, generum species, ut e sequentibus patet, varios apud auctores constituit.

*** Fungus ascophorus SPHeRIAS compositas sistit Persoonio, Albertinio et Schweinitzio; SPHarias hypocreas, inter connatas, Friesio (Syst. Mycol. tom. II [1823]), BerкeLeo et Broome; imo HYPOCREAS proprie dictas et eas maxime quæ nunc e subgenere HYPOMYCETUM habentur, eidem Friesio (S. Veg. S. Sc. [1849]) et discipulis ejus ut Berkelezo (Outl. of Brit. Fung. p. 383), Cessatio et Notarisio (in Act. Soc. Crypt. Itale, fasc. IV, p. 195); denique eundem Friesianum HYPOMYCETUM gregem Bonordenio in novissimis suis Dissertationibus mycologicis (1864), p. 84, n. 10.

**** Fungus integer nobis est HYPOMYCES, in Act. hebdom. Acad. Sc. par. tom. L, p. ${ }_{9}$, ineunte januario mense a. D. MDCCGLX, et paulo post in Ann. Sc. nat. ser. Iv, tom. XIII, p. 11-16.

Mrcelium byssinum ex floccis mollibus, lanosis, mucedineis, modice septiferis, ramosissimis, ramulis supremis abbreviatis, subulatis et sæpissime verticillatis, achroum aut varie fucatum, in fungis e variis ordinibus initio parasitatur, postea autem sæpius minime curat cujus naturæ sit suum sustentaculum; modo parcum videtur aut in matrice latet, modo abundat palamque effunditur, sæpe etiam demum evanidum stromatibus sparsis varie informatis aut sclerotiis sinceris locum cedit, ipsumve in strata crassiora et multiformia compingitur, bysso circumfusa pedetentim pereunte. Conidorum genus duplex; alia nobis microconidia, conidia proprie dicta vel acrosporæ nuncupata (quæ varia sistunt Verticillia, Botrylides, Tricothecia, Fusisporia, Cladotricha et Sporotricha auctorum), copiosissima aut rariora, 
achroa, ovata, oblonga vel cylindrica, levia, acrogena, simplicia v. pluriloculata, septis omnibus transversis et parallelis, nascuntur solitaria, fasciculata vel catenata, et cum seruntur germina varia (ipsa, duplici quidem modo, cito gemmifera) agunt; alia (quæ Asterophoras, Sepedonia, Mycogenas, Asterotricha, Stephanomata ac consimilia discriminant, et chlamydosporæ apud Ant. DE BARY dicuntur) prioribus modo parciora, modo contra copiosiora, vulgo autem multo crassiora, asperata, rarius levia et acro- vel mesogena, varie fucantur, ex utriculis paucis, inæqualibus, in seriem aut in globum sociatis singula fabricantur, rarius simplicia consistunt, germinaque, tempore et loco faventibus, item enituntur. Perithecia exigua, pallida v. læte colorata, globosa, in papillam v. rostellum breve rectum et terminale singula producta, glabra vel parce pilifera, in matrice v. hyphasmate natali demerguntur aut contra emersa eidem insident, omnia e parietibus facta tenuibus, subcarnosis, mollibus tandemque rugato-collapsis. Asci longe et anguste lineares v. obovati, monostiche octospori, rarius 2-4-spori, paraphysibus sinceris vulgo destituuntur. Spor $x$ lanceolatæ, elongato- v. oblongo-lanceolatæ, utrinque acutæ, imo breviter apiculatæ s. mucronatæ, leves, plasmate granoso refertæ, plerumque biloculatæ et nonnihil inæquilaterales, debito tempore in cirros exiguos, deformes et pallidos eructantur.

Fungilli quos sub HуромусетIs titulo congregamus, pallidi omnes v. late picti, in fungis aliis quos corrumpunt parasitantur aut saltem primam vitam ducunt; propter mycelium, duplici modo gemmiferum, quo plerique abundant, initio omnino mucedinei videntur, postea autem HY POCREAS sparsas $v$. pulviniformes potius imitantur, sed sporis lanceolatis et bilocularibus quidem sed non sectilibus, ab HypocaEIS sinceris jure recedunt.

Hypomycetum genus admodum naturale; vigendi modus omnibus fere idem, et maxime sporæ mire congruæ. Hæ satæ, antequam germinaverint, valde augentur omnemque deponunt mucronem; germina crassa, claviformia, torosa et multiloculata frequenter evadunt, aut talia edunt brachia quæ macroconidia mentiantur.

Plurimorum ex Hypomycetum gente forma perfectior nobis certe nondum innotuit; ii sunt qui sub Sepedoniorum aut Mycogenarum signo potissimum latent. Ne autem de Sepedoniis istis quæ nobis hactenus, ut videtur, gemmifera tantum obvenerunt, haud secus ac de bysso conidiophora Hypomycetis armeniaci nostri et roselli (Аьв. et Scнw.) sentiamus, adeo manifesta suadet analogia ut neutiquam dubitemus eosdem imperfectos Hypomycetes cum sincerioribus aut certioribus jam nunc his in pagellis jungere ${ }^{1}$. Eo itaque tutius futuris commen-

\footnotetext{
1 Quapropler vero nisi forsan erroris manifesti, saltem non modicæ temeritatis arguimur apud clar. Boxorden in
}

suis Abhandlungen aus dem Gebiete der Mykologie (1864), p. 41; futuri porro viderint mycologi. 
dabuntur indagatoribus queis, oculatioribus v. fortuna magis secunda utentibus, quatenus forma fungillorum nostrorum absoluta s. ascophora olim innotescat, votis exposcimus. De cætero quemadmodum hodierna nostra sententia circa probabiliorem Sepedoniorum naturam documentis ex historia Hypomycetis roselli et affinium ductis meritissime, ni nos omnia fallunt, hinc nititur, sic etiam illinc ea omnia quæ super variis sic dictorum Sepedoniorum formis, duplicique eorum seminifero apparatu, publici juris quondam fecimus in Actis hebdomaticis Academice Scientiarum parisince (tomo XLI, p. 615-618), die XxII mensis octobris, a. D. MDGGGLV, institutis ex hoc tempore observationibus iterum atque iterum comprobasse nobis videmur. Nunc etiam, ut opinamur, omni constat mycologo floccos conidiophoros achroos quibus singula Sepedonia, seminibus fucatis instructa, stipantur s. potius terminantur v. coronantur, ad eadem legitime spectare, nec sincera Verticillia, Sporotricha, Fusisporiave constituere. Quare beati Corde errorem miratur clar. Berкelews : " Conda, inquit, considers one " or two of the genera of this tribe (Sepedoniei Fr.) as parasitic upon other moulds, and in "consequence associates them with such fungi as Uredo, an association quite marvellous in "the hands of a person who had studied and accurately figured so many fungi. " (Introd. to crypt. Bot. [1857], p. 3o6.)

Præter Verticillium cylindrosporum Cовр et Fusisporium fungicolum ejusdem quæ in dissertatione supra citata notavimus, typi alii item Cordæani, ut Verticillium affine (Icon. Fung. tom. I, p. 20 , tab. v, fig. 276 ) et Helmisporium fusiforme (tom. cit. p. 13 , tab. III, fig. 194), conidia Sepedoniis peculiaribus seu quibusdam Conisporiorum generibus (nempe Conisporio Helminthosporii Corde, Ic. Fung. tom. I, p. 1, tab. I, fig. 2 ; et C. Verticillii ejusd. ibid. tab. I, f. 3) sistere videntur ${ }^{1}$. Pro Sepedoniis microconidia agentibus etiam habendæ sunt, ni erraverimus, mucedines nonnullæ quarum mentio est apud clar. ВомовреN, scilicet illius Monosporium agaricinum (Sporotrichum agaricinum aliis) et Monosp. spinosum, nec non Diplocladium majus et minus. (Cfr. Bonondeni Handb. der Mykol. p. $9^{5}$ et $9^{8}$, tab. v, fig. 112 et 119 ; tab. viI, fig. 148 , et tab. viII, fig. 168.)

Inter Hypomycetes genuinos locum sane reposcit Nectria torminosa Montanir (in Duriei Fl. Alg. t. I, p. 496, sub Spharia, et in suapte Sylloge pl. crypt. p. 225 , n. 788 ), in Lactario torminoso (Schefr.) obvia ${ }^{2}$; eam autem videre nobis non licuit. Spharia aurea Grev. (Fl. crypt. Scotice, t. I, tab. xuviI) etiam fungicola est et verisimiliter Hypomycetibus minime aliena. Nec aliter fortassis sentiendum est de Spharia epimycete Friesi (Syst. myc. t. Il, p. 499) quam Berkelews et Broome in Thelephora comedente NeEsi apud Anglos observasse declarant. (Cfr. Ann. and Mag. of nat. Hist. ser. 1, t. VI [1841], p. 362 , n. 187.)

Hypomyces genuinus manifesto est Nectria Cesatii Montanio in Ann. Sc. nat. ser. iv, t. VIII, (1857), p. 308 , n. 68, et Notarisio tum in Act. Soc. Crypt. It. fasc. IV (1863), p. 195 , tum in suis Sphariaceis Italicis, fasc. I (1863), p. 11, tab. II, fig. 5.

\footnotetext{
${ }^{1}$ Helmisporii fusiformis figuræ Cordæanæ, in tab. citatis I et III exhibitæ, inter se non plane quadrant.

${ }^{2}$ Differtne ab Hypocrea floccosa Friesi (nomine signata
}

in $S$. Veg. Sc. p. 564) quam Berkezey et Broome in Agrarico torminoso Sch жfF. etiam observarunt? (Cfr. Ann. and Mag. of nat. Hist. ser. alt. t. VII [1851], p. 186, n. 593 .) 
1. Macroconidia simplicia vel polymera, semper autem ex utriculis globosis ac sapius verrucosis facta, hisce insuper in seriem linearem aut globum coalitis.

* Macroconidiorum articulis in seriem ordinatis.

\section{Hyponyces ochraceus.}

* Fungus gemmiferus :

Mugor dendroides Bull. F. Gallice, t. I, p. 105, tab. Div, fig. 9, huc saltem pro parte spectat. Dactylium dendroides Friesir, Berkelei et aliorum potius ad Hypomycetem rosellam (Alb. et Schw.) pertinere videtur.

Botrytis agarigina Linkit in suis Obs. in Ord. pl. nat. Diss. I, ap. Mag. d. Gesellsch. naturf. Freunde z. Berl. ann. III (1809), p. 15 (inter heteroclitas), et in Sp. Plant. Linn. t. VI, parte I, p. 54, n. 6. - Ditmario in Sturmir Fl. Germ. parte in (mycographica), t. I (1817), p. 103, tab. LI. - Grevillio, Fl. Crypt. Scotice, t. III $(1825)$, tab. cxxvI.

Botrytis agaricina et dendroides Persoonio in sua Mycol. Europ. t. I, p. 34, n. 6 et 7 .

Verticillium agaricinum Corde, Ic. Fung. t. II (1838), p. 15 , tab. x, fig. 68.

** Fungus ascophorus, nisi specie decipimur :

SPheria ochracea Persoonio, Syn. Fung. p. 18 , n. 29 , et in sua Mycol. Europ. t. I, tab. I, fig. 1 et 2, absque descriptione; nos enim qua de re docuit schedula ex ipsa Persoonir manu in exemplare libri laud. quod in Biblioth. Musæi par. Hist. nat. continetur.

$$
\text { *** Fungus integer : }
$$

Hypomyces armeniagus Tul. in Ann. Sc. nat. ser. iv, t. XIII (1860), p. 12 , n. 6.

Agaricinus fungus plantulæ nostræ prima sua incunabula ministrat, ita quidem ut matrix illa, antequam perfecte explicetur, peculiariter impallescat, floccos niveos, laxos vel confertiores, ex omni parte ac maxime ex hymenio et stipite simul gignere videatur, subindeque collabatur et putredine pedetentim corrumpatur. Flocar autem, progrediente æata, modo matricem exiguam totam involvunt et velant, modo supra pileum ampliorem vix assurgunt, sed in aversa ejus pagina et suffulcro lætius densiusque multiplicantur. Quocunque modo se habeant, ad terram mox demittuntur, in omni jacente corpore, vivo mortuove late serpunt, sicque aranei instar in matricis pereuntis ambitu circum circa expanduntur, et aream quandoque spithameam demum occupant. Duplex seminum seu conidiorum genus ex his floccis nascitur qui filiformes, septisque parcis instructi, ramos alternos, oppositos aut ternatim verticillatos maximeque divaricatos iteratis vicibus agunt. Extrema eorundem brachia, rite sæpius verticillata sed cæteris graciliora et multo breviora, nempe $0^{\mathrm{mm}}, 004-0065$ crassa et $0^{\mathrm{mm}}, 05-06$ longa, conidium unicum, rarius duo triave fasciculata, ovata, obovata oblongave, recta vulgoque continua, aliquando tamen ob septum transversum biloculata, ex apice singulatim exserunt. Semina istius modi, pallida s. achroa leviaque, magnitudine variant, etenim $0^{\mathrm{mm}}, 01-02$, rarius $0^{\mathrm{mm}}, 03-04$ in longitudinem et 
$\mathrm{o}^{\mathrm{mm}}, 0_{1-013}$ in crassitudinem adipiscuntur dataque opportunitate e vertice obtusissimo aut simul e basi quam mucronulus designat, germen lineare citissime protrudunt. E germine autem, intra paucissimos dies, conidia nova, imo macroconidia, i. e. gemmæ multiloculatæ, claviformes et obtusissimæ, oriuntur; præterea vegetatio conidiorum hujus generationis aut subito sequitur, aut protelatur. Sinceriora vero macroconidia (chlamydosporce $\mathrm{B}_{\mathrm{ARYO}}$ ) in imis floccis conidiophoris maximeque in floccis aliis laxioribus qui in exteriore matrice humove reptant, ægre interdum conspiciuntur, conidiorumque minorum aut parcissimos aut penitus expertes se habuerunt, erecta stant, nunc subsessilia, nunc stipite exili, brevi et interdum 2-4-partito suffulta. Singula oblonga, quandoque nonnihil incurva, torosa, ex utriculis quatuor, rarius duobus vel tribus tantum, in seriem conjunctis, globosis, $\mathrm{o}^{\mathrm{mm}}, 02-03$ crassis, vulgo autem inæqualibus (extremis scilicet minoribus et sæpissime plasmate granoso destitutis), tandem verruculosis et ex albo pedetentim saturate rubro-lateritiis s. feces vini rubri colore æmulantibus, struuntur. Ubi conidiorum et gemmarum omnium generatio finem fecit, byssus etiam tota periisse videtur; conidia non superesse diceres et ipsa macroconidia nisi abundaverint et saturate fucentur, vel attentissimos fugiunt oculos; quæ autem adeo copiosa sæpissime adsunt ut pulverem dense instratum et primo obtutu conspicuum sistant. Quum rariora provenerunt et inter microconidia oculo vel armato ægre discernuntur, imo quum prorsus desiderantur, tunc etiam e mycelio byssino mox perituro aut jam partim evanido impositi nascuntur pulvinuli, perexigui alii, alii contra majores, qui enim $2-20^{\mathrm{mm}}$ et quod excedit diametro æquant, varie expanduntur, colorem e niveo stramineum, ochraceum aut vitellinum, texturam autem densam nec tamen sincere parenchymatosam assumunt, tandemque innumera fovent perithecia, novissimos et perfectiores fungilli nostri fructus. Conceptacula hæc globosa dimidiam millimetri partem crassitudine æquant, papillam brevem et obtusam super stroma in quo conferta sparsave, semper autem discreta et libera, demerguntur, singulatim efferunt, pariete tenui et membranaceo, ex utriculis tabularibus et polygoniis, definiuntur, coloreque inficiuntur læte armeniaco. Tнесе lineari-cylindricæ, obtusissimæ, imo subtruncatæ et quasi sessiles, $o^{\mathrm{mnt}}, 0_{2} 5-03$ in longitudinem obtinent, at $0^{\mathrm{mm}}, 0065$ vix crassiores sunt et omni paraphysium vestigio destituuntur. Spor z oblongo-lanceolatæ, octonæ et oblique monostichæ in singulis ascis deprehenduntur, septo medio nonnihil angustatæ dividuntur et utrinque mucronulo brevissimo augentur; illis longitudo circiter $\mathrm{o}^{\mathrm{mm}}, 035$ et quod superest, præter mucrones vix $\mathrm{o}^{\mathrm{mm}}, 0035$ sigillatim longiores, crassitudo autem $0^{\mathrm{mm}}, 0065$. Hæ sporæ, stato tempore, aliæ e peritheciorum ore elastice prosiliunt, aliæ cirros perexiles protrusæ constituunt, quare omnia circumjacentia veluti polline niveo obruunt; quum in aqua seruntur, in utriculos geminos globosos et contiguos singulæ paulatim et lente auctæ convertuntur, antequam germina exserant. 
Nascitur tum media serave æstate, tum etiam autumno, in Agarico emelico, adusto, camphorato et consimilibus fungis; conidiophorus apud nos (v. gr. Modoni et Cavillæ Versaliorum) frequens est, contra ascophorus longe rarior; perfectum tamen iterum atque iterum reperimus, Cavillæ, ab anno MDGCGLX.

Ubi evanuit mycelium conidiophorum, supersunt sæpissime sclerotia globosa, minima et albida quæ suam trahunt originem e floccis mire articulatis, incrassatis et chlamydosporas quodammodo mentientibus; inde fortassis sequeretur ut macroconidia sclerotiorum vices gererent singulaque ideo Hypomycetis novi, gemmæ instar, torpentem vitam aliquandiu foverent.

Russula emetica, fotens, adusta et consimiles agaricini fungi interdum etiam in omni parte superficiali sclerotiis minimis, pallidis globosisque æstate et autumno scatent quibus præesse solet byssus tenuissima, alba et abunde conidiophora; conidia autem anguste ovato-oblonga, $0^{\mathrm{mm}}, 004-013$ longa et sæpius simplicia, in summis spiculis erectis capitata generantur. Quoddam Hypomycetis genus (Hyp. miliarius nob. in sched.) his organis denuntiari videtur.

Hypomyces aurantius Pers. (sub Sphceria, in suis Icon. et Descr. Fung. parte II, p. 45, n. 5 1, tab. XI, fig. 4 et 5 ) seu Cryptosphacria aurantia Grev. (Fl. Crypt. Scotice, t. II, tab. LxxviII) Hypomyceti nostro oclraceo s. armeniaco manifeste affinis est. Pauca quæ olim de illo præstitimus (in Ann. Sc. nat. ser. Iv, t. XIII, p. $12, n .4)$, a fungis chilenis didiceramus; nuperiori tempore nobis occurrit in Polyporo versicolore $\mathrm{F}_{\mathrm{R}}$. ad Fontembellaqueum, hieme decedente; at longe perfectiorem vidimus in Agarico conchato Bubl. ${ }^{1}$ ex anglis terris a cl. Berkeley ad b. Mazerium abhinc plurimis annis missum. Probe distinguitur bysso lanosa, copiosa, longe lateque matrici instrata, ex albido in citrinum colorem mutata tandemque nitide aurea facta; conidia in mycelio recentiore de more potissimum nata, formam ovatam, obovatam oblongamve affectant, pallida et levia sunt, nec non continua vel sæpius ac quidem inæquo modo bipartita, $0^{\mathrm{mm}}, 01-015$ longa, $0^{\mathrm{mm}}, 006-008$ crassa. Fungillus pro typo Sphceriarum tomentosarum, nec prorsus immerito, habetur apud Sснмпттіом, in suis Fasciculis Mycologicis, parte alt. p. 28 , tab. I, fig. 17 .

\section{EXPLICATIO ICONUM.}

(Tab. VI, fig. 19 et 20.)

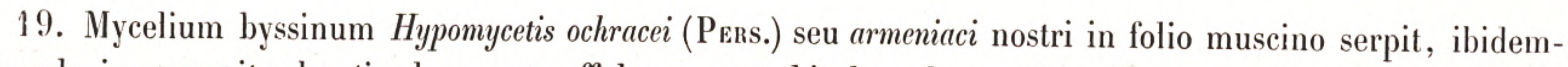
que plurima genuit sclerotia; hæcce et suffulcrum nota bis decuplo crassiora dantur.

20. Byssus ejusdem fungilli maxime aucta (nempe vices circa $\mathrm{CCL}$ ) simulque conidiophora $(c, c)$ et sclerotiorum ferax; sclerotia $s, s$, e monilibus crassis $m, m$, quibus undique monilia altera paulatim accedunt, originem trahere solent.

Hæ figuræ fungos tradunt qui Cavillæ Versaliorum, augusto medio (a. D. MDCCCLX), læte vigebant.

(Tabula VII.)

1. Pulvinuli armeniaci seu ochracei Hypomycetis nostri quisquiliis muscisve humi stratis incumbunt et nativa magnitudine delineantur.

2. Pulvinus recens (maxime auctus) in quo perithecia protuberare incipiunt.

\footnotetext{
' In Agarico eodem seu fortassis in Ag. flabelliformi Sснжғғ. (Fung. Ratisb. t. I, tab. xhII et xuIV), vix diverso

dari videtur icone Grevilliana, cæterum eximia, supra citata.
} 
3. Perithecia matura, nativam suam crassitudinem vicies excedunt; stratum tomentosum in quo orta sunt nunc maxime minuitur.

4. Apparatus conidiophorus, id est rami mire brachiati e mycelio repente undique assurgentes et conidia obovata, solitaria, bina ternave acrogena sustentantes; in bysso humi fusa stant præterea vel soluti jacent fructus torosi, fucati, papillis tandem asperati et macroconidia aut, cum clar. Baryo si loquamur, chlamydosporæ dicendi. Certe miraberis quanta similitudine sporæ illæ, cæteris longe crassiores, ad sclerotiorum primordia $(m)$ accedant quæ in tabula antecedente vi, fig. 20 , delineantur. Macroconidia soluta pulverem siccum sistunt et hyphis pereuntibus demum supersunt; sclerotia autem byssum natalem non exuunt, nisi maxime aucta vel maturilatem adepta.

5 et 6 . Macroconidia seorsim exhibentur quæ sclerotiorum naturam usurpasse videntur; solito exiliora sunt et cellulas novas hinc et inde agunt.

7. Thecæ; fertiles seu maturæ aliæ dantur, aliæ plasmate tantum, nondum autem sporis referciuntur.

8. Sporæ perfectæ, quales e peritheciis maturis exeunt, seorsim spectantur.

9 et 10 . Sporæ aliæ quæ in aqua satæ creverunt et didymæ factæ sunt.

Reliquæ figuræ, numero affixo non signatæ, microconidia multifariam germinantia repræsentant; nonnullorum germina in cellulam conidiomorpham, alia in curtam monilis speciem, macroconidium vel sclerotium inchoatum referentem, abierunt.

Icones omnes, præter priores 1-3, res tradunt pari modo auctas, scilicet vices circa Ccclxxx; ex fungis vivis delineatæ sunt, aliæ Petrifonte Compendiorum, julio medio a. MDCCCLVII, aliæ Cavillæ ad Versalias, æstate, anno S. MDCGCLX.

\section{Hypomyces LinkiI.}

Mrgogene rosea Linkio, Diss. I in Ord. Pl. nal. apud Acta Soc.nat. Scrutat. Berol. t. III (1809), p. 18, n. 17; et in Willdenowi Sp. Plant. Linn. t. VI, parte I, p. 29, n. 1. - Tul. in Act. hebdom. Acad. Sc. par. t. XLI (1855), p. 616 .

Mrcogene incarnata Persoonio, Myc. Europ. t. I, p. 26 , n. 1.

Sepedonidm roseum Friesio, Syst. Mycol. t. III, p. 438 , n. 2 ; Sum. Veget. Scand. p. 497.

Mycobanche rosea Wallrothio, Fl. Crypt. Germ. parte post. p. 273 , n. 1825.

Puccinia Mrcogone Corde, Ic. Fung. t. I (1837), p. 6, tab. II, fig. 99, juncto etiam Verticillio cylindrosporo ejusdem Cords, ibidem, p. 20 , tab. v, fig. 275.

Hy pomyces Linkit Tul. in Ann. Sc. nat. ser. iv, t. XIII (1860), p. 16 , n. 15.

Fungilli byssus conidiophora ex omni matricis parte epigæa brevis nascitur, candida nitet, mox autem propter macroconidia quæ enititur dilute rosea deinque subviolacea evadit, et quasi tomentum magis ac magis inspissatum serpit et expanditur. FloccI cylindrici plasmate interrupto et achroo referciuntur; exiliores qui assurgunt ramulos breves, nimirum $0^{\mathrm{mm}}, 02-05$ longos, simplices, longe et acute lenuatos proptereaque subuliformes, in verticillos discrete superpositos dense aut laxius exserunt; conidia ovata, oblonga v. cylindroidea ${ }^{1}$, simplicia, rarius biloculata, $0^{\mathrm{mm}}, 01-02$ longa et vix $0^{\mathrm{mm}}, 007$ crassiora, e singulis illis ramulis extrema solitariaque oriuntur; levia et achroa de more insuper observantur, dataque opportunitate progerminant. Ghlamydospor s sphæricæ, roseæ, verrucosæ, semipellucidæ et diametro $0^{\mathrm{mm}}, 03$ circiter æquantes, ex iisdem floc-

1 Conidia hæc figuris Cordæanis supra citatis perperam utrinque truncata et omnino cylindrica proponuntur. 
cis longe infra verticillos conidiophoros inordinatæ sed alternæ nascuntur; proveniunt etiam e filamentis aliis crassioribus quæ prioribus quidem commiscentur, at conidiorum expertia manent; singulæ pediculo s. ramulo contracto $\left(0^{\mathrm{mm}}, 02-03\right.$ longo $)$ et erecto-patulo sese excipiunt, prætereaque utriculo unico v. duobus exiguis, plus minus fucatis, jmo quandoque verruculosis, ut sporis imperfectis evehuntur. Microconidia quæ, loco favente, germen agunt, pleraque ex eodem conidiolum cito exserunt sua vice progerminaturum; alia in fila longiora, ramosa nudaque protrahuntur et septis transversis paucis supervenientibus incrassata (et evacuata) dividuntur. Germina conidiorum extrema cum aliis transversis frequenter coalescunt. Fungus perfectior, ascophorus, nobis nondum innotuit.

Parasitatur autumnali tempore in Agarico (Amanita) rubescenti Persoonir, Ag. rimoso Bull. aliisque quos corrumpit. Haud infrequens nobis occurrit prope Parisios, Compendium et Fontembellaqueum.

Chlamydosporarum forma et colore a congeneribus omnibus facillime distinguitur.

Sporæ fuscæ et ovatæ Agarici rimosi BuLL. cujus in hymenio fungillus noster frequens hospitatur, $0^{\mathrm{mm}}, 01$ sæpius paulo longiores, et $\mathrm{o}^{\mathrm{mm}}, 004-006$ crassæ, simulque seminibus utriusque generis Hypomycetis parasitantis omnino dissimiles deprehenduntur.

\section{Hypomyces rosellus.}

* Fungillus gemmifer :

Huc sane pro parte spectant pleraque e synonymis quæ sub titulo Hypomycetis armeniaci nostri gemmiferi modo recensita sunt; sequentia rosello magis priva videntur :

Trichothecium agariainum et candidum Bonordenir in suo Man. Mycolog. p. 99, tab. v, fig. 114 , et tab. vili, fig. 167 .

Dactylium dendroides Fr. Syst. Mycol. t. III, p. 414, n. 6; Summ. Veget. Scand. p. 491. - Berkeleo, Outl. of Brit. Fung. p. 351.

** Fungus ascophorus :

Spileria rosea Pers. Syn. Fung. p. 18 , n. 28.

Spiteria rosella Alb. et Schw. Consp. Fung. Lus. sup. p. 35, n. 106, tab. vil, fiğ. 3 (quoad colorem eximia). - Neesio, Syst. der Pilze, p. 318 , n. 63, tab. xurv, fig. 362 в, de Schweinitzio sumptis. - Grevillio, Fl. Crypt. Scot. t. III $(1825)$, tab. cxxxviII.

Spheria rosea et rosella Friesii, Syst. Myc. t. III, p. 338 et 441, n. 31 et 277.

*** Fungus integer :

Hypomyges rosellus Tul. in Ann. Sc. nat. ser. iv, t. XIII (1860), p. 12, n. 7, et in tomo II hujus Carpologice, p. 273 , tab. $\mathrm{xxx}^{1}$, fig. $6-9$.

Fungiluds recens mucedinem sinceram, læte et conspicue fertilem, prorsus men-

${ }^{1}$ Occasione data, expedit ut moneamus Pleosporam
nostram Clavariarum (Desu.) quæ in hac tabula xxx adum-
bratur, eumdem prorsus videri fungum atque Pezizam nigram Sowerber (fortassis P. Lecideolam Friesio, juxta Ind. Syst. Myc.), in Clavaria coralloide L. olim apud Anglos obviam. 
titur, namque floccis mollibus, laxe implexis et candidissimis constat; cum autem matricem funginam ex qua primum traxit nutrimentum, totam corruptam invaserit, circum circa paulatim expanditur, sternitur, arenamque ambientem, muscos et quisquilias hyphasmate densiori facto vestire incipit. E bysso mucedinea, ubicumque jaceat aut irrepserit, flocci assurgunt rigidiores qui millimetrum aliquando excedunt ac in ramos breves $\left(0^{\mathrm{mm}}, 03\right.$ circiter longos), interrupte verticillatos et rarius oppositos, semper vero erecto-patulos, sursum versum discedunt; rami autem s. brachia spiculiformia (numero III-VI in singulis verticillis) tot capitula v. sertula gerunt e conidiis plurimis subsessilibus, cylindrico-oblongis, utrinque obtusissimis, basi autem nonnihil papillatis, trilocularibus, muticis, rectis v. quadantenus incurvatis, longitudineque $0^{\mathrm{mm}}, 025$-o 35 et crassitudine $o^{\mathrm{mm}}, 0_{1-013}$ æquantibus. Dum conidia ista generantur et in matrice $\mathrm{v}$. strato byssino copiosissima demittuntur, byssus ipsa, extremum præter marginem, simul et pars ima floccorum conidiferorum colorem læte purpureum, v. ex ochraceo aut flavido plus minus rubentem et in dies saturatiorem factum, pedetentim induunt, conidiis contra vix mutatis. Subinde præterea ex hyphasmate rubefacto sparsim confertimve nascuntur perithecia concolora, nitide scil. purpurea, subpyriformia, utrinque primum obtusissima, mutica, sessilia, imo sæpius in strato natali plus minus demersa, glaberrima aut pilis raris rubris brevissimisque primitus ornata. Conceptacula hæc, de more carnosula et mollia, poro terminali vix conspicuo tandem pervia fiunt et sporas in cirros albidos breves contortosque excludunt. Tнес E anguste lineares $0^{\mathrm{mm}}, 15$ in longitudinem adipiscuntur et $\mathrm{o}^{\mathrm{mm}}, 0065$ crassitudine æquabili non excedunt; obtusissimæ et subsessiles pleræque videntur nec unquam, ni fallimur, sinceris stipantur paraphysibus. Sporæ in singulis ascis octonæ et monostichæ, formam anguste lanceolatam, nonnihil incurvatam, utrinque in modum appendiculæ rectæ vel curvulæ acutissime tenuatam, ac demum in medio septifero angustatam obtinent. Maturæ plasma oleosum et granosum sub tegmine levi tenuique fovent. Postea autem, favente loco et tempore, pars utraque uniuscujusque sporæ in cellulam globosam aucta informatur, appendiculam deponit et filum lente exserit crassum septisque subinde partitum. Sunt etiam sporæ e quarum cellulis alterutra non increscit et alii contra tumenti appendicis speciem ministrare videtur. Sporæ paucæ rite uniloculares s. continuæ biloculatis sæpissime commiscentur; quæ etiam germinantes et tumentes septum haud assumunt. Cum floccosum plantulæ tapetum aut violaceum, aut purpureo-cervinum evaserit, frequenter accidere videtur ut conceptacula neutiquam in eo generentur, conidia autem maxima et a prædictis longe aliena manifestentur. Semina hæc perfectiora ea sunt quæ apud Sepedonia et Mycogenas sporæ s. chlamydosporæ vulgo salutantur; ex imis floccis assurgentibus et ad normam assuetam conidiferis ut ramuli solitarii, alterni et abbreviati parca nascuntur singulaque ex utriculis II-v globosis, crassis, asperatis, in seriem rectam ac breviter suffultam adnato-sociatis, mox opacatis et tandem purpurascen- 
tibus fabricantur. De horumce macroconidiorum germinatione nil adhuc compertum habuimus.

Parasitatur ab æstate extrema in ver usque anni subsequentis tum in Russulis, v. gr. emetica et alutacea, tum in Agaricis variis, pariter carnosis, quos cum enecaverit putredine consumptos relinquit, indeque cuiviscunque fulcimini, vivo emortuove, humo quidem et lapillis, circum circa irrepit et late propagatur. In Polyporis etiam, v. c. P. cuticulari Bull. alnicola, lignosis et exoletis, viget, rubet et conceptacula super areas varie effiguratas diametroque 1-2-pollicares gignit.

Fungillum mucedineum, niveum aut varie purpurascentem, haud infrequentem vidimus Modoni prope Versalias, in sylva Compendiensi (anno MDGGGLVII) et circa Fontembellaqueum (Samoreau, Champagne, anno MDCGCLVIII et proxime sequenti); ascophorum autem s. perfectum et nitide (in peritheciis saltem) rubicundum multo rarius legimus, nempe Cavillæ agri Versaliensis, mense martio MDCGCLIX (in Polypori alnei Pers. [P. cuticularis Bull.] hymenio), et Modoni Clamariique, novembri insequente (in Agaricis corruptis).

Universa conceptaculorum fabrica, thecis sporisque, cum Hypomycete lateritio $F_{\mathrm{R}}$. infra descripto plane congruit, crescendi autem ratione, vita primitus tantum parasitica, nec non propter macroconidia s. chlamydosporas conidiis mixtas, Hypomyceti ochraceo s. armeniaco, supra adumbrato, prorsus analogum se præstat.

Mycelii color ruber et fungilli nota princeps, ad membranam ipsam qua filamenta struuntur, minus autem ad humorem quem vehunt, plasmave in ipsis contentum, pertinet. Paraphyses sinceras inter ascos in conceptaculis tum maturis tum junioribus frustra quæsivimus.

Quando fungillus in Agarico carnoso mox corrupto natus est, nonnisi in suffulcris v. matricibus secundariis ut tellure ambiente, lapillis, muscis vivis, culmis aut quisquiliis aridis conceptacula edere solet; in Polyporis autem lignosis totam vitam, omnimodo fertilem, pedetentim explet. Præterea mucedineam indolem aliquando non exuere videtur, colorem niveum ac naturam laxe floccosam haud mutat, et in edendis conidiis minoribus supra descriptis, nempe cylindrico-oblongis, levibus et triloculatis, totus consumitur. Alias contra densius contextus, parciorem edit microconidiorum copiam, sed macroconidiorum ferax est et feces vini rubri aut Amanita rubescentis P $_{\text {ERs. }}$ (Syn. Fung. p. 254 , n. 13 ) carnem exoletum colore æmulatur. Fungillus tamen ascophorus præ cæteris conceptaculorum indigentibus læte purpurascit, conidiis autem majoribus sæpius destitutus videtur, etsi minoribus abundat.

Vix dubitamus fungillum nostrum eumdem esse ac Persoonianum citatum qui terra vigere dicitur; quum enim prior ascophorus factus humi reptat et purpurea facie oculos allicit, tunc etiam prope nullum superest vestigium primariæ ejus originis ex Agarico corrupto.

Primitus etiam in Agaricis cito corruptis et Polyporis vetustis parasitatur Cladotrichum ternatum BonoRD. Elem. Mycol. p. 78 , tab. iv, fig. 84, subindeque in arena, muscis et quolibet stramine extenditur. Fungus est, ni fallimur, qui apud Diтmarium (in Sturmi Fl. Germ. parte iII, tomo I, p. 105 , tab. LiI) Botrytis densa audit. Conidiis proprie dictis, niveis, ovato-oblongis, biloculatis ac in monilia longa et fastigiata digestis non modo superbit, sed etiam macroconidiis 4-6-meris quæ chlamydosporas Hypomycetis roselli (ALB. et ScHw.) forma et magnitudine prorsus imitantur. Non potuimus ideo quin mentionem Hypomycetis ternati (Bonord.) olim, data occasione (in Ann. Sc. nat. ser. Iv, t. XIII, p. 16 , n. 17), fecerimus. Plantam autem, licet circa Versalias et Fontembellaqueum hieme miti non infre- 
quentem, nondum perfectam s. ascophoram vidimus. Sane cæterum dolemus nos a clar. Bonondenio super hoc argumento etiam dissentire. (Videsis novissimas illius Disputationes mycologicas, p. 41.)

\section{INTERPRETATIO ICONUM.}

(Tab. V.)

1. Cæspes muscinus (ex Bryo undulato, Polytricho communi et alicujus Jungermannice surculis repentibus) inter lapillos crescens et Hypomycetis roselli nostri electa sedes, natura quadruplo major depingitur. Fungilli mycelium folia plantularum omnium investit, et in iisdem extremis potissimum densatur, sæpius autem in solis caulibus quos arctissime involutos quasi fusiformes facit conceptacula gignit ascophora ; ubique contra in baculos conidiophoros abundantissime assurgit; serpit etiam in terra, calculis et quisquiliis humi jacentibus, quare in plagas v. areas tandem saturate rubentes et in ambitu nunc plane steriles, nunc parce conidiophoras, semper autem pallidiores, extenditur.

2. Mycelio gemmifero imponuntur peridia immatura sed inæqualis ætatis quæ Erysipharum more, filamenta articulata e pariete externo agunt, alia rigidiora, erecta, alia decumbentia et ab hyphis mycelii sinceris ægre discriminanda; baculi conidiophori in paniculas mire discedunt quæ semina, in capitula densa primum digesta, tandem dimittunt; semina inde plurima in mycelio substrato sparguntur.

3-5. Conidia quæ juxtaposita sata, isthmis brevibus alia aliis juncta paulo post reperta sunt; quædam insuper germina libera exseruerunt.

6-8. Conidia alia discreta quæ germinare cœperunt.

9-14. Conidia altera quorum germina pleraque, ætate provectiora, in ampullas varias creverunt.

15 et 16 . Horumce conidiorum germina in clavulas articulatas informata sunt quæ plasmate ita abundant ut reliqua plantula admodum evacuata videatur.

17 et 18. Perithecia recentissime nata globulos referunt.

Omnes figuræ fungos exprimunt Modoni Versaliorum vivos repertos novembri et decembri, a. S. MDCGCLIX, parique modo, nempe vices circiter cccLxxx, præter primam et alteram, augentur.

\section{(Tab. VI, fig. 1-18.)}

1. Conidia Hypomycetis roselli (A Ab. et Schw.) in aqua recens sata, jamque isthmis tum inter se, tum filamentis fortuito proximis juncta.

2. Conidium aliud, discretum, pari modo filamentum juxtapositum agoreditur.

3-7. Conidiorum germina multifaria exhibentur; pleraque clavulis moniliformibus et plasmate spisso refertis insigniuntur.

8-9. Conidia quorum germina erecta cauliculi ramiferi et sua vice elegantissime conidiophori subito facta sunt.

10. Thecæ duæ fertiles, tertia sterili accedente.

11. Sрожæ seorsim delineatæ.

12. Spora quæ germen lineare edidit.

13. Spora nondum mutata, alteraque cujus germen crassum et articulatum plasmate copioso refertur.

14-17. Sporæ germina varia enixæ, pleræque mucrone hinc aut illinc, nisi utrinque, adhuc instructæ.

18. Sporæ aliæ germina egerunt filiformia quæ jam prælonga et septifera evasere moniliaque crassa, conidiorum instar, sustinent.

Hæ figuræ nativam rerum magnitudinem omnes pariter, scilicet vices circa ccclxxx, excedunt, Parisiisque depictæ sunt, decembri medio, a. D. MDCGCLIX; conidia et endosporæ domi germinarunt. 


\section{Hyponyces CHRysospermus.}

\footnotetext{
* Fungus cum matrice simul sumptus :
}

Tubiporus sulphuratus seu $C_{\grave{P} P E}$ soufré Pauletio, Traité des Champ. tom. II (1793), p. 391, tab. clxxxiII, fig. 1 et 2 ; ed. Lev. p. $9^{8}$ (Boletus subtomentosus Linv.). ** Fungillus macroconidiis s. chlamydosporis fucatis, aureis, instructus, minoribus autem coni-
diis quæ pallida sunt, omnino prætervisis :

Reticularia chrysosperma (in Boletis) Bull. Champ. de la Fr. tab. cccclxxvi, fig. 4, cum brevi descriptione. Sowerb. Engl. Fungi, tom. III (1803), tab. ccclxxvili, fig. 13.

Mugor ghrysospermus Bull. op. cit. t. I (1791), p. 99, tab. div, fig. 1.

Uredo mycophila Pers. Obs. Mycol. parte I $\left(179^{6}\right)$, p. 16 , n. 29, et Syn. Fung. (1801), p. 214 , n. 1. Candollio, Fl. Gall. tom. II, p. 230 , n. 616.

Uredo mycophlla seu polius Trichoderma mycophilum aut parasiticum Alb. et Schw. Consp. F. Nisk. (1805), p. 122 , n. 338 .

Sepedonidm mycophildm Neesio, Syst. der Pilze (1817), p. 44, tab. iII, fig. 38 (pessima). - Mart. Fl. Crypt. Erlang. (1817), p. 334. - Linkio, Obs. in ord. pl. nat. Diss. I, p. 16; et in Willdenowir Sp. pl. Linn. t. VI, parte I (1824), p. 29 , n. 1. - Grevillio, Fl. Crypt. Scotice, t. IV $(1826)$, tab. cxcviII (in Boleto). - Chevall. Fl. gén. des envir. de Paris, tom. I (1826), p. 53, tab. iII, fig. 16 (mala). - Conde, Ic. Fung. tom. IV (1840), p. 7 , tab. III, fig. 23. - Rabenh. in Klotzschi Herb. viv. mycol. ed. alt. fasc. II (1855), n. 184 (in Agaricis).

Mycobanche chrysosperma Pers. Champ. Com. (1818), p. 133. - Wallr. Consp. Fl. Germ. p. post. p. 272 , n. 1823 . Sporotrichum mycophilum Spreng. Syst. Veget. tom. IV $\left(18_{2} 7\right)$, p. 549 , n. 24 , ubi autem plantula in fungis
aridis hospitari perperam dicitur.

Sepedonium chrysosperam Friesio, Syst. Myc. t. III (1829), p. 438, n. 1; Sum. Veget. Sc. (1849), p. 497.

*** Fungillus, protoconidiis ejus simul et macroconidiis observatis :

Sepedonidm chrysospermum Tul. in Act. hebdom. Acad. Sc. par. tom. XLI (1855), p. 616.

**** Fungus integer, perfectus :

Hypomyces chrysospermus Tul. in Ann. Sc. nat. ser. iv, t. XIII (1860), p. 16 , n. 13.

Funginam vivamque matricem fungilli nostri vel recentissimam si dissecueris, bysso peregrina, alba, ut sincera mucedine, ex omni parte jam infartam plerumque videbis. Brssus hæc ad lucem properans venit, et hospitem miserum aut totum aut rarius pro parte tantum, indumento primum niveo postea autem luteo-virente tandemque nitide luteo v. aureo pedetentim obtegit. Simul etiam interaneas ejusdem hospitis lacunas et cavernulas, si quæ sunt natura volente vel ex insectorum injuria, pari modo vestit aut implet. Donec niveus consistit, conidiorum minorum s. protoconidiorum ferax est, quæ ovata v. oblonga, utrinque obtusissima, in medio quandoque nonnihil angustata et septo quidem instructa, $\mathrm{O}^{\mathrm{mm}}, 006-02$ in longitudinem et $\mathrm{o}^{\mathrm{mm}}, 005-01$ in crassitudinem obtinent, atque summis floccis longe protractis, arreclis, alternis, oppositis, interdum etiam subverticillatis, sæpius solitaria geminave efferuntur. Corpuscula sunt de more admodum 
levia, pallido et limpido replentur humore, dataque opportunitate in filiformia abeunt germina. Conidia autem majora s. chlamydosporæ ramis brevibus, simplicibus v. paucibrachiatis, erecto-patulis et inordinatis acrogena nituntur, et, prout loca natalia sinunt, modo in racemos compositos seu longissimas et angustas quasdam paniculas digeruntur, modo contra byssum inter densatam compinguntur. Omni ætate sphærica sunt, matura diametro $\mathrm{o}^{\mathrm{mm}}, \mathrm{o}_{1} 3-\mathrm{o}_{2}$ æquant, verruculis conico-obtusis in episporio crasso dense asperantur, colore e luteo tandem aureo-fusco saturate fucantur, liberataque et in pulverem soluta nullum suffulcri vestigium retinere solent. Quædam etiam occurrunt breviter pyriformia vel obovata; alia didyma, biloculata, ex utriculis duobus vix æqualibus coalitisque fabricantur, et Puccinice formam imitantur. In pedicello æquo modo exili et achroo, multo rarius nonnihil inflato et partim fucato singula utcumque se habeant, consistunt; sunt autem nonnulla, rarissima equidem, ovato-oblonga nec acrogena, quæ scilicet in filamentum iterato conidiferum ultra apicem breviter protrahuntur. Semina hæc omnia nitide fucata tum in intimis alienæ matris penetralibus, tum in summa ejus pulpa vulgo abundantissime generantur, ita ut fungus hospes, qui sæpe monstrosus fit, quasi totus in pulverem aureum abire et dissolvi videatur; quandoque autem in ejusdem superficie tantummodo nascuntur. Haud aliter atque protoconidia, conidia majora, si locus tempusque faverint, progerminant. Conidiis utriusque generis oppressa cum subsederit matrix, tunc in ea sub luce proveniunt innumera perithecia in stratum colliculosum densissime compacta, et in aureo conidiorum pulvere partim demersa; singulis uterus est sphæricus, diametro circa semi-millimetralis, e parietibus membranaceis, tenuibus, glabris, dilute et sordide aureis factus, et in mucronulum brevissimum obtusumque superne productus. Theсе anguste cylindricæ, obtusissimæ, deorsum attenuatæ, $\mathrm{o}^{\mathrm{mm}}, 15-2 \mathrm{o}$ longitudine adipiscuntur, crassitudine autem vix $0^{\mathrm{mm}}, 01$ æquant, et paraphysibus intermixtis, ul Hypomycetem decet, destituuntur. Sporæ octonæ et oblique monostichæ in singulis ascis, formam lanceolatam, nonnihil incurvam et utrinque aut hinc tantum mucronulatam obtinent, $o^{\mathrm{mm}}, 023-03$ in longitudinem et $\mathrm{o}^{\mathrm{mm}}$, oo 5 -o 065 in crassitudinem consequuntur, septoque transverso in locellos duos inæquales, quorum minor sæpius vacuus consistit, singulatim dividuntur; præterea leves sunt et maturæ in cirros breves pallidæ eructantur.

Frequens parasitatur æstate et autumno in Bolelis ac potissimum in B. subtomentoso, eduli, luridoque; eum quoque offendimus, nec semel, tum in Agarico involuto et Sclerodermate verrucoso agri parisiensis, tum in Melanogastro variegalo Tul. et Octaviana asterosperma VitTad. apud Pictones. Plantula autem ascophora semel duntaxat, sed copiosa, nobis hactenus occurrit in pileo supremo Boleti subtomentosi, querceti cujusdam sub umbra, ad pagum Villacoublay agri Versaliensis, augusto ineunte, a. D. MDCGCLX; quare nunc tantummodo primum prodit fungilli integri descriptio. 
Sporæ omnes in singulis ascis pari modo se habent, atque nunc locellum suum vacuum et minorem, nunc contra crassiorem ad asci verticem convertunt; rarius accidit ut locelli ambo pariter sint fertiles, plasmate scilicet granoso-oleoso pallidoque similiter referciantur; articulus sterilis vulgo obtusus est. Pileus boletinus qui peritheciis onustus nobis obvius est, maxime emaciatus erat, et crustam carnosam, millim. II vix crassiorem, introrsus fuscam udamque, extrorsum vero pro maxima parte in pulverem sordide aureum mutatam, aridiorem, et peridiis contiguis at vix cohærentibus passim velatam referebat. Peridia hæc colore Sepedonium imitantur atque de cætero sic se præstant ut dubium movere non liceat quin formam perfectiorem seu absolutam, quæ tamen, confitemur, rarissima videtur, fungilli initio mucedinei repræsentent.

\section{EXPLICATIO ICONUM.}

(Tab. VIII, fig. 1-13.)

1. Filamenta vides bifariam conidiophora Hypomycetis nostri chrysospermi, sive Sepedonium mycophilum $\mathrm{N}_{\mathrm{EESIO}}$, in angustiis seminiferis Boleti subtomentosi cujus basidia ordinata $h, h$ adumbrantur, ipsum læte fructiferum ; macroconidia aurea, asperata $m, m$, quasi in racemos digeruntur; candida autem microconidia $c, c$, hyphas summas longe protractas et perexiles factas solitarie terminant; omnia nativam magnitudinem vices circiter cccLxxx excedunt.

2. Macroconidia progerminantia, et maxime aucta, ejusdem Hypomycetis chrysospermi qui exeunte junio, a. S. MDCGCLIII, in Boleti luridi interaneis Cavillæ Versaliorum hospitabatur.

3. Microconidia item egerminantia ipsiusmet fungilli boletophagi qui figura 1 exprimitur; Hericii ad Sequanam, septembri currente, a. MDCGCLVIII, vigebant.

4-7. Microconidia altera quorum germen simplex aut jam brachiatum conidiola edidit, alia ovata et pallida, alia crassiora, sphærica, coloris saturatioris et quasi mentita macroconidia.

8 et 9. Macroconidia solito crassiora et quidem didyma; omnia in Agarico involuto, septembri, a. S. MDGCCLVIII, Hericii generata vidimus.

10. Cæspes ex peritheciis Hypomycetis illius chrysospermi boleticolæ quem, ut supra diximus, Cavillæ Versaliorum (ad Villacoublay), augusto mense a. MDCGCiLX, perfectum reperire nobis contigit; conceptacula e strato byssino, crasso, et propter macroconidia inspersa læte aureo emergunt.

11. Portiuncula hujus cæspitis, antice dissecti, quinquagies præter nativam crassitudinem augetur; perithecium medium pulticulam fructiferam suam eructat; alterum prorsus evacuatum a vertice dimidiatur.

12. Thecæ, pleræque gravidæ; sporarum cellula sterilis modo sursum, modo deorsum spectat; sporæ autem in singulis thecis, qua de ratione, vulgo inter se congruunt.

13. Sporæ maturæ seorsim delineatæ.

Figuræ 1, 3-9, 12 et 13 simili modo amplificatæ sunt, nempe circa vices CGCLxxx.

\section{Hypomyces cervinus.}

Mycogone cervina Ditm. in Sturmit Fl. Germ. sect. ili, t. I (1817), p. 107, tab. LiII. - Pers. Mycol. Europ. t. I, p. 26 , n. 3. - Lк. Sp. Plant. Linn. t. VI, parte i, p. 3o. - Rabenn. Herb. Mycol. ed. alt. fasc. VII (1858), n. $67_{2}$ (in Helvella elastica, auctore Cesatio). - Berk. Introd. to Crypt. Bot. p. 3o4. - Huc etiam spectant, ni fallimur, Mycogone simplex et Fusisporium fungicolum Corde, Ic. Fung. t. VI (1854), p. 2 , tab. I, fig. 4; nec non Mycogone rosea BеRк. Introd. to Crypt. Bot. p. 304; minime autem plantula homonyma Linkio.

Racodiun? Mycobanche Pers. Myc. Europ. t. I, p. 72, saltem pro parte.

Sepedonidu aervinum Fr. Syst. Mycol.t. III, p. 439 .

Mrgobanche cervina Wallr. Fl. Germ. parte post. p. 273 , n. 1826. 
Puccinia (Mycogone) cervina et Sporotrichum Fungordm Corde, Ic. Fung. t. IlI (1839), p. 4, tab. i, fig. 12. Hypomyces cervinus Tul. in Ann. Sc. nat. ser. iv, t. XIII (1860), p. 16 , n. 14.

Non manifestatur nisi quum fungus hospes adoleverit et perfectum obtinuerit incrementum. Hicce propterea neutiquam abnormis evasit, nec parasito laborare videtur. Нуромусетем nascentem denuntiant maculæ orbiculares ex bysso tenuissima adpressa niveaque, quibus undequaque crescentibus matrix intra diem unum et alterum quasi panno primum nitidissime candido, subinde autem cervino, tota involvitur. Constat hyphasma ex filamentis ramosis et omnibus fere pariter exilibus; quæ assurgunt præ cæteris semina edunt copiosissima duplicisque naturæ. Conidia proprie dicta semper nivea aut ovato- vel lanceolato- oblonga, interdum curvula, continua, rarius propter septum medium vix conspicuum biloculata, longitudine $0^{\mathrm{mm}}, 013-016$, crassitudine autem $0^{\mathrm{mm}}, 003-0035$ æquant, et in summis filamentis dense fasciculata vel subsolitaria generantur. Semina autem altera, matura cervini coloris, ramusculis arcuatoassurgentibus, simplicibus, vix $0^{\mathrm{mm}}, 01$ longis, laxe alternis et rarius suboppositis, quasi pedicellis propriis singulatim finem imponunt; a chlamydosporis Hypomycelis chrysospermi nostri, modo descripti, forma et crassitudine vix discrepant; singula enim ex utriculis globosis duobus coalitis, inæqualibus et dissimilibus, altero, superiore scilicet, $\mathrm{o}^{\mathrm{mm}}, 0_{1} 3$ circiter crasso et spinulis stipatissimis ornato, altero levi, longe dilutiore et $\mathrm{o}^{\mathrm{mm}}$, oo 8 vix crassiore, utroque sursum deorsum nonnihil depresso, struuntur. Fungus perfectus, ascophorus, nondum nobis innotuit.

Vigentem legimus in Peziza macropode Pers. et P. Acetabulo L. nec non in Helvella monacella Pers. (nigra), mense maio abeunte junioque currente, a. S. MDGGGLX, Modoni et Bellævistæ agri parisiensis. Similiter in Peziza macropode Pers. nobis occurrit Cavillæ prope Versalias, augusto medio ejusdem anni. Abhinc etiam semel atque iterum obvium fungillum habuimus in agro versaliensi.

Mucedineum hyphasma aliquot dies candidum manet tandemque colorem cervinum, initio dilutum, subinde autem sporis pluribus maturescentibus, saturatiorem induit; interim fungina matrix carnosa, imo nonnihil tumefacta subsistit. Parasiti denique nil nisi pulvis quasi filamentorum expers superest.

Macroconidia cum maturescere cœperint in Helvella monacella Pers. dilute rubent antequam infuscentur; de cætero non differunt ab iis quæ in Pezizarum patera hospitantur.

*: Macroconidiorum articulis in globum coalitis.

\section{Hyponyces Pezize.}

* Fungillus macroconidiorum ferax simul cum matrice sumptus :

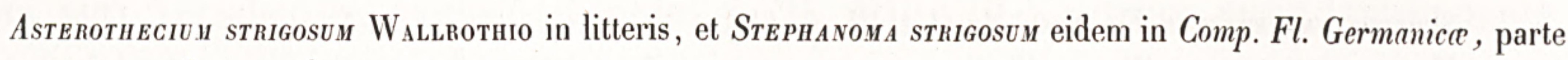
post. p. 269 , n. 1820. 
*** Fungus similiter gemmiferus, solus :

Racodium? Mrcobanche Pers. Myc. Europ. t. I, p. 72 , n. 19, saltem pro parte.

Aspergillus Mycobanche Linkio, in Willdenowir Spec. Plant. Linn. t. VI, parte i, p. 65.

Aspergilli species plerumque sterilis Friesio, Syst. Mycol. t. III, p. 386.

Asterophora $P_{\text {EZiza }}$ Corde (qui fungilli microconidia prætervidit), Ic. Fung. t. VI (1854), p. 3 , tab. i, fig. 6. - Berk. Introd. to Crypt. Bot. p. 304.

*** Fungus bifariam conidiophorus :

Hypomyces Pezize Tul. in Ann. Sc. nat. ser. iv, t. XIII (1860), p. 16, n. 16.

Funglulus totus byssinus universum Peziza hospitalis cyathum tomento niveo, brevi el densissimo vestit, nuncque rasus est et substerilis, nunc contra breviter villosus et læte gemmifer. Conidi alba, ovata vel oblonga, ut Hypomycetibus assolet, e summis floccorum ramusculis subulatis nascuntur. Chlamydospore contra albidæ ramulos breves exilesque in imis floccis terminant, aut rarius in floccis ipsis absque pediculo sedere videntur; singulæ ex utriculo constant globoso-cubico qui plasmate pallido refercitur, $0^{\mathrm{mm}}, 013-016$ diametro circiter æquat, vesiculisque IV-VI adnatis in ambilu, et una vel una et altera in vertice, cunctis globosis, achrois nec $0^{\mathrm{mm}}, 01$ crassioribus, mirum in modum stipatur. Chlamydosporæ præterea utriculo quam ipsæ sunt minore, modo hyalino nudoque, modo contra propter plasma contentum vix secus opacato, etiamque vesiculis externis hærentibus sed paucis ornato, quasi alteri macroconidio singulatim imponuntur. Fungum ascophorum frustra hactenus quæsivimus.

Crescit sera æstate autumnalique tempore in hymenio Pezize Labelli Bulc. (Fung. Gall. t. I, p. ${ }_{2} 62$, tab. caiv), i. e. Pez. hemispharica Wigg. Hofrm. et Fr. (Syst. Mycol. t. II, p. 82, n. 1$)^{1}$; infrequens reperitur in silvula Boloniensi, Parisiis suburbana, Cavillæ Versaliorum, et in quercetis arenosis circa Fontembellaqueum.

Conidia sata mox progerminant conidiolaque e germinibus extremis solitaria agunt; chlamydosporas autem germinantes nondum vidimus.

Thecæ sporæque in Peziza matrice non semper prorsus deficiunt, sed longe solito pauciores generantur; assuetam præterea crassitudinem formamque vix assequuntur. Endosporæ (rite informatæ) late ovatæ sunt et in externo tegmine minutissime granulosæ; hinc $0^{\mathrm{mm}}, 022$ et illinc $0^{\mathrm{mm}}, 013$ æquant, guttasque II crassas oleosi humoris hoc modo fovent ut exinde biloculatæ fieri videantur. Paraphyses capitatæ in articulos lineares dividuntur.

Olim fortassis quis quærat utrum pro perfectiore seu ascophora Cordæanæ Asterophorce Pezize forma fortassis habendum sit Ceratostoma (Melanospora Corde) brevirostre Fuckelio, in cupula Pezizce arenosce ejusdem auctoris, fungilli scilicet Peziza hemisphcerica Hofrs. ut videtur, maxime analogi, crescens et de quo sequentia germanice traduntur in Ephemeride Botanica Berolinensi (tom. XIX, p. 250 , n. v, tab. x, fig. Iv), die xxx m. augusti, a. D. MDCCCLXI. «Perithecia, ait L. FucкеL, sæpius stipatissima « discum Pezizce hospitalis integrum velant; globosa sunt, glabra et dilute fulva, quindecimam lineæ

${ }^{1}$ Hæc Peziza hemisphcerica (Hofrn.) datur in Mazeri Stirpib. cryptog. Gallice, edit. princ. fasc. XXVII (1843), n. 1311 . 
«partem diametro circiter æquant, parietibusque tenuibus, collo autem brevi, tereti ac in ore ciliis exiclibus et niveis ornato utuntur. Sporæ lanceolatæ, inæquilateræ, simplices, in ascis claviformibus oc“ tonæ generantur; horumce membrana tandem solvitur et evanescere videtur, simulque sporæ maturæ « saturate infuscatæ et vix pellucidæ eructantur, ac subinde in glebulas adglutinantur nitide atras quæ «spiraculi ciliis aliquandiu hærent." Postquam autem id Spherice seu Ceratostomatis brevirostris Fuck. sedulo scrutati sumus ${ }^{1}$, fungillum cognovimus Spharice Zobelii nostræ (Fung. Hypog. p. 186 , tab. xIII, fig. 1) valde proximum, et a solita Hypomycetum genuinorum indole recedentem.

2. Macroconidia ovata v. oblonga, simplicia, solitaria vel in series catenata.

* Macroconidiis verrucoso-asperatis.

\section{Hypomyges ASterophorus.}

* Fungillus chlamydosporis solummodo instructus et cum matrice (nempe Agrarico parasitico Bult.) simul sumptus :

Fungoldaster parvis ex spadiceo rufescens, capitulo villoso spharico, pane fornicato, fungis semiputridis innascens, semine stellato, Мıсн. N. Pl. Gen. p. 200 , tab. Lxxxı, fig. 1, fungillos mire gracilipedes nec vulgatioris habitus exprimente.

Elvella Clavus Scheff. Fungi Ratisb. tom. III, tab. cclxxix, et tomo IV, Ind. I, pag. 111; fungum in pulverem demum solutum auctor sane non vidit.

Agarigus lycoperdonoides Bull. Champ. de la France, tab. clxvi (in Agarico fusipede) et,t. dxvi, fig. 1 (in Ag. adusto, ut videtur), ubi pulvis conidiorum evolans ex sinceris Agarici seminibus constitui pronunciatur. Sowerb. Engl. F. tom. III, tab. ccclxxxiII (in Agarico elephantino). - Pers. Syn. Fung. p. $3{ }_{2} 5$, n. 126 ; Myc. Europ. tom III, p. 127 , n. 209.

Asterophora Linkio, tum apud Schraderual, N. Journ. für die Bot. tom. III, parte III (18og), p. 17, quo in loco genus uti dicitur "pileo superne sporophoro, sporis stellatis et lamellis sterilibus, $n$ simulque intermedium habetur Agaricum inter et Lycoperdon, tum in Mag. der naturf. Fr. z. Berlin, anno III (1809), p. 33.

Asterophora lycoperdoides Ditm. in Schrad. N. Journ.f.d. Bot. t. III, parte in modo citata, p. 56, tab. il, fig. 2 ; et apud Sturm, Deutschl. Fl. part. in, fasc. II (1814), pag. 53, tab. xхvi. - Rавеnh. Herb. Myc. ed. alt. fasc. III, n. 235 .

Merulius lycoperdoides Candollio, Fl. Fr. tom. II, p. 128.

Agaricus (Asterophora) lycoperdoides Nees, Syst. d. Pilze, p. 206, n. 3o, tab. xxiv, fig. 194 (ex Ditmario sumptis ).

OnYgena agaricina Schw. F. Carol. sup. p. 65, sub n. 1429.

Asteropiora agaricoides, lycoperdoides, physaroides et trichioides Fr. Obs. Myc. t. II, p. $36_{7}$.

Asteropiora agaricoides, lycoperdoides et physaroides ejusd. Syst. Myc. t. III, p. 205 et 206.

AsteropHORA LYCOPERDOIDES et TRICHIOIDES ejusd. S. Veget. Sc. p. 446.

Asterosperma agaricoides Pers. Champ. Comest. p. 132 et 134.

Asteropiora agaricoides et lycoperdoides Wallr. Comp. Fl. Germ. p. post. p. 270, n. 1821 et 1822.

Asterophora lycoperdoides et physaroides Bonord. Handb. der Mycol. p. 134 , tab. xi, fig. 224.

Nyctalis asterophora Fr. Epicr. Hymen. p. $371 ;$ S. Veget. Sc. p. $312 .-$ Ant. de Bary, in Bot. Zeit. t. XVII (1859), p. 385 et 397 , tab. xIII, fig. 1-11.

Continetur enim in Rabenhorsti Herb. Mycol. ed. alt. fasc. VII (1858), n. 63o, sub titulo Pezizce hemispherice Hofrs. quippe anticam hujusce Pezize paginam con- stipatissimis et cumulatis peritheciis integram obducit. Nullum autem Asterophorce, si quia olim exstiterit, vestigium superest. 
** Fungus gemmiferus, scil. chlamydosporis donatus, solus et in seipso consideratus :

Sepedonivi angulatum Klotzsch in Dietr. Fl. regni Bor. tab. dxxxil (auctore Baryo).

Asterophora agarigicola Corde, Ic. Fung. t. IV, p. 8 , tab. iII, fig. 24. - Tul. in Ann. Sc.nat. ser. III, t. XX (1853), p. 27 , nota 2.

Asterophora lycoperdoides Corde, op. modo cit. t. VI (1854), p. 2, tab. I, fig. 5.

Artotrogus asterophorus Friesio, S. Veget. Scand. p. 497.

Asterophora Berk. Introd. to crypt: Bot. (1857), p. 305.

Asterotrichum Ditmari Bonord. Handb. der Mykol. p. 82. - Th. Ball, Syst. der Pilze, p. 104, tab. xxxiII, fig. inf. dextris.

*** Fungus gemmiferus simul et ascophorus :

Hypomyces asteropilorus Tul. in Ann. Sc. nat. ser. iv, t. XIII (1860), p. 14 , n. 12.

Fungillus matricis suæ funginæ interanea simul et summas partes occupat. MrceliI inter filamenta achroa vel pallida, ramosissima et implexa, alia admodum exilia, $\mathrm{o}^{\mathrm{mm}}, \mathrm{o} \mathbf{1}$ vix crassa nempe consistunt et tenuis instar tomenti ita quandoque sternuntur ut oculo inermi æore conspiciantur; alia vero crassiora et peculiariter nodoso-articulata deprehenduntur. Microconidia e filamentis tenuioribus originem ducunt; ex his enim rami nascuntur alterni vel fasciculati qui in brachia exiliora, obsolete verticillata, longissima, arcuato-demissa, ipsaque semel aut semel atque iterum frequenter dichotoma discedunt; crura ista gracillima, quippe $0^{\mathrm{mm}}, 0035$ crassitudine vix superant, in articulos innumeros, $\mathrm{o}^{\mathrm{mm}}, 01-015$ longos, tot septis transversis dividuntur, moniliaque seu antennas corniformes integra fingunt; mox autem in conidia simplicia, linearicylindrica solvuntur, vitamque sic implent. Crassiora contra mycelii filamenta ramos agunt qui in macroconidium unicum, aut plura in seriem linearem contigue digesta desinunt. Macroconidia ovata vel oblonga, $0^{\mathrm{mm}}$, o $18-025$ longa et $0^{\mathrm{mm}}, 01-013$ crassa, tuberculis crassis et obtusis asperantur, colorem cervinum matura ducunt, pulveremque copiosum tandem constituunt, inde hospita substantia tota in peregrina dissolvi semina, nudatumque Lycoperdi maturi meditullium æmulari videtur. Præterea in bysso effusa generantur perithecia, sessilia et densissime inspersa, ovato-globosa, in collum plus minus tenuato-producta oreque acuto ac ciliato pervia; diametro $0^{\mathrm{mm}}, 07$ o 9 æquant nec $\mathrm{o}^{\mathrm{mm}}, 15$ longitudine vulgo excedunt, parietes achroos et pellucidos ex utriculis globosis, amplis, humoreque limpido refertis, obtinent, et sporarum quas fovent colorem dilute luteo-fuscum tradunt. Hж sporæ formam anguste lanceolatam, utrinque mucronatam curvulamque usurpant, $\mathrm{o}^{\mathrm{mm}}$, o 25 -0 35 in longitudinem et $\mathrm{o}^{\mathrm{mm}}$, o o 6 in crassitudinem nanciscuntur, in loculos duos æquales septo transverso dividuntur guttulasque duas oleosas vel plasma granosum includunt; thecæ in quibus singulis arctissime primum, IV-VI insimul, conglobantur, late ovatæ sunt, deorsum abrupte tenuantur et membrana tenuissima citoque destructa fabricantur. Paraphyses sinceras non vidimus.

Parasitatur æstate exeunte in Agarico aduslo PERs. semivivo, at lætius etiam in Nyctali aste- 
rophora $\mathrm{F}_{\mathrm{r}}$. superinsita; bifariam conidiophorus nobis sexcenties occurrit in nemoribus agri versaliensis, compendiensis et cæt. ascophorus vero longe rarior est et talem se nobis primum præstitit circa Fontembellaqueum, augusto mense a. MDGGCLVIII.

Fungillus simul cum Nyctali matrice nascitur et crescit, ita ut pars ejus sincera facile diceretur; hospitem enim substantiam ab intimo pilei meditullio ad superficiem usque suis infarcit seminibus; perithecia tamen nonnisi in aere nuda et libera, ut decet, explicare solet. Nyctalis præonans sæpius deformatur, pileum valde incrassatum, subglobosum, lamellas, si quæ sunt, angustissimas, tenuissimas et substeriles monstrat, Lycoperdonque exiliter pedicellatum, primum album et tomentellum, dein autem cervini coloris et in pulverem totum fatiscens refert. Hypomycetis mycelium nulli parcit Nyctalis parti sed in ejus pileo copiosius generatur; perithecia in stipite frequenter sparguntur.

Agaricus ille exiguus (Ag. parasiticus Bull. s. Nyctalis species $\mathrm{F}_{\mathrm{r}}$ ) qui fungillum nostrum sæpius hospitio excipit, ipse in Agarico altero, scil. Ag. adusto Pers. parasitatur, ejusque interdum legitima sed abnormis proles videtur; originem vero e sincera prolificatione neutiquam trahit, quippe forma universa, lamellarum indole et dispositione nec non sporis minoribus a sua nutrice toto cœlo differt. Miramur ideo cur de ejus natura autonoma dubitaverit cl. Cessti his verbis : «Quo magis rationes « Nyctalis ejusque incolæ examino et perpendo, eo magis mihi suadere lubet Nyctalim vix aliud esse ac « prolificationem quam maxime morbosam et anomalam ipsissimorum fungorum quos inhabitat; quæ "proles, parasiti causa quem præ se gerit, normaliorem evolutionem attingendi impos fit... Lamel«larum evolutio, ubi optima adest, semper imperfectæ vegetationis mihi specimen præbet." (Cfr. Raвenn. Herb. Mycol. ed. alt. fasc. III [1856], n. 235.)

Ad Hypomycetem asterophorum ( $\mathrm{F}_{\mathrm{R} .}$ ) affinitate accedere nobis videbatur Hypomyces Melanostioma noster cujus olim descriptiunculam præstitimus in Ann. Sc. nat. ser. 1v, t. XIII, p. ${ }_{17}$; eumdem ex hoc tempore iterum offendere nobis non contigit.

In Russula adusta Fr. simul cum Hypomycete nostro asterophoro quandoque etiam hospitatur Hypomyces fusisporus (nob. in schedis) quem æore distinguas nisi peritheciis protractis, nempe $0^{\mathrm{mm}}, 15-20$ longis, nec tamen $0^{\mathrm{mm}}, 05-06$ basi crassioribus, thecis brevibus late obovatis et endosporis quaternis obovato-fusiformibus, $\mathrm{o}^{\mathrm{mm}}, 05$ circiter longis, $\mathrm{O}^{\mathrm{mm}}, 01$ crassis deorsumque exiliter cuspidatis. Fungillus cæterum æque ex albido squalibus fit ac Hypomyces asterophorus, ejusque fortassis forma abnormis quibusdam videbitur. Cavillæ passim reperiebatur augusto mense MDCCCLX.

De habitu, natura molli, glabritie, exiguitate, forma tubulosa et colore mutabili, cum præcedentibus typis adeo consimile se habet Sphacroncma quoddam, eorumdem in Agarico adusto non infrequens comes, ut vix teneamur quin pro alterutrius pycnidio illud habeamus. Uterum supra gobobsum, $0^{\mathrm{mm}}, 16-19$ diametro crassum et ex parietibus tenuissimis, albidis tandemque infuscatis factum, in fistulam angustam, teretem ac $0^{\mathrm{mm}}, 7-8$ longam assurgit, et ciliis tubulosis extrorsumque recurvis in ore dilatato ornatur. Stylosporæ anguste ovatæ vel ovato-oblongæ, rectæ, continuæ, utrinque obtusæ, demumque fuscæ et liberæ, $0^{\mathrm{mm}} 0_{065-01}$ in longitudinem et $0^{\mathrm{mm}}, 0035$ in crassitudinem æquant; initio autem in summo sterigmate quaternatim divaricatæ hærent, tria scilicet semina in quoviscunque sertulo seu capitulo quoquoversus patent, dum quartum stat in fulcimine; cæterum sterigmata omnia longa, admodum exilia simpliciaque sæpius offenduntur. Apud Spharonema subulatum Fr. ${ }^{1}$ (Syst. Myc. t. II, p. 536 , n. 1), rarius nobis obvium (in Agarico [pulverulento v. caudicino?] arido), peridii cilia terminalia

1 Sphcerice species Todeo, F. Meckl. sel. parte alt. p. 44 , n. 41, tab. xv, fig. 117; sub Friesiano autem Spharonce- matis titulo apud Greviluiun ( $F l$. Crypt. Scotice, t. IV, tah. cLxxxix) adumbratur. 
minime demittuntur, stylosporæ ovatæ hinc aristula, illinc fulcro persistente et similiter perquam exili augentur, sertulaque in fibris articulatis laxa sed uberrima struunt.

\section{EXPLICATIO ICONUM.}

(Tab. IX.)

1. Agaricus parasiticus Bull. recens natus et Hypomycetis asterophori nostri electa sedes, factus, a vertice dimidiatur; omni lamellarum vestigio inops est et formam illam globosam sumpsit quæ Agarico lycoperdoidi BulL. solennis est; natura quintuplo major adumbratur, ejusque superficies nivea et integra est, hospite nondum maturo.

2. Agarici duo lycoperdoides Bull. inæqualis magnitudinis (ambo autem pariter natura quadruplo majores expressi) et a vertice item dissecti, pulvere cervino e macroconidiis Hypomycetis asterophori, mixtis microconidiis albis, in pileo obruuntur. Lamellas summopere angustatas fungus major obtinuit, minor vero longe magis abortivus lycoperdon stipitatum quodammodo mentitur.

3. Cæspes ex utroque filamentorum conidiophororum genere; hyphæ graciliores et pallidæ macroconidia, tandem cervina, $m, m$ generare solent; crassiores autem et fucatiores microconidia $c, c$, quæ semper albida in monilia exiliter linearia et longissima primum digeruntur; ex hyphis fucatis perithecia $p, p$ etiam debito tempore nascuntur.

4. Perithecia, matura alia et sporas liberas eructantia, alia contra clausa et gravida vel nondum perfecta, mycelio repenti simul imponuntur; nonnulla autem e stramine assurgunt filamenta quorum brachia sæpius verticillata in monilia gracillima, dichotoma, arcuata totaque e microconidiis linearibus $c, c$ sociatis, abeunt; macroconidia pauca, $m, m$, passim sparguntur.

5. Perithecium evacuatum seorsim delineatur; oris margines ex utriculis modo lineari-acutis, arrectis discretisque, modo contra obtusis et arctius ex integro sibi invicem cohærentibus struuntur.

6 . Theca dispora, duabus nondum gravidis accedentibus.

7-8. Thecæ disporæ et altera tetraspora.

9. Asci recentes nil nisi plasma dilutum fovent; spora vix matura juxtaponitur.

10. Endosporæ maturitatem nactæ; quædam geminatæ constiterunt, licet uteri materni parietes ex toto perierint.

Figuræ, præter primam et alteram, nativam rerum magnitudinem simili modo, nempe vices cccLxxx, excedunt; omnes ex fungis vivis delineatæ sunt, alia (fig. 4) Hericii, septembri mense, a. S. MDCCGLVIII, aliæ (fig. 3 et 5-9) Parisiis, novembri et decembri anni subsequentis, cæteræ autem Cavillæ Versaliorum, augusto et septembri currentibus, a. D. MDCGCLX.

\section{** Macroconidiis levibus.}

\section{Hyponyces luteo-virens.}

SPHeria LUteo-VIRENS Fr. Syst. Mycol. t. II, p. 339 , n. 35, saltem ut videtur.

Hy pocrea LUteo-VIRENS Fr. S. Veget. Sc. p. 383. - Berk. et Br. in Ann. and Mag. of nat. Hist. ser. alt. t. VII (1851), p. 186 , n. 594. - Berk. Outl. of Brit. Fung. p. 383 , n. 7.

Hypomyees luteo-virens (Fr.) Tul. in Ann. Sc. nat. ser. iv, t. XIII (1860), p. 13 , n. 8.

Ав Hypomycete chlorino infra descripto prima fronte parum discrepat, byssus autem brevis et subrasa in qua consistit colorem potius sordide cinereum quam luteum as- 
sumit. FlocGr omnes similiter exiles reperiuntur, extremaque eorum brachia, sæpe terna et longe attenuata, conidia de more ovata et levia, $0^{\mathrm{mm}}, 007-015$ longa, $0^{\mathrm{mm}}, 005-006$ crassa, solitariaque sustentant. Macroconidia (chlamydosporce Baryo) anguste ovata, minutissime granulosa, sæpius $0^{\mathrm{mm}}, 016$-0 2 longa et $0^{\mathrm{mm}}, 01$ crassa, colorisque sordidi et dilute fusci, brevibus floccorum ramis acrogena sese excipiunt, et cujuslibet utriculi subtus expertia sunt, ita ut prorsus simplicia simul et solitaria in suffulcris suis appareant. Sunt etiam quæ floccis maternis, reptantibus, sessilia aut subsessilia hærent. Perithecia exigua, ovato-globosa obtusaque, laxiusculo ordine matrici insperguntur, thecisque longe linearibus referciuntur; endosporæ de more lanceolatæ, biloculatæ et octonæ in singulis ascis generantur.

Hospitatur æstate in Boletis quos corrumpit. Nobis occurrit duplici modo conidiophorus, julio mense MDCCCLVII, in Boleto quodam putredine semidestructo, sub umbra fagorum sylvæ Compendiensis (prope Petrifontem) cujus in arena Boletus castaneus et B. cyanescens vix pauciores quam B. subtomentosus, dicto tempore, reperiebantur. Eundern abhinc iterum vidimus, semper autem mere gemmiferum, in nemoribus agri versaliensis. Quidquid ideo circa fungum perfectiorem seu ascophorum præstitimus, e speciminibus anglicis, aliis scilicet quæ benevolo C. E. Broone olim debuimus, aliis vero quæ in Mycotheca Mazeriana'(ap. Mus. Bot. par.) continentur, eruimus.

Etsi fungillus modo descriptus Hypomycetis chlorini nostri speciem imitatur, ei propter macroconidia omnino dissimilis est. Hæcce quandoque solito angustiora, $0^{\mathrm{mm}}, 025$ longitudine adipiscuntur. Conidia sevimus quæ germina linearia protruserunt.

Ad Hypomycetem luteo-virentem (Fr.) similitudine accedit Hypomyces noster tuberosus (in sched.) propter conidia duplicis generis quibus ipse donatur et formam his seminibus privam; totus autem albus est et in sclerotia innumera, crassa, sparsa coalitave diuque lacrymantia mire excrescit. Tubera istiusmodi, globosa v. hemisphærica, in stipite lamellisque Agarici (Lactarii) acris Bucl. exserta sedent. Villus matricem vestit brevissimus ex quo gemmæ utriusque indolis solito modo proveniunt. Macroconidia pleraque subsessilia nascuntur et chlamydosporis Hypomycetis luteo-virentis duplo fere minora sunt, quare solam conidiorum proprie dictorum (alborum) crassitudinem excedunt, iisdemque sæpe breviora consistunt. Fungus nobis obvius factus est tum in quercetis agri versaliensis (loco dicto Jardy), augusto ineunte, tum etiam prope Salmurium (S. Martin, Longué) apud Andecavos, septembri currente MDCCCLXI. Sclerotiis crassissimis et exsertis prima fronte distinguitur ab Hypomycete? miliario nostro, item sclerotiophoro sed admodum diverso, de quo supra p. 43 pauca verba fecimus.

\section{EXPLICATIO ICONUM.}

(Tab. VIII, fig. 14-16.)

14. Hypomycetis luteo-virentis Fr. perithecia matura, quinquagies præter naturam aucta, in ore tubulorum Boleti cujusdam e terris anglicis, hærentia dependent, tomento conidiophoro substrato; tubuli autem adumbrati longitrorsum dissecti sunt.

15. Hyphæ solito modo conidiophoræ proponuntur, ita ut macroconidia $m, m$, fucata et asperata, nec 
non microconidia seu conidia proprie dicta $c$, $c$, candida leviaque, simul exhibeant; in Boleto castaneo Bull. Petrifonte Compendiorum, julio medio, vigebant.

16. Thecæ fertiles fungilli anglici modo adumbrati (fig. 14) simili modo ac hyphæ præcedentes, nempe vices circiter $\operatorname{cccLxxx}$, amplificantur.

\section{Hypoiygers Baryanus.}

* Fungillus simul cum matrice sumptus :

Agarigi parasitigi Bull. (Fung. Gall. t. dLxxiv, fig. 2) forma peculiaris, seminibusque antea inauditis scatens, Baryo in Schlechtendali Ephem. Bot. Berol. t. XVII (1859), p. 393 et seq. tab. xill, fig. 14-19.

** Fungus solus, gemmifer :

Hypomyges Baryanus Tul. in Ann. Sc. nat. ser. iv, t. XIII (1860), p. 13 , n. 10.

Husus loci omnino est Hypomyces ille qui instar Hypomycetis asterophori de quo modo agebatur, hospitatur etiam in Agarico parasitico Bull. sed macroconidiis s. chlamydosporis admodum levibus et coloris saturatioris insignitur. Agaricus Hypomycete nostro gravidus a longe distinguitur stipite sæpius gracili, pileo mediocri ac lamellis paucis, cinereis ét mirum in modum incrassatis. Plantulæ parasiticæ mycelium totum viget intestinum et macroconidiorum ferax est. Hæcce plerumque solitarie acrogena vel mesogena, in utraque lamellarum hospitalium pagina præsertim abundant, formam ovato-oblongam affectant, in medio nucleifero peculiariter infuscantur, in utroque autem apice vacua et pallida deprehenduntur. Conidia minora et fructus ascophoros nunquam reperimus.

Estate autumnoque crescit, interdumque non infrequens est in silvis agri versaliensis.

Agraricus parasiticus Bulc. nunquam simul alere videtur Hypomycetem asterophorum et Baryanum, sed in eodem Agarico adusto Pers. recenti vel exoleto nigroque (annotino) quandoque una reperiuntur cæspites plurimi ex Agarico parasitico Bulc. alii Hypomycete asterophoro, alii Baryano laborantes. Quamcunque hospitio exceperit ex his peregrinis plantulis, Agaricus parasiticus propterea non omnino sterilis evadit et aliquando, sicuti compertam rem non semel habuimus, basidia tetraspora in suis lamellis gignere valet.

\section{Hypomyges ghlorinus.}

Hypomyces ahlorinus Tul. in Ann. Sc.nat. ser. iv, t. XIII (1860), p. 13, n. 9 .

Byssum sistit brevissimam, erectam, primitus albidam v. cineream, deinque conidia enixam sordide luteo-virescentem, cujus strato ubique pariter tenuissimo hymenium fungi matricis, imo quandoque et pileus cito velantur et decolorantur. Flocar fere omnes similiter exiles, ramulos paucos subverticillatos sursum versus agunt, e quibus summis conidia ovata oblongave, alba v. pallida, $0^{\mathrm{mm}}, 0065-013$ longa, et $\mathrm{o}^{\mathrm{mm}}, 003-005$ 
circiter lata, vulgo solitaria nascuntur. Iisdem floccis, imis autem, insistunt macroconidia, singula brevi suffulta pediculo, ovata, obtuse mucronulata v. acutiuscula, basi subrecte truncata cellulæque obconicæ, exiğ $\mathrm{o}^{\mathrm{mm}}, \mathrm{o} 35-042$, illinc $\mathrm{o}^{\mathrm{mm}}, 016$ vulgo nanciscuntur, e pariete crasso levique fabricantur, plasma granosum includunt, coloreque læte chlorino insigniuntur. Fungus ascophorus nobis nondum innotuit.

Viget æstate et autumnali tempore in Boleto cyanescenti Bulc. subtomentoso L. scabro Bull. et congeneribus haud infrequens. Gemmiferum invenimus julio mense MDCGCLVII in nemoribus Modoniis, prope Parisios, et sylva Compendiensi; æstate etiam et autumno anni subsequentis in quercetis et fagetis Fontebellaqueo (Samoreau, Valvins, et c.), nec semel.

Quum Boletus fungillum parasitantem debito tempore aluit, corrumpitur et tetrum spirat odorem. Hypomycetis mucedo, instar Sepedonii mycophili Lк. simul cum Boleto nasci videtur, altiora ejus penetralia ab initio occupat, conidiaque minora in aere et luce tantum, majora contra et fucata in opaciore meditullio, v. gr. in intima pilei substantia hymeniique compage, copiosissima, lucifuga gignere solet. Boleti subtomentosi L. hospitis præ cæteris assueti, sporæ anguste lanceolatæ et dilute fuscæ (etiamsi singillatim eas conspicias) $0^{\mathrm{mm}}, 013 \mathrm{hinc}$, illinc autem circiter $0^{\mathrm{mm}}, 005$ æquant, et non obstante mucedineo Hypomycete abundantissime generantur.

\section{EXPLICATIO ICONIS.}

(Tab. VIII, fig. 17.)

17. Mycelium binario modo conidiophorum Hypomycetis chlorini nostri modo descripti; vigebat augusto mense a. S. MDCGCLVIII, in Boleto subtomentoso, haud procul a Fontebellaqueo, loco dicto Valvins; macroconidia s. chlamydosporæ, $m$, et microconidia $c$, singula suis suffulcris hærent; Boleti nutritii basidia et sporæ impositæ simul adumbrantur.

\section{Hyponyces violaceus.}

Spheria violacea Schmidtio in Herb. Kunzeano, docente Friesio in suo Syst. Myc. t. II, p. 441, n. 278. Hypomyces violageus Tul. in Ann. Sc. nat. ser. iv, t. XIII (1860), p. 14, n. 11.

Flocar vagi, tenuissimi et in byssum albam compacti, e ramis sæpius alternis, maxime divaricatis et paniculas laxissimas fingentibus, tum conidia proprie dicta anguste ovata s. lineari-oblonga, 1-2-loculata, pallida, recta v. curvula, $0^{\mathrm{mm}}, 01-022$ longa, et $0^{\mathrm{mm}}, 005-007$ crassa, tum etiam macroconidia late ovata, utrinque obtusissima, $0^{\mathrm{mm}}, 023-029$ longa, $0^{\mathrm{mm}}, 016-022$ crassa, admodum levia et saturate fusca, exserunt. Conidia minora de more in floccis supremis, chlamydosporæ autem in inferioribus oriuntur; singula cæterum ramusculis similiter contractis et exiliter subulatis finem imponunt. Conidia raro geminata vidimus, chlamydosporas autem nunquam; seminis utrumque genus, data opportunitate, solitum edit lineare germen. Perithecia globosa, perexigua, ostioloque obtuso et ægre conspicuo pervia, plerumque natali 
hyphasmate immerguntur; thecæ angustissime lineares sporas minimas, ovatas, rectas, muticas et biloculatas fovent.

Parasitari dicitur in Fuligine violacea Pers. (Ethalio septico Fr.). Semel tantum et gemmiferus nobis occurrit, septembri ineunte, a. MDGGCLVIII, in pinetis Fontisbellaquei (loco dicto Croix de Guise); tunc etiam hospitabatur in Fuligine quadam obsoleta. Fungum ascophorum e terris finnicis allatum clar. Gul. NyLANDro debemus.

Fungillus ob indolem chlamydosporarum suarum a congeneribus omnibus facile discriminatur.

\section{Hyponyces decipiens $†$.}

Agrarici mellei $\mathrm{V}_{\mathrm{AHLIO}}$ peculiaris apparatus fructifer, judice BARYo, in Ephemeride Bot. Berolinensi, tom. XVII (1859), p. 401-403, tab. xiII, fig. 20-25 (nisi saltem nos omnia fallunt).

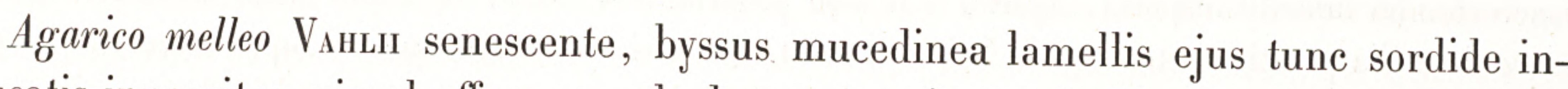

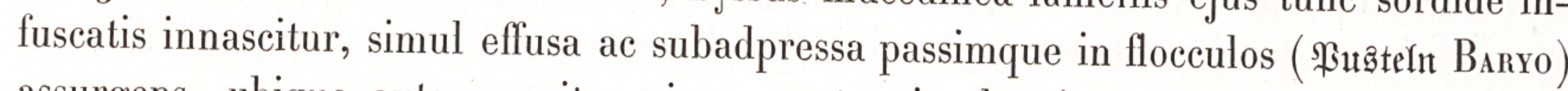
assurgens, ubique autem pariter nivea, pertenuis, brevis et fragillima, cujus enim filamenta exilissima ( $\mathrm{o}^{\mathrm{mm}}, 0035$ vix crassiora) facillime, aqua præsertim affusa, in bacillos rectos, maxime inæquales, nempe $\mathrm{o}^{\mathrm{mm}}, 01-025$ et quod excedit longos, rupta solvuntur. Innumera hæc fragmenta conidiorum vices agere videntur. Simul autem adsunt flocci parcius articulati, imo longiuscule continui, qui macroconidio primum quasi sphærico, postea vero nonnihil obovato, singuli terminantur, et ramos similiter fertiles aliquandoque oppositos passim agunt. Macroconidia prorsus levia, $\mathrm{o}^{\mathrm{mm}}, \mathrm{o}_{1-0} 3$ diametro majori æquant, plasmate oleoso tandem in guttam crassam unicam, duas vel rarius plures inæquales coacto integra (floccorum instar) replentur, ægreque a suffulcro suo solvuntur. Eadem vulgo sub exstante floccorum tegmine copiosissima generantur, in ceræ genus dilute vel sordide roseolum densantur, moxque in glebulam, bysso laxa albaque aliquandiu velatam, ita adglutinantur ut coccum lanigerum mentiantur; moles vero tandem nudatur et omni floccorum vestigio superest. Hi macroconidiorum acervuli sparsi, crassitudine maxime varii, saturatum colorem materni fulciminis cito usurpant, subindeque tabescere et evanescere videntur. Forma fungilli perfectior, si qua est, nondum nobis innotuit.

Nascitur extremo octobri et novembri currente, nec rarus quotannis est Cavillæ Versaliorum, Fontebellaqueo et in omni loco agri parisiensis ubi Agaricus melleus VAHL. (Ag. polymyces Pers.) occurrit.

Fungillus quasi totus matrici externus primo obtutu haberetur, nonnulla tamen illius filamenta, solito tenaciora, remotius septifera et fertilia quidem, macroconidiorum scilicet assueto modo feracia, in hymenii agaricini et tramæ suppositæ parenchymate passim immersa deprehenduntur. Insuper ani- 
madvertamus breves quosdam hypharum exsertarum ramos in sacculorum species late oblongas, duplo vel triplo conidiis majoribus longiores, interdum curvulas et basi quasi breviter calcaratas, oblique abire; ægre autem nos augurari ad quid talia fungillo prosint organa.

Conidiola baculiformia, inæqualia, e floccis ruptis, cum in aqua seruntur, postero die jam exegerunt germina. Hæcce sæpius e conidiolo extremo et sub angulo recto prodeunt; pauciora conidiolum protrahere videntur; cuncta conidiolo suo vix macriora sunt. Uno aut altero die elapsis, germina plurima jam apice tument et macroconidium sphæricum generant; germina alia longius producuntur, at priusquam ramusculos ediderint, pleraque in articulos breves, conidiola scilicet sincerrima, pro maxima parte solvuntur. Ideo e conidiolis satis utrumque conidiorum genus in planta adulta obvium, redux habere licet, proptereaque fungillus cujus mentio est cum cæteris Hypomycetibus aptissime congruit.

Sporæ (basidiosporæ scilicet) Agarici mellei ovatæ, quadantenus inæquilateræ, albæ, vix $0^{\mathrm{mm}}, 0065$ longiores, levesque, cum nulla parasiti parte commutari queunt. Quum ejusdem Agarici pileus aquam pluviam abunde ebibit, byssus omnis Hypomycetis nostri sæpius evanuit, simulque macroconidiorum acervuli dissolvuntur, ita ut plantula tota periisse videatur. Libenter fingeremus hunc madefactum Agaricum melleum clar. BarYo solum obvium fuisse, indeque nobilem virum perperam arbitratum fuisse macroconidia lamellis inspersa, Agarico ipsi esse propria. Nos autem fugit quo modo acciderit ut macroconidia illa pro thecis tetrasporis habita fuerint. Quod si e contrario sacculi supra memorati thecas has nondum perfectas sisterent, num oculatissimus BARYus macroconidia præterviderit?

\section{Macroconidia nulla vel ignota.}

\section{Hyponyces lateritius.}

* Fungillus simul cum matrice imprudenter sumptus :

Merulius helvelloides Sowerbeo, Fung. Brit. supplem. I (1809), tab. cccciI.

Hypolyssus ventricosus Persoonio, Mycol. Europ. parte alt. (1825), p. 7 , n. 2, docente Elia Fries in sua Epicr. Syst. Myc. (1838), p. 532, ubi tamen fungillus noster, lapsu sane calami, Sphceria testacea, nec lateritia nuncupatur.

Agaric déliciedx, variété dénaturée, Ludovico Secretan, Mycogr. Helvet. t. I (1833), p. 467.

Lapacendro infarinato apud Insubres agri Benacensis, auctore Antonio Venturi in suis Stud. Mycol. (1842), p. 40, tab. XIII, fig. 122 et 123 .

** Fungillus solus et in seipso consideratus :

Spheria lateritia Fr. Syst. Myc. t. II, p. 338; Elench. t. II, p. 66. - Moug. et Nestl. Stirp. Vogo-Rhen. fasc. XIV (1854), n. 1334. - Fred. Curner, in Trans. Soc. Linn. Lond. t. XXII (1858), p. 267 , n. 46 , tab. xuvi, fig. 47. - Minime autem Candollio cui enim Sphcerice lateritice nomine designatur quoddam Hypoxyli genus. (Cfr. supra t. II, p. 34.)

Hypocrea (Hy pomyce) lateritia Fr. S. Veg. Sc. p. 383.

Hypomyes lateritius Tul. in Ann. Sc. nat. ser. Iv, t. XIII (1860), p. 11, n. 3, et tomo Il hujus Carpologice, p. 273 , tab. $\mathrm{xxx}$, fig. 5 .

Hy pocrea lateritia (Fr.) Mazerio, Pl. Crypt. Gallice, ser. noviss. fasc. XVI (1860), n. 776 (in Lactario delicioso $\mathrm{F}_{\mathrm{r} .}$.).

Parasitatur in Agarico (Lactario) delicioso L. cujus propterea lamellæ, salva plerumque reliqui pilei forma et crassitudine, aut prorsus deficiunt aut brevissimæ con- 
sistunt. Mycelium insitivæ plantulæ, totum e filamentis multifariam ramosis, septiferis (articulis plus minus vesiculoso-inflatis, supremis præsertim dilatatis et subcapitatis) ac valde intricatis, stupam candidam et aere scatentem refert, universumque super matricis hymenium dense sternitur, ita ut liræ s. valles inter lamellas, si quæ obsoletæ exstiterint, admodum æquentur. Pilei ad margines et circa verticem stipitis, elementa byssi laxiora fiunt et conidia edunt sphærica $0^{\mathrm{mm}}, 0035-007 \mathrm{crassa}$, achroa, levia, spiculoque exiliter subuliformi et $\mathrm{o}^{\mathrm{mm}}, 03-04$ longo singulatim innixa; spicula autem e supremis filamentorum articulis solitarie nascuntur et divaricata patent v. assurgunt. Conidia consimilia passim etiam in certis exiguisque strati byssini centralioris areis, conceptaculis deficientibus, generantur. Perithecis hæcce ovato-globosa, exigua, in omni ferme mycelio abundantissima nidulantur, nonnisi vertice levi et vix papillato emergunt, bysso maternæ deorsum hærent, et parietem membranaceum, tenuem, diu pallidum, tandem vero sordidule infuscatum obtinent. Tнеск æquo modo lineari-cylindricæ, obtusissimæ, et deorsum versus vix tenuatæ, $0^{\mathrm{mm}}$, o 07 crassitudine non superant, in longitudinem vero $\mathrm{o}^{\mathrm{mm}}, 25$ et quod excedit flexuosæ adipiscuntur. PAraPHYSES sinceræ inter thecas desiderantur, ni pro talibus habeas fila quædam exilia et rarissima quæ potius asci steriles videntur. SPOR octonæ et monostichæ circa dodrantem uniuscujusque thecæ occupant, singulisque lanceolatis, utrinque acutis, muticis, $0^{\mathrm{mm}}, 015-020$ longis, $0^{\mathrm{mm}}, 0035$-0045 crassis, inæquilateris indeque nonnihil curvulis, paries est tenuis, levis et achrous, plasma autem granosum, cavitasque in loculos duos æquales septo ægre conspicuo divisa.

Specimina supra descripta in quibusdam agri pictavici pinetis prope Saint-Romain-sur-Vienne, octobri novembrique MDCGCLVIII, a cl. amico Sosth. de LACroIx, presbytero, lecta sunt, nobiscumque benevole viva communicata. Ex iisdem locis provenerunt exempla quæ in Stirpibus Mougeotianis et herbario Mazeriano, modo laudatis, evulgata sunt.

Conidiorum apparatus et universi prope strati fertilis natura, observatoris memoriam ad Epichloem typhinam $\mathrm{F}_{\mathrm{R}}$. revocant; endosporæ autem nonnisi minore crassitudine a seminibus Hypomycetis asterophori nostri discrepant. Fungilli iconem analyticam videas in tomo secundo hujus Carpologice, tab. xxx,
fig. 5 .

Typus præcedenti admodum analogus est Hypomyces Lactifluorum Schweinitzio (sub Sphcerice titulo, in sua Syn. Fung. Carol. sup. p. 3o, n. 34, et in Syn. Fung. Am. Bor. media, p. 191, n. 1190 ), saltem juxta specimina e sylvis Ohiensibus quæ b. Mazerius a clar. BеRкеLеo olim accepit. Agaricus (Lactarius) hospes colore nitide cinnabarino totus rubet, ejusque pileus deformis et contractus subtus levis est, lamellis omnino deficientibus. Hypomycetis perithecia non modo lamellarum locum tenent, sed vel in stipite, nec laxiori quidem ordine insperguntur, semi-immersa glaberrimaque prominent et saturate coccinea micant. Latet autem byssi quodcunque genus. Endosporæ formam genuinam, i. e. oblongolanceolatam, dimeram et utrinque cuspidatam obtinent, at præter consuetudinem parce verrucosæ deprehenduntur; hinc $0^{\mathrm{mm}}, 025-035$, illinc $0^{\mathrm{mm}}, 006-008$ maturæ æquant.

Hujus loci etiam omnino videtur Spharia hyalina ejusdem Schweinutz (Syn. F. Carol. sup. p. 30 , 
n. 35, et Syn. F. Am. Bor. p. 191, n. 1191) quæ in Russula fetenti Pers. parasitari dicitur. Contra dubiam vel remotiorem cum Hypomycetibus affinitatem ostendunt Spharia tubericola et $S$. hydnicola quas fungicolas stirpes laudatus auctor in Pensylvaniæ sylvis quondam detexit. (Cfr. ejus Syn. F. Am. Bor. media, p. $19^{1}$, n. $119^{2}$, et p. $19^{2}$, n. 1207 .)

\section{Hypomyces aureo-nitens $†$.}

Fungilli byssus nitide aurea rasaque ex fibris brevibus, densatis et partim assurgentibus constat, matricemque suam largo stramine vestit; fibræ parce ramosæ vel subsimplices sunt dissepimentaque pauca et remota ostendunt. Perithecia globosa, obtusissima, vix papillata et ostiolo punctiformi obscuro quasi umbilico notata, aliquid tomenti parcissimi et nitide aurei primum induunt posteaque squalide ochracea et glabriora evadunt; cæterum in bysso materna gregatim laxoque ordine nuda et alia ab aliis discreta sedent. Theq anguste lineari-cylindricæ, obtusæ et absque paraphysibus stipatissimæ, sporas viII oblique monostichas singulæ fovent. Spore autem ovato-oblongæ, bipartitæ, in medio quadantenus coangustatæ et utrinque plus minus acutatæ, $0^{\mathrm{mm}}, 01-013$ in longitudinem et $0^{\mathrm{mm}}, 0035$ in crassitudinem æquant, dataque opportunitate in germina filiformia de more abeunt.

Nascitur in hymenio Merulii tremellosi PERs. ${ }^{1}$ jampridem arefacti et partim destructi, nobisque semel occurrit in trunco querneo exsucco, humi jacente, ad Fontembellaqueum (Forêt de Barbeau), octobri decedente, a. MDCGCLXI.

Nuda propter perithecia, minime nempe subiculo immersa, fungillus noster Nectrias æmulatur, ob byssum autem cui eadem hærent, Hypomycetibus potius accedit; super endosporis, inter ambo genera dubius stat.

Non possumus quin præterea moneamus byssum plantulæ recentis auream nivea quadam superaddita integram aliquando velari, idque, nisi erraverimus, ita prope fieri perinde ac si filamenta nivea ex aureis protractis ducerent originem. Achroa hæc filamenta $0^{\mathrm{mm}}, 1-2$ longitudine et $0^{\mathrm{mm}}, 006-008$ crassitudine æquant, vulgo simplicia assurgunt superneque in brachia brevia, iterum iterumque dichotoma et simul contractissima desinunt; inde singulis fibris penicillus oritur cujus ex apicibus catenata procedunt conidia lineari-ovata, continua, $0^{\mathrm{mm}}, 004-005$ longa, et $0^{\mathrm{mm}}, 0025$ circiter crassa. Quid certo valeat id Penicillii albi et microspermi, futuris indagatoribus olim sane licebit eruere.

${ }^{1}$ Id fungi videsis apud Mazerium, Stirp. Crypt. Gallice, ed. I, fasc. XII (1832), n. 553. 
SECTIO III. Nectriei pulvinati vel columelliformes, quandoque etiam sine stromatis vestigio sparsi; conidiis nudis, unius modi aut genere diversis, vulgo ex ramusculis solutis aut articulis dissociatis; pycnidïs microspermis seu spermogonïs longe rarioribus. - Eunectriei seu Nectriei genuini.

\title{
V. NECTRIA.
}

(Tab. X-XIII.)

\begin{abstract}
Fungus conidiophorus hinc varia Tuberculariarum genera constituit Todeo, Persoonio, Friesio, Corde et innumeris eorum discipulis, illinc autem pauca $F_{\text {USARIA }}$ v. FUSISPoria Linkio, Friesio et aliis, nec non Chemostromata Corde et Psilonias Mazerio; ascophorus contra quærendus est inter Epistromata Persoonil (Champ. Comest. p. 54 et 150 ), SPherias caspitosas aut byssisedas Friesil (Syst. Myc. t. II), Nectrias Hypocrearum ejusdem (Syst. Orb. Veg. p. 105), Cucurbitarias Grevillit, Nectrias Notarisianas et Cesatianas (in Act. Soc. Cryptog. Italce, fasc. IV, p. 193 et seq.), etc.
\end{abstract}

Mycelium byssinum, pallidum, sæpius parcum, imo quandoque inconspicuum.

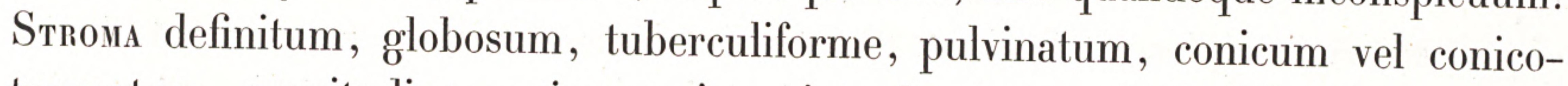
truncatum, crassitudine maxime varium, interdumque typice nullum. Conidia albida, coloris carnei, rubra vel fuscula, ex ipso mycelio aut e stromate nata, ovata, oblonga, cylindrica vel lanceolata, recta incurvave, simplicia aut septifera, solitarie acrogena, ut ramuli alterni superposita, in monilia digesta aut fasciculato-coalita, unius modi aut multigena, aliquando etiam prorsus nulla. Pycnidia microsperma s. spermogonia composita, rarissima. Perithecia libera, cæspitosa sparsave, globosa et ovata, obtuse aut acute papillata, levia s. verruculosa, glabra aut saltem ad tempus piligera, nigra, rubra, lateritia aut pallida, mollia carnosa et tandem varie collapsa, aut contra firmiora, subcornea et evacuata quidem formam rigentem retinentia. Tнесж lineari- vel obovato-oblongæ, octosporæ vel myriasporæ, paraphysibus sæpius crassis et articulatis vulgo primum accedentibus. ENDOSPOR duplicis generis, saltem quosdam apud typos; octonæ seu crassiores ovatæ, oblongæ vel lanceolatæ, 2-4-loculatæ et aliquando quidem multipartitæ, rarissime continuæ, pallidæ aut rubentes et semi-opacæ, muticæ vel appendiculatæ, leves nec nisi raro verrucoso-inæquales, et in singulis ascis monostichæ aut multimodis conglobatæ; endosporæ autem minores, quæ scilicet numero indefinitæ sunt, spermatiformes, exilissime et brevissime lineares, continuæ, muticæ, leves ac nonnihil arcuatæ; glebulis v. cirris, ex utroque seminum genere, tandem exclusis. 
FungILLI apud nos per annum vulgatissimi et latis picti coloribus, alii in arborum fruticumve corticibus demortuis aut ligno nudo nondum exsuccis, alii contra in foliis jam arefactis, herbis fructibusve corruptis, pauciores autem in Fungis et Lichenibus semivivis aut aridis crescentes.

Ad stromatis et apparatus conidiophori variationes si respicias, Nectriarum genus quale descriptum infra proponimus, quodammodo heterogenum tibi videbitur; ejus autem criterium in quadam habitus et structuræ conformitate, peritheciis nempe molliusculis, nitide coloratis et emersis, endosporisque sæpius pallidis et bipartitis versatur. Nectrice, monente Friesio, « a genuinis Spheriis facile dignoscuntur, analogiam cum Cordicipite et Hypocrea præ" bent; at in præsente generis Sphariarum statu, ab eisdem æore limitantur, licet colore facile "dignoscantur." (Cfr. Fr. S. Veget. Scand. p. 387 , nota 2.)

Stroma quo Nectrice plurimæ utuntur, a mycologis fere omnibus inter fungos sui generis hactenus etiam accipitur; quandiu enim sterile vel mere gemmiferum constat, Tubercularia nomine salutatur; ubi contra perithecia exseruit, fructibus alienis ornari et stirpem parasitantem hospitio excepisse creditur. Neque revera aliter sentit b. Tode ${ }^{1}$, neque propterea culpatur a Greviluio dicenti othe remarkable resemblance between the receptacle of this "species (scilicet Nectrice cinnabarince [PERs.]) and the Tubercularice cannot escape the intel"ligent observer." (Fl. crypt. Scotia, t. III [1825], tab. cxxxv.) Utrum vero hic aut illic hæ sic dictæ Tubercularice aptius in systemate militent, jamdiu maxime ambigitur. Sunt qui eas Lycoperdis libenter accensuerunt, alii Uredineos inter fungos et Byssaceos, auctore Mazerio (Pl. Crypt. Gallice, ed. I, fasc. Iv $\left[18_{2} 6\right]$, n. 170), medias volunt, denique in numero Tremellineorum nonnullis habentur. Tuberculariarum cum Tremellis necessitudines $\mathrm{M}_{\text {Azerio ipsi }}$ (loco cit.) post Friesium (Syst. Myc. t. III, p. 463) indubiæ videntur, at miramur quod earumdem fabricam Dacryomyceti analogam æstimaverit, sicque parenchyma solidum, ex utriculis polygoniis sociatis, quo merito superbiunt, minime noverit. Tubercularice in veteri systemate Friesiano (1. modo cit.) Coniomycetibus omnibus præsunt et privatum præterea ducunt agmen; neque minoris existimantur apud Condar (Anleit. z. Stud. der Myk. p. 159 et seq.) et Bonondenium (Handbuch der Myk. p. 130 ); etenim a priore fungis basidiophoris, ab altero mycetinis suis ${ }^{2}$ præponuntur. Nihilominus tamen de Tuberculariarum autonomia jampridem disputatur, namque biologicæ rationes quæ eas inter et Spharias Nectrias intercedunt neminem unquam fugere poterunt. «Stroma Spharice cinnabarina, ait Friesius (Syst. Myc. t. II "[1822], p. 412), Tuberculariis maxime affine est, ne dicam idem; sæpe pro magna parte "denudatum et vera Tubercularia." Se autem " in re ancipiti" tunc temporis "ancipitem" locutum fuisse postea ingenue confessus est, licet iteratis disquisitionibus plane persuasum

\footnotetext{
${ }^{1}$ Narrat enim illustris auctor Sphariam suam cinnabarinam in summo stipite Tremella purpurea L. seu Tubercularice suæ vulgaris $\alpha$, dejecto pileolo putrescentis, nec non ad basim ejusdem fungilli gregatim generari, quæritque an globuli in fundo modo dictæ Tremella a b. WeigeLio antea observatæ, forte eadem sua Sphceria " parasitica » forent.
}

(Cfr. Todei F. Meckl. sel. parte alt. p. 9 et 10 , tab. ix, fig. 68.)

${ }^{2}$ De sua circa Tubercularius sententia minime decessit cl. Bonorden in novissimis suis Disputationibus Mycologicis, multoties jam supra citatis, quarum enim videsis pag. 69 , $7^{0}, 9^{6}$ et 97 . 
denuo habuerit «Tuberculariam vulgarem non esse autonomam plantam, sed Spharice cinnaba"rince statum abortivum; Sphcriasque" analogas " eodem modo in Tubercularias etiam abire, "ac plurimas inde oriri Tubercularias." (Cfr. FriesI Elench. Fung. parte alt. [1828], p. 80.) Recentiori tempore "Tuberculariarum statum vulgarem non esse typicum" item declarat ill. magister, simulque "varios fungos præbere status a Tuberculariis vix discernendos" monet, quare Tubercularias pro tot formis diversorum fungorum atypicis existimandas fore, ideoque Variolariis Lichenum omnino respondere arbitratur. (Cfr. Fr. S. Veg. Scand. [1849], p. 361, nota 2.) Quemadmodum autem Variolarice ad Porinas præcipue spectant, sic Tubercularice ad Nectrias. Nec obstat quod Friesio iterum docente (loc. ult. cit.), Tubercularice nonnullæ formas quorumdam Discomycetum secundarias potius referre videantur; etenim Tubercularice typum in Tubercularia vulgari cum Topeo, generis conditore, intueri decet, atque id fungilli cum stromate Dermatearum vel Calloriarum tuberiformi vix commutari potest. Ideo de hoc principi et vulgatissimo Tuberculariarum typo et super consimilibus hic loquimur, quos ad Nectrias abortivas verisimillime trahendos Friesius ipse jamdudum decrevit (in Fung. Elencho, t. II [ $18_{2} 8$ ], p. 79, 83 et 122 , ac Syst. myc. t. III [1829], p. 464), licet inter fungos autonomos, Discomycetes nempe, posthac eos iterum admiserit. (Cfr. ejus $S$. Veg. Scand. [1849], p. 361.)

Qui de Tubercularïs nostris ex professo disseruit, J. Kochius, Jeverinus, easdem pro Sphoriis degeneribus et quasi pro Variolariis inter Fungos similiter habuit. Ipse tamen hoc animadverterat, scilicet quod in eodem grege Tubercularice illæ quæ imam matricem tenent, sæpissime Spherias agant, dum contra superiores nonnisi pulvere conidieo obruantur. Atqui hunc modum si intellexisset quo Nectriarum stromata crescere, et ab ima matre ad supremas ejus partes, Valsarum more ${ }^{1}$, pedetentim ascendere soleant, Tubercularias fungis recentibus, nondumque perfectis, Valsis ex. gr. cytisporeis, minime autem degeneribus vel abortivis typis accensendas æstimasset, Nectrias e Tuberculariis adultis rite legitimeque enasci, nec Tubercularias e Nectriis languidis, commutatis provenire docuisset. (Cfr. Schlechtexdali Ephemer. Bot. Berol. t. I [1843], p. 153-16o.)

Tubercularias sinceras nihil prorsus esse nisi stromata conidiophora Nectriarum, attento observatori omnia suadent, quare minime dubitamus quin futuri mycologi nobis omnes de hoc argumento assentire velint. Lis cæterum plane, ut opinamur, eo solvitur quod compertum habuerimus tuberculariam Nectrice dilissima nostræ (vid. infra, p. 73) ab ejusdem mycelio byssino constanter oriri et conidiorum feracem longe ante fieri quam indolem floccosam deposueril et in parenchyma solidum conversa fuerit. Perithecia etiam tum ex bysso ipsa conidiophora, tum e sinceris tuberculariis, quasi ex membris disparibus ejusdem fungi, indiscriminatim proveniunt.

Nectrice paucissimæ quæ apud nos Hypomycetum mores quodammodo sequuntur, nonnisi demortuos fungos occupare solent nec reapse parasitantur; una ex his Nectriis pro legitima suæ matricis parte Greviluı imprudenter habita est. (Vid. infra, p. 92.)

Nectriarum subiculum incrassatum vitam et fecunditatem suam ultra annum protrahere valet, proptereaque fructus jampridem effetos et aridos simul cum recentissimis proferre.

\footnotetext{
${ }^{1}$ De hoc argumento conferas tomum secundum hujus libri, p. 173 .
} 
In hoc sæpe causa versatur cur Nectriarum cæspites coloribus nitidissimis partim niteant, partimque sordidis infuscentur; quos ideo variegatos aspicis, perennes etiam sæpius merito dicas.

1. Corticicola vel lignicola.

a. Conidiis modo unius modi, lunulatis aut rarissime prosthemieis, nunc contra bifariis et incequalibus, majoribus in arcum curvatis; spermatiis, curvis et exilissimis, interdum accedentibus; peritheciis scepius ccespitosis, quandoque tamen sparsis. - F USARIELLE.

* Conceptaculis caspitosis, atro-caruleis.

\section{Nectria pulicaris.}

* Fungus conidiophorus :

Selenosporium pyrochroum Mazerio, in suis Plantis Cryptog. Gallica, edit. princ. fasc. XXXVII (1849), n. 1847 , et ed. alterius fasc. XXXI (1849), n. 1547 (utrinque in cortice arido Sambuci); nec non in ejusdem herbarii serie noviss. fasc. I (1853), n. 22 (in Tilia) et ap. Ann. Sc. nat. ser. III, t. XIV (1850), p. 111. - Sosth. de Lcrx. Plantes de la Vienne (1857), p. 23 , quem sagacem virum minime fugit id Selenosporii solitum esse nuntium et præcessorem Nectrice pulicaris Fr. $^{1}$

Huc etiam, ni fallimur, adduci queunt:

Fusarium roseum Linkio, Dissert. I in Ord. pl. nat. ap. Commentaria Soc. nat. scrut. Berol. t. III (1809), p. 1 o, n. 12 , tab. I, fig. 10.

Fusarium incarnatum (Roв.) Mazerio, in suis Pl. Cimpt. Gallice, ed. princ. fasc. XXXV (1848), n. 1703 (in anthodiis putrescentibus Tagetis erectee), et in Ann. Sc. nat. ser. III, t. XI (1849), p. 274, n. 4.

Fusisporiem adrantiacum Linkio (op. modo cit. p. 19), quod in caulibus putridis Zece et peponibus Cucurbitarum corruptis crescere dicitur.

Selenosporium sarcochroum (fungus Laburnicola) Mazerio, in Ann. Sc. nat. ser. III, t. XIV (1850), p. 112.

Selenosporium lateritium eidem magistro in suis Stirpib. Cryptog. Gallice, ser. noviss. fasc. XVI (1860), n. 796 , in cortice arido Sarothamni scoparii agri Pictonum vigens; etenim pulvini hujusce sic dicti Selenosporii non modo conidiis obruuntur, verum etiam conceptacula ascophora Nectrice pulicaris $\mathrm{F}_{\mathrm{r}}$. jam fovent.

** Fungus ascophorus :

a. Recens natus, sterilis :

Sclerotium violaceum Corde, Ic. Fung. t. III (1839), p. 18, n. 2, tab. iII, fig. 50.

$b$. Perfectus, maturus :

Spheria Pulicaris Friesio, in Schmidti et Kze. Fasc. Mycol. parte alt. $(1823)$, p. 37 , n. 11; Syst. Myc. t. II, p. 417 , n. 217 ; Elench. Fung. t. II, p. 82, n. 216. - Frid. Curreio in Act. Soc. Linn. Londin. t. XXII, p. ${ }_{282}$, n. 181 , tab. xuix, fig. 180. - R R SPHERIa CYANOGENA M Mzerio, in Ann. Sc. nat. ser. III, t. X (1848), p. 352, n. 18 , et in suis Stirpib. Crypt. Gallice, ed. I, fasc. XLII (1850), n. 2060 , et ed. alt. fasc. XXXVI, n. 1760 , utrinque in caulibus putridis Brassica.

1 Sosthenis nostri qua de re sententia iterum redit apud Mazerium, in suis Stirpib. Crypt. Gall. ser. noviss. fasc. XVI (1860), sub n. 777 (Nectria coccinea Fr. ficicola). 
Spheria cyanea Sollmannio in Schlechtendalit Ephemer. Bot. Berolinensi, t. XXI (1863), p. 193 et 211 , tab. viII, fig. 1-2 4 .

Gibbera pulicaris Friesio in sua Summa Veget. Scand. p. 402 , n. 3, dummodo, jam monente Sosthene de LaCRoIx (loco sup. cit.), peculiaris dehiscendi modus et sporæ simplices fungillo Friesiano immerito tribuantur. - Berkeleo, Outl. of Brit. Fung. p. 403.

Botryospharia pulicaris Not. et Cesatio in Actis Soc. Cryptog. Itale, fasc. IV (1863), p. 212.

Fungilli mycelium byssinum, pallidum, laxum et admodum subtile vulgo sub tenui matricis epidermide, rarius nudum serpit, passim densatur stromataque gignit exigua, sed Friesio ipso judice, tuberculariarum æmula, nempe obtuse protuberantia, pulvinata, ovata vel hemisphærica, atque e parenchymate dilute luteo-fusco ac demum, saltem pro parte, atro-cæruleo facta. Conidia lineari-lanceolata, utrinque acuta, curvula, 6-8-loculata, pallida, $o^{\mathrm{mm}}, 0_{2} 5-035$ longa, $\mathrm{o}^{\mathrm{mm}}, 005-006$ crassa, sessilia oriuntur tum e byssinis mycelii stratis s. pulvinulis, tum e stromatibus modo dictis spissioribus seu parenchymatosis et tubercularinis. Conıdi hæc pulpam vel ceram roseam, licet nonnulla interdum atro-cærulea evadant, simul constituunt, joveque pluvio diffluunt et evanescere videntur. Quæ postea, favente loco et tempore, germinare valent, multo majora simul et summopere torosa fiunt. Conidiis jam quasi evanidis, perithecia e stromate partim saltem nigrefacto prodire incipiunt; dentem conicum atro-cæruleum et perexiguum primitus fingunt, pedetentim vero augentur et formam globosam vel turbinatam obtinent; prope integra e tuberculo natali adulta emergunt, sessilia, pusilla et obtusa sunt, oculoque armato nonnihil rugoso-verrucosa; plerumque præterea confertissime cespitosa crescunt stromaque integrum cui inseruntur velant. In his reperies thecas obovato-oblongas, subsessiles, obtusissimas, octosporas atque sporis quadruplo et quod excedit longiores. Spore ovato-lanceolatæ, curvæ, utrinque subobtusæ et muticæ, sæpius quadriloculatæ, rarius 5-8-meræ, levissimæ torulosæque, longitudine conidia æquant et crassitudine superant, nempe $0^{\mathrm{mm}}, 008$ diametro medio pleræque nanciscuntur, oleo vel humore limpido tandem integræ replentur, singulatimque spectatæ pallidissimæ videntur, cumulatæ autem roseum assumunt colorem. Semina hæc ex ostiolis peritheciorum vix prominulis pultis sub specie vulgo protruduntur, disseminatæque conidiorum instar cito progerminant. Uterus evacuatus tabescit, collabitur et arescendo cupulam plus minus imitatur.

Crescit omni fere anni tempestate at maxime autumno, hieme, vereque, locis suffocatis, in quisquiliis corticatis humi jacentibus, fructibus putrescentibus, etc. Sexcenties nobis occurrit in corticibus demortuis Sambuci nigra, Salicum, Pseudoplatani, Tilice, Ulmi, Rubi fruticosi, Robinice, Pseudaccacic, Cytisi Laburni cæt. nec non in surculis hornis quercus, brassicarum caulibus aridis, pyris et cucurbitis corruptis. Forma conidiophora, fusariea, ascophoram s. sphærieam quandoque longe antecedit.

Præmissa descriptio ad fungillum sambucicolam hiemali tempore vegetum maxime spectat; stromata 
ejus perfectiora ex epidermidis lenticellis suberosis, fulvis, crassis rimosisque prodeunt et exstant. Perithecia omnino fere superficialia laxiusque acervata in virgultis Robinice suffocatis vidimus. Cæspites contra densissimi simul et crassissimi in Cytiso Laburno L. quandoque reperiuntur. Thecæ et paraphyses in fungillo sambuci brevi solvuntur et evanescunt, ita ut uterus maturus quasi solis sporis liberis repleatur.

Minime dubitamus Sclerotium violaceum Соврж (loco cit.) nihil aliud esse atque conceptacula fungilli nostri novissime nata et ex parenchymate adhuc homogeno integra facta.

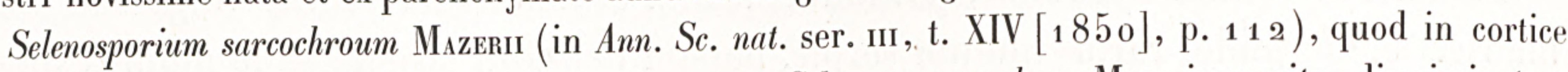
Cytisi Laburni circa Parisios non infrequens est, a Selenosp. pyrochroo $\mathrm{M}_{\mathrm{Az}}$. immerito discriminatur, genuinaque Sphcerice pulicaris Fr. inchoamenta solenni modo denotat.

Sub titulo Nectrice atractophorce formam N. pulicaris spermatiophoram olim, ni fallimur, in schedis nostris notavimus. Stroma ejus proprie dictum formam globoso-pulvinatam induit, tuberculariamque exiguam prorsus imitatur; etenim ex cellulis polygoniis quasi suberosum efficitur, coloreque roseo pallido inficitur. Tota illius superficies sterigmatibus obtusis, brevibus, subsimplicibus denseque stipatis vestitur quæ conidia lanceolata s. fusiformia, modice arcuata, utrinque acuta, septis I-III divisa, $0^{\mathrm{mm}}, 025$-0 35 longa, vixque $0^{\mathrm{mm}}, 0035$ crassiora, ex apice gignunt. Corpuscula hæc, coloris dilute rosei, in pultem, jove pluvio, conglobantur et lente diffluunt, tempore autem sicciore in pulverem solidum inspissantur. Dum conidia lente disseminantur, perithecia plurima in ipsis pulvinuli penetralibus connascuntur et increscendo tegmen conidiferum pedetentim imminutum exuunt, donec admodum nudata appareant. Conceptacula sunt anguste ovata, perexigua, levia, atra, glebulasque subfragiformes et prominentes consociata sistunt; spermogoniorum natura his fructibus sæpius impertiri videtur, quippe pulte alba e spermatiis cylindricis, tenuissimis, rectis, vix $0^{\mathrm{mm}}, 0035$ longis mucoque parco immersis referciuntur. Ex intima conceptaculorum uniuscujusque glebulæ coalitione oritur spermogonium quasi unicum structura maxime multiplex, extus varie mamilloso-rugosum, intusque reticulatim multilocellatum. Spermatia solitam genesim e sterigmatibus brevissimis ostendunt. Crescit in Carpini Betuli L. cortice emortuo, et epidermide laciniata cingitur, excipitur; Cavillæ agri versaliensis, mense martio MDCCCLVI, nobis occurrit.

\section{EXPLICATIO ICONUM.}

(Tab. XIII, fig. 5-9.)

5. Stromata exigua Nectrice pulicaris $\mathrm{F}_{\mathrm{r}}$. sambucicolæ; alterum hinc peritheciis maturis, illinc autem conceptaculis recentibus simul et conidiis pallidis (Fusario s. Selenosporio pyrochroo Maz.) oneratur; in altero multo juniore at copiosius gemmifero pauca conceptacula prominere incipiunt; utrumque nativis suis demensionibus decuplo crassius exhibetur.

6. Conceptaculum recentissime natum (Sclerotium violaceum CORDE), pulvillusque conidifer quo innititur, a summo dissecantur.

7. Theca octospora seorsim delineata.

8. Conidia quæ februario exeunte MDCGCLVIII seminata, mox crassiora facta sunt edideruntque germina; a diebus viI pleraque vigent.

$9^{a}$ et $9^{b}$. Sporæ seorsæ conidiorum instar, dato loco et tempore, incrementum ceperunt et quidem germinaverunt; septorum numerus quibus dividuntur maxime variat.

Fig. 6-9 pari modo, nempe circa vices cccLxxx natura majores dantur. 
** Conceptaculis latius coloratis, nempe carneis $v$. nitidius rubentibus ac scepius cespitosis.

\section{Negtria Stilbospore $†$.}

Colore nitide rubro-violaceo quo mycophilos oculos allicit, et sede sua solita suos inter congeneres fungitlus noster sine negotio discriminatur. Oritur enim tum in acervis conidiorum, tum in stromatibus ascigeris Melanconeos nostræ macrosperme, carpinicolæ, quam supra videsis descriptam tomo II, pag. 132 , tab. xıv, fig. $13-23$. Priore in loco mycelium suum, byssinum et candidum, fusius et abundantius explicare videtur; hujus enim tenuissimæ partes atram pulvereamque matricis molem alte intrant et varie marmorant, dum præterea eandem superne inspissatæ velant. E mycelio peculiariter densato sæpe etiam provenit sincera tubercularia, utriculis polygoniis, ut mos est, confecta. Adsit vero id tuberis parenchymatosi, aut duntaxat peculiariter condensetur exterum fungitli mycelium, pari fere modo ex alterutro nascuntur conidia copiosissima, lineari-lanceolata, utrinque acutiuscula, modice arcuata, primum continua, $0^{\mathrm{mm}}, 04-05$ longa, $0^{\text {nim }}, 004-007$ crassa, initioque sterigmatibus filiformibus et ramosis brachiorum instar suffulta. Eadem in ceram pultemve grate rubro-violaceam congeruntur; aptato sata loco singula brevi augentur, in articulos vi-vIII aut plures quidem septis dividuntur, simulque germina longissima, potissime ex apicibus, exserunt. Perithecia globosa, exigua, carnosa, brevissime papillata, levia, glaberrima et coloris conidiorum æmula, nunc in mycelio inspissato aut tubercularino facto, nunc in ipsa matrice quasi nuda, mycelio latente, sessilia generantur et cæspites laxos densosve struunt; si aruerint collabuntur et patelliformia vel deformia evadunt. Theс lineari-cylindricæ, obtusissimæ et monostiche octosporæ, $0^{\mathrm{mm}}, 07-10$ in longitudinem et $0^{\mathrm{mm}}, 01-013$ in crassitudinem adipiscuntur nec paraphysibus sinceris stipari, maturæ saltem, videntur. Endospor longitudine, crassitudine autem $\mathrm{o}^{\mathrm{mm}}, 0065-01$ æquare solent; ubi in aqua seruntur sensim augentur, salva forma, et singula hinc vel hinc, sed ex utroque loculo, prælonga agunt germina.

Primum nobis occurrit fungillus in silva cæsa ad Fontembellaqueum, februario abeunte MDGCCLX, deinde Modoni agri versaliensis, etiam hiberno tempore. Nisi a longinquo, saltem prima fronte, propter colorem rubro-violaceum agnoscitur.

Cum eadem Nectria Stilbosporce modo descripta ob habitationem convenit Nectria nostra Pandani (in schedis) quam enim in sementicula atra et acervata Melanconii Pandani Leverlueo (in Ann. Sc. nat. ser. III, t. III $[1845]$, p. 66 , n. 3 19$)$ hospitari comperimus. Colore autem pallido et peritheciorum constipatione Nectriam citrino-aurantiam Lcrx. vel ochraceam $\mathrm{F}_{\mathrm{r}}$. potius imitatur; ejus tamen conceptacula formam ovato-globosam et papillatam Nectrice coccinea, fagicolæ, s. ditissime nostræ (infra p. 73 ), 
æmulantur, arescendo item non collabuntur, sed contentis recedunt. Thecæ enim anguste obovatolineares, $\mathrm{o}^{\mathrm{mm}}, 08$ in longitudinem et $\mathrm{o}^{\mathrm{mm}}, 006$ in crassitudinem circiter adipiscuntur, singulæque sporas octonas partim monostichas, breviter lanceolato-acutas, rectas, muticas, $0^{\mathrm{mm}}, 01$ vix longas, nec $0^{\mathrm{mm}}, 004$ crassiores, atque non distincte bi- vel quadripartitas fovent. In hujus Nectrice consortio sæpissime viget fungillus mucedineus et microsporus ab Acrostalagmo cinnabarino Cовре vix diversus, sed diu albidus nec nisi senescendo, ut videtur, colorem lateritium usurpans, structura vix mutata.

\section{EXPLICATIO ICONUM.}

(Tab. XI, fig. 11-19.)

11. Corticem carpineum vides aridum et epidermide partim exutum; quapropter prorsus nudatæ veniunt duæ ex areis in quibus crevit Stilbospora macrosperma Pers. Nunc pulveri obsoleto hujus sic dicti coniomycetis incumbit mycelium niveum byssinumque Nectria nostræ parasiticæ, scilicet $N$. Stilbosporce, conidiferum simul et conceptaculorum ferax. Conidia autem et perithecia sæpius nonnisi e stromate carnosulo, mycelium centrale paulatim vestiente, nascuntur; ceram roseam ex conidiis Nectrice et cirrum atrum e seminibus Stilbospore, stroma supremum $h$, pro parte nudatum, simul exigit.

12 et 13. Perithecia Nectrice congesta, simul cum subiculo duplici, a vertice dimidiantur.

14. Nectrice mycelium byssinum e stilbosporeo pulvere assurgens, quasi subito in stroma densum transit; hujusce portiuncula tenuis centrum pellucidum, interiora prima conceptaculi ascophori stamina, ostendit.

15. Stromatis recentis pars suprema conidiis binc onusta, illinc perithecio nondum perfecto; perithecium etiam aliud quasi sub ipsis conidiis cœpit informari.

16. Conidia germinantia; ex articulis nunc facta videntur et germinum ope alia aliis mire religantur.

17. Thecæ, paraphyses sporæque didymæ una spectantur.

18 et 19. Endosporæ in aqua, martio mense, progerminaverunt; germina longiora dies quatuor nata sunt.

Icones 11 et 12 naturam vicies circiter excedunt, tertia decima autem triciens, cæteræ æquo modo circa vices cCGLxxx; omnes martio mense, a. D. MDCGCLX, Parisiis juxta fungos Fontebellaqueo lectos, delineatæ sunt.

\section{Nectria Selenosporit †.}

* Fungus conidiophorus :

Selenosporium Urticearum (Corde), Fici, Mazerio in suis Pl. Crypt. Gallice, serie noviss. fasc. XIV (1859), n. 658. - Rabenh. Fung. Eur. exs. fasc. IV (1861), n. 388 (ex agro Pictonum, cura et opere b. Sosthenis de Lacrorx, mycologi, dum viveret, ornatissimi).

Huc etiam sane spectat Fusarium lateritium, Mori, eid. Mazerio in eodem Herbario, edit. princ. fasc. XVIII $(1837)$, n. 883 , et ed. alterius fasc. II $(1837)$, n. 83 .

** Fungus ascophorus :

Nectria Coccinea (Fr.) Mazerio in suis Stirpib. Crypt. Gallice, ser. noviss. fasc. XVI (186o), n. 777 (in cortice arido Ficus, apud Pictones cultæ).

Funglluus tenui sub epidermide Ficus demortuæ nascitur, corticulum substratum ex molli solutoque parenchymate comedit et in seipsum convertit; initio parcus, byssinus et achrous est, subinde vero crustæ in modum dilute roseæ atque, ubi exaruit, quasi reticulatim rimoso-diffractæ, late quoquoversus expanditur. Id crustæ præterea 
in sinceras tubercularias diversiformes, semper autem pulvinatas et roseas, exiguas crassioresve, passim tumet, easdemque per alieni et hospitalis velaminis rimas protrudit. Quum ex variis crustæ latitantis partibus, tum etiam e tuberculariis nudatis conidia oriuntur innumera, lunulata, scilicet anguste lineari-lanceolata et curvula; magnitudine variant, longitudinem enim $0^{\mathrm{mm}}, 02-03$ et quod excedit adipiscuntur, crassitudine autem $\mathrm{o}^{\mathrm{mm}}, 003-005$; majora et perfectiora tri- vel quadriloculata fiunt, nonnulla vero indivisa consistunt. Perithecia forma tandem collapsa, exiguitate coloreque nitide rubro-aureo, fructus digniores Nectrice Stilbosporce nostræ æmulantur; summo tubere conidiophoro nunc circinata sedent, nunc idem integrum occupant et cæspitosa velant. THEC guste ovato-oblongæ, rectæ, bipartitæ levesque, forma et magnitudine organa homonyma Nectrice nostræ Pezizce (infra, p. 77 ) imitantur.

Adumbrata specimina ab humanissimo presbytero Sosthene de Lacrorx, jam laudato, olim accepimus; una cum Mazerianis supra citatis ad Heraldicastrum ea crevisse novimus.

Stirps nostra eximium præstat exemplum miræ Nectriarum cum Fusarïs s. Selenosporïs societatis, cujus tutæ interpretationi id summopere favet quod priorum ascophora conceptacula ex Fusarïs læte vegetis et abunde fertilibus suam originem, ut nostrum sentire postulat, trahere soleant. Qua de re conferas quæ attulit Sosthenes de Lacrorx in suis Plantes de la Vienne (loc. cit.), licet nosse et eruere non curaverit utrum Nectrice parasitentur necne.

\section{Negtria ditissima $†$.}

\footnotetext{
NECTRIA COCGINEA fagicola, nostra, quam scilicet obiter attigimus in tomo II hujus Carpologice, p. 243.

Huc etiam sane spectat, saltem pro parte, Spharia coccinea complurium de re mycologica scriptorum, v. gr. Persoonir, Syn. Fung. p. 49 , n. 92 ; Ic. et Descript. Fung. fasc. alt. p. 47, tab. xiI, fig. $2, a, b, c ;-$ Movg. et Nestleri, Stirp. Vogo.-Rhen. fasc. II (1811), n. 180 (in fagineo cortice); - MazeriI, Pl. Crypt. Gallice, ed. princ. fasc. VIII $(1829)$, n. 380 (in cortice crasso Fagi nostratis); - Fred. Currey in Actis Soc. Linn. Londin. t. XXII, p. 282 , n. ${ }_{17} 5$, tab. xuIx, fig. $174 ;-$ minime vero Friesi in sua Summa Veget. Scand. p. 387 , nota 2 , in fine.

Fungus conidiophorus aliquando, ni fallimur, audierit Tubercularia minor.
}

$\mathrm{I}_{\mathrm{N}}$ hospitali cortice, sub epidermide varie lacera solutaque prominent stromata seu tubercula exigua, discreta, rarius passim coalita, ac zona byssina mox destituta, quæ formam depressam et angulosam crescendo obtinent, coloremque primitus albidum in rubro-aureum (intrinsecus primum) pedetentim mutant. Recentiora, tota albida, ceram seu pulverem humidum ex innumeris conidiis albis levibusque ab omni pariete libero gignunt. Conidia alia longe cylindrico-fusiformia, arcuata, utrinque obtusa, subsessilia et matura vI-VIII-loculata, $o^{\mathrm{nm}}, 06-07$ in longitudinem ac $0^{\mathrm{mm}}, 005-007$ in crassitudinem adipiscuntur; plura vero alia candidiora, ovata v. ovato-oblonga, continua et recta, hinc $0^{\mathrm{mm}}, 006-01$, illinc autem $0^{\mathrm{mm}}, 0035$ tantummodo æquant ac suffulcris 
subsimplicibus, rigidulis et $\mathrm{o}^{\mathrm{mm}}, 03-\mathrm{o} 4$ longis solitarie acrogena utuntur; alia denique cæteris multo pauciora et crassitudine summopere varia, majora inter et minora ambigunt. His omnibus commistis gongylis sociantur etiam, sed parciori copia, spermatia exilissima, curva, $0^{\mathrm{mm}}$, o $_{2} 2$ circiter longa, pariterque, ut videtur, albida. Priusquam integra conidiorum spermatiorumque generatio evanuerit, e stromate aureo facto prodeunt perithecia stipatissima, sessilia, initio globoso-obtusissima, dein breviter ovata et acutata, imo nonnihil papillata, levissima, nitide coccinea et ex pariete tenui sed rigenti facta. Theсе clavato-lineares sporas octonas, ovatas, rectas, utrinque obtusissimas et muticas, $\mathrm{o}^{\mathrm{mm}}, 01-013$ circiter longas, $\mathrm{o}^{\mathrm{mm}}, 004-006$ crassas, biloculatas, pallidas levesque singulæ fovent.

Frequentem vivamque legimus, julio mense MDCCCLVII, cortici subexsucco truncorum vel ramorum crassiorum Fagi cæsæ insitam, in silva Villersiana agri Compendiensis; autumno ejusdem anni iterum obviam habuimus apud Carthusienses Gratianopolitanos, tum in corticibus fagineis, tum etiam in acerinis.

Quæ præmittuntur potissimum valent de fungillo fagicola et acericola; eundem vero sibi constantem non semel observavimus in corticibus ulmeis ${ }^{1}$ et æsculinis, circa Parisios et Versalias. Stromata recentia, tubercularia scilicet, dilute rosea, mere microsperma et assueti pulvini Nectrice cinnabarina (Tope) ribicolæ prorsus æmula, subiculis pallidioribus et potissime macrospermis, i. e. fusarieis, in Ulmi cortice aliquando ita miscentur, simulque formæ manifestissime mediæ mixtæ hoc modo abundant ut dubitare nequeas quin eundem et ipsissimum, sed multimodis gemmiferum et polychroum, intuearis fungillum. Uteri præterea ascophori, quum in matrice ulmea, tum in acerina, gregatim absque ordine et pulvillo conspicuo interdum discreti sparguntur, sociis tamen cæspitibus solitis. Quandoque etiam perithecia sparsa vestigiis stromatis effusi, interrupti et tenuissimi aut exigue punctiformis, sed nihilominus tamen abunde conidiophori insident; ita ut par sit conditio et tuberculariis et fructibus perfectioribus; tunc vero tuberculariæ minimæ imperfectæ, vix parenchymatosæ, mycelii naturam byssinam quasi ex integro retinent, byssoque pariter conidiophoræ sociantur. Præ tali fungillo, Sphariam sanguineam (Siвth.) Greviluit (Fl. Crypt. Scotice t. IIl, tab. clxxv, fig. 1 sup.) inspicere nobis videmur.

Nectriam ditissimam nostram omnino imitantur tum Nectria coccinei coloris quæ in Laburni cortice cæspitosa vigere solet et mucedinea albugine sæpissime invaditur ${ }^{2}$, tum etiam Spharia sanguinea quæ Fiedleri opera datur in cortice populneo agri megapolitani, apud Rabenhorstium, Herb. Mycolog. edit. principis fase. XVIII (1853), n. ${ }_{17} 32$.

Nectriam laburnicolam modo dictam videre licet sub titulo Sphariac coccinec Pers. seu S. deciduce Tod. ${ }^{3}$ in Friesir Sclerom. Suecia, fasc. VI (1821), n. 183 (saltem ap. exempl. Weddellianum quod præ manibus olim habuimus); quapropter miramur cur idem magister ascos quidem clavatos, sporas autem elongato-filiformes Spharia suæ coccinece tribuerit. (Cfr. ejus Summ. Veget. Scand. p. 387, nota 2.)

\footnotetext{
1 Auctore clar. Leone Durour in Herbario Mazeriano (e thesauris Musæi Bot. par.), Nectria ulmicola quam indigitamus vera est Nectria coccinea FriesII.

${ }^{2}$ Hæc Nectria Parisiis minime rara occurrit in hortis et ambulacris suburbanis, ex gr. Clodoaldensibus, Clamariis et Cavillanis; Compendii item obviam habuimus; specimina
}

pictavica olim nobiscum benevole communicavit b. Carolus Delastre, qui ne minimam quidem agri sui natalis plantulam unquam despexit.

${ }^{3}$ Sphceria decidua Topei, F. Meckl. Sel. fasc. alt. p. 31 , n. 28 , tab. xIII, fig. 104, Nectria est alnicola, nec forsan differt a Nectr. epispharia quam adumbratam infra videas. 
Monendum præterea habemus Nectria laburnicolæ loco etiam interdum præstari in Scleromycetibus Friesianis Nectriam corylicolam ${ }^{1}$ peritheciis dense cæspitosis, rubris glabrisque, sed plus minus depresso-umbilicatis, eodemque prorsus modo myriasporis ${ }^{2}$ simul et disparibus quo Nectria Cucurbitula

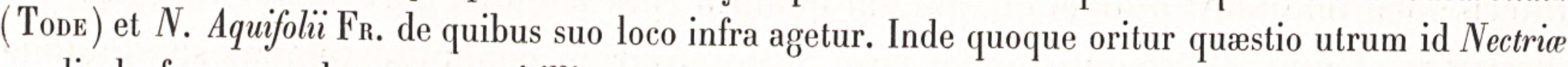
corylicolæ formam polysporam typi illius reapse sistat cujus laburnicola et ulmicola concolores formam normalem et octosporam, an contra alio spectet; atqui sedulo perpensis rationibus omnibus analogicis, vix dubitamus fungillum Coryli hic retinere, Nectriam ditissimam super thecarum fecunditate æque biformem æstumare ac modo dictas Nectriam Cucurbitulam, pinicolam, et Nectriam Aquifolii $\mathrm{F}_{\mathrm{R}}$. idque eo minus mirari quod levia tantum discrimina octosporos horum fungillorum alios ab aliis removeant.

\section{EXPLICATIO ICONUM.}

(Tab. XIII, fig. 1-4.)

1. Stromata duo contigua Nectrice ditissime nostræ a vertice secantur, dimidiantur; aliud (sinistrum) conidiorum nondum expers, peritheciorum rudimenta minima hinc protrudit; aliud vero ætate provectius conceptaculis circinatim cæspitosis ornatur, in centro autem, conidiis nunc disseminatis, nudum sterileque deprimitur.

2. Stroma alterum junius strato conidiorum crasso pallidoque tegitur, velatur.

3. Fragmentulum tenuissimum hujusce stromatis mere conidiophori a vertice dissecti; conidia majora, septifera et in arcum curvata, alia minora cylindrica v. oblonga, continua rectaque, nec non et spermatia linearia et curva ex eodem hymenio promiscue nascuntur.

4. Thecæ paraphysibus articulatis stipantur.

Fig. 1 et 2 nota bis decuplo majores proponuntur, fig. autem 3 et 4 vices ccclxxx præter naturam auctæ sunt; cunctæ juxta fungos vivos fagicolas modo descriptos Petrifonte Compendiorum delineatæ sunt.

\section{Negtria armeniaca $†$.}

Synonyma omnia quæ ad Nectriam dilissimam supra trahuntur, huc etiam, saltem pro parte, verisimillime speclant.

Epidermidem fagineam jam protuberantem et varie scissam si amoveris, fungilli nostri stroma conspicis primum orbiculare tenueque vel conoideo-excavatum, zona alba circumcirca definitum, in centro autem et lateribus ob prolem editam cito armeniacum; color enim e conidiis pendet quæ innumera gignuntur pultemque seu ceram solidam pedetentim supra corticem emersam micantemque struunt. Iisdem fulcimine exiliter filiformi longoque singulatim instructis, forma est admodum peculiaris et quasi e spiclis torosis, ab axi brevi pariter toruloso prodeuntibus et quoquoversus divaricato-directis

\footnotetext{
${ }^{1}$ Conferas enim specimina soluta, ex herbario laudato magistri upsaliensis excerpta, quæ in mycotheca Mazeriana apud Musæum Bot. parisiense passim continentur.

${ }^{2}$ Peculiarem hanc Nectrice Friesianæ focunditatem acutissima indagatione primus compertus est clar. Notarisius, genuensis, eamque notam fecit in suis Observationib. super
}

nonnullis Pyrenomycetum Sphceriaceorum generibus, apud Parlatoris Ephemeridem Bot. Italam, anno I, t. alt. (1845), p. $49,50,52$ et seq. Iterum novissimis his temporibus ejusdem structuræ meminit in suis Sphreriaceis Italicis, fasc. I (1863), p. 10 et 13 . 
compacta. Hæc inter conidia nascitur varia spermatiorum copia, imo spermatia passim seorsa generantur; fila sunt exilia, $0^{\mathrm{mm}}, 03-04$ longa, subsessilia et curva, a suis suffulcris facillime solvuntur et in pultem quam a cera conidiophora oculo inermi ægre discernas abeunt. Postquam duplex hæc protosporarum generatio tempus spatiumque suum explevit, stroma pro maxima parte tunc denudatum sed multo crassius factum, ex utriculis polygoniis dense coalitis totum constat et colorem læte luteum in saturate cinnamomeum mutat. Ex eo undequaque oriuntur peridia numerosa, libera, constipata, globoso-ovata, acutiuscula, glaberrima, levissima, initio nitide rubra seu coccinea, postea opacata seu ferruginea, tandemque sordide infuscata; parietibus subcartilagineis rigentibusque intrinsecus hæret thecarum agmen quæ cylindricæ, $o^{\mathrm{mm}}, 1$ circiter longæ, $0^{\mathrm{mm}}, 008$ crassæ, obtusissimæ, deorsumque breviter attenuatæ, sporas viII monostichas, ovatas, utrinque obtusissimas et muticas, biloculatas, rectas, pallidas, atque $0^{\mathrm{mm}}, 013$ in longitudinem et $\mathrm{o}^{\mathrm{mm}}, 065$ in crassitudinem æquantes, debito tempore singulatim includunt. Paraphyses inter ascos perfectos vix reperiuntur; quæ supersunt articulatæ et ramosæ videntur.

Provenit in cortice crassiori Fagi sylvalica L. cæsæ, demortuæ, ab æstate in hiemem usque. Jutio medio (an. MDCGCLVII) vivam, maturam, legimus in sylva Compendiensi ad Petrifontem. Jamdiu ibidem clarissimo Ad. Brongniart obvia fuerat. (Cfr. mycothecam Musæi Bot. par.)

Apparatus conidiophorus modo descriptus Cheirosporam Friesi (Syst. Orb. Veg. p. 365), at propius etiam Prosthemium stellare Riessio, cujus pauca verba fecimus in tomo II hujus Carpologice, p. 234 et 243 , imitatur. De conidiorum germinatione nil experimento comperimus. Peritheciorum densi cæspites sæpius lata spatia in cortice materno congregati tenent, et e longinquo micant. Quo modo fungus perfectus a Nectria ditissima nostra, supra descripta, tuto discriminetur, æore perspicimus; incunabula autem peritheciorum diversissima hic et illic deprehenduntur.

\section{EXPLICATIO ICONUM.}

(Tab. X, fig. 1-12.)

1. Cortici fagineo, epidermide partim exuto, simul imposita vides stromata inæquæ ætatis Nectrie armeniaca nostræ; alia $a$, $a$, centrum marginibus propter conidiorum copiam crassissimis et læte armeniacis definitum exhibent; aliud $b$, conidiis pro maxima parte dimissis, extenuatum et in medio demissius videtur; perithecia in alterius $c$ ambitu jam adparent, quæ in superiore $d$ adulta et stipatissima congeruntur.

2. Stroma denudatum $b$ figuræ antecedentis nunc a vertice sectum exprimitur.

3. Pars dimidia stromatis alterius pari modo dissecti quod rtate provectius formam multiplicem et cacumina plura obtinuerat.

4. Stroma (similiter dissectum) post conidia diffusa crassius factum, perithecia pauca nondumque perfecta enititur.

5. Perithecia adulta in ambitu incrassato stromatis a vertice dimidiati conferta insident, media subiculi parte tenuiore et nuda.

6. Stroma alterum (item dimidiatum) ubique crassissimum peritheciis sessilibus obruitur. 
7. Portiuncula stromatis junioris conidiophori et a summo dissecti; e parenchymatis $p$ superficie oriuntur conidia $c, c$ fulcris longissimis et exilibus innixa, singula e baculis torulosis mire consociatis, botryosa aut spiclifera, nec non filamenta arcuata $s, s$, utrinque acutissima et quæ spermatia sistere videntur. Id spermatiorum genus partem demissiorem collis gemmiferæ et planitiem stromatis tenere solet.

8 et 9 . Conidia variæ ætatis seorsim conspiciuntur, ut modus quo eorum structura pedetentim magis ac magis multiplex efficitur, manifestior pateat.

10. Thecæ fertiles et paraphyses ex utriculis sociatis factæ.

11 et 12. Sporæ liberæ quæ germina protruserunt.

Figuræ 1-6 natura bis decuplo majores sunt, reliquæ autem vices cGCLxxx aucłæ traduntur; omnes medio julio anni D. MDCGCLVII, Petrifonte, ad oras sylvæ Compendiensis, ex fungis vivis sedulo observatis delineatæ sunt.

Inter Nectrias conidiis dissimilibus instructas locum etiam reposcere videtur $N$. cicatricum $\mathbf{M}_{\Delta Z}{ }^{1}$ quæ in Buxi arido cortice ac potissime in foliorum delapsorum cicatricibus et pulvinulis nascitur atque nitido rubet colore. Cionidiophora pagina corticeo strato sub epidermide arctissime applicita, albida et late patens, Discella ${ }^{2}$ speciem constituit atque de more semina inæquæ crassitudinis gignit; minora exiliter lineari-cylindrica $0^{\mathrm{mm}}, 007$ longitudine et $0^{\mathrm{mm}}, 003-004$ crassitudine æquant; majora contra ovata v. ovato-oblonga et utrinque obtusa, $0^{\mathrm{mm}}, 016-019$ in longitudinem et $\mathrm{o}^{\mathrm{mm}}, 007-008$ in crassitudinem obtinent; utrumque vero conidiorum genus rectum, continuum et muticum est, fulcrisque exiliter filiformibus, longis, flexuosis et subsimplicibus solitarie acrogenum innititur. E strato gemmiparo passim in conulos truncatos incrassato stromata fieri comperimus in quibus perithecia circinata vel cæspitosa generantur. Hæc conceptacula exigua, levia, glaberrima, sæpe conferta et ruberrima, ubi arescunt rugato-collapsa fiunt; maturis insunt thecæ lineari-oblongæ, in apice quasi truncatæ, ex membrana tenuissima factæ sporisque octonis late ovatis, obtusissimis, rectis, muticis, levibus, roseis, hiloculatis, $0^{\mathrm{mm}}, 013-016$ longis et $0^{\mathrm{mm}}, 007^{-01}$ crassis singulatim foetæ. Moneamus tamen stratum conidiorum sæpissime deficere pulvinosque ascophoros crassitudinem mediocrem vulgo nancisci, imo minime raro propter tenuitatem structuramve laxiorem a matrice æogre discriminari.

*** Peritheciis rubris et sparsis.

\section{Nectria Peziza.}

Spheria Peziza Todeo, Fung. Meckl. Sel. fasc. alt. p. 46, n. 44 , tab. xv, fig. 122. - Corde ap. Sturmi Fl. German. parte III, t. II (1829), p. 27, tab. xII (omissa thecarum membrana). - Minime vero, ni fallimur, Spharia Peziza Mazerio in suis Stirpib. Crypt. Gallice, ed. princ. fasc. I (1825), n. 35 (in cortice inte-

\footnotetext{
${ }^{1}$ Spharia sanguinea var. cicatricum Berkelao in Mag. of Zool. and Bot. t. I (1837), p. 48, n. 25 , tab. III, fig. 6 ; Nectria coccinea var. cicatricum Mazerio in Ann. Sc. nat. ser. III, t. X (1848), p. 351, n. 16, et in suis Pl. Crypt. Gallice, ed. I, fasc. XXXVI, n. 1757 ; Nectria Mazerii DNTrs. Sphar. Ital. fasc. I (1863), p. 10, tab. I, fig. Iv. Fungi endosporas liberas, sub titulo Sphcerice (Nectrice) coccinece Pers. adumbravit Fred. Curreius in Actis Soc.
}

Limn. Londin. t. XXII, parte III (1858), p. 182 , n. 175 tab. xuIx, fig. 175 .

${ }^{2}$ Super Discellis Berkeleianis conferas tomum II hujus operis p. 181,182 et passim. Discella quædam rosea, spectabilis, in ulmeis corticibus, sub epidermide, apud nos etiam quandoque generatur; stylosporis ovato- vel cylindrico-0blongis crassisque utitur, nec alienam fortassis se habet Nectrice coccinece s. ditissime ulmicolæ. 
riore Ulmi); neque præsertim Spharia Peziza, minor, ejusdem magistri in herbarii laudati serie novissima, fasc. VIII (1856), n. 371 (in Peltigera canina), quæ enim nil nisi Nectria lecanodes, stirps Cesatiana (vid. infra p. 94), manifesto est.

Spheria Sanguinea (Bolt.) Friesio, in suis Scleromycetib. Suecice, fasc. VIII (182.2), n. 264 (saltem ut nobis videtur), non autem n. 127, sub quo enim Nectria epispharia (Tod.) in Sphceria quaternata Pers. proponitur (juxta mycothecam Mazerianam e thesauris Musæei Bot. par.). - Fortassis pro parte Grevillio, Fl. Crypt. Scotice, t. III, tab. cLxxv, fig. 1 .

Negtria Peziza Friesio, Summ. Veget. Scand. (1849), p. 388, n. 14. - Berkeleo, Outl. of Brit. Fung. p. 393 . n. 13 , tab. xxiv, fig. 6 , fructibus perperam tuberculosis. - Tul. Sel. F. Carpol. t. I, p. 41, 57 et 223.

Huc etiam trahenda videtur Nectria sanguinea Kroмвноцzıo in suis Iconib. et Descript. Fungorum, fasc. I (1831), p. 77 , tab. vi, fig. 7 , quæ rudes sunt.

Fungild mycelium subtilissime byssinum est, parcissimum, achroum et vix conspicuum; nascitur in ligno carioso, potissime populneo, indeque omni corpori circumjacenti, quisquiliis, muscis vivis e. s. p. pedetentim irrepit; cæterum ubicunque adsit, oculos vel attentissimos effugeret, nisi fructibus editis tandem proderetur. Conceptacula ascophora gregatim sed absque ordine sparsa oriuntur, ab invicem discreta sessiliaque consistunt et byssi parcissimæ ac brevissimæ ope suæ matrici hærent. Jam ab initio, cum scilicet $0^{\mathrm{mm}}, 08$ diametro nondum excedunt, colore aurantio insigniuntur; adolescendo formam perfecte globosam retinent, mox nitidissime rubent, glaberrima et sublevia manent, dimidium millimetrum diametro tandem æquant, et neutiquam in ore ægre perspicuo prominent. Nucleus albus, totus ex thecis lineari-cylindricis, obtusissimis, subsessilibus, $0^{\mathrm{mm}}, 08-1$ longis, $0^{\mathrm{mm}}, 0065-008$ crassis et octosporis constat; paraphyses rarissimæ occurrunt aut prorsus desiderantur; sporæ aut oblique monostichæ, aut rarius inordinatæ, thecas subintegras liberæ replent, singulæ ovatæ, biloculatæ, leves, muticæ, $\mathrm{o}^{\mathrm{mm}}, 013$ longæ, $0^{\mathrm{mm}}, 0065$ crassæ, debitoque tempore, quum ascorum membrana quæ a principio tenuissima est, demum extenuata periit, in cirros albos, longiusculos, mire contortos simulque perexiles, nimirum $0^{\mathrm{mm}}, 03-05$ crassos, aut, jove humidiore, in guttam turbidulam eructantur. Has sporas solito modo germinare, salva forma et crassitudine, comperimus.

Viget potissime autumno seriori, octobri scilicet novembrique, in ligno corrupto, nudo, Populi nigrce, tremule, et cæt. nec frequens apud nos reperitur; læte passim crescebat Cavillæ Versaliorum, anno D. MDCGCLXI exeunte.

Perithecia, evacuata præ cæteris, arescendo vel tabescendo collabuntur et cupulas mentiuntur, inde sane fungillo nomen inditum.

Non possumus quin moneamus fungilli nostri matricem interdum mire albescere et quasi furfurosam evadere, ob innumera conidia ubique inspersa et peculiariter acervata. Conidia hæc forma, colore et crassitudine endosporas adeo mentiuntur ut neutiquam ab eis discriminari valeant, parique modo germinant. Quod ad originem attinet, fingimus ea ex hyphis mycelii inconspicuis in sertula sessilia oriri; nascuntur etiam, ni fallimur, ex ipsis peritheciorum parietibus quos pulvere niveo, abunde nec sine lege conspergunt. E mycelio præterea simul assurgunt monilia exilissima, simplicia, breviter pedi- 
cellata, sæpius solitarie sparsa, $0^{\mathrm{mm}}, 05-07$ alta, totaque e conidiolis ovato-globosis, vix $0^{\mathrm{mm}}, 0035$ longis et presso ordine catenatis. Tantillum aquæ si affuderis, conidia et conidiola a suffulcris suis et ab invicem subito solvuntur, humorem combibunt et brevi tempore similiter egerminant. Nonnihil dubii nobis tamen in mente remansit utrum duplex illud conidiorum genus ad Nectriam modo descriptam reapse spectet, an contra ad fungillum quemdam hospitem et alienum. Hoc igitur futuris irdagatoribus decernendum relinquimus.

b. Conidiis unius generis, exiliter cylindricis et brevibus. - EUNEGTRIA.

\section{Negtria cinnabarina.}

* Fungi stroma s. subiculum conidiophorum, pro planta absoluta et sui generis perperam habitum :

Lichenoides tuberculosum, amœne purpureum (in Populo tremula vigens) Dillenio, Cat.pl. Giss. (1719), p. 206 ; Hist. Muscor. (1741), p. 127 , n. 6 , tab. xvII, fig. 6 ; synonymis plurimis allatis quæ ab anghlis scientiæ patribus sumuntur.

Nostoc granulosus (sic), coccineus, arboribus innascens VallLantio, Bot. paris. (1727), p. 144 , n. 6.

Tremella Purpurea Linnæo, Spec. Plant. ed. princ. t. II (1753), p. 1158 , n. 7 , inter Algas. - Hoffu. Veget. Cryptog. fasc. I, p. 29 , tab. vi, fig. 2.

SPhERIa convexa, miniata, hirsuta Hallero, Hist. Stirp. Helvet. t. III (1768), p. 121, n. 2189.

SPHeria tremelloides Weig. Obs. Bot. (1772), p. 46, n. 8, tab. III, fig. 1; sphærulas III-IV in imis tuberculi stromatici penetralibus oriri arbitrabatur auctor, easque imprudenter delineavit.

CLavaria coccinea, pro parte, ut videtur, Sowerbea, Engl. Fung. t. III (1803), tab. ccxciv.

Tubercularia vulgaris Todeo, F. Meckl. Sel. fasc. I, p. 18 , tab. iv, fig. 30 et 31. - Pers. Syn. Fung. p. 112. n. 2. - Friesio, Scler. Suec. fasc. VII (1822), n. 255 (in Ribis cortice); Syst. Mycol. t. III, p. 464, n. 1 , - Linkio, Sp. Plant. Linn. t. VI, parte alt. p. 99. - Moug. et Nestr. Stirp. Vog. -Rhen. fasc. I (1810), n. 84 (in Ribe rubro L.). - KLotzsch, Herb. Myc. fasc. II (1832), n. 185 (in Populo). - Mazerio, Plant. Crypt. Gallice, ed. I, fasc. IV (1826), n. 170 (in ribesio cortice), et ed. alt. fase. XVII (1843), n. 827 (item in Ribe). - Raвenh. Herb. Myc. ed. alt. fasc. VIII (1858), n. 777 (in Rsculo).

Huc etiam trahitur apud HaLerum Lichen-Agaricus caspitosus, acaulis, ruber, in Abietum corticibus innascens... Michelil, N. Pl. Gen. p. 105, n. 3, sed potiori jure ad Nectriam Cucurbitulam Fr. propter sedem indictam duceretur. Hujus autem loci omnino videntur Lichenes-Agarici Micheliani rubri vel rubro-ferruginei qui in Anagyride fretida, Ulmo et Castanea crescere dicuntur (loc. cit. n. 2 et 4). Sphcreria miniata, acaulis, suboglobosa, solitaria, glabra BoLtoni, Fung. Halif. t. III (1789), p. 127, tab. cxxvi, fig. superioribus, cum nostro fungo minus convenit quam vulgo æstimatur, nisi plurima auctoris errori concedere velis.

Pro formis sic dictæ Tubercularice vulgaris Toper plus minus aberrantibus, minime autem typice diversis, habemus :

Tremellam nigricantem Bull. F. Gall. I. 1, p. 217 , tab. cccclv, fig. 1, i. e. Tuberculariam nigricantem Linkio. Sp. Pl. Linn. t. VI, parte alt. p. 102 , n. 9, et Friesio, Syst. Myc. t. III, p. 465 , n. 5.

T'uberculariam discoideam Pers. Syn. Fung. p. 111, n. 1. - Fr. in suis Scler. Suec. fasc. VII, n. 256 (in Ulmo). et in Indice Syst. Myc. p. 197, ubi fungillus ad Tuberculariam minorem Linki ducendus æstimatur.

Tubberculariam granulatam Pers. Syn. Fung. p. 113, n. 3. - Candollio, Fl. Gall. t. VI, p. 109, n. $739^{a}$. Fr. Scl. Suec. fasc. VII, n. 257 (in Tilia); Syst. Myc. t. III, p. 465, n. 4. - Grev. Fl. Cryptog. Scotice, t. IV (1826), tab. clxxxvir. - Klotzsch, Herb. Myc. fasc. I (1832), n. $99^{a}$ (in Robinia), et fasc. alt. n. $99^{b}$ (in Populo). - Moug. et Nestr. Stirp. Vog.-Rhen. fasc. XI (1840), n. 1090 (in Pseudoplatano). Mazerio, Stirp. Crypt. Gallice, serie noviss. fasc. X (1857), n. 452. - Rabenh. Fung. Eur. exs. fasc. III (1860), n. 279 , ex aureo-rubro pedetentim fucatam, nigrefactam, in cortice populneo crescentem, et pro 
forma illa habitam quæ Conde cava dicta est. (Conf. hujus magistri Icones Fung. t. II, p. 33, tab. xIv, fig. 117 , super initiali sporarum ordine non magis fida ac figura contigua 116 , i. e. Tubercularice vulgaris $\beta$ purpuratce adumbratione.)

Tuberculariam confluentem Pers. Syn. Fung. p. 113 , n. 4. - Friesio, Scl. Suec. fasc. supra cit. n. 258 ; Syst. Myc. Ind. p. 196. - Moug. et Nestr. Stirp. Vogg.-Rhen. fasc. VI (1818), p. 576. - Rabenh. Herb. Mycol. ed. alt. fasc. VI (1857), n. 595 (in cortice Robinice), et fasc. VIII, n. 778 (in cortice arido Sophorce japonica ad Constantiam Helvetiorum cultæ).

Tuberculariam Castanee Pers. Syn. Fung. p. 114, n. 5. - Candollio, Fl. Gall. t. VI, p. 109 , n. $738^{\text {a }}$.

Tuberculariam Menispermi Fr. Obs. Mycol. t. I (1815), p. 208 , n. 298.

Tuberculariam Sarmentordm ejusd. Fr. in suis Scler. Suec. fasc. VII $(1822)$, n. 259 (in virgis Menispermi canadensis).

Tuberculariam minorem Linkio, Sp. Plant. Limn. t. VI, parte alt. p. 100 , n. 3. - Kneiff et Harti. Crypt. Bad. exs. fasc. III (183o), n. 107 (in Esculo). - Mazerio, Pl. Crypt. Gall. ed. I, fasc. IV, sup. cit. n. 171 (in cortice populneo), et ed. alt. fasc. XVII (1843), n. 828 (in Ulmi cortice).

Tuberculariam mutabilem (Neesio) Lk. Sp. Pl. Limn. t. VI, parte alt. p. 101, n. 4.

Tuberculariam expallentem (Fr. Ind. Syst. Myc. p. 197) Movg. et Nestl. Stirp. sup. cit. fasc. XI (1840), n. ${ }_{1091}$ (in cortice carpineo). - Mazerio, Pl. Crypt. Gallice, ed. I, fasc. IV (1826), n. 172 (in cortice betulino, ni fallimur).

Plures alias minus notas, v. gr. Cordæanas bene multas, consulto omittimus. Ad fungilli conidiophori formam dilute rubram, cinnabarinam miniatamve potissimum spectant Tremella purpurea Linner, Spharia tremelloides Weigelio, miniata Boltoni, Tubercularia vulgaris Todes, confluens Pers. minor Linkio; ad formam contra varie fucatam vel nigrescentem quæ apud nos in cortice æsculino, tiliagineo, castaneo, ulmeo acerinoque frequentius oritur, trahendæ sunt Tubercularia granulata Pers. nigricans Fr. mutabilis Lк. cæt. Specimina Mazeriana Tubercularice minoris Lk. supra citata manifestissime testantur id funginæ formæ ad Tub. granulatam Persoonio (Mazerioque loco sup. laud.) in eadem et ipsissima sede transire. Tubercularia Menispermi Fr. inter consimiles peculiariter microsperma videtur; quem fungillum ex agro Heraldicastrensi Pictonum, Sosthenis de Lacrorx presbyteri gratia, olim habuimus et in eo parasitantem vidimus Sphariam cupularem (PErs.) infra descriptam.

*** Fungus ascophorus :

Spheria cinnabarina Todeo, F. Meckl. Sel. fasc. II, p. 9, tab. Ix, fig. 68 , quo auctore fungillus in basi Tubercularice vulgaris insidet, parasitatur. (Cfr. etiam laudati libri partem I, p. 19.) - Fr. Syst. Myc. t. II, p. $412_{2}$, n. 201 ; Elench. Fung. t. II, p. 81. - Mazerio, Pl. Crypt. Gallice, ed. i, fasc. I (1825), n. 34, et ed. alt. fasc. XX (1845), n. $97^{0}$ (utrinque in Ribe, saltem apud exempla quæ penes nos sunt). - Rabenh. Herb. Mycol. ed. alt. fasc. VII (1858), n. 633 (in Carpino).

Spheria decolorans Pers. Syn. Fung. p. 49, n. 91; Friesio, Scler. Suec. fasc. VI (1821), n. 184 (in Ribe et Ulmo, saltem apud mycothecam Weddellianam et Mazerianam quas adiimus) '. - Movg. et Nestr. Stirp. Vog.Rhen. fasc. VI (1818), n. 570 (item in cortice Ribis, apud exemplum quo usi sumus).

SPheria PeZizoidea, a rubro-fusca, Candollio, Fl. Gall. t. VI, p. 125 , n. $781^{\mathrm{f}}$.

Cucurbitafia cinnabarina Grev. Fl. Crypt. Scotice, t. III (1825), tab. cxxxv, mentione facta miræ similitudinis soliti peritheciorum receptaculi cum sic dictis Tuberculariis.

Negtria cinnabarina Friesio, Sum. Vegeet. Scand. p. 388, n. 2. - Eug. Coemans ap. Rabenh. Fung. Eur. exs. fasc. IV (1861), n. $3{ }_{2} 4 \beta$, exclusa autem forma $\alpha$, spermogonifera dicta, scilicet Ncemaspora microspora LiserTIE, quæ potiori jure ad Valsam ambicntem (populicolam) nostram trahenda videtur. (Cfr. supra t. II, p. 176.) Spharia (Nectria) cinnabarina et decolorans (saltem ut videtur) Frid. Correio in Actis Soc. Linn. Londin. t. XXII, p. 282 , n. ${ }_{17} 6$ et ${ }_{177}$, tab. xuIX, fig. ${ }_{17} 5^{\text {a }}$ et 176 .

Sтromata fungilli gregatim crescunt, discreta vel rarius stipatiora et passim coalita, mycelioque imponuntur byssino, albo, plerumque parco, imo ægre conspicuo, quod

"Spharia seu Nectria decolorans, $n$ ait ipse El. Friesius in recentissima commentatione, $r$ est status senilis Spho- "rice cimnaburince Todei. (Videsis Schlechtendali Ephemerid. Botanicam, t. XXII [1864], p. 189, n. 177.) 
nunc matricis cortici, sub ejus epidermide, nunc ligno ipsi obrepit. Formam præterea semi-globosam, elato-pulvinatam aut breviter columnarem, semper vero truncato-obtusissimam et crassitudinem summopere variam, licet vulgo mediocrem, obtinent, parenchymateque solido ex utriculis polygoniis, miro ordine sociatis, intrinsecus plus minus croceo, circum circa autem aureo vel læte rubente, multo rarius undique sordide fulvo aut pallidiore et albido struuntur. Hos inter pulvinulos, cunctos supra materna tegmina exsertos, permulti densissimam filamentorum gemmiferorum sylvam gerunt, conidiisque adglutinatis obruuntur; filamenta autem fertilia quadantenus flexuosa et $0^{\mathrm{mm}}, 06-\mathrm{og}$ circiter longa, $\mathrm{o}^{\mathrm{mm}}, 0 \mathrm{o} 3$ diametro æquali vix excedunt, in ramos parcos laxosque cæspitose discedunt et conidia solitaria, ab invicem remotissima, erecta, sessilia vel subsessilia, e summis suis articulis agunt. Conidia linearicylindrica, subovata et utrinque obtusissima oleo homogeno replentur, baculis maternis non crassiora fiunt et $\mathrm{o}^{\mathrm{mm}}$, o o 7 longitudine vix superant; colorem sæpius dilute rubrum, albo temperatum, quandoque contra rutilanti-rubrum, multo rarius umbrinum et quidem spisse fuscum nigrentemque assumunt; pulverem cæterum constipata sistunt glutinis ope plus minus cohærentem imbribusque lente solutum; quæ dilute rubent præ cæteris facile pulverea evadunt et citius disperguntur. Subicula etiam occurrunt ruberrima quæ tota conidiorum expertia manent aut gemmas istius modi pauciores ex areæ pulvinaris centro edunt; hæc inter tubercula, alia semper glaberrima deprehenduntur, alia e contrario pilos crassiusculos, erectos, flexuosos, simplices, primum roseos, tandemque pallidiores et sordide luteolos induunt, ita ut horrida v. tomentosa pro ætate appareant. Conceptacula ex omni stromatum genere, conidiis si qua fuerint jam sparsis aut parce superstitibus, modo pauca, modo abundantiora nascuntur, ipsa nuda vel pilifera; sub exteriore parenchymate generantur posteaque pedetentim protuberant; quum tota emerserint, globosa sunt, nonnihil umbilicata, undique minute verrucosa, sessilia vel subsessilia, tuncque cæspites s. glomulos læle rubros, cinnabarinos, rubroferrugineos, fulvos vel plus minus infuscatos fingunt, et tuber nativum tandem integrum obducunt. THEс clavato-oblongæ, obtusissimæ, $\mathrm{o}^{\mathrm{mm}}, 16$ et quod super est longæ, e membrana tenuissima fabricantur et in stipitem filiformem ac longitudine varium, aliquando etiam subnullum, atlenuantur; sporas octonas singulæ fovent, paraphysibusque lineari-clavatis, crassis, ramosis, articulatis ac demum evanidis commiscentur. Sров incurvatæ, in medio septifero sæpe quadantenus coangustatæ, leves, pallidæque in seriem duplicem intra singulorum ascorum uterum sæpius ordinantur, et hinc $0^{\mathrm{mm}}, 015-018$, illinc vero $0^{\mathrm{mm}}, 005-007$ circiter æquant; maturæ conglobantur et adglutinantur, cirri vel pultis roseolæ sub specie excluduntur, deindeque dato loco et tempore opportunis increscunt et libentissime progerminant; quædam etiam, instar $\mathrm{Pe}_{e-}$ ziza vesiculosce Bull. et Bulgarice inquinantis $\mathrm{F}_{\mathrm{r}}$. corpuscula s. conidiola ovata et sessilia 
simul cum germine solito enituntur. Conidia cæterum genuina, e tuberculariis scilicet nata, ubi seruntur item suam augent molem et in germina filiformia abeunt.

Vulgaris crescit, sicuti propria iterataque experientia compertum habuimus, quovis anni tempore, in ramis emortuis omnium fere arborum et fruticum nostratium, ex. gr. Mali, Oxyacantha, Populorum, Salicum, Castanece, Betula, Juglandis, Ulmi, Acerum et præ cæteris Aceris Pseudoplatani, Platani ipsius, Frangula, Esculi, Hibisci syriaci culti, Ribis rubri et Grossularie, Sophorce japonica cultæ, Pyri, Rosarum, Ailanti, Tilia, cæt. rarius autem Quercus; reperitur quoque in caulibus aridis Brassica et herbarum majorum. Sexcenties nobis jampridem quotannis occurrit in agro parisino et versaliensi, sæpissime vero conidiophora tantum. Autumno imprimis hiemeque sporas ex ascis maturas eructat.

Fred. Currex, ni fallimur, inciderit in endosporas Nectrice nostræ germina enixas nec in stylosporas ejusdem sinceras (si modo aliquæ sint), licet de germinum seu appendicum filiformium natura ille dubia moverit. (Cfr. ejus loc. supra cit.)

Quomodo Nectria punicea Schм. qualis saltem in Frangule ramis circa Parisios haud infrequens nascitur $^{1}$, a Nectria cimnabarina Fr. modo descripta tute, nisi colore nitidiore, discriminetur, ægre perspicimus; hujusce formam illam admodum sistit quæ in virgis corticatis Ulmi campestris L. apud nos etiam vulgaris est. Istius ulmicolæ stroma vulgo exiguum, sæpe decolor v. pallens, modo conidiis solitis abunde parciusve illinitur, modo contra eorumdem prorsus expers est, tuncque capsulis ascophoris seu peritheciis a cinnabarino colore ad fuscum vergentibus, verruculosis et umbilicatis totum velatur. Super conidiorum sporarumque forma et crassitudine minus sibi constare videtur quam fungillus ribicola. In eodem et ipsissimo Ulmi ramulo simul aliquando deprehendisse nobis videmur perithecia alia furfuraceo-verrucosa, umbilicata et collabentia, alia sublevia, papillata rigentiaque, alia denique levia et collapsa.

Ad Nectriam cinnabarinam ducenda videtur Spharia Tubercularia DC. Fl. fr. t. II, p. 295 , dubius ipsi sagacissimo Friesio (Syst. Myc. t. II, p. 496) fungillus; quæ saltem suppetunt specimina (in herb. typico Floræ Gall. Candollianæ, e thesauris Mus. paris.) nil nisi Tuberculariam vulgarem Ton. in cortice Juglandis natam, exhibent ${ }^{2}$.

Nectri, Ralfsii Вевк. et Br. (in Ann. and Mag. of nat. Hist. ser. alt. t. XIII [1854], p. 467 n. 780 ), stirps anglica et, ni fallimur, ulmicola, cujus exempla authentica exstant in mycotheca Mazeriana, Nectriam cinnabarinam (Торег) habitu prorsus mentitur, sed licet aurea sit in fructus parietibus, tota extrinsecus furfuraceo-tomentella albescit; nucleum tamen aureo-rubrum fovet. llli sunt endosporæ ovato-oblongæ, rectæ et biloculatæ.

Non possumus quin occasione data hic obiter verba faciamus de Sphceria cupulari Pers. (Obs. myc. parte I $[17.96]$, p. 65 , n. 119 , et Syn. Fung. p. xxir et 53, n. 100, tab. I, fig. 8-10 $)^{3}$. Id fungilli in

1 Simillima datur itemque frangulicola in Rabenhorstir Herb. Mycol. ed. alt. fasc. VII (1858), n. 634.

${ }^{2}$ Fungus Candollianus nunc generis novi (Castagnece) typus magistro Upsaliensi videtur. (Cfr. SchlechtendaliI Ephem. Bot. Berolinensem, t. XXII [1864], p. 189 , in nota.)
${ }^{3}$ Sphceria cupularis Fr. Scl. Suec. fasc. VII (1822), n. 231 ; Syst. Myc. t. II, p. 416 , n. $215 ;$ Sum. Veget. Scand. p. $39_{1}$, n. 72. - Moug. et Nestl. Stirp. Vog.Rhen. fasc. VIII $(1823)$, n. $77^{1}$, et fasc. XV (1860), n. 1455, sub titulo Spharice Cucurbitule Toder. - Fred. Curreı, in Act. Soc. Limn. Londin. t. XXII, p. 281 , n. 172 , 
tuberculis vivis Nectrice cinnabarince $\mathrm{F}_{\mathrm{R}}$. parasitari solet; illius stroma e parenchymate firmo et aterrimo, rubram aureamve matricis substantiam alte immissum varie marmorat, aut quasi superficiale hinc et inde maculat; cæterum super vesiculis s. cellulis polygoniis quibus constat, ab ipso hospite non discrepat. Ex innatis stromaticisque maculis filamenta assurgunt densissime stipata, cæspitose ramosa, brevissima et dilute fuliginea, quæ in fragmenta plurima minimaque debito tempore rupta solvuntur. Fragmenta ista recta, utrinque truncata, nec sæpius $0^{\mathrm{mm}}, 01$ longiora, pro tot conidiis haberi volunt, pulpamque adglutinata sistunt quæ jove pluvio lente diffluit aut cœlo sicciori arescit et valde induratur. Atris supremisque fungi nostri partibus tandem insident perithecia minima, globosa, cæspitosa, obtusissima, undique tuberculosa, glaberrima et aterrima, quæ postquam endosporas protruserint, arescunt simulque ita flaccescunt et collabuntur ut cupulas quodammodo mentiantur. Asci obovato-clavati, obtusissimi et breviter deorsum attenuati, sporas octonas anguste lineari-cylindricas, curvas, utrinque obtusas, albidas, continuas, oleo homogeno repletas, $0^{\mathrm{mm}}, 011$ circiter longas et vix $0^{\mathrm{mm}}, 0_{02} 5$ crassiores singuli fovent. Hospitatur fungillus hiberno tempore vereque tum in Nectria cinnabarina $\mathrm{F}_{\mathrm{R}}$. conidiophora, tum etiam in eadem ascophora; prope Parisios et Versalias sexcenties nobis occurrit in cortice Juglandis regice, Esculi Hippocastani, Aceris Pseudoplatani, Ulmi, Ribis rubri, Sorbi hybrida cultæ, Populi nigrce cæt.

Prout parce aut latius insito hospite occupatur, stroma Nectrice cinnabarina $\mathrm{F}_{\mathrm{r}}$. nunc colore atro, extrinsecus simul et suis in penetralibus, variegatur, nunc quasi totum nigrum deprehenditur. Item peregrina conceptacula, Nectrice peritheciis multo minora, modo iis commiscentur, modo contra, hisce exclusis, integram matricem obruunt. Quandoque etiam accidit ut Nectrice subiculum tenue, crustosum et vix effiguratum, ex toto plantula hospitante abscondatur quæ propterea in cortice arido nec in Nectria viva insidere tunc videtur. Super vita parasitica fungilli de quo agitur, hactenus, ni fallimur, omnes siluerunt mycetographi; habitu et colore Cucurhitariam mentitur, ob endosporas contra ad Valsas quasdam propius accedit. Hæ sporæ, ubi seruntur, sæpius non morantur quin solito modo progerminent.

\section{EXPLICATIO ICONUM.}

(Tab. XII.)

1. Ramulus ribesius ex quo demortuo cæspites varii Nectrice cinnabarina (ToDe) prodeunt, decuplo circiter nota major proponitur; stromata conidiophora, quæ tubercularice dicuntur et Tuberculariam vulgarem Toder constituunt, læto pallidoque colore insigniuntur, et fructus perfectos s. ascophoros jam enixa sunt; stromata alia similibus peritheciis, senioribus factis, tota obruuntur, hymenio conidifero aut prorsus deficiente, aut nunc obsoleto, destructo; sunt quoque pulvinuli recentiores et conidiis pariter destituti, sed pilis mollibus vestiti.

2. Pulvillus adhuc nonnisi conidiorum ferax et mera tubercularia seorsim delineatur.

3. Stromata item gemmifera tantum, ex Platani cortice nata sunt; alia de more rubra, alia fulvis notata

tab. xLvill, fig. $170 .-M_{A Z E R I O}$, in suis Stirpib. Crypt. Gallice, ser. noviss. fasc. XVI (186o), n. 780 (in Robinia). - Berк. Outl. of Brit. Fungology, p. 396 , n. 62 , inter Sphcerias erumpentes caspitosas. - Huc vulgo trahitur Spharia Cucurbitula $\beta$ nigrescens Toder, F. Meckl. Sel. parte alt. p. $3_{9}$, sed fortassis vix merito, quippe fungus pinicola dicitur.

De fungillo nostro, ni fallimur, verba facit Schweinıтzuss, sub titulo Spharice parasitantis, in Actis Soc. philos.
Amer. ser. alt. t. IV (1834), p. 206, n. $1430 ;$ r rarus, inquil, et valde memorabilis est, $n$ Tuberculariam in Robinice cortice occupat ibique secum consortem habet Sphariam cinnabarinam, licet stroma proprium nigrum sibi vindicet.

Auctore Mazerio, loco sup. citato, Spharia cupularis Pers. rarius apud Nectriam cinnabarinam quam in coccinea hospitaretur; hoc autem sentire cum vero circa Parisios minime quadrat. 
maculis, alia denique tota saturate castanea v. æquo modo nigra. Pulvinuli item versicolores (Tubercularia granulata plurimorum) in Tilice cortice haud infrequenter proveniunt.

4. Stroma capitatum, pilosum, rubrum, in quo conceptacula recentissima exstare cœperunt; conidia omnino desiderantur.

5. Alterum similiter conidiis destitutum, at parcius piligerum; conceptacula innata magis protuberant.

6 et 7. Sic dictæ Tubercularice, a summo dissectæ, quæ conidia e vertice, conceptacula autem pilosa e lateribus exserunt.

8. Stroma item recens at conidiorum expers et peritheciorum cæspes factum, dimidiatum exhibetur; conceptacula adulta pilos dimiserunt.

9. Subiculum similiter partitum perithecia lateralia nuncque glabrata gerit, in vertice autem pallido conidiis obruitur.

10 et 11 . Duo alia stromata sua interanea pari modo discissa monstrant; conceptacula matura parenchymati seniori insident; pulvinulus autem supernus, pallens et recentior, conidiorum in ambitu ferax est, iisdemque corpusculis cumulatis pro maxima parte formatur.

12. Conceptaculorum cæspes maturus a vertice sectus; sporæ adglutinatæ, coloris dilute carnei, in cirros exeunt, aut capsularum in ore coacervantur. Icon hæc et antecedentes 2-11 nativas rerum demensiones bis decuplo nota majores ostendunt.

13. Fragmentulum tenuissimum, et vices ccL circiter auctum, sterigmata conidiophora $c$, pilosque $p$ quibus conceptaculorum parietes extrorsum primitus ornantur simul exhibet. Lacuna expallens quæ cortici saturatius fucato ac piligero supponitur, perithecium recens natum indicat.

14. Fragmen alterum tenue, magis (nempe ccclxxx vices) auctum, portiunculam perithecii submaturi simul et stromatis materni adhuc etiam conidiferi constituit; istius parenchyma $t$ in corticem $u$ fructus nonnihil mutatum transit. Paraphyses articulatæ et brachiatæ thecis octosporis commiscentur.

$15 a, b$. Conidia quæ februario ineunte (MDCCCLVI) sata maximum capessiverunt augmentum et fila prælonga ediderunt; crassiora abhinc decem dies crescunt.

16. Sporæ quæ decembri ineunte MDCCCL germina crassiora protruserunt.

17. Sporæ aliæ aprili mense MDCGCLVII seminatæ, conidiola ex suismet lateribus, aut e germine filiformi et contracto, copiosa egerunt; conidiola ista, soluta v. dimissa, ipsa subinde in fila protrahuntur. Hæ figuræ, et præcedentes 15 et 16 , simili modo, nempe vices ccclxxx, præter naturam augentur.

Fungilli qui fig. 1-2, 4-14 et 17 exprimuntur in Ribe rubro hiemali tempore, abhinc decem annos, viguerunt; qui conidia (ruberrima) figuris $15 a$ et $15 b$ tradita ediderunt, ex Aceris Platanoidis cortice nati sunt $^{1}$, qui autem sporas fig. 16 , ex Juglande.

(Tab. XIII, fig. 14-21.)

14. Cortici nuceo insident stromata nuda, gemmifera, el cæspites ascophori Nectrice cinnabarince (Tod.) in quibus omnibus Sphcria cupularis Pers. parasitatur. E stromatibus seu tuberculariis nudis, aliud fungilli peregrini quasi expers est et parce illius causa maculatum; aliud contra ejusdem conidiis atris copiosissime inspersis totum fucatur. Inter peritheciorum cæspites unum etiam vides qui e solis Sphcerice cupularis Pers. fructibus componitur; in cæteris vero hospes non ita Nectrice domum usurpavit ut omnem legitimam prolem prohibuerit.

15 et 16. Stromata duo mere conidifera a vertice dissecta proponuntur; utriusque major pars, rubens,

${ }^{1}$ Conidia quæ nitidissime rubent et ea quæ multo pa!lidiora sunt, discretis stromatibus utuntur, at in iisdem acerinis ramulis eodemque tempore proveniunt; omnia pari modo germinant, saturatiora autem, ni fallimur, cæteris citius. 
ad Nectriam cinnabarinam spectat; quidquid autem peculiariter atrum adparet, parasitatur, et Sphcerice cupularis subiculum est.

17 et 18. Stromata altera similiter dimidiata, in quibus fungus insitus maximum obtinuit locum; Nectria e contrario nonnisi in utriusque pulvinuli ambitu rubet, maxime angustatur, et pauca valuit perithecia eniti; conceptacula minima Sphcerice cupularis parenchymati alte nigrefacto stipata imponuntur. Icon hæc et antecedentes nativam rerum magnitudinem bis decuplo æquo majorem pariter ostendunt.

19. Hic datur fragmentulum tenuissimum stromatis duplicis naturæ, cujus scilicet parenchyma pallidum, $r, r$, ad Nectriam cinnabarinam (Tod.), nigrum autem, $a, a$, ad Sphcariam cupularem Pers. prioris hospitem pertinet. Conceptacula duo $p$, ejusdem alieni fungilli, recentissime nata dissectaque, a sinistra vides quorum meditullium adhuc homogenum mansit. Sylva densa e filamentis articulatis et solubilibus seu adparatus conidifer Spharice istius cupularis simul in conspectum venit; fila quædam cæteris crassiora, ramosa et saturatius fucata, in articulos rarius solvuntur; conidia nonnulla $c$ discreta insperguntur. Conidia autem Nectrice matricis et filamenta quibus generantur littera $n$ designantur.

$20 a, b$. Thecæ recentes, gravidæ aliæ aut effełæ, simul et sporæ liberæ.

21. Sporæ quas ineunte januario a. MDCCCLXI in aqua severamus, sub finem ejusdem mensis germinantes adumbratæ sunt.

Figuræ 19-21 simili modo, nempe vices circiter cacLxxx, amplificantur.

\section{Negtria miltina.}

Spheria miltina Mntgn. in Duriei Flora Alg. t. I, p. 477.

Nectria miltina eidem Montanio in sua Syll. Pl. Crypt. p. 225 , n. 786 . - Rabenh. Herb. Myc. ed. alt. cent. VII (1858), n. 631 (e Cannis Galloprov.).

Numerosas inter congeneres, Nectriam Aquifolii $\mathrm{F}_{\mathrm{r}}$. habitu præsertim N. miltina imitatur, quandoque etiam minores Nectric cinnabarina ulmicolæ, supra descriptæ (pag. 82), cæspites mentitur. Perithecia ejus globosa, obtusissima, imo umbilicata (saltem exsiccata), nonnihil furfuracea, extus fusco-rubra, intus autem nitide cinnabarina, in stromate exiguo, firmo aurantioque dense stipata sedent; dissecta thecas tradunt angustissime lineari-clavatas, $0^{\mathrm{mm}}, 065$ vix longiores, nec $0^{\mathrm{mm}}, 004$ crassiores, subsessiles, paraphysibusque tandem paucis et filiformibus stipatas. SPor $x$ in singulis ascis octonæ et oblique monostichæ forma et crassitudine conidia minora Nectrice modo dictæ, i. e. sporas Tubercularice vulgaris ToD. imitantur, breviter enim lineares, nempe $0^{\mathrm{mm}}, 0065$ circiter longæ et in crassitudinem quinto minores, utrinque veluti recte truncatæ, curvulæ v. rectæ, muticæ et continuæ deprehenduntur. Tubercula conidiophora non vidimus; quæ enim fructus ascophoros enituntur, iisdem constipatissimis obruuntur et conidiis, ut mos est, destituuntur.

Provenit in scapo et foliis aridis, putrescentibus, Agares americance ad littora maris Mediterranei cultæ; lynceo indagatori, cl. Durieu, apud Mauritanos occurrit, nobis autem circa Bormes Galloprovinciæ inferioris, autumno extremo anni MDGCGXLVII. Suppetunt in mycotheca Mazeriana, nunc e thesauris Musæi Bot. parisini, specimina a clariss. L. Durour, ad Gades Hispaniæ australis olim collecta. 
Conceptaculorum forma et mira exiguitate, necnon notis ex interna ductis fabrica, ad præcedentem Nectriam miltinam Mntgn. accedit N. citrino-aurantia Lcrx. (in MazeriI Pl. Crypt. Gall. ser. noviss. fasc. XVI [1860], n. 778 , et Rabenhorsti Fungis Eur. exs. fasc. IV [1861], n. 325 ) quæ in corticibus salignis apud Pictones Heraldicastrenses hieme reperta est. Cespites struit exiguos, obtusissimos et dilute flavidos s. ochraceos, ex innumeris stipatissimisque peritheciis stromati seu nucleo admodum velato impositis; hæcce globosa et umbilicata $0^{\mathrm{mm}}, 13$ diametro vix excedunt, thecasque fovent anguste obovato-lineares, $0^{\mathrm{mm}}, 05$ circiter longas, sæpissime $0^{\mathrm{mm}}, 005$ non crassiores singulasque octosporas; sporæ lineari-cylindricæ, vix ovatæ, $\mathrm{o}^{\mathrm{mm}}, 006-008$ in longitudinem adipiscuntur, nec $0^{\mathrm{mm}}, 0035$ in crassitudinem superant; quas biloculatas, imo fortassis quadripartitas tandem fieri æstimare licet. Fungillus colore æmulatur Nectriam ochraceam Friesir (sub Spharice titulo in suo Elencho Fung. t. II, p. 79, n. 201 a), qualis saltem intelligitur Montanio in suo Florce Fernandesiance prodromo apud Ann. Sc. nat. ser. alt. t. III (1835), p. 353, n. 41, et in mycotheca Mazeriana nunc e thesauris Musæi Bot. parisiensis. Colore luteo-virente nitidiore insignitur Nectria chrysites Wallr. item ulmicola, saltem in Rabenhorstil Herb. Mycol. ed. alt. t. VII (1858), n. $632_{2}$ (e Saxonia).

c. Conidiis vulgo deficientibus, conceptaculis autem bifarïs et utrisque ascophoris. - Cugurbitulez.

\section{Nectria Cugurbitula.}

Spheria coccinea $\beta$ abietina Candollio, Fl. Gallica, t. VI, p. 126, n. $781^{\mathrm{g}}$.

Spheria Cucurbitula (Tode) Friesio, Sclerom. Suecice, fasc. VIII (1822), n. 263 (fungillus scil. myriasporus in ramulis pineis corticatis); Syst. Mycol.t. II, p. 415, n. 209. - Spharia autem Cucurbitula TodeI, F. Meckl. Sel. parte alt. p. 38, n. 34, tab. xıv, fig. 110 , sicut et Spharia Ribis ejusdem, ibidem, p. 31, tab. xı, fig. 103 , potius ad Nectriam cinnabarinam supra descriptam trahantur.

Nectria Cugurbitula Friesio, Sum. Veget. Scand. p. 388, n. 4. - Rabenh. Herb. Mycol. ed. alt. fasc. III (1856), n. 248 (in cortice Pinus sylvestris agri Schwerinensis, «ascis, auctore Rabenhorstio, subclavatis, sporis uni$\sim$ serialibus, subnavicularibus aut cylindraceis, diblastis, $\leadsto$ constipatis).

Spharia (Nectria) Cugurbitula (Tode) Gurreio in Act. Soc. Limn. Londin. t. XXII, parte III (1858), p. 282 , n. ${ }^{179}$, tab. xurx , fig. $178, a, b, c$, quibus trifaria endosporarum natura traditur. - De fungillo nostro etiam verisimiliter locuti sunt Berkeleus et Br. in Ann. and Mag. of nat. History. jam forsan ser. i, t. VI (1841), p. 360 , n. 174 (in surculis fraxineis), at certius ser. alt. t. VII (1851), p. 188, n. 609 (thecis polysporis).

NECTRIAM ditissimam nostram fagicolam prorsus imitatur; sori ejus crassitudine varii stromate tum perexiguo aut subnullo, tum contra incrassato, semperque nitide aureo utuntur; singuli e peritheciis ovato-globosis, papillatis, parce furfurosis aut levibus, rubro-lateritiis v. aurantiis, et, ill. Friesı pace dicamus, vix v. neutiquam collabentibus. Thecas et sporas sæpius easdem fovet quas modo dicta Nectria ditissima fagicola. Quod ad conidia altinet, raro, ni fallimur, in subiculis perfectioribus proveniunt, brevioraque et exiliora quam in pulvino seu tubercularia Nectrice cimnabarince deprehendisse nobis videmur. Quæ vero sequuntur monita velimus; primum scilicet conceptacula ascophora quandoque in pineis corticibus longe solito crassiora, turgida, acute papillata et rigentia occurrere, tuncque thecas $0^{\mathrm{mm}}, 01$ et quod super est longas, nec $0^{\mathrm{mm}}, 013$ 
angustiores, sporas autem oblique monostichas, late ovato-oblongas, $0^{\mathrm{mm}}, \mathrm{o}_{2}$ circiter longas, $\mathrm{o}^{\mathrm{mm}}, 007^{-0008}$ crassas, nonnihil inæquilaterales et de more biloculatas monstrare; secundo offendi quoque in eadem pinea matrice cespitulos e peritheciis minoribus et sæpe deformibus (aridis saltem) quibus inesse facillime cognosces thecas late claviformes, turgidas, obtusissimas, subsessiles, $\mathrm{o}^{\mathrm{mm}}, 08-09$ longas, $\mathrm{o}^{\mathrm{mm}}, 01-013$ crassas, fragillimas innumerisque repletas seminibus, unius modi vel sæpius duplicis generis, aliis enim brevissime linearibus, nempe $0^{\mathrm{mm}}$, o 035 longitudine non excedentibus, curvulis, exilissimis et continuis, aliis contra anguste lineari-cylindricis s. lineari-oblongis, $0^{\mathrm{mm}}$, oo8-0 1 longis, vix $\mathrm{o}^{\mathrm{mm}}, 0035$ crassis, bipartitis et appendicula curvula (endospora minore quasi accedente) utrinque auctis.

Quidquid supra adfertur de fungitlis illis dicimus qui in cortice crassiore et exsucco v. ramulis aridis Abietum demortuarum et Pinorum autumno vigent. Abieticolas abunde legimus, mense octobri ineunte, anno MDCGCLV, circa Carthusiam principem Gratianopolitanam, apud Delphinates; potissimum sedebant in deformibus his Abielis excelse virgulis quæ propter Ecidium elatinum ALв. et Schw. mire intumescunt, contrahuntur et magicas quæ dicuntur scopas præter naturam sanam densatæ struunt. Pinicolas autem fungillos nonnisi aridos et in mycothecis contentos quas evolvere nobis datum est, hactenus vidimus.

Fungus ramulicola e foliorum cicatricibus disciformibus præsertim oritur. Fructus myriasporus interna structura non differt a peritheciis item polysporis quæ in Corylo et Aquifolio reperiuntur, minor autem sæpius consistit; attentos non fugerat oculos BЕRкеL.е et Bвоомег quorum enim verba conferas in Annals and Mag. of nat. History, ser. alt. t. XIII [1854], p. 468, sub n. $7_{81}$.

\section{Negtria Aquifolit.}

* Fungus octosporus simul et macrosporus, sporis sæpius muticis :

SPHERIA AQUIFoLII Friesio, Elench. Fung. parte alt. (1830), p. 82, n. 202 , ubi sane utraque fungilli forma sub dato titulo indiscriminatim ab inscio auctore intelligitur. - Movg. et Nestr. Stirp. Vog.-Rhen. fasc. IX (1826), n. 879. - Berkelexo et Br. in Lindeei Gardeners' Chronicle, ad ann. MDCGCLIV, p. 470, fig. 4; et priori in suis Elem. Mycet. Brit. p. 3933 , n. 6. - Fred. Curreio in Actis Soc. Limn. Londinensis, t. XXII, p. 283 , n. 184 , tab. xutx, fig. 183 .

** Fungus polysporus et microsporus, vel octosporus cum sporis minimis et appendiculatis :

Nectria InaURata Berk. et Br. in Ann. and Mag. of nat. History, ser. alt. t. XIII, p. 467, n. 781 bis, junio mense MDCGCLIV. - Berkeleo in Lindla modo citata Ephem. Hortulanorum ad diem xxiI mensis julii ejusdem anni MDCCCLIV, p. 470, cum iconibus (fig. 1-3); et in sui ipsius libro inscripto Outl. of Brit. Fung. p. 393 , n. 7 , tab. I, fig. 11. - Rabenн. Fung. Eur. exs. fasc. I $(1859)$, n. 46 , ubi specimina anglica Broo-
meana præstantur.

De Nectria inaurata BERK. et BR. etiam mentio fit apud Curreianam commentatiunculam super organis Fungorum propagatoriis, in Ephemer. trim. Scientice microsc. t. III (1855), p. 270 , in nota.

Perithecionum cæspites densi haud secus atque Nectria ditissima (supra, p. 73 ), fagicolæ, conceptacula, stromati luteo-aurantiaco et tuberculiformi imponuntur; uteri 
autem singuli formam superne depresso-umbilicatam aut quasi cupulæ æmulam immaturi vel ariditate collapsi obtinent, proptereaque Sphceriam cupularem Pers. quodammodo imitantur; plerisque insuper, initio saltem, furfur aureo-virens parcior copiosiorve inspergitur, qui pro maxima parte tandem evanescil. E stromate, primitus conico, ante peridia nascuntur conidia perquam minima seu spermatoidea, innumera, exiliter linearia, brevissima, recta et continua, quæ suffulcris vix longioribus primum hærent et de more in pultem parcam aliquandiu adglutinantur. Fructibus perfectis includuntur thecæ anguste aut latius cylindricæ, obtusæ, breviter deorsum attenuatæ et nunc octosporæ, nunc contra myriasporæ. Endospor e octonæ quæ in peritheciis levibus s. parcius furfurosis potissimum generari videntur, de forma, structura et crassitudine semina ascogena Nectrice ditissima, fagicolæ, prorsus æmulantur, nisi tamen quod utrinque appendiculatæ nonnunquam cernantur; quæ pariter octonæ in fructibus diutius pulverosis gignuntur, sæpius multo minores et angustiores deprehenduntur, atque hinc et inde appendicula recta, spermatium mentiente, acutatæ ornantur. Præterea in uteris cujuslibet generis et auratis imprimis, simul reperiuntur thecæ aut solis corpusculis spermatiomorphis et innumeris, aut iisdem unaque sporis dimeris fœetæ. Myriasporæ exiguitate vix sibi constant; minores octosporis minoribus vulgo sociantur.

Viget in ramis demortuis Ilicis Aquifolii L. per annum; haud infrequentem reperimus, mense maio MDGGCLIV, Langesiaci Turonum; julio autem MDCGCLVII in saltibus sylvæ Compendiensis ad Petrifontem; postea, æstate etiam, prope Fontembellaqueum (Valvins), et autumnali tempore tum in Burgundia silvosa, circa monasterium B. V. Deiparæ ad Petram gyrantem, tum in montibus agri Lugdunensis, haud procul a pago quem Dième dicunt.

Ob endosporas duplicis, imo triplicis generis, Nectriam Cucurbitulam et ditissimam corylicolam de quibus supra suo loco agitur, Nectria Aquifolii Fr. imitatur, immeritoque, præter BевкеLег sententiam, in typos duos dirimeretur; ejus enim cæspites furfure parciori copiosiorive distincti, omnes in iisdem ramis et ipsissimo certe mycelio mixti nascuntur; imo furfuris copia in singulis uteris unius et ejusdem cæspitis maxime inæqualis deprehenditur. Icon Curreiana supra citata ascum fertilem fungilli levioris, sporis nempe muticis gravidum exhibet.

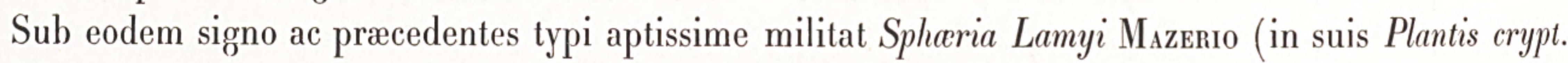
Gallice, ed. alt. fasc. I, n. 39) seu Nectria Lamyi DNtrs. (Sfer. Ital. manip. I, p. 13 , tab. rx) quæ Cucurbitarice Berberidis (PErs.). ${ }^{1}$ societatem affectare solet; etenim cum iisdem propter habitum, colorem et multiformia semina mire congruit, nec fortassis nisi macrosporis vulgo polymeris et undique appendiculatis discriminatur. Dubitare licet meritone SolLmannios spermatia nuper dixerit microsporas illas quibus innumeris fungilli thecæ sæpissime replentur. Cui autem non apparebit, Coburgensis mycologi dissertationem si legerit, ficta veris imprudenter fuisse commista, spermatia, quæ dicuntur, in ascis nec in sterigmatibus generari, impeditum iter minime sequi quod ingredi æstimentur, denique in macrosporarum pariete manifeste oriri ubi inserta conspiciantur? (Cfr. Ep.lem. Bot. berolinensem, t. XXII [1864], p. $265-268$ et $27^{3-2} 7^{6}$, tab. xI, fig. $1-26$.)

'Quam videsis descriptam in tomo II hujus Carpologice, p. 219. 


\section{EXPLICATIO ICONUM.}

(Tab. X, fig. 13-19.)

13. Cæspites Nectrice Aquifolii e materno cortice per epidermidem diffractam exeunt; stromata quædam globosa, obtusissima, fructus ascophoros nondum enixa, sed conidiorum s. spermatiorum feracissima, sub corticeo velamine partim adhuc latitant.

14. Duo ex his stromatibus conidiferis juxtaposita et strato tenuiore inter se juncta, a summo dissecantur ut forma quam induunt manifestior pateat; pulvis conidiorum tenuissimus e junioribus s. demissioribus pulvillorum partibus copiosior nascitur; fungillus aqua immersus inspicitur.

15. Portiuncula minima tenuissimaque stromatis conidiferi, hujusce parenchyma $p$, villum $v$ e sterigmatibus stipatissimis quo inæqualis ejus superficies tegitur, et innumera conidia s. spermatia $c, c$ circumnatantia simul exhibet.

16. Stroma peritheciis onustum a vertice dimidiatur.

17. Alterum similiter dissectum, partibus demissioribus, imo crustiformibus, olim spermatiophoris at nunc sterilibus, utrinque stipatur.

18. Thecæ et paraphyses quæ in peridiis furfurosis potissimum gignuntur.

19. Eadem organa, qualia autem in peritheciis golabris sæpius observantur. Sporæ demensiones multo majores et formam potius ovato-oblongam quam lanceolatam hic obtinent, raroque appendiculis augentur; interdum tamen microsporæ, his appendiculis vix dissimiles, macrosporis parce vel abundantius commiscentur.

Figuræ 13, 14, 16 et 17 nativam rerum magnitudinem vicies tantum excedunt, reliquæ vices circa cccLxxx; præter ultimam (19) cui delineandæ profuerunt specimina anglica a cl. Broome nobiscum benevole communicata, cæteræ juxta fungillos agri Diemensis Lugdunensium, octobri mense MDCGCLVI, in villa Dareizeana, hoc in libro jam laudata, adumbratæ sunt.

d. Conidiis sinceris ut videtur nullis; fructibus caspitosis et disparibus, aliis nempe spermogonieis et multiloculatis, aliis simplicibus et ascophoris. - SINOPEA.

\section{NeGtria sinopica.}

* Fungus nondum ascophorus :

Tubercularia Sarmentorum Friesio, Obs. Mycol.t. I (1815), p. 208 , n. 297 , saltem pro parte, et Syst. Mycol. t. III, p. 465, ipso monente magistro in suo Elencho Fung. t. II $(1898)$, p. 81, n. $202 c$.

** Fungus absolutior :

SPHERIA SINopica Friesio, Elench. Fung. loco modo cit. - Berk. in Ann. and Mag. of nat. History, ser. i, t. I (1838), p. 206 , n. 97. - Mazerio, Pl. Crypt. Gallice, ed. princ. fasc. XXVI (1843), n. 1259 , et ed. alt. fasc. XVI, n. 759. - Moug. et Nestl. Stirp. Vog.-Rhen. fasc. XIV (1854), n. 1335. - Fred. GurRey in Ephem. trim. Sc. microsc. t. III (1855), p. 270, n. 3.

Negtria sinopica Friesio, S. Veget. Scand. p. 388, n. 5. - Notarisio, Sphar. Ital. fasc. I (1863), p. 11, n. 6 , tab. II, fig. vi.

Suв matricis epidermide facile soluta et annulatim vulgo discissa, e cortice levi nec peculiariter fucato v. maculato, quasi imposita aut vix emergentia nascuntur fungilli III. 
spermogonia; tot globulos leves, nitidos, dilute luteo-aureos ac semi-pellucidos primitus fingunt et Dacryomycetum primordia mentiuntur; subinde vero opaca fiunt et saturatius rubent, ita quidem ut quasi sanguinea evadant; simul increscunt tandemque pulvere sulfureo v. aureo consperguntur, sed grano papaveris minora sæpius consistunt, naturamque carneo-mollem retinent. Modo simplicia, globosa et obtusa, basi angustissima suffulcro suo adhærent superneque papillam perviam et brevissimam ostendunt; modo contra uteros plures, sessiles, ovatos discretosque e suis parietibus ut e subiculo communi circinatim singula enituntur indolemque multiplicem sic adipiscuntur. Spermogonir seu pycnidii penetralia, e parenchymate molli et aurei coloris, in locellos perexiguos et innumeros dividuntur, quorum parietes sterigmatibus exiliter linearibus, stipatissimis, ramosis et vix $\mathrm{o}^{\mathrm{mm}}, \mathrm{o}_{2}$ longis vestiuntur; ex hisce, sæpius ramulorum instar, nascuntur corpuscula, spermatia s. microstylosporæ, linearia, brevissima, nempe vix $0^{\mathrm{mm}}$, o 035 longa, recta aut vix curvata, quorum copia pultem modo pallidam, modo dilute auream constituit. Conceptacula ascophora minima, globosa, vix papillata, levia, glabra v. furfure sulphureo conspersa, colorisque saturate rubri ac tandem fucatioris, modo spermogoniis in eodem subiculo, luteo-aurantio angustoque commiscentur, modo eorumdem consortio repudiato, cæspites globosos et stipatissimos sola fingunt. Arescendo partim collabuntur et in umbilico infuscantur. Thec $x$ linearicylindricæ, obtusissimæ, deorsum breviter acutatæ, e membrana tenui factæ, $0^{\mathrm{mm}}, 08$ in longitudinem et $0^{\mathrm{mm}}, 008$ in crassitudinem vulgo obtinent; sporas octonas, ovatas v. obovatas, rectas, pallidas, rubellas (acervatas si eas videris), leves, muticas, biloculares, oleo homogeno stato tempore fotas, $0^{\mathrm{mm}}, 01$ circiter longas, $0^{\mathrm{mm}}, 0065$ vix crassiores, et oblique monostichas singulæ quasi oppletæ fovent, paraphysibusque linearibus, quam ipsæ sunt longioribus, basi cæspitose ramosis, tandemque hyalinis evacuatis et ægre conspiciendis stipantur.

Crescit in ramis emortuis Hederce Helicis L. totum fere per annum, at hiemali imprimis tempore, nec prope Parisios (v. gr. Modoni, Bellævistæ, Biveriæ, cæt.) infrequens est.

Nullum conidiorum genus nobis innotuit; quare sinceram adesse tuberculariam maxime dubitamus. Conidia quorum mentionem fecit (loc. cit.) clar. Fred. Curner, ipse, ut opinamur, non deprehenderit; eum etiam verisimiliter præterierit labyrinthea s. multiloculata spermogonii structura. Ejusdem auctoris si verba recte interpretati fuerimus, thecas arbitraretur in eodem oriri conceptaculo quod antea spermatia fuderit; quam autem spermogonii metamorphosim pro maxime dubia non habere nequimus. Spermatia modo sterigmatibus summis solitaria imponuntur, modo ex eorumdem lateribus ut tot ramusculi gignuntur; aqua immersa mire trepidant. Uteri hisce corpusculis gravidi oculos Notarisir effugisse videntur. Sporas quæ nondum perfectæ sunt continuas diceres; absoluta autem maturitate, septum aperte manifestatur. 


\section{EXPLICATIO ICONUM.}

(Tab. XI, fig. 1-10.)

1. Pars brevis et partim nudata sarmenti hederacei demortui, aridi, in quo Nectria sinopica Fr. læte viget; sorus medius et supremus e solis conceptaculis ascophoris, nonnihil collapsis struuntur; sorus alter, iconis in lævo margine, spermogonia seu pycnidia microsperma admittit quæ papilla terminali præsertim distinguuntur; spermogonia alia variæ crassitudinis in sarmento nudato sparguntur.

2. Perithecia quinque stromati eidem insident, simulque a summo dimidiantur.

3 et 4 . Perithecia altera spermogonium centrale stipant.

5-7. Spermogonia, pleraque basi inter se connata, a vertice dissecantur et substantiam sementivam ex apice forato vomunt; omne perithecii vestigium desideratur.

8. Portiuncula tenuissima et summopere aucta spermogonii a summo dissecti; conceptaculi interanea in locellos complures per septa hic angustissima, illic crassiora dividuntur, spermatiaque e sterigmatibus miræ exilitatis nascuntur.

9. Perithecii spiraculum terminale, appendicibus filiformibus brevibusque deorsum instructum; infra stant thecæ, paraphysibus commistis.

10. Sporæ quæ satæ septembri medio, a. D. MDCCCLX, intra paucos dies germinaverunt; conidiola ovata e nonnullis germinibus oriri videbantur.

Figuræ omnes, præter decimam, decembri mense, a. S. MDCCCLIV, Parisiis delineatæ sunt, et fungillum hederæcolam agri Modonensis et Cavillensis exprimunt; cunctæ etiam veras rerum demensiones plus minus
excedunt; decima vices circiter ccclxxx augetur.

2. Fungicolex; conidïs varïs aut nullis; peritheciis caspitosis vel sparsis. - Cosmarie s. Cosmospore.

\section{NeGtria epispheria.}

SPherla epispiteria Todeo, Fung. Meckl. sel. parte alt. p. 21, tab. xi, fig. 89. - Pers. Syn. Fung. p. 57 , n. 110. - Friesio, Scler. Suecice, fasc. VIII (1822), n. 265 (in Spharia Stigmate Hofru.). - Greviluio, Fl. Crypt. Scotice, t. III (1825), tab. clxxv, fig. 2. - Mazerio, Stirp. Crypt. Gallice, ed. alt. fase. VI (1838). n. 272 (in Splucria Stigmate).

Spheria coccinea a faginea Candollio, Fl. Gall. t. VI, p. 126 , n. $781^{8}$, sicut ex descriptione liquet.

Nectria sanguinea et epispineria Friesio, Sum. Veg. Scand. p. 388 , n. 16 et 18 , ex auctoribus laudatis.

Fungilui conceptacula vulgo matrici nudæ, saltim de specie, ut subiculo alieno insperguntur nec ordinem servant, aut pauca insimul in ea coacervantur; longe rarius stromati privo, legitimo definitoque cæspitose insident. Id stromatis crassitudinem variam, colorem sordide vel contra nitide sanguineum, naturamque dense parenchymatosam ac passim parce piligeram sic dictæ Tubercularice vulgaris Toder obtinet, at vix tumet sæpiusque crustam tenuem, inæqualem, villo conidiophoro ramoso et brevissimo, nempe $o^{\mathrm{mm}}, 03$ vix crassiori, indutam refert. Conidia quod ad originem attinet, corpuscula ejusdem indolis imitantur quæ in Nectria cinnabarina (Tope) generantur; pleraque cylindrica sunt, curva, utrinque obtusa, $0^{\mathrm{mm}}, 0065$ vix longa, nec $0^{\mathrm{mm}}, 001$ crassiora; alia tamen longe majora, ob formam lineari-lanceolatam et lunulatam quam 
assumunt, fusariea dici volunt. Antequam villus conidifer totus evanuerit, stroma substratum inæquo modo protuberat, conceptacula scilicet globosa enititur quæ fere superficialia, congesta aut laxius insita, pedetentim incrassantur. Ubi adoleverunt, Nectriam dilissimam nostram (supra, p. 73 ) tum habitu, tum interna fabrica prorsus imitantur.

Hospitatur autumno, hiemali tempore vereque in pyrenomycetibus variis, obsoletis, nec infrequens circa Parisios et Versalias occurrit. Perfectissimam vidimus in Sphcria quercina Persooni , sparsam contra et stromate sincero sæpius destitutam in Sphceria Stigmate et deusta Hoffunni. Cæespitose effertur supra Valsam quamdam polysporam et alnicolam, Modoni minime raram, tuncque, ni omni specie decipimur, non differt a Nectria Purtoni Curr. quam Greviluers simul cum Valsa Abietis Fr. mera illius matrice, pro fungo simplici, dichroo et macrocephalo, nempe Cucurbitaria sua Pinastri, incautus sumpserit. (Cfr. Grev. Fl. Crypl. Scotia, t. I, tab. L; et Cunner Dissert. synopticam de fructib. Sphæriar. composit. Herbarii Hookeriani, in Actis Soc. Limn. Londin. t. XXII, parte III [1858], p. 282 , n. 182 , tab. XLIx, fig. 181 , ascum gravidum exprimente.) Grevilui error Berkeleum non fugit, sicut ex hujusce Elem. Mycologice Brit. p. 394, n. 17 , elucet; iterum nuper advertitur ab Elia Fries in ScheqchtenDALII Ephem. Botanica, t. XXII (1864), p. 189.

In fungis jam demortuis et exsuccis plantula de qua agitur oriri solet, quare vix merito, cum Pвrsoovio et aliis, parasitica diceretur.

\section{Negtria cosmariospora.}

Cosmospora coccinea Rabenhorstio, in suis Fungis Europ. exs. fasc. V (1862), n. 459, et in Hedwigice tomo alt. manip. $x$ (1862), p. 59 , tab. x, fig. mediis præter dextram.

Nectria cosmariospora Not. et Ces. in Comment. Soc. Crypt. Italce, fasc. IV (1863), p. 195.

NECTRIA ditissimam nostram (supra, p. 73 ) in cortice lignove ulmeo gregatim sparsam, ipsa gregaria et inordinate sparsa, non modo quod ad vigendi modum, sed super habitu et crassitudine, æmulatur, saturate rubet, uterosque crassos ex parietibus rigentibus, arescendo scilicet minime collabentibus factos, et matrici nudæ passim impositos ostendit. Theсе obovato-clavatæ solito ampliores sunt, quippe $0^{\mathrm{mm}}, 08-10$ in longitudinem et $0^{\mathrm{mm}}, 013-16$ in crassitudinem æquant, et ex membrana tenui struuntur quæ nucleo ac sporis peculiariter hæret, proptereaque integ్gra et continua æorre conspicitur. Spor late ovatæ, utrinque obtusissimæ, bipartitæ, imo interdum quadantenus didymæ, $o^{\mathrm{mm}}, 013-016$ longæ, et $\mathrm{o}^{\mathrm{mm}}, 01$ circiter crassæ, tuberculis obtusis spissisque præter Nectriarum mores asperantur ${ }^{1}$, et colore rubro ita fucantur ut semi-opacæ effi-

1 Verruculosas etiam vidit Notarisius endosporas Nectrice Lamyi M Mz. (Cfr. ejus Sphariaceos Italicos, fasc. I, p. 13 , tab. iI, fig. Ix.) Nos autem ut et Solcmannius supra citatus (pag. 88), easdem nonnisi septis solito crebrioribus divisas, sæpeque ex omni parte appendicu'is brevibus quasi horridas deprehendimus. 
ciantur; octonæ et monostichæ in singulis ascis nascuntur et sibi invicem aliquandiu hærent; inferiores et supremæ axim asci sequuntur, mediæ vero eidem contrariæ et transversariæ vulgo deprehenduntur. Has omnes propter notas Nectria cosmariospora Ces. et Not. quam ad Nectr. Pezizam v. ditissimam prima fronte libentissime ducas, ab utraque contra sine negotio, equidem oculis attentis et armatis, discriminatur. Cæterum in ejus fructibus nil pycnidei nobis innotuit quod Cesatir et Notarisi præsensa comprobare queat.

Crescit in hymenio arido et infuscato Polypori cujusdam nostratis, resupinati, late effusi, tubulis longis, inæqualibus et quasi gradatis. Vivam semel legimus in fagetis sylvæ Compendiensis ad Petrifontem, julio exeunte MDCGCLVII.

Fungillus apud Rabenhonstium (loco sup. cit.) datur etiam in hymenio Polypori modo dicti, nec in ligno nudo et corrupto, præter dresdensis mycologi enuntiata. Item pro astomo perperam habetur, quippe de peritheciorum forma minimaque et poriformi apertura a Nectria ditissima neutiquam differt. Mycelii conspicui vestigia fungo maturo desunt.

3. Folïcole, conidiorum apparatu vario, perithecïs sparsis, nudis vel setigeris.

* Stromate subnullo v. inconspicuo; peritheciis autem glabris vel tomentellis. - NECTriELLE.

\section{NeGtria pyrochroa.}

* Fungus conidiophorus (saltem ut videtur):

Hymendla Platani Lev. in Ann. Sc. nat. ser. III, t. IX (1848), p. 128.

Fusarium Platani Montanio, in iisdem Collectaneis, ser. ili, tomo XI (1849), p. 55, ubi etiam synonyma inedita traduntur. - M MzErio, in suis Stirpib. Cryptog. Gallice, ser. princ. fasc. XXXV (1848), n. 1749 , et edit. alt. fasc. XXVII, n. 1349 .

** Fungus ascophorus :

Spheria (Nectria) pyrochroa Mazerio in suis Pl. Cryptog. Gallice, ser. noviss. fasc. VIII (1856), n. $37_{2}$, et apud Comment. Soc. Bot. Gall. t. IV (1857), p. $99^{8}$, n. 35.

Huc etiam merito ducturi nobis primum videbamur simillimam Sphceriam erubescentem (Rов.) ejusdem M M in Ann. Sc. nat. ser. III, t. VI (1846), p. 72, n. 18 , et in suis Plantis Crypt. Gallice, ed. I, fasc. XXXVI $(1849)$, n. ${ }^{1} 766$, et ed. alt. fasc. XXIX, n. 1416 , quam vero ubi accuratius rimati fuerimus, notis non paucis recedere cognovimus, v. gr. ob utriculos multo minores quibus densius compactis uteri parietes struuntur, nec non propter thecas obovato-oblongas et sporas equidem lineari-lanceolatas, modice arcuatas et 4-loculatas, sed longitudine $\mathrm{o}^{\mathrm{mm}}, 02$ et crassitudine media $\mathrm{o}^{\mathrm{mm}}, 0035$ plerumque non excedentes.

EGRE tenemur quin æque legitimum et sinceræ affinitati congruum arbitremur, ac solenne videtur, consortium illud quod Nectriam pyrochroam Maz. inter et Hymenulam Platani Lev. nuper animadvertebamus. Hymenula tum pustulas perexiguas in postica foliorum Platani pagina, tum punctula oblonga ovatave in eorumdem petiolis aridis 
efficit; tenuissima sub epidermide nascitur, minime autem conceptaculo privato sed utero alieno el spurio e matricis partibus vix mutatis, utitur, ita ut nonnisi post velum ruptum aut amotum suam fundat sementiculam. Hæcce tota ex conidiis ovatis, rectis aut quadantenus reniformibus, continuis, $0^{\mathrm{mm}}, 01$ circiter longis et $0^{\mathrm{mm}}, 004-006$ crassis constat, albida est et ceram mentitur. Conidia autem in arbusculas breves et ramosas catenata nasci, glutineque achroo diu compingi videntur; uteri parietes pallidi et tenuissimi a sementi acervata ægre distinguuntur. Nectrice conceptacula globosa, glabra, sessilia, brevissime papillata, arescendo autem umbilicata facta, colorisque e rubro-ferrugineo tandem sordide fucati, sparsa proveniunt inter Hymenula nidos, in utraque foliorum hospitalium pagina; perithecii parietes ex utriculis globosis majusculis, scil. $0^{\mathrm{mm}}, \mathrm{O}_{2}$ et quod excedit diametro crassis, et laxe sociatis fabricantur, extrorsumque propterea inæquales et verruculosi, oculo saltem armato, apparent. Theс quasi apodes formam late ovatam et utrinque subacutatam affectant, $0^{\mathrm{mm}}, 05-06$ in longitudinem et $\mathrm{o}^{\mathrm{mm}}, \mathrm{O}_{2} \mathrm{o}_{2} 6$ in crassitudinem obtinent, debito tempore pereunt et sporas maturas nudant. Hæ senæ octonæve in singulis ascis, eosdem integros dense fasciculatæ replent, utut lineari-lanceolatæ curvæque lunulatæ dici queunt, septis tribus in articulos quatuor sigillatim dividuntur et hinc $0^{\mathrm{mm}}, 04-05$, illinc vero $0^{\mathrm{mm}}, 005-007$ æquare solent.

Datur apud Mazerium, locis supra citatis, in foliis aridis Platani; vivam autem nos ipsi nondum reperimus.

Suadente b. magistro insulensi, fungillus modo dictus, quod ad fructum attinet, cum Spharia flavida Corde (Icon. Fung. t. IV [1840], p. 40, n. 1, tab. viII, fig. 117) quæ propter indolem molliter carnosam et colorem lætum, omnino est, ut videtur, e Nectrieorum grege ${ }^{1}$, quamdam analogiam ostendit; sed longe propior est tum Nectrice erubescenti Rов. supra citatæ, tum etiam Nectrice luteole ejusdem botanophili (apud Mazerium cujus conf. Pl. Crypt. Gallice, ed. I, fasc. XLII [185o], p. 2078 et Dissert. XIX de Fungis gallicis novis, in Ann. Sc. nat. ser. III, t. XVI [1851], p. 314 ). Hæcce pari modo in foliis aridis (Fraxini, Tremula, Aceris cæt.) nascitur et formam umbilicatam arescendo assumit; illius autem endosporæ lanceolato-acutæ, rectæ aut vix incurvatæ, sæpius tantummodo biloculatæ fiunt ${ }^{2}$, nec $0^{\mathrm{mm}}, 013$ longitudine, crassitudine vero $0^{\mathrm{mm}}, 003$ excedere solent; thecæ distiche octosporæ et oblongo-sublanceolatæ $0^{\mathrm{mm}}, 0$ 7-09 in longitudinem consequuntur.

Ad præcedentes fungos etiam proxime accedit Nectria lecanodes Ces. ${ }^{3}$ item mire depressa seu patelli-

${ }^{1}$ Etenim Nectria flavida dicitur Friesio in sua Summa Veget. Scand. p. 388, n. 11; habitu mentitur, auctore Berkelexo (in Amn. and Mag. of nat. Hist. ser. alt. t. VII [1851], p. 188 , n. 610), Hypocream farinosam Berk. et Br. (ibid. p. 186 , n. $59^{2}$ ), propter endosporas exiguas et ovatas discriminatu facillimam.

${ }^{2}$ Sporulas seu guttulas III-IV deprehendisse sibi visus est Mazerius; item thecarum demensiones æquo minores fecisse videtur. (Cfr. Annalium Sc. nat. locum sup. cit.)
Id fungilli crescit in utraque pagina Peltigerce canine, maxime autem in antica, modo adhuc vegeta et vix maculata, nunc contra partim corrupta aut saltem decolori. Datur tum e montibus Bugellensibus l'edemontii, tum e sylvis Domitzanis agri Mecklenburgensis, apud Rabenhorstium, Herb. Mycol. ed. alt. fasc. VI (1857), n. 525. Idem ipse fungus est qui Nectria Peziza, minor, audit in MazerıI Stirpib. Crypt. Gallice, ser. noviss. fasc. VIII (1856), n. $3_{7} 1$, et ejusdem dissertatione XXIV de fungis gallicis quam videas 
formis et alte umbilicata ubi exaruit; e lichene nutritio minime rupto sed potius perforato ab initio et vix conspicua jam erumpit, libera sessilisque augetur et ex albida dilute roseola fit. Endosporæ lanceolato-acutæ, rectæ aut nonnihil incurvatæ, biloculatæ vel obscure quadripartitæ, $0^{\mathrm{mm}}, 011-013$ longæ et $0^{\mathrm{mm}}, 004$ crassæ, in thecis anguste fusiformibus ac $0^{\mathrm{mm}}, 08$ circiter longis, disticho et octono ordine generantur.

A Nectria autem lecanode Ces. quacum sede congruit, sine negotio discriminatur Nectria erytlrinella Nylandri in Actis Societatis pro Fauna et Flora Fennicis, ser. altera, t. I, fasc. I (1859), p. 125 , n. 23 ; hæcce enim colore læte aureo-rubro, intus maxime, insignitur, uterum suum globosum et minime collabentem in matrice asterisci instar rimosa totum recondit, nec nisi papillam nonnihil globosam et prominulam ostendit. Thecæ brevi pereunt; sporæ ovato-oblongæ v. oblongo-lanceolatæ, rectæ et æquo modo biloculatæ, in majorum numero apud Nectrias haberi merentur, quippe $0^{\mathrm{mm}}, 022-025$ in longitudinem atque $0^{\mathrm{mm}}, 007$ et quod superest in crassitudinem nanciscuntur. Ex sedula speciminum authenticorum collatione percepimus Nectriam hanc erythrinellam, in agro fennico ad Helsingforsiam novembri mense MDCCCLVIII observatam, eandem prope esse quæ antea Nectria Robergei a Mazerio (in suis Pl. Crypt. Gallia, ser. noviss. fasc. VIII [1856] n. 374, e Neustria, et Act. Soc. Bot. Gall. t. IV, p. 999 , n. 37 ) et Cryptodiscus lichenicola a Cesatio (apud Rabenhonstiom, Herb. Mycol. ed alt. fasc. VI [1857], n. 523 et in ejusdem Hedwigia, tomo II, p. 8) nuncupata fuerat. Fungilli neustrii endosporæ minores
videntur.

Nectria oropensis Ces. (Herbarï modo cit. n. $5_{2} 4$ ) item fungillús lichenicola est et læte pictus; mycelio albo, laxe byssino, tenuissimo et evanido primum denotatur. Nec vivam, nec perfectam vidimus. Pari modo, sed in muscis, viget Nectria bryophila Roв. (apud Mazerium in Ann. Sc. nat. ser. iII, t. XVI [1851], p. 306 ) quæ Mazerio ipso opinante (in suopte herbario), non differt a Nectria muscivora Berk. et BR. in Ann. and Mag. of nat. Hist. ser. II, t. VII (1851), p. 188, n. 608 ; hujusce perithecia congesta et aurantia, endosporæ autem ovatæ, utrinque acutæ s. breviter fusiformes, nec non biloculatæ nisi quidem quadripartitæ dicuntur. (Cfr. anglos autores modo laud.)

Alius exstat sphæriaceus typus, atque lichenicola, qui vero locum Nectrias inter et Hypomycetes medium obtinere videtur. Nectria affinis Friesio est ${ }^{1}$; conceptaculis utitur carnosulis, mollibus et pallidis, endosporis autem oblongo-lanceolatis, trilocularibus, rectis v. sigmoideis et utrinque exiliter aristatis; auctore clar. Russelio nostro, Fontebellaqueo in Ephebe pubescenti Fr. non infrequens est. (Cfr. Mycothecam Mazerianam in Musæo Bot. parisiensi.)

Ad Nectrias fusisporas cinnabarinas sparsasque etiam spectare decernimus Nectriam Bloxami Bевк. et Br. in Ann. and Mag. of nat. Hist. ser. alt. t. XII $(1854)$, p. $46_{7}, \mathrm{n} .781$, herbicolam, cujus endosporæ "quadrinucleatæ" in conceptaculis subglabris et tandem valde collapsis informarentur. Nobis nondum innotuit neque etiam Nectria ochraceo-pallida eorumdem Вевк. et Вв. (in anglis Collectaneis modo citatis, ser. alt. t. VII $[1851]$, p. $18_{7}$, n. 607$)$, stirps pariter britannica, quæ gregatim vigere fertur in

in collectaneis inscriptis Bulletins de la Soc. Bot. de France, t. IV (1857), p. 997, n. 34. Nobismetipsis occurrit, etiam in supradicto lichene peltigero, ad Fontembellaqueum, februario mense a. MDCCCLX. Conidiophora compages, si qua Nectrice locum tenet priusquam conceptacula ejus appareant, nos quærentes semper latuit.

${ }^{1}$ Spharia affinis Grevillio, Fl. Crypt. Scotice, t. IV $(1826)$, tab. cLxxxvi, fig. 1, quod ad endosporas attinet minime fida; Friesio, Elench. Fung. t. II, p. 93, n. $311 c$; et Mazerio, in Ann.Sc.nat. ser. iv, t. IV (1855), p. 128 , n. 12 , accedente accurata descriptione; Nectria autem affinis Friesio, Sum. Veget. Scand. (1849), p. $38_{7}$, in nota secunda; et Bornetio, in Ann. Sc. nat. ser. III, t. XVIII $(1852)$, p. 165 , in nota. Pro fructu Stigonematis nonnullis perperam habita est. (Cfr. Berkeleum et Br. in Ann. and Mag. of nat. Hist. ser. alt. t. VII [1851], p. 188 , supra.) 
ulmeis corticibus, peritheciisque donari plus minus collabentibus, nec non endosporis fusiformibus, arcuatis et quadripartitis.

\section{NeGtria carnea.}

* Fungillus conidiophorus :

Psilonia Pellicula Mazerio, in suis Plantis Crypt. Gallice, ed. princip. fasc. XXIX (1845), n. 1411 , edit. vero alterius fasc. XIX (1845), n. 911. Auctore eodem magistro (citatis locis), huc etiam spectat Psilonia Luzulce Libertie, Crypt. Arduenn. n. 386 , quam nondum novimus.

** Fungus ascophorus :

Spharia (Nectria) carnea Mazerio, Herb. modo cit. serie noviss. fasc. VIII (1856), n. $37^{3}$, et in Actis Soc. Bot. Gall. t. IV (1857), p. $99^{8}$, n. 36 , utrinque saltem pro dimidia parte, nempe quatenus caricicola.

Mycelir vices agit substantia fungina tenuissima, parca, non conspicue byssina, potius contra nonnihil furfurosa, propter quam matrix passim extrinsecus albescit et maculatur; maculæ exiguæ figuram ovatam v. lineari-oblongam describunt pedetentimque in crustam tenuem, ceraceam, dilute stramineam, helvolam carneamve, limbo albido et angustissimo definitam, bene multæ convertuntur. Crusta maxime e conidiis spermatiformibus acervatis et adglutinatis constat quæ exilissime linearia, recta et continua, $0^{\text {mm }}$, o o 5-o o 6 longitudine vix excedunt, ac Bacteria habitu æmulantur. Crustam eandem altius præterea si attentis rimatus fueris oculis, sterigmata reperies exilitate spermatiis haud imparia, duplo autem v. triplo longiora, parce ramosa et maculæ funginæ densissimo agmine insita. Pauca hæc de sic dicta Psilonia Pellicula Mazeri præmisisse satis est; nunc de perfectioribus fungilli nostri fructibus agendum. Perithecia sunt globosa, exigua, brevissime papillata, glabra, ex albo pedetentim helvola vel dilute carnea ${ }^{1}$; in crusta albida, gemmifera aut conidiorum experti, sparsa sed gregata sedent nec arescendo collabuntur. Tнесе lineari-oblongæ, sublanceolatæ, sessiles, sæpe quadantenus incurvatæ, $\mathrm{o}^{\mathrm{mm}}, 04-05$ longitudine et $\mathrm{o}^{\mathrm{mm}}, 005-006$ crassitudine æquant, sporisque octonis, multiplici ordine sibi invicem incumbentibus, integræ sigillatim replentur. Sровж exiliter lineari-lanceolatæ, rectæ, vix continuæ (3-4-meræ, volente Mazerio), $0^{\mathrm{mm}}, 0_{1} 3$ in longitudinem apiscuntur, crassitudine vero $\mathrm{o}^{\mathrm{mm}}, \mathrm{oog}_{2}$ vix excedunt.

Crescit in utraque pagina foliorum Caricum, postquam aruerunt, maxime vero in postica.

Nectria Psiloniaque in iisdem maculis funginis una nascuntur, et parem induunt colorem, quare, suadente cæterum analogia, non dubitamus quin unius et ejusdem fungi diversa sint membra. Uterque plantulæ fertilis modus, matrici, juxta erysipheos mores, totus externus videtur, ei a principio imponitur nec velum alienum unquam admittit.

Quidquid tamen hic præstamus, lectorem velimus admonitum, minime nos docuerunt fungi vivi no-

\footnotetext{
${ }^{1}$ De fungillo arido loquimur; vivus, auctore Mazerio, sæpius flammeus est.
} 
bis obvii, sed specimina Mazeriana supra citata; ideo minus confidimus nos specie veri non fuisse deceptos. Floccos aut villum in fungilli incunabulis seu crusta albida sede illius assueta animadvertisse contendit Mazerius; præterea sporidia oblonga et binotata Psilonic suæ tribuit; nos autem in utraque parte dissimilia observavimus. Mazerium etiam non prorsus latuit assueta Psilonice suæ et Nectrice prædictæ in Caricibus societas; exinde autem nil inferendum arbitratus est.

Quandam similitudinem Nectriam inter carneam Maz. et Nectr. arenulam Вевк. et Br. juxta Berkeleiana scripta deprehendere nobis videmur; nec multum etiam sane differt Nectria graminicola eorumdem auctorum; utraque stirps in foliis aridis Airce caspitose apud Britannos vigere fertur. (Cfr. Ann. and Mag. of nat. Hist. ser. alt. t. IX [1852], p. $33_{20}$, n. $62_{2}$, tab. Ix, fig. 5 , et ser. III, t. III [1859], p. 376 , n. 897 , tab. xI, fig. 40.$)$

Tubercularice nomen, supra sexcenties adhibitum, lectoris memoriam utique revocaverit ad Psiloniam Buxi Fr. quam Candoluivs inter sinceras Tubercularias, incerto quidem animo, olim admiserat. Hic porro locus est ut pauca de hoc fungillo perhibeamus, idque eo magis expedit quod habitu et seminum origine, ni nos omnia fallunt, plantula manifesto multiplex est, nec pauca super argumento nostro docet. Cæterum indole molli et læto suo colore ad Nectrieorum plebem optimo jure pertinet.

** Stromate conceptaculisque setigeris. - Chetostroma Corde.

\section{Negtria Russeliaja ${ }^{1}$.}

* Fungus conidiophorus :

Tubercularia Buxi Candollio, Fl. Gall.t. VI, p. 110 , n. $742^{\text {b }}$.

Fusidida BuXI (Sснмidtio, in litt.) Linkio, Sp. Plant. Limn. parte alt. p. 97, n. 3.

PSILONIa ROSEA Eliæ Friesio, in suis Scler. Suecice, fasc. VI $\left(18_{21}\right)$, n. 220 (auctore Mazerio in suopte herbario ).

PSILONIA BU.II eidem magistro Upsaliensi, seu Psilonice suæ prototypus, in suo Syst. Orb. Veget. p. 187 , n. 231. - Duby, Bot. Gall. t. Il, p. 926.

Fusisporidu BuXi item Friesio, Syst. Myc. t. III, p. 447, n. 12 ; Summa Veg. Sc. p. 473 . - Moug. et Nestr. Stirp. Vog.-Rhen. fasc. XII (1843), n. 1194, ubi plantulas inter conidiophoras, plurimæ aderant perfectiores, ascophoræ (nempe perithecia Nectrice Russeliance $\mathrm{M}_{\mathrm{NTgN}}$. infra citatæ), insciis sane sociis auctoribus. - $\mathrm{M}_{A-}$ zerıo, Pl. Crypt. Gallice, ed. princip. fasc. XIX (1838), n. 928, et ed. alterius fasc. V, n. $2_{2} 8$.

Chemtostroma Buxi Corde, Icon. Fung. t. II (1838), p. 3o, tab. xiI, fig. 107; Anleit. z. Stud. d. Mykol. p. c, tab. G, fig. 68, n. 28-31. - Rabenh. Herb. Mycol. ed. alt. fasc. III (1856), n. 280 (ex agro Dresdensi), et Fung. Europ. exs. fasc. I (1859), n. 71 (e Bohemia). - De Chatostromate Buxi Corde et fungillis sociis pauca etiam verba fecit G. Fresenius in Flora seu Ephemeride Botanica ratisbonensi ad annum MDCGCXLVII, parte 1 , p. 9 , simulque conidiorum ejusdem plantulæ figuram maxime auctam, sed vix fidam, nempe æquo breviorem et crassiorem præstitit (tab. I, fig. 14).

Volutella BuXI Berkeleo et Br. in Ann. and Mag. of nat. History, ser. alt. t. V (185o), p. 465 , sub n. 495. - Berkeleo soli in suis Elem. Mycol. Brit. (1860), p. 340 , quare miramur eruditum auctorem anno præcedente Deвatio libenter assensisse. (Vid. infra.)

Antiquius ejus cognominum pro nostro instituto si retineremus, fungillus de quo nunc agitur Nectria Buxi dicendus esset, ita ut mutato duntaxat genere, Candolliano titulo in præsens salutaretur; quum autem jam exstet Nectria buxicola, videlicet Nectria coccinea var. cicatricum
Berk. cujus supra (p. 77) meminisse oportuit, eo satius nobis videtur designatione Montaniana uti quod et ipsi nos delectamur nomen viri optimi, de mycologia bene meriti, his in pagellis quodammodo celebrare. 
** Fungus ascophorus :

Spheria Fulva Friesio, Elench. Fung. parte alt. (1830), p. $9^{\circ}$, n. 275 b, saltem Berkeleo volente in Ann. and Mag. of nat. History, ser. I, t. VI (1841), p. 361, n. 182.

Negtria Russeliana Montanio apud Castanium, Pl. Massil. suppl. (1851), p. 44, et in suamet Sylloge Pl. Crypt. (1856), p. 224 , n. 784 . - Berkeleo et Br. in Ann. and Mag. of nat. History, ser. III, t. III (1859), p. $37_{6}$, n. 898 , ubi de fungilli forma viridi agitur simulque animadvertitur formam hanc et Sphceriam fulvam ${ }^{1}$ Friesir unam et eandem stirpem cum Nectria Russeliana Mntgn. et Chatostromate Buxi Cordæano, demonstrante Debatio nostro, sistere. - Berkele etiam in suis Outl. of Brit. Fungology, p. 394, n. 24.

Nectria carnea Mazerio, saltem pro dimidia parte, nempe quatenus buxicola, tum in suis Sirpib. Cryptog. Gallice, ser. noviss. fasc. VIII (1856), n. 373 , tum in sua Dissert. XXIV, apud collect. inscripta Bull. de la Soc. Bot. de Fr. t. IV (1857), p. $99^{8}$, n. 36 .

Huc etiam fortassis spectat Spharia Buxi Curreio in Comment. Soc. Linn. Londin. t. XXII, parte III, p. 283 , n. 187 , tab. xulx, fig. 186 , endosporas liberas et indivisas exprimente; contra longe recedit, nisi forsan endosporis, saltem habitu et vigendi ratione, Mazerianus typus ejusdem nominis qui cum notis traditur in Stirpib. crypt. Gallice, ed. princ. fasc. XXVI (1843), n. $1280^{2}$.

\section{*** Fungus integer :}

Chemtostroma Buxi Debatio, in Ann. Sc.nut. ser. iv, t. IX (1858), p. 84-9o, tab. v. - Minime autem Corde et discipulis, sicut e supra allatis constat.

Mrcelium e tenuissimis filamentis paginam posticam folii Buxi sempervirentis Lins. intestinum occupat, totum latet sed innumeros minimosque gignit nodulos qui pertusa epidermide exserti tument simulque quum pilis paucis, rigidis et sterilibus, tum etiam setulis multo brevioribus, exilioribus, densissime confertis et apice conidiophoris horrent. Pili steriles parce septiferi et simplices, sursum tenuantur et $0^{\mathrm{mm}}, 16-19$ longitudine æquant; fertiles contra circiter quadruplo breviores et confertim ramosiusculi deprehenduntur; utrumque genus pallidum et sordide luteolum. E summis pilis fertilibus subsolitaria nascuntur conidia anguste lanceolata, scilicet $0^{\mathrm{mm}}$, o o6 65-0 1 et quod excedit longa, $\mathrm{o}^{\mathrm{mm}}, 002-003$ crassa, recta et continua. Conidia autem in ceraceas glebulas aut pulvisculum concretum, albidum, roseum ochraceumve, cumulata adglutinantur; sæpissime quoque accidit ut pulvinuli s. cæspituli conidiophori vulgo denso agmine sparsi, imo subcontigui, suam commisceant sementiculam, indeque folium hospes multimodis conspurcetur. Cæspites inter gemmiferos s. nudisporos, pauca copiosiorave e bysso latenti nascuntur perithecia globosa, sessilia, iisdemque setis sterilibus horrida quæ pulvillos conidiophoros ornant; alia ipsismet pulvinis subeffœetis insident; forma omnibus globosa, brevissime et obtuse papillata, paries tandem crassiusculus dilute nitidiusve ochraceus, rarius virens aut squalide lateritio-rubescens, atque e cellulis factus polygo-

${ }^{1}$ Fungilli hujus quem El. Fries ad Nectrias jure et merito trahendum fore nuper iterum monuit (in Ephem. Bot. Berol. t. XXII [1864], p. 190 , n. 220), endosporas CurReius delineavit, continuas alias, bipartitas alteras. (Cfr. Acta Soc. Linn. Londin. t. XXII, parte Iv [1859], p. 314 , n. 220 , tab. LVII, fig. 5.) Anglus idem scriptor, graphidis accuratæ in rebus mycologicis peritus, ibidem etiam seminum digniorum Nectrice Pezizae, sanguinece et epispharice figuras præstitit (p. 319, n. 264-266, tab. LVII, fig. 44, 45 et 47 ).

${ }^{2}$ De sua Spharia Buxi disseruit etian Mazerius in Annalib. Sc. nat. ser. alt. t. XIX (1843), p. 354, n. 30. 
niis et tabularibus. Nucleus albidus fit prope e solis thecis, innumeris, lineari-oblongis, sublanceolatis, sessilibus, obtusis, $0^{\mathrm{mm}}, 06-07$ longis et $0^{\mathrm{mm}}, 006-01$ crassis, quæ ipsæ sporis octonis et obscure distichis singulæ opplentur. Sров ж autem ovato-lanceolatæ, rectæ aut nonnihil incurvatæ, continuæ pallidæque sunt et hinc $0^{\mathrm{mm}}, 013-0^{\mathrm{mm}}, 016$, illinc $\mathrm{o}^{\mathrm{mm}}$, o o 5 -0o65 æquant.

Oritur æstate et autumno in pagina aversa foliorum Buxi semivivorum; non semel eam vidimus in agro parisino et compendiensi, specimina autem perfecta quæ præmissæ adumbrationi præ cæteris profuerunt, humanissimo viro, clar. Roussel, cui Meloduni occurrerant, abhine decem annis debuimus.

Longe a vero recessisse arbitramur clar. DEват qui perithecia provenire contendit ex utriculis illis quos medios aut subextremos in pilis rigidis fructigenis viderit; id sententie Balianum prorsus imitatur errorem, ab Antonio DE $\mathrm{B}_{\mathrm{ARY}}$ notatum, super strati ascophori origine apud Epichloem typlinam $\mathrm{F}_{\mathrm{R}}$. (Cfr. Floram seu Ephem. Botanicam ratisbonensem ad ann. MDCCCLXIII, manip. xxvr.)

Ad Nectrias foliicolas accedit, suam propter sedem assuetam, Spharia nostra lepophaga cui Tubercularia persicina Diтм. subiculum fortassis suppeditare nobis olim videbatur; utriusque fungilli historia caligine hactenus premitur, idque hoc in loco animadvertere, argumento quod tractamus conducit. Cæterum videsis quæ jam præstitimus in Ann. Sc. nat. ser. Iv, t. II (1854), p. 83 et 84, in nota.

\section{SPHEROSTILBE.}

(Tab. XIII et XIV.)

* Fungus conidiophorus :

STILBUM Todeo, F. Meckl. sel. t. I (1790), p. 1o, et Persoonio, Myc. Eur. t. I, p. 347 et seq. saltem pro parte apud utrumque scriptorem. - Friesio, S. Myc. t. III (1832), p. $299 ;$ S. Veget. Sc. p. 469 (partim saltem utrobique).

CLAVARIE species Sowerbeo, F. Brit. t. III, tab. caxciv.

ATRACTIUM Linkio, Diss. I in Ord. Plantar. nat. ap. Acta Soc. nature scrut. Berolin. t. III (1809), p. 10 , n. 13; saltem ex descriptione, minus enim quadrat icon allata (tab. I, fig. 11).

MICROCERE spec. Mazerio in Annalib. Sc. nat. ser. III, t. X (1848), p. 359 .

** Fungus perfectus :

STILBUM Tul. in Ann. Sc. nat. ser. iv, t. V, p. 114.

SPHEROSTILBE Tul. Sel. Fung. Carp. t. I (1861), p. 130 , in nota.

Mycelium plerumque parcum æogre conspicitur. Sтroмa carnosum, tuberculiforme et sæpius læte coloratum, in columellam pistilliformem, sibi consubstan- 
tialem apiceque abunde conidiophoram abit. Conidis ovata, oblonga, vel linearilanceolata, simplicia et continua aut contra septifera et pluriloculata, modo recta, nunc curvula, ceram fluxilem in globum densatam constituunt. Perithecia globosa, exigua, sessilia, vix papillata, minute verrucosa, nuda, rubea molliaque, in imo stromate seu columellæ pedibus congeruntur. Theсж quasi sessiles, cylindricæ vel lineari-oblongæ, octosporæ sunt; sporæ autem ovatæ, sæpius biloculatæ, rectæ aut curvulæ, pallidæ el muticæ. Paraphyses vulgo raræ aut subnullæ.

Fungilla cortices aut ligna arida incolentes, rarius Torrubiarum more insectis demortuis insidentes.

Spherostilbe ad Nectrias proximæ accedunt, nec nisi apparatu conidiophoro in clavulam exstructo differre videntur; ipsa autem conidia modo ovata et brevia sunt, atque Tuberculariarum genuinarum semina æmulantur, modo longiora sese Fusariis magis analoga præstant, inde Sphcrostilbre aliæ Eunectriis, aliæ Fusariellis nostris respondent.

Quo rite et certe spectent Stilba illa læte picta quæ Mucorum more ${ }^{1}$ in fimetis et corporibus putridis habitant, nondum cognovimus; ad naturam Spherostilbarum duplicem, hinc scilicet conidiophoram, illinc et ascophoram, saltem si attendas, plane judicabis hæc sic dicta Stilba, quale Stilbum erythrocephalum Ditmaris, minime esse fungos perfectos et autonomos, ut vulgo æstimantur. Cæterum palam est veram plurimorum fungillorum stilbiformium naturam mycologis hactenus latuisse. De Graphïs quæ Stilborum habitum imitantur, jam verba fecimus in tomo I hujus Carpologice, p. 66, 128 et seq. nec non in tomo II, p. 288.

Haplographium delicatum Вевк. et Вr. in Ann. and Mag. of nat. Hist. ser. III, tom. III (1859), p. 360 , n. 818 , tab. Ix , f. 4, stipite filiformi, simplici et olivaceo-nigrente, sporis autem concatenatis, hyalinis, ovatis, exiguis nec partitis, non modo pro typo generico novo haberi neutiquam meretur, sed, nisi nos omnia fallunt, conidiophorum tantummodo et dematicum eum sistit apparatum qui permultos apud Pyrenomycetes occurrit. A sinceris Graphiis quibuscum loco cit. confertur, multo magis recedere videtur.

Quod ad Monotosporam sphcrocephalam eorumdem auctorum (loc. cit. p. $361, \mathrm{n} .81 \mathrm{~g}$, tab. cit. fig. 5) attinet, quum sæpius Haplographium delicatum mixta comitetur, formam istius nondum fertilem, peculiarem v. effœtam, nempe Haplographium, conidiorum dimissa coma, vix cunctantes eam arbitramur; gemmifera enim ejus modi instrumenta, pro ætate et tempestatis conditione, minime sibi constare iterata nos edocuit experientia.

" Stilbum, ait Linkius (Obs. in Ord. pl. nat. Diss. I, "p. 28), ad Mucores accedit; inter Gastromycos mucidos, pone Pilobolum, ab eo admittitur (in sua Diss. II, apud
Comm. Soc. nature scrutat. Berol. t. VII [1816], p. 40 , n. 6$)$. 
1. Conidïs ovatis, brevibus et rectis. - STILBA proprie dicta, quædam saltem, de re fungina scriptoribus.

\section{Spherostilbe aurantiaca.}

* Fungus mere conidiophorus :

CLavaria coccinea Sowerbeo, Engl. Fungi, t. III (1803), tab. ccxciv, saltem fig. sinistris, opinante etiam Mazerio, loc. infra cit.

Tubercularia vulgaris varietas Friesso aliisque, monente eodem magistro insulensi.

Stilbum aurantiacum Babingtoni in Actis Soc. Linn. Londinensis, anno D. MDGGGXXXIX (auctore Berkeleno); ipsi autem Berkeleo in Ann. and Mag. of nat. Hist. ser. I, t. VI (1841), p. 432, n. 223 , tab. xII, fig. 14. - Mazerio, in Ann. Sc. nat. ser. II, t. XIX (1843), p. 337.

** Fungus integer, gemmifer simul et ascophorus :

Stilbum aurantiacum Tul. in Actis hebdom. Acad. Sc. par. t. XLII (1856), p. 704 , et eodem anno in Ann. Sc nat. ser. Iv, t. V, p. 114.

Spherostilbe aurantiaca Tul. Sel. Fung. Carp. t. I (1861), p. 130 , in nota.

StıPIтES millim. II-II longi, lineares, varie compressi vel dilatati, rarius cylindrici, e basi plus minus incrassata aut solitarii, aut cæspitosi assurgunt, coloreque læte rubroaureo oculos a longe alliciunt; solidi sunt integrique e parenchymate firmo et intrinsecus albido, nimirum e cellulis angustissime linearibus et arctissime fasciculatis struuntur. In clavulam brevem singuli sursum abeunt ex qua innumera conidia pedetentim oriuntur quæ in globum dilute roseum et jove pluvio lente diffluum adglutinantur. Occurrunt etiam stromata e stilis abortivis, brevissimis, quæ nihilominus tamen conidiorum feracissima sunt et Nectriarum solitas tubercularias omnino mentiuntur. Conidis in quolibet subiculi genere ovata, oblonga aut quasi cylindrica, utrinque obtusissima, levissima, continua, recta, $0^{\mathrm{mm}}, 013-02$ longa, $0^{\mathrm{mm}}, 005-007$ crassa, humore homogeno pallidoque replentur, et ex elementis filiformibus summæ columellæ solutis, articulatis, acrogena et solitaria procedunt. Conceptacula minima, gobosa, obtusissima et rugulosa, e basi incrassata stipitum clavigerorum, quasi e stromate pulviniformi sincero, sero tempore coacervata nascuntur, coloreque saturate rubrofusco sicut columella ipsa, inficiuntur; sunt etiam quæ pulvillis omni baculo clavato destitutis stipata insident. Illis omnibus paries est crassus et carnosus, uti fungum Nectriis affinem decet. Tнеск late claviformes, obtusissimæ, sporas octonas, coacervatodistichas, ovato- vel obovato-oblongas, muticas, leves, biloculatas, rarius quadripartitas, septis nonnihil contractis, humoreque subhomogeno ac pallido refertas singulæ includunt. Hæ sporæ germina filiformia, flexuosa moxque ramosa, ex omni parte ac 
potissimum ex apicibus, loco temporeque opportunis, agunt, simul etiam crassiores fiunt, nonnullæque, loculis tunc dimidiatis, tetrameræ veniunt.

Oriri solet in ramis ulmeis corticatis aut partim nudatis, cæsis, demortuis, nuncque cortice, nunc ligno sedet. Recentiori ævo occurrit primum Church. Babingtoni in Anghia, posteaque apud nos b. Mazerio insulensi, utrique autem mere conidiophora. Perfectam nos autumno hiemeque reperimus tum Modoni et Cavillæ prope Parisios, tum in ambulacris oppidi Carnutum et in Alpibus Delphinatus, haud procul a Gratianopoli.

lcones Sowerbæanas supra citatas potius ad Ditiolam suam radicatam trahit El. Friesius (Syst. Myc. t. II, p. ${ }^{1}$ 71), sed immerito, ni decipimur.

\section{EXPLICATIO ICONUM.}

(Tab. XIV, fig. 1-13.)

1. Portiuncula extrema ramusculi ulmei resecti, corticati aridique (Modoni, prope Parisios, januario MDCGCLVI lecti) cui innumeras Sphorostilbes aurantiace (Вав.) modo descriptæ clavulas insitas vides, alias ligno nudo, alias ligno scissum inter corticem, alias denique cortici ipsi hærentes; quædam peritheciorum cæspite denso parciorive stipantur, plures autem iisdem destituuntur; exstant etiam pulvinuli e peritheciis acervatis, omni clavulæ conidiferæ vestigio deficiente. Clavulæ contiguæ apice ceraceo, e conidiis diffluentibus, cohærent.

2. Clavula conidiophora et stroma cui simul cum conceptaculis recentibus innascitur, a vertice dissecantur; fungus cortici materno, epidermide fracta, imponitur.

3. Fragmentulum tenuissimum et maxime auctum summæ clavulæ quæ in filamenta discedit ramosa et apice conidifera; conidia plurima soluta in ambitu sparguntur.

4-6. Conidia quæ seminata incrementum ceperunt et germina ediderunt; quædam in cellulas duas nunc septo dividuntur.

7. Thecæ sporis maturis gravidæ.

8. Theca altera, basi rupta, sporas dimittit. Sporæ liberæ juxta jacent.

9-13. Sporæ germina egerunt inter quæ plurima jam in ramos discesserunt. Sporæ ipsæ quandoque increscunt et tri- v. quadripartitæ evadunt.

Fig. 1 justas rerum demensiones bis decuplo majores exprimit, fig. altera easdem ter decuplo; cæteræ circiter $\operatorname{cccLxxx}$ vices naturam excedunt.

\section{Spharostilbe gracilipes.}

Stilbum gracilipes Tul. in Act. hebdom. Acad. Sc. par. tom. XLII, p. 704, et in Ann. Sc. nat. ser. iv, tom. V, p. 114.

Spilerostilibe gracilipes eorumd. Sel. Fung. Carpol. t. I (1861), p. 130 , in nota.

Colunelue conidiferæ subteretes, graciles, $0^{\mathrm{mm}}, 002-005$ longæ, quandoque lineis spiralibus sursum versus notatæ, minutissime (oculo armato) papillosæ aut subleves, rarius parce pubentes, violaceo-fuscæ, senescendoque sordide fucatæ, solitariæ sæpius stant in pulvinulo roseolo-fusco et exiguo; quæ tamen minores manent cæspitulos potissimum efficiunt; omnibus solidis parenchyma inest firmum et cinereo-fuscum 
ex utriculis linearibus ac constipatissimis. Consdia perexigua, ovata, $0^{\mathrm{mm}}, 005$ illinc, $\mathrm{o}^{\mathrm{mm}}, 002$ hinc vix excedunt, in globum crassum et carnei coloris, simul atque procreantur adglutinantur, summæque hærent columellæ. StERigmata quibus primum suffulciuntur exiliora et breviora quam apud Stilbum aurantiacum $\mathrm{B}_{\mathrm{AB}}$. modo descriptum observantur. Conceptacula ad styli gemmiferi pedes aut in pulvinis columna destitutis nata, aggregata (xII-xv insimul), formam solitam gobobosam, ostiolum terminale, coloremque roseum obtinent; parietibus tenuibus et croceis struuntur, lentisque ope inspecta, quasi furfuracea videntur. THEс monostichas, ovatas, biloculatas, guttula oleosa in utroque loculamento intra plasma subachroum fœtas, in medio nonnihil coangustatas, muticas, atque $o^{\mathrm{mm}}, 01-015$ longitudine, minore autem diametro $\mathrm{o}^{\mathrm{mm}}, 00$ 4-005 æquantes singulatim includunt.

Nascitur hieme in ramis aridis Castanee vescae et Coryli avellance; eam legimus in caldariis horti Bot. parisiensis, decembri mense, a. D. MDGGCLV.

A præcedenti Spharostillbe aurantiaca $B_{A B}$. quacum habitu prorsus congruit, Spharostillbe gracilipes differt præsertim columella longiore, peculiariter exili, aliterque fucata, nec non conidiis multo minoribus. Illius etiam cum Stilbo xanthocephalo KIскхII proximam, ut videtur, necessitudinem jam notavimus (Sel. Fung. Carpol. t. I, p. 129 , not. 5).

\section{EXPLICATIO ICONUM.}

(Tab. XIV, fig. 1/1-19.)

14. Clavulæ conidiferæ et perithecia cæspitosa Spharostilbes gracilipedis TuL. in virga castanea, corticata et arida, sparsa inseruntur. Cæspites s. glomuli ascophori clavam centralem sæpissime fovent; stroma cui singuli imponuntur quandoque formam pulvinatam perfectiorem obtinet et clavulas plurimas, breves, aut columellam unicam substerilem agit.

15. Stroma exiguum e cortice materno trans epidermidem prodit; conceptaculis et clava media, maxima, simul oneratur, integrumque a summo vertice dimidiatur.

16. Subiculum crassius similiter dimidiatum; clavulæ eccentri cauliculus fractus hinc et inde numerosis conceptaculis stipatur. 17. Portiuncula maxime tenuata summi styli conidiferi; conidia alia sterigmatibus filiformibus acrogena
hærent, alia libera circumcirca sparguntur.

18. Sterigmata conidiophora seorsim delineata et summopere aucta.

19. Ascorum fasciculus et sporæ liberæ, pari modo atque sterigmata quorum mentio supra fit, aucta monstrantur.

Fig. 14 præter naturam bis decuplo amplificata est, figuræ 15 et 16 ter decuplo, fig. 17 vices circa cCGLXXx, et reliquæ 18 et 19 vices GGCGLXxx.

\section{Spherostilbe cinnabarina.}

* Fungus conidiophorus :

Stilbum (Atractium) cinnabarinum Montanio in Am. Sc. nat. ser. alt. t. VIII $(1837)$, p. 360 , n. 39 , et in Ramonis de Sagra Hist. ins. Cubce, part. Bot. Pl. cell. (ed. Gall. 1842), p. 308, tab. xı, fig. 3. 
E sтrомате tenui, sordide lateritio, et in supremis corticis materni stratis latitante, cæspitosi v. discreti per rimas prodeunt baculi saturate rubeo-fusci, exiles, glabri, millim. II-IV longi, erecti aut flexuosi, ac sursum versus in clavulam obovatam sensim incrassati. Pro more hanc super clavam undique generantur conidia ovata, recta, indivisa minimaque, scilicet $\mathrm{o}^{\mathrm{mm}}, 0035$ vix longa et duplo angustiora. Conceptacula sæpius in ipsis baculorum conidiophororum pedibus pauca insimul nascuntur; admodum sessilia sunt, nitide rubro-aurantiaca, glaberrima, globosa nec conspicue papillata, atque propter naturam molliorem arescendo quadantenus collabuntur. Elementa nuclei albidi quem singula matura fovent, in hujus libri tomo primo (loco sup. cit.) descripsimus.

Provenit in corticibus arborum demortuarum Americæ calidioris, occurritque primum illustri viro Ramoni de $\mathrm{S}_{\text {agra }}$ in Cuba insula, postea autem clar. Mullero in monte Orizaba Novæ Hispaniæ. (Conf. Herb. Mus. par.)

Conceptaculorum simul et sporarum crassitudine a congeneribus præsertim discriminatur.

2. Conidïs lineari-lanceolatis et arcuatis. - Atractia Linkir.

\section{Spherostilbe flamiea.}

* Fungus conidiophorus:

Atractiva fla mameum Berk. et Ravenelio, in Ann. and Mag. of nat. History, ser. altera, t. XIII, p. 461, n. 757 (mense junio, a. MDGGCLIV).

** Fungus integer :

Stilbum flamanem Tul. in Actis hebdom. Acad. Sc. par. t. XliI, p. 704 , et in Ann. Sc. nat. ser. iv, t. V (1856), p. 114.

Spherostilbe flamaea Tut. Sel. Fung. Carpol. t. I (1861), p. 130 , in nota.

Cuavdue conico-lineares, sursum scilicet attenuatæ, roseæ, aliquando inferne pallidiores et in fibrillas solutæ, e pulvino concolore ac variæ crassitudinis, nunc solitariæ, nunc plures insimul, liberæ vel partim coadultæ assurgunt, nec sæpius, ut videtur, lineam longitudine excedunt. F ILA exilia, $0^{\mathrm{mm}}, 0035$ crassa, æqualia, parce septifera, e membrana tenuissima et achroa, quibus sociatis modiceque cohærentibus clavulæ fabricantur, superne relaxantur vel dissociantur conidiaque anguste lineari-lanceolata, maxima, nempe $0^{\mathrm{mm}}, 08-09$ longa, $0^{\mathrm{mm}}, 0065$ autem vix crassiora, incurva, utrinque acuta, 5-8-loculata, et dilute rubea enituntur. Pевітнecia golobosa, nitide rubra et vix levia, in pulvinis columniferis vel nudis laxe congeruntur, aut ex columellis ipsis 
sparsa, itemque sessilia, nascuntur. Thecrs singulis obovato-oblongis sporæ octonæ insunt ovatæ, utrinque obtusissimæ, muticæ, biloculatæ et in medio septifero nonnihil angustatæ. Germina ex his nata, exilia et sæpius terminalia vidimus.

Viget in cortice saligno, emortuo vel semivivo; obvia primum fuisse dicitur in Carolina australi Americæ borealis clar. Ravenelo, posteaque clar. Ralfsio in Britannia, teste clar. Berkeleo (loc. cit.) cui benevolo specimina modo descripta (americana) debemus.

Præcipuum fungilli criterium in conidiorum forma et magnitudine versari palam est. Fila rigida et obtusa quibus intextis columellæ ejus formantur, ramos sibi parallelos paucos agunt, ac præterea isthmis brevissimis rectisque alia aliis passim religantur.

\section{EXPLICATIO ICONUM.}

(Tab. XIII, fig. 10-13.)

10. Saligni corticis frustum proponitur cæspitibus Spharostilbes flammece Tut. maxime auctis onustum; columellæ fungi conidiferæ in crura plurima inferne pleræque solvuntur et peritheciorum incunabula fiunt.

11. Columella perquam exigua summopere (scilicet vices circiter CaL) amplificatur ut ejus fabrica filamentosa conidiorumque generatio terminalis simul in conspectum veniant; perithecia globosa, recentissima, in eadem latitant quæ mox accreta protuberabunt.

12. Conidia matura, soluta, et vices circiter ccclxxx aucta, seorsim spectantur.

13. Sporæ quæ germina ediderunt, nativam suam crassitudinem pari modo excedunt.

Speciminibus americanis quorum mentio modo facta est, quum ad præmissam descriptionem, tum ad figuras quæ accedunt describendas usi sumus.

\section{Spharostilbe cocgophila.}

* Fungus mere conidiophorus :

Microcera coccophila Mazerio, in sua Dissert. XVI de Pl. Gall. novis, ap. Ann. Sc. naturalium seriem III, t. X $(1848)$, p. 359 , n. 29 , et in suis Plantis crypt. Gallice, ed. principis fasc. XXXV, n. ${ }_{7} 50$, et ed. alterius fasc. XXVII (eod. anno 1848), n. 1350. - L. Caldesio, in Rabenhorsti Fungis Europ. exsicc. fasc. III (1860), n. 269 .

Tubercularia coccophila Bonordenio in novissimis suis Disputationibus Mycologicis (1864), p. $9^{6}$, inter Mycetinos suos, sub n. 2.

** Fungus ascophorus :

Nectria episph fria L. Caldesio, loc. modo citato, n. $262 .-$ Non autem Todeo (sub Sphceria) nec aliis.

*** Fungus integer :

SPherostilbe coccophila Tul. Sel. Fung. Carpol. t. I (1861), p. 130 , in nota.

Sub crusta pallescenti Cocci cujusdam nostratis proxime demortui, hieme fungillus nascitur, ipse pallidus vel dilute roseus, carnosus, in ambitu parce byssinus et remissioris coloris, moxque animalculi exhausta substantia, parmulam circum circa exce- 
dit, eidem vix dimotæ marginem angustum et inæqualem suppeditat, subindeque in columellam unicam (rarius plures), crassam, obtusam, simplicem, et lineam, ut videtur, tandem circiter longam, pedetentim assurgit. Ex ista summa clavula saturatius rubente confertim nascuntur conidia lineari-lanceolata, curvula, $0^{\mathrm{mm}}, 065$ circiter longa, decuplo autem angustiora, et 4-6-loculata, quæ suffulcris tenuioribus primitus sese singulatim excipiunt. Conceptacula permulta in exteriore imæ columellæ substantia postea gignuntur; sæpissime etiam in ipso margine exigui stromatis, Cocci reliquiis pro maxima parte vestiti, clava deficiente vel abortiva, debito tempore generantur. Minima sunt, globosa, obtuse et brevissime papillata, sessilia, glaberrima, nitide rubra, carnosa et fragilia, quasi in cæspitem III-v insimul congeruntur et senescendo arescendove nonnihil collabuntur. Nucleus albidus, totus ex thecis constat linearicylindricis, $\mathrm{o}^{\mathrm{mm}}, 06-\mathrm{o} 8$ longis, $\mathrm{o}^{\mathrm{mm}}, 0065$ circiter crassis, obtusissimis, subsessilibus, singulisque octosporis et ex membrana factis tenuissima; paraphyses vulgo quasi omnino desiderantur; sporæ leves, muticæ, subachroæ et sæpius oblique monostichæ, formam ovatam et rectam obtinent, hinc $0^{\mathrm{mm}}, 01$, illinc $0^{\mathrm{mm}}, 005$ nanciscuntur et septo medio in partes duas æquales nonnihil constrictæ dividuntur.

In truncis vivis et junioribus cum Salicum, tum Fraxini excelsioris L. februario mense (a. MDCGGXLVII), prope Ladomum, oculatissimo viro de mycologia optime merito, D. RoBERGe, conidiophora abunde occurrit; ab eodem, per benevolum amicum Raimondum LeмовиаND, specimina bene multa accepimus; perfectior autem plantula reperta est, maio currente a. MDCGCLX, a L. CaLdess, in truncis Lauri nobilis L. et viridario florentino notissimi nominis, Boboliano scilicet, quod MıcheLI studia mycologica in sæculo superiore jam illustrarunt.

Utrum Coccus fungiferus nostras et florentinus ab invicem discrepent, necne, percipere nequimus; prior, apud Westendonpium (in libro inscripto Cryptog. classées d'après leurs stations naturelles, p. 212 ), ad Coccum Tilice L. trahitur.

Fungillus modo descriptus, licet entomophilus, Spharostilles flammea (Вевк.) corticicolæ admodum congener est, proptereaque Stilba mucorea, quæ scilicet in matrice putrida vel stercorea vigent, cum Stilbis lignicolis media fortassis conjungit. Inter fungos tubercularineos pone Fusarium, ob sporas, et

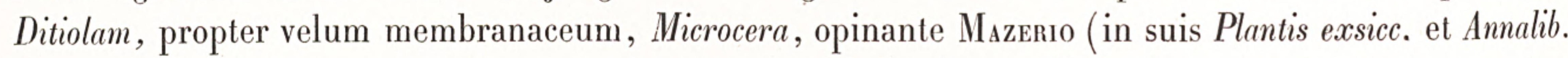
Sc. nat. locis cit.), locum obtinere merebatur; porro Sphariis nectriiformibus nunc consociata, a propinquis jure primum indigitatis non removetur. Quidquid autem de fungilli velo et indole phalloidea apud clar. Mazerium affertur, multo minus, ni fallimur, valet; soli enim mycelio albenti quo adplicito stroma densius factum tegitur, omnis veli species debetur, nullaque sincera volva adest. Cæterum conferas fusiorem adumbrationem laudati auctoris. Specimina dantur Robergiana quæ columellas plurimas ex ambitu ejusdem Cocci natas et decumbentes monstrant, et has inter sunt quæ Stilba Todeana genuina admodum æmulantur. Exempla autem Caldesiana conidiorum longe parciora sunt.

Microcerce clavula super forma et exilitate filamentorum ex quibus constat, Stilbum flammeum Bврк. prorsus imitatur; hæcce etiam sibi invicem isthmis brevissimis conjunguntur et in ramos strictos parcosque singula discedunt. 
Analogia duce, suspicari licet Stilbum Buquetii Carolo Roвıs (Hist. nat. des Vég. parasites, p. 640 , tab. vIII, fig. 3 et 4 , tab. Ix, fig. 4 et 5 et tab. xI, fig. 1-3), fungillum item entomoctonum, ad quamdam sphæriaceam stirpem etiam pertinere; quid autem de Stilbis mollioribus et magis mucoreis rectius sentiendum sit, adhuc dubio premitur.

Priusquam Nectrieorum ordinem claudamus, non possumus quin notam paucis verbis faciamus Valsam illam quæ, sicuti jam supra (p. 3) denuntiavimus, horum pyrenomycetum colorem lætum et indolem carnosam mirum in modum imitatur.

Valsa chrysoides $†$. - Fungilli mycelium e strato byssino, ochraceo, sub lacera matricis epidermide, in cortice exoleto parcum serpit. Huic stramini sparsim imponuntur stromata carnosa, molliuscula, ex toto nitide aurea, grani miliacei crassitudine, de specie glaberrima, pleraque conico-truncata et frequenter in medio plus minus excavata v. depressa, marginibus obtusissimis et sinuosis. Conidia innumera, anguste ovata, recta, continua, vix $0^{\mathrm{mm}}, 0035$ longa, ex omni stromatum pagina nascuntur, summis sterigmatibus subsimplicibus, $\mathrm{o}^{\mathrm{mm}}, 03$ circiter longis, erectis et stipatissimis solitarie primum innituntur, solutaque in pultem nitide auream congeruntur, quam imbres detergunt. Conidiorum generatione absoluta, tunc perithecia lageniformia, carnosa, mollia et integra coloris carneo-aurati, in imis pulvini gemmiferi penetralibus conferta generantur, ostiolaque concolora vix proferunt, ita ut prorsus lateant. Nucleum singula fovent pallidum, ex thecis tenuibus, lineari-cylindricis, $0^{\mathrm{mm}}, 1-13$ longis, nec $0^{\mathrm{mm}}, 007$ crassioribus, subsessilibus et octosporis. Sров utrinque obtusissimæ, in medio quadantenus angustatæ, ob septum transversum biloculatæ, $0^{\mathrm{mm}}, 01$ circiter longæ, $\mathrm{O}^{\mathrm{mm}}, 0065$ crassæ, leves et pallidæ sunt. Innumeros inter ascos paraphyses sinceræ vix conspiciuntur.

In ramis emortuis Cytisi Laburni L. Modoni Versaliorum, aprili mense a. MDCCCLVIII, et prope Fontembellaqueum (ad pagum dictum Féricy), augusto medio ejusdem anni, vigentem reperimus.

Suum propter colorem nitidum, naturam mollem et carnosam, apparatum conidiophorum, sporarumque formam et ordinem, Nectrieos pyrenomycetes, conceptaculorum autem super dispositione Valseos imitatur, ideoque ambos greges connectere videtur; cum Valsis quas novimus, eam si conferamus, Friesianæ vestite (descriptæ supra tomo II, p. 204, n. 14) quam cæteris propiorem arbitramur.

\section{EXPLICATIO ICONUM.}

(Tab. III, fig. 15 et 16 .)

15. Particula stromatis aurei et gemmiferi Valse nostræ chrysoidis, vices circa cccLxxx præter naturam amplificatur; conidia alia suffulcris suis insistunt, alia libera accedunt.

16. Thecarum fertilium par simili modo nota majus factum; endosporæ exclusæ juxtaponuntur. 


\section{NOTE.}

De Tettigometra in campis Novæ Hispaniæ fungipara quam supra, p. 11, paucis attigimus, fusius semel atque iterum hispano sermone tractavit vir nobilis Leopoldus Rio DE LA Loza (in collectaneis inscriptis Boletin de la Sociedad mexicana de Geographia y Estadistica, tomo X, n. 4, julio et septembri a. MDCCCLXIV), sub titulo el Animal-Planta, simulque accuratas fidasque ejusdem attulit icones; veram autem fungilli naturam minime novit, quippe pro appendice quadam insoliti seu morbosi animalisque generis eum habere vix dubitat.

Omnia quæ ad Hypomycetem nostrum aureo nitentem, supra (p. 64) descriptum, spectant, quum jampridem scripseramus, britannum quemdam fungillum, totum niveum, priori tamen mire analogum, ab humanissimo C. E. Broose accepimus. Hoc genus novum quod Hypomycetem Broomeanum dicere nobis placet, nascitur in Polyporo annoso Fr. (abieticola) arido ac putrescente, potissimumque in illius hymenio quod bysso mucedinea obtegit. Byssus autem penicillos contractos et minute conidiophoros agit quales in Hyp. aureo-nitenti generantur, proptereaque Bвооме visa est quasi speciem Penicillii elegantis Corde (Ic. Fung. t. II, p. 18 , lab. xi, fig. 74 ) indueret, licet præstitæ fungilli hujus adumbrationi ex omni parte non respondeat. Perithecia ovato-acuta et semi-millimetrum alta denso ordine discreta sedent et brevi lanugine in omni pariete, absque summo rostello, horrent. Thecæ exilissime lineares $0^{\mathrm{mm}}, 13-14$ longitudine æquant nec $0^{\mathrm{mm}}, 0035$ crassiores sunt; endosporæ octonæ, contigue recteque monostichæ in singulis ascis, lineari-lanceolatæ, rectæ, muticæ, et de specie primum continuæ, $0^{\mathrm{mm}}, 013$ in longitudinem nanciscuntur itemque $0^{\mathrm{mm}}, 0035$ crassitudine non excedunt.

Endosporas Hypomycetis roselli (Ацв. et Schw.) et aurantii (P Рrs. $_{\text {. }}$ a Friderico Currey adumbratas videre est in Actis Soc. Limn. Londinensis, t. XXII, parte iv (1859), p. 314 , n. 217 et 221 , tab. LVII, fig. 3 et 6 .

His quæ supra, p. 87 et 88 , circa Nectriam Aquifolii (Fr.) et N. Lamyi DNTrs. afferuntur, minime

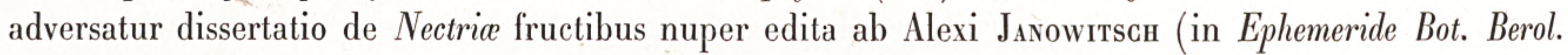
t. XXIII [1865], n. 19 , p. $149-153$, tab. viI), quo judice, corpuscula endosporis mixta ex iisdem progerminantibus nascuntur, nec masculinas vices, præter Sollmanni sententiam, agunt. Nectria Lamyi DNtrs. datur in Rabenhorsti Fungis Europ. exs. fasc. VIII (1865), n. 752.

Notarisius ipse cognovit Cryptodiscum lichenicolam Cess. cujus supra (p. 95) meminimus, societatem genuinorum Cryptodiscorum Corde (Stictidum Pers. et Fr. S. Veget. Scand. p. 373 et 428 ) qui inter Discomycetes jure militant, quasi respuere, contra e grege Pyrenomycetum Hypocreaceorum videri. (Cfr. Commentarios Soc. Cryptog. Itale, fasc. V [1864], p. 365.)

Has inter Nectrias quas varias propter causas in eodem loco supra citavimus, mentionem utique merebatur Nectria hirta Cưresi in Comment. Soc. Limn. Londinensis, t. XXIV, part. alt. (1863), p. 158 , tab. xxv, fig. 24 , utpote stirps endosporis late cylindricis, polymeris et miræ magnitudinis insignita. 
VI.

\section{PHACIDIEI.}


"Infinite considerazioni suggerisce l' attento esame di queste singolari produzioni....."

(G. De Notaris, Prime linee di una nuova disposizione de' Pirenomiceti Isterini, apud Parlatoris Ephem. Bot. Italam, ann. alt. t. II [1847], p. 10.) 


\section{VI.}

\section{PHACIDIEI.}

SCLEROCARPORUM Persooni (Syn. Fung.) pars exigua. = PHACIDIACEI PYRENOMYCETUM Friesianorum (Syst. Myc. t. alt. p. 31 7-319), admissis nonnullis PYRENOMYCETUM genuinorum typis. = PHACIDIACEI et STICTEI ejusdem Friesi in sua Sum. Veget. Scand. p. $36_{7}$ et seq. = HYSTERIACEORUM ordines, primo excluso, Conds, Anleit. z. Stud. d. Myk. p. $142-146 .=$ PYRENOMYCETES HYSTERIACEI Notarisio ap. Parlat. Eph. Bot. Ital. ann. alt. t. II, p. 5 et seq. nec non DISCOMYCETUM genera eidem magistro in Comment. Soc. Cryptog. Italke, fasc. V (1864), p. 357 et seq.

Absoluta Pyrenomycetum expositione, quam multas ob causas nec contractiorem nec perfectiorem promere valuimus, nunc nobis, protinus modicum pergentibus, de tribu altera et quidem nobiliore ascomycetum seu fungorum qui thecis utuntur, agendum est, scilicet, ut cum Friesio loquamur, de Discomycetibus. Hæc classis typorum diversitate Pyrenomycetibus longe præstat proptereaque in greges plurimos meritissime dividitur. Rerum autem creatarum, etiam in minimis, ea series a summo Conditore instituta est quæ simul ac earumdem methodicam ordinationem a physicis postulat, hancce summopere periculosam facit; quippe adeo inter se res illæ connectuntur ut hiatus æogre perspicias, aut commissuras, si quæ sunt, relaxare non audeas. Porro nemini mirandum erit si genera reperiantur quæ Pyrenomycetes cum Discomycetibus ita jungere videantur, ut sub utroque signo pari fere jure militare queant. Istiusmodi sunt fungi Hysterini genuini qui Phacidiaceorum Friesianorum maximan partem constituunt. (Videsis Friesir Sum. Veget. Scandinavia, p. 367-372.) Longius contra a Pyrenomycetibus recedunt Phacidia proprie dicta, licet b. PErsoonius olim arbitratus fuerit Xyloma suum pezizoides quod nunc apud Friesium et discipulos Phacidium coronatum audit, Sphcrias inter et Pezizas ambigere. (Cfr. Persoonir Ic. pict. Fungor. rarior. fasc. III, p. 41.) ${ }^{1}$

Hysteria Persooniana in cohortes duas apud Candollium (Fl. Gall. t. alt. p. 304-307)

\footnotetext{
Cur fungi Hysterini plerique ob naturam duram ac perennantem nec non formam linearem et anguste rimosam quibus insigniri soleant, maximam cum Pyrenomycetibus, minorem vero cum Discomycetibus necessitatem demonstrent; quomodo tamen nonnulli pezizeum typum
}

evidenter imitentur, bene exposuit clariss. DUby in sua Hysterinorum Monographia, p. 7-9, quam adeas in t. XVI (1862) Actorum Soc. Phys. et Hist. nat. Genevensis, p. $15-$ 70 , tab. I et II. 
dispertiuntur quarum prior, sub Hypodermatum titulo, seriem Hypoxylorum illorum claudit quæ fungoidia dicuntur et sementem suam maturo tempore sponte excludere æstimantur; tribus autem altera ex Hysteriis proprie dictis, seu nudis nec hypophlœodibus, compingitur, et Hypoxylis præponitur lichenoiditus, iis scilicet quorum semina, judice Candoluo, suis in natalibus capsellis semper latent aut saltem ignoto v. inconspicuo modo in lucem veniunt. Hypoderma xylomoides Candolli, Hysterium Pinastri Schrad. et Tryblidium quercinum Fr. prius signum sequuntur; alterum autem Lophium mytilinum Fr. quod Hysterium ostraceum Buldiardo est, et Hysterium pulicare Persoonir. Causa hujusmodi distributionis in eo versabatur quod Hypodermata affinitate Sphcerias contingere videbantur, reliqua autem Hysteria potius Opeographas. Nunc tamen omni patet mycologo Lophia et Hysteria sincera, ut Hysterium pulicare modo dictum, propius ad Pyrenomycetes legitimos accedere quam Hysteria loliis aridis vulgo insita quæ Phacidiis manifesto analoga sunt. Inde causam trahere liceat cur nos, dimissis Pyrenomycetibus, Discomycetum agmina nunc aggressuri, prima de typis illis verba faciamus qui cum sphæriaceis fungis majorem demonstrant necessitudinem. Equidem nos non fugit id etiam ex hoc oriri consilio, nimirum seriem nobis insolitam, quippe qui hactenus in libro hoc a dignioribus typis ad humiliores descendere consuevimus. Satius vero duximus affinitates quæ inter mycetum greges his in pagellis juxtapositos et continenter tractatos intercedunt, non abrumpere, transitus et commissuras quas ipsa fecit natura observare, quam inani servire symmetriæ, ubi præsertim nemo non videt methodum Ciandollianam nostram inverso seu Jussiæano ordini vix præstare.

Cæterum annis jam ante duodecim, de Hysterinis fungis, simul atque Discomycetum sinceriorum variam fœcunditatem agitaremus, paucis disseruimus ${ }^{1}$, nec quidem multo plura super eodem argumento hodie afferre nobis conceditur. Etenim ex his temporibus nil novi experimento et disquisitione percepimus circa Tryblidium quercinum Pers. cujus endosporas nigrefieri perperam censebat Candolums (in sua Fl. Gall. t. alt. p. 306 ); nihil etiam de Hysterio Fraxini Pers. quo vulgatior Hyslerographiorum Notarisianorum typus exprimitur ${ }^{2}$. Quod ad Lophodermata Friesiana, scilicet Hyslerium Rubi Pers. et affinia, ut commune ac scirpinum Friesi quæ simul attigimus, spectat, spermogoniis mire conspicuis adeo omnia abundant ut nullum fungorum curiosum sane nunc reperias cui hæc organa nondum innotuerint. Restat autem Hysterium Pinastri Schrad. quod, sicuti jam lectorem monuimus ${ }^{3}$, titulo Aulographi Pinorum Mazer. incaute salutavimus. Ejusdem fusiorem historiunculam hic præstare fortassis expedit.

1 Cfr. Annales nostros Historice naturalis, ser. III, t. XX (1853), p. 154-158, tab. xv, lig. 10-14. ad Hysterium Rulbi Pers. pertinentibus.

${ }^{2}$ Cfr. Parlatoris Ephemeridem Bot. Italam, anno alt. t. II (1847), p. 22. Fungillus a genuinis Hysteriis apud

Dubyum (Monogr. jam laud. p. 29, n. 16) minime removetur.

${ }^{3}$ Videsis hujus Carpologice t. I, p. 224 et 225 (adnot. XIII). 


\section{HYSTERIUM.}

(Tab. XVI, fig. 1-3.)

De HYSTERIO Todeano, sensu latiori sumpto, hic agitur.

\section{Hysteriun Pinastri.}

Hysterium Pinastri Schradero in suo Diario Bot. t. II (1799), p. 69, n. 23 , tab. III, fig. 4, $a$, $b$, tum habitum, tum lirellam auctam exprimentibus. - Pers. Syn. Fung. p. xxviII, n. $15 b$ ( $\alpha$ typicum et $\beta$ limitatum). - Moug. et Nestlero, Stirp. Vog.-Phen. fasc. I (1810), n. 76. - Friesio, Scler. Suecice, fasc. I (1819), n. $30 ;$ Syst. Myc. t. alt. p. 587 , n. 27 , et S. Veg. Scand. p. 368 , n. 22 , utrinque inter Hysteria subtecta. - Grevillio, Fl. Crypt. Scotice, t. I (1823), tab. Lx, quæ fungillum in foliis Pini sylvestris crescentem repræsentat, sed sporis exiguis et ovatis eum donari (sicut et analogum Hysterium Pinastri $\beta$ Juniperinum $\mathrm{F}_{\mathbf{R}}$. sive Hyst. Juniperi Grevillio, op. cit. t. I, tab. xxvi, et in sua Fl. Edin. [1824], p. $36_{7}$, n. 6 ) imprudenter prætendit. - MAzerıo, Stirp. Crypt. Gall. ed. I, fasc. II (1825), n. 84, saltem pro parte. - Berkelé, Outl. of Brit. Fung. p. 380 .

Hy poderama Pinastri Candollio, Fl. Gall. t. II, p. 305 , n. 823.

Lophodermidm Pinastri Cavalerio, Fl. agri Par. t. I. p. 436 , n. 4. - Notarisio, in Parlat. Ephem. Bot. Itala, anno alt. t. Il (1847), p. 45.

Aulographum Pinorum Tul. in Ann. Sc. nat. ser. ill, t. XX (1853), p. 157 et 158 ; minime autem Libertik et Mazerio, sicut jam id monitum fecimus in tomo I hujus Carpologice, p. 224 et 225 ; neque etiam Dubro in sua dissertatione, infra citata, de Hysteriis et confamiliaribus, p. 37 , ubi errore nostro ipse deceptus nos perperam citat.

Lophoderma Pinastri Dubyo, in sua Hysterinorum Monogr. p. 46, n. 7 (apud Acta Soc. Phys. et Hist. nat. Genevensis, t. XVI [1862], p. 58).

Folia Pinus sylvestris L. arida cum aliquandiu humi jacuerunt, magis ac magis pallescunt et annulis nigris hinc inde tandem signantur. Nota hujusmodi cognoscitur Hysterium Pinastri Schr. cujus fructus ex utraque folii pagina parce et sine lege mox sparguntur. Horum fructuum color communis fusco-nigricans, imo niger est, natura autem duplex; alii enim spermatia, alii endosporas edunt. Utrumque genus sub epidermide dura et nigrefacta nascitur, formam lineari-ovatam aut sublanceolatam obtinet, folio ipsi parallelum protrahitur et rima media debito tempore longitrorsum dehiscit. Spermogonia angusta simul et brevissima vulgo deprehenduntur, punctula quandoque mentiuntur, et spermatia vomunt exiliter filiformia, recta, continua, utrinque truncata, $0^{\mathrm{mm}}, 0065$ circiter longa, nec $0^{\mathrm{mm}}, 001$ crassiora. Lirelle seu fructus digniores millimetrum longitudine non excedunt; maturæ, cœlo pluvio favente, ore hiant late ovato cujus margines obtusi durique maxime ex epidermide folii materni, nigrefacta et commutata, constant. Reliqua lirellæ pars seu medulla, tota carnoso-pulposa, pallida, imo subachroa, acus ope industriaque manu e nidulo suo integra detrahi potest. Tнеск lineari-oblongæ, acutiusculæ et deorsum attenuatæ, $0^{\mathrm{mm}}, 11-13$ 
in longitudinem nanciscuntur, æquali autem diametro $0^{\mathrm{mm}}$, o 13 non superant. Spore octonæ in singulis ascis fasciculatæ generantur, longe et exiliter filiformes atque continuæ sunt et hinc, superne scilicet, in clavulam incrassantur, illinc contra tenuissime attenuantur; cum maturuerunt $\mathrm{o}^{\mathrm{mm}}, \mathrm{o}_{9} 5-11$ in longitudinem æquant, $\mathrm{o}^{\mathrm{mm}}, 0025-$ oo35 crassitudine non excedunt, mucoque achroo, maxime in vertice, indutæ reperiuntur. Paвaphyses filiformes, clavatæ, simplices et pallidæ inter thecas inseruntur, aliquando tamen paucissimæ sunt et desiderari videntur.

Viget potissimum hiberno tempore soletque vere maturescere. In pinetis sylvulæ boloniensis, Parisiis suburbanæ, olim quotannis abundabat.

Ubi asci maturi ex hypothecio solvuntur, sporæ confestim retrorsum exeunt, simul cum reliquo plasmate in quo informatæ sunt. Mucus quo hæc fila teguntur in eorum vertice incrassato ipse crassior est et globulum v. capitulum ibidem constituit.

\section{EXPLICATIO ICONUM}

(Tab. XVI, fig. 1-3.)

1. Folia gemina Pinus sylvestris L. utrinque rupta auctaque, hoc modo proponuntur ut Hysterii Pinastri Schrad. fructus bifarii et maculæ ex mycelio intestino transversim lineares simul in conspectum veniant; e conceptaculis ascophoris alia novissime nata integra sunt, alia adulta anguste aut latius dehiscunt; spermogonia minima modice protuberant et a peritheciis recentissimis ægre distinguuntur.

2. Spermatia exclusa seorsim et valde aucta delineantur.

3. Theca gravida, theca rupta partim evacuata et sporæ liberæ vices circiter cccluxx pariter amplificatæ dantur.

Hæ figuræ anno MDCCCLIII delineatæ sunt juxta fungos illos e sylvula boloniensi agri parisiensis quos attigimus in Annalib. Sc. natur. ser. III, t. XX, p. 157 et 158 , sub falso titulo Aulographi Pinorum Lis.

Hysteria illa, præ cæteris congeneribus fungis, spermogoniis mirum in modum superbiunt quæ Hysterio Rubi Pers. cujus historiunculam et adumbrationem in Annalibus Historia naturalis, loco supra citato, scilicet ser. III, t. XX (1853), p. 155-157, tab. xv, fig. 10-14, olim præstitimus ${ }^{1}$, analoga sunt et in foliis aridis potissimum vigent, ut Hysterium folïcolum $\mathrm{Fr}$. seu Hypoderma xylomoides Candoldir, in Oxyacantha et Berberide sæpius obvium, Hysterium Hederce Martir et Conde (Hypodermatis species Notarisio), Hyst. maculare Friesis, quale saltem in foliis Vaccinii uliginosi Vogesorum provenit ${ }^{2}$, ac bene multa alia quæ proprio nomine singulatim salutare longius deduceret ${ }^{3}$. Liquet præterea eadem Hysteriorum genera

Ex iconibus nostris hic citatis patet endosporas Lophodermatum sinceriorum, præter Friesil sententiam (in sua S.Veg. Scand.p. 371, expromptam), minime esse filiformes; saltem lanceolato-oblongæ occurrunt, tum in Hysterio Rubi Pers. tum in Hyst. Hederce Mart. (Cfr. Mazeri Stirp. Crypt. Gallice, ser. noviss. fasc. IV, n. 172-180.) Ideo qua de re peccat etiam, Notirisio jam monente, adumbratio Grevilliana in Flora Cryptog. Scotice, t. III, tab. cxxix, fig. 1, præstita; et cum vero magis quadrat icon Cordæana quam videas in Iconib. Fungorum magistri Pragensis, tom. V, p. 76 , n. 4, tab. Ix, fig. 57 (Hysterium Hederce Mart. exprimentibus).

${ }^{2}$ Cfr. Mougeoti Stirp. Crypt. Vog.--Rhen. fasc. XI (1840), n. $107^{2}$.

${ }^{3}$ Plura ex his videre licet apud Mazerium (Stirp. Crypt. Gallice, ser. noviss. fasc. IV), simul cum Hypodermate $x y$ lomoide CAnd. et Hypodermate Hederce DN Trs. Spermogonia horum fungorum pro typo sui generis, nimirum pro Lep- 
ad Phacidia, mediante Phacidio trigono Sснмгтті, manifeste transire, ita quidem ut Phacidia bilabiata dici queant. Id autem monitum velimus, nimirum spermogonia perquam legitima Hysteriis quæ in corticibus crassioribus stirpium lignosarum oriri solent, minime denegari, nosque propterea non posse non mirari quod cl. Duвr, fungillorum nostrorum historiographus, his organis (quæ cæterum parvi facit quia ob nimiam ex omni parte similitudinem, ea ad methodicam Hysterinorum distributionem non multum valere decernit ${ }^{1}$ ) adeo non attenderit, ut in solo Hysterio agorregato DC. illorum peculiariter meminisse voluerit. Attamen in quolibet fere Hysteriorum typo, ne dicamus exemplo, spermogonia attentis oculis si quæsieris, sæpius ea copiosa parciorave adesse comperies. Apud Hysteria genuina ut Hyst. pulicare Persoonir, sive formam ejus humilem et vulgatiorem, sive exempla exstantia s. cuneiformia quæ in Dubyana Monographia titulo Ostreichnii europee signantur ${ }^{2}$, scrutari velis, spermogoniorum vices agunt tubercula globosa, minima, discreta, sessilia, aterrima, ex eodem duroque parenchymate atque lirellæ quibus commiscentur; cavilate simplici et angusta confodiuntur, et spermatiis innumeris, globosis aut nonnihil ovatis, vix $0^{\mathrm{mm}}, 001$ crassioribus, pallidis mucoque achroo immersis replentur ${ }^{3}$. Hæc autem corpuscula e sterigmatibus filiformibus et brevissimis nascuntur quibus conceptaculorum interni parietes vestiuntur. Spermatia vix dissimilia observantur in Hysterio curvato Fr. (Duв. Monogr. p. 30, n. 21) cujus fructus dense conferti et implexi tomento fulvo aut saltem crusta nigrescente imponuntur.

\section{RHYTISMA.}

(Tab. XV et XVI.)

\footnotetext{
* Fungus spermatiophorus :
}

MELASMIARUM genus Leveilleo, in Annalib. Sc. nat. ser. III, t. V (1846), p. 276 , in numero Cytisporeorum habitum, et tom. IX (1848), p. ${ }_{2} 52$, inter Clinosporeos endoclines collocatum. = CRYPTOSPORIA epiphylla Friesio, S. Veget. Scand. p. 423 et 424, inter Pyrenomycetes phyllosticteos.

** Fungus asciger, perfectus :

MUCORUM species Buldardo, XYlomatum Persoonio et Candoluio; PlaCuntia Ehrenbergio (Sylv.

tostromate vulgari $\mathrm{F}_{\mathrm{R}}$. et potissime pro forma ejus peculiari, orbiculata dicta, MAzErius incautus habuit. (Cfr. ejus Stirp. Crypt. Gall. ed. 1, fasc. XX, n. $99^{8}$, et ed. alt. fasc. VI, n. 298 , scilicet utrinque Hysterium commune Fr. in Solidagine Virga-aurea crescens.) Mazeri autem amicus devotissimus, Robergius oculatissimus, punctula Leptostromatis in perithecia hysterina tandem augeri existimabat, quod prior vehementer infiliabatur, nunquam enim ausus arbitrari duplex seminum genus eidem fungo, pro varia ætate, aliquando impertiri. (Cfr. mycothecam Mazerianam nunc in Musæo Bot. par. depositam.)

${ }^{1}$ Conferas laudati auctoris dissertationem s. monographiam jam citatam, p. 15 , in nota.

2 Vir bene oculatus semel et accuratissimus naturæ funginæ investigator, clar. G. Оттн, bernensis, monet etiam tum in schedula sua Lxiv quam legere est in herbario Mu- sæi parisiensis, tum in collectaneis inscriptis Mittheilungen der naturforschenden Gesellschaft in Bern, n. 531-552 (1863), p. 75 , n. 48, seipsum vera discrimina percipere non potuisse Hysterium pulicare $\mathrm{P}_{\text {ERs. inter et Ostreichnion }}$ europeum Duв. Prioris adumbrationem in Corne Introd. ad art. mycologicam, pag. хсI, tab. F, n. 59, fig. 5-8, sub IIysterographii titulo præstitam, cum vero congruere autopsi comperimus.

${ }^{3}$ Contra clar. E. Coemans, gandavensis, spermatia vidit in Hysterio pulicari Pers. cylindrica, recta, $\mathrm{o}^{\mathrm{mm}}, 002-003$ longa, $o^{\mathrm{mm}}, 001$ circiter crassa et sæpe in medio quasi angustata; vix dissimilia etiam reperit in Hysterio Prostii Dов. Nosne propterea duplex acrosporarum minimarum genus Hysteriis impertitum fuisse æstimemus? (Cfr. collectanea quæ inscribuntur Bulletins de l'Acad. roy. de Belgique, ser. alt. t. V [1858], n. 12.) 
Myc. Berol. p. 17 et 29 , n. $\left.47^{\mathrm{a}}\right)$; POLYSTIGMATUM species Wallrothio et Rabenhorstio; RHYTISMATUM genus Friesio et discipulis ejus; MELANOSORI Notarisio.

Sтroma intestinum, tandem crassum, carnoso-suberinum seu sclerotieum. ConcEPTAGUla nudispora, pycnidea scilicet et spermatiophora, exigua, orbiculari-depressa vel obtuse conoidea, sementiculam debito tempore in cirros nitide cereolos per porum terminalem ejiciunt. Spermatia brevissima, recta aut quadantenus incurvata; alia sinceriora exiliter filiformia; alia crassiora lineari-oblonga. Microstylosporæ præterea ovato-globosæ aliquando occurrunt. Fructus ascophori lirellas lineares vel oblongas, discos placentasve referunt, velum atrum seu corticulum crassum et varie dehiscentem maturi exuunt, hymeniumque pallidum ac molle nudum ostendunt. Theсж obovato-lineares et octosporæ paraphysibus filiformibus, simplicibus et clavatis stipantur. Endospore lineari-lanceolatæ et flexuosæ vel late ovatæ, utrinque obtusissimæ rectæque deprehenduntur.

RhYtismata fungi sunt vere entophyti, folïs aut cortici quarumdam arborum nostratium infesta se habent myceliique latitantis ope in ïsdem matricibus diutissime perennare solent.

Minime nos fugit quam multis notis Rhytisma maximum Fr. infra descriptum (p. 122) a cæteris congeneribus recedat; attamen, brevitatis causa, Grevillianum titulum quem obtinuit, Friesiano antiquiori prorsus æquare noluimus; fortassis enim satis est ut hoc gregis nostri membrum, peculiariter utique discrepans, indito cognomine distinctum signemus.

* Endosporis filiformibus s. linearibus. - Eurhytismata (Xylomata Rhytismatum Friesio; Melanosori Notarisio).

\section{Rhytisma acerinum.}

* Fungus spermatiophorus :

Melasmia agerina Leveilleo, in Ann. Sc. nat. ser. III, t. V (1846), p. 276 , n. 382, et t. IX (1848), p. 252 , nec non apud Mougeotum, Stirp. Vog.-Rhen. fasc. XV (1860), n. $1470 .-$ Melasmia autem acerina Lev. præter Friesir sententiam, minime est Leplothyrium acerinum nec Corde, Icon. Fung. t. II, p. 25 , n. 2 , tab. xII, fig. 92, nec Friesio ipsi (in sua Sum. Veget. Scand. p. 423 et 424), quo judice, hoc Leptothyrium habitu Discosiam imitari, charactere autem ad Cryptosporia epiphylla seu Leptothyria Mazeriana pertinere videtur.

Huc etiam sane potissimum spectant:

Xyloma punctatum Pers. Obs. Mycol. parte alt. p. 100, n. $152 ;$ Syn. Fungor. p. 104, n. 4. - Alb. et Schw. Consp. Fung. Lusatice, p. 63 , n. 175 . - Candollio, Fl. Gall. t. II, p. 303 , n. 817, et t. VI, p. 155 , nec non in Comment. Musaei par. t. III $(1817)$, p. 321, n. 15 , tab. III, fig. 4 b, ubique inter Micromata. - 
Moug. et Nestr. Stirp. Vog.-Rhen. fase. V (1815), n. 477 (in foliis Pseudoplatani). - Letellier, Fungor. tab. DCXXIX, fig. 1.

Rhytisma punctatum Kretschiario apud Rabenh. Herb. Mycol. ed. alt. fasc. VIII (1858), n. 740 (in foliis Aceris campestris $\mathrm{L}$.$) .$

Xyloma (Spiloma) Pseddoplatani Candollio, in Actis Musci Hist. nat. paris. t. III, supra citato, p. 318 , n. 2 , tab. III, fig. 4 a, et sua Fl. Gall. t. VI, p. 152, n. $815^{\text {a }}$.

** Fungus aut immaturus et sclerotieus, aut absolutus et thecaphorus :

Mucor grandlosus Bulliardo, F. Gall. t. I, p. 109 , tab. div, fig. 13

Xyloma acerinum Persoonio, Dispos. meth. Fungor. (1797), p. 5; Syn. Fung. p. 104, n. 3. - Candollio, in Actis supra cit. Mus. par. t. III, p. 318 , n. 1 (in Spilomatum superiore loco), tab. III, fig. 9, et Fl. Gall. t. II, p. $30_{2}$, n. 815. - Moug. et Nestr. Stirp. Vog..-Rhen. fasc. l (1810), n. 77. - Neesio, Syst. der Pilze, p. 25 , n. 2 , tab. II, fig. 21. - Grevillio, Fl. Crypt. Scotice, t. II, tab. cxvir, fig. superioribus, tum Xylomatis acerini genuini, tum umbonati figuram exprimentibus, sed quod ad endosporas attinet minime fidis.

Xyloma acerinum a Alb. et Schw. loco sup. cit. n. 174.

Placuntidm acerinum Ehrenb. Sylv. Myc. Berol. (1818), p. 17, ubi animadvertit auctor se nondum comperisse quibus characteribus Plac. punctatum (Pers.) et Plac. Pseudoplatıni ( $\mathrm{C}_{\mathrm{And}}$.) ab acerino discriminari queant.

Rhytisma agerinum Friesio, Scler. Suec. fasc. IV (1820), n. 207 ; Syst. Myc. t. II, p. 569, n. 14. - Letellier, Fungor. tab. dcxxix, fig. 2. - Mazerio, Stirp. Crypt. Gall. ed. I, fasc. XV (1834), n. 725 (æstate lectum est nec nisi spermatiferum datur), ed. alt. fasc. IX (1840), n. 420 (speciminib. item imperfectis), et serie novissima, fasc. XIV (1859), n. 698 (exemplis aliis recentibus, aliis e contrario adultis et ascophoris). - Corde, Anleit. z. Stud. der Mykol. p. xcII, tab. F, n. 59, fig. 22-24 a, circa endosporas quæ ovatæ describuntur minime fidis. - B Buio, Syst. Fung. parte alt. (1858), p. 57 et 89 , tab. xviII, figuris ex Grevilito sumptis, nec melioratis; et apud Rabenhorsti Herb. Mycol. ed. alt. fasc. II (1855), n. 160 (in foliis Pseudoplatani, spermatigerum), et fasc. VI $(1857)$, n. $57_{2}$ (in foliis iisdem, verno autem tempore et maturum s. ascophorum lectum).

Melanosorus acerinus Notarisio, in Parlatoris Ephem. Bot. Itula, ann. alt. t. II, p. 50.

Suв ipsa folii acerini pedetentim pallescentis et arescentis cuticula atrata fungillus gregatim nascitur, epidermidis utriculos potissime exedere videtur totque maculas nigras, orbiculares, minimas s. punctiformes et discretas primum efficit quot spermogonia gignit. Hæcсе obtusissime protuberant, pulvinulum deplanatum referunt et dimidiam folii materni crassitudinem vix æquant. Intrinsecus columellam mediam solidam sæpius ostendunt, imusque eorum paries sterigmatibus horret exilissimis, stipatissime erectis, subsimplicibus nec sæpius $0^{\mathrm{mm}}$, o $_{5} 5$ longioribus. Spenmatia filiformia, teretia, recta aut quadantenus incurvata, continua et utrinque truncatula, $\mathrm{o}^{\mathrm{mm}}, 0065$ longitudine vulgo non superant, interdumque hine nonnihil crassiora sunt ac quidem subcapitata; ubi eructantur, quoddam ceræ aureæ genus fingunt, conceptaculi faciem, maxime in spiraculi ambitu, illinunt et arescendo nitent; subinde crustula ex iis glutinatis acus ope detrahi potest. Spermogonia quandoque in singulis folii maculati areolis exiguis discreta manent aut stromate intermedio passim duntaxat alia cum aliis connectuntur, et exinde oritur ea fungilli species quæ Xyloma punctatum Persoonso dicta est. Neque etiam raro accidit ut simillima species e stromatis ipsius parca sterilique distributione proveniat. Sæpius vero area pulla cui spermogonia insperguntur, mycelio seu stromate conspicuo tota intrinsecus tenetur et in cuticula nigrescit, licet tamen tenuis consistat, spermo- 
goniorum vestigiis diu superstitibus. Interea folium circumcirca pariter nigrefactum mire tumet, stroma enim funginum paulatim peculiariter incrassatum fovet. LireLLe ascophoræ, lineares, ovatæ aut rarius exigue disciformes, in hoc subiculo sclerotieo, sub cuticula nigerrima, absque ordine certo generantur et vere primo maturescunt. Tunc temporis corticulus unicuique lirellæ impositus, medius dehiscit et hymenium revelat cinerei coloris ex quo endosporæ ut fumus avolant. Id corticuli e duabus constat membranis atris et coalitis quæ tamen mediam fovent ceram citrino-virentem, copiosam, ex innumeris corpusculis aqua affusa mire trepidantibus. THeсє obovato-lanceolatæ, octosporæ et paraphysibus filiformibus ac simplicibus stipatæ, stratum struunt $0^{\mathrm{mm}}, 13$ circiter crassum et ad Phacidium coronatum Fr. infra descriptum (p. 134) memoriam observatoris revocant. Endospore filiformi-lanceolatæ, flexuosæ, imo interdum partim circinatæ, continuæ et in singulis ascis fasciculatæ, $0^{\mathrm{mm}}, 08$ in longitudinem nanciscuntur, crassitudine autem $0^{\mathrm{nm}}, 0035$ vix æquant. Inter germinandum non manifeste augentur nec septa concipiunt; germina sæpius e medio semine oriuntur, variis modis et quandoque in circinum flectuntur, moxque in clavulam crassescunt.

Oritur frequens æstate media in foliis vivis Aceris Pseudoplatani et platanoidis L. quæ maculis a longe conspicuis inficit; non autem perficitur nisi vere primo anni subsequentis, in iisdem foliis humi jacentibus et pæne destructis. In agro parisino et versaliensi quotquot annis abundat.

CandoluI verba quæ sequuntur cirros e spermatiis seu melasmieos, manifeste designant; e des taches " noires, arrondies, irrégulières, très-minces (du champignon), $\ldots$ on voit sortir çà et là une matière “jaunâtre assez compacte, disposée en filaments courts et crépus, analogues à ceux des Némaspores." (Vid. Candoliin Fl. Gall. t. II, p. 302 et 3 o3.)

Fungi « superficiem in labia flexuosa dehiscentem" jam observaverat Persoonius cujus conferas Syn. meth. Fungorum, loco sup. citato.

\section{ICONUM INTERPRETATIO.}

(Tab. XV, fig. 9-12.)

9. Portiuncula amplificata folii Aceris Pseudoplatani L. quæ medio augusto (anno MDCCCL), propter innatum Rhytisma acerinum $F_{R}$. nigro fucatur colore et plura gerit conceptacula, recens nata et discreta, ita ut tum Melasmiam acerinam Lev. tum quoque formam illam fungilli nostri repræsentet quæ Rhytisma punctatum bene multis dicta est. Conceptacula omnia naturam spermogoniorum sortita sunt et cirros ex spermatiis glutinatis pleraque excludunt.

10. Spermogonia a vertice, cum folio supposito, dissecta (extremo augusto a. MDCCCLII) proponuntur; spermatia circa nucleum solidum s. columellam mediam exeunt et cirros aut pultem constituunt.

11. Particula tenuissima ex spermogonio dimidiato (eodem supra dicto tempore) sumpta et summopere amplificata; columella opaca, sterigmatum sylva densissima, et spermatia acervata sparsave, sub velo epidermideo soluto et forato, simul in conspectum veniunt. 
12. Endosporæ quæ maio mense (anno MDCGCLI) maturæ recentesque satæ sunt, et germina suis e lateribus ediderunt; vicibus circiter GCCLXxx justo crassiores exprimuntur.

Fungi vivi, ex agro parisiensi, has omnes figuras præstiterunt.

\section{Rhytisita salicinum.}

* Fungi spermogonium pycnisve :

Melasmia saligina Leveilleo in Herb. b. Mérat, botanogographi parisini (e thesauris Musæi Bot. par.).

** Fungus perfectior, paucissimis autem scriptoribus rite notus, plerisque enim nonnisi sclerotieus et sterilis obvius :

Xyloma Salicindm Persoonio, Disp. meth. Fung. p. 5, supra, et p. 46, tab. II, fig. 4, fungum maturum et reticulatim dehiscentem monstrante; Syn. meth. Fung. p. 103, n. 1. - A A s. et Schw. Consp. F. Lusatice sup. p. 62 , n. $172 .-\mathrm{N}_{\mathrm{Ees}}$, Syst. Fung. p. 25 , tab. II, fig. $20 .-\mathrm{G}_{\mathrm{RevilLio}}$, Fl. Crypt. Scotice, t. II,
tab. cXviII, fig. inferioribus.

Xyloma levcogreas $\alpha$ et $\beta$ Candollio, in Actis Musci par. t. III (1817), p. $33_{9}$, n. 9, tab. ili, fig. 5 ; Fl. Gall. t. II, p. 303 , et t. VI, p. 154 , utrinque sub n. 816 . - Moug. et Nestlero, Stirp. Vog.-Rhen. Casc. II (1811), n. 175 .

Rhytis.ia Salicinum Friesio, Scler. Suec. fasc. IV (1820), n. 208 ; Syst. Myc. t. II, p. 568, n. 12. - Mazerio, Stirp. Crypt. Gall. ed. I, fasc. XV (1834), n. 724 , et ed. alterius fasc. IX, n. 419 ; immatura autem specimina, autumno lecta, saltem apud exemplaria quod penes nos sunt, utrinque dantur.

Rhytis.a salicinum (Pers.) Rabenh. Herb. Myc. ed. alt. fasc. II (1855), n. 159, immaturum.

Rhytisma umbonatum (Hoppe) Mazerio (Stirp. mod. cit. ed. I, fasc. XXXV [1848], n. 1736 , et ed. alt. fasc. XXVII, n. 1336 ) et Telderio (Fungor. tab. DCXxix, fig. 3), item salicinum, neutiquam a salicino genuino discrepat; sed immaturum quoque magistro insulensi tantum innotuerit ${ }^{1}$.

Incipit fungus puncto perexiguo et pallescente, mox autem majori, fusco pedetentimque nigrescente, colore eccentrum juxta modum progrediente. Macula fungina millimetrum diametro nondum excessit, jamque umbonem medium obtusum et atrum profert. Obsessa folii nutricis penetralia tota pulla fiunt quasi aruerint, epidermis vero potissime nigrescit, nonnihil incrassatur et in funginum tegumentum mutatur. Porro dimidiatum hunc ipsum intra corticulum capsella informatur cui prædictus umbo debetur; peridii istius primogeniti demensio solennis $0^{\mathrm{mm}}, 13-16$ in latitudinem est, imusque paries sterigmatibus exilissimis, dense ramosis et stricte cæspitosis nec $0^{\mathrm{mm}}, 0_{1} 6-0_{2} 3$ altioribus vestitur, cæteris lateribus levibus et nudis. E sterigmatibus nascuntur spermatia lineari-cylindrica, exilia, utrinque obtusa, recta curvulave, continua, $0^{\mathrm{mm}}, 005$ oo 6 longa et pallida quæ adglutinata porus inconspicuus tempore stato excludit. Sunt etiam maculæ quibus spermogonium præter centrale, capsella altera aut una et altera

1 Xyloma umbonatum dicitur in SchweInıtzir Fungis Niskiensibus, p. 62 , n. $17_{2} ;$ Xyloma salicinum $\beta$ in W WHLENBergir Flora Lapp. (1812), p. 524, n. 1015 ; Rhytisma autem umbonatum apud Rabenhorstium, Fl. Crypt. Germanice, p. 162 , n. 1471 . 
pari modo spermatophoræ, discretæ aut juxtapositæ insistunt. His editis fructibus, maculæ aliæ arescere videntur, aliæ in stroma crassum sed exigui diametri convertuntur atque Xyloma umbonatum WaLroтнго et aliis scriptoribus constituunt; aliæ denique circum circa expanduntur et prioribus longe ampliores fiunt. Tunc etiam in hisce sequentia contingunt. Fungi cortex ater late sed modice in ambitu spermogonii intumescit, simulque deduplicatus in capsulam planam formatur, poro minimo unico vel pluribus dehiscit et pultem albidam aut roseolam ex microstylosporis eructat. Fundus enim istius capsulæ deplanato-colliculosæ sterigmatibus filiformibus, rigide erectis, simplicibus, stipatissimis, $\mathrm{o}^{\mathrm{mm}}, 0_{1} 6-026$ altis et vix $\mathrm{o}^{\mathrm{mm}}, 0_{0} 3$ crassioribus, ut strato albido et semipellucido integer vestitur. Microstylospore ex summis istis suffulcris solitariæ pronasci sæpius videntur; ovato-globosæ, simplices et pellucidæ sunt atque hinc $0^{\mathrm{mm}}, 0035$ et illinc $0^{\mathrm{mm}}, 0015-0025$ æquant. Id pycnidis quantumcumque pateat, partem tantummodo maculæ funginæ, eamque vulgo mediam occupat; reliqua nota ex solo etiam cortice atro, solido autem nec lacunoso, primum constat; subinde vero ubique fere huic tegmini substernitur parenchyma sclerotieum, niveum, quod initio tenuissimum et in antica folii pagina solummodo obvium, postea valde crassescit et sub utraque folii pellicula generatur. Ea est stromatis origo; hocce tamen nonnisi in folio delapso humique jacente, extremo autumno currenteque hieme perfici videtur; vere facto millimetrum aut sesquimillimetrum crassitudine adeptum est, totum suberinocarnosum reperitur, intus albidum est et in utroque cortice aterrimum; cæterum folio emaciato incluso et decimam millimetri partem crassitudine vix superanti transversarie dimidiatur. Hymenum ascophorum sub cortice paginæ superæ decedente hieme informatur; e strato sordide albido, nonnihil luteolo, levi et $\mathrm{o}^{\mathrm{mm}}, 3$ circiter crasso constat, nuncque stroma integrum vestit, nunc eidem medio parcit et nihilominus in orbem extenditur; interdum etiam insulæ steriles duo vel tres in eodem stromate discretæ observantur et quidquam corticis retinent. Corticeum velum quo hymenium tegitur debito tempore rimis dehiscit ejusque laciniæ inæquales et dentiformes jove pluvio circumstant, arido contra iterum disco fertili incumbunt; harum laciniarum numerus maxime varius, in discis minoribus millim. II-III diametro æquantibus trinæ aut senæ occurrunt, in aliis duplo majoribus senæ-denæ. THEG lineari-clavatæ, acutiusculæ deorsumque longe attenuatæ, paraphysibus nonnihil longioribus, simplicibus, filiformibus, flexuosis, continuis, superneque anguste clavatis ac quasi solidis abunde stipantur et endosporas vir fasciculatas singulæ fovent. Spore aliæ exiliter filiformes, aliæ nonnihil lanceolatæ, continuæ, albidæ, rectæ aut quadantenus curvatæ, hinc obtusæ et brevissime uncinatæ, illinc rectæ et acutatæ, $0^{\mathrm{mm}}, 1$ circiter longæ et $0^{\mathrm{mm}}, 004$ vix crassæ, quasi fumus avolant, sicut fungis pezizeis assuetum est, et pulvisculum albidum in vitro caute opposito sistunt. Satæ paulo crassiores fiunt sed continuæ persistunt et germinis speciem ex ventre vel latere submedio agunt quæ exilissima sta- 
timque, ut videtur, contorta, in glebulam vel massulam breviter obovatam aut irregularem accrescendo contrahitur.

Oritur in pagina antica foliorum vegetorum Salicis caprea L. et cum æstate adparet; julio currente, læte spermatiferus simul et acrosporus reperitur, ascophorus autem nonnisi post hiemem elapsam, ab aprili mense ineunte in maium usque extremum; sæpissime vere primo aridus humi jacet, tuncque humefactus intra paucos dies perficitur. Fungus exoletus, endosporis dimissis, insectis aut cochleis vulgo devoratur; ejus autem reliquiæ æstate extrema etiam reperiuntur.

Hymenium in postica folii matricis pagina, licet fungi stroma et in illa tumere soleat, nunquam generatum vidimus. Ejusdem strati fructiferi ne vestigium quidem extremo adest octobri, quum Salices folia sua jam cœperunt demittere. Stroma autem tunc temporis totam prope suam crassitudinem adeptum fuisse diceres; e parenchymate niveo ac sclerotieo fabricatur et utrinque cortice hærenti, atro crassoque tegitur. Endosporæ nondum perfectæ simul in spiram contortæ quandoque videntur. Fungus in ampulla vitrea conclusus, discos suos si maturuerit et aperuerit, adversos ejusdem parietes endosporis projectis obnubilat; ubi in aerem adducitur, fumum ex iisdem copiosum, Pezizarum more, eructat '.

Fungus verno tempore ascophorus, perfectus et dehiscens, Persoonio jam innotuerat ${ }^{2}$; Caxdolli autem et Grevilui oculos effugerat. (Cfr. Fl. Gall. t. II, p. 3o3, et Fl. Crypt. Scotica, I. sup. cit.)

\section{EXPLICATIO ICONUM.}

(Tab. XV, fig. 13-22.)

13. Folium Salicis caprea L. vivum et Rhytismate salicino Fr. æstate media maculatum, nativa magnitudine exprimitur; maculæ maxime inæquales sunt, minores pleræque spermogonia fovent.

14. Fasciola ex folio maculato, dissecto (julio abeunte a. MDCCCLXIV), conceptacula duo spermatiophora quæ in ipsa hospitis epidermide dimidiata nidulantur ostendit.

15. Sterigmata et spermatia insita, accedentibus spermatiis solulis.

16. Tæniola ex dissecto stromate quod eodem æstivo tempore longe lateque patebat nec nisi microstylosporas tunc temporis edere valuerat; seminula hæc, rupto stromatis atro corticulo, effunduntur.

17. Sterigmata et microstylosporæ valde amplificata.

18. Stromata ascophora quæ exeunte aprili (anno MDCCCLXIII) matura dehiscunt et fumum avolantem ex endosporis exclusis vomunt.

19 et 20 . Stromata istius modi crassissima a vertice dimidiantur; cupulas ascophoras geminas singula gerunt; folii nutritii residua emaciata niveam stromatum substantiam quasi per medium inclusa dividunt.

\footnotetext{
"De Xylomate salicino observavi, ait Persoonius, illud "tempore vernali nec non pluvioso semina tali modo elasrtice protrudere qualis Pezizarum mos est. " (Cfr. laudati magistri Disp. meth. Fungorum, p. 5.) Fungillum vivum "per rimas corticis in scuta irregularia rupti copiose fu«mantem» semel, maio pluvio, deprehenderunt ALbErtini et Schweinitz. (Conf. eorum Consp. F. Lusatice, p. 62 , n. 172.$)$

«Ut plurimum clausum quidem occurrit (Xyloma sa111.
}

«licinum), sed specimina vernali tempore a me collecta "vidi... quæ superne in particulas scutis testudinis simirles rumpuntur, e quibus fissuris pulvis seminalis, fumi "ad instar, avolat. (Pers. Syn. Fung. p. 103.) Fungo destructo, cochleis vorato, superest area atra rugosaque, nimirum, ut videtur, «macula n illa « opaca, cinereo-nigrescens et asperulan cujus apud $\mathrm{W}_{\text {allzothium }}(F l$. Crypt. Germ. parte alt. p. 412, n. 2300$)$ mentio est. 
21. Stroma alterum pariter dissectum, ex iis est quæ discum ascophorum unicum, nucleo medio sterili onustum exhibent; suprema hujus nuclei seu conuli truncati pagina hymenium nudisporum olim fovebat.

22. Thecæ gravidæ et dispares paraphysibus clavatis stipantur; endosporæ nondum perfectæ aut abortivæ et peculiari modo contortæ in asco minori continentur; a dextra accedunt tum endosporæ perfectæ et maturæ, tum endospora quædam immatura cui plasma inest interruptum.

Icones omnes adumbratæ sunt juxta fungos vivos ex agro rarisiensi; fig. 18 nativis demensionibus quadruplo major facta est; fig. 19-21 easdem decuplas exhibent; fig. 14 et 16 bis decemplicantur; denique fig. 15,17 et 22 vices circa ccclxxx justam mensuram superant.

** Endosporis late ovatis. - CRyptomycetes Grevilliani.

\section{Rhytisua maximum.}

Rhytisma maximum Friesio, Sclerom. Suec. fasc. VII (1822), n. 250 ; Syst. Myc. t. II, p. 566, n. 3, inter Rhytismata erumpentia. - Berkelexo, Outl. of Brit. Fung. p. 379, ubi citatur Sowerber tab. ccclvi quæ Sphcriam auream Sow. salicicolam, cum fungillo nostro non prorsus congruentem, exprimit ${ }^{1}$.

Cryptomyces $W_{\text {adchi }}$ Greviluio, in sua Flora crypt. Scotice, t. IV, tab. ccvi. - Berk. in Smithin Fl. Brit. t. V, p. 214 , n. 1. - Corde, Anleit. z. Stud. d. Mykol. p. xarv, tab. F, n. 61, fig. 6-11 (fungo inter Pyronemeos collocato [ibid. p. 191]).

Xyloma Cigatrix Wallrothio, Compend. Fl. Crypt. Germ. t. alt. p. 412, n. 2301, in numero Hymenomycetum.

Polystigma Gicatrix Rabenhorstio, in sua Flora Cryptog. Germanice, t. I, p. 167, n. 1508 , inter Sphceriaceos genuinos.

Is cortice vivæ Salicis anguste maculato, sed ad lignum usque tabefacto, licet adhuc succoso, fungillus ipse maculiformis integra sub epidermide nascitur, coloreque flavido, saltem in ramulis, primum denotari solet. Pedetentim vero tumidior factus et in crustam effusam informatus, ubique extrinsecus nigrescit ac simul centimetra $\mathrm{I}-\mathrm{x}$ et quod superest, in longitudinem adipiscitur, contra millimetra v-xv latitudine, nec millimetrum aut sesquimillimetrum crassitudine vulgo excedit. Genuinorum more Rhytisnatum, e parenchymate carnoso firmoque, veluti sclerotieo, intus niveo, corticem vero crassum et aterrimum superne induenti constat. In summa crusta, sub epidermide nonnihil laxata, innumera generatur copia spermatiorum seu microstylosporarum, corpusculorum scilicet quæ formam ovatam et continuam ostendunt, hinc $0^{\mathrm{mm}}, 005$, illinc $\mathrm{o}^{\mathrm{mm}}, 003$ circiter obtinent, muco copioso soluta innatant, et sub humoris viscosi seu glutinis violacei specie per cuticulæ rimas seu poros inconspicuos exiguntur; exclusa autem matricem ut lacryma nitente illinunt. Deinde crustam spermatophoram inter et parenchyma niveum suppositum lente informatur hymenium ascophorum. Fit

\footnotetext{
' Fungus Sowerbianus in Salice cinerea et caprea vigere dicitur, vernali tempore limbo aureo circumdari, corticem hospitalem in seipsum, nempe quasi in crustam nigram pedetentim vertere, autumnoque potissimum pulverem
}

atrum. copiosum ac strato vario, ex albido parenchymate, impositum fovere. Id pulveris in fungo nostro nunquam deprehendimus. 
primum e copiosissimis paraphysibus, exiliter filiformibus, simplicibus et fusculis quæ ex utroque cuniculi fertilis latere originem indiscriminatim ducere primo obtutu videntur, mucoque hyalino et ab invicem dissepiuntur et simul adglutinantur. Lacunæ amplæ et vacuæ passim in mediis paraphysium mœnibus primum reperiuntur. Postquam stratum ex paraphysibus debitam prope crassitudinem nactum est, tunc interpositæ apparent thecæ obovato-cylindricæ et rectæ quæ nonnisi ex inferno hymenei tractus pariete, ut assolet, oriuntur, obtusissimæ consistunt, in basi autem breviter tenuantur, nec membrana præter modum crassa struuntur. Endospore viI ovatæ, rectæ, hinc et inde obtusissimæ, continuæ, pleræque $0^{\mathrm{mm}}, 002-0_{2} 6$ longæ et $0^{\mathrm{mm}}, 01-13$ crassæ, in singulis ascis monostiche gignuntur eosque subintegros replent; tegumentum læve, subachroum et muco aliquandiu vestitum induunt, plasmaque granosum ac dilute pullum nec non nucleolum situ varium fovent. Fungus, absoluta maturitate, corticem nigrum quo hymenium velatur simulque alienam culiculam sibi hærentem circumcirca solutos excutit, totusque in facie nudatur; colorem tamen saturate fuscum retinet et nonnihil undulatus apparet, ita ut hymenii Rhizince undulate $\mathrm{F}_{\mathrm{r}}$. quamdam speciem referat; tunc etiam thecæ aliæ in natali strato demersæ latent, aliæ contra ex omni parte duplo majores evadunt, ultra hymenii paginam protrahuntur, longe exstant et papillas hyalinas mentiuntur. Fungo obsoleto postea arescente, illius parenchyma superstes, quantæcumque sit adhuc crassitudinis, ex toto nigrescit, carbonis indolem coloremque assumit et matrici languidæ aut arefactæ diutissime adhæret.

Gregatim parasitatur in ramis vivis Salicis albe $\mathrm{L}$. et affinium quos tabe conficit et paulatim enecat. Omni anni tempestate licet vivus reperiatur, vere tamen et æstate spermatia potissimum fundit, nec nisi maio currente, junioque ineunte hymenium suum maturum, jam hornotinus nisi quidem tunc ætate provectior, revelare solet. Cæterum per longos annos in iisdem arboribus persistit, sicuti Cavillæ Versaliorum ad littora stagnorum sylvestrium nobis jampridem spectatum est. Intestinum mycelium ægre conspicitur.

Minime dubitamus huc trahere Cryptomycetem Wauchii, fungum Grevillianum, cujus præstita descriptio cum nostro bene quadrat. Discrimen, judice Friesio, ex hoc oritur quod epidermis matricis in perithecium Cryptomyceti non vertatur ${ }^{1}$; porro id commutationis apud Rhytisma maximum F $_{\text {r. nec cor- }}$ ticem integrum destruere, nec saltem ramum salicinum tali velamine orbare solet quale a GreviLiıo delineatur; ideo, ut opinamur, licet Friesı et magistri edinensis interpretationes non multum inter se differant, fungi quos tangunt etiam longe magis sibi invicem congruunt.

Endosporæ quas sevimus germen breve exseruerunt cujus incremento mox finem imposuit utriculus globosus et terminalis; spermatia in aqua item aliquandiu demersa, salva forma aucta sunt, sed
minime progerminaverunt.

Super endosporis id insuper animadvertendum est, quod scilicet, etsi simplici ordine vulgo dige-

Cfr. Friesu Sum. Vegel. Scand. p. $37_{2}$, lin. 8 et 9 , nec non et nola priori in fine. 
rantur, thecas communes seu minores et abditas quasi integras oppleant, contra majorum seu protractarum partem supremam solam occupent, simulque in hisce solito crassiores fiant. Nemo ideo hic non meminerit Ascobolorum quorum endosporæ crassitudine item mire variant, summasque thecas exsertas tenent. Thecæ autem fungilli nostri, in exigendo farto, apice breviter et vix conspicue laceræ dehiscunt, nec operculum semiliberum, ascoboleo more, dimittunt.

A Rhytismatibus foliicolis, maximum Friesianum notis haud exigui momenti recedit, nempe tum modo quo hymenium suum stato tempore nudat, tum etiam forma late ovata qua ejus endosporæ Rhizinam potius, et Pezizarum principes imitantur quam Rhytismata reliqua nostratia mire leptospora.

Duplex pyrenomycetum genus in Rhytismate maximo parasitatur. Aliud fungum vivum nondum autem perfectum aggreditur; constat e capsulis exiguis, globosis ostioloque minimo et vix prominente perviis, quarum parietes nigrentes ex mutata hospitis substantia facti videntur. Cellulis breviter et anguste ovatis denseque stipatis parietes isti introrsum formantur s. vestiuntur, atque e singulis sessiles et solitariæ nascuntur stylosporæ minimæ, late ovatæ, rectæ, utrinque obtusissimæ, $0^{\mathrm{mm}}, 0065-008$ rarius $0^{\mathrm{mm}}, 01$ longæ, et $0^{\mathrm{mm}}, 0035-005$ crassæ, initio albidæ et continuæ, tum septo transverso dimidiatæ et colore atro fucatæ. Puls copiosa aterrimaque, ex his seminibus muco achroo immersis et glutinatis, in cirros ejicitur et corticem maternum inquinat. Id fungilli pycnidei seu diplodice microspermæ tum in parenchymate albo et crassiori Riytismatis, tum in crusta nigra et molli super insita abunde generatur illiusque conceptacula contigua s. laxiora modo in seriem unicam digeruntur, nunc ordines duos superpositos et interruptos ostendunt. Læte vigebat novembri medio MDCCCLXIV, Cavillæ Versaliorum, in Rhytismate maximo quod hymenium suum ascigerum nondum perfecerat.

Sequentia de altero pyrenomycete parasitico valent. Ubi Rhytisma nostrum, omni velamine proprio alienove nudatum, vitam suam endosporas edendo absolvit, brevi arescit et penitus ut supra dictum est nigrescit, crustam carbonaceam duramque matrici tabefactæ innatam refert, et hac sub specie per plurimos annos durat. In crusta istius modi frequenter sparguntur tubercula paris carbonaceæ indolis colorisque atri, minima, globosa, obtusissima, discreta, sessilia, subastoma, quorum alia pulvere fuligineo, alia albido referciuntur. Nigrum autem pulvisculum sistunt seminula (acrosporæ) globosa et simplicia quæ germina flexuosa, mox articulata ramosaque loco favente exserunt; contra pulvis albidus constat e stylosporis lineari-cylindricis, longiusculis, continuis, rectis curvulisve, quæ etiam in germina longe linearia cito abire facili arte comperimus. Quod autem utrumque conceptaculorum genus eidem fungo spectet minime dubitamus, neutrum contra ad Rhytisma nostrum traheremus, quippe ambo ex illius reliquiis arefactis aliena vivunt.

\section{EXPLICATIO ICONUM.}

(Tab. XVI, fig. 9-15.)

9. Ramuli salicini quorum cortex, propter Rhytisma maximum $\mathrm{F}_{\mathrm{R}}$. innatum, multifariam fucatur et intumescit; pars virgulæ anticæ superior monstrat initia fungi microsperma.

10. Ramo altero, utrinque truncato, fungi parasitantis stromata in seriem linearem de more ila instructa incumbunt, ut inferiora nunc matura revelentur, indusiis amotis, media dehiscere incipiant, superiora vero, prorsus imperfecta, adhuc sub maternis tegminibus prorsus lateant; punctula extrema, di:creta et nimbo albo cincta, ex his sunt quæ nudisporas vomere solent.

11. Stroma recens et spermatiferum a vertice transversim dissectum est; pulpa spermatiorum dilute violacea in strato nigerrimo sub membrana corticis exterioris nascitur et per hujusce rimas excluditur. Id autem strati nigri et spermatiferi parenchymati niveo, sclerotieo crassoque arcte adplicatur. 
12. Particula maxime aucta ejusdem strati nigri et fertilis sterigmatibus horret.

13. Stromata ascophora matura quæ autem rimis nondum patuerant transverse dissecantur. Stratum nigrum, olim spermatophorum, veli vices nunc agit, et quum dirumpetur, hymenium ascophorum simul nudabitur.

14. Thecæ et paraphyses dissimiles, filiformes aliæ, articulato-moniliformes alteræ; thecæ maturæ quæ jam prope sunt ut conceptam sementem foras ejiciant, mirum in modum protrahuntur et simul dilatantur, quare in hymenio, ascoboleo more, longe exstant; endosporæ exclusæ muco aliquandiu obvolvuntur.

15. Endosporæ quæ satæ germinaverunt; germen sæpissime in utriculum seu conidiolum desinit, antequam sane longius protrahatur.

Fig. 9 nativas demensiones vix excedit; fig. autem 10 iisdem quadruplo major est; fig. 11 et 13 bis decemplicatæ exprimuntur; denique fig. 12,14 et 15 circa vices ccclxxx auctæ sunt. Omnes adumbrałæ sunt juxta fungos cavillanos in Salice alba vigentes, scilicet fig. 9,11 et 12 junio et julio a. MDCCCLXI, fig. 14 et 15 junio medio MDCCCLXIV, et reliquæ novembri insequente.

\section{STICTIS.}

(Tab. XVI, fig. 4-8, et tab. XVIII, fig. 1-11.)

Genus ex typis plerisque Persoonianis.

Sub eodem titulo, magistrorum auctoritate fidentes, typos duos admodum dissimiles hic comprehendimus, simulque propterea nominum spatiique compendium facimus; quum præterea fusior utriusque descriptio infra sequatur, principes eorum notas solito modo contractas præmittere omnino supervacuum arbitramur. Non dubitamus enim unumquemque meritissime esse sui generis.

* Endosjoris cylindricis et curvulis. - Propolis Fr. et DNTrs. pro parte.

\section{Stictis cinerascens.}

Stictis cinerascens Pers. in schedis et Mycologia sua Europ. t. I, p. 339 , n. 11, testibus Leveluleo el Novтаnı, in Herb. Musæi Parisiensis. - Nobismet in tomo I hujus Carpologice, p. 222, adnot. Ix.

Bene multa inter synonyma quæ huc sane spectant, sequentia cæteris minus dubia, sicuti comperisse nobis videmur, afferre satis est, nempe :

Hysterium Fagineum Schradero, Ephem. Bot. t. alt. (1799), p. 68, n. 21, et Persoonio, Syn. Fungr. p. xxviil n. $11 c$, quod fungi nostri formam vulgatiorem, niveam gilvamve repræsentat, et Tremella saligna ab ALBERtinio et Schweinitzio (Consp. F. Nisk. p. 303, n. 9o6, tab. x, lig. 7), Stictis autem saligna ab ipso Persoonio (Myc. Eur. t. I, p. 337, n. 7) dictum est.

Stictidem (Propolim) farinosam et versicolorem Friesio, Syst. Myc. t. II, p. 198 , n. 16 et 17, saltem pro maxima parte.

Stictidem versicolorem Corde, Ic. Fung. t. II, p. 38 , tab. xv, fig. 133 ; Anleit. z. Stud. der Myli. p. xcy, tab. G, n. 64, fig. 5-8. 
Xylograma versicolor Wallototho, Fl. Crypt. Germ. t. alt. p. 510, n. 2649.

Propolim versicolorem Friesio, Sum. Veget. Scand. p. $37^{2}$, n. 6. - Notarisio, in Comment. Soc. Cryptog. Itala, fasc. V (1864), p. 363 .

FuxglLus intestinus nascitur sub tenui pariete ex lignea corticeave matrice, capsulam ideo clausam, ovatam v. oblongam, millim. I-III et quod excedit diametro majori æquantem, primitus constituit, maturo autem tempore latera superna varie lacera ut velum spurium excutit proptereaque laciniis circumstantibus quasi limbo accessorio, ut cum Friesio loquamur, stipatur, marginatur, simul atque deinceps interanea sua nuda ostendit. Velum tamen ex hospita materie vix quidquam de fungo sumpsit; item discus reliquus in fossula seu nido natali latens, subiculo pallido ut matrici ipsi nec corticulo manifesto, sicut Phacidiis plerisque mos est, incumbit. Id disci semper plus minus convexum s. pulviniforme deprehenditur, effetum vero quadantenus subsidit; naturam carnosam s. ceream et solidiusculam obtinet, quapropter ubi nonnihil exaruit, fragmina tenuissima cultro cedit. Furfuribus niveis, albidis, cinereis s. gitvis, imo castaneis s. dilute rufo-cervinis, abunde primum conspergitur; senescendo autem detergitur. AscoRUм focunditas modo legem assuetam sequitur et sporis octonis declaratur, nunc contra numero earumdem quasi indefinito superbit. Asci octospori lineari-cylindrici, obtusissimi et basi breviter attenuati, $\mathrm{O}^{\mathrm{mm}}, 11-14$ in tongitudinem et $\mathrm{o}^{\mathrm{mm}}, 01-013$ in crassitudinem nanciscuntủr, membrana achroa, tenui et fragili fabricantur, atque paraphysibus filiformibus quarum apices vix incrassati et frequenter brachiati stratum crassum, pallidum et conglutinans thalamio universo superpositum intrant, arctissime stipantur. Endospore, de octonis dicimus, cylindricæ, utrinque obtusissimæ, curvæ, continuæ, albidæ v. luteolæ, $0^{\mathrm{mm}}, 0_{2}-03$ longitudine et $0^{\mathrm{mm}}, 0065$ crassitudine æquant guttulasque duas, rarius III vel v remotas, inter plasma oleosum et subhomogenum vulgo includunt; ascos integros duplici ordine replere solent. TheС myriasporæ in fungis castaneis v. cervinis potissimum generari videntur; item cylindricæ sunt sed ascis octosporis in utraque parte majores, quippe $0^{\mathrm{mm}}, 16-18$ in longitudinem et $0^{\mathrm{mm}}, 016$ in crassitudinem obtinent, inferneque abrupte et brevissime tenuantur; in vertice nonnihil fucantur. Endospore innumeræ et multiplici indigestoque ordine in singulis ascis confertissimæ, formam anguste cylindricam, curvam, continuam et utrinque obtusam describunt, $0^{\mathrm{mm}}, 016-019$ longæ sunt nec $0^{\mathrm{mm}}, 0035$ vulgo excedunt, valde ideo minores sporis octonis consistunt; de oleo v. plasmate contento guttulisque s. nucleolis immersis minus recedunt. Utrumque endosporarum genus, iodea aqua illud si madefeceris, colorem solitum, nempe fusco-luteum, propter contenta ducit, in membrana enim qua fabricatur achroum manet. Item debito tempore, cœloque favente, endosporæ omnes, qualescumque sint, in germina exilia pari modo abeunt; hæcce autem, ut mos est, ex alterutro vel ex utroque seminis apice sæpius quam ex ejusdem lateribus prodeunt. 
Frequens provenit apud nos, hiberno potissimum tempore, in ligno nudo, jampridem arido et quidem putrescente arborum frondosarum, maxime autem Quercus, Castanea, Coryli et Populorum; longe rariorem vidimus in corticibus querneis. Fungitlus effetus, aridus, diu persistit.

Disculos reperire est quos ex duobus coalitis factos libenter existimes. Friessus fortassis non adverterit fungilli clausam seu primordialem conditionem, perperamque credit hymenium in pulverem fatiscere, nec nisi in extrema ætate farinaceum offendi. (Cfr. Syst. Myc. t. II, p. 198.) Furfures enim quo magis abundant, eo recentior fungus est, minimeque ex hymenio soluto proveniunt; eosdem potius analogos dixeris quisquiliis illis niveis aut luteo-virentibus quibus Tympanis conspersa, Valsa nivea et leucostoma, Cenangium Cerasi, cæt. initio teguntur.

Thecæ maturæ, gravidæ, maxime apud fungum cervinum myriasporum, ubi aquam combiberunt subito mire protrahuntur antequam solutæ s. ruptæ sementiculam suam fundant; id sane vix secus accidit atque in Spheria herbarum Persoonn, Pleosporis affinibus aliisque ascomycetibus pluribus; asci tamen membrana exterior vix manifeste scinditur, quare eandem simul cum interiore augeri credas.

Endosporæ, inter germinandum, vix augentur; plasma autem oleosum et nucleoli pedetentim turbantur et consummantur. Dissepimenta fieri non comperimus.

Fungum æruginosum (Stictidem viridem Pers. Myc. Eur. t. I, p. 338 , n. 10 , monente Friesio) aut nigrescentem (Hysterium pezizoides $\mathrm{W}_{\mathrm{AHL}}$. volente eodem magistro upsaliensi) qualem norunt mycetographi bene multi (cfr. Frissi Syst. Myc.t. II, p. 198 ), nondum ipsi vivum reperimus; exempla autem virescentia in mycotheca Mazeriana continentur quæ a niveis gilvisve octosporis et vulgatioribus non differre videntur nisi endosporis brevioribus et vix aut neutiquam incurvatis. Hisce minime niti posset Melittiosporium versicolor CORDE, cupula carneo-membranacea et obscura nec non endosporis multilocellatis insignitum, licet hymenio æruginoso et origine ex ligno putrido cum plantula nostra congruere videatur ${ }^{1}$. Quare veremur ne de Melittiosporii typo prorsus erraverint tum Friesius (Sum. Veget. Scand. p. 372), tum etiam clar. Notarisius (in Comment. Soc. Cryptog. Itale, fase. V, p. 364).

Stictidem contra cinerascentem nostram prorsus de specie imitatur Stictis pinicola quædam (Stictis Leonis nob.), nivea dicta Leoni Dufoun in herbario Mazeriano, quæ autem thecis sporisque dissimilem se habet. Discus illi est ovatus, cæsio-cinereus et pulverosus, thecæ longe cylindricæ, amplæ et monostiche octosporæ, sporæ denique late ovatæ v. ovato-oblongæ, admodum rectæ et muco achroo involutæ. Sparsa viget in cortice crassiore Pinus maritima, et Friesir pace dicamus, qui eam novisse et supradicto cognomine persooniano designasse videtur, remotam duntaxat cum vera Stictide nivea PErsoon (Myc. Europ. t. I, p. 339, n. 14) quæ in solis Pinorum et maxime Pinus maritima Lмк. ${ }^{2}$ foliis nidulatur, necessitudinem demonstrat. Hujusce Stictidis nivece Pers. endosporæ longe lineares et flexuosæ sunt, easque videre Notarisio non contigerit. (Cfr. Act. Acad. Sc. Taurin. ser. alt. t. III [1841], p. 62, n. 5, fig. v.) A seminibus Stictidis Leonis toto cœlo discrepant.

E contrario has propter endosporas Stictis nivea Pers. genuina ad Stictidem radiatam Pers. (Obs. Myc. parte II, p. $7^{3}$, n. 114 ) accedit quæ enim endosporis capilliformibus et intra singulas thecas arcte primum fasciculatis utitur. Inde ducto charactere tutius niteretur Sclmitzomia Friesiana quam

1 Videas Corde Ic. Fung. t. II (1838), p. 38, n. 1, tab. xv, fig. 131 , et Anleit. z. Stud. der Mykol. p. xav et 151 , n. 395 , tab. g, n. 63 , fig. $5-8$.

2 Eamdem etiam habemus in foliis Pinus sylvestris L. ligusticæ, ab humanissimo Notakisio acceptan. Dalur in acubus Pini maritimce apud Mougeotium, Stirpib. Crypt. Vog.-Rhen. fasc. XI (1840), n. 1095. 
fictis notis ex edisco in golobulum gelatinoso-ceraceum, floccosum, coagulato, deciduo." (Cfr. FriesII Sum. Veg. Sc. p. 363.) Criterium hujus modi rectius interpretatus est Notarisios in Act. Soc. Crypt. Itale, fasc. V (1864), p. 361 et 362 . Assueta inter Schmitzomice radiate Fr. conceptacula, pauca alia vidimus, angustius dehiscentia et vere pycnidea, quæ enim solis stylosporis longe lineari-cylindricis, curvulis, vix continuis, sæpiusque stylo brevissimo geminatim insistentibus, scatent.

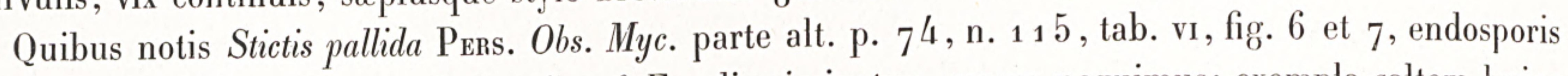
ovatis et simplicibus donata, ab Agyrio rufo Fr. discriminetur, eruere nequimus; exempla saltem hujus sic dictæ Stictidis quæ in Friesianis Scleromycetib. Suecia, sub n. 275 tradita sunt, ipsissimum hoc Agyrium rufum, quale in iisdem Scleromycetib. Suecanis, n. 280 , ipsum datur, manifeste repræsentant. (Cfr. Mycoth. Mazerianam in Herb. Musæi parisini.) Contra fungus alius omnino est Cryptodiscus pallidus tum b. Corde (Ic. Fung. t. II [1838], p. 37 , n. 1, tab. xv, fig. 129 , et Anleit. z. St. d. Myk. p. xciv, infra, tab. g, n. 63, fig. 1-4), tum Notarisio (in Comment. sup. laud. Soc. Crypt. Itale, fasc. V, p. 365$)$, cui enim endosporæ tetrameræ tribuuntur.

\section{EXPLICATIO ICONUM.}

(Tab. XVI, fig. 4-8.)

4. Posticam s. internam vides corticis quernei jampridem arefacti paginam, in qua placentæ plurimæ Stictidis cinerascentis PERs. nidulantur; quæ fucantur thecas polysporas et microspermas fovent; cæteræ contra, niveæ vel albidæ, structuram vulgatiorem, octosporam ostendunt.

5. Cæspes ex thecis octosporis s. macrosporis, tribus gravidis, quarta autem jam effeta; paraphysium apices nodis $\mathrm{v}$. brachiorum rudimentis variis augentur.

6. Endosporæ majores, ex octonis scilicet, quæ satæ germinarunt; pleræque simul fiunt crassiores.

7. Thecæ polysporæ et paraphyses e placentis rufulis desumptæ; inter thecas adhuc gravidas una assurgit quæ sementem suam modo excludebat.

8. Endosporæ minores, nempe ex his quæ innumeræ in singulis ascis nascuntur, seorsim dantur; nonnullæ, loco favente, germina ediderunt.

Fig. 4 nota quadruplo major proponitur, cæteræ naturam vices circiter ccclxxx excedunt; omnes, præter octavam, adumbratæ sunt extremo februario MDCCCLXI, juxta fungos vivos modonenses quorum meminimus in tomo I hujus libri, pag. 222 ; figura autem octava sporas germinantes exprimit fungillorum qui tum in ligno coryleo, tum in castaneo Cavillæ Versaliorum vigebant, decembri MDCCCLXIV et januario proxime sequenti.

** Endosporis ovatis, incequilateris, crassioribus. - Typus ad fungos Pezizeos transiens. Ocellaria nob.

\section{Stictis ogellata.}

Peziza ocellata Pers. Syn. Fung. p. 667, n. $121 ;$ Myc. Europ. parte I, p. 313, n. 258.

Peziza Lecanora Schm. et Kze. F. exsicc. fasc. VII, n. 174, docentibus Persoonio (Myc. Europ. p. 313 . n. 259$)$ Friesioque.

Stictis ocellata et St. Lecanora Fr. Syst. Myc. t. II, p. 193 , n. 2 et $3 ;$ Sum. Veget. Scand. p. 373 , n. 8 et 9 . Stictis Lecanora (Fr.) Kneiff et Hartm. Crypt. Bad. exs. fasc. III (1830), n. 115 (in cortice salicino). Mazerio, Stirp. Crypt. Gallice, ed. I, fasc. XVIII (1837), n. 869 (in Salice), et ed. alt. fasc. II, n. 69 (etiam 
in cortice salicino). - Siegundio ap. Rabenh. F. Eur. exs. fasc. V (1862), n. 457, in Salice fragili Bohemiæ (Reichenberg).

Stictis ocellata (Fr.) Tul. in Schlechtendali Ephem. Bot. t. XI (1853), p. 52 , et in Ann. Sc. nat. ser. III, t. XX, p. $147^{-149}$.

Phacidium Popdli Laschio apud Rabenh. Herb. Mycol. ed. alt. fasc. VI (1857), n. 519 (in cortice Populi tremulce prope Driesen), pro fungo novo perperam exhibitum.

Propolis Lecanora (Fr.) et P. Populi (Lasch) Notarisio in Actis Soc. Crypt. Itale, fasc. V (1864), p. 364.

Schmitzomia chrysophea (salicina, Dresdensis) Rabenhorstio in suis Fung. Europ. exs. fasc. VIII (1865), n. 787; minime autem Peziza aut Stictis Persooniana ejusdem nominis, pinicola vel abieticola, vixque, ni fallimur, Stictis chrysophcea (ulmicola) Berk. et Br. in Ann. and Mag. of nat. Hist. ser. III, t. VII (1861), p. 451 , n. g66, tab. xvi, fig. 19 .

OCELLARIA AUREA nob. in schedis.

FuxglLLo populicolæ crescendi modus hic est. Sub epidermide tenui, pallida nec xgre detrahenda, stromatum omnium initia in cortice primum saturate fusco moxque aterrimo sine lege sed gregatim laxoque ordine sparguntur, tot disculos (juvante sementicula acervata) umbonatos, carnosulos, albidos et mycelio subconcolori, laneo, brevi, parcoque circum circa limbatos referunt. Disculi autem alii aliis longe dissimiles adolescendo fiunt. Sunt qui marginem et axim acutiusculum nigrentes assumunt et in conulum depressum conformantur, aut margines incumbentes longius protrahunt et in capsulam late apertam coarctantur, sed, utcunque se habeant, humida stylosporarum copia, ut cera albida, obruuntur vel replentur. Cera vero fertilis per epidermidem anguste foratam aut quadantenus laceram in cirros crassos, primum niveos tandemque fucatos exit. Disculi contra alii multo magis quam priores crassescunt, formam globoso-depressam affectant, colorem aureum ex omni parte ducunt et postquam verticem suum conicum ac tandem abscissum dimiserint, maternumque amoverint velamen, discum nonnihil concavum seu patellam auream et margine inæquali aut lacero-fimbriato descriptam, nudam exhibent. Disculi pycnidei, perfectioribus de more præcociores, nunc mycelio ipsi latitanti aut strato stromatico tenui intusque luteolo solitarie imponuntur, nunc verticem seu latera stromatis ascophori nondum absoluti occupant, ita ut in dubium vocare nequeas sincerrimam eorum cum cupulis pezizeis necessitudinem; millim. I-II diametro æquant et sterigmatibus crassis, ramosis implexisque antice introrsumve, ut pro variis formis quas induunt, apte simul loquamur, vestiuntur. STyLospore singulæ in summis sterigmatibus arrectis solitariæ nascuntur, formam continuam, obovato-oblongam, obtusissimam, basi mucronulatam, rectam vel nonnihil incurvatam, parietes autem crassiusculos et leves obtinent, guttasque oleosas primitus includunt quæ subinde in plasma granosum pedetentim integræ convertuntur. Semine maturo, superest nucleolus golobosus, exiguus, medius, parietalis, pellucidus, roseolus oculum mentiens. Id seminis $0^{\mathrm{mm}}, 03-05$ in longitudinem et $0^{\mathrm{mm}}, 013-016$ crassitudine adipiscitur; cum e nido exiit, mox fucatur, septis transversariis (II-III) sæpe dividitur, simulque hine et inde in longa abit germina. Patelle disculis s. capsellis nudisporis 
majores sunt, solitariæ aut passim contiguæ crescunt, imo aliquando coaluisse videntur; disci color nitide aureus cito in badium convertitur; hymenio insunt thecæ longe obovatæ, crassæ, obtusæ, subsessiles, typice octosporæ, minime raro autem depauperatæ fœcunditatis, ex membrana initio crassa factæ, paraphysibusque simplicibus, baculiformibus, plasmate ocellato refertis, apice modice clavatis sed aureis et glutinatis abundantissime stipatæ, strato glutinoso et aureo-fusco supereffuso. Endospore forma et crassitudine stylosporas mirum in modum imitantur, utrinque autem simili modo obtusæ sunt neque nucleolum persistentem ostendunt; continuæ sunt, plasmate granoso et luteo-virenti referciuntur, membranaque crassiuscula et subachroa fabricantur. Ubi disseminatæ sunt, stylosporarum instar colorem intentum, atro-virentem, vel in sua membrana induunt et trimeræ vel quadripartitæ pleræque fiunt, simul etiam longa et filiformia protrudunt germina quibus in informandis plasma totum consumitur quo initio replebantur. Germina istiusmodi rigida primum et simplicia, ex filamento mox cæruleo-nigrescenti singula constant.

Frequens viget, prope quolibet anni tempore, in cortice Populi tremule L. recens demortuæ, Modonique et Cavillæ quotannis abundat, autumno potissimum hiemeque.

Mycelium senescendo fit sordide ærugineum, imo nigrescit; pari modo etiam fucatur tomentellum aureum et adpressum quo cupulæ adhuc clausæ parce copiosiusve teguntur.

Pycnides maxime in truncis capsuliformes generari, contra in ramorum cortice sæpius aperte patere et minus cavari videntur; priores præ aliis olim paucis attigimus. De stylosporarum nucleolo pellucido, parietali, secus etiam modo dixerimus atque in Annalibus Sc. naturalium (loco sup. cit.), quippe aliter eum hodie libenter interpretamur. Ejus tamen natura nobis adhuc incerta manet.

Cupulæ recentes melleum spirant odorem et in seminibus projiciendis eadem vi intentionis qua Pezizce sinceriores utuntur. Quin imo, ut ipsi comperimus, si aruerint, hanc vim post elapsos menses duos et quod superest, madefactæ recuperant. Spermatia quorum olim meminimus, frustra novissimis his temporibus quæsiimus; de iisdem propterea supra tacuimus.

Fungillum modo descriptum sibi constantem vidimus in cortice Salicis cujusdam angustifoliæ, prope monasterium princeps Carthusiensium Gratianopolitanorum, septembri MDCCCLVII, quare non dubitamus quin Peziza ocellata Pers. populicola et P. Lecanora Schм. et Kze. Salicum demortuarum hospes, unum et eumdem constituant typum. Synonyma in fronte historiunculæ nostræ supra exposita nostrum qua de re sentire prænuntiaverunt.

Fungus populicola in agro Lemovicensi, monente clar. Lamy in Mycotheca Mazeriana, rarus offenditur; illius mentio fit in clariss. viri opusculo inscripto Simple Aperçu sur les Plantes Cryptog. et Agrames du Départ. de la Haute-Vienne (1860), p. 28.

\section{EXPLICATIO ICONUM.}

(Tab. XVIII, fig. 1-11.)

1. Cortex populneus passim dehiscens cæspites perfectiores aut stromata conidiophora Stictidis ocellate (PERs.) prodit; conidia exclusa acervulos s. glomulos pallidos efficiunt.

2. Stromata tria mere conidifera a vertice dimidiantur; singula variis modis cavantur et conidiis congestis 

replentur, sed propter tenuitatem peculiarem quam servaverunt, nunquam sane hymenium ascophorum ge-
nuissent.

3. Stroma multo crassius item dissectum; in sinistro latere fossulam gemmiferam ostendit; sub vertice autem et in medio parenchymate pars seu regio ascophora postea profecto apparuisset, ut e sequentibus exemplis patet.

4. Stroma validum dimidiatum etiam proponitur, cujus pagina superior vallibus conidiophoris excavatur, penetralia autem solida colorem saturatiorem sub culminibus majoribus induerunt sicque proximum strati intestini et ascophori ortum prænuntiant.

5. Stroma alterum a summo partitum; conidia nunquam edidisse videtur, sed rudimenta hymenii ascigeri sub vertice fovet.

6. Cupula recens parenchymate pallidiori cujus in sinu informata est utrinque adhuc stipatur nec velum quo ab initio occluditur nondum excussit; a vertice secta exprimitur.

7. Exemplum hic proponitur modi alterius supra descripti quo cupula ascophora interdum sub capsella conidiophora solito constrictiore ac subocclusa generatur et in cortice nutritio altiuscule primum latitat; c0nidia exacta in cortice hospitali congeruntur.

8. Particula maxime aucta byssi conidiophoræ, sumpta de pariete externo stromatis cavati et gemmiferi.

9. Conidia quæ sata cito germinarunt; pleraque, diebus paucis elapsis, dimera, tripartita aut sæpius tetramera evadunt, nec tamen majorem crassitudinem nanciscuntur; conidia alia item egerminantia sub fig. 8 delineata sunt.

10. Thecæ et paraphyses quarum apices glutinantur.

11. Endosporæ progerminant; conidiorum instar, septis inter germinandum dividuntur et omni plasmate pedetentim evacuantur. Germina et episporium mox simul infuscantur.

Figura 1, julio ineunte MDCGCLII delineata, nota decuplo major est; figo. 2 , 3 et 5-7 nativas demensiones bis decemplicatas exprimunt; fig. 4 easdem ter decuplas; reliquæ multo magis auctæ sunt, nimirum vices circiter ccclxxx. Figura 7 simul cum nonnullis e seminibus germinantibus (fig. 9 et 11 ) eodem tempore atque fig. 1 descripta est, cæteræ autem decembri currente MDCCCLXIV, omnes similiter juxta fungos vivos et in cortice Populi tremula L. natos.

\section{PHACIDIUM '}

(Tab. XV, fig. 1-8.)

Fungus spermatifer mycographos sæpissime præteriisse videtur aut pro SPHERIA v. XYLOMATE habitus est; pycnideus inter CYTISPORAS et CEUTHOSPORAS ${ }^{2}$ præsertim computatur; perfectus s. asciger XYLOMATIBUS Persoonianis et Candollianis olim annumeratus, nunc phacidieum typum, Friesio volente, constituit. (Cfr. Sснмпртп Monogr. Phacidiorum in suis Fasc. Mycol. parte I, p. 19-44.)

\section{Mrceliun intestinum, pallidum fucatumve. Fructus saltem duplicis generis, nu-}

${ }^{1}$ Id Friesiani cognominis a græcis vocibus Gaxòs et

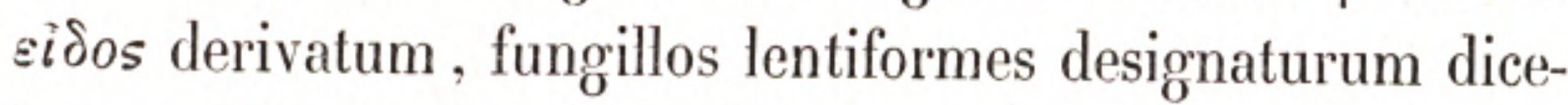
batur. (Cfr. Friesir Syst. Myc. t. alt. p. 571, et laudatam Sснміртіг Monogr. Phacidiorum.)

${ }^{2}$ Ceuthospora Visci Solmananio in Rabenhorstil Fung. Eur. exsicc. fasc. VII (1864), n. 651, et Hedwigice tomo alt. (1863), p. 187-192, tab. xIII, fig. 1-12, est Spharia atro-virens, Visci, Aьв. et Schw. (M Maz. Stirp. Cirypt. Gall. ed. I, fasc. XVII, n. 842), quæ nunc solitum propter thecarum defectum, Sphceropsis atro-virens Leveilleo et BerкELEo (Outl. of Brit. Fung. p. 316) dicitur; longe ideo stat a Ceuthosporis Grevillianis. 
dispori alii, ascophori alteri. Priores conceptaculiformes, clausi, simplices aut multilocellati tandemque anguste dehiscentes; spermatiis exiliter linearibus, brevibus, rectis aut curvulis; stylosporis obovato-cuneatis vel cylindricis, rectis et continuis. Fructus thecaphori, placentiformes sive utriculosi, velum varie scissum sub maturitatem exuentes, aut superne rimosi hiantes. Endospor $Æ$ filiformes et flexuosæ aut ovatæ et rectæ, vulgoque continuæ.

FunglLLI in foliis aridis aut corticibus arborum demortuarum hieme vigentes, sapissime etiam in foliis vivis sed languidis et maculatis astate parasitantes.

Vigeant Phacidia in foliis aut corticibus, aridas matricis partes quas inhabitant, parenchymate fungino fusco-nigro, ex cellulis minimis reticulato-sociatis, infarciunt, simul atque easdem exesas in se ipsa plus minus convertunt; inde fit ut excipulum atrum quo fœecunda eorum viscera involvuntur pro alieno tegmine immerito haberetur. Errorem hujusmodi non devitaverat Elias Fries qui Phacidii sui coronati lacinias s. pinnas marginales ex hospitis rupta epidermide oriri existimabat; postea autem id excipuli aptiore perithecii cognomine designavit. Item verba discus et nucleus compagem seminiferam congruentius indicant quam vox pileus a magistro upsaliensi primum etiam adhibita. (Cfr. Friesir Obs. Mycol. t. I, p. 167, et Syst. Myc. t. alt. p. 571 et seq.)

* Endosporis linearibus. - Lophodermiorum pars Notarisio.

\section{Phacidium dentatum.}

* Fungus spermatiophorus :

Lichen castanearius, crusta lactea subimperceptibili, tuberculis minimis nigris, Lamk. Dict. Encycl. de Bot. t. III $(1789)$, p. 471, n. 3.

Spheria punctiformis, ambigua, Persoonio, Syn. Fung. p. 91, n. ${ }_{7} 5 \gamma$, scilicet, ut bonus arbitratur auctor, punctula nigra in foliis quercinis aridis et maculato-decoloribus sparsa, quæ forsitan insectorum puncturis suum debent ortum.

Xyloma lichenoides Lamk. et DG. Fl. Gall. ed. III, t. II, p. 304, n. 819, et Syn. Fl. Gall. p. 63, utrinque saltem pro parte, scilicet formæ $\alpha$ et $\beta$, in Robore et Castanea obviæ.

Spheria lichenoides $\alpha$ quercicola et $\beta$ castanececola Candoldio, Fl. Gall. t. VI, p. 147, n. $807 \alpha$ et $\beta$.

Huc etiam pro parte spectat Leptostroma vulgare, orbiculatum MAzerir, sicut e schedis Robergianis elucet quæ in mycotheca magistri insulensis continentur.

** Fungi forma perfectior :

Phacidium dentatum Schir. et Kze. F. Germ. exs. fasc. V, n. 2, docente Schmidtio ipso in Fasc. Mycol. parte I, p. 41, n. 10, ubi fungillus inter Phacidia libera admittitur. - Moug. et Nestr. Stirp. Vog.-Rhen. fasc. VI (1818), n. 561, in foliis quercinis. - Mazerio, Stirp. Crypt. Gallice, ed. I, fasc. IV (1826), n. 186, et ed. att. fasc. IX (1840), n. 417 , utrinque etiam in foliis querneis.

Phacidium (Xyloma) dentatum Friesio, Syst. Myc. t. II, p. 577, n. 17. - Corde, Ic. Fung. t. III, p. 31, tab. v, fig. 81, super endosporis minime fida. - BaLio, Syst. Fung. p. 57 et $9^{0}$, tab. xviII, fig. inferiorib. 
a b. Corda sumptis nec vero, quod ad endosporas pertinet, magis congruis. - Fresenio, Comm. Mycol. p. 69 , tab. viII, fig. 12-16, fungilli fagicolæ paraphyses, quercicolæ autem habitum, thecas sporasque proponentibus.

Lophodermidm dentatum Notarisio in Parlat. Ephem. Bot. Itala, anno II, t. il (1847), p. 43.

Antequam quodvis fungilli vestigium oculo vel armato manifestetur, folium aridum cui mox innascetur, passim assuetum suum castaneum colorem deponit, tenuatur, imo interdum semipellucidum efficitur; inde maculæ oriuntur albidæ, initio minimæ et orbiculares, quæ autem postea inæquo modo augentur, fines suos discretos et plus minus sinuosos retinent aut rarius eosdem aliæ cum aliis passim confundunt, ita quidem ut folium prope universum aliquando invadant. Maculæ præterea circumcirca vagæ sunt nec definitæ, aut lineis nigris et prominulis partim describuntur et delimitantur; sunt etiam quæ iisdem insuper, ut venis, dirimuntur vel signantur. Singulis in maculis ineunte hieme apparent punctula plurima, minima, quæ sine lege sparsa videntur sed pleraque tamen nervulis folii hospitis imponuntur; rufa nascuntur, mox vero nigrescunt, imo colore aterrimo glaberrima nitent, tuncque $0^{\mathrm{mm}}, 1-15$ diametro æquant. Eadem acute dissecta attentis si observaveris oculis, utriculos agnosces globoso-depressos, uniloculatos, ex parietibus $0^{\mathrm{mm}}, 01-013$ crassis et undique nigerrimis factos, nec non in parenchymate folii sub epidermide quam exesam et nigrefactam sui partem fecerunt, enatos. Stratum albidum, $0^{\mathrm{mm}}, \mathrm{o}_{2}$ vix crassum, sterigmatibus perquam exilibus, stricte ramosis et densissime cæspitosis, integrum uteri fundum vestit, nec parcam fundit spermatiorum copiam. Hæc corpuscula tot bacillos tenuissime lineares, rectos, utrinque truncato-obtusos et $0^{\mathrm{mm}}$, oo $5-0065$ longos referunt, e sterigmatibus ut ramuli oriuntur et pultem constituunt fusculam quæ per porum unicum aut ostiola II-III rotunda el ægre conspicua quibus paries uteri supernus congruo tempore perforatur, in cirros exigitur. Spermogonia evacuata collabuntur, aridaque diutissime persistunt. Jampridem eadem adoleverunt quum conceptacula perfectiora seu ascophora apparere incipiunt. Ista prioribus absque ordine, sed multo pauciora, commiscentur, similiter saturate nigrescunt, minus autem nitent. Initio minima sunt et punctiformia, subinde autem obtuse angulata, trigona, quadrata vel pentagona; millimetri dodrantem aut millimetrum integrum diametro matura æquant, tuncque in tot valvas (III-v) a centro dehiscunt quot latera monstrant et hymenium pallidum revelant. Theс lineari-oblongæ, acutiusculæ, subsessiles, ex membrana tenui fabricantur, $0^{\mathrm{mm}}, 08$ in longitudinem et $\mathrm{o}^{\mathrm{mm}}$, o o6 $65-008$ in crassitudinem adipiscuntur, singulæque sporas octonas longe et exiliter filiformes, continuas, in vertice nonnihil incurvato vix conspicue incrassatas fovent, quibus fasciculatis prope integræ replentur. Paraphyses tenuissime filiformes, simplices nec apice manifeste clavatæ, inter thecas seipsis breviores arctissime constipantur, muco s. glutine achroo quasi deficiente.

Crescit frequentissimus in utraque pagina foliorum aridorum et delapsorum Quercus, 
Fagi et Castanex, maxime autem in antica. Spermogonia hieme medio, decembri scilicet et januario, in foliis hornis humi jacentibus copiosa reperiuntur; scutellæ clausæ deinde sed lente sequuntur, nec sæpius, ut videtur, perficiuntur, nisi hieme subsequenti aut saltem post elapsum longum temporis spatium, foliis natalibus tunc pæne destructis. Modoni et Cavillæ quotquot annis, maxime spermatiferus, abundat.

Super vera endosporarum forma pariter erraverant b. Ditmarius et clar. Greviluius qui enim minimas, golobosas, numeroque in singulis ascis non definitas, eas deprehendisse ambo sibi videbantur. FRESENII verba et icones supra citatæ cum vero longe magis congruunt.

\section{Phacidium coronatum.}

* Fungi initia acrospora :

Ad fungillum spermatophorum etiam sane spectant synonyma omnia quæ Phacidium dentatum recens natum designant. (Cfr. supra p. 132.)

** Fungus ascophorus :

PEZIZa comitialis (quercicola extusque reticulato-venosa) Batschio, Elench. Fung. contin. I (1786), p. 217220 , n. cLiI, tab. xxvir, fig. $152 a-d$.

PEZIZa viridis Boltoni, F. Halif. t. III, p. 28 , n. 133 , tab. cix, fig. 1 (editionem Willdenow. citamus).

Xyloma pezizoides Pers. Syn. Fung. p. 105 , n. 7; Icon. pict. spec. rarior. Fung. fasc. III, p. 40-41, tab. xviII, fig. 1, a-d. - Alb. et Schw. Consp. F. Nisk. p. 66, n. 180. - Candollio, Fl. Gall. t. VI, p. 160 , n. $818^{\text {b. }}$ Ascobolus coronatus Schum. Enum. pl. Saell. t. alt. (1803), p. 437, n. 2134 (ubi fungillus in foliis Fagi et Castanece crescere dicitur).

Phacidium cononatum Fr. Obs. Mycol. parte I $(1815)$, p. 167 , n. $216 ;$ Syst. Mycol. t. II, p. 577, n. 16 ; Scler. Suec. fasc. V $\left(18_{2} 1\right)$, n. 165 , in foliis aridis Fagi, et Discosiam fagineam Lis. ${ }^{1}$ amplificatam referens. - Schindio, in suis Fasc. Mycol. parte 1, p. 36, n. 7, primum inter Phacidia libera tenens locum. Diтм. ap. Sturi, $F l$. Germ. parte in, t. I $(1817)$, p. 127, tab. LxiII, fungilli in foliis fagineis crescentis iconem fidam, super habitu saltem, præstante. - Greviluto, Fl. Crypt. Scotice, t. I, tab. LII, quod ad habitum in foliis quercinis eximia, de sporis autem quas ovatas minimasque repræsentat, vero longe aliena. - Movg. et Nestr. Stirp. Vogo.-Rhen. fasc. VI (1818), n. 559, in foliis quercinis et fagineis. - Mazerio, Stirp. Crypt. Gallice, ed. I, fasc. XII $(1832)$, n. 570 , et ed. alt. fasc. IX, n. 416 , utrinque in foliis quercinis et fagineis. - Rabenh. et Cesatio, in prioris Herb. Mycol. ed. alt. fasc. VIII (1858), n. 716 (in fol. fagineis). - BerKEL Eo, in collect. inscriptis Mag. of Zool. and Bot. t. I (1837), p. 513, n. 58, tab. xv, fig. 5, a, b. Cords, Icon. Fung. t. III, p. 31, n. 1, tab. v, fig. 81, et Anleit. z. Stud. der Mykol. p. cxir, tab. F, n. 59 , fig. 25-29, adumbratione autem quod ad endosporas attinet, utrinque vero minime congruis. - Fresenıo, Beitr. z. Myk. p. 70 , tab. viII, fig. 22 et 23 , thecas gravidas et paraphyses seorsas exprimentibus. Curreio, in Actis Soc. Limn. Londin. t. XXIV, parte alt. (1863), p. 155, tab. xxv, fig. 7, ascum gravidum exprimente, sed quod ad sporarum formam et dispositionem attinet, vix fida. - Sollaiannio, in Rabevn. Fungis Eur. exs. fasc. VII (1864), n. 652, in foliis querneis ex agro Coburgensi.

Lophodermium Phacidium Notarisio, in Parlat. Eph. Bot. Itala, ann. alt. t. II (1847), p. 42.

Huc eliam, sed immerito, ut arbitramur, trahitur Sclerotium quercinum $\mathrm{V}_{\mathrm{AHLII}}$ in Florce Danice t. VIII, fasc. xxiII (1808), p. 8, tab. Mccclxxx, fig. 2, et fungus homonymus Persoonio, in suis Ic. pictis, fasc. III, p. 42 , tab. xvIII, fig. 2 .

Parem atque Phacidium dentatum modo descriptum, coronatum sedem eligit, serius

${ }^{1}$ Quam videsis apud Mazerium, Stirp. Crypt. Gallice, ed. I, fasc. XXVII, n. 1347 , et ed. alt. fasc. XV, n. 747 . 
autem provenire videtur, maculis foliorum natalium decoloribus latius patentibus, imo utramque eorumdem paginam quasi integram tenentibus. Spernogona minima disculos atros aut sæpius punctula imitantur, mire abundant, sed, propter exiguitatem, scrutatoris oculos fugere queunt; pleraque vidimus $0^{\mathrm{mm}}, 16-25$ diametro crassa et spermatiis exilissime linearibus, rectis, inter se inæqualibus nec vulgo $\mathrm{o}^{\mathrm{mm}}, 0065$ longioribus fœeta. Fructus ascophori absque ordine certo el confertim gregarii inter spermogonia nascuntur; formam orbicularem et colorem atrum a principio affectant, lenticulas enim punctiformes nitidasque primum referunt, deinde autem discos coloris hebetioris nonnihil cupuliformes aut saltem late umbilicatos, limboque angusto pallidiori et tenuiori circumdatos; maturitatis tempore, in placentam exstantem, millimetrum unum v. sesquimillimetrum diametro æquantem, et undique in externo pariete similiter aterrimam singuli convertuntur. Tunc cœlo pluvio favente superna illorum pagina in lacinias complures, acutas, dentiformes et circumstantes a centro dehiscit, hymeniumque luteolum et oculo armato rudiusculum revelat. Stratum fertile $0^{\mathrm{mm}}, 15$ circiter crassum parenchymati tenuiori, albo, e cellulis polygoniis facto imponitur. THEс lineares, nonnihil acutatæ, deorsum attenuatæ, $\mathrm{o}^{\mathrm{mm}}, 11-13$ longæ et $\mathrm{o}^{\mathrm{mm}}, 013-016$ superne crassæ, e membrana tenui et achroa fabricantur, paraphysibusque nonnihil longioribus, exiliter filiformibus, simplicibus et minutissime capitatis abunde stipantur, glutine admodum pallido interposito et hymenium summum copiosius infarciente. SPOR octonæ in singulis ascis informantur, quasi sparsæ primum, demum autem in summa theca fasciculatim congregatæ; formam lineari-clavatam, hinc quadantenus incurvatam simul et obtusam, illinc acutam, affectant, continuæ sunt et $0^{\mathrm{mm}}, 06-08$ in longitudinem, atque vix $0^{\mathrm{mm}}, 0035$ in crassitudinem nanciscuntur.

Hieme currente in foliis hornotinis nascitur, eodemque tempore in bimulis perfectum reperitur, spermogoniis nondum tamen prorsus effotis. Modoni et Cavillæ longe rarius offenditur quam Phacidium dentatum cujus fere imago est in fructibus dignioribus omni modo ampliata, in spermatophoris e contrario deminuta.

Fungos æore fingas qui duplicem naturam manifestius declarent quam Phacidium dentatum et coronatum supra descripta; etenim in dubium vocare non licet quin punctiformia seu discoidia conceptacula quæ attigimus, nudispora alia, thecaphora et crassiora altera, tam necessitudine quam solita societate alia aliis connectantur.

Quibus notis Phacidium coronatum Fr. recens natum et solis constans spermogoniis, a Ph. dentato Sснм. item adhuc mere spermatophoro, tute discriminetur, nisi maculis vulgo majoribus, æore perspicimus; imo reticere nequimus quod in fructum Phacidii dentati Schn. perfectum et proxime apertum aliquando inciderimus qui in ipsis Phacidii coronati (Schum.) maculis natalibus, copiosa inter illius spermogonia lenticellasque olim ascigeras, solitarius sedebat. Porro licet hic fructus forma acute quadrata sui generis insigniretur, thecas tamen solito majores et endosporas magis lineari-claviformes ostendebat, ita ut super his notis medius stare videretur Phacidium inter dentatum Schм. et coronatum Fr. Inde fortassis quis colligendum existimabit hos fungillos pro formis diversis unius et ejusdem typi merito esse 
habendos. Huic sentire favent quæ præstantur apud Persoonium (Ic. pict. loc. supra cit.) super Phacidii coronati (Schum.) in quatuor partes cruciata nonnunquam scissura.

Iisdem fungis et maxime Phacidio coronato Fr. ex omni parte manifesto analogus est Coccomyces tumidus Notarisir ${ }^{1}$ et Dubyi (Monogr. Hyster. p. 49), i. e. Phacidium trigonum Schmidti in suis Fasc. Mycologicis, parte I, p. 40 , tab. alt. fig. 12, sive Hysterium tumidum $\beta$ trigonum nisi forsan Friesir (Syst. Myc. t. II, p. 592 et El. Fung. t. II, p. 145 , n. 40), saltem Mazeri (Stirp. Crypt. Gallice, ed. i, fasc. XVI [1836], n. 781 , et ed. alt. fasc. VIII, n. 368, utrinque in foliis quercinis); quippe hic fungillus non modo ovatus et trigonus, sed etiam suborbicularis promiscue deprehenditur, ita ut ne habitu quidem a frequentiore seu typica Phacidii coronati Fr. forma constanter recedat. Quod ad fabricam internam spectat, endosporæ minime ovatæ sunt, ut Schmidrio et Friesio olim videbantur (cfr. Syst. Myc. t. II, p. $59_{1}^{1}$, n. 40), sed exiliter lineari-lanceolatæ, rectæ aut quadantenus incurvatæ, $0^{\mathrm{mm}}, 03$ circiter longæ, $\mathrm{o}^{\mathrm{mm}}$, o 035 crassæ, nec manifeste clavatæ nec deorsum attenuatæ, septisque plurimis ut videtur divisæ. Tales saltem eas deprehendimus in exemplis Mazerianis modo citatis. Neque super iisdem vero congruenter loquitur clar. Duby in sua Hysteriorum et affinium monographia; endosporæ enim Coccomycetis tumidi Duв. thecas sociatæ non constituunt, nec maturæ e basi fixæ permanent" ut paraphyses filiformes mentiantur. Veremur ne magister genevensis in fungum maturum et perfectum nunquam inciderit. Endosporæ enim maturæ, in fasciculum constipatæ, summam thecam ovato-acutam tenent, asco reliquo deorsum longe attenuato et vacuo.

\section{Phacidium Pini.}

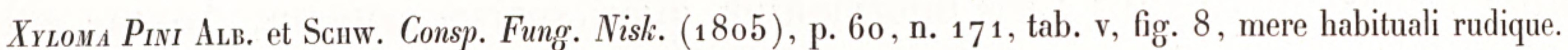
Hysterium Valvatum Neesio, Syst. Fung. p. 282 , n. 1, tab. xxxix, fig. 299, super endosporis minime fida; quem fungillum huc pertinere docuit Schмidтuus infra laudatus (loc. cit.).

Phacidivm (ex erumpentibus) PINI Schmidtio, in suis Fasc. Mycol. parte I (1817), p. 3o, n. 1, tab. iI, fig. 11 , quæ autem a vero quod ad endosporas "ovatas» spectat, non minus recedit quam adumbratio Neesiana modo citata. - Friesio, Scler. Suec. fasc. V $(1821)$, n. 163, in cortice pineo crasso; Syst. Mycol. t. II, p. 573 , n. 5 ; Sum. Veget. Scand. p. 369 , n. 11. - Mazerio, Stirp. Crypt. Gall. ed. I, fasc. XXVII (1843), n. 1348 , ed. autem alterius fasc. XV, n. 748 , utrinque in cortice Pini sylvestris L. - Tul. in Ann. Sc. nat. ser. III, t. XX (1853), p. 158. - Fr. Curreio, in Actis Soc. Linn. Londin. t. XXIV, parte II (1863), p. 155 , tab. xxv, fig. 36 , endosporam liberam exprimente ${ }^{2}$.

Pyrenochivm Pini Linkio, Handb. z. Erk. d. Gew. t. III (1833), p. 385, n. 2. - Balio, Syst. Fung. p. 57 et 89 , tab. xviII, figuris a NeEsio sumptis.

Phacidium Pini Fr. ad Coccomycetum suorum gregem, cujus typus est Hysterium tumidum Fr. $^{3}$ jam supra citatum, merito ducendum fore decernit Notarisius in Actis Soc. Crypt. Italce, fasc. V (1864), p. $371^{4}$.

1 Apud Parlatorem, Ephem. Bot. Itala, anno alt. t. II $(1847)$, p. 39 .

${ }^{2}$ Laudatus auctor verba facit in eadem commentatione tum super Xylaria vaporaria Berk. e sclerotio nata, quam autem vix dissimilem arbitramur aut Xylarice pedunculatce Dicks. genuinæ, aut pusille nostræ (supra t. II, p. 1720, tab. II), tum etiam, sub Valsce titulo, de Spharia lageniformi Sollm. cujus nos ipsi meminimus, 1. cit. p. $25 \mathrm{~g}$. (Videas Actorum modo cit. dictum fasciculum, p. 157 , tab. xxv, fig. $16, a, b, c, d[$ ad Valsam lageniformem Curr. spectantibus], 17 et 26 [Xylariam vaporariam Вевк. exprimentibus].)

${ }^{3}$ Cfr. Notarisil commentationem de fungis Hysterinis apud Parlatorem, Ephem. Bot. Itala, anno alt. t. II, p. 39 , et Duby Monographiam Hysteriorum et affinium, p. 49 .

${ }^{4}$ Ibidem declarat accuratus auctor ascos in Phacidio carbonaceo Fr. desiderari, inesse autem sporas oblongas, 
Fungillo nostro longe dissimile est Phacidium (Tryblidium) Pinastri Fr. (Scler. Suec. fasc. II [1820], n. 55; Elench. Fung. parte alt. p. $1_{13}$, n. 2) sive Cenangium (Tryblidium) Pinastri ejusd. (Syst. Myc. t. II, p. 184, n. 12) pro cujus forma monstrosa s. sphæriacea habetur Sphceroncema bullosum Fr. in suis Scler. Suec. fasc. I (1819), n. 28. (Cfr. Friesir Syst. Myc. t. II, p. 184, n. 12.) Id Cenangii Pinastri Fr. sub Tympanidum signo descriptum infra videsis, p. 151.

Nascitur apud nos intra pelliculas supremas corticis arescentis Pinus sylvestris L. autumno potissimum hiemalique tempore; lente crescit et totum fere per annum in quodam ætatis suæ momento reperitur. Fructus dignioris initia latent et ægre observantur, nisi peculiaris adhibeatur attentio; lentem refert superne convexiorem et sæpe umbonatam, totam ex parenchymate carnoso et extrinsecus niorescente, licet propter aliena velamina minime raro cinereus videatur. Idem quum adolevit, millimetrum unum aut unum et alterum diametro æquat, magis tumet et subhemisphæricus quandoque fit. Sunt etiam exempla quæ nonnihil angulosa et deformia evadunt. Conceptaculum maturum in lacinias dehiscit, nimirum parietem suum supernum, ex atra et crassa membrana, rumpit, discumque levem et fusculum revelat. Hymenium s. compages fertilis strato crassiori albo, ex parenchymate sclerotioide, imponitur, et simul cum eo corticea valvula nigra supposita excipitur. THeсе lineari-obovatæ, obtusæ et deorsum longe tenuatæ, paraphysibus exiliter baculiformibus, simplicibus, continuis aliis, septiferis alteris, superne clavatis, infuscatis et invicem glutinatis abunde stipantur. Endospore octonæ et fasciculatæ in singulis ascis, formam longe obovatolinearem obtinent, utrinque in cuspidem tenuem desinunt, septis v-Ix transversis dividuntur coloreque nigricante inficiuntur. Ascigera præter conceptacula, alia iis sine lege commista sæpiusque non pauciora, imo etiam copiosiora, reperire est quæ item nigra sunt sed longe minora, vulgo quasi punctiformia et acute umbonata; nihilominus tamen ex pari substantia ac fructus majores isti fabricantur indubiamque cum prioribus necessitudinem demonstrant. Illis cavitas est angusta, sinuosa, simplex, parietes autem sterigmatibus undique vestiti filiformibus et brevissimis, imo etiam spermatiis subsessilibus, exiliter linearibus, quandoque curvulis, sæpius $o^{\mathrm{mm}}, o_{1}$ longis, vix autem $0^{\mathrm{mm}}, 001$ crassioribus, innumeris et pallidis.

Fungillus parce gregarius viget ubicumque agri parisiensis et versaliensis colitur Pinus sylvestris L. Spermatiophorus quum æstate, tum hiberno tempore, ascophorus vero et perfectus, cupula hiante, potissimum hieme extrema reperitur.

dimeras et pallidas, sicque ea comprobat quæ jam præstitimus in tomo II hujus Carpologice, p. 181, circa id men- titi Phacidii quod Discellam carbonaceam dixerunt BerKeLews et socius Brooneus. 
** Endosporis ovatis. - Phacidia legitima Notarisio.

\section{Phacidium Ilisis.}

* Ad fungum pycnideum potissime spectant :

Spiteria bifrovs Sowerbeo, Fung. Angl. t. III (1803), tab. cGcxvi (rudi et vix quidem habituali), jam suadente Grevillio.

Ceuthospora phacidioides Grevillio, Fl. Crypt. Scotice, t. V (1827), tab. cclili, icone sat fida, admissis autem in descriptione notis plurimis, ex. gr. dehiscendi modo, quæ ad formam thecaphoram, Greviluio certe minime obviam, potius spectant. - Friesio, Syst. Myc. Ind. p. 69. - Mazerio, Stirp. Crypt. Gallice, ed. I, fasc. XII (1832), n. 571 , ed. autem alterius fasc. IX (1840), n. 421 (saltem pro parte in utroque loco, nimirum quatenus ilicicola), et in Dissertaiione sua XV de Stirpib. Crypt. Gallice, apud Ann. Sc. nat. ser. III. t. IX (1848), p. 330-337. - Berкeleo in Ноoкeri Fl. Brit. t. V, parte alt. (1836), p. 283 , n. 1. Fresenio, Beitr. z. Mykol. (1852), p. $7^{1}$ et 72 , tab. viri, fig. 33-42. - Balio, Syst. Fungor. parte alt. (1858), p. 69 et 81 , tab. xiv, fig. $1-4$, ex Grevillio sumptis.

Cevthosporarum typus Bonordenio in suis novissimis Disputationib. mycolog. (1864), parte iv, p. 77 , n. 24.

Ascochyta Aquifolit Libertie, Crypt. Ard. exs. fasc. IV (1837), n. 351 , docente Mazerio in Annalium nostrorum loco sup. cit.

Consulto sed verisimiliter sine justa causa, hic omittimus synonyma omnia quæ ad Ceuthosporas sede s. origine Aquifolio alienas, ut Cytisporam foliicolam (Lib.) Mazerio (in Ann. Sc. nat. ser. alt. t. XVII [1842], p. 117) et Mougeotio (Stirp. Vogo.-Rhen. fasc. XII [1843], n. 1176), fungillum in Vinca provenientem, nec dissimilem, judice magistro insulensi, tum Ceuthosporce phacidioidi Grev. ilicicolæ, tum Ceuthosporis quæ in foliis Laurocerasi, Hederce, Populorum, Quercus et cæt. nascuntur. (Cfr. Mazeri Stirp. Crypt. Gallice, ed. I, fasc. XII $\left[183_{2}\right]$, n. 571 , fasc. XXXIII $[1847]$, n. 1626 , et ser. noviss. fasc. II $[1853]$, n. $73,7_{4}^{4}$ et 75 .) Moneamus tamen fabricam horum fungillorum cum Ceuthospora Grevilliana ilicicola apte quadrare, prætereaque nos in eodem Vince folio simul reperisse pycnides et conceptacula ascophora quæ tum fungum Grevillianum, tum Libertianum digniorem, utrumque ilicicolas, ex omni parte mentiuntur. (Cfr. Mycothecam Mazerianam in Mus. Bot. Par.)

Huc insuper merito trahenda videtur, Friesio ipso nunc consentiente (in Ind. Syst. Mycologici, p. 166), Sphceria Hederce (Fr.) $\beta$ Ilicis Neesiorum in N. Act. Acad. nat. cur. t. IX, p. 256 , n. 3, tab. vi, fig. 23 , licet ad Stegias ducendam fore idem Friesius primum fuerit arbitratus (in Syst. suo Mycol. t. II, p. 522, sub n. 512$)$.

Hujus quoque loci est, et integrum quidem, Phacidium multivalve (DC.) Fr. (Syst. Myc. t. II, p. 576, n. 14), quippe judice magistro upsaliensi, cytisporeum genus est et Phomali propius, ut Cavalerius (Fl. par. t. I [1826], p. 442 infra) opinatus est. (Cfr. Friesir Elench. Fung. t. II [1830], p. 136 , n. 14, et Indicem Syst. Myc. [1832], p. 140.)

** Fungum perfectiorem, majorem et ascophorum præsertim designant :

XYloma multivalve Candolito, Fl. Gall. t. alt. p. 3o3, n. 818; Syn. Pl. Gall. p. 63, n. 818; el in Actis Musai Par. t. III (1817), p. 324, n. 28 , tab. III, fig. 8, $a, b$ (mere habituali); merito autem animadvertit $\mathrm{M}_{\text {AZERIUs }}$ in sua Dissert. XV supra laudata, CAndolli verba quum ad fungum ascophorum s. phacidieum, tum etiam ad nudisporum i. e. ceuthosporeum atlinere.

Phacidium (ex liberorum ordine) multivalve Schmidtio (qui tamen fungillum non viderat) in suis Fasc. Mycolog. parte I, p. 42, n. 11, quod caveas, inquit auctor, ne cum Phacidio Aquifolii Scнм. (Xylomale Aquifolii DC.) incaute confundas. - Moug. et Nestr. Stirp. Vogg.-Rhen. fasc. VI (1818), n. 560.

Phacidium Ilicis Libertie, Crypt. Ard. exs. fasc. IV (1837), n. 367 (docente Mazerio). - Mazerio ipsi tum in suis Stirpib. Crypt. Gallice, ed. princ. fasc. XXXIII (18/47), n. 1643, ed. autem alt. fasc. XXV, n. 1243 , tum in loco jam cit. Ann. Sc. nat. ser. III, t. IX (1848), p. 330-337. - Fresenio, Beitr. z. Mykol. (1852), 
p. 70 , tab. viII, fig. 20 et 21 , thecas gravidas el endosporas liberas exprimentibus. - Notarisio in Comment. Soc. Cryptog. Italee, fasc. V (1864), p. 370.

Suв matricis epidermide tenuata et pellucida disculus nascitur seu placenta orbicularis, millim. I-II diametro lata, in stroma solidum s. sclerotieum et intus atro-virens incrassata, suisque hospitalibus integumentis hæret. Pars suprema lentis hujusmodi utero unico centrali et sæpius pluribus minimis, sparsis vel circinatis, confoditur; uteri autem modo discreti ore perexiguo, et propter epidermidem solutam abicante singuli dehiscunt, modo conferti in spiraculo communi et latiore aperiri videntur; intrinsecus stylosporis vestiuntur simul et replentur. STyLоs longæ et vix $\mathrm{o}^{\mathrm{mm}}$, o o 35 crassiores, continuæ, rectæ, leves et muticæ, quasi sessiles generantur, congruoque tempore albidæ ejiciuntur. Sтвома ascophorum placentam mere pycnideam externa facie prorsus imitatur sed cavernulam longe ampliorem vulgoque unicam ostendit, et Phacidiorum more in lacinias late dehiscit, simul atque in solo fundo disciformi hymenium fertile induit. Id hymenii albidi ex thecis obovato-oblongis $0^{\mathrm{mm}}, 1$ circiter longis, $\mathrm{o}^{\mathrm{mm}}$, o o 8-o 1 crassis, et distiche octosporis, nec non paraphysibus simplicibus immixtis et vix protractioribus constat. Endospore ovato-lanceolatæ, rectæ aut rarius nonnihil incurvatæ, continuæ pallidæque, hinc $0^{\mathrm{mm}}, \mathrm{o}_{1}$, illine $0^{\mathrm{mm}}, 0035$ æquant.

Sub utraque specie frequens oritur in foliis et cortice arefactis Ilicis Aquifolii L. lente crescit et omni anni tempestate in variis incrementi sui stadiis reperitur.

Pycnideum fungum sexcenties, ascophorum contra rarissime vidimus apud Turones, in agro lugdunensi, bibractensi et compendiensi, nec non circa Fontembellaqueum (Valvins, Héricy). Stylosporæ ubi in aqua seruntur, valde augentur, didymæ fiunt, paulatim fucantur simulque in germen crassum mox prælongum, articulatum et ramosum, ramis gracilibus ac flexuoso-contortis, utrinque protrahuntur. Endosporæ non secus progerminant.

Primus intellexisse videtur b. Mazerius formas duas funginas ilicicolas apud Candoldium et posteriores mycologos vulgo coadunari, idque non dubitavit iis errori vertere. Mazerium secutus est FreseNıs qui licet solitam earum societatem et similem habitum ipse pariter compererit, aliam ab alia, propter fabricam disparem, salva conscientia removit. Nos tamen periculum alterius interpretationis subire, minime temerarium arbitrati, hanc jampridem proposuimus quæ supra iterum redit, nec hodie etiam cunctamur quin Phacidium Ilicis Lis. pro fungillo biformi habeamus.

Stylosporæ in folio Vinca minoris natæ minime differunt ab ilicicolis; endosporæ autem paulo angustiores in Vinca quam in Aquifolio generari videntur. Neminem fugerit id interpretationi nostræ summopere favere, nimirum quod Ceuthospora nudispora seu pycnidea cum Phacidio ascigero non modo in Aquifolio, sed etiam in Vinca coire soleat.

Animadvertendum velimus in Aquifolii foliis aridis etiam occurrere Discosiam quamdam ${ }^{1}$ ex punctis atris, minimis, confertissimis et passim coalitis, poro epidermideo albicante singulatim notatis, stylospo-

Fortassis Discosiam Leucostigma Lev. in Ann. Sc. nat. ser. III, t. V (1846), p. 286 , n. 421. 
rasque lineares et continuas foventibus quæ ciliis quidem subterminalibus de more ornantur ${ }^{1}$, semina vero Ceuthosporte nostræ phacidioidis forma, colore et demensionibus adeo imitantur, ut vix continearis quin dictam Discosiam pro definito Ceuthosporce seu Phacidii membro habendam existimes ${ }^{2}$.

Non possumus insuper quin moneamus foliis illis Aquifolii marcidis quæ Phacidium nostrum alunt, sæpissime etiam hospitio simul excipi fungillum minorem et placentiformem qui squamam disciformem ex matricis epidermide soluta stato tempore excutit proptereaque sine negotio discriminatur. Stegia Ilicis (Fr.) a $\mathrm{M}_{\text {azerio }}{ }^{3}$ dicitur sed a Trochilis Friesianis ${ }^{4}$, jam opinante BевкеLеo ${ }^{5}$, vix merito distinguitur; atque si illius hoc in loco meminerimus, causa princeps in eo est quod non modo Phacidio nostro frequens sit socius, sed etiam ejusdem ascos et endosporas prorsus imitetur.

\section{ICONUM EXPLICATIO.}

(Tab. XV, fig. 1-8.)

1. Anticam vides folii ilicini paginam in qua sedent sena pycnidia Phacidii Ilicis Libertis, conceptacula scilicet Ceuthosporce phacidioidis Greviluio, quorum pleraque spiraculis pluribus donantur; disculi præterea minimi ex pyrenomycete quodam, nempe Microthyrio microscopico MazERII (in Amn. Sc. nat. ser. II, t. XV [1841] , p. 138 , tab. xIv, fig. superioribus, et in suis Stirpib. Crypt. Gallice, ed. principis fasc. XXII, n. 1092) aut saltem fungillo, ut videtur, vix dissimili, folio insperguntur.

2 et 3. Pycnidia hujusmodi a vertice dimidiantur et locellos plurimos, rarius unicum, semente pallida farctos vel jam evacuatos, suis in penetralibus monstrant; medium folium hospitale, parenchymatis consumpti loco, occupant et utrique epidermidi arctissime hærent.

4. Pycnidia alia transverse dissecta sunt ut locellorum ordo s. distributio eo magis innotescat.

1 Discosice quarum meminerunt Notarisius (in Act. Acad. Sc. Taurin. ser. alt. t. X [1849], p. 355-363, cum iconib.) et Fresenıus (Beitr. $z$. Myk. fasc. II, p. 66-69, tab. viII, fig. 1-11) seminibus septiferis et longe, ut videtur, crassioribus a nostra discrepant. Sporarum appendiculas filiformes prorsus terminales apud Discosiam alneam Lib. (Sphariam Artocreas Todei) exprimit Curreius, simulque hæc semina in ascis cito destructis generari arbitratur; imo ascos, immaturos quidem, in eadem Discosia alnea deprehendisse sibi videtur. (Cfr. Acta Soc. Linn. Londin. t. XXII, part. Iv, p. 332 et 333 , n. 379 et 380 , tab. Lrx, fig. 143, stylosporas Discosice Artocreatis exprimente.)

${ }^{2}$ Id Discosice datur in Mougeoti Stirpibus Vog.-Rhen. fasc. VI (1818), n. 562, pro Phacidio Aquifolii Sснм. in suis Fasc. Myc. parte I, p. 34, n. 5, quod est Xyloma Aquifolii Candollio, in Actis Muscei Par. t. III, p. 324 , n. 29 , tab. III, fig. 7 (habituali), et Spharia Ilicis Friesio, Syst. Myc. t. II, p. 501, n. 449.

${ }^{3}$ Cfr. hujus magistri Stirp. Crypt. Gallice, ed. princ. fasc. XV (1834), n. $7_{2} 3$. Fungillus primum inter Spharias, sub titulo Sph. concavce, apud Sowerbeun (F. Brit. t. III, tab. cccviI) computatur, postea autem Xylomatibus a Greviluio ( Fl. Edin. p. 368, n. 8) annumeratur, subinde
Eustegia Ilicis a Friesio nuncupatur in suo Elencho Fung. parte alt. p. 112 et 113 , et Stegilla Ilicis a Rabenhorstio in Fl. Crypt. Germanice, t. I (1844), p. 163 , n. 1478. Continetur in ejusdem Rabenhorstir Herb. Myc. ed. alt. fasc. V (1857), n. 441 , et Fungis Eur. exs. fasc. V (1862), n. 463.

${ }^{4}$ Videsis Friesir $S$. Veget. Scand. p. 367 , nec non $\mathrm{M}_{\mathrm{A}}$ zerir Stirp. Crypt. Gallice, serie noviss. fasc. X (1857), n. 451 (scil. Trochilam Populorum Mazeri et notas accedentes). Trochilae apud Arminium Hofruans (Ind. Fung. p. 92 et 93$)$ sub Phacidiorum titulo numerantur.

${ }^{5}$ Conferas ejus librum inscriptum Outlines of British Fungology, p. 381, in nota. Proximam Stegice cum Trochila analogiam minime negat Notarisius, sed contendit notam ex caduco prioris velo nobis abunde esse cur utrumque signum s. genus merito retineamus. (Cfr. Acta Soc. Crypt. Italae, fasc. V [1864], p. 371 .) Velum simillimum ex matricis corticulo, suo tempore dimittit etiam Stictis fenestrata MaZerii (in Ann. Sc. nat. ser. III, tom. XVI [1851] . p. 321, et Pl. Crypt. Gallice, ed. alt. fasc. XXXIII, n. 1601), quæ in scapis aridis Scirpi lacustris L. hospitari solet; nondum, saltem quod sciamus, a cæteris Stictidibus aliter dehiscentibus remota est. 
5. Particula tenuis ex pycnidio a vertice dissecto desumpta est et valde amplificata; parietem fertilem in acie superna et stylosporas ibidem quasi sessiles natas ostendit.

Stylosporæ quæ februario (a. MDCCCLX) satæ germinaverunt et per longum mensem multimodis creverunt, passim inter figuras quæ ad fungillum nostrum hic spectant delineantur; omnes in germinando plus minus auctæ et fucatæ sunt simulque dimeræ aut polymeræ et torosæ factæ; germina quoque multifariam articulata et ramosa evasere.

6. Aliud folii ilicini fragmentum pycnidia simul et conceptacula ascophora exhibet; hæcce late dehiscunt et in labiis farina alba eadem consperguntur quæ etiam nitescit in pycnidiorum ore.

7. Conceptacula duo ascophora a summo dissecantur; pycnidum instar, cum superstitibus folii materni membranis utrinque, at maxime cum superna, coaluerunt; fructus utriusque cavitas simplex hymenio fertili in fundo vestitur.

8. Hymenii ascophori particula tenuis valde aucta.

In sinistra parte hujus figuræ, sursum et deorsum, dantur endosporæ quæ in aqua satæ sunt mense februario decedente (a. MDCCCLX) et per hebdomadem creverunt ac germina protrudere cœperunt.

Figuræ omnes februario et martio MDCCCLX adumbratæ sunt, juxta fungos ad Fontembellaqueum (Valvins) in foliis Aquifolii jampridem deciduis, sub initio dicti februarii mensis, tempestate pluvia, frigida, lectos.

Figuræ 1-4, 6 et 7 justis demensionibus bis decuplo majores factæ sunt, figuræ autem 5 et 8 , nec non stylosporæ et endosporæ omnes germinantes et sparsæ, vices cGcLxxx naturam excedunt.

Sunt etiam Phacidia quæ in plantis vivis hospitantur vitamque propterea sincerius parasiticam ducunt. Ex horumce numero est Phacidium Medicaginis Lis. cujus prima verba fecisse videntur b. Libertia, Malmedensis, in Botanico suo Ardennensi (n. 176), tum Mazerius in Actis Soc. Agric. Sc. et Artium insulensis, ad ann. MDCCCXL, p. 579 , et Stirpibus suis Cryptog. Gallice, ed. alt. fasc. XV (1843), n. $749{ }^{1}$. Fungillus frequens apud nos provenit, xtate recedente autumnoque, in foliis languidis Medicaginis sativa L. Maculis fuscis, orbiculatis, millim. I-II latis parceque gregariis hospitem inficit et ex iisdem fructus suos protrudit. Præter cupulas ascophoras quarum fabricam scrutatus est magister insu-

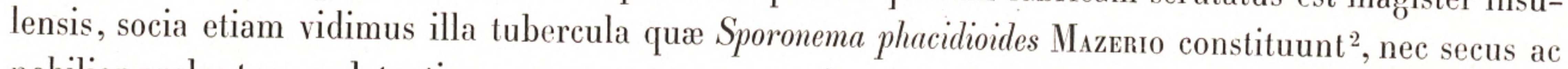
nobilior proles tum pedetentim emergunt, tum postea in valvas dehiscunt. His pycnidiis inest parva albidaque microstylosporarum copia quæ formam ovato-oblongam, rectam et continuam affectant, $0^{\mathrm{mm}}, 005$ longitudine vix excedunt et duplo angustiores sunt; sterigmatibus summis, quasi aciculis arrectis, singulæ primum solitarie innituntur. Pycnidiorum cavitas perexigua est et simplex videtur. Endosporæ ovatæ, nonnihil citriformes, rectæ, continuæ, oleoque pallido et homogeno refertæ, octonæ in singulis ascis lineari-oblongis generantur, et hinc $0^{\mathrm{mm}}, 01$, illinc $0^{\mathrm{mm}}, 005-006$ circiter æquant. Talia ideo

\footnotetext{
1 Continetur etiam fungoillus in Rabenhorsti Herbario Mycologico, ed. alt. fasc. IV (1856), n. 311, ubi prostant specimina Cesatiana ex agro subalpino Vercellensi. Ejusdem meminit Notarisius in Comment. Soc. Cryptog. Italee, fasc. V (1864), n. 370, sub Phacidiorum genuinorum signo. Adumbratio quæ præstatur in Durier Flora $\mathrm{Al}$ geriensi, tab. xxviIr, fig. 1, assuetum fungilli nostri habitum minime refert, et potius, ni fallimur, ad Phacidium divergens Roвergio (in Mazeri Stirpib. Crypt. Gallice, ed.
}

alt. fasc. XXV, n. 1241), quod in foliis Medicaginum etiam viget nec terræ mauritanicæ alienum est (cfr. op. modo laud. p. 56o), spectat. Sporonema phacidioides $\mathrm{M}_{\text {AZERII }}$ perperam interpretatus est cl. Streinz in suo Nomenclutore Fungorum, p. 440 et 577 .

${ }^{2}$ Cfr. Annal. Sc. nat. nostros, ser. III, t. VIII (1847), p. 182 , n. $7^{6}$, nec non Mazeri Stirp. Cryptog. Gallice, ed. I, fasc. XXXIII, n. 1645 , et ed. alt. fasc. XXV (1847), n. 1245 . 
sunt hæc seminula qualia Notarisius apud legitima sua Phacidia fore decrevit. (Cfr. Comm. Soc. Crypt. Itala, manip. V, p. $37_{0}$ et $37^{1}$.)

Ascobolus Trifolii Bivone (Pl. Sic. manip. IV, p. 27 , tab. vi, fig. 3), seu Peziza Trifoliorum Lib. quam Ascobolis longe alienam et veram esse Trochilam arbitratur magister genuensis modo laudatus (Comm. cit. fasc. V, p. 358), a Phacidio Medicaginis Lıв. æore, ut saltem nobis visum est, distinguitur ${ }^{1}$.

Ne quidem sincerum Phacidiorum habitum reapse imitantur tum Phacidium carbonaceum Fr. in suis Scleromyc. Suecice, fasc. VI (1821), n. 21 o, quod Discellarum Berkeleianarum nobilem præstat typum, tum etiam Phacidium commutatum ejusdem magistri (collect. modo cit. fasc. V [1821], n. 164), fungillus populicola et sæpius pycnideus, ita ut modo Diplodiam mutilam Friesir macrosporam, nunc pycnidium microspermum Dothidece sphcerioidis Fr. (Syst. Myc. t. II, p. 552 , n. 11) repræsentet. Prioris jam verba fecimus in tomo II hujus Carpologice, p. 181. Alterius in cortice arido Populi tremula L. apud nos hieme vulgatissimi, exempla perfecta nuper tantum cognovimus; formam contra pycnideam quam videre licet in Mazeri Stirpibus Crypt. Gallice, ed. I, fasc. X (1830), n. 480, sexcenties offendimus. Id pycnidis populicolæ sibi quidquam summopere analogum habet in FriesI Scleromycetib. Suecanis, fasc. IV (1820), n. 129 , sub titulo Hysterï Sorbi W thideam pyrenophoram Fr. (Syst. Myc. t. II, p. 552 , n. 12 ) sorbicolam ${ }^{2}$ ad Dothideam spharioidem Fr. po- $^{-}$ pulicolam proximam accedere ${ }^{3}$; illinc Hysterium modo dictum pro forma minore sterilique Dotlidere pyrenophore Fr. magistro upsaliensi haberi. (Cfr. Syst. Myc. t. II, p. 553.) Longius, de specie saltem, a Diplodia mutila Fr. (Syst. Myc. t. II, p. 424, n. 235 , sub Spharia) recedit pycnidium microsporum Dothidea spharioidis Fr. quamvis olim illi analogum (in Syst. Myc. t. II, p. 425), ac nuper unum et idem cum ea fuerit æstimatum. (Cfr. Summ. Veg. Scand. p. 417 , n. 2, ubi citatur Scler. Suec. n. 164.) Diplodiam mutilam Fr. saltem populicolam ${ }^{4}$, cujus meminimus in tomo II hujus libri, p. $7^{4}$, ad Dothideam sphcerioidem $\mathrm{F}_{\mathrm{r}}$. etiam si traxeris, tunc huic concedes, præter fructus ascophoros, quasi triplex pycnidiorum genus, nec non et spermogonia. Pycnidia macrospora, e tuberculis crassis sæpius discretis et multiloculatis, alia stylosporis oblongis, utrinque obtusissimis, rectis, albis et sæpius continuis, alia seminibus subsimilibus at nigris et dimeris scatent; utraque sub Diplodia mutila titulo a plerisque mycologis, dissimilitudinis insciis, conjunguntur. Pycnidia autem microspora quæ in fungillo Mazeriano supra citato (Stirp. Crypt. Gallice, ed. I, fasc. X, n. 480) præsertim abundant, stylosporas ovatas,

${ }^{1}$ Contra Phacidium (Tryblidium) calyciiforme Friesı (El. Fung. t. II, p. 131, n. 1) meritissime apud eumdem rei mycologicæ peritissimum virum a Phacidiis sinceris removetur et pro typo novi generis, Blitrydii anagrammatice dicti, traditur (loco cit. p. 374). Fungillus est in agro Versaliensi minime frequens; Calosphariam nostram verrucosam (sup. t. II, p. 113 , tab. xxIv) habitu quodammodo imitatur, endosporis autem crassis, ovatis v. ovato-oblongis ac muriformibus, Hysteria et Verrucarias bene multas. Judice Friesio (Syst. Mycol. t. alt. p. 183, n. 11) non differt a Cyphelio scabrosulo Acharir (in Actis Acad. Sc. Holmiensis, ad ann. MDCCGXV, p. 266, n. 5, tab. vi, fig. 10) cujus tamen verba cum solitis plantulæ nostræ characteribus vix congruunt.
${ }^{2}$ Quæ est Pyrenochium Sorbi Linkio, Handb. z. Erkenn. d. Gewcechse, parte III, p. 385, et Dothiora pyrenophora (Sorbi) Friesio, in sua Summa Veget. Scand. p. 418; continetur in RabenhorstiI Fungis Europ. exsicc. fasc. IX (1865), n. 872 .

${ }^{3}$ Id analogiæ, Friesio duce, jampridem indigitavit Notarisius in Actis Acad. Sc. Taurin. ser. alt. t. XVI (1857), p. 471. Pycnideam formam Dothidece sphcrioidis Fr. populicolæ videre est in Raвenнorsti Fungis Europ. exsicc. fasc. VIII (1865), n. 754 .

${ }^{4}$ Hujusce formam simplicem et phæosporam adumbravit Notarisius in Actis Acad. Sc. Taurin. ser. alt. t. VII (1845), p. 27 , icone viI. 
uniloculares, $0^{\mathrm{mm}}, 0065$ circiter longas et dimidio angustiores, pallidas et rectas vomunt. Spermogonia intimis in parietibus saturate nigrescunt, cuniculis labyrintheis confodiuntur et spermatiis angustissime ovato-linearibus, rectis et vix $0^{\mathrm{mm}}, 00_{2}$ longioribus referciuntur. Quod ad tubercula thecis gravida spectat, fructus ascophoros Dothidea ribesice $\mathrm{F}_{\mathrm{r}}$. et affinium super notis principibus imitantur: locelli fertiles item parietibus propriis et paraphysibus simul destituuntur; thecæ longe cylindricæ, obtusissimæ, subsessiles, e membrana crassissima struuntur singulæque sporis octonis, monosticho vel partim disticho ordine digestis, quasi integræ replentur; hæ sporæ formam oblongam, utrinque obtusam, rectam, in medio septifero angustatam proptereaque didymam obtinent, $0^{\mathrm{mm}}, 0_{2} 6$ et quod excedit longitudine, $0^{\mathrm{mm}}, 008$ crassitudine majori æquant, septaque II-III transversa et unum aut unum et alterum contrarium in utroque dimidio sub maturitate concipiunt ${ }^{1}$.

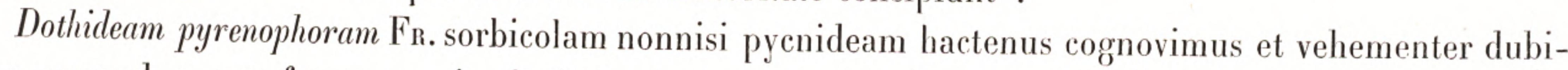
tamus eundem esse fungum qui sub titulo Ascospora pyrenophore apud Bonordeniun thecaphorus adumbretur. (Cfr. ejus Handb. d. Mykol. p. 63, tab. III, fig. 65, endosporas cylindricas et curvulas exprimente.)

${ }^{1}$ Semina hæc polymera a Curreio sub signo Sphcerice mutila $\mathrm{F}_{\mathrm{r}}$ in Actis Societatis Linnaeance Londinensis, t. XXII, parte III (1858), p. 284, n. 192, tab. xuIx, fig. 191, tradita fuisse, nobis non constat, quippe anglus magister accuratiorem naturæ funginæ observatorem se præstare solet. 
VII.

PEZIZEI. 
«Fungoides est plantæ genus cujus signatura a figura potissimum pendet. Nonnuliæ enim species cyathum, aliæ py«rum inversum, quædam infundibulum vel scutellum, vel lentem, vel denique hypocraterem forma simulant. Rursus «aliquæ species ornatæ pediculo, aliæ eodem destitutæ. Omnes vero seminibus minutissimis, vel rotundis, vel ovatis. «supernam partem infectæ, quæ semina deinde vel contractis, dum explicantur plantæ, fibris, vel levissimo quovis "etiam lenis auræ succussu in altum instar fumi aut scintillarum ejiciuntur."

(Мıсн. N. Plant. Gen. p. 204.) 


\title{
PEZIZEI.
}

\author{
FUNGORUM HELVELLOIDEORUM Persoonir, HELVELLACEORUM autem seu HYMENOMYCE- \\ TUM UTERINORUM Friesir qui postea etiam DISCOMYCETES ab eodem magistro et discipulis \\ ejus dicti sunt, pars maxima. = HYMENOMYCETUM ASCOPHORORUM fimiliæ XLIX-LII, \\ typis paucis exclusis, Corde, in sua Introd. ad Mycolog. stud.p. 1/49-156. = ELVELLACEORUM \\ pleraque genera Berкel.a, Outl. of Brit. Fungology, p. 358 et seq.
}

Discomycetum centrum, nobilis Fungorum familiæ nobilissimos typos, nunc attingimus, jam vero fractis viribus, librum nostrum paucis absolvere cogimur. Ex Helvellaceis proprie dictis sive Discomycetibus majoribus, pileatis aut clavæformibus, nullus duplex seminum genus nobis hactenus ostendit, ita ut hoc super argumento Ascomycetum magnates videantur Hymenomycetum principes libenter imitari. Longe vero alia est plebis indoles; vulgus præterea Discomycetum, ut humillimis et exiguis formis præsertim constituitur, typorum diversorum multitudine et prodigiosa individuorum copia, Helvellaceos majoris dignitatis, quum mitratos, tum clavatos, mire antecellit. Decuit ideo et sapientissimis naturæ legibus s. universæ mundi hujus œconomiæ congruenter jussum est, ut huic plebi varia et fecundissima generatio impertiretur. Fructuosæ istius indolis pauca tantum exempla nec nisi velut exiguum specimen his in pagellis proponere nobis hodie conceditur; confidimus tamen id brevis expositionis satis futurum esse causæ cur indagatores ad multifariam Discomycetum naturam altius scrutandam olim accendantur.

De his ipsis Discomycetibus nobis tractandum est quos in justa genera digerere et ordine disponere nuper tentavit Notarisius in Actis Soc. Cryptog. Italce, fasc. V (1864), p. 357-388. Veremur autem ne plurimi quilbus mycologia curæ est, nobiscum doleant magistrum genuensem prudentia æquo majori usum fuisse, quum secum constituisse videatur horum solummodo characterum in instituendis generibus rationem habere qui e fructibus dignioribus seu ascigeris trahantur, silentioque præterire quidquid ex altera parte ad genera definienda et illustranda conducere valeat. Non dubitamus autem quin præmissa hæc Notarisiana dissertationem alteram minus mancam, systema absolutius, nobis prænuntient; id saltem nobis maxime in votis est. Nec minus avide exspectamus quæ de Pezizarum vigendi modo se brevi expositurum pollicitus est Antonius de BARY, anno proxime elapso, in præfamine ad suam 
multiplicem commentationem cui titulus est : Beiträge zur Morphologie und Physiologie der Pilze (1864).

Sectio I. Conidia, si qua sunt, e stromate nata. Fructus saltem biformes; omnes, cujuscunque sint generis, initio clausi et conceptaculiformes. - Нетеro Реżz..

\section{SCHIZOXYLUM.}

SCHIZOXYLUM genus est Persoonianum nomenque; a suo conditore posteaque Candollio et aliis inter Lichenes computatur, nunc vero Durieo Montanioque veriorem demonstrantibus analogiam, pro fungino potius habetur.

Relictis fungis Phacidieis sincerioribus, in Pezizeorum fronte collocare sane licebit fungillum patelliformem, olim dubiæ sedis, quem tamen inter priores, imo inter Phacidia genuina, quidam de re fungina scriptores, iique e commendatissimis, haud cunctanter admiserunt. Typum solitarium, ut videtur, etiam nunc constituit.

\section{Schizoxylum SEPINCOLA.}

Schizoxylum sepincola Pers. in Ann. Soc. Wetteraw. tom. alt. fasc. I (1811), p. 11, n. 6 (in Lichenum numero, licet ambigua plantulæ natura auctorem minime fugerit), tab. x, fig. 9. - Moug. et Nestr. Stirp. Crypt. Vog.-Rhen. fasc. II (1811), n. 174, in lignis abietinis fabrefactis et quasi farina albida parcissime conspersis, ex agro Argentoratensi. - Montanio et Durieo in Fl. Algerice, t. I, p. 558, pone Ostropam, ad calcem fungorum Hysterinorum, tab. xxviI, fig. 4. - Mazerio, Stirp. Crypt. Gall. ser. noviss. fasc. IX (1857), n. 429, origine non declarata; opinante autem magistro insulensi fungilli locum aptiorem in systemate Ostropam inter et Phacidium versari, quod sentire jam publici juris fecerant clar. auctores Florce Algeriensis supra cit. anno D. MDCGCXLIX. - Leveilleo in Demidoffi Itin. Ross. t. alt. (1842), p. 151, ad Lichenum calcem, Collemata inter et Calicia, tab. iv, fig. 6, analysi admodum manca.

Patellaria? sepingola Candollio, Fl. Gall. t. VI, p. 181, n. $952^{2}$, in Lichenum numero.

Calycium? sepincolum Dub. Bot. Gall. t. II, p. 639 , n. 21.

Calycium inquinans, $\gamma$ sempincola Scher. Enum. Crit. Lichen. (1850), p. 164.

Gycledum sepincola Wallr. Fl. Crypt. Germ. parte IV, p. 511 , n. 2652.

Lecanidion sepincola Rabenh. Fl. Cryptog. Germanice, t. I (1844), p. 342 , n. 2624.

Phacidivm schizoxylon Friesio, Scler. Suec. n. 412 (docentibus Mazerio et Montanio, locis sup. cit.): Sum. Veg. Scand. p. 369, n. 3. Fungillum antea pro lichene sincero ex grege Limboriarum Acharir, magister upsaliensis habuerat. (Cfr. ejus Syst. Myc. t. II, p. 572, et El. Fung. parte alt. p. 13o, obs. 3.) - Huc autem minime spectal, non obstantibus synonymis allatis, Xylographa Schizoxylon Notarisio in Comment. Soc. Cryptog. Italie, fasc. V (1864), p. 375 , quippe descriptio ibidem præstita neque cum fungo nostro, neque cum Montaniana adumbratione quadrat ${ }^{1}$.

Biformes, nigri, duri et suberoso-lignei erumpunt fructus plantułæ nostræ, ex ma-

${ }^{1}$ Error alius in dissertatione Notarisiana circa Xylographam sane irrepserit, quum enim id generis niti dicatur figura quinta tabulæ vigesimæ octavæ Florce Algeriensis, qua autem icone nil nisi Peziza phacotricha Dur. et Ler. 
terie nuda, modo quasi pulvisculo seu farina albida parcissime conspersa, velata, modo detersa, sed nihilominus tamen albicante. Eadem propterea tuberculis minimis, obtusis, semïmmersis et variæ crassitudinis, simul et scutellis longe paucioribus absque lege sed laxiuscule conspergitur. Tubercula plurima, reliquis minora et quadantenus conica, nil nisi mera pycnidia sunt, quippe ex cavernula clausa et simplici per porum angustum vomunt microstylosporas cylindricas, curvas, utrinque obtusissimas, continuas, pallidas, $0^{\mathrm{mm}}, 0035-005$ longas, vixque $0^{\mathrm{mm}}, 002$ crassas. Sunt autem tubercula jam ab initio magis obtusa et semiglobosa quæ tot scutellas recentes et nondum explicatas sistunt; crassitudine mox cæteris præstant, tum vertice dehisci s. aperiri videntur paulatimque discum revelant atrum et excipulo concolori marginalum. Scutelle quum adoleverunt, late patent, millimetrum et quod superest diametro æquant, subsessiles sunt, ex parenchymate pallido suis in penetralibus fabricantur, crustam autem atram undique induunt et thalamium planum aut convexum, fusculum, ipsumque strato crasso et nigerrimo s. atro-violaceo tectum fovent. Tнвск longe lineari-cylindricæ, in utraque parte acutatæ. $0^{\mathrm{mm}}, 013-016$ in longitudinem adipiscuntur, sed $0^{\mathrm{mm}}, 0065-0095$ crassitudine non̉ excedunt; e membrana crassiuscula fabricantur, maturoque tempore sporis longe filiformibus integræ replentur quæ in fragmenta innumera vix $0^{\mathrm{mm}}, 0035$ longiora tandem singulæ solvuntur. Paraphyses copiose immixtæ, exiliter filiformes sunt, multimodis ramosæ nec in apicibus manileste incrassatæ.

Crescit in ligno pineo v. abietino nudo, etiam fabrefacto, sed jampridem cœeli injuriis obnoxio proptereaque exeso et varie destructo.

Plantulam descripsimus juxta exempla matura et perfecta, parisina dicta, quæ ex herbario b. ThulLLERII in Meratianum migraverant, nuncque in Musæo Bot. parisiensi continentur. Endosporarum numerus in singulis thecis quis reapse sit, æore comperimus; series autem earumdem manifesto saltem duplex est in qualibet asci parte. Hæ sporæ quas vidisse paucis contigerit, antequam in fragmentula abeant, septis transversis presso ordine signantur.

Montaniana fungilli adumbratio apud Durı.si Floram Algeriensem in eo peccat quod crusta thalamio imposita justo longe tenuior nec saturate fucata exprimatur. Quum plantula perfecta formam admodum pezizeam obtineat, inter Discomycetes sinceros, ut opinamur, militare meretur, licet non velimus analogiam illam infitiari quam cum Pyrenomycetibus perquam legitimis, ut Torrubia ophioglossoide et congeneribus, aut Propoli Berkeleiana Desm. fungillo item clauso et sphæriiformi ${ }^{1}$, propter endosporas tandem minutatim concisas ostendit. Thalamium et reliquæ fungi partes, iodea aqua affusa, minime

exprimitur. Sincerum Xylographarum Friesianarum typum in Xylogr. parallela Fr. (S. Veg. Sc. p. $\left.37_{2}\right)$, scil. in Hysterio parallelo WahL. (Fr. Scler. Suec. fasc. III, n. 95 ) s. Hyst. abietino Pers. (Moug. Stirp. Voog.-Rhen. fasc. VII, n. 656 ) si intueamur, iisdem Schizoxylum Persoonianum ægre consociaverimus.

' Pulchram hanc plantulam cujus jam meminimus in tomo 1 hujus Carpologice (p. 79 et 227), Fontebellaqueo primum obviam habuimus; eandem iterum reperimus hieme proxime elapsa, caulibus aridis Cirsii angustifolii sedentem, in saltibus udis vallis Cavillanæ; exempla illa nostratia Mazerianis (Melodunensibus) quæ videre licet in Plantis Crypt. Gallice, ser. noviss. fasc. I (1853), n. 14, nullo modo dissimilia sunt. 
cærulescunt, sed colorem fusco-luteum assuetum induunt; quare liquet etiam ex hac nota Schizoxylum immerito Lichenibus olim fuisse consociatum; cæterum ne Calycia quidem fabrica interna imitatur.

Contra Agyrium rufum Fr. ${ }^{1}$ propter sedem suam assuetam cum Schizoxylo nostro prorsus congruum, in aqua iodea subito saturate totum cærulescit, ideoque se Lichenibus propius quam Fungis ostendit. Qua de re tamen pugnant clar. Nrlander ${ }^{2}$ et Jos. Notarisius. (Cifr. prioris Tentam. de Lichenib. instruendis, Dissert. alt. p. ${ }^{187}$, et Prodr. Lichenogr. Gall. p. 148, necnon alterius commentationem de Discomycetum ordinatione in Actis Soc. Cryplog. Itala, fasc. V, p. 365.) Agyrï rufi Fr. capitula s. cephalodia hemisphærica margine omnino destituuntur, nec dubitamus quin Stictidem? rufam Persoonir (in suis Obs. Mycol. parte alt. p. 74 , n. 116 , tab. vi, fig. 8 ) reapse repræsentent. Thecæ in icone Cordæana (Anleit. z. Stud. d. Mykol. p. xciv, tab. F, n. 62 , fig. 8 , ex Iconib. Fungor. sumpta) nec justam formam, nec solennem suam distributionem obtinuerunt. Tubercularia (Agyrium) rufa Corde in suis Iconib. Fungorum, t. I, p. 4, tab. I, fig. 65, alio sane spectat, licet pragensis magister eandem pro vero Agyrio rufo Friesi proponere non dubitet. Ejusdem Agyrï rufi cum Pyronemate analogia, Notarisi pace sit dictum, multo minus movemur.

\section{TYMPANIS.}

(Tab. XIX, fig. 10-12.)

Genus Todeanum quo PEZIZE nonnullæ Persoons et aliorum, sicut fungilli pauci SPHERIIS olim apud Friesius annumerati, nune simul comprehenduntur. $=$ TYMPANIDES Notarisio, in Actis Soc. Cryptog. Italee, fasc. V (1864), p. 382 , n. 20.

Fructus dense cæspitosi, rarius solitarie sparsi, biformes, nudispori et spermogoniei alii, ascophori alteri; priores uterum Sphariis simplicibus assuetum mentiuntur, et modo discreti oriuntur, nunc contra ascophoris qui patellas breviter suffultas imitantur, adnascuntur. Spermatia exilia, recta et brevissima sterigmatibus item gracillimis ac ramosis insistunt et in cirros ejiciuntur. Patella ascigeræ margine crassiusculo et integro explicatæ definiuntur, stratoque duro et atro in fronte vestiuntur. Thесж late cylindricæ, obtusissimæ, myriasporæ, paraphysibus filiformibus et simplicibus stipantur. Endospor m minimæ, spermatiomorphæ.

FungiLLI corticicola, duri, cornei, glabri aut tenuiter furfurosi, lente crescentes et suum habitum arescendo vix mutantes, quare duplici de causa veluti perennes.

Jampridem mirati sumus cur decreverit Elias Fries Tympanidum genus a Cenangiis longe

\footnotetext{
Quod videsis in collectaneis Mougeotianis s. Stirpib. Crypt. Vogeso-Rhenanis, fasc. XI (1840), n. 1096.

${ }^{2}$ Nylandro assentit E. Coemans qui Aggrium rufum Fr. ut et Hysterium parallelum $\mathrm{W}_{\mathrm{AHL}}$. ad Lichenes infimæ notæ
}

ducenda arbitratur. (Cfr. ejus animadversiones circa stirpes nonnullas cryptog. Belgicas minus notas, in Actis Acad. Sc. Belg. ser. alt. t. V, n. xir.) 
recedere et aptiorem inter Pyrenomycetes quam sub Discomycetum signo sedem habere. (Cfr. illius Elenchum Fung. parte alt. p. 17, et Summ. Veget. Scand. p. 364, in nota extrema.) Quod primitus « veræ Spherice" sint, aut saltem Sphcerias habitu mentiantur, non negamus, at necesse nobis est hanc interpretari similitudinem. Atqui Tympanides recentes sola Pyrenomycetum pycnidia imitantur et varii fungorum ascophororum ordines ea inter se necessitudine devinciuntur ut non magnopere demirandum arbitremur si eorundem affinitates pycnidiis subsimilibus etiam denuntientur. Quum autem Fungi ut cætera vegetabilia juxta notas ex entibus perfectis ductas ordinari soleant, Tympanidum cupulatarum prius quam pycnidearum rationem habere decet, si veram earum dignitatem rite metiri velimus. Eadem valent de Cenangïs quæ item ad Pyrenomycetes libentissime traxisset magister upsaliensis. (Clr. ejus Syst. Myc. t. II, p. 178 .) Duplicem Tympanidum indolem olim exposuimus in Annalib. Sc. naturalium, ser. III, t. XX (1853), p. $141-143$.

\section{Tympanis Pinastri.}

PeZtza PInastri Pers. Obs. Mycol. parte alt. p. 83, n. $130 ;$ Syn. Fung. p. 672, n. 139 . - Candollio, Fl. Gall. t. VI, p. 20, n. 191 f. - Movg. et Nestl. Stirp. Vogo.-Rhen. fasc. VI $(1818)$, n. 587 , in cortice Pini Picea et Abietis.

Pinacididm (Tryblidium) Pinastri Friesio, Scler. Suec. fasc. alt. (1820), n. 55, in cortice abietino, scil. idem et ipsissimus fungus qui continetur in Rabenнorsti Fungis Europ. exs. fasc. I, n. 33 , infra cit.

Cenangiva $\left(T_{\text {ry }}\right.$ bidium $)$ Pinastri Friesio, Syst. Myc. t. II, p. 184 , n. 12. - Dub. Bot. Gall. t. II, p. 736 , n. 9 .

Tryblididm Pinastri Friesio, S. Vegét. Scand. p. 369 , n. 3.

Lecanidion atrum Rabenhorstio, in suis Fungis Eur. exs. fasc. I (1859), n. 33 (in cortice abietino Austriæ superioris), excluso synonymo allato (Patellaria atrata Fr.); minime autem eidem magistro in sua Fl. Crypt. Germanice, t. I (1844), p. 342 , n. 2623 .

Pro fungillo nostro monstroso habet Friesius suum Spharoncema bullosum in Sclerom. Suec. fase. I (1819), n. 28 (quod sentire æore probaverimus, exemplis quæ nobis suppetunt si confidere licuerit), et Pezizam Pinastri, y ramosam Alb. et Schw. Consp. F. Nisk. p. 344, n. 1029. (Cfr. Friesir Syst. Myc. t. Il, p. 184, et Summ. Veget. Scand. p. 369 , nota 1.)

Aв initio et in extremam usque æatatem fungillus simul aterrimus, glaberrimus et gelatinoso-cartilagineus est, arescendoque durus et corneus fit, ita ut fragomina tenuissima cultro acuto facillime cedat. In cæspites gregatim dispersos viget, rarius fructus solitarios spargit. Singuli autem cæspites cupulas plurimas, confertissimas, brevissimo suffultas stipitulo aut subsessiles, e stromate tuberculiformi prorsus latente in corticibus crassioribus edere solent; in tenuioribus contra easdem pauciores spermogoniis mixtas aut spermogonia sola protrudunt. Fructus utrumque genus globulum perexiguum in principio refert; spermogonia verum mucronulo citissime denotantur; cupulæ contra umbilico minimo. Spermogonium perfectum sæpius formam plus minus ovatam affectat nec $0^{\mathrm{mm}}, 2$ longitudine excedit, parietes crassos obtinet et cavitate simplici confoditur. Sterigmata quibus confertissimis intrinsecus in omni parte consitum deprehenditur, exilissime filiformia, et ramis strictissimis multibrachiata, $\mathrm{o}^{\mathrm{mm}}, 035$ longitudine vix exce- 
dunt, copiamque spermatiorum edunt qua conceptaculum vulgo repletur. Hæc autem corpuscula de more tenuissima sunt, recta, continua, nec $0^{\mathrm{mm}}$, o o 35 longiora. Gupulis adolescentibus, umbilicus in discum anguste acuteque marginatum convertitur, cujus pagina nitidula indolem reliqui excipuli aliquandiu adeo retinet ut universam cupulam eadem et ipsissima crusta tectam credas. Postea vero disci materies quadantenus pallescere videtur et ad crustæ illius naturam accedit quæ summas paraphyses thecasque apud bene multos discomycetes conglutinare solet. Attamen velum de quo agitur peculiariter crassum, durum et continuum in fungillo nostro semper observatur. Theс lineari-cylindricæ, nonnihil clavatæ, obtusissimæ et subsessiles, $\mathrm{o}^{\mathrm{mm}},{ }_{1} 3$ in longitudinem adipiscuntur, licet $0^{\mathrm{mm}}$, oo 7-0og $^{-0}$ majori crassitudine non excedant, membrana crassiuscula, maxime in apice, fabricantur, integræque sementicula constipatissima replentur. Hæc autem tota ex innumeris constat corpusculis exilissimis, rectis aut subincurvatis, continuis, $\mathrm{o}^{\mathrm{mm}}, 002$ vix longis et in aqua mire trepidantibus. Paraphyses filiformes, rigidulæ, simplices, sursum versus nonnihil clavatæ simul et infuscatæ, veli s. hymenii crassi nigrique thalamio superpositi gratia adglutinantur.

Nascitur autumno hiemeque in corticibus Abietum recens demortuarum; vivum maturumque vidimus in truncis cæsis Abietis pectinate DC. montium (Carthusiensium) Gratianopolitanorun, septembri, anno MDCCCLVII.

Præmissa descriptio potissimum valet de fungillo Carthusiensi qui vivus nobis occurrit; ab exemplis vogesiacis (Mougeotianis), suecanis (Friesianis) et germanicis (Rabenhorstianis) supra citatis quæ inter se ne iota quidem discrepant, eo recedere videtur quod fructus ejus cupuliformes in singulis cæspitibus seriem duplicem vulgo ordinent proptereaque extrorsum protractiores et in suo suffulcro nonnihil eccentri evadant; bene multi etiam rugosi v. sinuosi insuper apparent. Cupulæ solitariæ formam in omni parte magis regularem ostendunt. Majorum diametros sesquimillimetrum raro excedit. Endosporas spermatiis ipsis exiliores et breviores generari miramur.

Persoonius qui fungillum de quo agitur in cortice Abietis excelsce DC. crescentem sane viderat, qualis scilicet in mycotheca Friesiana et Rabenhorstiana modo citatis traditur, scutellas ejus sæpius solitarias quam cæspitosas deprehenderat, easque hinc cum Peziza sua Cerasi et P. Prunastri, illinc cum fructibus ascophoris Lichenum contulerat. (Cfr. ill. magistri loc. sup. citatos.)

Cum fungillo nostro minime quadrant verba illa Friesiana : « Cenangium... demum in lacinias plures, obtusas, dehiscens, disco albido \%. (Syst. Myc. t. II, p. 184.) Reliqua autem descriptio et synonyma allata plantulam de qua locuti sumus manifeste designant. Cupulam ejus laceram nunquam vidimus, nec in disco albentem.

Non leviter erravit clar. Raвеnновsт qui fungillum nostrum Lecanidii nomine salutavit perinde ac si veram Patellariam atratam Fr. præ oculis habuisset. Hi fungilli colore quidem inter se conveniunt, seminibus autem luculenter differunt. Præterea Patellariis spermogonia competere nondum cognovimus.

Tympanidem Pinastri (P Prs. $_{\text {. }}$ et potissime fungillum in Abiete pectinata DC. vigentem proxima imitatur Tympanis illa populicola cujus olim sub titulo Tympanidis saligna. Top. meminimus ${ }^{1}$. Contra de specie

${ }^{1}$ Cfr. Ann. Sc. nat. ser. III, t. XX, p. 141 , nota 4. 
longius recedit Tympanis conspersa Fr. $^{1}{ }^{1}$ qualem saltem in Mali sylvestris (Fontebellaqueo, Cavillæ) et Sorbi aucuparice L. corticibus aridis albo-pruinosam vidimus ${ }^{2}$. Exempla quæ in Corylo et Quercu multo rariora offendimus, more Tympanidis in Populo tremula L. obviæ, glaberrima se habebant.

\section{EXPLICATIO FIGURARUM.}

(Tab. XIX, fig. 10-12.)

10. Fructus nostræ Tympanidis Pinastri ex arido cortice Abietis pectinatce montium Gratianopolitanorum in cæspites densos erumpunt; globus medius seu major fit quasi e solis scutellis duplici ordine digestis; superus autem e scutellis minoribus simul et spermogoniis; inferior denique e solis spermogoniis constipatissimis. Scutellæ pleræque extrorsum libentius expanduntur quapropter stipitulo eccentrato hærent. Cæspites omnes quod ad veram crassitudinem spectat, bis decuplati monstrantur.

11. Thecæ gravidæ et paraphyses; endosporis plurimis exclusis et circum circa disseminatis.

12. Spermatia simul cum sterigmatibus quibus primum innituntur. Figura hæc et quæ antecedit, vices circa CCCLxxx pariter amplificatæ sunt.

Hic fungillus ob solitam suam duritiem vere corneus est ejusque sori globosi et crassi e fructibus plurimis utriusque generis densissime coalitis, maxime autem ex spermogoniis stipatissimis vulgo struuntur. Varium suum propter habitum diversissimis nominibus nuncupatur. Dicitur enim Lichen-Agaricus (quintus tertii ordinis) Michelio, $N . P l$. Gen. p. 105, scilicet Lich.-Ag. ceespitosus, acaulis, nigricans et qui dum sub arborum cute erumpit, pulvisculo farinaceo quo est involutus, sese exonerat (quod autem synonymon, maxime propter Friesir auctoritatem qua niti licet, attulimus); = Peziza sphcerioides Rотніо, in Pauli Usteri Ann. der Bot. t. I (1791), p. 11, n. 10, tab. I, fig. $6 ;=$ Peziza Pyri Persoonio, Syn. Fung. p. 671, п. $134 ;$ Myc. Europ. t. I, p. 327 , n. $298 ;=$ Peziza Aucuparice eid. Pers. Myc. Europ. t. I, p. 327, n. $300 ;-$ Movg. et Nestu. Stirp. Crypt. Vog.-Rhen. fasc. VIII (1 823$)$, n. 789 , in cortice Sorbi aucuparia; $=$ Peziza sphariceformis (sorbicola) Rebent. Fl. Neom. p. 387, n. 1344 ; = Peziza conglomerata Waнlens. Fl. Lapp. (1812), p. 534, n. $1083 ;=$ Spharia conspersa Friesio, in Act. Acad. Sc. Holm. ad ann. MDCGGXVII, p. 112, n. 128; Sclerom. Suec. fasc. I (1819), n. 12, in cortice Sorbi; = Cenangium conspersum eidem Friesio, Scler. Suec. fasc. V (1821), n. 171 , in cortice betulino; = Cenangium Aucuparice BaLIo, Syst. Fung. parte alt. p. 60 et 91 , tab. xIx, quæ adumbrationem Todeanam Sphcerice cespitosce Tod. non mutatam tradit; = denique Tympanis conspersa Fr. Syst. Myc.t. II, p. ${ }_{7} 5$, n. 6 ; El. Fung. t. II, p. 19 , n. 6, ubi monet nobilis auctor se in fungum globulo etiam coronatum aliquando incidisse; Summ. Veget. Scand. p. 399, n. $1 ;-$ Grev. Fl. Crypt. Scotice, t. VI, tab. cccxxxviII, vix fida nec absoluta ut jam animadvertit Notarisius, l. infra citato, quippe fructus sphæriiformes omittit, endosporasque sphæricas imprudenter exprimit; - Duв. Bot. Gall.t. alt.p. 737 . n. $3 ;-$ Corde (Anleit. z. Stud. der Mykol. p. xcvi, tab. G, n. 64, fig. 34-39) qui endosporas non novit;-TUL. in Schlecht. Ephem. Bot. t. XI, p. 53, et Ann. Sc. nat. ser. III, t. XX, p. 141-143, tab. xvi, fig. 15 et $16 ;-$ Notarisio in Act. Soc. Crypt. Italce, fasc. V (1864), p. 382. Huc etiam apud Streinz (Nom. Fungor. p. 634) trahitur Sphceria fissivela Toder (F. Meckl. sel. parte alt. p. 18 , n. 14 , tab. $x$, fig. 86 ) cujus autem notæ peculiares vix cum fungillo nostro apte quadrant.

${ }^{2}$ Item tenuiter parceque albo-farinosa offenditur Tympanis alnea Friesir (Syst.Myc. t. II, p. 174, n. 2, et El. Fung. parte alt. p. 18, n. 2) seu Peziza alnea Persooni (Syn. Fung. p. 673 , n. 142 , et Myc. Eur. t. I, p. 325 , n. 290) quam Albertinius et Schweinitzius Sphariam versiformem nuncupant (Consp. F. Nisk. p. 52, n. 149 , tab. Ix, fig. 3); eandem præterea cum Tympanide con-

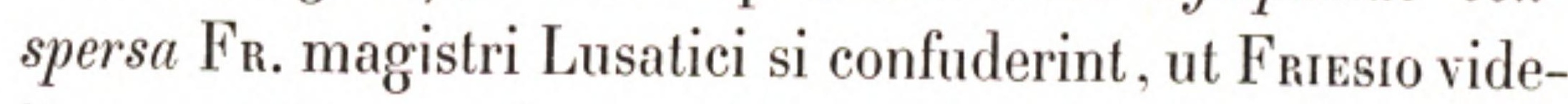
batur, minime profecto mirabimur, quippe hanc conspersam ex omni parte mentitur; contra a Dermatea Frangule nostra, i. e. Sphceriaversiformi, Rhamni, Aцв. et Schw. longe recedit, quod upsaliensis magistri pace dicamus. Utrum vero rectius censeat Friesius de Spńceria sua inversa alnicola qua Tympanidis alnece status primordialis exprimatur, plane ignoramus. (Laudati viri conferas loc. modo citatos et Syst. Myc. t. II, p. 415.) Tympanidem alneam Fr. et

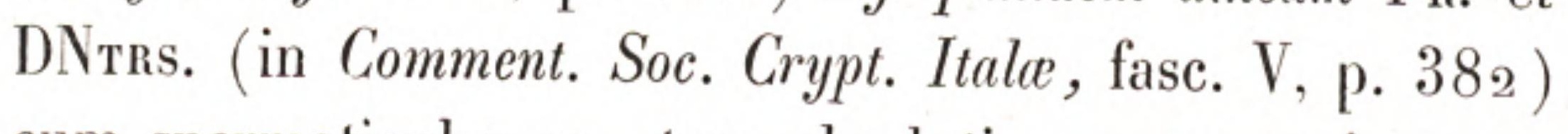
cum spermatiophoram, tum absolutiorem seu ascigeram, non semel reperimus in cortice et Alni grlutinosce $\mathrm{G}_{\text {FRT }}$. nostratis, Modoni Cavillæque Versaliorum, et Alni incance DC. in Delphinatu ac Sabaudia, autumno. 


\section{Tympanis Ligustri.}

Tympanis saligna (Tode) Berkeleo et Br. in Ann. and Mag. of nat. Hist. ser. alt. t. VII (1851), p. 185 , n. 584, et priori tum in Ноокеri Ephem. Bot. t. III (1851), p. 320, tab. ix, fig. 1, tum in suismet Elem. Mycol. Brit. p. 37 4, n. 4, tab. I, fig. 10, de præcedenti loco sumpta et simul thecas ac paraphyses conidiophoras exprimente. - Bвоомеo in Raвеnнorsti Fungis Europ. exsicc. fasc. III (1860), n. 229 (ex Anglia).

TYMPANIS in Ligustro vigens cujus olim meminimus in Ann. Sc. nat. ser. III, t. XX, p. 142, in nota.

Eruere nequimus utrum huc spectet necne vera Tympanis saligna Toder in suis $F$. Meckl. sel. parte J, p. 24, tab. Iv, fig. 37, quam Elias Fries in Salicibus aridis etiam viderit. (Cfr. hujusce Syst. Mycologicum, t. alt. p. 176, n. 7.) Utriusque magistri verba cum fungilli nostri solitis characteribus non plane quadrant; «velum bombacinum et candidum r cujus meminit Friesius, vel in planta recentissima nunquam deprehendimus. His perpensis, cognomine usi sumus quod fungillo nostro melius congrueret.

Fungr pinicolæ rarissime in arborum frondosarum partibus simul vigent, quare, frustra suadente similitudine, nulli sane placebit Tympanidem Ligustri, nostram, fungillum item ex omni parte atrum et glaberrimum totumque gelatinoso-corneum et durum, ad Tympanidem abieticolam modo descriptam trahere. Cæterum acuta non desunt discrimina quæillius autonomiam declarent. Fructus ejus ascophori, quos solos hactenus novimus, laxe quidem gregarii sunt at sæpius discreti seu solitarii; e medio matricis cortice singuli assurgunt. Cupula eorumdem ubi adolevit late aperta et millimetrum circiter lata, marginibus subintegris et acutiusculis, deprehenditur, stipiteque brevi, tereti, crasso, subtus obtusissimo et pro maxima parte in matrice latenti sese excipit; originem scutellæ hujus si quæsieris, capitulum reperies obtusum initioque integrum, quo in vertice subinde hiascenti, discus ater pedetentim revelatur. Huic disco seu thalamio incumbit crusta crassa, dura, atro-fuliginea; contra hymenium ipsum intrinsecus pallidum est. Theск late cylindricæ, obtusissimæ, subsessiles, $0^{\mathrm{mm}}, 095-112$ longæ et $0^{\mathrm{mm}}, 016$ circiter crassæ, endosporis minimis, ovato-globosis aut brevissime angusteque ovatis nec $o^{\mathrm{mm}}$, oo 2 longioribus, pallidis, innumeris et constipatissimis integræ singulatim referciuntur. Accedit quoque paraphysium admodum exilium et simplicium copia non parva.

Nascitur in ramis emortuis Ligustri vulgaris L. autumno hiemeque, nec infrequens est in saltibus cavillanis agri versaliensis.

Frustra hactenus fungilli spermogonia quæsiimus.

In eadem ligustrina virga clariss. Bевкецеy et Broone aliquando simul repererunt Tympanidem modo descriptam, rite ascophoram, Diplodiam quamdam sporis crassis, dimeris et longo funiculo singulatim suffultis insignitam, imo et fructus heteroclitos, disciformes scilicet ac thecigeros, cum seminibus diplodieis intermixtis. (Cfr. Ноокевг Ephem. Bot. supra cit. loco dicto.) Singulare hoc duplicis indolis exemplum videre nobis nondum contigit; imo et veremur ne in quidquam hujusmodi nos unquam incidamus, quippe, Bевкецжг pace dicamus, Tympanidis endosporæ ejusque sic dictæ stylosporæ tum forma, 

tum crassitudine, adeo inter se discrepant, ut vix dubitemus magistrum laudatum veri specie fuisse
deceptum.

\title{
III. DERMATEA.
}

\author{
(Tab. XIX, fig. 13-17.)
}

Hodiernæ nostræ DERMATEE, modo pycnideæ vel spermatiophoræ sint, constituunt SPHERIAS Todeo, Persoonio, Candollio, Linkio et aliis, Ceratostomata Friesio, Microperas Leveilleo, POLYTHECIA Bonordenso; perfectiores autem, nimirum ascigeræ factæ, PEZIZE dicuntur Persoonio ejusque discipulis, DERMATEE, TYMPANIDES aut CENANGIA Friesio, nec non CYCLEDA et TYMPANIDES Walrothio; respuunt contra typos quos DERMATEAS aut PEZIZAS olim nuncupavimus in Ann. Sc. nat. ser. III, t. XX (1853), p. $143-147$.

Conceptacula nudispora pycnidea v. spermogoniea aut simul utriusque generis; modo breviter tubulosa vel longiora et lageniformia tuncque cæspitosa et fructibus nobilioribus seu ascophoris vulgo sociata; modo contra ovata vel depresso-globosa et sphærïformia, solitaria aut cæspitosa. Sperмatia filiformia el sæpius incurvata. STYlospora continuæ aut parce septiferæ, nunc lineari-lanceolatæ, flexuosæ s. arcuatæ, nunc ovato-oblongæ, utrinque obtusæ, recte vel lunulatæ. Patellæ sessiles aut brevissime pediculatæ, vix unquam, ne quidem initio, velatæ, tandem late explicatæ, imo convexæ et pulvinatæ. Тнесж lineari-oblongæ, octosporæ, sporis cylindricis et curvulis, vel ovato-oblongis et rectis, quandoque parce septiferis. Paraphyses summæ incrassatæ, fucatæ, et cum strato mucoso concolori crassoque coalitæ.

FUNGILLI in arborum fruticumve demortuorum corticibus subexsuccis gregatim ac prope omni anni tempestate crescentes, saturate fucati, arescendo duri et coriacei evadentes talesque diu persistentes.

Quemadmodum de Tympanidibus, sic de Cenangïs seu Dermateis nostris senserunt El. Friesius et discipuli ejus; quum enim animadverterint ea in principio mentitam Sphoriarum faciem affectare, postea e contrario Pezizas sinceras imitari, non dubitaverant quin Cenangia medium locum inter ordinem fungorum cupulatorum et Pyrenomycetes tenerent. (Cfr. FriesII Syst. Myc. t. II, p. 177.) At minime constat eosdem magistros unquam suspicatos fuisse formam priorem seu sphærieam structura definita insigniri, quippe qui eandem in cupulatam s. perfectiorem demum mutari censerent. Cur tamen non viderint sagax Friesius, Persoonius ${ }^{1}$, Albertinus aliique id vix credibile fore, Sphreriam scilicet fallacem Whanengergir, dubiam PersoonI et consimiles, longe tubulosas aut subuliformes, in discos pezizeos latos et plerumque

\footnotetext{
${ }^{1}$ Cujus videsis Mycologiam Europacam, t. I, p. 329-331.
} 
subsessiles unquam transire s. converti? (Cfr. libr. cit. p. 180 et 181.) Profecto mycologi illi ad veritatem non propius accederant, qui Cenangiorum pycnides pro Sphcriïs imprudenter habuerant, at transformationes non proposuerant quæ fidem excederent. Qui ex altera parte, iique e neotericis sunt, duplicem Cenangiorum et affinium indolem negant, oculos habent, sit venia verbo, ut non videant; parum est enim contendere probatas nobis consociationes naturæ repugnare, mycologosque brevi earumdem fore pertæsum ${ }^{1}$; utinam viri doctrinæ nostræ contradicentes olim satius ducant controversas res attentiori animo pensare, fungos vivos iterum investigare, et aptiorem seu vero congruentiorem multiplicis eorum indolis interpretationem, si quam ejusmodi reperire eis contigerit, in medium proferre!

Dermatearum gregem eodem prorsus modo hic intelligere volumus atque Jos. Notakisius in novissima sua de Discomycetibus ordinandis dissertatione, in Commentariis Soc. Crypt. Italie, fasc. V, evulgata; quare etiam pro generis hujus prototypo habemus Dermateam Cerasi Fr. Notis autem apud laudatum auclorem allatis, has pro more nostro addere opportuit quæ ex pycnideis fungis trahuntur.

Iterum non dubitamus quin Micula Mongeotii Dubyo, i. e. Spharia Micula Fr. cujus jam meminimus in tomo I hujus Carpologice, p. 224 , omnino sit hujus loci et pycnis sincera, Spherice dubice Pers. analoga. Id quidem necessitudinis eo manifestius nobis hodie patet quod duplex illud stylosporarum genus quod magistro genevensi innotuerit, nos ipsi recentiori tempore in pycnidiis Dermatece Cerasi Fr. item deprehenderimus. Fungillum Dubyanum inter Sphcrias cytisporeas imperfectas recensendum fore arbitratur Curreius in Actis Soc. Linn. Londinensis, t. XXII, parte Iv $(1859)$, p. 322 , n. 288 , tab. LvII, fig. 70 (macrostylosporas solas exprimente).

* Dermatea sinceriores, stylosporis lineari-lanceolatis, arcuatis aut flexuosis, endosporis continuis. - . EUdERMATEE.

\section{Dermatea Cerasi.}

\footnotetext{
* Fungus pycnideus v. spermogonieus :
}

SPheria dubia Persoonio, Ic. pict. fasc. IV, p. 48, tab. xx, fig. 1, quam autem adumbrationem videre nobis nondum licuit.

Spheria achroa Candolito, Fl. Gall. t. VI, p. 125 , n. $781^{\circ}$.

SPHERIA FALLAX Wahlenb. Fl. Lapp. (1812), p. 522, n. 1008.

Cenangivm Cerasi a junius Friesio, Syst. Myc. t. II, p. 180.

Micropera Drupacearum et M. roseola Lev. in Ann. Sc. nat. ser. III, t. V (1846), p. 283 , n. 410 et 411.

Dermatea CErasi (Fr.) pycnidifera Coemansio apud Rabenh. Fung. Eur. exs. fasc. III (186o); n. 232 , ex agro gandavensi. lbidem simul (sub n. ${ }_{2} 33$ ) ab eodem mycologo datur, saltem ut arbitrabatur, forma fungilli nostri spermogoniophora, quæ autem nil nisi cytisporam Valsa leucostomatis (PErs.) promere videtur. Errorem ipse postea cognovit. (Cfr. Schlechtendali Ephem. Bot. t. XIX [1861], p. 102 et 261.)

Polythecis species Bonordenio in supra citata Ephem. Bot. Berol. t. XIX (1861), p. 204.

Micropera CERasi ejusd. in suis novissimis Disput. Mycologicis (1864), p. 133 , n. 2.

${ }^{1}$ Cfr. Bonordeni Disputationes Mycologicas (1864), p. 135. 
** Fungus perfectior, scyphophorus :

Peziza CERasi Persoonio, Disp. meth. Fung. p. $35 ;$ Syn. Fung. p. 673, n. 141; Myc. Europ. t. I, p. 329, n. 3o4. - Candollio, Fl. Gall. t. VI, p. 19 , n. $19^{1^{e}}$, saltem ut videtur. - Movg. et Nestl. Stirp. Vogo.Rhen. fasc. V (1815), n. 494 .

Tubercularia Cerasi Schum. Fl. Scell. t. alt. p. 184 , n. 137 4, ipso volente Friesio, in Elencho Fungor. t. alt. p. 21, n. 3.

Cenangium (Scleroderris) Cerasi $\beta$ adultum Friesio, Syst. Myc. t. II, p. 180. - Mazerio, Stirp. Crypt. Gall. ed. I, fasc. XIV (1834), n. 665 , et ed. alt. fasc. XII (1841), n. 571 .

CEnangivm $C_{\text {Erasi }}$ Dub. Fl. Gall. t. II, p. 735 , n. 4. - Curreio in Ephem. Sc. microsc. t. VII (1859), p. 229 , tab. xI, fig. 11 et $12 .-$ Bеrк. Outl. of Brit. Fung. p. 374 (sine descriptione).

CYcledum Cerasi Wallr. Fl. Crypt. Germ. t. alt. p. 512, n. 2655.

Dermatea Cerasi Fr. Summ. Veg. Scand. p. 362, n. 5. - Rapenn. Herb. Mycol. ed. alt. fase. VI (1857), n. 517 , ex agro Dresdensi. - Notarisio, in Act. Soc. Cryptog. Italce, fasc. V (1863), p. 372.

*** Fungus integer aut saltem bifariam fertilis :

Cenangivm Cerasi Tul. in Schlecht. Ephem. Bot. t. XI, p. 53 ; Ann. Sc. nat. ser. III, t. XX (1853), p. 138 et seq. tab. xvı, fig. 12 et 13 , et in hac ipsa Carpologia, t. I, p. 224 , et tomo II, p. 113 et 114 , tab. xxIv, fig. 1-4; olim autem simul nobis incautis perperam habitum (saltem quod ad pycnidia) pro Sphcerice (Valsce) Leveillei nostræ parte spermogoniea (in variis locis quæ citantur in tomi superioris p. 113).

Fungus tantummodo biformis est, licet semina triplicis generis ostendat; causa in eo versatur quod spermogonia et pycnides eandem prorsus faciem vulgo præ se ferant, nec nisi sementis natura quam singula fundant, manifeste discriminentur. Sori fertiles ex internis et stuppeis corticis hospitalis stratis erumpunt ubi ubi membranacea seu pergamena eorumdem tegmina quamlibel ob causam transversim scinduntur et plus minus hiant; plerique propterea figuram linearem v. lanceolatam describunt et demensionibus maxime variant; sunt qui ramum maternum quasi integrum ambiunt; minores carcerem suum corticeum ipsimet sæpius disciderunt. Singuli vulgo e fructibus monosticho ordine stipatissimis ac dissimilibus constant, nudisporis mediis, ascophoris contra utrinque accedentibus; soros etiam videre est bene multos e fructibus utriusque habitus et naturæ quasi promiscue sociatis compactos; neque præterea raræ occurrunt lirellæ ex fructibus unius et ejusdem generis. Sтro⿰л omnibus est crassum, continuum, carnoso-subereum, e parenchymale luteo-virente et fuscis variegato maculis; alte latet fructusque inferne plus minus coalitos (licet sæpissime natura dispares) et furfuribus luteo-virentibus, ærugineis, albidis, roseisve extrinsecus conspersos simul enititur. SpErrogonia et pycnides in fistulas diversiformes at semper angustissime uniloculatas protrahuntur nuncque vix exstant, nunc e contrario tubulos rigide assurgentes, coriaceos el tenuato-pungentes, ore pallido, fingunt. Spermogonia pycnidiis minora sæpius consistere, saltem longe rariora occurrere videntur; adulta steriomatibus filiformibus, ramosis et brevissimis, ad fauces usque spiraculi introrsum densissime vestiuntur. SPERмати item filiformia, continua, utrinque truncatula, modice incurvata aut flexuosa, rarius subrecta, $\mathrm{o}^{\mathrm{mm}}$, o $_{3-016}$ in longitudinem obtinent. Pycnidum interni parietes similem sterigmatum sylvam induunt et ex iisdem stylosporas gignunt lineari-lanceola- 
tas, curvas, flexuosas aut sigmoideas, $0^{\mathrm{mm}}, 04-05$ longas, in medio vix $0^{\mathrm{mm}}, 0035$ crassiores, et plasmate pallido v. oleo tandem homogeno refertas; horum seminum copia cirrorum aut pultis in modum, pro aeris conditione, ejicitur et colore pallide luteovirenti aut sordide roseolo inficitur. Quæ aptato loco et opportuno tempore industria manu seruntur, intra paucos dies prælonga, exilissima flexuosaque e summis lateribus, rarius ex ventre edunt germina; nihilominus tamen formam suam et nativam crassitudinem retinent, at septa antea dubia aut ægre conspicua, tunc manifestiora, semper autem paucissima, ostendunt. Fructudu digniorum seu ascophororum initia tot punctula exigua referunt sive stromatis communis summitates truncatas, retectas, colore cæsio-virenti aut magis nigrescenti fucatas et margine elevato furfuribusque citrinovirentibus ornato circumdatas. Poslea disculi hujusmodi lente dilatantur; diu plani et in ambitu sinuoso-irregulares consistunt, pedetentim autem, simul ac magis infuscantur et quidem saturate nigrescunt, plus minus convexi efficiuntur, ita ut perfectiorem statum quum attigerint, pulvinos imitentur hemisphæricos, marginibus reflexis et prorsus latentibus. Horumce majores millim. III-Iv diametro circiter æquant et in singulis lirellis modo solitarii vel pauci, nunc abundantiores, ut deni, duodeni aut plures, occurrunt; omnibus natura est dura, suberea s. dermea. Hynenium o ${ }^{\mathrm{mm}}, 1$ 4-16 crassum, strato ex muco concreto et rubro-nigrente integrum tegitur, in quo summæ paraphyses, clavatæ simul ac fucatæ, immittuntur et quasi fasciculatim conglutinantur. Thec longe claviformes sporas octonas, ovato- v. lineari-oblongas, utrinque obtusas, continuas, curvulas, $0^{\mathrm{mm}}, 013-02$ longas et $\mathrm{o}^{\mathrm{mm}}, 0035-0055$ crassas, singulæ fovent.

Per totum annum reperitur apud nos, haud infrequens, in ramis cæsis aut natura demortuis, nondum autem exsuccis, Cerasorum tum cultarum, tum etiam sylvestrium; viget tamen potissimum brumali hibernoque tempore, cœlo pluvio, ita ut qui sera æstate autumnoque spermogoniis aut pycnidiis abundare cœperat, nonnisi hieme abeunte vereque insequenti fructibus ascophoris maturis superbire valeat. Fungus aridus et obsoletus in cortice natali diu persistit.

Tubulis seu fistulis nudisporis, modo brevibus, subtruncatis et vix exsertis, nunc contra protractioribus et millim. III-v longis, fungillus variat; item propter furfures iisdem fructibus parce v. copiosius inspersos, æruginosus aut albidus, imo roseolus apparet; furfures autem ejusdem coloris sunt in lagenis nudisporis et marginibus discorum ascophororum qui accedunt. Disci ipsi quisquiliarum istius modi semper expertes, initio humidi et quasi visciduli, deinde velıti pulvere fusco-nigrenti plus minus conspersi videntur; rarissime leves et nitidi, nisi arte detergantur, dici queunt. Cirri e stylosporis aut spermatiis protrusis, pulsque ex prioribus pluvia roreve solutis albida, pallide luteo-virentia aut roseola deprehenduntur; ipsæ autem stylosporæ et spermatia semper, ni erraverimus, forma et crassitudine sibi constant.

Stylosporas e pycnidibus recens exclusas novembri MDCCCLXIV prospere sevimus; sementes autem istiusmodi antea plurimas variis anni temporibus tentaveramus quæ non bene successerant.

Spermatia ante annos proxime elapsos nobis nondum manifesta innotuerant; verba super iis hodie 
non facimus nisi post iteratas et accuratas disquisiliones, Cavillæ Versaliorum præsertim institutas. Specimina autem spermatifera etiam vidimus quæ Meloduni clar. Rousser, viro fungorum studiosissimo, obvia facta fuerant.

\section{INTERPRETATIO ICONUM}

(Tab. XIX, fig. 13-1 7.)

13. Dermatea Cerasi $\mathrm{F}_{\mathrm{R}}$ e e rimoso cortice Cerasi vulgaris MrLl. erumpit; a sinistra vides pycnidia recentia, furfurosa ; cæspites autem crassiores e patellis plus minus expansis simul et pycnidiis componuntur.

14. Cæspes ex utroque fructuum genere a summo dissectus proponitur; pycnidia stromatis centrum tenent et sementem suam in cirros eruclant.

15. Stylosporæ quæ maturæ et recentes in aqua satæ sunt, novembri medio (MDCCCLXIV), et intra paucos dies læte germinarunt; germina nonnulla apice coalescunt et semina discreta isthmis filiformibus jungere videntur.

16. Spermatia pauca seorsim delineantur.

17. Thecæ paraphysibus stipantur.

Fig. 13 et 14 nativis rerum demensionibus decuplo majores sunt; cæteræ vices CGCLXxx auctæ sunt.

A præcedenti typo cerasicola vix differre videntur quum Dermatea Prunastri Fr. $^{1}$ tum etiam Derm. Padi ejusdem auctoris (in sua Summa Veg. Scandinavice, p. 362) ${ }^{2}$. Prioris sori fertiles, juxta exempla Libertiana alia, Mougeotiana altera, quæ nobis præsto fuere, sæpius ovato-globosi, item ex fructibus unius generis, aut pycnidiis simul et patellis ascophoris dense sociatis, imo partim coalitis, constant. Pycnides mire tubulosæ, e basi crassa ad apicem continuo tenuatæ s. acutatæ, duræ, rigidæ, ex parietibus introrsum fusco-atris factæ, millimetrum longitudine aliquando excedunt, et gummi seminiferum sub guttæ specie per spiraculum suum excludunt. Gutta autem initio albida, postea contra infuscata, in stylosporis lineari-lanceolatis, lunulatis, utrinque acutis, continuis, $0^{\mathrm{mm}}, 02-023$ longis et vix $0^{\mathrm{mm}}, 0035$ crassioribus tota fere consistit. Scutellæ minores forsan quam apud Dermateam Cerasi $\mathrm{F}_{\mathrm{r}}$. deprehenduntur, at super fabrica, thecarum sporarumque forma et demensionilsus, eundem fungum prorsus imitantur.

${ }^{1}$ Fungus hic pycnideus vel spermogonieus constituit Sphariam Prunastri Persoonio in herb. Achariano (docente Friesio); - Sphariam rigidam Candollil, Fl. Gall. t. VI, p. 132 , n. $789^{1}$; - Ceratostoma spurium FriesII, Obs. Mycol. t. II, p. 338, n. 316; - Cenangium (Scleroderrim) Prunastri $\beta$ rigidum ejusdem in suo Syst. Myc. t. II, p. 18o. Cupuliformis autem et absolutus factus, dicitur : Peziza Prunastri Persoonio, Disp. Fung. p. 35; Syn. Fung. p. 673 , n. $140 ;$ Mycol. Europ. t. I, p. 33o, n. 305 ; Candollio, Fl. Gall. t. VI, p. 20 , n. $191^{\mathrm{g}}$; ALвеrт. et Schw. Consp. F. Lus. sup. p. 345, n. $1030 ;-$ Cenangium Prunastri a Friesio, Syst. Myc. t. alt. p. 180 , n. 4 ; - et nuperius Dermatea Prunastri eidem in sua Summa Veget. Scand. p. 362, n. 7. A typo nostro differre videtur Dermatea Prunastri (upsaliensis) Theodori Fries apud Rabenhorstium, Fung. Eur. exs. fasc. II (1860), n. 125 ; itemque propterea Cenangium Prunastri Notakisı, in Act.Soc. Crypt.Italce, fasc. V (1863), p. 384, quod enim fungillo modo dicto herbarii Rabenhorstiani niteretur.

${ }^{2}$ Ex fungo padicola imperfecto et acrosporo, pycnideo scilicet sive spermogonieo, orta est Spharia fallax $\mathrm{W}_{\mathrm{AHLEN}-}$ веrGir in sua Fl. Lapponica (1812), p. 522, n. 1008 ; nec non Sphceria padina (Pers. in litt.) Mougeoti in suis Stirpib. Crypt. Voğ.-Rhen. fasc. VII (1820), n. 667, ipso monente auctore in Herbarii sui exemplo quod in Musæo Bot. par. continetur. Ex plantula autem ascophora s. cupuliformi fit Peziza Cerasi $\beta$ A p. 345 , n. 1031 ; - Cenangium fallax FrIesI , in Actis Acad. Sc. Holmiensis ad ann. MDCCGXVIII, p. 361, et nuperius eidem tum Cenangium Cerasi $\beta$ Padi in suo Syst. Mycol. t. II, p. 180, tum Dermatea Padi in Sum. Vego. Scand. p. 362 , n.6; - item Dermatea Padi Laschio in Rabenhorsti Herb. Myc. ed. alt. fasc. VIII (1858), n. 711, ex agro Driessenio. 
Specimina item Libertiana Dermatece Padi Fr. quæ in herbario Mazeriano continentur, de fructibus dignioribus a typo vulgari cerasicola nostrati pariter, ni fallimur, minime recedunt; pycnides autem quas a b. Movgeotro acceptas in Botanico Musæi parisini vidimus, formam peculiariter ovatam et obtusissimam, parietes solito crassiores et stylosporas ovato-oblongas, subrectas, utrinque aut hinc saltem acutas, $\mathrm{o}^{\mathrm{mm}}, 016-019$ longas, $\mathrm{o}^{\mathrm{mm}}, 0035$ crassas continuasque ostendunt.

Longius a Dermatea s. Cenangio Cerasi Fr. recedit Cenangium Arice (P Prs. $)^{1}$, quamvis ad seminum duplicis generis scutellarumque quibus utitur formam et indolem coriaceam si attendas, indubiam ejus cum fungillo cerasicola supra descripto necessitudinem agnoscas. Fructus utriusque naturæ, glaberrimi et purpureo-nigrentes, ex cortice materno sine lege sparsi, at copiose oregarii, plerique discreti aut rarius cæspitosi emerount, et epidermide lacera stipantur. Pycnidia minima quæ Sphceronamatis conici Fr. (Scler. Suec. fasc. III $[1820]$, n. 106) maximam partem constituunt ${ }^{2}$, conulos obtusos referunt et stylosporis lineari-lanceolatis, lunulatis, $\mathrm{o}^{\mathrm{mm}}, 01-015$ longis et decuplo angustioribus referciuntur, quæ sterigmatibus filiformibus, rigide erectis, subsimplicibus et $0^{\mathrm{mm}}, 013-02$ longis ipsæ primum singulatim innituntur. Scutellæ vel recentissimæ jam discum revelant, adolescendo magis ac magis applanatæ dilatantur, millimetrum aut sesquimillimetrum diametro nanciscuntur, singulæque stipitulo crasso, brevissimo, medio et latente sustinentur. Disci seu hymenii pagina strato nigro duroque fit; thecæ obovato-clavatæ paraphysibusque stipatissimis mixtæ, sporas octonas anguste lineari-lanceolatas, curvulas, continuas, $0^{\mathrm{mm}}, 01$ circiter longas et vix $0^{\mathrm{mm}}, 003$ crassas debito tempore singillatim fovent. Neminem fugerit qua similitudine stylosporæ et endosporæ inter se conveniant; forma et longitudine quasi pares sunt, endosporæ autem crassiores et utrinque minus acutæ.

\section{Dermatea seriata.}

Phacidivm (Trublidium) seriatum Friesio, Scler. Suec. fasc. V $(1821)$, n. 161, in cortice betuligno, crasso; Elench. Fung. parte alt. p. 131 , n. 4.

Cenangium (Tryblidium) seriatum eidem Friesio, Syst. Myc. t. II, p. 185, n. 15. - Dub. Bot. Gall. t. alt. p. 736 , n. 10. - Mazerio, Pl. Crypt. Gallice, ed. I, fasc. VIII (1829), n. 384, in cortice betulino Galliæ borealis. - Leveilleo in Mougeoti Stirp. Crypt. Vogg.-Rhen. fasc. XV (1860), n. 1479, in Betula agri Modonensis Versaliorum.

Huc ducit Friesius (Syst. Myc. 1. cit.) Pezizam truncatulam Rebent. Fl. Neom. p. 388, n. 1348, quæ ab homonymo fungo Persooniano (Syn. Fung. p. 673 , n. 143), fagicola, diversa existimatur.

Cenangium seriatum Fr. in expositione nostra silentio non prætereundum est, quippe

Id est Peziza Arice Persoonio, Myc. Europ. t. I, p. $3{ }_{2} 5$, n. $29_{2}$; Moug. et Nestr. Stirp. Vog.-Rhen. fasc. IX $(1826)$, n. 888 , in cortice Cratcegi Arice et Sorbi aucuparia ; - Tympanis Arice Friesio, Syst. Myc. t. II, p. 175 , n. 5 ; Elench. Fung. parte altera, p. 18 , n. 5, ubi contenditur fungillum juniorem et globiferum inter Spharias genuinas apud Albertinium et Schweinitzium (Consp. Fung. Nisk. p. 51, n. 147), sub titulo Spherice conica Alb. et Scrw. computatum fuisse, prætereaque hanc ipsam Sphceriam nihil aliud esse quam Sphcerice Cotoneastri Fr. formam peculiarem sorbicolam, in Syst. Myc. t. II, p. 494, n. 430 b, minime omissam, nimirum Spharoncema conicum ejusdem Friesir in suis Scleromycetib. Suecice, fasc. III (1820), n. 106; - Cenangium Arice Tul. in Schlecht. Ephem. Bot. t. XI, p. 53, et Ann. Sc.nat. ser. III, t. XX, p. 136.

${ }^{2}$ Haud immerilo monet clar. Notarisius (in Actis Soc. Crypt. Itale, fasc. V [1864], p. 383) Tympanidem Arice Fr. quatenus saltem hoc Sphceroncemate conico exprimitur, solitos Tympanidum characteres minime præ se ferre; fungillum ascophorum si novisset, ad Dermateas suas quarum pro typo Dermateam Cerasi Fr. habet (manip. modo cit. p. $37_{2}$ ), profecto eum duxisset. 
Tympanidem seu Patellariam habitu et colore, Cenangium autem Cerasi et consimilia interna fabrica ita imitatur ut de gemino loco characteres suos sumere videatur. E cortice betuligno recens arefacto et potissime e lenticellis transversim accretis angusteque hiascentibus, in series lineares, simplices, millim. v-xx et quod excedit longas erumpit. Longe prius quam fructus appareant, pergamenæ corticis nutritii membranæ niveum suum nativumque colorem pro fusculo mutant simulque strata crassiora supposita ad lignum usque maculantur, zona nigra lineari-ovata sub soris singulis circumducta. Spermogonia, pycnidia et scutellæ in iisdem cæspitibus monostichis miscentur, nec super colore atro, glabritie, natura cornea duraque dissimilia sunt; item stromate tenuissimo imo vix conspicuo contigua discretave una sedent. Spervogonia tuberculo minimo depressoque singula constant, pycnidia autem productiora in conulos breves assurgunt. Priora ex utero simplici spermatia vomunt exiliter filiformi-lanceolata, in arcum contractum curvata, et $0^{\mathrm{mm}}, 015$ circiter longa; pycnidia vero suis in parietibus cavernosis stylosporas gignunt lineari-lanceolatas, mire flexuosas, continuas, utrinque acutas et triplo circiter spermatiis longiores. Discus scutellarum strato atro tegitur; thecæ obovatæ s. clavatæ paraphysibusque stipatæ sporas lineari-lanceolatas, utrinque acutas, $0^{\mathrm{mm}}, 035-045$ longas, $\mathrm{o}^{\mathrm{mm}}, 003-004$ crassas, plasmate oleoso refertas, nec non curvulas seu flexuosas includunt.

Reperitur hieme vereque in cortice truncorum cæsorum v. demortuorum Betule albe L. Modonique Versaliorum raro nobis occurrit.

Stylosporæ et endosporæ super forma mire congruunt, priores tamen magis flexuosæ deprehenduntur; spermatia etiam deminutam et contractiorem stylosporarum imaginem quodammodo repræsentant.

Eore intelligimus quod Friesius fungillum nostrum $x$ in lacinias obtusas dehiscentem " viderit.

** Typi recedentes, seminibus longe crassioribus et utrinque obtusis, stylosporis scilicet rectis curvatisve, endosporis rectis et quandoque septiferis. - DERMateLLE; ad PEZICULAS nostras transeunt.

\section{Dermatea Frangule.}

Peziza (Scleroderris) Frangule Pers. Myc. Europ. t. I, p. 324, n. 288. - Moug. et Nestl. Stirp. Crypt. Vog.-Rhen. fasc. IX (1826), n. 887, in cortice Rhamni Frangulce L.

Sphteria versiformis (forma saltem rhamnicola) Alb. et Schw. Consp. F. agri Nisk. p. 52, n. 149 , tab. Ix fig. 3 .

Spherontam vensiforme (Alb. et Schw.) Friesio, Scler. Suec. fasc. III (1820), n. 102 , in cortice Frangule.

Tubergularia nigra Schum. Fl. Sacll. t. alt. p. 184, n. 1377 , docente Friesio, qui Sællandicum fungum ipse sane viderit. (Cfr. ejus El. Fung. parte alt. p. 18 et 21.)

TYMPANIS FRANGULA Fr. Syst. Myc. t. alt. p. 174, n. 1; Elench. Fung. parte alt. p. 18 , n. 1, ubi animadvertitur fungum quandoque tubercularieum se præstare; Summ. Veget. Scand. p. 400, n. 3. - Dub. Bot. Gall. t. II, p. 737 , n. 1. - Laschio ap. Rabenh. Herb. Myc. ed. alt. fasc. VII (1858), n. 661, ex agro Driessenio. 
Cenangium Frangule Tul. in Schlecht. Ephem. Bot. t. XI (1853), p. 53, et Ann. Sc. nat. ser. III, 't. XX, p. 136 et 137 , tab. xvi, fig. $1-8$.

Fungilur agmina densissima et nigro-virentia corticem maternum longe lateque occupant. Fructus ipsi aut discreti et inordinati vigent, aut in series lineares et longiusculas contigui, imo et partim coaliti instruuntur, rarius in cæspitulos gemini ternive sociantur. Omnes pariter exigui naturaque coriaceo-suberosi sunt; quidam sphæriiformes et pycnidei manent, poro minimo hiant, intusque cavernosi, simplices et nudispori inveniuntur. Stтlospor a obovato-oblongæ et rectæ, $\mathrm{o}^{\mathrm{mm}}, 0_{2} 5$ in longitudinem et $\mathrm{o}^{\mathrm{mm}}, 0065$ in crassitudinem pleræque nanciscuntur, initioque continuæ sunt. Fructus nobiliores seu ascophori, pari fere modo propter margines contractos primum clauduntur et spermatia sub ore sæpissime gignunt. Hæcce autem anguste linearia rectaque e sterigmatibus exilibus et cæspitose brachiatis nascuntur, brevique evanescunt. Cupdu in discum crassum, planum, orbicularem, integerrimum diametroque vix millimetro majorem explicantur et stipitulo centrali brevique innituntur. Hymenium humidum reliquis fungilli partibus pallidius est attritumque facile læditur, minuitur aut tollitur. Tнесе late cylindrico-oblongæ, obtusissimæ, basi abrupte et breviter tenuatæ, $0^{\mathrm{mm}}, 065$-0 8 longitudine et $\mathrm{o}^{\mathrm{mm}}, 013-016$ crassitudine æquant, sporas quatuor monosticho ordine includunt, paraphysibusque simplicibus et in vertice nonnihil incrassato nigrentibus arctissime stipantur. ENdospor w virenti-nigrentes in summa theca primum maturescunt et sui coloris discum participem faciunt; formam ovatam v. ovato-oblongam, rectam et utrinque obtusissimam affectant, septisque III-Iv transversis et parallelis pleræque tandem dividuntur. Nonnullas vidimus quæ jam intra thecæ parietes germinare cœperant.

Crescit potissimum autumno hiemeque, in cortice nondum exsucco Rhamni Frangule L. demortuæ, nec infrequens est in saltibus Modoniis et Cavillanis agri Versaliensis.

Hujus loci propter universum habitum omnino est Dermatea s. Cenangium nostrum Fraxini ${ }^{1}$ cujus multiplicem structuram olim notam fecimus in Annalibus parisinis Scientiarum naturalium. Quemadmodum conceptacula ascophora Dermatece Frangule supra adumbratæ spermatia quandoque in extremis suis marginibus gignunt, sic etiam pycnides Dermatece Fraxini analoga corpuscula simul cum stylosporis vomere queunt. Nec præterea huic fungillo fraxinicolæ desunt spermogonia solis fœta spermatiis, quare Dermatece Cerasi et D. seriatee, de quibus modo agebatur, hinc analogum se habet. Animadvertendum insuper est eundem ob sterigmatum indolem, ac spermatiorum formam et originem, Peziculas

${ }^{1}$ Quod est Peziza Fraxini Schweinitzio, Syn. F. Car. sup. n. ${ }_{1262}$, in Actis Soc. nat. Scrut. Lips. ser. alt. t. I, p. 123 , saltem ut arbitratur Friesius, l. infra ctato; = Tympanis Fraxini Friesio, Syst. Myc. t. II, p. 174, n. 3; Elench. Fung. parte alt. p. 18, n. 3; Sum. Veget. Scand. p. 400, n. 4; = Spharia Fraxini Friesio, Syst. Myc. t. II, p. 493 , n. 426 , docente magistro ipso upsaliensi in suo Elencho Fungorum, 1. supra citato; = Spheroncema columnare Wallrothio, Fl. Crypt. Germ. t. Il, p. 763 , n. 3684, volente Friesio, in sua Summa Veget. Scand. 1. supra cit. = Cenangium Fraxini Tul. in Schlechtendali Ephem. Bot. t. XI, p. 53 , et Ann. Sc. nat. ser. III, t. XX (1853), p. 140, n. 7 , tab. xvi, fig. 14. 
infra descriplas imitari. Ex illius pycnidiis sane constant et Spharia Fraxini Fr. et Sphacroncema columnare WALLR.

\section{CENANGIUM.}

(Tab. XIX et XX.)

Generis protolypus pycnideus SPHERIIS olim annumeratus, nuper FUCKELIA audiit apud BonordenIUM in suis Disputationibus Mycologicis, p. 77, n. 27, et p. 134, n. 11; idem vero perfectior seu ascophorus, sicut el proximi sui, inter PEZIZAS apud Persoonium, Candoluium et discipulos olim militabant, postea CENANGIORUM Friesianorum partem constituerunt, TYMPANIDIBUSque Wallrothianis membra quædam fuerunt.

Strona modo crassum et pulviniforme, nunc tenuius et effusum, imo subnullum et inconspicuum. Conidia, si qua sunt, ex imo stromate nata, ovata, minima. Spermogonia sincera, indubia, nondum manifesta. Pycnidia sessilia, nunc globosa, multiloculata, solida et astoma, nunc ovata s. conica, sphæriæformia, intrinsecus uniloculata vel multiplicia ac sæpe microspora, ut spermogonia æque dicenda sint. Cupule ascigeræ initio utriformes et clausæ, tandem vero cyathoideæ aut repando-sinuosæ, marginibus tunc lacero-fimbriatis vel subintegerrimis. Hymeni discus nudus aut tenuiter vestitus. Thece lineari-oblongæ vel obovatæ, octosporæ. Endospore forma in variis typis maxime variæ, nempe tum cuneatolineares v. lineari-lanceolatæ simulque septiferæ et multi-articulatæ, tum contra ovatæ vel lineari-cylindricæ, continuæ, rectæ aut curvulæ. Paraphyses sæpe in vertice vix vel neutiquam incrassatæ nec sibi invicem glutinatæ.

Fungilli spisse fucati, corneo-membranacei, morum Dermatearum cemuli, gregatim scilicet corticicola vel lignicolce, scepissime prceterea in caspites inordinatos vel series lineares digesti, conspirati.

* Endosporis linearibus et septiferis. - Scleroderais Notarisi in Act. Soc. Crypt. Itala , fasc. V, p. 383.

\section{Cennangium Ribis.}

* Fungus pycnideus :

SPH ERIA RIBESIA Linkio, Handb. z. Erk. der Gewächse, t. III (1833), p. 376, n. 156, inter typos nectrieos. Fuckelia Ribis Bonordenio in suis Dissert. Mycol. (1863), parte IV, p. 135.

* Fungus pezizæformis, ascophorus, aut saltem pro thecigero habitus, quippe plurimos perfectus latuit :

Peziza ribesia Persoonio, Dispos. Meth. Fung. p. 35 ; Syn. Fung. p. $67_{2}$, n. 138 , utrinque in coriacearum numero, primumque, animadvertente magistro, "omnino clausa et Sphcrice similis; " Myc. Europ. t. I, 
p. 331 , n. 306 (Hylostomatis typus). - Aьв. et Schw. Consp. Fung. Lus. sup. p. 344, n. 1028. - Candollio, Fl. Gall. t. VI, p. 19, n. 191 ${ }^{\mathrm{d}}$ - Friesio, Scler. Succ. fasc. IV (1820), n. 131, ubi proxima fungilli cum Cenangiis affinitas animadvertitur. Cenangium (SGleroderris) Ribis Friesio, Syst. Myc. t. alt. p. 179, n. 1; Elench. Fung. parte alt. (183o), p. 21, n. 1 ; Summ. Veget. Scand. p. 364, n. 1. - Mazerio, Stirp. Crypt. Gallice, ed. i, fasc. XLI (1850), n. 2013 , et ed. alt. fasc. XXXIII, n. 1613 (utrinque in Ribe rubro L.). - Tul. in Ephem. Bot. Berol. t. XI (1853), p. 53 , et Ann. Sc. nat. ser. III, t. XX, p. $133-135$, tab. xvi, fig. 9-11.

Tympanis Ribis Wallr. Fl. Crypt. Germ. t. alt. p. 430, n. 2354.

Scleroderits Ribis Notarisio, in Actis Soc. Cryptog. Itale, fasc. V (1864), p. 383.

Fungus ligno arido sub integro cortice innascitur; globulum e parenchymate solido, quasi sclerotieum, intus pallidum aut luteolo-virens, extus fulvum sparsimque et parcissime pubêns, nec non matrici latiuscule et arctissime applicitum refert. Tubercula hujusmodi adhuc hypophlœodia seu prorsus latitantia et semimillimetro vix crassiora reperire est quæ in imis suis lateribus concaviusculis aut contra tumidulis, parcam vel copiosiorem, semper autem nudam, promunt conidiorum copiam. Conidis ovata, recta, continua, alba et minima sunt, nempe $0^{\mathrm{mm}}, 0035-005$ longitudine et $0^{\mathrm{mm}}, 003$ crassitudine vulgo non excedunt, singulaque sterigmate lineari-ovato, brevissimo, simplici et in acumen producto primum innituntur. Sub materno cortice soluta coacervantur donec stroma tuberiforme, magis ac magis accretum, natale suum frangat velamen, et iis ut avolent et disseminentur, rimam aperiat. Ubi in lucem venit, stromatis vertex mox ampliatus exstat, inæqualis fit et pilulas gignit globosas, læves, salurate fulvas aut quidem nigrescentes, sessiles v. subsessiles, quæ præterea duplicis generis sæpius observantur. Aliæ enim sinceras pycnides constituunt nuncque discretæ et sphæricæ manent, nunc contra variis modis concrescunt nec raro in molem mamillosam unicam aut placentam orbicularem v. ovatam, concavam sinuosamve coalescunt. Pilulæ vero aliæ cupulas arcte clausas representant primoque obtutu propter verticem nonnihil depressum s. umbilicatum a pycnidiis dignoscuntur. Pycnidia admodum solida sunt et corticem gobrabrum, fulvum, crassiusculum aut tenuiorem induunt; intrinsecus ob septa angusta, reticulata nec colore et natura parenchymatosa cortici dissimilia, in loculos innumeros et inæquales dividuntur. Loculi autem stylosporis albis et densissime stipatis semper replentur; quæ ovato-oblongæ, rectæ, continuæ, $\mathrm{o}^{\mathrm{mm}}, 0065$-0 1 longæ vixque $0^{\mathrm{mm}}, 004$ crassiores, sterigmatibus lineari-ovatis, quasi cuspidatis, sæpius $0^{\mathrm{mm}}, 002$ haud longioribus, simplicibus et constipatissimis singulatim primum suffulciuntur. Pycnidia rimis inordinatis dehisci videntur, in frusta a vertice pedetentim abeunt lenteque integra pereunt, cicatrice concaviuscula aut placentiformi in stromate relicta. Strlospor e disseminatæ, loco tempestateque faventibus, augentur, dimeræ fiunt et ex utraque parte germina filiformia protrudunt. Pilulæ cavæ seu cupulæ recentes el clausæ, formam suam globosam paulatim mutant, quasi obverse turbinatæ efficiuntur et velo aureo-virenti, pubenti et continuo ut tympana diu occluduntur; quum autem millimetrum v. sesquimillim. diametro nactæ sunt, tunc dehiscunt et arescentes veli dif- 
fracti partes suos ad margines retrahunt; licet tamen subinde latius pateant, formam concavam, parietibus tenuibus et membranaceis, nunquam deponunt. Sтratum hymeninum $0^{\mathrm{mm}}, 15-18$ crassum est, albido-cinereum, quasi cereæ indolis et prorsus nudum, quippe ex elementis liberis, superne quidem, nec muco adglutinatis conslat; thecis scilicet lineari-obovatis, obtusis, deorsum longe attenuatis, $o^{\mathrm{mm}}, 14-16$ longis, $0^{\mathrm{mm}}, 007-008$ crassis, e membrana tenui factis et singulatim octosporis; nec non paraphysibus paulo longioribus, exiliter filiformibus, simplicibus et in apice vix clavato nonnihil corrugatis. Endospore initio sine lege sparsæ, tandem in summa theca dense congregantur, donec per verticem fissum modo Pezizis sinceris assueto, elastico scilicet, projiciantur; lineari-clavatæ sunt, hinc obtusæ, illinc acutæ, rectæ, $0^{\mathrm{mm}}, 035-038$ et quod excedit longæ, $0^{\mathrm{mm}}, 004-005$ crassæ, vix continuæ s. quadantenus torosæ et indistincte septiferæ, extremitatemque crassiorem in summum ascum omnes convertunt. Ubi disseminantur, pulvere albido aut si abundaverint, dilute citrino-virenti, omnia disco fœcundo supposita vel adversa et cupulæ ipsius margines tomentosos adspergunt; cupula simul humore turbidulo excluso madefit, imo ut rore paulatim repletur. In aqua satæ si fuerint, endosporæ intra paucos dies crassiores fiunt et manifestius 3-6-articulatæ, posteaque variis modis germinant; nonnullæ hinc protrahuntur, velut ipsarum axis continuaretur; plurimæ autem insuper germina ex mediis articulis simul agunt.

Gregarium crescit, autumno potissimum hiemeque miti, in ramis demortuis Ribis rubri L. sylvestris, nec infrequens est apud nos in udis et umbrosis saltibus agri Modonensis et Cavillani.

Cæspites fructiferi cujuslibet indolis, globosi v. transversarie protracti, millim. iv-vI et quod superest diametro majori æquant, ita ut pycnidia $\mathrm{I}-\mathrm{xx}$ vel cupulæ totidem, sæpius vero conceptacula utriusque generis promiscua, in uno eodemque stromate simul congerantur. Quandoque etiam accidit ut cupula solitaria in media placenta pycnidea aut in vasculo continuo ex pycnidiis plurimis item coalitis sedere videatur. Non possumus ideo quin summopere miremur clar. Bonordenium in fungillum mere pycnidiophorum semper incidisse, proptereaque cupulas ascigeras jampridem a nobis adumbratas (in Annalib. Sc. nat. 1. sup. cit.) pro adventitiis et alienis fructibus nuper habuisse (in suis Disput. Mycol. sup. cit. p. 135). Stromatis arefacti materies, dura et quasi cornea, frustula tenuissima cultro cedit; utriculi polygonii quibus sociatis efficitur, parietes crassissimos, cavernulam contra angustam obtinent. Conidia stylosporis longe minora sunt, at sterigmatibus vix dissimilibus primum sustinentur; eadem olim nos fugerant.

Quidquid de endosporarum disseminatione et germinatione supra præstitimus, ex domi, hieme medio, institutis experimentis percepimus; cupulæ fertiles seu pezizæ maturæ in lagena vitrea conclusæ, fumum suum seminalem in parietes adversos, centimetrum et quod excedit distantes, copiosum projecerunt, eosdemque nubeculis albidis hoc modo inquinarunt, obscurarunt.

Exempla Cenangï Ribis $\mathrm{F}_{\mathrm{R}}$. in Finlandia boreali ad Lappajarvi, septembri mense MDCCCLXII, W. J. Fellmannio obvia, benevolo Gul. Nylaxdro debemus, quæ cum parisinis nostris ex omni parte congruunt. Ardennensia in botanico Meratiano vidimus quæ a b. clariss. Libertia quondam collecta sunt. 
Quibus notis Cenangium repandum Fr. (Elench. Fung. parte alt. p. 22 , n. 11), in Ribe petrceo Wulf. Vogesorum a b. Моugeot olim repertum ', a Cenangio nostro Ribis tute discriminetur, hodie iterum Friesir pace dicamus, minime perspicimus.

\section{EXPLICATIO ICONUM.}

(Tab. XIX, fig. 1-9.)

1. Cæspes ex fructibus dissimilibus Cenangii Ribis Fr. tribus scilicet ascophoris, duobus autem pycnideis; unus e prioribus pezizæ s. cyathuli in modum patescit, marginibus laceris; reliqui juniores modo dehiscunt; pycnidia globosa et integra in antica cæspitis parte sedent.

2. Stromata duo recens nata et hinc conidifera, a vertice dimidiata monstrantur; utrumque eorum corticem crassiorem inter et epidermidem natum, nondum in lucem venerat; pannulus ex epidermide vertici unius adhuc hæret.

3. Fragmentum tenuissimum et valde amplificatum parietis conidiophori, simul et conidia libera, acervata.

4-5. Stromata bifariam fertilia a summo dissecta proponuntur; pycnidia sessilia, globosa et exigua de more sunt; cupulæ, præter majorem adultiorem, velum suum nondum diruperunt.

6. Particula tenuis de pycnidio a vertice dissecto sumpta et summopere aucta, parenchyma varie effiguratum ostendit in stromatico stipite, pycnidis corticulo et septis fertilibus; stylosporæ in locellis constipantur.

7. Stylosporæ quæ decembri exeunte satæ, dimeræ factæ sunt et progerminarunt.

8. Thecæ gravidæ aut recentiores, immixtis paraphysibus; endosporæ liberæ passim sparguntur.

9. Endosporas vides quas ex uteris suis natalibus non ita pridem exclusas, hieme miti in aqua severamus; intra denos dies pleræque maxime creverant, polymeræ et torosæ evaserant simulque in germina longa solito modo discesserant. Parem sementem iterum iterumque fecimus, decembri et januario, et vix semel male cessit.

Figuræ omnes juxta fungos vivos hieme proxime elapsa Cavillæ Versaliorum adumbratæ sunt; fig. 1, 4 et 5 nativas demensiones bis decemplicatas, fig. autem 2 easdem ter decuplo justo majores exhibent; icones reliquæ vices circiter cccLxxx præter naturam amplificatæ sunt.

\section{Cennangium fuliginosum.}

$T_{\text {ry blidium difforme }}$ Pers. in litt. docentibus Mougeotio et Neste. l. infra cit.

Cenangidu difforme (Fr. in litt.) Movg. et Nestr. Stirp. Vogo.-Rhen. fasc. IX $(1826)$, n. 889 , in cortice Salicis capreac L. - Dubro, Bot. Gall. t. II, p. 736 , n. 12.

Cenangiva fulaginosum Friesio, in Elencho suo Fungorum, parte alt. (1830), p. 23 , n. 15 , quo in loco dubium movetur num fungus ille forma sit perfectior Spherice fuliginosie Persoonir (Fr. Sysl. Myc. t. II, p. 423, n. 231); Summa Veget. Scand. p. 364, n. 11, inter Cenangia diu clausa, demum autem ore lato et repando hiantia. - Tuz. in Ann. Sc. nat. ser. III, t. XX, p. 135. - Laschio apud Raвenh. Herb. Mycol. ed. alt. fasc. VIII (1858), n. 710, in Salice triandra agri Driessenii.

Fungilli examina pro sua ætate ferruginea, saturate cervina, imo fuliginea, glabra,

1 Cifr. Moug. et Nestleri Stirp. Crypt. Vog.-Rhen. fasc. IX $(1826)$, n. 890 . Idem fungus nuperius clariss. Carestie, presbytero mycophilo, ad Rivam Benacensium obvius factus est, ejusdemque viri cura et opere nunc prostat inter Rabenhorstil Fungos Europ. exsicc. fasc. VIII (1865), n. 727 . 
sæpius heteroclita densaque, fructibus tamen plerisque discretis, lata spatia in cortice materno quem peculiariter fucaverunt, tumidumque, rugosum et lacerum effecerunt, occupant. Eidem suffulcro sub epidermide sternitur stroma fuscum, tenuissimum, vix conspicuum, aut saltem a subiculo ægre passim discernendum. Pycnidia omnia obtusa et uniloculata parietibus crassis utuntur; alia autem minima quasi semper immersa latent et anguste dehiscunt, ut Sphcrias nudisporas quodammodo imitentur; alia vero longe crassiora, obovata, globosa vel irregularia, subsessilia emergunt et millimetrum diametro nanciscuntur. Sterigmata vulgo brevissima occurrunt, quapropter stylosporæ in ipsis pycnidii parietibus sessiles generari videntur. Ex his seminibus cumulatis et humefactis pulpa fit albida qua conceptaculum cujuscumque sit ætatis, integrum, dum viget, repletur. Singulæ lineari-lanceolatæ, utrinque acutæ, modice lunulatæ aut subrectæ, $0^{\mathrm{mm}}, 02-03$ in longitudinem et $\mathrm{o}^{\mathrm{mm}}, 003$ in crassitudinem obtinent, septisque tribus vulgo dividuntur, licet tamen plasma de specie continuum aliquando foveant. Cupule initio admodum clausæ, obovato-globosæ et obtusissimæ, a pycnidiis primo obtutu eo discriminantur quod in vertice depresso umbilicatæ el striis fibrillosis notatæ appareant; cæterum explicantur et dehiscunt eodem prorsus modo atque fructus ascophori Cenangï Ribis $\mathrm{F}_{\mathrm{r}}$. hymeniumque albido-cinereum similiter revelant cujus elementa tibera manent nec muco glutinantur. Paraphyses exiliter filiformes item in apice non incrassantur. Thес ж clavato-lineares et $\mathrm{o}^{\mathrm{mm}}, 15$ circiter longæ, sed paraphysibus breviores, singulæ sporas octonas, fasciculatas, filiformi-lanceolatas, utrinque enim tenuato-acutas, $0^{\mathrm{mm}}, 0035$ vix crassiores, rectas vel nonnibil flexuosas, inter se valde inæquales, plerasque vero septis transversis et primum ægre conspicuis in articulos viII-x, singillatim $0^{\mathrm{mm}}$, oo 6 circiter longos, divisas adultæ fovent. Endosporæ liberæ in fragmenta facili arte, non autem ut videtur natura solvuntur; qua de re nos olim erravisse nunc compertum habemus.

Crescit in corticibus tabescentibus Salicis caprea L. et affinium, monticolaque videtur; in Vogesis obvius est Movgeotro cui exempla prope omnia debemus quæ rimati sumus. Prope Parisios nondum in eum incidimus.

Quid veræ similitudinis et sinceræ analogiæ fungillum nostrum inter et Sphariam fuliginosam Pers. (Obs. Myc. parte alt. p. 68, n. 103 , et Syn. Fung. p. 52, n. 99), suadente nomine utrique indito, revera intercedat, e solis Persoonir verbis eruere nobis licet; plantulam ipsam Persoonianam sane noverat ill. Friesius qui estromate, loco et habitu, Cenangium suum fuliginosum illi «adeo simile" existimabat ut "pluribus licet differentiis " illud recedere videret, dubius tamen hærebat « num perfectior" hujus Spharia esset "status." (Cfr. Friesi Elench. Fungor. parte alt. p. 23.) Id sentire magistri upsaliensis si probaveris, tibi quoque eo magis persuasum habebis Sphariam fuliginosam (Pers.) MouGEOTII (in suis Stirpib. Crypt. Vog.-Rhen. fasc. VIII, n. 770), quercicolam, cum fungillo homonymo Persooniano remotissimam ostendere necessitudinem, quoniam enim Sphcerice americanæ Quercuum Scuw. verissimam apud nos imaginem ea repræsentet. (Cfr. Indicem Stirpium Mougeotianarum modo laudat. et tom. II hujus Carpologice, p. 83.) 


\section{INTERPRETATIO ICONUM.}

(Tab. XX, fig. 1-4.)

1. Cenangium fuliginosum Fr. e cortice arido Salicis caprece L. Vogesorum, cæspitosum gregariumque prodit; a fronte pycnidia emergunt, in posteriore parte fructus ascophori seu pezizæformes.

2. Cupula ascigera nondum explicata, et pycnidia gemina, simul a summo dimidiata auctaque monstrantur.

3. Particula tenuissima parietis fertilis de pycnidio adulto sumpta et valde amplificata.

4. Thecæ gravidæ paraphysibus simplicibus aut bifurcis stipatæ, accedentibus endosporis exclusis, maturis.

Fig. 3 et 4 multo magis quam reliquæ naturam excedunt, nempe vices circa ccclxxx; cæterum juxta exempla Mougeotiana omnes adumbratæ sunt, priores scilicet (fig. 1 et 2 ) junio MDCCCLII, aliæ autem februario mense anni excurrentis MDCGCLXV.

** Endosporis ovatis et continuis. - Cuithris Fr. (Syst. Myc. t. II, p. 186), quod ad typum principem spectat. - Cenangiorum et Trochilarum species Notarisio.

\section{Cenangium ferruginosum.}

Peziza Abietis Pers. Syn. Fung. p. 671, n. 133. - Moug. et Nestl. Stirp. Crypt. Voğ.-Rhen. fasc. IV (1813), n. 399 , in cortice pineo, ni fallimur, nec abietino, præter auctorum dicta. - Candollio, Fl. Gall.t. VI, p. 20 , n. $191^{\mathrm{i}}$.

Peziza pinicola (Rebent.) Laschio apud Rabenh. Herb. Myc. ed. alt. fasc. VI (1857), n. 508, in cortice Pini sylvestris agri Driessenii.

Cenangidm ferruginosum Friesio, in Act. Acad. Sc. Holm. ad ann. MDCGGXVIII, parte alt. p. 361, n. 2, Scler. Suec. fasc. VIII $(1822)$, n. $29_{2} b$ (in cortice pineo); Syst. Myc. t. alt. p. 187, n. 18 (in fronte gregis Clithrium); Elench. Fung. parte alt. p. 23 , n. 18 ; Summ. Veget. Scand. p. 364, n. 8. - Greviluio, Fl. Crypt. Scotice, t. IV, tab. cxcvir, fungillum in cortice Pini sylvestris MiLl. vigentem exprimente. - NotaRisio, in Act. Soc. Crypt. Itale, fasc. V (1864) p. 384, in numero Cenangiorum genuinorum. - Corde, Anleit. z. Stud. der Mykol. p. xcvi, tab. g, n. 64, fig. 30-33. - Mazerio, Stirp. Crypt. Gallice, ed. I, fasc. XLI (1850), n. 2015 , et ed. alt. fasc. XXXIII, n. 1615, utrinque in cortice tum Pini sylvestris, tum P. Abietis L. - Fiedlero apud Rabenh. Herb. Myc. ed. alt. fasc. VI, supra citato, n. 514, in cortice pineo. Cenangivm Abietis Dubyo, Bot. Gall. t. II, p. 736 , n. 11.

Huc etiam trahuntur apud Friesium et varios scriptores :

Peziza cervina Pers. Syn. Fung. p. 647, n. 50.

Peziza strobilina Candollio, Fl. Gall. t. VI, p. 21, n. $19^{j}{ }^{j}$, quæ tamen, judice Challettio, a P. Abietis Pers. longe recedit.

Trybldidm pinevm Pers. Myc. Europ. t. I, p. 332 , n. 1, cujus enim fungilli descriptio aptissime cum plantulæ nostræ characteribus quadrare videtur.

Migropera roseola Levelleeo, in Ann. Sc. nat. ser. III, t. V (1846), p. 283 , n. 411, quæ vero longe alio spectat.

Colone Cenangium Ribis $\mathrm{F}_{\mathrm{r}}$. et C. fuliginosum Fr. supra descripta fungillus noster imitatur, sed habitu iisdem dissimilem se præstat. Recens natus pycnidiis parce utitur quæ exigua et obtuse conica in corticea matrice ita immerguntur ut sæpissime ægre 
reperiantur. Hæc intra conceptacula stylosporæ generantur anguste ovatæ, continuæ et pallidæ. Cupule ascophoræ subsessiles et peculiari modo confertæ nascuntur; cæspites efficiunt aut in series breves, discretas, vel sibi invicem contiguas, flexuosas et quasi reticulatas digeruntur. Initio obovato-globosæ, clausæ et alte umbilicatæ deprehenduntur; adolescendo autem late patent, tuncque si aruerint longitrorsum replicantur, suos nempe margines involutos iterum contrahunt et quasi rima lineari dimidiantur. His cupulis, natura subcoriaceis, subest stroma tenue, concolor, a matrice æore distinguendum, ex quo pycnidia etiam antea suam duxerunt originem. Stratum fertile in qualibet cupula $0^{\mathrm{mm}}, 07-08$ crassitudine æquat et in summa pagina saturate infuscatur. Thece late obovato-oblongæ, sessiles et obtusæ, $0^{\mathrm{mm}}, 065$ in longitudinem et $\mathrm{o}^{\mathrm{mm}}, \mathrm{O}_{1}$ in crassitudinem circiter nanciscuntur, paraphysibusque simplicibus, rigidis et in tot clavulas sursum incrassatis dense stipantur. Singulæ præterea endosporis octonis incondito ordine replentur, quibus forma est ovata vel ovato-oblonga, utrinque obtusa et continua. Quod ad crassitudinem spectat, hæ sporæ stylosporis vix longiores sunt, sed duplo fere crassiores, quippe $0^{\mathrm{mm}}, 01$ in longitudinem et $0^{\mathrm{mm}}, 05-07$ in crassitudinem obtinent.

Crescit totum fere per annum, sed potissimum brumali tempore, in cortice recens demortuo Pinorum et rarius etiam Abietum. Circa Parisios in solo Pino sylvestri L. vigentem re-
perimus.

Omnes inter fungos cenangiiformes quos novimus optime discriminatur Cenangium ferruginosum $\mathrm{F}_{\mathrm{k}}$. ob endosporas ovatas, rectas et exiguas. Veremur ne typi plurimi ei non congruant ex his quos pro
analogis habuit Notarisios in tentamine suo novæ Discomycetum ordinationis.

\section{Cenangium Ligni.}

Cenangivm Ligni Mazerio, in suis Stirpib. Cryptog. Gallice, ed. i, fasc. XLI (1850), n. 2014, et ed. alt. fasc. XXXIII, n. 1614 ; nec non antea in Ann. Sc. nat. ser. III, t. III (1845), p. 364. - Tul. in Ann. Sc. nat. ser. III, t. XX (1853), p. $141 .-$ Notarisio, in Comment. Soc. Cryptog. Itala, fasc. V (1864), p. 369 ,
ubi fungillus Trochilis annumeratur.

Natura fructuum fungilli nostri saltem duplex. Quidam solis spermatiis fœeti, in matrice nuda sessiles, sphæriiformes, globosi v. ovati, vix mucronati, $o^{\mathrm{mm}}, 3$ circiter crassi, fusco-atri et glaberrimi, vulgo gregarii nascuntur, discreti manent aut rarius coalescunt, tuncque propterea gibbosi, deformes et pluriloculati efficiuntur. Internus eorundem paries sterigmatibus lineari-fusiformibus, subsimplicibus aut parce ramosis et $0^{\mathrm{mm}}, 0_{1} 6$ o 23 longis densissime vestitur; his autem summis solitaria, alternis vicibus, nituntur spermatia cylindrica vel lineari-ovata, utrinque obtusa, recta sive nonnihil incurvata, continua, pallida, vix $0^{\mathrm{mm}}, 0035$ longa, tandem innumera et in cirros exclusa. 
Fructus ascophori sinceræ pezizæ sunt; modo spermogoniis miscentur, nunc ab iis segregantur, agmina autem densa laxiorave semper constituunt; sessiles aut subsessiles absque stromate manifesto item deprehenduntur nec nisi raro geminatim vel ternatim angustissima basi coalescunt, licet passim in cæspitulos vigeant. Globosi clausique ut spermogonia nascuntur, citissime vero porum supremum ostendunt et urceolum mentiuntur, deinde in pocillum informantur, adultique late patent et semimillimetrum vel millimetrum integrum et quod excedit æquant. Extus coloris sunt saturate fusco-cervini, et granulosi vel papillosi habitus, intus contra leves, quasi ex cera facti, albidi v. cinerei primum, posteaque nigrescentes. Theq lineari-oblongæ, obtusæ, quasi sessiles et octosporæ, $0^{\mathrm{mm}}, 04-05$ in longitudinem et $0^{\mathrm{mm}}, 0035$ in crassitudinem vix superant atque paraphysibus clavato-filiformibus, continuis et simplicissimis stipantur. Endospore anguste lanceolatæ, nonnihil inæquilaterales, continuæ, leves et utrinque retusæ, $\mathrm{O}^{\mathrm{mm}}, 0065$ longitudine et $\mathrm{o}^{\mathrm{mm}}, 002$ crassitudine raro excedunt, maturæque summos ascos in series obliquas tenent.

Autumno hiemeque crescit in ligno querneo castaneove arido, decorticato, potissime in schidiis cumulatis, stipitibus avulsis, truncis rimosis, imo el asseribus qui cœli injuriis diu obnoxii permanserunt. Cavillæ Versaliorum in sylvis cæsis non infrequens occurrit.

Specimina Mazeriana quæ nobis licuit videre in Musæo Bot. parisiensi, cum nostris ex omni parte congruunt.

\section{EXPLICATIO ICONUM.}

(Tab. XX, fig. 5-7.)

5. Cæspites vides Cenanğ̈i Liğni Maz. ligno nudo querneo inspersos et natura bis decuplo majores factos; alii e solis cupulis seu pezizis, alii ex iisdem simul et spermogoniis aut e solis spermogoniis seu fructibus sphæriiformibus struuntur; nonnulla etiam spermogonia passim discreta vigent.

6. Fragmen tenue de spermogonio s. pycnidio microspermo desumptum et summopere (vices nempe CCCLXXx) amplificatum; sterigmata a fertili pariete soluta, spermatiaque libera simul cernuntur.

7. Thecæ et paraphyses simili modo atque particula supra dicta augentur.

Hæ figuræ juxta fungillos vivos Cavillanos, januario mense anni excurrentis MDCCCLXV, descriptæ sunt.

*** Cupulis amplis, membranaceis, late repandis et undulato-rugatis; endosporis breviter lineari-cylindricis, currulis. - Pezize v. Dermatea Encoelie Friesit, pro parte.

\section{Cenangium Ulmi †.}

Fungus intra suprema corticis ulmei strata gregarius nascitur; recens adhucque clausus et integer jam sua solvit incunabula et verticem nudatum prodit. Tunc e tuberculo constat quasi solido, obtusissimo, seminis raphani magnitudine, coloris ferruginei et 
adpresse tomentoso; subinde autem accretus ac magis ac magis cavus factus tandem dehiscit et paulatim in patellam orbicularem millim. II-v latam, plano-sinuosam, tenuem, exiguas et inæquales veli reliquias in margine monstrantem, explicatur. PAтELLE apertæ, utrinque glabræ et indolis nonnihil suberoso-coriaceæ, paries supremus levis et albidos. cervino-luteolus mox infuscatur et saturate badius aut fulvus fit; externus inæqualis et fusco-ferrugineus est. Scutula illa quandoque solitaria s. discreta et subsessilia deprehenduntur; sæpius vero in cæspitulos sociantur (II-IV insimul) et stipite communi, brevissimo crassoque, quadantenus coalita centro nituntur. Hymenium s. fertile stratum ex elementis stipatissimis nec $0^{\mathrm{mm}}, 1$ longioribus constat, thecis nempe innumeris, cylindricis, $0^{\mathrm{mm}}$, o 065 vix crassioribus, obtusissimis et octosporis, nec non paraphysibus haud paucioribus, simplicibus el admodum exilibus. Endospore lineari-cylindricæ, curvulæ, $0^{\mathrm{mm}}$, o 1-0 15 longæ, $0^{\mathrm{mm}}, 0_{2} 5$-0 o 3 vulgo non crassiores, utrinque obtusissimæ, continuæ, pellucidæ levesque, oleo homogeno nunc integræ replentur, nunc guttas duas remotas singulæ fovent. Spermogonia quæ cupularum cæspites plerumque contigua stipant aut discreta comitantur, in tubercula exiogua, obtusa, subtruncata vel obtuse conica, coloris fusco-ferruginei spissique, rimulis apice fatiscentia intusque cavernulis variis v. locello unico confossa informantur; eorundem interni parietes sterigmatibus tenuissime filiformibus, rigidis et cæspitose ramosis undique vestiuntur, quæ spermatia linearia, exilissima, recta et $0^{\mathrm{mm}}, 003$ circiter longa, ut tot ramulos abortivos et deciduos agunt. Ex his cumulatis spermatiis oritur ceræ genus sordide virenti-luteolum aut subalbidum quod copiosum parciusve exigitur, in fulcro natali effunditur eidemque arescendo summopere adhæret. Aliquando etiam spermatia vidimus crassiora generari, formam lineari-cylindricam et utrinque obtusissimam usurpare, potiusque microstylosporas rectas et continuas imitari; tunc etiam pultem albam, aqua affusa, sistere solebant.

Viget sero autumno hiemeque in cortice exsucco Ulmi campestris L. primumque nobis obvium factum est in ambulacris sylvulæ Boloniensis, Parisiis suburbanæ, abeunte decembri mense a. MDCCCLV; annis nonis postea elapsis iterum vegetum reperimus in ulmetis opacis, solitariis et udis sylvæ Modoniæ agri Versaliensis (1. dicto Villebon), exeunte novembri.

Spermatia sinceriora mentiuntur bacillos homonymos plerisque Lichenum solennes; quæ autem crassiora deprehendimus, microstylosporarum genus perexiguum fortassis constituunt.

Fungus noster proximus videtur Peziza (Encelice) tiliacea Fr. (Syst. Myc. t. II, p. 76 , n. 86), quæ autem, quantum sciamus, nobis nondum innotuit; manifestissime etiam imitatur Pezizam fascicularem

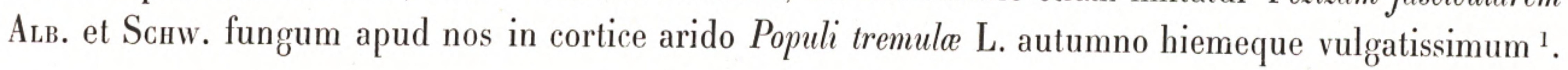

${ }^{1}$ Hic nempe dicimus de Peziza fasciculari a populina Alb. et Schw. Consp. F. Nisk. p. 315 , n. 9/12, tab. xıI, fig. 2, fungum populicolam exprimente; - Pers. Myc. Europ. t. I (1822), p. $29^{2}$, n. 193 , ubi præcedentium scriptorum Niskiensium verba compendiose afferuntur; $=$ Peziza fasciculari Friesio, Scler. Suec. fasc. VIII (1822), n. 291 (in cortice Tremule); Syst. Myc. t. II, p. 75 , n. 82 , inter Encœlias quæ fructificatione Cenangia, habitu 


\title{
INTERPRETATIO ICONUM.
}

\author{
(Tab. XIX, fig. 18-22.)
}

18. Ulmeo cortice, a sinistra parte supremis seu epiderminis stratis exuto, varia insident nostri Cenangii Llmi organa, discreta aut cæspitosa; minora et conica e tot spermogoniis constant et cirros e spermatiis glutinatis protrudunt; scutellæ autem membraniformes variis modis explicantur aut corrugantur.

19. Stroma duplici modo fertile, at maxime spermogoniorum ferax, a summo dividitur; spermogonia subsimplicia jam obsolescunt; e contrario cupula ascophora nondum adolevit.

20. Spermogonium vegetum et multilocellatum item dimidiatur; ex his est quæ discreta crescunt et cæteris crassiora evadunt; spermatia excluduntur.

21. Fragmentulum tenuissimum ex eodem spermogonio composito desumptum et valde auctum, ut spermatiorum origo pateat.

22. Cæspes ex thecis gravidis et mixtis paraphysibus; accedunt etiam endosporæ exclusæ.

Fig. 18 nota quadruplo major est, fig. 19 bis decuplo crassior, fig. 20 etiam paulo amplius augetur; figuræ autem 21 et 22 vices circiter ccclxxx amplificatæ sunt.

Cenangium acerinum Friesir in suis Scler. Suecice, fasc. VIII (1822), n. 293 , et sua Summa Veget. Scand. p. 364, n. $10^{1}$, cujus specimen authenticum, cortice Pseudoplatani insitum, videre nobis contigit in mycotheca Mazeriana (nunc e thesauris Musæi Bot. parisiensis), minime legitimum Cenangium et ne quidem fungus disciferus est, sed pyrenomyces quidam, tuberculariam mentiens, dothideiformis et bifariam pycnideus. Quæ sit autem forma illius perfectior, eruere non valuimus.

Quod ad Cenangium chlorellum Fr. (Elench. Fung. parte alt. p. 21, n. 8) attinet, fungillum scilicet in cortice Abietis pectinatc DC. Vogesorum gregatim vigentem, olimque viro oculatissimo, b. ModgEotio piæ memoriæ obvium, ille etiam inter Discomycetes militare neutiquam meretur, meliorique jure a b. Persoonio, in litteris ad magistrum Bruyerensem, pro forma "grisea" Spharice suæ cupularis habeba$\operatorname{tur}^{2}$. (Cfr. Mycothec. Mazerianam in qua fungillus Mougeotianus continetur, accedente inventoris ipsius schedula msc.) Libentius tamen id pyrenomycetis Nectriam chlorellam dixerimus, quippe indubiam cum Nectria sinopica Fr. fungillo hederæcola quem supra p. 89 , n. 11, adumbratum videas, necessitudinem ostendit. Stroma ejus exiguum et in superficie atro-ærugineum quasi totum in nutritio cortice latet; quod si dissectum accurate rimatus fueris, locellos sub nigra cuticula sparsim nidulantes reperies quorum parietes sinuosi et pallidi sterigmatibus exilissimis, stricte ramiferis, stipatissimis, nec $0^{\mathrm{mm}}, 03$

autem Pezizas genuinas imitari dicuntur; - Mazerı, Stirp. Crypt. Gallice, ed. 1, fasc. VI (1827), n. 269 , et ed. alt. fasc. XII (1841), n. 567, utrinque in cortice fraxineo; = Dermatea (Encólia) fasciculari Friesio, S. Veget. Scand. p. 362 , n. 1; - Rabenhorstio, Herb. Myc. ed. alt. fasc. VII (1858), n. 620, in cortice Populi tremula L.

Ad eandem stirpem ducenda quoque videtur, Friesso jampridem monente, Peziza populnea Pers. Disp. meth. Fung. p. 35, supra; Syn. Fung. p. 671, n. $135 ;$ Myc. Europ. t. I, p. 329 , n. 3o3; quæ vero perperam æstimatur eadem atque Peziza sphcerioides Rотні in Pauli Usteri Annal. der Bot. t. I (1791), p. 11, n. 10, tab. I, fig. 6. (Cfr. etiam Candoluir Fl. Gallicam, t. VI, p. 27. n. $233^{\mathrm{a}}$.)

Pycnides aut spermogonia in Peziza fasciculari Arb. et Schw. frustra hactenus quæsiimus.

${ }^{1}$ Fungillus hoc in loco Summe citatæ dubitanter inter Cenangia admittitur, quia sane nunquam apertus seu pezizæformis magistro suecano occurrerit. (Cfr. l. cit. in nota.)

${ }^{2}$ Postea tamen, auctore Wenceslao Streinz (Nomencl. Fung. p. 178 , n. ${ }_{2} 352$ ), fungillus de quo agitur Peziza chlorella Persoonio dictus est. 
longioribus vestiuntur, spermatiaque gignunt innumera, piliformia, recta et $0^{\mathrm{mm}}, 002$ vix longa. Perithecia pauca, minima, globosa, læte æruginea, glaberrima, aridaque nonnihil depresso-umbilicata et rugulosa, in singulis stromatibus seu pulvinulis, et spermatiferis quidem, stipatissima sedent. Endosporæ octonæ in quolibet asco, formam breviter ovato-oblongam, utrinque obtusissimam, muticam, levem rectamque affectant, septo medio dividuntur, longitudineque $0^{\mathrm{mm}}, 01-013$, crassitudine autem $\mathrm{o}^{\mathrm{mm}}, 004-005$ æquant.

A Cenangiorum societate item longe removendum est Cenangium pulveraceum Fr. (Syst. Myc. t. II, p. 181, n. 7) seu Peziza pulveracea Alb. et Schw. (Consp. F. Nisk. p. 342, n. 1023 , tab. viri, fig. 2) quæ minime ascomyces est sed hymenomyces et vera Cyphella, sicuti nobis constitit, inspectis tum exemplis in Ardennis clar. Montanio quondam obviis nuncque in Mycotheca Mazeriana contentis, tum etiam speciminibus minime disparibus quæ magister insulensis ipse evulgavit in suis Stirpib. Crypt. Gallice, ed. I, fasc. XIII (1833), n. 605 (sub Pezizce titulo). Nec miramur fungillum hunc sæpe quasi ramosum seu proliferum et cupulis plurimis eodem stipitulo suffultis superbientem offendi, nam analogum quidquam in Cyphella albo-violascenti (Аьв. et Schw.) ${ }^{1}$ jam denuntiavimus. (Cfr. tom. I hujus Carpologice, p. 149 , nota 2.)

Occasione data hic iterum contendere nobis liceat Pezizam anomalam Pers. nil certe nisi verissimam esse Cyphellam (Cyph. Hoffmanni nob. in tomo I hujus libri, p. 136); quippe ineunte novembri mense (anni proxime elapsi MDCCCLXIV), id fungilli Cavillæ reperire nobis contigit hymenio ex basidiis sincerrimis et læte tetrasporis manifestissime donatum; sporæ, quales apud fungos thelephoreos bene multos reperiuntur, breviter oblongo-cylindricæ, obtusæ et nonnihil inæquilaterales, sterigmatibus brevibus et sæpe ægre conspicuis singulatim primum innituntur. Solenia ochracea Hoғrм. quæ datur in Rabenhorsti Herb. Myc. ed alt. fasc. III (1856), n. $23_{2}$, non modo ehabitu et colore Pezizam anomalam fere refert," ut ait magister Dresdensis, sed ipsissima hæc Peziza anomala Pers. evidentissime est.

\section{HETEROSPH ERIA.}

(Tab. XVIII, fig. 16-22.)

Genus Grevillianum est ejusque prototypus infra descriptus, sicut et fungi quos Friesius affines existimat, docent huc esse trahendas SPHERIAS quasdam Toder, Persoonir Friesique, PEZIZAS paucas Candollianas vel Persoonianas, PHACIDIA nonnulla Friesiana, TYMPANIDES W

Ex fungis omnibus qui sub Heterospharice signo apud Friesium (S. Veget. Scand. p. 365) consociantur, nullum præter Helerosphreriam Patellam Grev. autopsi cognovimus, quare generis Grevilliani notæ peculiares et character in descriptione sequenti nobis integra continentur.

'Pezizam albo-violascentem A Lв. et Schw. (Consp. F. Nisk. p. 322, n. 962 , tab. vilI, fig. 4), Lachnellarum Friesianarum olim typum primarium (Fl. Scan. p. 343), quam fallacem dixit Persoonsus (Myc. Europ. t. I, p. 266 , n. 118), ad Cyphellas magistri upsaliensis pertinere jam supra monuimus (t. I, p. 134, nota 3), quare non miramur cur Notarisius, thecas genuinas in ea si quæsierit, suam perdiderit operam. Ascos in Peziza coriicali Pers. sæpe etiam desiderari aut ægre nasci, nos ipsi etiam comperimus. (Cfr. Notarisir verba de his fungillis in Act. Soc. Crypt. Itala, fasc. V [1864], p. 379, in fine.) PERsoonium non fugerat analogas esse Pezizam albo-violascentem Alb. et Schw. suasque pulveraceam et corticalem, quippe eas continua serie enumerat in sua Mycologia Europae, t. I, p. 266 et ${ }_{2} 67$, n. $118-120$. 
Heterosphcerice post Cenangia tocum in systemate, duce Friesio (Sum. Veget. Scand. p. 365), libenter concedimus. Plurimi forsan eandem in limine ordinis nostri, dimissis Hypoxylis lichenoidibus veterum, offendere maluerint, quippe Pyrenomycetum habitum adeo mentiri æstimatur ut etiam nunc apud nonnullos de re fungina scriptores, iis annumeretur. Neque profecto inficiari velimus Heterosphceriam acrosporam, qualis scilicet Bonordenio, alterius formæ inscio, innotuerit, ad pycnides Sphcriarum herbicolarum, ex. gr. Spharice herpotriche Fr. graminicolæ ${ }^{1}$, nisi externa similitudine, saltem ob internam fabricam, proxime accedere. Constat vero fungillum, ubi perfectior et ascophorus factus est, Phacidiorum aut Cenangiorum more dehiscere et discum revelare sincerrimum, nucleo Spheriarum fluxili longe dissimilem. Nihil est cæterum cur ill. Friesio iterum culpæ vertamus quod stylosporas Heterosphaerice pro ascis vacuis seu reductis habuerit, proptereaque ascos ipsos dixerit filiformes. (Cfr. ejus Elench. Fung. parte post. p. 134 ; Sum. Veg. Scand. p. 365, et Nov. Symb. Mycol. [1851], p. 1 o6.) Quum autem forma pycnidea, eaque admodum genuina, principi Heterosphcriarum typo æque fere solennis videatur atque forma absolutior seu ascophora, non potuimus quin his in pagellis meminerimus pristinæ nostræ de eodem fungo commentatiunculæ (in Annal. Sc. nat. loco infra cit.), paucasque attulerimus adumbrationes quibus hæc dissertatio tandem rite illustretur.

Heterosphcria cum Phacidiis supra descriptis et plerisque Cenangïs sincerioribus in eo manifeste convenit quod fructus ejus inferioris dignitatis seu acrospori, clausi et capsuliformes, poro aperiantur et sementem cirratam exigant, digniores contra plurifariam discissi late dehiscant. Inde simul comprobantur et Corda qui Heterosphariam in numero Phacidiorum genuinorum libentissime computasset, et Friesius quo judice, eadem Cenangia inter et Phacidia mediam se haberet. (Cfr. prioris Introd. ad Mycol. stud. p. 145 , et alterius Sum. Vegeet. Scand. p. 365, nota 1.)

\section{Heterospheria Patella.}

* Fungus mere pycnideus :

Heterospheria Patella (Grev.) Bonordenio, in suis novissim. Disputat. Mycol. (1864), p. 79 et 138, inter Excipulinos Sphæronæmeorum, tab. II, fig. 10, $a, b$.

** Fungus pro thecaphoro plerisque habitus :

a. Sphæriaceus potius creditus :

Spheria penetrans a Patella Tode, Fung. Meckl. Sel. parte alt. p. 45, n. 43, tab. xv, fig. 121, huc, Persoonio et neotericis volentibus, vulgo trahitur, licet fungilli pritzierensis descriptio cum charactere plantulæ nostræ Grevillianæ, GrevilLio jam animadvertente (1. infra cit.), non plane quadrare videatur.

Spheria Patella Pers. Syn. Fung. p. 76, n. 149. - Friesio, Syst. Myc. t. II, p. 511, n. 478.

Heterospheria Patella Grevillio (qui fungum ascophorum quidem, sed immaturum, offendisse videtur), Fl. Crypt. Scotice, t. II (1824), tab. cin (inter Hypoxyla Candolin ). - Mazerio, Stirp. Crypt. Gallice, ed. princip. fasc. V (1827), n. 215 (in caule Dauci Carote sylvestris).

Quam descriptam videsis in tomo superiore, p. 255 , sub Rhaphidophore signo. 
$P_{\text {Hacididm }} P_{\text {Atella }} \beta$ campestre Friesio, Elench. Fung. parte alt. (1830), p. 134.

Tympanis Patella a sphariaformis Wallr. Compend. Fl. Crypt. Germ. t. alt. p. 425 , n. 2343 , fungo, auctore magistro germano, "ascos albos coactos transfundenti.» - Streinz, Nom. Fung. p. 635, n. 10613.

b. Tandem late apertus, cupuliformis, proptereaque ad fungos pezizeos relatus :

Peziza levcomela $\beta$ umbelliferce Candollio, Fl. Gall. t. VI, p. 21, n. $194^{\mathrm{a}}$.

PEZIza Ligustici ejusd. ibid. n. $19^{4} 4^{\text {b }}$.

Peziza (Odontoloma) Challletis Pers. Myc. Europ. t. I (1822), p. 288, n. 182, fungillus scil. in caulibus Angelica sylvestris L. b. Chanletio obvius, nec Spharice? Patella (Pezize Liguastici DG.), judice Persoonio, primo intuitu valde dissimilis.

$P_{\text {EZIZA }} S_{C L E R o p y X I S}$ ejusd. ibid. p. 290, n. 189 , judice Friesio, in suo Syst. Myc. t. II, p. 144 , n. 78.

Peziza fimbriata Challetetio, olim, docente Friesio in suo El. Fung. t. alt. p. 133.

Phacididm Patella a alpestre Friesio ipsi, loco dicto Elenchi sui Fungorum.

Tympanis Patella $\beta$ pezizaformis Wallr. l. supra cit.

Tympanis Patella Rabenh. Fl. Crypt. Germ. p. 337 , n. $259^{2}$, saltem pro parte.

Heterospheria (Phacidium) Patella (Grev.) et Heterospiteria Patella $\beta$ campestris Cesatio, ap. Rabenh. Herb. Mycol. ed. alt. fasc. V (1857), n. 446 et 447 , ex campis Insubricis.

Huc etiam spectat Phacidium Patella $\beta$ campestre (Fr.) Mazerı in suis Stirpib. Crypt. Gallice, ed. alt. fasc. IX (1840), n. 415, in caule Angelica sylvestris, ni fallimur, crescens.

c. Fungus rite biformis creditus :

Heterospheria Patella (Grev.) Friesio, in sua Summa Vegot. Scand. (1849), p. 365. - Tul. in Actis hebd. Acad. Sc. parisina, t. XXXV, p. 844 (decembri MDCGCLII); Ephem. Bot. Berol. t. XI, p. 52, et Ann. Sc. nat. ser. III, t. XX (1853), p. 158-160. - Balio, Syst. Fung. (1858), p. 58 et 91, tab. xix, fig. ex Grevillio sumptis. -- Rabenh. Fung. Europ. exs. fasc. IX (1865), n. 839.

Sub membranaceo pellucidoque corticulo, fungillus in lignea nutricis materie aterrimus et durus, ut Sclerotium nascitur, sine lege spargitur, pro maxima parte glaber est et in nigra punctiformique sedet macula quam integram velat. Formam gobosodepressam et in medio, ubi arescit, alte umbilicatam ab initio usurpat, adolescendoque latius etiam cavatur, in marginibus semper obtusissimus. Solitam magnitudinem maturus si nactus fuerit, millim. I-II diametro majore æquat et in umbilico nonnihil hirsutus reperitur. Interna autem super fabrica biformis est, modo scilicet merum pycnidium, nunc contra perithecium sincerum. Mrnora conceptacula, superioribus matricis partibus pleraque insita, præ majoribus demissius natis, acrospora sæpius deprehenduntur, umbilico angustiori et minus depresso denotantur, poroque medio et vix conspicuo tandem dehiscere videntur. Parietes illis sunt peculiariter incrassati et ex parenchymate albido, qui silvam densam sustinent e sterigmatibus brevibus, filiformibus et pauci-ramosis. Strlospora lineari-lanceolatæ, in arcum curvatæ, utrinque acutissimæ, continuæ, pallidæ, $0^{\mathrm{mm}}, 025-03$ longæ, $0^{\mathrm{mm}}, 0035$ vix crassiores, e sterigmatibus ut rami abortivi, terminales lateralesve oriuntur, MАловuм vero conceptaculorum paries supernus tenuatus veli vices agit, stato tempore in lacinias phacidieo more late dehiscit, et discum pezizeum seu cyathum fertilem nudat. Hujusce stratum thecigerum $0^{\mathrm{mm}}, 1$ circiter crassum est et placentæ s. cupulæ applanatæ duplo crassiori imponitur. TheC 
lineari-oblongæ et distiche octosporæ paraphysibus filiformibus et simplicibus stipantur. Sров tinuæ et pallidæ, $0^{\mathrm{mm}}, 013-016$ in longitudinem et $\mathrm{o}^{\mathrm{mm}}, 003-004$ in crassitudinem æquant. Præter hoc duplex conceptaculorum genus, pauca alia amphibola reperies quæ pycnides solito crassiores referunt, licet hymenium ascophorum foveant; in his miraberis paraphyses plerasque sterigmata, solitas contra leges, effici et stylosporas sinceras sustentare; unde certissima evadit natura Heterosphcerice nostræ bifaria.

Nascitur abeunte æstate in caulibus adhuc semivivis aut recens demortuis tum Dauci Carote L. arida inter gramina, tum Petroselini culti et Angelice sylvestris L. nec nisi vere aut æstate anni subsequentis perficitur. Circa Parisios et Versalias haud infrequens est, potissime in Dauco sylvestri.

Præmissa descriptio de fungillo daucicola præsertim valet. Nisi endosporæ biformes sint, olim erraverimus (in Annalib. Sc. nat. l. sup. cit.) super earum forma et magnitudine solenniori; saltem secus dicere opportuit de his quæ nobis hodie suppetunt. Quam maximam merentur attentionem conceptacula illa amphibola quibus thecas et stylosporas simul gignere contingit. Exemplum focunditatis istius modi deprehendisse sibi visi sunt Berkeleos et Broose in Tympanide nostra Ligustri; cum autem huic fungillo non competant pycnides macrospermæ, hactenus non potuimus quin veriti simus ne in errorem lapsi sint illustres magistri. (Videsis supra p. 154.)

Vix miramur fungillum nostrum b. CoRDe quocumque modo fertilem nunquam obvium fuisse ${ }^{1}$, quippe fructus ejus nobiliores seu pezizei qui præ aliis scrutatoris oculos advertunt, sæpissime imperfecti reperiuntur.

\section{EXPLICATIO ICONUM.}

(Tab. XVIII, fig. 16-22.)

16. Fragmentum datur caulis arefacti Dauci Carotce L. sylvestris in quo fructus plurimi Heterospharice Patelle Grev. sedent; horumce seniores et perfectiores nunc hiant, os lacerum ex velo diffracto aperiunt et quasi urceolati facti sunt; e reliquis adhuc arctissime clausis minores aut mere pycnidei, aut amphiboli sunt.

17. Pars tenuis ex pycnide a summo dissecta, valde amplificata exhibetur.

18. Stylosporæ sterigmatibus innixæ seorsim proponuntur.

19. Particula de fructu s. hymenio amphibolo desumpta, paraphyses conidiophoras simul cum thecis immaturis ostendit.

20. Fructus ascophorus adhuc clausus dimidiatur.

21. Fructus alter paris naturæ itemque dissectus, sed ætate provectior, stratum hymeninum, velo rupto, revelat.

22. Cæspes ex thecis et paraphysibus; endosporæ exclusæ accedunt.

Iconibus his omnibus fungilli exprimuntur quos prope Versalias, junio exeunte MDCCGLII, reperimus; fig. 18,19 et 22 vices circa ccclxxx præter nativas demensiones augentur; reliquæ etiam plus minus sed inæquo modo amplificatæ sunt.

${ }^{1}$ Cfr. ill. magistri Introd. in Mycologice studium, p. 145. 


\title{
VI. DURELLA.
}

(Tab. XX, fig. 8-14.)

Peziza compressa Persoonir, propter pycnides quibus utitur, a plerisque Pezizis lignicolis manifesto recedit, quare sub præmisso titulo quem ab Elia Friesio sumpsimus, pro typo novo inter Discomycetum genera jam admissa eam proponere vix dubitamus. Quos autem socios inter reliquas Friesi Durellas, sibi olim jure ac merito jungere poterit, in præsenti plane ignoramus, quippe præter Pezizam Resinc Fr. cujus paucis meminimus in tomo I istius Carpologice, hi fungilli nobis nondum innotuerunt. Quod ad id plantulæ resinicolæ attinet, inter Lichenes athallios aptiorem locum habet. (Cfr. supra t. I, p. 130 , not. 1.)

Durellam nostram interna structura æmulantur Cryptodisci Cordæani, ut Cr. pallidus et atro-virens (Stictidum species Friesio), quos adumbratos videsis, priorem in Corde Iconib. Fung. t. II, p. 37, tab. xv, fig. 129 , et Intr. ad Mycol. stud. p. xciv, tab. g, n. 63, fig. 1-4, alterum autem in eadem pagina tabulaque (fig. 130) Icon. Fungorum, et apud Batium Syst. Fungor.p. $6_{2}$ et $9_{2}^{2}$, tab. xIx, fig. inferioribus.

\section{Durella compressa.}

\begin{abstract}
PeZtza compressa Persoonio, Disp. meth. Fung. p. 34; Syn. Fung. p. 67o, n. 129; Mycol. Europ. t. 1, p. 307 , n. 241, saltem pro parte, monente Friesio. - A - в. et Schw. Conspect. Fung. Nisk. p. 340, n. 1017, partim saltem. - Candolio, Fl. Gall. t. VI, p. 22 , n. $19^{44^{\circ}}$. - Friesio, Syst. Mycol. t. II, p. 152, n. 105, et Sum. Veget. Scand. p. 354 , n. 176 , utrobique inter Phialeas patelleas s. durellas. - Duby, Bot. Gall. t. alt. p. 754 , n. 136 (inter Patelleas Neesit). - Moug. et Nestl. Stirp. Vog.-Rhen. fasc. VI (1818), n. 586, in assulis coryleis, aprili. - Mazerio, Pl. Crypt. Gallice, ed. I, fasc. XXVIl, n. 1314, et ed. alt. fasc. XV (1843), n. 714, fungillo perfecto in palis, decembri mense, obvio. - Laschio apud Rabenh. Herb. Myc. ed. alt. fasc. VI $(1857)$, n. 509 , in lignis aridis nudisque agri Driessenii. - Berkelao, Outl. of Brit. Fung. p. 371 , n. ${ }_{2} 5$, inter Patelleas Friesianas, simul cum Peziza flexella, lecideola, lignyota, item Friesianis.
\end{abstract}

Fungillus noster in ligno nudo et late longeque nivea vel albida signato macula, gregarius minimusque nascitur. Fructus ejus glaberrimi in series lineares, secus fibras ligneas inter quas semi-immersi primum latitant, vulgo instruuntur, discreti vel hinc inde contigui. In principio prorsus clausi solidique sunt omnes, compresso-globosi, ovati vel lineari-ovati et semper obtusissimi; ubi vero debitam, non autem adultam s. normalem nacti sunt crassitudinem, rima unica longitudinali in vertice dehiscunt paulatimque magis ac magis hiascendo late aperiuntur et pezizæformes fiunt, marginibus crassiusculis subintegris aut quadantenus dentato-laceris; majores millimetrum longitudine tunc vix excedunt. Extrorsum colore fusco-nigrente inficiuntur, in disco verum pallescunt. Bene multi puram ostendunt pycnideam indolem et farragine intricata sterigmatum filiformium ac ramosorum simul et stylosporis insitis vel solutis integri refer- 
ciuntur, ita ut indolem gasteromycetum quodammodo imitentur. Stylospon w in sterigmatibus summis, eorum lateribus extremisque divisuris sessiles generantur; formam anguste oblongo-cylindricam, vix curvulam et utrinque obtusam obtinent, septo medio tenuissimo dividuntur, et $0^{\mathrm{mm}}, 008-011$ in longitudinem, atque $0^{\mathrm{mm}}, 0035$ in crassitudinem circiter nanciscuntur. Globulos alios propter rimam mediam bilabiatos aut jam. cupuliformes, stylosporarum quidem parciores, at thecis fertilibus etiam fotos olim reperisse nobis videbamur; quos autem utrum recte interpretati fuerimus hodie dubitamus. Abundant præterea cupulæ mere ascophoræ quæ tandem late patent. Sтүцоsporas in fructibus thecigeris, ut opinabamur, natas, paraphysibus summis inniti æstimabamus, quæ a sterigmatibus supra dictis pycnidum sinceriorum, in eo tantum recedebant quod longe pauciora ederent brachia et strictiora assurgerent. Theсе tum in fructibus seu conceptaculis heteroclitis, tum in genuinis cupulis, sibi admodum constant; clavatooblongæ sunt, sessiles et singillatim octosporæ. Endospore formam stylosporarum imitantur, sed omni parte et quidem subduplo majores sunt, prætereaque vulgo trimeræ et magis incurvatæ reperiuntur. Semina hujusmodi hymenio adulto abunde inspersa mox ex alterutro apice progerminant; germina autem exilia et primum simplicia stratum thecigerum, ut aciculæ pilulam, alte intrant et paraphyses admodum mentiuntur. Causa ea est cur vereamur ne in cupulas reapse heteroclitas non inciderimus, licet paraphyses de specie gongylophoras simul cum thecis recens natis advertisse nobis videamur.

Vulgatissimus crescit circa Parisios et Versalias, in lignis nudis, jampridem arefactis, ac potissimum in palis ex ligno castaneo aut querneo. Hieme currente cæloque pluvio læte viget ac sæpius duntaxat pycnideus reperitur in maculis recentioribus; saltem fructus ascophori in senioribus semper copiosiores generantur. Macula primum nivea cujus causa efficiens est, lente, succedentibus annis, undique et præsertim secus ligni fibras extenditur, simul autem nitorem suum paulatim deponit. Fungillus aridus diu persistit.

En ideo aliud exemplum Pezizce biformis seu duplicis indolis, nec non forsan fructus heterocliti, qualem in Heterospharia et Peziza benesuada nostra videre licet; atque parvi refert id apud fungum perexiguum offendi, quoniam profecto non minoris momenti habebitur ad thesim nostram comprobandam.

Endosporæ quæ jam prope sunt ut excludantur, in summis ascis sine ordine congregantur, sicut etiam endosporis plurimorum Ascobolorum et Pezizarum sincerarum mos est.

\section{INTERPRETATIO FIGURARUM.}

(Tab. XX, fig. 8-14.)

8. Peziza compressa Pers. in ligno nudo querneo, macula alba signato, viget; cupulæ ascophoræ patent aut juniores adhuc contrahuntur; pycnidia autem longe minora emergunt, recentiora integra sunt, adulta e contrario late dimidiata hiant. 

9. Pycnidia quatuor contigua, aliudque discretum a summo longitrorsum, secus rimam solitam, pariter
dimidiantur.

10. Pycnidium alterum transversim et a vertice dissectum est.

11. Portiuncula de pycnidio adulto sumpta et valde amplificata.

12. Stylosporæ quæ satæ germina protrudere cœperant.

13. Cupula ascophora a summo rescissa.

14. Thecæ et paraphyses; endosporæ plurimæ exclusæ sparguntur earumque bene multæ germina ediderunt quæ hymenium hoc intrant modo ut summis hærere paraphysibus ipsæ videantur; endosporæ quædam antequam egerminent torosæ fiunt.

Nativæ rerum demensiones figura 8 bis decemplicatæ efficiuntur, figuris autem 9 , 10 et 13 ter decuplantur; cæteræ figuræ vices circa CGCLXxx auctæ sunt. Icones omnes januario et februario anni vertentis juxta fungillos vivos, quercicolas alios, castaneicolas alteros, Cavillæ adumbratæ sunt.

Sест1о II. Conidia ex articulis solutis fibrarum hyphasmatis. Fructus nudispori, pycnidei vel spermogoniei, modo aperti, patelliformes, pulvinati vel in columellas informati, nunc contra clausi, utriformes aut globosi, scepiusque multilocellati. Fructus ascigeri rarissime velati, tandem disciformes ant cyathoidei. - РеZIZEI genuini.

\section{TROCHILA.}

TROCHILA, genus Friesianum e Discomycetibus patellariaceis, super PEZIZIS paucis exstructa est quarum nonnullæ inter SPHERIAS olim computabantur; FUSARIA et GLEOSPORIA quædam, ut opinamur, etiam vindicat.

Conceptacula pycnidea exigua, disciformia et modice concava vel utriculos conico-lenticulares referentia. STYLOSPOR nuæ, rectæ vel incurvatæ, e sterigmatibus brevibus et subsimplicibus natæ. DiscI ascophori a principio nudi et patentes; thecis obovatis et octosporis; sporis ovatis et simplicibus.

PEZIZULA sessiles, foliicola, erumpentes et gregatim vigentes.

Velum sincerum quale occurrit in Excipula Rubi Friesio, Cenangio Ribis Fr. nostrati, Phacidiis foliicolis supra descriptis et analogis fungis, apud Trochilas quas vidimus prorsus desi"deratur; discus enim hymenii in his plantulis recentissime natis nonnisi tegmine alieno ex tenuissimis matricis partibus velatur, sicut post Notarisium ipse advertit Friesius in sua Summa Veget...Scandinavia, p. $36_{7}$, nota altera. 


\section{Trochila Crateriun.}

* Fungus pycnideus s. stylosporeus, ni omni specie decipimur : Myxosporium Paradoxum Notarisio, in Act. Acad. Sc. Taurin. ser. alt. t. III (1841), p. 81, n. 10, fig. x.
Fusaridm PeZizoldes Mazerio, in sua Dissert. XX super Pl. Cryptog. novis Florce Gallick, ap. Ann. Sc. nat. ser. III, t. XVIII (1852), p. 373 , n. ${ }_{21}$, anteaque in suis Pl. Crypt. Gallice, ed. I, fasc. XLIV et ult. (1851), n. $216_{7}$, et ed. alt. fasc. XXXVII et ultimo, n. 1817 .

** Fungillus perfectior, ascophorus :

Spheria punctiformis $\beta$ Hederce Persoonio, Syn. Fung. p. 9o, n. 175 , volente Candollio, loco inf. citato. Spheria Craterium Candollio, Fl. Gall. t. II, p. 298 , n. 804, descriptione manca nec erroris experti. Notarisio, in Actis Acad. Sc. Taurin. t. III (1841), p. 76 , n. 6 , fig. vi.

Phacidium? Craterium (Fr. in litt.) Moug. et Nestr. Stirp. Crypt. Vog.-Rhen. fasc. X (1833), n. 986 , exemplis utramque fungilli formam simul monstrantibus. - Arm. Hoffransio, Ind. Fung. (1863), p. 92.

Peziza Caterium Libertie, in suis Pl. Crypt. Ard. exs. n. 229, auctorib. Rabenhorstio (1. infra cit.) el Arm. Hofmanaio (Indice Fung. p. 118).

Peziza insidiosa Mazerio, in suis Stirpib. Crypt. Gallice, ed. princ. fasc. XVII (1836), n. 829, et ed. alt. fasc. I, n. 29 , accedente utrinque accurata descriptione.

Trochila Craterium Friesio, Summ. Veget. Scand. p. 367, n. 1. - Rabenhorstio, in suis Fung. Europ. exs. fasc. VI (1863), n. 527, ex dono Th. Sprée. - Berkel eo, Outl. of Brit. Fungologgy, p. 381, qui lapsu sane calami fungillum ex Buxi foliis oriri scripsit.

Sicut præmissa declarant, fungillus biformis est, nempe tum nudisporus, tum etiam ascophorus. Formæ ambæ sub folii matricis cuticula tenuissima et pellucida gregarie nascuntur, modo promiscuæ, nunc discretæ. Nudispora perfectiorem antecedit, licet sæpius nondum evanuerit quando hæc manifestatur. Fungus nudisporus constat e placentulis carnosis, orbicularibus, $0^{\mathrm{mm}}, 3-5$ diametro æquantibus, vix prominulis, vulgo, at præsertim ubi effœetæ aruerunt, quadantenus concavis, flavidis et aliena cuticula, pellucida, semper velatis. Placente istæ sterigmatibus cylindricis, simplicibus, erectis, $0^{\mathrm{mm}}, 0_{1}$ 6-0 5 longis et stipatissimis superne horrent, atque ex his singulis stylosporas solitarie acrogenas edunt quæ late ovatæ, continuæ, leves, utrinque obtusæ, hinc $0^{\mathrm{mm}}, 008-01$, illinc $0^{\mathrm{mm}}, 005-007$ æquant guttamque centralem, crassam, ex oleo flavovirenti, intra parietes tenues et achroos fovent. Hæ stylosporæ gummi aureo-flavidum adglutinatæ constituunt et in cirros breves contortosque aut globulum seu guttam, per teguminis porum v. rimam inconspicuam excluduntur. Pateldule quæ fungi formam alteram et digniorem sistunt, quasi ab initio prominent et propter colorem saturate fuscum conspicuæ sunt; maternum velamen cito ruptum singulæ pedetentim exuunt, aridæque umbilicum medium ostendunt, ita ut majores propterea late cupuliformes evadant; maturis autem et humefactis quæ crassitudine placentas nudisporas vix superant, crassitudine vero $0^{\mathrm{mm}}, 13$ non excedunt, discus est planus aut nonnihil convexus, atro-virens et undique glaberrimus, cortex præterea ater et $0^{\mathrm{mm}}, 0_{1-02}$ crassus qui universam placentam thecaphoram excipit nec tamen ultra hymenii seu disci margines 
protrahitur. Sтватum fertile colorem atro-virentem s. fusculum intrinsecus dilutiorem quam in fronte obtinet; thecæ obovato-elongatæ, obtusissimæ et deorsum attenuatæ, $0^{\mathrm{mm}}, 05-06$ in longitudinem et $0^{\mathrm{mm}}, 013$ in crassitudinem nanciscuntur, sporasque octonas primum monostiche ordinatas, tandemque sine lege conglobatas singulæ fovent; accedunt paraphyses lineares, crassiusculæ, vulgo simplices et sub apice peculiariter incrassato, clavato et infuscato sæpissime septiferis. ENDOSPOR E maturæ forma late ovata et crassitudine stylosporas omnino mentiuntur, licet nonnihil majores pleræque videantur, guttasque geminas ex oleo pingui et colorato, ac tandem unicam mediam et crassiorem sub membrana pene achroa singulatim includunt, parte vacua semper utrinque conspicua.

Innumera fungilli agmina modo unius, nunc contra duplicis indolis, utramque foliorum Hederce languidorum vel aridorum paginam, maxime autem posticam, autumno hiemeque occupant diuque ibidem persistunt; Cavillæ Versaliorum in hortis et sylvaticis minime rara occurrunt.

Mira similitudo quæ Fusarium pezizoides $\mathrm{M}_{\text {azz }}$ inter et Pezizam Craterium Lıв. intercedit, simul et eorum assueta societas, quæ Mazerium minime latuit, omni mycologo, ut arbitramur, fidem facient hos fungillos unius et ejusdem typi diversa esse membra; saltem non dubitavimus, analogia duce, quin id sentire ex observatis nostris foret colligendum. Cæterum Noтавisium modo secuti sumus, quippe de Myxosporio suo paradoxo hæc verba fecit: « Non deerit, inquit, qui perspecta structura simpliciori hu"jusce fungilli, aberrationem potius alius speciei quam autonomam plantam esse contendat. " (Cfr. Acta supra cit. Acad. Sc. Taurin. ser. alt. t. III, p. 82.)

Trochila Laurocerasi $M_{A z}$. (sub Phacidii titulo) ${ }^{1}$ hederæcolam supra descriptam habitu, colore et crescendi modo prorsus imitatur, thecis autem longe angustioribus endosporisque lineari-ovatis et sublanceolatis discriminatur. Fungillus in hortis cavillanis item non infrequens est sero autumno hiemeque, potissime in aversa foliorum Pruni Laurocerasi L. pagina. Peziza smaragdina Lev. in Ann. Sc. nat. ser. 111 , t. V (1846), p. ${ }_{2} 52$, n. 278 , et apud Moug. Stirp. Crypt. Vogeso-Rhen. fasc. XIV (1854), n. 1345, quæ in foliis Pruni lusitanica L. apud nos cultæ, reperitur, idem et ipse fungillus est atque Trochila Laurocerasi ( $\left.\mathrm{M}_{\mathrm{Az} .}\right)$.

\section{Trochila Salicis †.}

Fungrluus media æstate in foliis vivis Salicis alba L. intestinus nascitur, eademque maculis nigrantibus longe lateque inficit. Maculæ istæ anticam folii paginam præsertim

\footnotetext{
${ }^{1}$ Quam plantulam videsis inter magistri insulensis Stirpes Cryptogamas Gallice, ed. 1, fasc. IV (1826), n. 188 , in foliis Pruni Laurocerasi, descriptione autem quæ accedit in eo cum veritate non congruente quod fungillum trifariam a centro dehisci asserit, et ed. alt. fasc. VI, n. 292, in foliis Pruni lusitanica; nec non apud Movgeoti
}

Botanicon Crypt. Vog. -Rhenanum, fasc. X (1833), n. 985 , sub signo Phacidii, in foliis Laurocerasi; et Rabenhorsti Fungos Europceos exsiccatos, fasc. II (1860), n. 156, item in foliis Laurocerasi, ni fallimur, atque sub eodem coğnomine Phacidii Laurocerasi Desu. 
afficiunt, a postica tamen etiam discernuntur; ex eo pendent quod parenchymatis utriculi tum in suis contentis, tum in membrana qua struuntur, fungi parasitantis causa misere fucentur. Atrata sub cuticula antice nidulantur permulta conceptacula depressoglobosa seu lentiformia, perexigua, simplicia et pycnideæ indolis, quorum enim parietes ab ambienti medulla vix distincti, stylis brevibus, crassis et monosporis dense vestiuntur. Stylosporarum autem genus duplex est : aliæ digniores seu crassiores, breviter cylindricæ, lunulatæ, utrinque obtusissimæ, continuæ et guttis oleosis duabus remotis fetæ, $\mathrm{o}^{\mathrm{mm}}, 016$ diametro majori et $\mathrm{o}^{\mathrm{mm}}, 0065$ minori æquant; aliæ contra anguste ovatæ rectæque $0^{\mathrm{mm}}, 0064$ in longitudinem et $0^{\mathrm{mm}}, 0025$ in crassitudinem non excedunt. Hæ stylosporæ dispares nunc commistæ generantur in iisdem uteris, nunc discreta et homogena implent conceptacula; sed utrumque genus in cirros albos pariter ejicitur. In his seminibus procreandis æstivalis fungi vita integra consumitur; postquam autem in folio tandem deciduo et humi arescente, per longos menses hibernavit, a somno surrexit vere superveniente, tuncque nobiliorem seu patelleam Discomycetum formam induit. Cupulas enim agit quæ in ambitu macularum olim pycnidiophorarum potissime emergunt, et ascis octosporis Trochilas genuinas supra descriptas admodum imitantur.

Trochilam hanc salicicolam pycnideam primum vidimus augusto exeunte a. MDCCCLIV, Sevris Versaliorum, posteaque, medio scilicet septembri a. MDCGCLVIII, haud procul a Fontebellaqueo, locis dictis Héricy et Vulaines; ascophoram autem domi habuimus, ineunte martio mense a. MDCGCLIV, in foliis earumdem Salicum quæ subinde plantulam pycnidiophoram Sevris nobis præstiterunt.

Pycnidia vix prominent et æore conspiciuntur, nisi folium maternum rescindas. Sterigmata in ipso parenchymate hospitali insidere diceres. Minime miraremur si pycnidia ista pro fructibus Gleosporii cujusdam habita fuerint; Gloosporio Ribis Maz. et Mntgn. (Ann. Sc. nat. ser. III, t. XII [1849], p. 296 ) cujus supra (t. II, p. 293 ) obiter meminimus, fabrica et seminum indole non multum dissimilia sunt. Gloosporium Salicis Westend. Fung. Exs. n. 1269 (auctore Arminio Hofrnann in suo Ind. Fungor. p. 60$)$, non novimus.

\section{PEZICULA†.}

(Tab. XXI.)

PEZIZARUM et potissime HELOTIORUM species Persoonio, Friesio el discipulis; - HELOTIA saltem Notarisio, in Act. Soc. Crypt. Itale, fasc. V, p. 377 et seq. - PATELLARIE aliis; - DERMATEE nonnullæ Friesio, Summ. Veğ. Sc. p. $362 ;$ - DERMATEA nostræ in Annalib. Sc. nat. ser. II, t. XX (1853), p. $143-147$, tab. xvi, fig. 17 et 18 .

Subiculum carnosum, depresso-pulvinatum, lentiforme vel conoideum, in omni superficie et simul aliquando suis in penetralibus multilocellatis protosporarum 
ferax. Conidia s. stylosporæ ovatæ v. oblongæ, rectæ, continuæ et nucleiferæ, nucleis autem pallidis et singulis quasi ex lacuna sphærica. Spermatia anguste linearia, brevia, recta vel incurvata, e sterigmatibus articulatis nata. Cupule cæspitosæ, brevissimo stipite suffultæ, ab initio planæ et disciformes aut plus minus convexæ, prorsus nudæ, marginibus sæpius acutiusculis. Тнес longe obovatæ, octosporæ; sporæ ovato-oblongæ, continuæ aut septiferæ, rectæ v. quadantenus reniformes.

FUNGILLI minuti, duriusculi, late picti, flavidi aureive, glaberrimi, gregatim ex arborum aridis corticibus erumpentes, autumno hiemeque.

Helotiis Persoonianis et Friesianis prope ex omni parte Pezicula nostræ analogas se habent ${ }^{1}$, notam autem peculiarem ex apparatu nudisporo trahunt. Generis prototypus est Peziza carpinea Pers. ${ }^{2}$ cujus olim historiam exposuimus in Annalium Hist. nat. loco supra citato.

Cum his Peziculis tum habitu et exiguitate, tum multiplici structura ac fecunditate congruere videntur variæ Pezize ab eis propterea non removendæ, ut Peziza rhabarbarina Berk. et $P$. Graminis $\mathrm{M}_{\mathrm{az}}$. quarum meminimus in commentatione nostra de Discomycetibus (Annal. 1. modo cit. p. 146 et 147 ). Prior Helotiis sinceris apud Noтarisium annumeratur ${ }^{3}$; altera minus apte inter Trochilas ejusdem auctoris militat. (Cfr. Acta Soc. Crypt. Italie, fasc. V, p. 368 , lin. ult. et p. 378 , infra.)

\section{Pezigula Coryli.}

Dermatea Coryli Tul. in Schlecht. Ephem. Bot. Berol. t. XI, p. 54 (januario MDCGGLIII), et in Ann. Sc. nat. ser. III, t. XX (1853), p. 145 et 146.

Fungilui stroma exiguum depresso-conicum, solidum, e parenchymate carnoso, firmo,

${ }^{1}$ Helotii aurei PERs. ob universam indolem quam præ se fert, cum Dermateis seu Peziculis nostris indubiam necessitudinem jam notavimus (supra, tomo I, p. 130 , nota 1), simulque formam ejus vulgatiorem, nimirum conidiophoram, paucis descripsimus; idem et ipse fungillus est quem gemmiferum etiam novit Rabenhorstius et $\mathbf{E u}$ stilbum Rehmianum dixit tum in Hedwigia sua, tomo alt. manip. X (1862), p. 59 , in fine, tab. x, fig. $b, c$, ad dexteram imæ tabulæe, tum in Fungis suis Europais exsiccatis, fasc. VII (1864), n. $6_{77}$.

${ }^{2}$ Varia huic fungillo imposita nomina sequuntur : Tubercularia est fasciculata Todeo, F. Meck. sel. parte I, p. 20, n. 2 , tab. iv, fig. $32, a-d$, fungum nondum plane explicatum proponentibus; = Peziza carpinea Pers. Syn. Fung. p. 673 , n. $144 ;-$ Moug. et Nestl. Stirp. Crypt. Vog.-Rhen. fasc. VIII $(1823)$, n. $7^{8} 7 ;-M_{\text {azerio, }}$ Pl. Crypt. Gallice, ed. I, fasc. XXII (1840), n. 1062 ; ed. alt. fasc. $X, n .462$, præstitis utrinque speciminibus ex agro

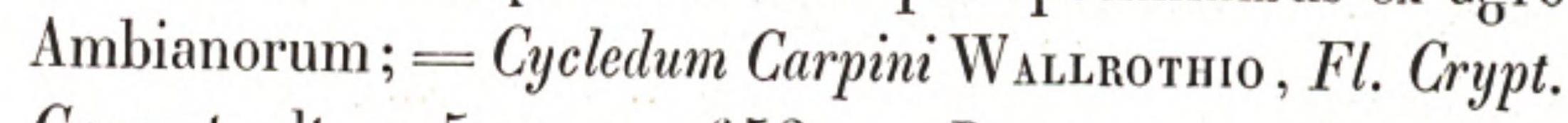
Germ. t. alt. p. 512 , n. $2653 ;=$ Dermatea carpinea F $_{\text {RIE- }}$ sio, Sum. Veget. Scand. p. 362 , n. 8 ; - Auerswaldio in Rabenh. Herb. Mycol. ed. alt. fasc. VI (1857), n. 518 (ex agro Lipsiensi); - Tul. in Sснцеснт. Ephem. Bot. t. XI, p. 54, et Ann. Sc. nat. ser. III, t. XX, p. 144, tab. XVI, fig. 17 et $18 ;=$ Ditiola paradoxa (Hedw.) Rabenh. Fung. Eur. exs. fasc. V (1862), n. 470, in cortice carpineo nec fagineo (saltem in exemplo quod præ oculis habemus), præter auctoris enuntiata; - quod etiam vera Ditiola paradoxa Friesi (Syst. Myc. t. II, p. 171), quæ est Octospora paradoxa Hedwign junioris (Obs. Bot. [1802], p. 13 et 19 , tab. Ix), huc merito spectet, vix ambigitur, nostra saltem sententia.

${ }^{3}$ Fuit etiam Helotium Rubi b. Libertie, judice RABenнопетіо in suis Fungis Europais, fasc. VIII (1865), 717. 
intus albido, extrorsum autem flavido factum, sub matricis corticulo generatur, ejusdemque tandem rupti laciniis, ubi emersit, parce stipatur. Id tuberculi primum conidia sola aut conidia simul et spermatia commista ex superna facie abunde gignere solet. Conidia obovato- ovatove-oblonga, continua, recta, basi nonnihil apiculata, initioque pallida, $0^{\mathrm{mm}}, 03-04$ in longitudinem et $0^{\mathrm{mm}}, 01-013$ in crassitudinem circiter nanciscuntur, sterigmate brevi singula primitus innituntur, paraphyses longe filiformes mixtas admittunt, mucique achroi gratia in siliginem albam laxe glutinatæ tandem exiguntur; plasmate cæterum granoso referciuntur et nucleolum aquosum, medium aut submedium, vulgo autem lateralem, ostendunt; ubi disseminatæ sunt, paulatim infuscantur et trimeræ, ni fallimur, in germinando evadunt. Spernatia dicimus fila exilia, recta, utrinque truncata et brevissima, nempe $0^{\mathrm{mm}}$, o o65-0 1 circiter longa ac vix $0^{\mathrm{mm}}, 0015$ crassiora, quæ inter conidia aut in certis discretisque stromatum partibus, e sterigmatibus articulatis oriuntur. Cupulis exiguis forma est obconico-truncata seu turbinata, discus tandem planus, imo nonnihil convexus et emarginatus, integer ac furfuraceus, parietes autem glabri, color universus amœne flavidus; paucæ insimul in singulis stromatibus, conidiis avolatis, sæpius monostiche ordinatæ, spissæ laxæve, sedent. Thec sequuntur, crassitudine vero $\mathrm{o}^{\mathrm{mm}}, 016$, sporasque octonas duplici ordine digestas singulæ stato tempore fovent. Endospore ovato-cylindricæ, curvulæ, continuæ, leves et utrinque obtusæ, $\mathrm{o}^{\mathrm{mm}}, 023-027$ in longitudinem et $\mathrm{o}^{\mathrm{mm}}, 008-01$ in crassitudinem obtinent oleoque limpido et pallido referciuntur. Paraphyses inter ascos abunde nascuntur, filiformes, simplices et erectæ, sibi invicem laxe cohærent singulæque utriculum terminalem, obovatum, seminiformem, $0,{ }^{\mathrm{mm}}, 016-019$ longum, ${ }^{\mathrm{mm}}, 005-006$ crassum et oleiferum super thecas evehunt.

Crescit infrequens circa Parisios, ex. gr. Modoni Versáliorum, æstate hiemalique tempore, in trunco arido ramisque cæsis Coryli avellance L. Nobis primum occurrit januario MDGCCLI, annisque x postea elapsis, iterum reperimus junio currente læte vigentem.

Fungillo nostro aliena est Peziza Avellance Laschio in Rabenhorsti Fungis Europ. exs. fasc. I (1859), n. 28, quæ indole membranacea, colore albo, marginibusque inflexis oculo etiam inermi sine negotio discriminatur.

\section{Pezicula ailoena.}

Dermatea amoena Tul. in Schlechtendali Ephem. Botanica, et Annalib. nostris Sc. naturalium, locis sup. citatis.

Fungilu stroma conicum et depressum, in figuram orbicularem vel ovatam expanditur; spermatiorum in culmine prius nudato, conidiorum autem in reliqua pagina minime rugosa potissime ferax est; præterea locellis internis inæqualibus, ut lacunis 
confoditur, qui ipsi non parcam stylosporarum seu conidiorum intestinorum copiam per rimas angustissimas fundunt. Spermatia exilissima, curvula rectave et continua, $0^{\mathrm{mm}}$, o o35-004, rarius $\mathrm{o}^{\mathrm{mm}}$, oo65 longitudine æquant. Stylospore anguste oblongæ, nonnihil claviformes, rectæ, continuæ, $0^{\mathrm{mm}}, 192-0225$ in longitudinem, et $0^{\mathrm{mm}}, 004-005$, interdum quidem $0^{\mathrm{mm}}, 0065$ in crassitudinem nanciscuntur, plasmate granoso et homogeno replentur, nucleolum medium lateralemque ex guttula conspicua fovent, ac stroma recens quasi polline albido vel cinereo-virenti cumulatæ obruunt. Cupule in summo stromate tunc nigricanti modo cæspitosæ, nunc circinatæ nascuntur, spermatiis jam evanidis, stylosporis autem s. conidiis sæpissime adhuc superstitibus; quidquam urceolati habitus initio affectant, subinde vero explicantur, formam obconico-truncatam tandem obtinent, disco orbiculari, plano vel convexo, immarginato, nec diametro millimetrum excedente; adultæ insuper carnosæ et glaberrimæ sunt ac totæ quantæ colore amœne flavido aureove micant. Тнеск longe clavatæ ex membrana tenui fabricantur, $o^{\mathrm{mm}}, 1_{2} 8$ longitudine et $0^{\mathrm{mm}}, 013$ crassitudine majore explent, singulæque sporas octonas duplici ordine instructas fovent. Spore ovato-oblongæ, continuæ, pellucidæ, quadantenus incurvæ seu inæquilaterales, $o^{\mathrm{mm}}, 016-019$ in tongitudinem et $\mathrm{O}^{\mathrm{mm}}, 0065$ in crassitudinem rquare solent plasmateque granoso referciuntur.

Autumno MDCGCLII Boloniæ Parisiorum vigebat in ramis querneis corticatis qui vere proxime elapso cæsi et in fasces compositi aruerant; imam eorundem partem luci, septentrionem versus, obnoxiam potissimum tenebat.

Pezicula nostra amæna præcedentem corylicolam habitu et colore læto æmulatur, abunde tamen, ni fallimur, certis notis discriminatur et maxime stylosporis s. conidiis gracilioribus ac brevioribus, nec non endosporis item omni parte minoribus et aliter effiguratis.

Stromata plurima ubi conidia et spermatia enixa sunt, nigrescere et arescere nec cupulas edere videntur; eorumdem vertex modo planiusculus est, modo in cristulam sinuatam effiguratur; arescendo subsidit et sordescit. Sunt stromata quæ spermatiis destituuntur, alia e contrario iisdem abundant; conidia rarius deficiunt. Conidia et spermatia quandoque in una eademque pagina commiscentur, sæpius autem utrumque protosporarum genus discretum gignitur.

\section{EXPLICATIO ICONUM.}

(Tab. XXI, fig. 1-9.)

1. Cæspites varii Pezicula amœnce Tul. e cortice hospitali erumpunt; nonnulli, avulsa epidermide, stroma conoideum, depressum, circum circa byssinum totumque pallidum, in quo sedent, nudatum ostendunt; tubercula quæ superiorem iconis partem tenent, reliquis juniora, conidia spermatiis juncta in cirros vomunt aut iisdem profusis congestisve obruuntur.

2. Conuli duo ex eodem stromate contigui assurgentes pariterque conidiorum feracissimi, a vertice dimidiati exhibentur; cera e spermatiis hinc propter aquam copiosiorem admissam laxior effunditur, illinc in cirros contracta protruditur. 
3. Conus alter ejusdem modi et similiter dissectus lacunas suis in penetralibus confossas fotasque seminibus monstrat, licet non parcius fertilis extrinsecus sit atque priores.

4. Fragmentum tenuissimum et maxime auctum stromatis multilocellati a vertice dissecti; spermatia $s$ conidiis multo minora, ex parte coni suprema præcipue nascuntur.

5. Conidia et spermatia, pari modo, nempe vices circa ccclXxx amplificata, seorsim traduntur.

6. Cæspes recens ex fungillis qui formam perfectiorem s. pezizeam induerunt, nec non et conus qui conidiis omnibus diffusis, cupularum rudimenta e vertice gignit; uterque a summo dimidiatur.

7. Cæspes integer et nudatus ex cupulis quæ assuetam suam magnitudinem nondum assecutæ sunt.

8. Thecæ fertiles vices circiter cccLxxx amplificatæ, seorsim spectantur.

9. Sporæ quæ pari modo nativam crassitudinem excedunt.

Icones omnes juxta fungos supra descriptos, dum viverent, adumbratæ sunt; omnes etiam, sed variis modis, naturam amplificatam ostendunt.

\section{Pezigula dissepta.}

Dermatea dissepta Tul. in Schlechtendali Ephemeride Bot. Berolinensi, et in Annalib. gallicis Sc. naturalis, locis supra cilatis.

Incipit fungillus bysso hypodermia et dilute fusca subindeque pulvinulo vix protuberante ex quo conidia et spermatia sub pultis aut ceræ albida specie sæpius insimul proveniunt. Priora obovato-oblonga, recta, continua, obtusissima, basi autem nonnihil acutata vel mucronulata, suffulcro crassiusculo, brevi vulgoque simplici et continuo singula primum innituntur. Spermatia autem, ut assolet, exiliter ac breviter filiformia, rigida, recta et $\mathrm{o}^{\mathrm{mm}}, 005-007$ longa, e sterigmatibus articulatis oblique nascuntur. Harum protosporarum generatio prope ex integro desedit quum scutellæ, genuinæ formæ et magnitudinis, apparent. Thес. membrana solito crassiori struuntur, sporasque octonas et primum distichas, singulæ apice dehiscentes enituntur. Paraphyses ascis longiores in vertice quandoque bifurco peculiariter crassescunt et colore aureo spissiore inficiuntur quam qui reliquæ scutellæ est. Enдозровж late ovato-oblongæ, sæpe curvulæ, utrinque obtusæ, $0^{\mathrm{mm}}, 02.029$ in longitudinem et $0^{\mathrm{mm}}, 007-01$ in crassitudinem æquant, septisque III transversis, rarius v-VII, in partes inæquales dividuntur.

Crescit in ligno arido et corticato Castanea, Alni cæt. nec frequens hactenus nobis obvius factus est prope Parisios et Versalias (Clamarii, Modoni, Cavillæ, etc.), autumno hiemalique tempore.

Conidia media plasmate granoso-oleoso, extrema autem oleo limpidiori de more replentur, ocellumque s. nucleolum pellucidum fovent; sata intra paucos dies progerminant, primumque vulgo ex basi seu apice acutiusculo, quapropter etiam endosporas tunc prorsus mentiuntur. Spermatia simul cum conidiis sata, habitum et crassitudinem non mutaverunt; sterigmata vero in aqua vitam servaverunt et spermatia nova enixa sunt. 


\title{
EXPLICATIO ICONUM.
}

(Tab. XXI, fig. 10-14.)

10. Cupulæ Pezicula dissepte nostræ e cortice castaneo, sub epidermide tumefacta et anguste rimosa recens natæ, ægre in lucem veniunt; tubercula quæ oculum clausum mentiuntur, nil nisi conidia et spermatia
hactenus prompserunt.

11. Portiuncula tenuissima stromatis conidiorum simul et spermatiorum feracissimi.

12. Conidia, seorsim delineata, suis in suffulcris singula sese excipiunt. Utrinque accedunt arthrosterigmata quibus spermatia ut brachiola insistunt.

13. Cæspites duo ex cupulis recentibus, a vertice dimidiantur.

14. Theca fertilis; endosporæ liberæ supra delineantur.

Icones juxta fungos vivos, in ramis emortuis Castanece vesce $\mathrm{L}$. januario MDCGCLI, Modoni prope Parisios, natos, omnes adumbratæ sunt; figuræ 11-14 naturam vices circiter cccLxxx amplificatam, cæteræ eandem longe minus auctam exprimunt.

\section{CHLOROSPLENIUM.}

\author{
(Tab. XX, fig. 15-19.)
}

Huc pertinent, volente Friesio, generis conditore, PEZIZE quædam Schweinitzianæ; HELOTIA pauca addidit Notarisius. (Cfr. Friesil $S$. Vegg. Sc. p. 356, et Notarisi Diss. de Discomycetib. jam laudatam, in Act. Soc. Crypt. It. fasc. V, p. 376 .)

Color æruginosus præ cæteris characteribus, Chlorosplenia, inter reliquas Pezizas veterum, designare videtur. Nostrum autem Chlorosplenium aruginosum DNTrs. spermogonio utitur pulviniformi et multiloculato cujus haud meminisse ii non poterunt qui posthac faciem integram Chlorospleniorum notam facere curæ habebunt.

\section{Chlorosplenium aruginosum.}

* Fungus spermogonieus :

Spharia moriformis (Tod.) varietas, in ligno virescente sedens, Schweinitzio in Herb. Musæi paris.

** Fungus absolutior, cyathophorus :

PEZIZA viridissima, petiolata, scypho infundibuliformi, НАLLeвo, Stirp. Helv. ed. alt. t. III, p. 131 , n. 2236 . Elvella erruginosa, minima, pileo difformi, viridissina (quercicola), Oedero, in Fl. Danica, t. III, fasc. IX $(1770)$, p. 7 , tab. Dxxxiv, fig. 2, ut saltem videtur. - Dicks. Crypt. Brit. fasc. II, p. 24. - Persoonio, Syn. Fung. p. $61_{7}$, n. 8, fungillo autem inter Helvellas dubitantèr admisso. - Sowerbso, F. Brit. t. III, tab. cCCXLvir, qui recte advertit ligneum fungilli suffulcrum item virescere.

Peziza ardginosa Persoonio, Obs. Mycol. parte I, p. 27 , n. $54^{1}$; Syn. Fungor. p. 663 , n. 105 ; Mycol.

${ }^{1}$ Hic quærit Persoonius num forte truncus quercinus quem colore viridi tinctum ipse etiam semper viderit, suum colorem fungillo impertiverit, inde, ut arbitratur. hicce Pezize imberbis BucL. mera varietas videretur. 
Europ. t. I (1822) tab. xiI. - Martino VAHL in Flora Danica, t. VII, fasc. XX (1797), p. 8, tab. mcc, ubi monet Vahlius se in fungi exempla nunquam incidisse quæ discum albidum exhiberent. - Schumachero, Fl. Sall. sup. laud. t. alt. p. 430, n. 2106 . - A ochraceum fieri dicunt nec in eo æruginis causam posuisse videntur. - Friesio, Syst. Myc. t. II, p. 130 , n. 39, inter Phyaleas calycinas. - Greviluio, Fl. Cryptog. Scotice, t. V (1827), tab. ccxus, ubi juste advertitur lignea schidia fungilli causa sæpissime virere, ejusdenı vero fructus perfectos multo rarius occurrere. Helotidu erdginosum Friesio, Sum. Veget. Scand. p. 355, n. 8. - Berk. Outl. of Brit. Fung. p. 372 , n. 6. Chlorosplenium erdginosum Notarisio, in Comment. Soc. Cryptog. Itale, fasc. V (1864), p. $376^{1}$.

Fungilli primordia colore peculiariter ærugineo denuntiantur quo lignea matrix, longe lateque extus maculata, alte etiam intrinsecus inficitur. Id coloris cunctas ligni partes indiscriminatim invadit et mycelii vices agere videtur, in eo scilicet quod omnis materies tincta aut propriam suam naturam mutat et funginam, salva forma, suscipit, aut saltem hanc funginam ut vestem induit. Cæterum quodlibet mycelii filamentosi v. parenchymatosi vestigium in æruginosis matricis penetralibus vulgo desideratur. In maculis duo nascuntur fungilli quos pro disparibus unius et ejusdem typi membris habere, solitus nexus et societas, color ærugineus idem et fabrica quidem ex simili compage, nobis admodum suadent. Prior sive, ut opinamur, fungillus noster spermogonieus, e pulvinulis constat globosis, millimetra I-II diametro crassis, sessilibus, solitariis vel in series lineares aut cæspitulos instructis, modo discretis, nunc contiguis, imo coalescentibus, atro-virentibus, glaberrimis et nonnihil rugosis. Quos si dissecueris, nucleum medium solidum, e parenchymate saturate ærugineo, atque circum circa cerebrinam s. labyrintheam et sinuosam videbis structuram quæ locellos innumeros, angustos, septisque erectis ut radiis divisos ostendit; septa tenuia colorem virenti-ærıgineum et naturam fibroso-parenchymatosam nuclei cujus processus sunt, retinent; locellorum vero interanea cinereo-fuscula apparent. Horum loculamentorum parietes sterigmatibus filiformibus, brevibus, nempe $0^{\mathrm{mm}}, 016$ vix longioribus et cæspitose ramosis, in omni parte densissimeque vestiuntur, ex quibus innumera proveniunt spermatia exiliter linearia, recta, continua et $0^{\mathrm{mm}}, 0035-005$ circiter longa. Pulvinus spermogonieus poris numerosis, minimis, saltem ægre conspicuis, spermaticam pultem excludere videtur. Fructus pezizei s. digniores ab initio amœnissime cæruleo-æruginei deprehenduntur; globulum sessilem perexiguum, vix pubens integrumque primitus sistunt; mox autem globulus in vertice foratur, pedetentim in urceolum vertitur simulque stipite in dies longiore sese excipit; subinde præterea in cupulam explicatur late apertam, sinuosam, tenuem, membranaceam, tenacem, utrinque glaberrimam, interdum pollicis trientem diametro subæquantem, semper æruginei coloris atque

\footnotetext{
${ }^{1}$ Hæc sunt Notarisıl circa fungillum nostrum : eSpori¿dia avolantia, teretiuscula, curvula, hyalina, virescentia, "nucleo obscure interrupto." Quare Helotiis sinceris, Friesio volente, si plantula annumeratur, eorumdem notam ex
}

ascis non dehiscentibus, nec propterea sporas elastice ejicientibus, ductam rescindit; veremur autem ne hoc Friesianum discriminis argumentum clauda nitatur observatione. (Cfr. Friesir Summ. Vego. Scanl. p. 354.) 
cauliculo concolori tereti et millim. I-Iv longo suffultam. Thec \& quasi filiformes ${ }^{\text {mm }}, 06$ in longitudinem neque $0^{\mathrm{mm}}, 0035$ in crassitudinem pleræque excedunt, sporasque octonas et oblique monostichas singulæ fovent; accedunt paraphyses exiliter filiformes nec in apice conspicue incrassatæ. Endospore (quæ Greviluio haud innotuerunt) linearicylindricæ, utrinque obtusæ, curvulæ, continuæ pallidæque, $\mathrm{o}^{\mathrm{mm}}$, o 5 vixque $\mathrm{o}^{\mathrm{mm}}, 0015$ crassiores.

Frequens crescit apud nos, v. gor. Modoni et Cavillæ agri Versaliensis, Fontebellaqueo, in sylvis Carthusianis Gratianopolitanorum et cæt. omni fere anni tempore, et lignum quercinum nudatum prædiligit, licet in ramis corticatis aliquando etiam vigeat. Anglica specimina Berkeleo et Broomeo debuimus.

Egre perspicimus quibus notis a Peziza aruginosa Pers. supra descripta tuto discriminabitur Peziza aruginascens Nylandri (in Herb. Mus. Fennici) cujus fungilli exempla ab ipso humanissimo Nylandro accepimus, quæ clar. P. A. Karsten, de Pezizarum borealium historia quum assiduis investigationibus, tum etiam scriptis bene merilus, in Ostrobottnia Finlandiæ repererat exeunte julio mense, anno MDCCCLXI.

Specimina Schweinitziana quæ in mycotheca Musæi parisini continentur, circa Bethleem Pensylvaniæ (Americæ borealis) lecta sunt et ni fallimur in ligno querneo etiam vigent; mere spermogoniea dantur nec a nostratibus, tum colore, tum fabrica discrepant.

Lignum propter fungillum nostrum læte virens ab anglis tornatoribus, docente BеRкеLеко (Outl. of Brit. Fung. p. 48), ad opusculorum suorum ornamentum adhibetur; quod quidem miramur, namque putre fragileque sæpius jam evasit. Ipsa fibrarum lignearum membrana viridi inficitur colore, eodem prope modo quo alios ob fungos et pyrenomycetes præ cæteris, sæpissime nigrescit et in carbonem mutari videtur ${ }^{3}$.

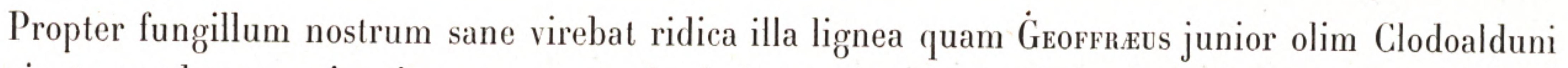
in vineto quodam reperit cujusque pauca verba fecit suos ante socios in Academia Scientiarum parisiensi anno MDCCXXVIII. Nobilem virum minime fugerat ligneam materiem, selenitæ coloris æmulam, scissilem et pro parte jam putridam esse, ac fungum intestinum verisimillime hospitio suscepisse. (Cfr. Acta Acad. Sc. par. ad annum prædict. MDCCXXVIII ; Hist. p. 5o. - Parisiis $\left.{ }_{17} 30.\right)$

Nuperiori tempore viri chymiæ periti in materiam quercinam æruginei coloris considerationem etiam intenderunt, et colorem immissum ipsum secreverunt sub specie corporis solidi, formæ crystallinæ expertis, in aqua minime solubilis ac cujus, ut videtur, ad artem tinctoriam pretium erit. Meritone autem negaverit D. Fordos id coloris ex fungo intestino suam originem trahere? (Cfr. in Actis hebdom. Acad. Sc. par. ad d. vi julii mensis a. MDCCCLXIII, tomo LVII, p. 5 o et seq. dissertationem illam cujus jam meminimus in tomo II hujus Carpologia, p. 258 , in nota.)

\section{EXPLICATIO ICONUM.}

(Tab. XX, fig. 15-19.)

15. Adumbratam conspicis Pezizam aruginosam Pers. spermatiferam simul et ascophoram; spermatiorum conceptacula, globosa seu pulviniformia, in ligno nutritio propter mycelium innatum læte v. saturatius æru-

Super hoc argumento videsis Berkeleum, Outl. of Brit. Fung. p. 48. 
ginoso sedent, discreta aut cæspitosa, interdum etiam cupulis recentibus sociata; harumce os semper integrum initioque vix conspicuum pedetentim dilatatur, quare disci acies aut plana aut nonnihil reflexa tandem evadit.

16. Spermogonia duo a vertice scinduntur ut loculi quibus in ambitu confodiuntur appareant.

17. Particula tenuis de iisdem pulvinulis modo præstrictis sumpta, quidquid loculis spermatiferis inest labyrintheæ fabricæ denotat.

18. Locelli spermatiorum natales a summo divisi et vices circiter cccLxxx aucti monstrantur.

19. Thecæ gravidæ et endosporæ exclusæ, pari modo ac figura antecedens amplificatæ sunt.

Fig. 15 nota quadruplo major est, figuræ autem 16 et 17 ter decemplicatæ traduntur.

\section{CORYNE.}

(Tab. XVII et XVIII.)

Fungus nudisporus inter elvellaS Schaffero, Dicksoni et aliis, TREMELLAS Bulliardo, Persoonio, Friesio et discipulis, aut quidem DACRYOMYCETES eidem Friesio computandus æstimatur, et CORYNES typum Nersio primum deinque Corde et Bonordenio constituit; ascophorus autem seu absolutior, PEZIZIS annumeratus est a plerisque de re mycologica scriptoribus, quales Hallerus, Bulliardus modo citatus, Persooniusque, OCTOSPORA est magno Hedwigio, contra BULGARIE forma Friesio.

Generis nota princeps in apparatu nudisporo versatur qui in pulvinos, columellas clavulasve solidas informatur, atque seminula biformia, conidia scilicet et spermatia, aut contra uniusmodi et spermatiomorpha, ex universa superficie fundit. Plantæ forma perfectior seu ascigera a sinceris Pezizis non recedit.

Fungi peculiariter gelatinosi et Tremellarum indolem usurpantes.

\section{Coryne sarcoides.}

* Fungus nudisporus, minoris dignitatis :

Elvella PURpurea Sch affero, F. Ratisb. t. IV, Indicis pag. 114, pro parte, formæ scilicet quæ in tab. cccxxiII proponuntur.

Tremella amethystea Bull. F. Gallice, t. I, p. 229 , n. 15 , tab. .ccccxcix, fig. v, r, s. - Candollio, Fl. Gall. t. II, p. 91, n. 236 .

Tremella Sarcoides W Wther. Arrang. of Brit. Pl. t. IV, p. $7^{8}$, quem autem scriptorem aliena fide citamus.

Tremella (Coryne) sarcoldes Fr. Syst. Myc. t. II, p. 217 , n. 2 ; Summ. Veget. Scandin. p. 341, ubi jure notatur fungum in consortio Bulgarice sarcoidis Fr. vulgo occurrere cui propterea apud veteres fuerit conjunctus; rem utique ulterius explorandam esse, nullum enim fore dubium "plures fungos fructificatione "apparenter diversissimos, modo esse ejusdem typi abnormes status. — Duв. Bot. Gall. t. alt. p. 731 , n. 9 . - Rabenh. Herb. Myc. ed. alt. fasc. V (1857), n. 417.

Acrospermum dubium Pers. Comm. de F. Clavaf. (1797), p. 92, n. 7, fortassis, ait auctor, "varietas illius polymorphæ nec non polynymæ Pezizce quacum colore et substantia convenit.

Tremella dubia eidem Persoonio, Syn. Fung. p. 630 , n. 25 , ubi recte iterum advertitur fungillum nil nisi varietatem fore Peziza tremelloidec Bult. "cum fungi ambo simul in uno eodemque loco sæpe crescant." 
Helvella Sarcoides Dicks. Veget. Cirypt. fase. I (1785), p. 21. - Boltoni, F. Halif. t. III, p. 16, n. 121 ,
tab. ci, fig. 2.

Coryne Acrospermum Neesio, Syst. Fung. p. 157 , tab. xv, fig. 143 , mere habituali et a Scherfero sumpta.
Coryne sarcoides Bonord. Handb. der Mylol. p.

Coryne sarcoldes Bonord. Handb. der Mykol. p. 149 , n. 3, tab. xi, fig. 233 (rudi).

Coryne sarcoides $\delta$ dubia Corde, Icon. Fungor. t. II, p. 34, n. 3 , tab. xiv, fig. 122.

** Fungus perfectior, ascophorus :

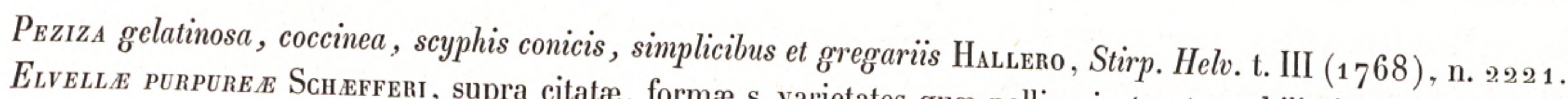
ELVELLE PURPURE S Sh fFFeri, supra citatæ, formæ s. varietates quæ polline instructæ nobili viro videbantur et
in suorum Fungorum Ratisbonensium tab. cccxxıv exhibentur.

Lichen SARCoides J J

Peziza porphyia Batschio, Elench. Fung. parte I, p. 127 , n. 28 , tab. xiI, fig. 53.

Peziza tremelloidea Bull. F. Gall. t. I, p. 240 , n. 6 , tab. ccccx, fig. I. - Candollio, Fl. Gall. t. II, p. 89 ,
n. 231 .

PEZIZA Metamorpha Schum. Fl. Sall. parte alt. p. 414, n. 2043.

PEZIZA Sarcoldes Pers. Syn. Fung. p. 633, n. 5; Myc. Europ. t. I, p. 320, n. $28_{2}$, formis variis enumeratis. PEZIZA (BULGaria) sarcoides Corde, Ic. Fung. t. V (1842), p. 79, n. 5, tab. 1x, fig. 68 .

Bulgaria Sarcoides Friesio, Syst. Myc. t. II, p. 168, n. 5. - Dub. Bot. Gall. t. II, p. 738, n. 2. - Rabenh.
Herb. Myc. ed. alt. fase. V (1857), n. 418. - Berkeleo, Outl. of Brit Fung. po 75 , fig. 6 . Huc etiam vulgo trahitur, sed vix merito, Octospora carnea Hedwigio, D. et Aüumbr. Musc. frond. t. II, p. 26 ,
tab. vir, fig. в, inferioribus.

Fungiludus laxe gregarius simul et dense cæspitosus crescit, sæpius e ligno putrescente cui innascitur per corticem anguste rimosum erumpit, ac propter colorem rubro-ianthinum quo totus nitet a longe conspicitur. Occurrunt in singulis cæspitibus columellæ plurimæ, simplices, clavatæ, spathulatæ seu linguiformes, quarum universa prope pagina copiose gemmipara efficitur. Pleræque gemmas conidieas in imis parietibus, spermatieas contra in superioribus edunt; conidia ovata hine $0^{\mathrm{mm}}, 0035-0065$, illinc $\mathrm{o}^{\mathrm{mm}}, 003$ æquant, aliquando etiam potius globosa generantur; spermatia exiliter filiformia aut vix oblonga, modo recta, nunc quadantenus incurvata nec $0^{\mathrm{nm}}, 0035$ longiora reperiuntur. Utrumque corpusculorum genus e sterigmatibus multiramosis nascitur quibus stipatissimis unaquæque columella vestitur; solita tamen conidiorum suffulcra longe crassiora et breviora atque spermatiorum sterigmata deprehenduntur. Gemmiferas inter columellas pezizæ i. e. cupulæ sinceræ oriuntur, subsessiles aut sigitlatim brevi suffultæ stylo, coloreque, glabritie et indole carnoso-gelatinosa easdem prorsus imitantur. Disci crustam fertilem, hymenium scilicet, $0^{\mathrm{mm}}, 08-11$ crassum, simul struunt paraphyses exiles et simplices, thecæ clavatæ et octosporæ, nec non mucus copiosissime interpositus cujus causa organa omnia immersa alia aliis arcte conglutinantur. Endospore lanceolato-oblongæ, recłæ aut nonnihil inæquilaterales et continuæ sunt, sed guttulam mediam pellucidam intra plasma granosum singulæ fovent.

Hiemali tempore frequens viget in lignis ac corticibus putrescentibus, et potissimum apud 
nos in Belula et Alno; gemmiferam sexcenties reperimus, ascophoram autem longe rarius. In truncis fagineis cæsis luxuriose crescebat exeunte septembri MDGCGLVII apud Gratianopolitanos, circa cœnobium princeps monachorum Carthusiensium.

Columellæ recentissime natæ, quæ scilicet millimetrum unum aut unum et alterum longitudine nondum excesserunt, nunc solis fere conidiis integræ adhuc obruuntur, nunc præterea spermatiorum in vertice jam feracissimæ factæ sunt. Villus spermatiophorus ex elementis exilissimis, $0^{\mathrm{mm}}, 03-05$ longis et stricte ramosis conficitur ut sylvæ gemmiferæ quibus Nectriarum solitæ tubercularice primum horrent; spermatia sinceriora ex iisdem arbusculis quasi rami abortivi nascuntur nec iisdem crassiora fiunt. Cionidiorum suffulcra modo subsimplicia et brevissima, nunc contra peculiariter brachiata et articulata reperiuntur.

Fungi totius materies e filamentis teretibus, ramosis, quasi solidis, $\mathrm{o}^{\mathrm{mm}}, 0035-0065$ diametro æquantibus et varie implexis, nec non muco achroo copiosissimo constat.

Peziza inquinans Persooni quæ apud Friesium ejusque discipulos typo præcedenti sub Bulgarice titulo vulgo consociatur ${ }^{1}$, magis ab eo recedit quam ut idem signum nunc jure sequatur; illius historiunculam in Annalibus Sc. naturalium nostris (ser. III, t. XX, p. 160-164, tab. xv, fig. 1-7) olim præstitimus, indeque apparuit multiplicis sementiculæ mirum præ cæteris exemplum. Allatis vix quidquam addere nobis hodie licet, nisi iconulas quarum ope melius innotescant peculiaria illa conidiola s. spermatia sporogena quæ ex endosporis germinantibus pronascuntur.

\section{EXPLICATIO ICONUM.}

(Tab. XVII, fig. 1-10.)

1. Varios conspicis Corynes sarcoidis cæspites, plerosque tum clavis nudisporis, tum etiam cupulis ascophoris constitutos.

2. Fungillus recentissime natus, in conum obtusum et villo fertili undique hirsutum conformatur simul atque bifariam nudisporum se præstat, conidia enim ovata potissimum ex infernis parietibus, spermatia autem e superioribus fundit.

3. Particula valde amplificata ejusdem conuli gemmiferi, ut generatio seminum utriusque generis manifestior pateat.

4. Clavulæ spermatophoræ inæquales, a vertice autem pariter dimidiatæ proponuntur.

5. Fragmentulum tenue de clava majori desumptum et magis auctum.

6. Sterigmata spermatifera summopere amplificata.

${ }^{1}$ Cfr. Friesir Syst. Mycol. t. alt. p. 167, n. 2 , ubi ingens synonymorum copia affertur; fungus enim e Tremellis et Elvellis, ut Coryne sarcoides, ad Octosporas seu Pezizas et quidem ad Ascobolos Neesianos migravit. Burcardia Schuedeli in Bulgariam ab Elia Fries mutatur. Bulgariam inquinantem post suecum magistrum descripserunt aut aridam suis in botanicis præstiterunt KNeifF et HartinanN, Crypt. Bad. fasc. III, n. 114; - KLotzsch, Herb.viv. Mycol. fasc. II (1832), n. 145, quæ exempla in cortice fagineo lecta fuisse dicuntur; - Mazerius, Stirp. Crypt. Gall. ed. I, fasc. XII (1832), n. 551, et ed. alt. fasc. XII, n. $569 ;$ - Corda, Anleit. z. St. der Myk. p. xcvi, tab. G, fig. 64, n. 20-2 3; - Tul. in Schlecht. Ephem. Bot. Berol. t. XI (1853), p. 54 et 55 , et in Ann. Sc. nat. ser. III, t. XX, p. 160-164, tab. xv, fig. 1-7; - Cesatius in RAвеNн. Herb. Mycol. ed. alt. fasc. VI (1857), n. 599 , quercicolam et in Pedemontio lectam; - Berkeleus, Outl. of Brit. Fungology, p. 375 , n. 1, tab. xxir, fig. 7; - Hofrmannius in Pringsh. Jahrb.f. wiss. Bot. t. II, fasc. $\mathrm{III}(1860)$, p. 291 , n. 34 , tab. xxxi, fig. 34 , thecas gravidas endosporasque liberas exprimente. Bulgaria inquinans cum sarcoide incaute commutatur ab Adalberto Schnitzlein apud Sturm, Fl. Germ. sect. III, fasc. XXXII (1851), p. 27-30, tab. xiv. 
7. Thecæ et paraphyses.

8. Endosporæ liberæ, seorsim delineantur.

Fig. 2 et 3 juxta fungos vivos e sylvis Carthusianis Gratianopolitanorum, septembri mense MDCCCLVII adumbratæ sunt; cæteras longe ante descripseramus ex plantis Cavillanis et Modonensibus. Fig. 5 , 7 et 8 nativas rerum demensiones vices circa cGcLxxx excedunt, reliquæ easdem plus minus amplificatas etiam
referunt.

9 et 10. Endosporæ Bulgarice inquinantis $\mathrm{F}_{\mathrm{R}}$. (quercicolæ) tum crassioris, tum minoris generis, proponuntur, quæ in aqua satæ (extremo autumno) intra breve temporis spatium germina longe filiformia aut brevius tubulosa et crassiora, simul atque ex iis conidiola ovata, subsessilia ac sæpissime cæspitosa prompserunt. Conidiola endosporio ipso dilatato et propter episporium discissum partim nudato etiam insistunt, germine filiformi tunc deficiente. Endosporæ minores et pallidæ haud secus in germinando se habent atque
reliquæ crassiores et fucatiores.

Iconulæ istæ pari modo, nempe vices circa GCCLXxx, notam rerum exiguitatem superant; juxta fungos agri parisini adumbratæ sunt anno D. MDCCCLIII.

Quum septembri decedente MDCCCLVI in villa Dareizeana agri lugdunensis degeremus, endosporæ utriusque generis Bulgarice inquinantis quercicolæ item in aqua sevimus, tuncque minores solæ, postquam molem suam nonnihil auxerint, aut germina nuda, aut conidiola duntaxat ediderunt; quasdam interea septo dimidiatas vidimus.

\section{Coryne virescens.}

E fungillo nudisporo factæ sunt, ut opinamur, Tremella VIrescens et T. Ginereo-viridis Schumacheri (Fl. Scell. t. II, p. 439 , n. 2146 el 2147) quæ simul sumptæ DAcryonycetem virescentem Friesio (Syst. Myc. t. II, p. 229 , n. 4; S. Veget. Scand. p. 471, n. 2) et Schumachero (in Fl. Dan. t. XI [1828], tab. mdccclvit, fig. 1) constituunt.

Ex altera parte fungus absolutus dici videtur PeZiza atro-virens Persoonio, Syn. Fung. p. 635, n. $13 ;$ Myc. Eur. t. I, p. 306, n. 237 ; - Alb. et Schw. Consp. F. Nisk. p. 308, n. $922 ;-$ Friesio, Syst. Myc. t. alt. p. 141, n. $71 ;=$ Calloria autem atro-Virens eidem Friesio, in sua Summ. Veg. Scand. p. 359 , n. 1. = Describitur apud Notarisium, in Act. Soc. Crypt. Italce, fasc. V (1864), p. 377 , sub Chlorospleniorum
signo.

Fungilues admodum exiguus est, natura saltem duplex, indole subgelatinosus, forma varius; colore virenti-ærugineo totus inficitur et in macula concolori minimaque insidit; laxe præterea gregarius viget fructusque suos modo sine lege solitarios spargit, nunc in cæspitulos aut series lineares instruit. Nudispori e cauliculo crasso, tereti, et capitulo globoso aut ovato, rarius quasi e solo capitulo subsessili et pulviniformi constant. Capitulum autem et pulvinulus sterigmatibus perquam exilibus, $0^{\mathrm{mm}}, 03-05$ longis, stricte ramosis et constipatissime erectis pariter horrent, atque Stilborum more, haud parcam fundunt seminum copiam quæ corpuscula sunt anguste et brevissime ovata, nimirum $0^{\mathrm{mm}}$, o 01 vix longa, perexigua, simplicia, ac singula in summo sterigmate nata. Spermogonia istius modi quum cæspitose nascuntur, sæpissime inter se partim coalescunt. Fructus majoris dignitatis seu pezizei haud aliter generantur, frequentius autem solitarii; alii formam obverse turbinatam, truncatam et vix margi- 
natam, alii pulvinatam, marginibus omnino reflexis, adolescendo induunt; discus omnibus est atro-virens, senioribus vix levis. Sтватum hymeninum o ${ }^{\mathrm{mm}}, 13-16$ crassitudine æquat. Theсж obovato-lineares, obtusæ, $\mathrm{o}^{\mathrm{mm}}, 11-13$ in longitudinem et $\mathrm{o}^{\mathrm{mm}}, 01-$ 011 in crassitudinem nanciscuntur, membrana tenui struuntur et sporas octonas, multimodis pro fungilli ætate ordinatis, singulæ fovent. Hæ sporæ lineari-cylindricæ, nonnihil lanceolatæ, utrinque tamen obtusæ, curvulæ, septis transversis III-vII, imo forsan aliquando pluribus divisæ, ac quadantenus torosæ, $\mathrm{o}^{\mathrm{mm}}, \mathrm{ol}_{1} 6-\mathrm{o}_{2} 3$ in longitudinem obtinent, at $\mathrm{o}^{\mathrm{mm}}$, oo 35 crassitudine non superant. Paraphyses exilissime filiformes, continuæ, dichotome ramosæ nec in apicibus conspicue incrassatæ, inter thecas abundant et muco interposito, maxime sursum versus, glutinantur. Ex his extremis nasci diceres corpuscula illa globosa v. ovata, continua et minutissima, nempe vix $\mathrm{o}^{\mathrm{mm}}$, o 01 crassa, quæ modo copiosa, nunc parciora, endosporis vulgo commiscentur nec a microconidiis s. spermatiis supradictis nisi specie magis gglobosa differre videntur; eadem ubi hymenii portiuncula in aqua conteritur, confestim in conspectum veniunt.

Oritur in ligno alneo nudo et putrescente, nobisque perfectus occurrit iǹ saltibus Cavillanis, novembri mense a. MDCGCLX.

E fungillis exoletis quasi e subiculis sinceris, ac potissimum e pezizis effœetis, fructus novelli alterutrius indolis assurount, inde causa oritur cur plantula nostra, cæterum habitus natura varii, etiam magis multiformis appareat.

Spermatia s. conidiola duplicis generis, qualia in Coryne sarcoide observantur, hic etiam generari videntur, at minori forsan discrimine alia ab aliis recedunt. Quod ad corpuscula endosporis mixta pertinet, ea ex his seminibus germinantibus verisimiliter provenire æstimabimus, dum analogiam ex Nectriis, Dacryomycetibus, Bulgaria inquinante Fr. et Pezizis bene multis quarum infra mentio est, ductam adhibeamus.

\section{EXPLICATIO ICONUM.}

(Tab. XVIII, fig. 12-15.)

12. Agmen multiforme Corynes virescentis nostræ in ligno alneo nudo spargitur; pulvinuli crassiores, sæpe proliferi, hymenio ascigero vestiuntur; minores subsessiles aut stylis innixi et quasi metuliformes, spermatiis illinuntur.

13. Duplex illud organorum genus nota multo majus factum et a summo dimidiatum proponitur; capitula spermatifera dextram iconis tenent, pulvini ascophori lævam.

14. Portiuncula tenuis et maxime amplificata, de capitulo spermatifero sumpta, ut sterigmata exilia, brachiata et constipatissima simul atque spermatia ex iis nata in conspectum veniant.

15. Thecæ et paraphyses, accedentibus tum endosporis liberis, tum globulis s. utriculis illis minimis quorum origo et natura nos hactenus latuerunt.

Fig. 12 et 13 naturam vicies excedunt, fig. autem 14 et 15 vices circa cGcLxxx auctæ sunt; omnes Cavillæ Versaliorum adumbratæ sunt, exeunte decembri MDCCCCLXIV. 


\section{CALloria.}

Fungus acrosporus seu conidieus sub DACRYOMYCETUM signo inter fungos Tremellinos immerito conscribitur, perfectior autem plerisque mycetographis PEZIZA est. CALLORIA, nomen Friesianum ( $F l$. Scanica [1835], p. 343), Bulgarieis fungillis impositum est.

Upsaliensi magistro docente (loco sup. cit. Flore suæ Scanicee), Calloria Discomyces est ex Bulgarieorum tribu, excipulo substantia uniformi et ceraceo-gelatinosa formato, disco nudo, ascis fixis persistentibus et clavatis. Quum autem ex omnibus Callorïs Friesir, dubiis certisve, nullum fungum vere pezizeum hactenus noverimus præter infra descriptum, Calloriarum notæ peculiares in sequenti adumbratione nobis integræ continentur.

\section{Calloria fusarioides.}

* Fungus imperfectus, gemmifer :

Tremella sepincola $\beta$ W Wlldenowio in Roeneri et Usteriı Bot. Mag. t. II, fasc. Iv (1788), p. 18 , n. 20 , saltem quatenus urticicola.

Tremella Urtick Persoonio, Syn. Fung. p. 628, n. 20 , sed vix Tremella sincera, judice magistro. - CanDollio, Fl. Gall. t. VI, p. 28 , n. $234^{\text {b }}$, quem non fugit ambigua fungilli natura. - Moug. et Nestr. Stirp. Vog.-Rhen. fasc. IV (1813), n. 396 .

Tremella $U_{\text {RTICA }}$ (WILld.) Friesio, in suis Scleromyc. Suecice, fasc. VI (1821), n. 217.

Dacryomyces Urtica eidem Friesio, Syst. Myc. t. II, p. 251 , n. 7 ; Sum. Veget. Scand. p. 471, n. 7. - Dub. Bot. Gall. t. alt. (1830), p. 729 , n. 4. - Kцотzsch, Herb. viv. Mycol. fasc. alt. (1832), n. 148. - Cоврж Ic. Fungor. t. I, p. 32 , tab. xIV, fig. 113 . - Mazerio, Pl. Crypt. Gallice, ed. alt. fasc. IX (1840), n. 402. - Rabenh. Herb. Myc. ed. alt. fasc. I (1855), n. 73.

Fusariem tremelloides Grevillio, Fl. Crypt. Scotice, t. I (1823), tab. x. - Friesio, Syst. Myc. t. III (1832), p. 470 , n. 2. - Mazerio, Stirp. Crypt. Gallice, ed. I, fase. VII $(1828)$, n. 327 . - Sostheni de Lcrx. in Rabenh. Fung. Eur. exs. fasc. IV (1861), n. 387 .

Cillindrocolla URtick Bonord. Handb. der Mykol.p. 149.

Crlindrocolla (URTIGE) seppincola ejusd. in suis novissimis Disputationib. Mycolog. (1864), p. 116.

** Fungus perfectior, ascophorus :

PEZIZa fuSariofdes Berkeleo in collect. inscriptis Magazine of Zool. and Bot. t. I (1837), p. 46, n. 12, tab. II, fig. 4, et recentiori tempore in suis Outl. of Brit. Fungology, p. 371 , n. 122, ubi similiter valere dicitur Peziza neglecta Libertie. - Mazerio, Pl. Crypt. Gallice, ed. I, fasc. XXII (1840), n. 1063, et ed. alt. fasc. X, n. 463. - Moug. Stirp. Crypt. Vog.-Rhen. fasc. XV (1860), n. 1476 . - Tus. in Ann. Sc. nat. ser. III, t. XX (1853), p. 167-169. - Bonordenio, in novissimis suis Disput. Mycol. supra cit. p. 123.

Calloria? fusarioldes Friesio, S. Veget. Scand. p. 359.

Calloria fusarioides Auerswaldio ap. Rabenh. Herb. Myc. ed. alt. fasc. VII (1858), n. 676, ubi advertitur plantulam nihil aliud esse atque Dacryomycetem Urtice $\mathrm{F}_{\mathrm{r}}$. rite evolutum.

Fungillus sub cuticula tenuissima et pellucida plantæ matricis inordinate laxeque gregarius et biformis nascitur; autumno hiemeque potissimum nudisporus reperitur verno autem tempore perfectior et ascophorus; sub utraque forma colore nitide rubro- 
aureo micat, glaberrimus est et mycetologi oculos allicit. Pulvilui nudispori depressosemiglobosi, disciformes, ovati, oblongi, imo lanceolati, millimetrum unum aut unum et alterum diametro majori æquant, naturamque mollem, humidam et quasi tremellosam ostendunt. Integri constant e filamentis exilibus, admodum pallidis, dichotome et iterato ramosis, articulatis, sæpius erecto-arcuatis et constipatissimis; quorum articuli $\mathrm{o}^{\mathrm{mm}}, 0065-015$ in longitudinem nanciscuntur, $\mathrm{o}^{\mathrm{mm}}, \mathrm{oo}_{2}$ crassitudine vix excedunt, tandemque ab invicem solvi et tot semina s. gongylos fingere videntur; sunt etiam ramuli bene multi qui in articulo unico cæteris haud impari consistunt. Dumis hujus modi vix subest stromatis continui vestigium. PEzize seu pulvini ascophori ex altioribus corticeis stratis emergunt, formam ovatam vel rotundatam assumunt, modice concavæ fiunt, pulvillos nudisporos crassitudine non superare solent at nitidius rubent et parciorem combibunt humorem. Hynesiun seu thalamium nudum prope totum efficitur ex thecis lineari-clavatis, obtusissimis et octosporis quæ vulgo suis suffulcris cæspitose insistunt; paraphyses si quæ sunt, ægre a thecis junioribus distinguuntur. Endospore lanceolatæ, curvæ, hinc sæpe crassiores et subcapitatæ, continuæ, læves, pallidæ et utrinque retusæ, duplici ordine in singulis ascis digeruntur.

Frequens oritur apud nos in caulibus arefactis Urtick dioece L. vulgoque brumali tempore apparere incipit, quum hi scapi jam pallescunt; eorumdem partem inferiorem potissime diligit. Crescentem etiam vidimus Cavillæ Versaliorum, ni fallit memoria, in caulibus Cannabis sative $\mathrm{L}$.

Vix assentire licet Bonordenı qui quum Cylindrocollam suam Tremellis affinem existimaret, libenter deprehendisse sibi visus est articulos ejus solutos quos sporas nuncupat, mucronem obliquum in basi ostendere ideoque pleurotropis seminibus, qualia apud Tremellineos fungos occurrunt, posse annumerari. (Cfr. Bonord. Disputat. Mycolog. recentiores [1864], p. 117.)

Pezizam Erythrostigma Montanio (in Amn. Sc. nat. ser. altera, t. XVIII [1842], p. 246 , n. 47, et sua Sylloge Pl. Crypt. p. 186, n. 628), stirpem muscicolam e Pezizis Plialeis seu Mollisïs Friesir, ut magistro parisiensi videbatur, quam autem Callorïs suis annumerandam existimavit ill. mycographus upsaliensis (in Summ. Veget. Scand. p. 359, nota 1), nihil aliud prorsus esse quam sincerum pyrenomycetem, Nectriam videlicet, sedulo inspectis Montanianis speciminibus, nuper cognovimus. His quæ super hoc fungillo præstita sunt, addere expedit, exemplis adultis, semina jam enixis, duplex inesse thecarum genus, alias scilicet gravidas, distiche octosporas, obovatas s. clavatas, $0^{\mathrm{mm}},{ }_{9} 5$ circiter longas et $0^{\mathrm{mm}}, 013-016$ crassas, alias contra effœtas duplo longiores sed angustiores, longitrorsum plicato-rugosas apiceque lacero hiantes, paraphysibus longe filiformibus accedentibus. Quod ad endosporas attinet, formam anguste oblongam, utrinque obtusam, rectam aut nonnihil inæquilateralem, continuam levemque obtinent, $0^{\mathrm{mm}}, 03-04$ longitudine et $0^{\mathrm{mm}}, 008-0095$ crassitudine æquant, guttis oleosis replentur, setaque filiformi, rigida, recta et $0^{\mathrm{mm}}, 0065$ longa augentur quæ a supero earum apice nascitur. Hæc appendicula quam apud semina intra thecæ parietes adhuc conclusa reflexam æore perspicias, MosTANII oculos fugerat. 


\section{PYRONEMA.}

(Tab. XVII, fig. 11 et 12.)

Huc potissime spectat PEZIZA exigua Persooniana quæ nonnullis pro hymenomycete incaute habila fuit, et nuperius PYRONEMA dicta est Caro, NeEsio, Corde et aliis.

Adurssa pro generis prototypo plantula miniata infra descripta, Pyronema dixeris pezizulam byssisedam, mollem, quasi ceream, discis dense gregariis, orbicularibus, tandem turgidis, convexis passimque coalescentibus, thecis longe cylindricis et octosporis, sporis autem ovatis, rectis et continuis. Huc adde nonnulla hyphasmatis filamenta in monilia ramosa e conidiis brevibus et catenatis aliquando abire.

Typo Neesiano antehac solitario socium, ut videtur, simillimum, nuperrime dedit clariss. Notarisius in Actis Soc. Crypt. Itale, fase. V (1864), p. 366, sub titulo Pyronematis Franzoniani $\mathrm{DN}$ Trs.

\section{Pyronema confluens.}

Peziza confluens Persoonio, Obs. Mycol. parte alt. p. 81, n. 126, tab. v, fig. 6 et 7 mediocribus; Syn. Fung p. 667 , n. $120 ;$ Myc. Europ. parte I, p. 274, n. 144 , exclusa forsan forma $\delta$ lilacina. - Alb. et Schw. Consp. Fung. Nisk, p. 337, n. 1008. - Mazerio, Stirp. Cirypt. Gallice, ed. I, fasc. IX (1829), n. 428 (ex agro insulensi). - Tul. Sel. Fung. Carpol. t. I, p. 74, nota 2.- Ant. de Bary, in Dissert. sua De explicatione fructus Ascomycetum (1863), p. 11-15, tab. 1I, fig. 1-14.

Peziza confluens et rosella Ehrenbergio, Sylv. Myc. Berol. $(1818)$, p. 17 et 29 , n. 48 , opinantibus Persoovio et Friesio.

PEZIZA OMPIIALOdES Friesio, Syst. Myc. t. alt. p. $7^{3}$, n. $7^{8}$, at, ni fallimur, præter formam $\alpha$ principem s. Bulliardianam, et $\delta$ Persoonianam.

PEZIZA o.MPhalodes, confluens, eidem Friesio, in sua Summa Vego. Scand. p. 350.

Peziza ouphalodes Berkeleo, Outl. of Brit. Fungology, p. 366, n. 33, inter Pezizas Humarias. - Minime autem, ut opinamur, Peziza omphalodes Bulliardi, F. Gall. t. I, p. 264 , n. 32, tab. cccclxxxv, fig. I, nec Candollit, Fl. Gall. t. II, p. 77 , n. $19^{8}$, descriptionibus enim et figuris ab utroque auctore præstitis cum fungillo nostro non congruentibus. Neque magis conveniunt, præter plurimorum sententiam, tum Fungoides coccineum, minimum, oris non pilosis (Мıсн.) Mulleri, in Flora Danica, t. IV, fasc. XI (1775), p. 8, tab. DCLvi, fig. 2, tum Peziza hepatica Batschio, Elench. Fung. contin. I (1786), p. 199, n. cхxхvir, tab. xxvi, fig. 138 .

PYronema marianum Caro et Neesio, in Novis Actis Acad. L. C. nat. Cur. t. XVII, parte i (1835), p. $369-375$, tab. xxviı. - Cord.x Anleit. z. St. der Myk. p. xaiv, tab. F, fig. 61, n. 1-5. - Leveilleo, in Ann. Sc. nat. ser. III, t. V (1846), p. 253 , n. 281. - Heuflero, in Comment. Soc. Zool.-Bot. Viennce Austr. t. VII. fasc. IV (1857), p. 629-632. - Rabenh. Fl. Crypt. Germanice, t. I, p. 3o8, n. 2417 , inter fungos Tremellinos; Fung. Eur. exs. fasc. III (1860), n. 267 , ex agro Gissensi et Francofurtano.

Thelephora cafibonaria Bertero ap. Smith, Fl. Brit. t. V, parte alt. $(1836)$, p. 169 , n. 25 , docente BerKELEO.

Corticium (ex Himantïs) Marianum Friesio, in sua Epicrisi Syst. Myc. (1838), p. 56o, n. 22.

PEZIZ confluentis Peris. historia tam multis scripta est ut omnino supervacaneum 
ducamus hic novam illius tentare descriptionem. Non quod tamen fungilli exordia nobis adhuc plurima ex parte lateant, sed dolemus vix quidquam hoc super argumento novisse quod dubitationes tollere et quæstiones enodare valeat. Porro quandoquidem id libri ad multiplicem fungorum generationem exponendam præsertim spectet, satis erit si meminerimus horum monilium ex conidiis catenatis quæ jam nota fecimus in tomo I, p. $7^{4}$, simulque eorumdem fidam imaginem præstemus. Peculiaria illa filamenta articulata frustra quæsierit Antonius de Bary. (Cfr. ejus dissertationem super Ascomycetibus supra laudatam.) Contra idem sagacissimus rei funginæ indagator hoc comperisse asserit, nimirum ex utriculis crassis et bifurcis qui in cæspites sociantur et initia disci ascophori denotant, nonnullos esse crassiores qui in appendicem circinatam singuli superne protrahantur, et has appendices summis aliis ascis macrioribus singulatim incumbere. Ad id autem conjunctionis s. copulationis oculos nostros non advertimus.

\title{
EXPLICATIO ICONUM.
}

(Tab. XVII, fig. 11 et 12.$)$

11. Una proponuntur organa varia Pezizce confluentis Pers. pari modo præter nativas demensiones circa vices ccclXxx amplificata; mycelio seu bysso repenti imponuntur non modo cæspites illi ex utriculis crassis et fibris simul assurgentibus qui cupularum exordium indicant, sed etiam cupulæ ipsæ adultiores, alia scilicet nondum perfecta, minima, occlusa, alia jam endosporis fœta et tubulos crassos ex imis suis parietibus agens. Præterea antice assurgunt aut decumbunt filamenta illa reliquo mycelio pallidiora et sursum in corymbos patulos discedentia, quæ etiam in articulos breves quasi in tot gemmas seu gongylos tota cito solvuntur et evanescunt.

12. Endosporæ liberæ et vices circiter ccccix auctæ; pleræque in germina utrinque protrahuntur; spora inter germinandum septo medio sæpe dividitur et germinis primum fusiformis simplicisque fit pars media et crassior, ut æọre mox dignoscatur.

Hæ figuræ juxta fungillos vivos Cavillæ Versaliorum adumbratæ sunt, duodecima scilicet decedente octobri MDCCCLIII, et prior jutio exeunte anni MDCCCLX.

\section{PEZIZA.}

\author{
(Tab. XVI et XXII.)
}

FUNGOIDIA cava, scutellata et turbinata Micheli, ELVELLARUM species posteris ut Gleditschio, Schærfero et aliis, OCTOSPoraruM magno Hedwigio, PEZIZaRUM autem Dillenio, Persoonio, Friesio et neotericis.

Innumeros inter fungillos qui bene multis amotis sociis, Pezize titulo etiam nunc salutantur, nullus, quod sciamus, doctrinæ nostræ .magis favet et congruentius, si dicere fas est, loquitur quam Peziza nostra benesuada, e Friesiano grege Mollisiarum; ejus enim structuram novissimis his temporibus quum iterum scrutati fuerimus, talem reperimus quatem olim 
notam fecimus in Annalibus Sc. naturalium, ser. III, t. XX, p. 169-1 $7^{1}$, tab. xv, fig. 8 et 9 . Qua autem de causa nomen a nobis huic fungo impositum, postea mutatum fuerit, cur scilicet rev. Benkelas Pezizam blandulam (in suis Outl. of Brit. Fung. p. 444, tab. I, fig. 13 ) eum dixerit, non clare perspicimus. Donec tamen nos plantulæ causa in errorem incidisse pateat, Peziza nobis benesuada fuerit.

Exemplum aliud paraphysium in articulos aut ramulos peculiares similiter solntarum nondum reperimus. Non tamen omnino desunt fungi scyphophori quorum paraphyses nisi in gemmas sinceras, saltem in articulos seminiformes desinant. Geoglossi glabri Pers. jam meminimus in tomo I hujus Carpologice, p. 44, nota 1, ob paraphyses in monile breve ex articulis globosis et inæqualibus singulas abeuntes; apud Geoglossum viride PErs. et difforme $\mathrm{F}_{\mathrm{r}}$. ut et Ascobolos complures, globulum seu capilulum discretum et simplex eadem filamenta parathecalia sustinent. Contra Peziza diplocarpa Cunnero (in Actis Soc. Linn. Londin. t. XXIV [1863], p. 153 , tab. xxv, fig. 30,32 et 33 ), quam nos etiam offendimus in sylvis acerosis Carthusiensium Gratianopolitanorum (septembri mense, anno MDCGCLVII) ${ }^{1}$, corpusculum ovato-lanceolatum, septiferum et vere seminiforme singulis suis paraphysibus evectum ostendit; inde cognomen illi inditum.

De paraphysibus insuper jam notavimus eas aliquando propter suum farticulum, disco fertili colorem impertire quo niteat, reique exemplo esse Pezizam aurantiam Mulc. et Pers. ${ }^{2}$ Alias contra, v. gr. in Peziza omphalode Bull. (F. Gall. t. I, p. 264, n. 32, tab. ccccuxxxv, fig. I), item aurei coloris, membrana ipsa quum paraphysium, tum thecarum, simulque plasma contentum, pariter nitide rubent. Uterque fungus endosporis præterea insignitur quæ apud priorem reticulato-cristatæ ${ }^{3}$, in altero autem sphæricæ reperiuntur. Contra plerisque Pezizis sporæ sunt ovatæ et leves. Inter germinandum nonnihil crassiores fiunt et oleum limpidum quo primum integræ replentur, turbidum fit et in plasma granosum paulatim vertitur, guttis plurimis et inæqualibus, ex humore aqueo, simul admissis. Germina, ut

\footnotetext{
${ }^{1}$ Fungilli Curreiani descriptionem, juxta exempla viva quæ obvia habuimus exaratam, hic tradere nobis liceat. Cupula ejus quasi sessilis centimetra II-IV diametro explet ac repanda late patet, valde etiam sinuosa, carnosa, subcoriacea, utrinque glaberrima, extrorsum præterea nonnihil verruculosa et coloris primum ferruginei tandemque nigrantis, in disco contra saturate fusco-æruginosa; cæterum e parenchymate atro-ianthino tota fit. Hymenium e paraphysibus et thecis commistis de more constat; paraphyses autem a solita fabrica recedunt; fila sunt exilia, simplicia, subachroa et $0^{\mathrm{mm}}, 1$ circiter longa, quæ singula in cuspidem lanceolatam, ob septa transversa bi- v. triloculatam, levem et spisse infuscatam, quasi in sporam acrogenam s. stylosporam dilatata fastigantur. Has autem acies natura decidere germinaque protrudere nunquam comperimus; cæteroquin omni plasmate granoso carent. Thecæ paraphysibus pauciores el paulo breviores, formam anguste cylindricam obtinent, $\mathrm{O}^{\mathrm{mm}}, 007-009$ crassitudine æquant, sporasque IV-VIII, alias monosticho ordine diges-
}

tas, alias conglobatas singulæ fovent. Sporæ ovatæ, utrinque subacutatæ, leves, pellucidæ et albidæ (saltem sigillatim spectatæ), simul exiguæ sunt, hinc enim $0^{\mathrm{mm}}, 007-01$, illinc $\mathrm{o}^{\mathrm{mm}}, 003-005$ explent; singulis insunt guttæ remotæ ex oleo limpido. Dato loco opportuno, hæ sporæ germina exiliter filiformia diuque simplicia assueto modo exserunt. Fungillus, ni fallimur, in liğno abiegno vigebat. Pezize versiformi Persoonio, qualem saltem a clar. Berkelea accepimus et ab eodem adumbratam videre est in suis Outl. of Brit. Fung. tab. alt. fig. 6 , sub Helotii titulo, habitu non multum dissimilis est.

${ }^{2}$ Continetur in Mazeril Stirpib. Crypt. Gallia, ed. princ. fasc. XI (1831), n. 521.

${ }^{3}$ Videsis quæ de his seminibus attulimus in tomo I hujus Carpologice, p. 77 et 225 (adnot. XV). Endosporas sphæricas simul et in tegmine reticulatas suæ Lamprosporce minialce tribuit Notarisius in Actis Soc. Crypt. Italee, fasc. V, p. 388 . 
mos est, ex utroque vel alterutro seminis termino potissimum oriuntur et in brachia mox discedunt quæ sæpissime adversa incedunt ut apicibus coalescant. Hæc omnia sine negotio comperire licet apud Pezizam vesiculosam Bull. rhizopodem Arb. et Schw. Acetabulum Lins. reticulatam Grev. et cæt.

Cæteris super genuinis Pezizis quas obiter fusiusve jam etiam attigimus, tum in Annalium nostrorum tomo XX modo citato, tum in hujus Carpologice tomo primo, iterum verba facere minime necesse arbitramur, nisi prout postulant earumdem icones quas hodie præstamus. Tres ex his fungis, nimirum Peziza tuberosa Buldiandi ${ }^{1}$, Duricana nostra et Curreiana BerkeL\&I simul vernales sunt, et mycelio tuberoso pariter utuntur. Prioris sclerotium nunc pro radice aliena mutata, nunc pro fungo sui generis habitum est; mycologis autem qui rectius sapiunt, hypogæa legitimaque Pezize pars est ${ }^{2}$. Cavillæ Versaliensium quotannis abundat nobisque propterea comperire licuit fungillum ex corruptis Anemones nemorose L. rhizomatibus vulgo pronasci et quasi prolem eorumdem videri, ita ut stipes seu funiculus scyphophorus in rhizomate fistuloso facto pro parte sæpissime lateat. (Cfr. tab. nostram XXII, fig. 1-4.)

Peziza tuberosa Bull. et Duricana Tur. inter se præterea et cum P. vesiculosa Bubl. bolari Batschiana et Cylichnio Tur. in eo congruunt quod suæ endosporæ, ubi seruntur, copiosissima edant conidiola seu spermatia illa sporogena quæ primum nota fecimus in Annalibus Sc. naturalium, ser. III, t. XIX, p. 213 et seq. ac denuo attigimus in eorumdem collectaneorum t. XX, p. 164 et 171-179 ${ }^{3}$. Peziza nostra Cylichnium (in hoc t. XX Annalium nostrorum, p. 174 ) idem fungus fortassis est atque Hedwigiana Octospora violacea ${ }^{4}$, i. e. Peziza ianthina Friesil, Syst. Myc. t. II, p. 130, n. 38.

Super conidiolis quæ ex endosporis satis subsessilia proveniunt, eandem Pezizam Cylichnium Tul. omnino imitatur Spathularia flavida Pers. cujus sporæ digniores s. ascogenæ, li-

\footnotetext{
${ }^{1}$ Quæ est Peziza radicata Jacobo Reichard in collectaneis quæ inscribuntur : Beschäftigungen der Berlin. Gesellsch. naturf. Freunde, t. III (1777), p. $214-216$, tab. Iv, fig. 4-6, tubere preterviso; - Pers. Syn. Fung. p. 642, n. 33; $=$ Octospora tuberosa Hedwigio, Descript. et Adumbr. Musc. frond. t. II (1788), p. 33, tab. x, fiğ. в; = Peziza tuberosa Dicksoni, Pl. Crypt. Brit. fasc. alt. (1790), p. 25 ; - Bull. F. Gall. t. II, p. 266 , n. 34, tab. ccccluxxxv, fig. III, к-м; - Sowerb. Fung. Brit. t. I, tab. LXiII, ubi fungus dicitur certe parasitari in Lycoperdo Tubere cujus enim substantiam non continet; simulque convenire, tubere excepto, cum Peziza radicata Bulliardi - Pers. Syn. Fung. p. 644, n. 41; Mycol. Europ. parte I (1822), p. 234 , n. 36 ; - Moug. et Nestr. Stirp. Vog.-Rhen. fasc. IV (1813), n. 397; - Candoldio, Fl. Gall. t. II, p. 84 , n. 220 ; - Duв. Bot. Gall.t. II. p. 741 , n. 20 ; - Mazerio, Pl. Crypt. Gallice, ed. princ. fasc. XXXV (1848), n. ${ }_{17}^{3} 9$, ed. alt. fasc. XXVII (1848), n. 1339 , utrinque e Vogesis; - Tul. in Ann. Sc. nat. ser. III, t. XX (1853), p. ${ }_{17} 5 ;-$ Raвenh. Herb. Mycol. ed. alt. fasc. IV
}

(1856), n. 308, e pratis sylvaticis tum Bohemiæ, tum agri Darmstadiensis.

${ }^{2}$ Hæc sunt Persoonil in sua Mycologia Europaca, t. I, p. 235 , super Peziza tuberosa Bril. eTuberculum radi«cale subglobosum, nigrum, intus album, 3-4 lin. mag"num, est vera hujus speciei pars, nec pro sclerotio, tubere "quodam, aut alius plantæ perfectioris radice habenda, «nam substantia interna et cortex exterior tuberculi et sti"pitis hujus fungi eadem sunt natura.» Contra Hedwigrus loco cit. "Radicem tuber nigrescens repræsental, sed pe«regrinum certe corpus cui continuo parasitica est hæc "(Octosporce $)$ species, fibrillis tenerrimis infixa. "De tubere insuper adnotat : "mihi quidem trunculus, seu ut bota"nicis hactenus placuit, radix emortua Anemones nemo"rosa, esse videtur.

${ }^{3}$ Videsis supra, t. I, p. ${ }_{9}^{5}$.

${ }^{4}$ Cujus iconem videsis in illustris magistri petropolitani Descript. et Adumbr. Muscor. frond. t. alt. (1788), p. 27, tab. viII, fig. A. 
neari-lanceolatæ et flexuosæ, imo interdum hinc circinatæ, endosporas Rhylismatis acerini vel salicini supra (p. 116 et 119 ) descriptas quodammodo mentiuntur. Postquam in aqua paucos dies degerunt, hæ sporæ salvis forma, crassitudine, alboque colore, septis VII-XI transversis dividuntur et utriculum globosum ac subsessilem e singulis articulis, potissimum in latere convexo, agunt. Id olim, nempe ante decem annos et quod excurrit, medio septembri, compertum habuimus, apud pineta Dareizeana agri montosi lugdunensis ${ }^{1}$.

Quum jam dissertationem quam de Discomycetibus constitueramus, ad suum exitum modo perduxerimus, eandem paucis verbis super Morchellis duabus, titulo s. argumento non mutato, absolvamus. Monitum enim velimus endosporas albas Morchelle semiliberce DC. nota admodum peculiari sæpe insigniri, nempe umbilico seu fenestrula ovata et laterali, ex tenuato nisi quidem aperto episporio. Simul affusis acido ex sulphure et iodo soluto, tunica seminis interior dilute cærulescit et ante fenestram dehiscit, ut illac etiam sua contenta dimittat. Spora, ubi evacuatur, episporii achroi foramen longe manifestius ostendit. Idem osculum pariter conspicuum fit quum endospora germen edidit, quippe istius germinis solita via minime est. Inde quoque apparet partes alias ei impertiri quam foraminibus fungillorum uredineorum. (Cf. Ann. Sc. nat. ser. III, t. VII, p. 43 et seq. tab. VI et vir, et ser. Iv, t. alt. p. 77 , tab. vII-XI.) Osculum non dissimile item vidimus in seminibus Morchelle esculente Pers. sed
rarissimum.

Longe aliæ species sunt quæ Morchellam bohemicam Kronвп. (Abbild. d. Schw. fasc. III [1834], p. 3-5, tab. xv, fig. 1-13, et tab. xviI, fig. 5-8 $)^{2}$ mycologis commendant. Fungus apud nos minime frequens provenit ${ }^{3}$ et thecis utitur lineari-oblongis quæ licet amplissimæ sint, nimirum $\mathrm{o}^{\mathrm{mm}}, 2-25$ longitudine et $\mathrm{o}^{\mathrm{mm}}, 02-022$ crassitudine expleant, duntaxat tamen endosporas geminas singulæ fovent. Hæ vero oblongo-ovatæ, utrinque obtusæ rectæque, $0^{\mathrm{mm}}, 08$ in longitudinem et $0^{\mathrm{mm}}, 016-019$ in crassitudinem nanciscuntur; simplices sunt, at in germinando septis transversis I-II dividuntur, simul atque multo longiores et crassiores fiunt. Cordæanæ ideo adumbrationes, tum in Sтurui Flora Germanica, fasc. XIV, p. 117 , tab. LVI, tum in KronвноцZI opere supra citato editæ, a vero plurimum distant in eo quod thecas octosporas et sporas ovatas exprimunt. Accuratior est Mazerius in Annalibus Sc. naturalium, ser. III, t. VIII $(1847)$, p. 189 , n. 86, quippe qui magistrum pragensem jam ipse merito reprehendit, ejusdem errorem, suis compertum oculis, item denuntiante clariss. viro mycologo, Ludovico Bouteille.

\footnotetext{
${ }^{1}$ Conidiola, auctore Eugenio Coemans, ex endosporis; Ascobolorum germinantibus etiam proveniunt; alia, in se ries simplices digesta, Torularum monilia articulata æmulari, alia potius arbusculas vel corymbos, ut Penicillin, struere dicuntur, omnia autem pari modo demum spisso eodem fucari colore quo endosporæ ipse, germinibus contra semper achrois. (Cfr. Acta Soc. reg. Bot. Belg.t. I, n. $1[1862]$, p. $79 \cdot)$
}

\footnotetext{
${ }^{2}$ Morchella dubia dicitur Meratio in libro inscripto Revue de la Flore parisienne cæt. (1843), p. 493, Verpa autem dubia Leveilleo in Ann. Sc. nat. ser. III, t. V (1846), p. 250 , n. 266 .

${ }^{3}$ Semel hactenus nobis occurrit haud procul a Versaliis (loco dicto Jardy), in sepibus, ineunte aprili mense, a. MDCCCLXII.
} 


\section{EXPLICATIO ICONUM.}

(Tab. XVI, fig. 16-20.)

16. Endosporæ maturæ Morchelle semiliberce DC. quæ e thecis suis natalibus nuperrime exierunt; oleo homogeno replentur, atque $0^{\mathrm{mm}}, 015-02$ longitudine et $0^{\mathrm{mm}}, 01-013$ crassitudine æquant.

17. Sporæ aliæ postquam in aqua satæ sunt, intra breve temporis spatium maxime creverunt et germen utrinque protruserunt, oleo contento simul turbido facto et in plasma heterogenum mutato.

18. Sporæ bene multæ rimam ovatam v. ostioli speciem hinc aut inde et sæpissime in medio pariete ostendunt, qua in parte episporium solito tenuius seu fragilius, imo vere perforatum videtur; id foraminis $0^{\mathrm{mm}}, 005-0065$ majori diametro æquat.

Hæ figuræ (pari modo omnes amplificatæ) exeunte aprili MDCGCL adumbratæ sunt juxta semina viva Morchellarum quæ in ambulacris sylvulæ boloniensis Parisiorum creverant.

19 et 20. His figuris, vices circiter cccclx præter naturam similiter amplificatis, proponuntur endosporæ illæ Peziza vesiculosa Bulc. quarum olim meminimus in Annalib. Sc. nat. ser. III, t. XX, p. 177 ; in hymenio fungilli exclusæ jacebant ibidemque brevissima crassaque protruserant germina quæ conidiolis copiose exsertis superbiebant; conidiola soluta item sparguntur. Ex quo icones istæ adumbratæ sunt (medio scilicet maio an. MDCCCLIII), idem endosporarum genus novembri sevimus (a. MDCCCLVII), nec nisi germina prælonga et cito ramosa tunc edita vidimus.

(Tab. XXII.)

1. Peziza tuberosa Dicks. adulta e radice nigrefacta et putrescente Anemones nemorose L. in qua sclerotium. quoddam discretum item insidet, assurgere videtur.

2. Idem fungus simul cum radice hospita et sclerotio insito a vertice dividitur, inde apparet cyathuli stipitem ex ipso tubere reapse oriri et radicis penetralia duntaxat percurrere.

3. Peziza altera cujus stipes item e sclerotio natus intra radicem nutricem pro maxima parte latet.

4. Cupula nondum explicata stylo in basi de more tuberiformi et e radice corrupta orto innititur.

5. Sclerotium nudum datur ex quo cæspitose assurgunt pezizae plurimæ et recentes.

6. Endosporæ quæ in aqua satæ, intra diurnum spatium germinarunt; multæ in conidiolis procreandis extenuantur, aliæ germina filiformia exserunt.

7. Endosporæ aliæ quæ jampridem in ipsa cupulæ pagina exclusæ viguerant; humore aqueo replebantur et germina omnia multimodis conidiophora evaserant.

Fig. 1-5 nativas rerum demensiones exprimunt, reliquæ autem vices circiter cGccLX amplificantur; cunctæ juxta plantas vivas adumbratæ sunt; prioribus enim 1-4 proponunfur fungi Cavillæ Versaliorum, aprili medio (a. MDCCCLXIII), tempore scilicet quo Anemones nemorosa L. semina læte progerminant, reperti, reliquis 5-7 fungi illi e sylva boloniensi Parisiis suburbana quos olim attigimus in Annalib. Sc. nat. ser. III, t. XX, p. 175 et 176 .

8. Peziza nostra Cylichnium in trunco solo tenus exciso crescit et nativa magnitudine adumbratur.

9. Theca gravida et endosporæ exclusæ; ex his seminibus duo quæ plasmate granoso referciuntur, non ita pridem ex asco materno prodierunt; cætera nunc evacuata et achroa septisque divisa, in conidiolis procreandis omnem vitam suam consumpserunt; conidiola libera circumjacent. 
10. Endosporæ conidiophoræ.

Hæ figuræ fungum Modoni lectum exprimunt; nona et decima justam mensuram circiter vices ccccLX excedunt.

11. Peziza Curreiana Berк. quam descripsimus in tomo I hujus Carpologice, p. 105 , nota 1 , e sclerotio suo assurgit quod in culmo Junci effusi L, latitat.

12 et 13. Ejusdem Peziza exempla altera, bifera, sclerotio nudato.

14. Particula tenuis et valde amplificata simul exhibet sclerotiei parenchymatis partes dispares, nempe tum corticalem nigrentem, ex utriculis exiguis et confertissimis, tum mediam laxam, fibrosam, et cellulis asteriformibus medullæ juncinæ variatam, nec non et fibrosam quoque imi stipitis cyathophori substantiam.

15. Cupula a vertice dimidiata parietem suum internum mire sulcato-rugosum ostendit.

16. Thecæ et endosporæ exclusæ.

17. Endosporæ quæ satæ magnopere creverant et in germina seipsis vix angustiora jam protrahebantur.

Fig. 11-13 naturam non excedunt, cæteræ pari modo vices circiter ccctxxx auctæ sunt; cunctæ juxta fungos vivos quos exeunte aprili MDCCCLX ab humanissimo viro C. E. Broone acceperamus, adumbratæ sunt.

18. Endosporæ Peziza bolaris Batsch de quibus olim verba fecimus in Annalib. Sc. nat. ser. III, t. XX p. $17^{1}$ et seq. Aliæ germina filiformia assueta exserunt, aliæ conidiola bene multa globosa, in capitula vel monilia digesta. Dum vigent, septis dividuntur et pedetentim evacuantur.

19. Endosporæ aliæ ejusdem modi quæ nunc omnino vacuæ sunt; conidiola nonnulla passim sparguntur.

Has figuras, vices circa cCCCLX similiter amplificatas, præstiterunt fungi vivi, aprili mense (anno MDCCCLIII) in sylvula boloniensi Parisiorum collecti.

20. Carex arenaria Lins. quæ in arena agri garumnensis media æstate (a. MDCCGLVII), antequam flores rite explicaret, misere contabuit propter innatam Pezizam Duriaanam TuL. supra descriptam, t. I, p. 1o3, nota 1; culmus supernus Epidochio ambienti $\mathrm{M}_{\mathrm{Az}} . e, e$, scilicet fungilli nostri, ut videtur, apparatu æstivo, nudisporo, passim circumcirca maculatur, imus autem fongitrorsum dehiscit et sclerotia ejusdem latentia $s, s$, revelat.

21. Particula tenuis et valde aucta ex Epidochio transverse dissecto desumpta; culmi caricini lacunæ vacuæ, fungillique tum parietes fertiles, tum filamenta vaga simul traduntur.

22. Sclerotia et Pezize quas vere enixa sunt, nativis suis demensionihus exprimuntur.

23. Peziza sclerotio suo suffulta et valde amplificata.

24. Endosporæ quæ satæ germina et conidia prompserunt.

Figuræ 22-24 ex fungis vivis domi (Parisiis) cultis aprili et maio MDCCCLVIII adumbratæ sunt; fig. 20 et 22 justam rerum mensuram non excedunt, fig. autem 21 et 24 vices circa ccclxxx amplificatæ sunt. 

INDEX. 
\#\#: 


\section{INDEX}

\section{F U N G O R U M O M N I U M}

QUi IN TOMO TERTIO GITANTUR AUT DESGRIBUNTUR.

Asterisco, ut consuevimus, tum nomina admissa, tum descriptiones, compendiosas vel fusiores, notavimus; numeri paginas designant.

Acanthomyces Leb. (Isaria spec. Pers.), 4.

_- aculeatus Leв. (Isarice sphingophile Diтм. forma?), * 12 .

Acrophyton Leb. (Torrubice spec. nob.), 4.

- tuberculatum Leв. (Torrubia nostra Sphingum), ${ }^{*} 12$.

Acrospermum compressum Tode, 37 .

dubium Pers. (Coryne sarcoides nostra nudispora), * 190 .

lichenoides Tode (Spharia riccioidea BoLt.), ${ }^{*} 37$.

Acrostalagmus cinnabarinus CORDE, 72 .

Ethalium septicum Fr. 61.

Agaric délicieux var. dénaturée Secret. 62.

Agaricus L. 38, 46, 47 et passim.

— adustus Pers. 31, 43, 56, 59.

caudicinus Pers. 56.

conchatus Bull. 43.

emeticus Poll. 43.

flabelliformis Schғағ. 43.

involutus BАTSCH. 5 o.

- lycoperdoides Bull. NeEsio, 54, 57 .

melleus $\mathrm{V}_{\mathrm{AHL}}$ 61, 62.

- parasiticus Bull. 54, 56, 58, 59.

polymyces Pers. 61.

pulverulentus BuLL. 56.

Agaricus (Lactarius) acris Bult. 58.

- (Lactarius) camphoratus BuLc. 43.

- (Lactarius) deliciosus L. 62.

(Lactarius) torminosus Sch EFF. 40.
Agyrium rufum Fr. $128,{ }^{*}{ }_{1} 50$

Amanita rubescens PErs. 47.

Animal-Plante ( $E l)$ Rio de LA LozA, 108.

Artotrogi (Mntgn.) Fr. 38.

Artotrogus asterophorus Fr. (Hypomycetis nostri asterophori forma gemmipara), ${ }^{*} 55$.

Ascoboli Pers. Fr. cæt. 177, 192, in nota, 199, 201 , in nota 1.

Ascobolus coronatus Schum. (Phacidium coronatum Fr.), $* 134$.

- Trifolii Biv. (Phacidium Medicaginis Liberte? ?), 142.

vinosus BERK. XVI.

Ascospora pyrenophora Bonord. 143.

Aspergilli (Мıсн.) Вевк. Lк. Fr. cæt. 9, 38, 53.

Aspergillus Mycobanche Lк. (Hypomyces Pezize Tur. gemmifer), ${ }^{*} 53$.

Asterophora Lk. (Hypomycetes conidiophori), 38, ${ }^{*} 54$.

- agaricicola Corde (Hypomyces asterophorus Tuz.), $\because 55$.

- agaricoides Fr. (Hypomyces noster asterophorus), ${ }^{*} 54$.

lycoperdoides Diтu. (Hypomyces noster asterophorus), 54 et ${ }^{*} 55$.

Pezizæ Corde (Hypomyces Peziza nob.), ${ }^{*} 53$, 54.

physaroides Fr. (Hypomyces asterophorus TuL.), * 54 .

trichioides Fr. (Hypomyces asterophorus nob.), ${ }^{*} 54$. 
Asterosperma agaricoides PERs. (Hypomyces asterophorus noster gemmiferus), ${ }^{*} 54$.

Asterothecium strigosum Wallr. (Hypomyces Peziza noster simul cum matrice sumptus), ${ }^{*} 52$.

Asterotricha Bonord. (Hypomycetum formæ nob.), 38.

Asterotrichum Ditmari Bonond. (Hypomyces asterophorus noster conidiophorus), ${ }^{*} 55$.

Atractium (genus Linkianum e Spharostillis nonnullis conidiophoris), ${ }^{*} 99,{ }^{*} 104$

_ cinnabarinum Mntgn. ${ }^{*} 103$.

Aulographum Pinorum Liв. Maz. 112, $113,114$.

Pinorum Tul. (Hysterium Pinastri Schrad.), * 113 , 114.

Blitrydium calyciiforme DNTrs. 142 , in nota 1.

Boleti Linv. $38,49,57$.

Boletus castaneus Bult. 58.

— cyanescens Bull. 58, 60 .

edulis BulL. 50.

- luridus Schefr. 50.

scaber Bull. 60.

subtomentosus Lins. 48, 50, 51, 58, 6 o.

Botryosphæria pulicaris DNTrs. et CEs. ${ }^{*} 69$.

Botrytides Pers. DC. Lk. cæt. (quarum spuriæ nonnullæ Hypocreas et Hypomycetes gemmiferos constituunt), 38 .

Botrytis agaricina Lk. (Hypomyces noster ochraceus conidiophorus), ${ }^{*} 41$.

— dendroides Pers. (Hypomyces ochraceus Tul. gemmiparus $),{ }^{*} 41$.

densa Diтn. (Hypomyces ternatus nob.), ${ }^{*} 47$.

lignifraga DC. (Hypocrea rufa $\mathrm{F}_{\mathrm{R}}$. gemmipara), *3o.

Bulgaria inquinans Fr. 81, 192, ${ }^{*} 19^{3}$ (tab. xvII, lig. 9 et 10$), 194$.

- sarcoides Fr. (Coryne nob.), xv, 190 et * 191 .

Burcardia Schмер. (Bulgaria Fr.), 192, in nota.

Byssacei fungi Mazerio, 66 .

Byssus filamentis erectis, distinctis, crassiusculis.... R RCardo (Torrubia Sphingum nob.), " 12.

"Calloria Fr. nob. xvI, $67,{ }^{*} 195$.

— atro-virens Fr. (Coryne nostra virescens), ${ }^{*}{ }_{19} 3$.

— Erythrostigma Fr. (potius Nectrice sp.), ${ }^{*} 196$.

*fusarioides Fr. $19^{5-1} 9^{6 .}$

Calosphæria verrucosa Tul. 142 , in nota 1.

Calycium inquinans, $\gamma$ sæpincola, Sснжв. (Schizoxylon sepincola Pers.), ${ }^{*} 148$.

sepincola Dub. (Schizoxylum Pers.), ${ }^{*} 148$.

Castagnea Fr. (cujus typus Spharia Tubercularia DC.), 82.
${ }^{*}$ Cenangium Fr. 155, * 163 et seq. (tab. xix et xx), 174.

Abietis Dub. (Cenang. ferruginosum Fr.), ${ }^{*} 168$.

acerinum Fr. (minime Cenangium sincerum), ${ }^{*} 172$.

Aucupariæ Balio (Spharia cespitosa Tode), 153 , in nota 1.

Ariæ Pers. ${ }^{*} 161$.

Cerasi Fr. (Dermutea Cerasi ejusd. nobisque), 127 , ${ }^{*} 156,157$.

Cerasi, $\beta$ Padi, Fr. 159 , in nota 2.

chlorellum Fr. (potius Nectrice spec.), ${ }^{*} 172$.

conspersum Fr. (Tympanis conspersa ejusd.), 153 , in nota 1.

difforme Fr. (Cenangium fuliginosum eidem), ${ }^{*} 166$.

fallax Fr. 159 , in nota 2.

${ }^{*}$ ferruginosum Fr. 168-169.

Frangulæ Tul. (nunc Dermatece sp. nob.), , ${ }_{1} 62$.

Fraxini Tul. (potius Dermatea), 162.

*fuliginosum Fr. 166-168 (tab. xx, fig. 1-4).

* ligni Maz. 169-170 (tab. xx, fig. 5-7).

Pinastri Fr. (Tympanis Pinastri nob.), ${ }_{137},{ }^{*}{ }_{1} 51$.

Prunastri, rigidum, Fr. 159 , in nota 1.

pulveraceum Fr. (Cyphelle spec.), $17^{3}$.

repandum Fr. 166.

* Ribis Fr. ${ }^{*}$ 163-166 (tab. xix, fig. 1-9), 179.

seriatum Fr. (Dermatea nob.), ${ }^{*} 160$.

*Ulmi nob. 170-1 72 (tab. xix, fig. 18-22).

Cèpe soufré Paulet, ${ }^{*} 49$.

Ceratonema Crabronis Pers. 17.

Ceratostoma brevirostre F чск. ${ }^{*} 54$.

- spurium Fr. (Dermatece Prunastri Fr. fructus nudispori), 159 , in nota 1.

Ceratostomata Fr. (Dermatece nondum ascophoræ), " 155.

Ceuthospora phacidioides Grev. (Phacidii Ilicis pycnidia), ${ }^{*} 138$ et seq.

Visci Solum. (Spheria atro-virens A A b. et Schw.), 131 , in nota 2 .

Ceuthosporæ Grev. Bonord. 131,137 .

Chætostroma Buxi Corde, Debatio (Nectrice Russeliance Mntgn. pars), $97,{ }^{*} 98$.

Chætostromata Corde (Nectrice nondum perfectæ nob.), $65,{ }^{*} 97$.

Cheirospora Fr. $7^{6 .}$

Chicharra Mexicanorum (cicada fungipara), 11.

* Chlorosplenium Fr. 187 (tab. xx).

— ${ }^{*}$ æruginosum DNTrs. 187-188 (tab. xx, fig. 15$19)$.

atro-virens DNTrs. (Coryne nostra virescens), ${ }^{*} 193$.

Cladotricha (Corde) Bonord. 38.

Cladotrichum ternatum Bonord. (Hypomyces noster ternatus gemmifer), ${ }^{*} 47$.

Clavaria capitala HoLmsk. (Cordylia capitata Fr.), ${ }^{*} 22$. 
Clavaria cæspitosa Wulf. 34.

- coccinea Sow. (Sphcerostilbe aurantiaca nostra gemmipara, ut videtur), $79,{ }^{*} 101$.

coralloides L. 45, in nota.

- entomorrhiza Act. Soc. Entom. Lond. (Torrubia sinensis [Вевк.]), 14, in nota 1.

farinosa Sow. (Torrubia militaris nostra), ${ }^{*} 6$.

granulosa Bulc. (Torrubia militaris ascophora nob.), ${ }^{*} 6$.

Ligula Schefr. 35,36 .

militaris VAlLL. (Torrubiarum prototypus nobis), $5,{ }^{*} 6$.

- ophioglossa HoLmsk. (Ophioglossi species sincera), 20.

- parasitica WILLD. (Torrubia ophiogoglossoides nostra), ${ }^{*} 20$.

- radicosa Bull. (Torrubia ophioglossoides), ${ }^{*} 20$.

simplex, oblonga, pulvinata Sснмгd. 35.

sobolifera Hill et Wats. (Torrubice sp. nob.), ${ }^{*} 10$.

Clavarice Valle. Linn. Sowerb. et aliis (Torrubice gemmiferæ, imperfectæ), ${ }^{*} 4,{ }^{*} 10,{ }^{*} 12,{ }^{*} 99$.

Claviceps alutacea BaLIo (Hypocrea nob.), ${ }^{*} 35$.

— microcephala Tú. 24.

purpurea (Fr.), 24.

typhina BaL1o (Epichloe typhina $\mathrm{F}_{\mathrm{R} .}$ ), ${ }_{2} 5$.

Clavicipites Tur. 4, $24,36$.

${ }^{*}$ Clithris Fr. (Cenangiorum ejusdem pars), 166.

Coccomyces tumidus DNTrs. $136,{ }^{*} 137$.

Conisporium Helminthosporii Corde, 40.

Coralloides Buxв. (Torrubice spec. nob.), 4.

— clavata, lutea... Buхв. (Torrubia militaris nostra), ${ }^{*} 6$.

Cordiceps acicularis Raven. 19.

— alutacea Lk. (Hypocrea sp. nobis), ${ }^{*} 35$.

armeniaca Berk. et Curt. 19.

capitata Lk. (Torrubia nob.), ${ }^{*} 22$.

entomorrhiza Fr. (Torrubice sp. nob.), * 14 .

fuliginosa Crs. 20.

gracilis Dur. et Mntgin. $15,{ }^{*} 16$.

Gunnii Berk. 14.

Humberti Robinio, 18.

militaris Lk. (Torrubia nob.), ${ }^{*} 7$.

myrmecophila Ces. 19 .

ophioglossoides Lк. ${ }^{*} 2$.

stylophora Веrк. et Br. 18.

Tayloris Вевк. 14.

typhina Fr. (Epichloes Friesianæ prototypus), ${ }_{2} 5$. Wallaysii Westend. 8.

Cordicipites Fr. 3, 4, 29, 34, 66 .

Cordylia FR. 4, 20.

ophioglossoides Fr. ${ }^{*} 20,22$.

Corticium Marianum Fr. (Peziza confluens Pers.), ${ }^{*} 197$.
${ }^{*}$ Coryne Nees. Fr. nobisque, 190 et seq. (tab. xvir et xVIII).

- Acrospermum NeEs (Coryne sarcoides nostra nudispora), ${ }^{*} 191$.

"sarcoides Fr. 190-193 (tab. XVII, fig. 1-10).

- sarcoides, dubia, Corde (Coryne sarcoides Fr. nondum perfecta), xv et ${ }^{*} 191$.

* virescens nob. 193-194 (tab. xvill, fig. 12$15)$.

Cosmariæ s. Cosmosporæ nob. (Nectriarum pars), 91.

Cosmospora coccinea Rabenh. (Nectria cosmariospora DNtrs. et CEs.), ${ }^{*} 92$.

Creopus Lk. (Hypocrearum sp. Fr.), 29.

Cryptodisci Corde (Stictides Pers.), $108,177$.

Cryptodiscus atro-virens Cords, 177.

— lichenicola Ces. $95,108$.

- pallidus Conde, DNtrs. 128,177 .

Cryptomyces Wauchii Grev. (Rhytisma maximum Fr. nondum perfectum), ${ }^{*}{ }_{122},{ }_{12} 3$.

Cryptosphæria aurantia Grev. (Hypomycetis sp.), *43.

Cryptosporia epiphylla Fr. (Melasmice Lev.), ${ }^{*} 115$.

Cucurbitaria Berberidis (Pers.) Grev. 88.

— cinnabarina Grev. (Nectria Fr.), ${ }^{*} 80$. Pinastri Grev. 92.

Cucurbitariæ Grev. 65.

Cucurbitulæ nob. (Nectrice quædam), * 86 et seq.

Cycleda Wallr. (Dermatece Fr.), 155.

Cycledum Carpini Wallr. (Peziza carpinea Pers.), 183 , in nota 2.

— Cerasi Wallr. (Dermatea Cerasi Fr.), ${ }^{*}{ }_{1} 57$.

- sepincola Wallr. (Schizoxylum Pers.), " 148.

Cylindrocolla Bonond. 196.

- sepincola Bonond. (Calloria fusarioides nostra gemmipara), ${ }^{*} 195$.

— Urticæ Bonord. (Calloria eadem fusarioides gemmifera), ${ }^{*} 195$.

Cyphelium scabrosulum Асн. (Phacidium calycïforme Fr. ?), 142 , in nota 1.

Cyphella albo-violascens (Ацв. et Sснw.), 173.

- Hoffmanni nob. (Peziza anomala Pers.) ${ }^{*} 173$.

- pulveracea (Peziza Ацв. et Schw.), 173.

Cytispora foliicola (Liв.) $\mathrm{M}_{\mathrm{Az}}$. (Ceuthospora phacidioides Grev.?), ${ }^{*} 138$.

Cytisporæ Ehrens. Fr. cæt. 131.

Cyttaria rufa Bovord. (Hypocrece sp. Fr.), ${ }^{*} 30$.

Cyttariæ Berk. (fungi australes), 27.

Cyttariæ Bonord. (Hypocrearum Fr. nostratium pars), ${ }^{*} 29$.

Dacryomyces NeEsio, 66 .

Urticæ Fr. (Calloria fusarioides Fr. gemmipara), ${ }^{*}{ }_{19} 5$. 
Dacryomyces virescens Fr. Schum. (Coryne nostra virescens?), " 193 .

Dacryomycetes NeEsII, Fr. cæt. xVI, 190, 194, 195 .

Dactylium dendroides Fr. (Hypomyces noster rosellus conidiophorus), $40,{ }^{*} 45$.

*Dermatea Fr. nob. $67,{ }^{*} 155$ et seq. (tab. xix).

— amœna Tul. olim (nunc Pezicule sp.), " 184.

dissepta Tul. olim (nunc Pezicula), , 186.

carpinea Fr. (Pezicularum nostrarum prototypus), 183, in nota 2.

*Cerasi Fr. ${ }^{*} 156-159$ (tab. xix, fig, 13-17), 160 , in nota 2,162 .

Coryli Tul. (nunc Pezicula), ${ }^{*} 183$.

fascicularis Fr. 172, in nota.

* Frangulæ Tul. (Peziza Pers.), 153 , in nota 2, * 161-162.

${ }^{*}$ Fraxini nob. (Tympanis Fr.), 162.

${ }^{*}$ Padi Fr. $159,{ }^{*} 160$.

*Prunastri Fr. 159 .

${ }^{*}$ seriata nob. ${ }^{*}{ }_{160-161}, 162$.

Dermateæ Encœliæ Fr. 170.

- nostræ olim, nunc Pezicule, , ${ }^{1} 182$.

Diplocladia Bonord. (Sepedonia microsperma, ut videtur), 38 .

Diplocladium majus Bonond. 40.

- minus Bonord. 40.

Diplodia mutila Fr. ${ }^{*} 144$.

Discella buxicola ex Nectria cicatricum $\mathrm{M}_{\mathrm{Az}} .{ }^{*} 77$.

carbonacea Berк. et Br. (Phacidii sp. Fr.), 137 , in nota, 142 .

Discomycetes Fr. 3, 111, 147 et passim.

Discosia alnea Lib. (Spheria Artocreas Tode), 140 , in nota 1.

- Artocreas (Tode) Friesio, 140 , in nota 1.

- in Aquifolio, 139 .

_ Leucostigma Lev. 139 , in nota 1.

Discosiæ Fresenianæ et Notarisianæ, $\mathbf{1 4 0}$, in nota 1.

Ditiola Fr. 106.

— paradoxa Fr. 183 , in nota 2.

Dothidea pyrenophora Fr. 143.

— ribesia (PERs.), 38, 143

sphærioides Fr. * 142.

- typhina Fr. (Epichloes typus), ${ }^{*} 25$.

Dothiora pyrenophora $F_{\text {R. }} 142$, in nota 1.

*Durella (Fr.) nob. 177 et seq. (tab. xx). * compressa (PErs.), 177-179 (tab. xx, fig. 814).

Durellæ (Pezizæ) Fr. 177 .

Elaphomyces granulatus NeEs10, 20, 21, 22, 23 .

- Leveillei Tur. 31. variegatus VItTad. 20-23.
INDEX.

Elvellacei Вегк. 147

Elvella arruginosa, minima... OEdeno (Chlorosplenium ceruginosum DNTrs.), ${ }^{*} 187$.

Elvella Clavus Sсндfғ. (Hypomyces asterophorus noster gemmifer), ${ }^{*} 54$.

purpurea Schefr. (Coryne sarcoides Fr. nudispora), ${ }^{*} 187,{ }^{*} 19^{0}$.

Elvelle Scheff. Gleditzsci, cæt. 38, $190,198$.

"Epichloe Fr. 4, " 24.

"typhina Fr. * 2 4-2 $6,36,63,99$.

Epidochium ambiens Maz. ${ }^{*} 203$.

Epistromata Pers. 3, 65.

* Eudermateæ nostræ, 156 et seq.

${ }^{*}$ Eunectriæ nostræ, ${ }^{*} 79$ et seq. 100.

*Eunectriei nob. 64 .

* Eurhytismata nob. (Xylomala Rhylismatum Fr.), 116.

Eustegia Ilicis Fr. 140 , in nota 3.

Eustilbum Rehmianum Raвenн. 183, in nota 1.

Excipula Rubi Fr. 179 .

Fracidia alutacea Fr. (Hypocrea nob.), ${ }^{*} 35$.

Fuckelia Bonord. (Cenangiorum Fr. pycnidia), * 163 .

- Ribis Bonorid. (Cenangium Ribis Fr. pycnideum), ${ }^{*} 163$.

Fuligo violacea Pers. 61.

Fungoides coccineum, minimum... Мгсн. 197.

Fungoidia cava, scutellata et turbinata Michelio (Pezize recentiorum), ${ }^{*} 198$.

Fungus difficulter ad ullum notorum generum referendus... OEdero (Torrubia capitata [Pers.]), ${ }^{*} 22$.

Fusaria Lк. Fr. aliisque, 65, $73,106,179$.

Fusarium incarnatum ( Rов.) Maz. (Nectrice pulicaris forma gemmifera), ${ }^{*} 68$.

__ lateritium (Mori) Maz. (Nectria Selenosporii Tur. gemmipara?), ${ }^{*} 72$.

pezizoides Maz. (Trochila Craterium Fr. gemmifera) $,{ }^{*} 180,181$.

Platani Mntgn. (Nectrice pyrochroce Maz. pars, ut videtur), $9^{3}$.

roseum Lк. (Nectria pulicaris Fr. conidiophora), ${ }^{*} 68$.

— tremelloides Grev. (Calloria fusarioides Fr. nudispora), ${ }^{*} 195$.

Fusariellæ nostræ (Nectriarum pars), ${ }^{*} 68$ et seq. 100.

Fusidium Buxi (Ссна.) Lк. (Nectrice Russeliance Mntgn. pars), ${ }^{*} 97$.

Fusisporia Lk. Fr. et aliis, 39,65 .

Fusisporium aurantiacum Lk. (Nectrice pulicaris Fr. pars), ${ }^{*} 68$.

Buxi Fr. * 97 .

fungicolum Corde (Hypomyces cervinus noster), $40,{ }^{*} 51$. 
Gasteromycetes Fr. 3.

Geoglossum difforme FR. 199.

o glabrum Pers. 199. viride Pers. 199.

Gia Torrubie (Torrubia sphecocepliala $\mathrm{K}_{\mathrm{L}}$. ut videtur), $* 16$.

Gibbera pulicaris Fr. (Nectrice spec. nob.), 69.

Gloosporia MAZ. 179 .

Glœosporium Ribis $\mathrm{M}_{\mathrm{AZ}}$. et MNtgN. 182. Salicis Westend. 182.

Graphia Lк. 100.

Gyn!nomycetes FR. 3.

Gymnospermi Pers. 3.

Haplographium delicatum Bекк. et Bв. 100.

Haplomycetes Fr. 3.

Helmisporium fusiforme CORDE, 40.

Helvella elastica (CES.), 51 .

- monacella PErs. 52.

- sarcoides Dicks. (Coryne sarcoides nostra nudispora), ${ }^{*} 191$.

Helvellacei Fr. 147.

Helvelloidei Pers. 147.

Helotia Pers. DN

Helotium æruginosum Fr. (Chlorosplenium nob.), ${ }^{*} 188$.

- aureum PERs. 183 , in nota 1.

Rubi Lis. 183 , in nota 3.

— versiforme Berk. 199, in nota 1.

Heteropezizæ nostræ, 148.

*Heterosphæria Grev. * 173 et seq. (tab. xvin) , 178.

— * Patella Grev. $17^{4-176}$ (tab. xviII, fig. 16$22)$.

Hia-Tsao-Tom-Tchom Sinensium (Torrubia sinensis Вегк.), 14.

${ }^{*}$ Hydnopsis TuL. ${ }^{*} 6$.

— Eugeniæ nob. 26 . * graminicola nob. 28.

Hymenomycetes ascophori Corde, 147.

- uterini Fr. 147.

Hymenula Platani Lev. (Nectrice pyrochroce Desmaz. pars), ${ }^{*} 93$.

${ }^{*}$ Hypocrea Fr. xv, * 29 (tab. III et Iv), 34, 66.

— *alutacea (Pers.), 34-37 (tab. Iv, fig. 1-6).

Buchneriana Lev. (Torrubia sobolifera nob.), * 10. citrina Fr. ${ }^{*} 34$.

cupularis $\mathrm{F}_{\mathrm{r}} 37$.

* delicatula Tul. 33-34 (tab. iv, fig. 7-13).

farinosa Berk. et Br. 94 , in nota 1.

floccosa Fr. 40.

lateritia Fr. (Hypomyces nobis), ${ }^{*} 6$.

- luteo-virens Fr. (Hypomycetis spec. nob.), ${ }^{*} 57$. myrmecophila CEs. $17,19$.
Hypocrea parmelioides M MTGN. 37 .

${ }^{*}$ rufa Fr. ${ }^{*} 3_{0}-32$ (tab. III, fig. 1-10), 36 .

typhina Fr. (Epichloes prototypus nobis), ${ }^{*}{ }_{2} 5$. Vitalbæ BеRк. et Br. xv.

Hypocreacei DNTrs. 3 .

nostri, * 24 et seq.

Hypocreæ Fr. et aliis, 3, 4, $24,{ }^{*} 29,36,37$.

Cordicipitum Fr. 3.

Hypomycetes FR, 38 .

Sphæriarum connatarum FR. 29 .

Sphæriarum pulvinatarum FR. 3, 29 .

Hypoderma Hederæ DNTrs. 114.

- Pinastri DC. (Hysterii spec. Schrad. nobisque) * 113.

xylomoides DC. 112, 114.

Hypodermata DC. 112.

Hypolyssus ventricosus Pers. 62.

${ }^{*}$ Hypomyces Fr. Tul. 38 et seq. (tab. v-ix).

- armeniacus TuL. olim, nunc ochraceus, $39,{ }^{*} 41$ 45,47 .

*asterophorus TUL. ${ }^{*} 54-57$ (tab. Ix), 58, 59, 63.

* aurantius Pers. (sub Sphcerice titulo), 43,108

*aureo-nitens nob. ${ }^{*} 64,108$.

? aureus Grevillio (sub Sphceria), 40.

*Baryanus Tul. 59 .

${ }^{*}$ Broomeanus nob. 108.

*cervinus Tul. 51-52.

Cesatii Montanio (sub Nectria), 40.

* chlorinus Tul. $57,58,{ }^{*} 59$ (tab. VIII, fig. 17), 60.

* chrysospermus TuL. 49-51 (tab. viII, fig, 1$13)$.

*decipiens TUL. 61-62.

? epimyces Fr. (sub Spharia), 40.

* fusisporus Tul. 56.

* Lactifluorum (Schw.), 35, ${ }^{*} 63$.

${ }^{*}$ lateritius (Fr.) TuL. $35,47,{ }^{*} 62$.

${ }^{*}$ Linkii Tul. 44 et 45 .

* luteo-virens (Fr.) TuL. 57-59 (tab. VIII, fig. 14$16)$.

- Melanostigma TuL. 56.

${ }^{*}$ miliarius Tul. $58,{ }^{*} 42$ et $* 43$.

*ochraceus (Pers.) Tul. * 41-44 (tab. vi, fig. 1920 , et tab. vil), 47.

* Pezizæ Tú. 52-53.

${ }^{*}$ rosellus (Alb. et Schw.) Tul. 34, 39, 41, ${ }^{*} 45$ 48 (tab. v et tab. vi, fig. 1-18), 108.

*ternatus (Bonord.) Tul. 47.

torminosus Mntgn. (sub Nectria), 40.

*tuberosus Tul. 58.

violaceus Tul. 6o-61. 
Hypomycetes Fr. 4, 24, 29, 30, 32, 33, 67.

Hypoxyla Bull. 4, 29.

- fungoidia DC. 112.

— lichenoidia DG. 112.

Hysteria Pers. DG. 111, 112 et seq. passim.

- subtecta Fr. 113.

Hysteriacei CoRde, 111.

Hysterini fungi Dur. 111 et seq. passim.

${ }^{*}$ Hysterium Tode, nob. 113 (tab. xvi).

- abietinum Pers. 149, in nota.

aggregatum DG. 115.

commune Fr. 112, 115 , in nota.

curvatum Fr. 115.

- fagineum Schrad. (Stictis cinerascens Pers.), ${ }^{*} 125$.

- foliicolum Fr. 114.

- Fraxini Pers. 112.

- Hederæ Mart. 114.

- Juniperi Grev. 113.

- maculare Fr. 114.

- ostraceum Bull. 112.

— parallelum WaHLens. 149 , in nota, 150 , in nota 2.

pezizoides Wahlens. 127.

*Pinastri Schrad. 112, * 113-114 (tab. xvi, fig. 1-3).

Pinastri, $\beta$ juniperinum, Fr. 113.

- Prostii Dub. 115 , in nota 3.

— pulicare Pers. Fr. $112,115$.

- Rubi Pers. 112, 114.

- scirpinum Fr. 112.

- Sorbi Wahlenb. 144.

- tumidum Fr. 136.

- tumidum, $\beta$ trigonum, Fr. MAz. ${ }^{*} 136$.

_ valvatum Nees. (Phacidium Pini Sснм.), ${ }^{*} 136$.

Hysterographia DNTrs. 112.

Hysterographium pulicare Corde, 115 , in nota 2.

Isaria Pers. Fr. 4, 5 et passim.

arachnophila Diтм. $8,{ }^{*} 9$.

Aranearum Schw. 8, 13 .

Cicadæ Mio. 11.

crassa Pers. Alb. et Schw. (T'orrubia militaris nostra conidiophora), ${ }^{*} 6$.

Eleutheratorum NeEs. ${ }^{*} 8,{ }^{*} 9$.

farinosa Fr. ${ }^{*} 6,8,9$.

gigantea Mntgi. 9 .

Hypoxyli Kalkbr. (Isaria umbrina Pers.), 6, in nota 1.

phalangiophila Lk. 8, in nota 4, 13 .

sphecophila Diтм. 17.

sphingophila Lk. (Torrubia Sphingum nob.), ${ }^{*} 12$.
Isaria Sphingum Schw. (Torrubia Sphingum nob.), 9, ${ }^{*} 12$.

truncata Pers. ${ }^{*} 6$.

umbrina Pers. 6 , in nota 1.

velutipes Pers. LK. ${ }^{*} 6$.

Kentrosporium WaLLr. (Torrubiarum spec. nob.), * 4 .

clavatum W ALLR. ${ }^{*} 7$.

granulatum WaLLr. (Torrubia entomorrhiza nostra), ${ }^{*} 14$.

militare WaLLr. ${ }^{*} 7$.

Lamprospora miniata DNTRs. ${ }^{199}$, in nota 3.

Lapacendro infarinato Insubrium (Lactarius deliciosus Fr. Hypomycete lateritio Fr. prægnans), ${ }^{*} 62$.

Lecanidion atrum Rabenh. (Tympanis Pinastri nob.), * 151 .

_ sepincola Rabenh. (Schizoxylum Pers.), ${ }^{*} 148$.

Leptostroma vulgare, orbiculatum, Fr. 115, in nota, 132 .

Leptothyria Mazeriana, 116 .

Leptothyrium acerinum Corde, Fr. 116.

Lichen castanearius Lamк. (Phacidii dentati Schm. et Kze. primordia), ${ }^{*}{ }_{1} 32$. sarcoides JacQ. (Coryne sarcoides nob.), ${ }^{*} 191$.

Lichen-Agaricus Мıсн. (Torrubia militaris Vallu.), ${ }^{*} 6$.

ccespitosus, acaulis, nigricans... Мгсн. (Tympanis conspersa $\left.\mathrm{F}_{\mathrm{R} .}\right),{ }_{1} 53$, in nota 1.

ccespitosus, acaulis, ruber... Mгсн. ( Nectria Cucurbitula nostra?), 79 .

Lichenes-Agarici Micheliani, rubri vel rubro-ferruginei (Nectria cinnabarina Fr, conidiophora?), 79 .

Lichenoides tuberculosum, amone purpureum Dillen. (Nectrice cinnabarince Fr. stroma conidiophorum), ${ }^{*} 79$.

Lophia Fr. 112.

Lophium mytilinum Fr. 112.

Lophoderma Pinastri Dub. (Hysterii sp. Schrad.), ${ }^{*} 113$.

Lophodermata Fr. 112, 114, in nota 1.

Lophodermia DNTrs. 132.

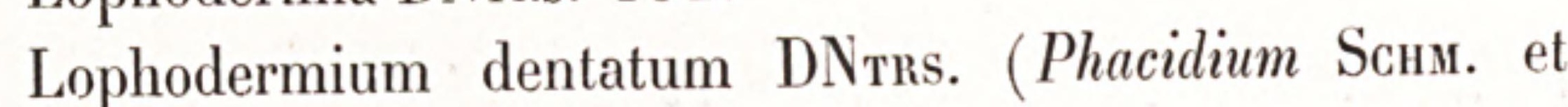
Kze.), ${ }^{*} 133$.

Phacidium DNTrs. (Phacidium coronatum Fr.), ${ }^{*} 134$.

Pinastri Caval. (Hysterium Schrad.), ${ }^{*} 113$.

Lycoperda Tournef. 66.

Lycoperdon Tuber (L.) Sowerb. 200 , in nota 1.

Melanconis macrosperma Tul. 70 .

Melanconium Pandani Lev. 71.

Melanosori DNTrs. (Rhytismata Fr.), ${ }^{*} 116$.

Melanosorus acerinus DNTrs. (Rhylisma acerinum Fr.), ${ }^{*} 117$. 
Melanospora brevirostris ( $\left.\mathrm{F}_{\text {Uck. }}\right),{ }^{*} 53$.

*parasitica Tul. 10 (tab. III, fig. 11-14).

Melasmia acerina Lev. ${ }^{*} 116,118$.

_ salicina Lev. ${ }^{*} 119$.

Melasmiæ LEv. (Rhytismatum Fr. primordia nudispora), ${ }^{*} 115$.

Melittiosporium versicolor CORde, 127.

Merulius (HaLL.) Sowerb. DG. 38.

helvelloides Sowerb. (Hypomyces lateritius Fr. simul cum matrice sumptus), ${ }^{*} 62$.

lycoperdoides DC. (Hypomyces noster asterophorus una cum matrice sumptus), ${ }^{*} 54$.

- tremellosus Pers. 64.

Microcera Desmaz, * $99,106$.

— coccophila Maz. (Spharostilbes cujusdam forma conidiophora nobis), ${ }^{*} 105$.

Micromata DC. (Rhytismalum sp. Fr.), ${ }^{*} 116$.

Micropera Cerasi Bonond. (Dermatece Cerasi Fr. pars), ${ }^{*} 156$.

Drupacearum Lev. (Dermatea Cerasi Fr.), ${ }^{*} 156$. roseola Lev. (Dermatea Cerasi Fr.), ${ }^{*}{ }_{156} 5$, 168.

Microperæ Lev. (Dermatearum Fr. fructus minoris dignitatis), ${ }^{*} 155$ et seq.

Microthyrium microscopicum Dessr. 140.

Micula Mougeotii Duв. 156.

Monosporia (Riess) Bonord. 38.

Monosporium agaricinum Bovord. 40

- spinosum Bonord. 40.

Monostichæ (Sphæriæ) Pers. 3.

Monotospora sphærocephala Вевк. et Br. 100.

Morchella bohemica Квомвн. ${ }^{*} 201$.

— dubia Meratio, 201, in nota 2.

- esculenta Pers. 201.

- semilibera DC. ${ }^{*} 201$ et ${ }^{*} 202$ (tab. xvI, fig. $16-$ 18).

Mouche-Plante Bosc (Torrubia sobolifera nob.), ${ }^{*} 10$.

Mouche Végétante s. Vegetable Fly Hitr et Wats. Holmsk. cæt. (Torrubia sobolifera nob.), ${ }^{*} 10,11$.

Mucor chrysospermus Bull. (Hypomyces ejusdem cognominis nobis), ${ }^{*} 49$.

_- dendroides BucL. (Hypomyces ochraceus noster conidiophorus $), ~ * 41$.

granulosus Bull. (Rhytisma acerinum Fr.), * 117. - lignifragus Bult. (Hypocrea rufa Fr. gemmipara), ${ }^{*} 30$.

Mucores Mich. Bull. 38, $100,{ }^{*} 115$.

Mycobanche Pers. 38.

— cervina W WLLr. (Hypomyces cervinus Tul.), ${ }^{*} 51$. chrysosperma Pers. (Hypomyces chrysospermus noster), ${ }^{*} 49$.

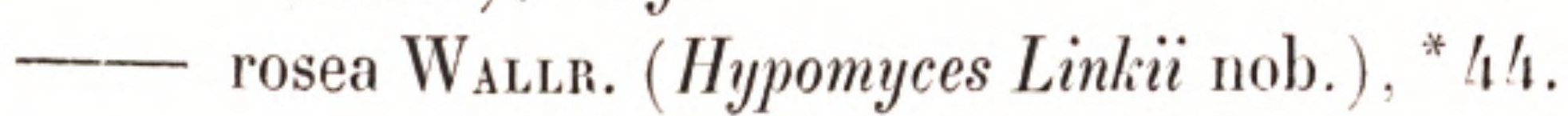

Mycogenæ Lк. (Hypomycetes conidiophori nob.), 38, 39 .

Mycogene cervina Dıтм. (Hypomyces noster ejusd. nominis), ${ }^{*} 51$.

- incarnata Pers. (Hypomyces Linkii TuL), ${ }^{*} 44$.

— rosea Bеrк. (Hypomyces cervinus Tul.), ${ }^{*} 51$.

—_ rosea Lk. (Hypomyces Linkii Tur.), " 44.

simplex Conde (Hypomyces cervinus noster), * 51 .

Myxosporium paradoxum DNTrs. (Trochila Craterium Fr. gemmipara), ${ }^{*} 180,181$.

Næmaspora microspora Liв. Cоем. 80.

Næmatothecii Pers. 3.

${ }^{*} \operatorname{Nectria}($ Fr. $)$ Tur. ${ }^{*} 65$ et seq. (tab. X-XiII), $108,192$.

- affinis $\mathrm{F}_{\mathrm{R} .}{ }^{*}{ }_{9} 5$.

*Aquifolii (Fr.) , $75,{ }^{*} 87-89$ (tab. x, fig. 13-19). 108.

- Arenula Berk. et Br. 97 .

*armeniaca Tul. 75-77 (tab. x, fig. 1-12).

* atractophora Tul. (Nectrice pulicaris forma?), 70.

— Bloxami Berk. et Br. 95 .

— bryophila Ror. 95 .

* carnea $\left(\mathrm{M}_{\mathrm{az} .}\right)$ Tul. ${ }^{*} 96,97$ et 98 .

- Cesatii Mrtgin. (Hypomyces genuinus nobis), 40.

chlorella nob. (Cenangium chlorellum Fr.), ${ }^{*} 172$.

chrysites Wallr. 86 .

cicatricum (buxicola) $\mathrm{M}_{\mathrm{AZ} .}{ }^{*} 77$.

* cinnabarina Tode, Pers. $65,74,{ }^{*} 79-84$ (tab. xII et tab. xiII pro parte), 86,91 .

- citrino-aurantia Lcrx. $71,{ }^{*} 86$.

—_ coccinea Pers. et aliis, ${ }^{*} 73,74$.

- coccinea, cicatricum, MAz. 77 , in nota, 97, in nota.

_ coccinea, fagicola s. ditissima, Tul. $71,{ }^{*} 73$.

coccinea, ficicola, (Nectr. Selenosporii nob.), 68 . in nota, ${ }^{*} 72$.

* cosmariospora DNTrs. 92 et 93 .

${ }^{*}$ Cucurbitula (Tode) $75,{ }^{*} 86-87,88$.

decidua (Tope), alnicola, 74 , in nota.

* ditissima Tul. $67,{ }^{*} 7^{3-75}$ (tab. xIII, fig. 1-4), $86,88,9^{2}, 9^{3}$.

episphæria CaLdesio (Sphcerostilbe coccophila nostra), ${ }^{*} 105$.

* episphæria (Tode) Fr. 74 , in nota $3,{ }^{*} 91 \cdot 92$, $9^{8}$.

erubescens Rов. 94 .

- erythrinella NYL. ${ }^{*} 95$.

- Erythrostigma (Mntgn.) nob. * 194 .

flavida Fr. 94 , in nota 1.

graminicola Berк et Br. 97 .

hirta Curr. ${ }^{*} 108$. 
Nectria inaurata Bевк. et Br. (Nectrice Aquifolii forma), ${ }^{*} 87$.

Lamyi (Maz.) DNTrs. ${ }^{*} 88,92,108$.

lecanodes Ces. * 94,95 .

luteola Roв. ${ }^{*} 9$ /.

Mazerii DNTrs. (Nectr. coccinea, cicatricum, MAz.), 77 , in nota 1.

miltina Mntgn. 85-86.

ochracea Fr. 71,86 .

ochraceo-pallida Berк. et Br. $9^{5}$.

oropensis CEs. 95 .

${ }^{*}$ Peziza (Tode) Fr. Tul. $73,{ }^{*} 77-79,93,98$.

${ }^{*}$ Peziza, minor, $\mathrm{M}_{\mathrm{AZ}}$. (N. lecanodes Cess.) 94 , in nota 3.

* pulicaris Fr. 68-7o (tab. xIII, fig. 5-9).

punicea Sснм. ${ }^{*} 8_{2}$.

Purtoni Curr. $9^{2}$.

* pyrochroa (Maz.) Tul. $9^{3}$ et $9^{4}$.

Ralfsii ВеRк. et Br. 82.

Robergei Maz. 95 .

Russeliana Mvrgn. 97-99.

sanguinea Fr. (Nectr. epispheria nob.), ${ }^{*} 91$.

sanguinea Квомвн. (Nectr. Peziza nob.), ${ }^{*} 78$.

sanguinea Siвтн. $7^{4}, 9^{8}$.

* Selenosporii Tul. $7^{2-7} 3$.

* sinopica Fr. * 89-91 (tab. xi, fig. 1-10), 170.

Stilbosporæ TuL. " 71-72 (tab. xı, fig. 11-19), 73 .

torminosa Mntgn. (Hypomycetis species, ut videtur), 40.

Nectriæ $F_{R}$. DN et passim.

Hypocrearum Fr. ${ }^{*} 65$.

${ }^{*}$ Nectriei nob. 3 et seq. genuini TuL. ${ }^{*} 64$.

Nectriellæ nob. ${ }^{*} 93$ et seq.

Noștoc granulosum, coccineum, arboribus innascens VAlLL. (Tubercularia vulgaris ToDE), ${ }^{*} 79$.

Nyctalis Fr. 38.

—_ asterophora Fr. 54, 55. parasitica Fr. 55, 56.

Ocellaria nob. (Stictidum Pers. Fr. pars), " 128. _- aurea nob. (Stictis ocellata Friesir), * 129. Octaviania asterosperma VItTad. 50.

Octospora carnea Hedw. (Coryne sarcoides Fr.), ${ }^{*} 191$.

— paradoxa HEdw. jun. 183, in nota 2.

— tuberosa Hedw. 200

— violacea HEDw. 200.

Octosporæ Hedw. (Pezizae recentiorum), " 198.

Ombrophila sarcoides Fr. (Corynes typus nobis), xv.

Onygena agaricina Schw. (Nyctalis asterophora $\mathrm{F}_{\mathrm{r} .}$ ), ${ }^{*} 54$.
Ostreichnion europæum Duв. (Hysterii sp. PERs.) 115. Ostropa Fr. 148.

Patellaria atrata Fr. 151,152 .

olivacea Batsch, XvI. sepincola DG. (Schizoxylum Pers.), * 148.

Patellariæ HEdw. Fr. 182.

Penicitlia Berk. Xṽ, 9, 201, in nota 1.

Penicillium elegans Corde, 108.

* Peziculæ nostræ, ${ }_{182}$ et seq. ( tab. xv).

—_ * amœna Tul. 184-186 (tab. xv, fig. 1-9). ${ }^{*}$ Coryli Tul. 183-184. * dissepta Tul. 186.

* Peziza L. nob. $19^{8}$ et seq. (tab. xvı et xxiı).

- Abietis Pers. (Cenangium ferruginosum $\mathrm{F}_{\mathrm{r} .}$ ), ${ }^{*} 168$. Acetabulum L. 54, 200.

- æruginascens Nylandro, 189 . - æruginosa Pers. (Chlorosplenium DNTrs.). * 187. alnea Pers. (Tympanis Fr.), 153 , in nota 2. anomala Pers. (Cyphella Hoffmanni Tur.), ${ }^{*} 173$. arenosa $\mathrm{F}_{\text {Uck. }} 53$.

Ariæ Pers. ${ }^{*} 160$.

atro-virens Pers. (? Coryne nostra virescens), ${ }^{*} 193$. Aucupariæ PErs. 153 , in nota 1.

aurantia Mull. 199.

benesuada Tul. $178,198,199$.

blandula Векк. (P. benesuada nostra), 199 .

bolaris BАтsch. nob. 200 et 203 (tab. xхıI, fig. 18 et 19 ).

- carpineaPers. (Pezicularum nostrarum prototypus), 183.

Cerasi Pers. (Dermatece sp. Fr. nobisque), 152 , ${ }^{*} 156$.

- Cerási $\beta$ (Padi) Atb. et Schw. 159 , in nota alt. cervina Pers. (Cenangium ferruginosum Fr.), ${ }^{*} 168$. Chailletii Pers. (Heterosphceria Patella Grev.), ${ }^{*} 175$.

- chlorella Pers. (Nectrice spec. nob.), ${ }_{172}$, in nota 2.

Clavariarum $\mathrm{M}_{\mathrm{Az}} .45$.

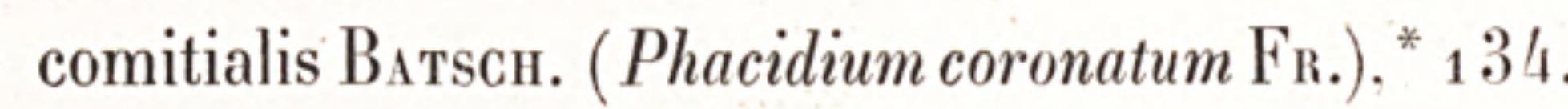

compressa Pers. (Durella nostræ typus), ${ }^{*} 177$.

confluens Pers. (Pyronematis Car. typus), * 197 .

conglomerata $\mathrm{W}_{\mathrm{AHLENB}}$. (Tympanis conspersa $\mathrm{F}_{\mathrm{R} .}$.). 153 , in nota 1.

corticalis Pers. 173 , in nota.

Craterium Liв. (Trochila spec. Fr.), ${ }^{*}{ }_{1} 80,181$.

Curreiana Berk. 200 et 203 (tab. xxII, fig. 11-17).

Cylichnium Tul. 200 et 202 (tab. XxII, fig. 8-10).

diplocarpa Curr. xvi, ${ }^{*} 199$.

Duriæana Tul. 200 et 203 (tab. xxir, fig. 20-24),

Erythrostigma Mntgn. (Nectrice spec. nob.), ${ }^{*} 196$.

fallax Pers. ( $P$. albo-violascens A Aв. et Schw.), ${ }_{17} 3$, in nota. 
Peziza fascicularis Aus. et Schw. 171, 172, in nota.

- fimbriata Chailt. (Heterospharia Patella Grev.), ${ }^{*}{ }_{17} 5$.

- flexella Fr. 177.

- Frangulæ Pers. (nunc Dermatece sp. nob.), ${ }^{*} 161$.

Fraxini Schw. (Dermatea nob.), 162 , in nota.

- fusarioides Berk. (Calloria Fr. et nob.), * ${ }^{1} 195$.

- Graminis Maz. (Pezicula sp. nob.), 183.

- hemisphærica (Hoffn.) Rabenh. 54, in nota.

- hemisphærica WIGG. 53.

- hepatica Ватsch. 197.

- ianthina Fr. 200.

imberbis Bull. 187 , in nota.

inquinans Pers. (Bulgaria Fr.), 192 .

insidiosa M $\mathrm{Az}$. (Trochila Craterium Fr.), ${ }^{*} 180$.

Labellum Bult. ${ }^{*} 53$.

- Lecanora Schm. et Kze. (Stictis ocellata Fr.), * 128 , 130.

- Lecideola Fr. 45, in nota, 177.

- leucomela (Umbelliferæ) DC. (Heterosphceria Patella Grev.), ${ }^{*} 175$.

lignyota Fr. 177 .

- Ligustici DC. (Heterospharia Patella Grev.), ${ }^{*} 175$.

macropus Pers. 52.

metamorpha Schum. (Coryne sarcoides nob.), , 191. neglecta Liв. (Calloria fusarioides Вевк.), * 195.

nigra Sowerb. 45 , in nota.

ocellata Pers. (Stictidis sp. Fr.), * 128,130 .

omphalodes Bull. 197, 199.

omphalodes Fr. Berk. (Pyronema confluens nob.), * 197 .

phæotricha Dur. et Lev. 148 , in nota.

Pinastri Pers. (Tympanis nob.), ${ }^{*} 151$.

Pinastri, ramosa, Alb. et Schw. 151.

pinicola (Rebent.) Lasch. (Cenangium ferruginosum Fr.), ${ }^{*} 168$.

- populnea PErs. $17_{2}$, in nota.

porphyria Batsch (Coryne sarcoides Fr.), ${ }^{*} 191$.

Prunastri Pers. (Dermatea Fr.), 152, 159 , in nota 1.

— pulveracea A Ar. et Schw. (Cenangii sp. Fr. sed potius Cyphella), 173.

- Pyri Pers. (Tympanis conspersa Fr.), 153, in nota 1.

— radicata Reich. (P.tuberosa Bull.), 180 , in nota 1.

- resinæ Fr. 177.

— reticulata Grev. 200.

— rhabarbarina Bекк. (Pezicula sp. nob.), 183.

— rhizopus Aьв. et Schw. 200.

- ribesia Pers. (Cenangium Ribis Fr.), ${ }^{*} 163$.

- rosella Ehrens. (Pyronema confluens nostrum), * 197 .
Peziza sarcoides Pers. (Corynes ascophoræ typus), xv et ${ }^{*} 191$.

Scleropyxis Pers. (Heterospharia Patella Grev.), ${ }^{*} 175$.

smaragdina Lev. (Trochila Laurocerasi Desu.), 181. sphæriæformis Rebent. ('Tympanis conspersa $\mathrm{F}_{\mathrm{R}}$.), 153 , in nota 1.

sphærioides Rотн (Tympanis conspersa Fr.), 153. in nota 1,170 , in nota.

strobilinaDC. (Cenangium ferruginosum $\mathrm{F}_{\mathbf{R}}$ ), ${ }^{*} 168$.

tiliacea Fr. (inter Encelias), 171.

tremelloidea Bull. (Coryne sarcoides nostra ascophora), $190,{ }^{*} 191$.

Trifoliorum Lis. (Phacidium Medicaginis ejusd.?), 142.

- truncatula Reвent. (Dermatea seriata nostra?), ${ }^{*} 160$.

- tuberosa Bull. 200 et 202 (tab. XXII, fig. 1-7).

versiformis Pers. ${ }_{199}$, in nota.

vesiculosa Bull. 81, 200 et 202 (tab. xvi, fig. 19 et 20.)

viridis Boцt. (Phacidium coronatum Fr.), ${ }^{*} 134$. viridissima, petiolata, scypho infundibuliformi, $\mathrm{H}_{\mathrm{AL}}$ LERo (Chlorosplenium aruginosum DNTrs.), ${ }^{*}{ }_{187}$.

Pezizæ L. Pers. 111, 145, $150,173,178,179,182$, $187,19^{\circ}, 19^{4}, 197,199$ et passim.

Pezizæ Encœliæ Fr. 170.

* Pezizei nostri, 147 et seq. (tab. XVI-xxII).

- nostri genuini, 179 et seq.

Phacidia legitima DN

Phacidia tum genuina, tum spuria, 111, 112, 115, 173 , 174,179 .

Phacidiacei Pyrenomycetum Fr. 111.

* Phacidiei nostri, 111 et seq. (tab. xv, xvi et xvIII).

*Phacidium Fr. * ${ }_{1} 31$ et seq. (tab. xv), 146.

- Aquifolii Sans. 138, 140 , in nota 2.

- calyciiforme Fr. (Blitrydium DNTrs.), 142, in nota 1.

- carbonaceum Fr. (Discella sp. Вевк. et Вr.), 136 , in nota 3,142 .

commutatum Fr. 142 et 143.

* coronatum Fr. 111, 118, $132,{ }^{*}{ }^{1} 134136$.

Craterium Modg. et Nestr. (Trochila Craterium Fr. ), ${ }^{*} 180$.

*dentatum Schm. et Kze. ${ }^{*}{ }_{1} 3_{2}$ et ${ }^{*} 133,135$.

divergens Rов. 141 , in nota 1.

"Ilicis Lir. 138-141 (tab. xv, fig. 1-8).

Laurocerasi M Mz. (Trochila sp.), 181.

Medicaginis Liв. ${ }^{*} 142$.

multivalve DC. Fr. (Phacid. Ilicis Lis.), ${ }^{*} 138$.

Patella Fr. Desmaz. (Heterospharia Patella Grev. et nob.), ${ }^{*}{ }_{17} 5$. 
Phacidium Pinastri Fr. (Tympanis Pinastri nob.), ${ }_{13} 3$, ${ }^{*} 151$.

${ }^{*}$ Pini Schir. Fr. $136-137$.

Populi Lasch. (Stictis ocellata Fr.), ${ }^{*} 129$.

Schizoxylon Fr. (Schizoxylum sepincola Pers.), ${ }^{*} 148$.

seriatum Fr. (Dermatece sp. nob.), ${ }^{*} 160$.

- trigonum Schм. $115,{ }^{*} 136$.

Pilobolus Tode, 100 , in nota.

Placuntia Ehrevs. (Rhytismata Fr.), * 115 .

Placuntium acerinum Ehrens. ${ }^{*} 117$.

Pleospora Clavariarum (Maz.) Tul. 45, in nota.

Pleosporæ Rabenh. 127.

Podisoma Lk. 27.

Polistophthora Leb. (Torrubize spec. nob.), ${ }^{*} 4$.

_- Antillarum Leв. (Torrubia sphecocephala Kьотzsch), ${ }^{*} 17$.

Polypori Pers. 34.

Polyporus alneus Pers. 47.

- annosus Fr. 108.

— cuticularis BuLL. 47.

versicolor Fr. 43.

Polystigma Cicatrix Bonord. (Rhytisma maximum Fr.), $* 122$.

typhinum DC. (Epichloes typus Fr.), ${ }^{*} 24$.

Polystigmata Wallr. et Rabenh. (Rhytismata Fr.), 116.

Polythecia Bonord. (Dermatearum Fr. fructus nudispori), ${ }^{*} 155,156$.

Poriæ Pers. 34.

Poroniæ Hypoxylorum Fr. 37 .

Propolis Berkeleiana MAz. 149 .

— Lecanora DNTrs. (Stictis ocellata nostra), * 129 .

Populi DNTrs. (Stictis ocellata nostra), * 1 29.

versicolor Fr. (Stict. cinerascens Pers.), * 126 .

Prosthemium stellare Riess, 76 .

Psilonia (Fr.) Maz. 65.

- Buxi Fr. (Nectrice Russeliance Mntgn. pars), ${ }^{*} 97$. Luzulæ Liв. 95.

- Pellicula Maz. (Nectrice carnece Maz. pars, ut videtur), ${ }^{*} 96$.

rosea Fr. (ead. atque Psil. Buxi Fr.), ${ }^{*} 97$.

Puccinia cervina Corde (Hypomyces cervinus Tul.), ${ }^{*} 52$.

Mycogene Corde (Hypomyces Linkii nob.), ${ }^{*} 44$.

Pucciniæ (sinceræ, uredineæ) PERs. 49.

- (spuriæ) Corde (Hypomycetes conidiophori nob.), 38 .

Pyrenium Tod. ${ }^{*} 29$.

_lignorum et vulgare Tode (Hypocrece rufae Fr. membra), ${ }^{*} 30$.

Pyrenochium Pini Lk. (Phacidium Pini Schm.), ${ }^{*} 136$.

— Sorbi Lk. 142 , in nota 1.
Pyrenodermia Bonord. 29 .

Pyrenomycetes hypocreacei DNTrs. 108.

- hysteriacei DNTrs. 111.

* Pyronema Caro, 15o, * 197 (tab. xviI).

- ${ }^{*}$ confluens (Pers.), 197-198 (tab. xvII, fig. 11 et 12 ).

—_ Franzonianum DNTrs. 197.

Racemella CEs. 4.

memorabilis Ces. (Torrubice sp. nobis), 14.

Racodia Pers. 38.

Racodium? Mycobanche Pers. (Hypomyces cervinus et Hyp. Peziz(e nobis), ${ }^{*} 51,{ }^{*} 53$.

Ramaria farinosa HoLмsк. (Torrubia militaris nostra conidiophora), 5 , in nota, ${ }^{*} 6$.

Ramariæ HoLmsk. 4.

Reticularia chrysosperma Bull. (Hypomyces chrysospermus nob. gemmifer), ${ }^{*} 49$.

Rhaphidophora herpotricha (Fr.), $17^{4}$.

Rhizina undulata Fr. 123.

* Rhytisma Fr. 115 et seq. (tab. xv et xvı).

— ${ }^{*}$ acerinum Fr. ${ }^{*} 116-119$ (tab. xv, fig. 9-12), 201.

* maximum Fr. 116, * $122-125$ (tab. xvi, fig. 9$15)$.

punctatum Kretschn. (Rhytisma acerinum Fr.), ${ }^{*} 117,118$.

*salicinum Fr. ${ }^{*} 119-122$ (tab. xv, fig. 13-22), 201.

umbonatum (Hopp.) Maz. (Rhytisma salicinum Fr.). ${ }^{*} 119$.

Russula adusta Pers. 43, 56.

- alutacea Pers. 47.

emetica Pers. 43, 47.

fœtens PErs. 43, 64.

* Schizoxylum Pers. * $148,150$.

* sepincola Pers. 148 et 149.

Schmitzomia Fr. 127.

— chrysophæa Rabenh. (Stictis ocellata Fr.), * 129. radiata Fr. * 128 .

Sclerocarpi Pers. 3, 111.

Scleroderma verrucosum Fr. 50 .

Scleroderris DNTrs. (Cenangiorum nostrorum pars), ${ }^{*}{ }_{1} 63$.

- Ribis DNtrs. (Cenangium Ribis Fr.), * 164 .

Sclerotium quercinum $\mathrm{V}_{\mathrm{AHL}}$. 134.

— violaceum Corde (Nectria pulicaris Fr. nondum perfecta), ${ }^{*} 68,{ }^{*} 70$.

Selenosporia (CоRde) Maz. 73 .

Selenosporium lateritium MAz. (Nectria pulicaris Fr. gemmipara), ${ }^{*} 68$. 
Selenosporium pyrochroum $\mathrm{M}_{\mathrm{Az}}$. (Nectria pulicaris Fr.), ${ }^{*} 68,70$.

— sarcochroum (laburnicola) $\mathrm{M}_{\mathrm{Az} .}{ }^{*} 68,70$. Urticearum (Corde), Fici, Maz. (Nectria nostra Selenosporii conidiophora), ${ }^{*} 72$.

Sepedonia Lк. $38,39,40$.

Sepedonium angulatum KLotz. (Hypomyces asterophorus noster), ${ }^{*} 55$.

- cervinum Fr. (Hypomyces cervinus TUL.), ${ }^{*} 51$. chrysospermum Fr. (Hypomyces chrysospermus TuL.), ${ }^{*} 49$.

- mycophilum Lk. (Hypomyces chrysospermus nob.), $* 49,60$.

- roseum Fr. (Hypomyces Linkii Tur.), ${ }^{*} 44$

Sinopeæ (Nectriæ) nob. ${ }^{*} 89$ et seq.

Solenia ochracea (Hofrm.) Rabenh. (Peziza anomala Pers. seu Cyphella Hoffmanni Tur.), 173.

Spathularia flavida Pers. ${ }^{*} 201$.

Sphæria achroa DG. (Dermatece Cerasi Fr. initia), ${ }^{*} 156$.

— affinis Grev. * 95 .

- agariciformis BoLt. (Torrubia capitata nob.), ${ }^{*} 22$.

— alutacea Pers. (Hypocrea nobis), ${ }^{*} 35$.

- Aquifolii Fr. (Nectria nob.), ${ }^{*} 8_{7}$.

- Artocreas Tode (Discosic spec. recentioribus), 140 , in nota 1.

- atro-virens, Visci, Ацв. et Sснм. 131, in nota 2. aurea Grev. (Hypomycetis spec.?), 40.

- aurea Sowerb. (Rhytisma maximum FR.?), 122.

- bifrons Sowerb. (Phacidii Ilicis Lib. pars), ${ }^{*} 138$.

— brevirostris F $\mathrm{FGK}_{\text {UC. }}{ }^{2} 54$.

- Buxi Curr. 98 .

- Buxi Mazerio, 98 .

— cæspitosa Tode, 153 , in nota 1.

— capitata Pers. (Torrubice spec. nob.), ${ }^{*} 22$.

- carnea $\mathrm{M}_{\mathrm{Az} .}$ (inter Nectrias), ${ }^{*} 9^{6}$.

- cinnabarina Tode (Nectrict sp. Fr.), 67, ${ }^{*} 80$.

— clavata Sow. (Sphatria alutacea Pers.), ${ }^{*} 35$.

coccinea (PERs.) Fr. $7^{4}$.

- coccinea, abietina, DC. (Nectria Cucurbitula nostra), ${ }^{*} 86$.

- coccinea, faginea, DC. (Nectria episphceria nob.), ${ }^{*} 91$.

concava Sowerb. (Stegilla Ilicis Rabenh.), 140 , in nota 3.

conica Fr. 160 , in nota 1.

_- conspersa Fr. (Tympanis conspersa ejusd.), 153 , in nota 1.

- convexa, miniata, hirsuta HaLl. (Tubercularia vulgraris Toder et Nectria cinnabarina Fr.), ${ }^{*} 79$.

- Cotoneastri Fr. 160 , in nota 1.

- Cucurbitula Tode (Nectria cinnabarina nostra, ut videtur), 86 .
Sphæria Cucurbitula (Tode) Fr. (Nectria nostra Cucurbitula), ${ }^{*} 86$.

- Cucurbitula $\beta$ nigrescens Tode (Spharia cupularis Pers.?), 83, in nota.

Craterium DC. (Trochila Craterium Fr.), ${ }^{*} 180$.

cupularis Fr. (e Poroniis), 37 .

cupularis Pers. $80,{ }^{*} 82-83,84$ et 85 (tab. xilI, fig. 14-21), 172 .

- cyanea Soldar. (Nectria pulicaris $\left.\mathrm{F}_{\mathrm{R} .}\right),{ }^{*} 69$.

cyanogena $\mathrm{M}_{\mathrm{Az}}$. (Nectria pulicaris $\mathrm{F}_{\mathrm{R}}$ ), ${ }^{*} 68$.

decidua Tope, 74.

decolorans Pers. Fr. Curr. cæt. (Nectria cinnabarina $\mathrm{Fr}_{\text {r. }), ~}{ }^{*} 80$.

deusta Horrar. 92.

dubia Pers. (Dermateca Cerasi Fr. primordia), 155 , ${ }^{*} 156$.

entomorrhiza Dicks. (Torrubia nob.), ${ }^{*} 14$.

entomorrhiza Maddane (Torrubia sphecocephala nostra), ${ }^{*} 16$.

entomorrhiza Robinio (Torrubia Curculionum nob.), ${ }^{*} 14,20$.

epimyces Fr. (Hypomycelis spec.?), 40.

erubescens (Ков.) Maz. 93 et 94.

fallax W $W_{\text {Ahlenb. }}$ (Dermatea Cerasi F $\left.F_{\text {R. }}\right), 155,{ }^{*} 156$, 159 , in nola 2.

— fissivela Tope, 153 , in nota 1.

flavida Corde, 94.

Fraxini Fr. 162, in nota.

fuliginosa Modgeotil (Sphceria quercuum $\mathrm{S}_{\text {chw.) }} 165$. fuliginosa Pers. (Cenangium fuliginosum $\mathrm{F}_{\mathrm{R}}$ ? ). $166,167$.

- fulva Fr. 98 .

gelatinosa $\alpha$ et $\beta$ Tode, 32 et 37 .

— Hederæ, $\beta$ Helicis, NEEs. (Ceuthospora phacidioides Grev.?), 138.

- herbarum Pers. 127.

herpotricha Fr. 174.

Hugelii Corde, 14.

hyalina Scнw. 63.

hydnicola Schw. 64.

- Hypoxylon L. 17.

Ilicis Fr. 140 , in nota 2.

inversa $F_{R}$. (Tympanidis alnece $F_{\mathbf{R}}$ primordia), 153, in nota 2.

—_Lactifluorum Scrw. (Hypomycetis spec.), ${ }^{*} 63$.

lageniformis Soldm. (Valsce sp. Cunreio), 136 , in nota 1.

- Lamyi Maz. (Nectria Notarisio), ${ }^{*} 88$.

lateritia Fr. (Hypomyces nob.), ${ }^{*} 62$.

- Leveillei Tul. 157.

- lichenoides, quercicola et castaneæcola, DC. (Phacidium dentatum Sснм. et Kze.), ${ }^{*} 132$. 
Sphæria lœpophaga Tul. 99 .

luteo-virens Fr. (Hypomyces nob.), ${ }^{*} 57$

- Micula Fr. 156.

- militaris Енвн. (Torrubia prototypus nob.), ${ }^{*} 6$ (tab. I, fig. 19-31), $14,25,36,37$.

militaris Kцотzsch (Sph. ophioglossoides Eнrн.), ${ }^{*} 7$. militaris, sphærocephala, Scнn. 14.

miltina Mntgn. * 85 .

miniata, acaulis , subğlobosa, solitaria, glabra BoLt. 79 .

morbosa Schw. * 27 .

moriformis (Tode) Schw. ${ }^{*} 187$.

mutabilis PErs. 28 , in fine.

mutila Fr. 143 , in nota 1.

ochracea Fr. (Nectrice spec.), 86.

ochracea Pers. (Hypomycetis spec. nob.), ${ }^{*} 41$.

olivacea Willd. (Hypocrea rufa Fr.), ${ }^{*} 30$.

ophioglossoides Eнвн. (Torrubia sp. nob.), $6,{ }^{*} 20$, 36.

— padina Pers. 159 , in nota 2.

- parasitans Schw. (Sph. cupulıris Pers. ut videtur), 83 , in nota.

parmelioides Mntgr. ${ }^{*} 37$.

- Patella Pers. (Heterospharia Grevillianæ typus), ${ }^{*} 174$.

penetrans, a Patella, Tode (Heterosphceria Patella Grev.?), 174.

* perisphæria Tul. 28.

Peziza Maz. 77 .

Peziza Tode (Nectrice sp. nob.), ${ }^{*} 77$.

- Peziza, minor, Maz. (Nectria lecanodes Crs.), 78 , ${ }^{*} 9$.

pezizoidea, rubro-fusca, DC. (Nectria cinnabarina Fr.), ${ }^{*} 80$.

Prunastri Pers. 159 , in nota 1.

- pulicaris Fr. (Nectrice spec. nob.), ${ }^{*} 68,70$.

- punctiformis, ambigua, Pвrs. (Phacidii dentati Schm. et Kze. initia), ${ }^{*} 132$.

- punctiformis, Hederce, Pers. DC. (Trochila Craterium Fr. ?), ${ }^{*} 180$.

purpurea Fr. (Claviceps nob.), 36.

- pyrochroa Maz. (inter Nectrias), ${ }^{*}{ }^{3}$.

quaternata Pers. 78 .

- quercina Pers. 92.

Quercuum Schw. 167, in fine.

rådicosa DC. (Torrubia ophioğlossoides nob.), ${ }^{*} 20$.

ribesia Linkio (Cenangium Ribis Fr.), ${ }^{*} 163$.

Ribis Tode (Nectria cinnabarina Fr.), 86.

riccioidea BoLt. ${ }^{*} 37$.

- rigida DC. (Dermatece Prunastri Fr. pycnidia), 159 , in nota 1.

-- rosea Pers. (Hypomyces noster roselius), ${ }^{*} 45$.
Sphæria rosella Aub. et Schw. (Hypomyces nob.), ${ }^{*} 45$.

- rufa Pers. (Hypocrea nob.), * $30,35$.

sanguinea (Bort.) Fr. (Scl. Suec.), 78.

sanguinea (Sівтн.) Grev. ${ }^{*} 74$.

sanguinea, cicatricum, Bекк. 77, in nota 1.

sinensis Bегк. (Torrubice spec.), $13,14$.

sinopica Fr. (Nectria nob.), " 89 .

sobolifera Berk. (Torrubia nob.), ${ }^{*} 10$.

sphecocephala (Kьотz.) (Torrubia nob.), ${ }^{*} 17$.

spiculifera Sow. (Epichloe typhina Fr.), ${ }^{*} 24$.

Stigma Hofru. $9^{2}$.

subulata Tode (Sphceroncematis sp. Fr.), * 56 .

torminosa Mntgn. (Hypomyces?), 40.

tremelloides Sснuм. 30.

tremelloides Weigetio ( Tubercularia vulgaris Tode), ${ }^{*} 79,80$.

Tubercularia DC. (Nectria cinnabarina Fr.?), 82.

tubericola Schw. 64.

typhina Pers. (Epichloes Fr. prototypus), ${ }^{*} 24$.

versiformis A

- versiformis. Rhamni, Aцв. et Schw. 153, in not. $2,{ }^{*} 161$.

violacea Scнm. (Hypomyces nob.), ${ }^{*} 60$.

virgultorum Fr. 27.

Zobelii Tul. 54.

Sphæriæ Tode, Pers. DC. cæt. 111, 131, 173, 179 et passim.

- byssisedæ Fr. 3, 64, 65 .

cæspitosæ Pers. Fr. 3, 64, 65.

caulescentes PERs. 3, 4.

circinatæ Fr. 4.

compositæ Pers. 3, 29 .

connatæ Fr. 29 .

degeneres Косн. 66.

genuinæ Fr. 66.

- hypocreaceæ DN 29.

Hypocreæ Fr. 38.

-_ periphæricæ Pers. 29.

— pulvinatæ $F_{\text {r. }}$ 3, 4, 29 .

-...... tomentosæ Sснм. 43.

—_. Xylariæ Pers. 3, 4.

Sphæronæma bullosum Fr. (Tympanidis Pinastri nostræ forma monstrosa?), $136,137,151$.

columnare WALLR. 162 , in nota.

conicum Fr. (Cenangium Arice Pers.), ${ }^{*} 160$.

parasiticum Tul. 10.

subulatum Fr. ${ }^{*} 56$.

versiforme $\mathrm{F}_{\mathrm{r}}$. (Dermatea Frangula nob.), ${ }^{*} 161$.

in Agrarico adusto Pers. * 56 .

Sphæropsis atro-virens Lev. et Berk. 131 , in nota 2.

${ }^{*}$ Sphærostilbe Tul. 4, ${ }^{*} 99$ et seq. (tab. xiII et xiv). *aurantiaca Tul. 101-102 (tab. xiv, fig. 1-13). 
${ }^{*}$ Sphærostilbe cinnabarina Tul, 103 et 104.

— ${ }^{*}$ coccophila (M M.) Tul. 105 et 106.

* flammea Tul. * 104 et 105 (tab. xiII, fig. 10-13), 106.

* gracilipes Tul. 102 et 103 (tab. xiv, fig. 1419).

Sporonema phacidioides $\mathrm{M}_{\mathrm{Az}}$. (Phacidii Medicaginis Lıs. pars), ${ }^{*} 143$.

Sporotricha Lk. 38,39 .

Sporotrichum agaricinum Lk. 40.

- mycophilum Spreng. (Hypomyces chrysospermus noster), ${ }^{*} 49$.

Stegia Fr. 138.

- Ilicis Fr. MAz. 142 .

Stegilla Ilicis Rabenn. 142 , in nota 3.

Stephanoma WaLLr. 38.

- strigosum W WLlR. (Hypomyces Peziza nob. simul cum sua nutrice sumptus), ${ }^{*} 52$.

Stictei Fr. 111

${ }^{*}$ Stictis Pers. 125 et seq. (tab. xvi et xviII).

- a atro-virens Pers. 177.

- chrysophæa (pinicola) Pers. 129

—— chrysophæa (ulmicola) Berk. et Br. 129.

* cinerascens Pers. 12 5-128 (tab. xvi, fig. 4-8).

- farinosa Fr. (Stictis cinerascens PErs.), ${ }^{*} 125$.

fenestrata $\mathrm{M}_{\mathrm{Az}} .{ }_{142}$, in nota 5.

- Lecanora Kneiff et Hartm. (St. ocellata Fr.), ${ }^{*}{ }_{12} 8$.

Leonis Tur. * 127 .

nivea Pers. ${ }^{*} 127$.

* ocellata (Fr.) nob. 128-131 (tab. xviII, fig. 1$10)$.

pallida Pers. 128,177 .

—_ radiata PERs. ${ }^{*} 127$.

— rufa Pers. 150.

— saligna Pers. (St. cinerascens ejusd.), ${ }^{*}{ }_{12} 5$.

- versicolor Fr. ${ }^{*}{ }_{12} 5$.

- viridis Fr. 127.

Stilbospora macrosperma PERs. 72.

Stilbum Tode, Tul. ${ }^{*} 99,100,101,106$.

- aurantiacum Bab. TUL. ${ }^{*} 101$.

— Buquetii Roв. 107.

- cinnabarinum MNTGN. * 103.

— erythrocephalum Diтм. 100.

— flammeum BERK. et RAV. ${ }^{*} 104,106$.

- gracilipes TuL. ${ }^{*} 102$.

- xanthocephalum KIскx, 103.

Stromatosphæria typhina Grev. ${ }_{2} 5$.

Thamnomycetes Ehrens. 14.

Thelephora carbonaria Bert. (Peziza confluens Pers.), ${ }^{*} 197$. - comedens NeEs. 40.

* Torrubia Lev. Tul. * 4-24 (tab. I et II), 36, 100.
* Torrubia cæspitosa Tul. 11.

- ${ }^{*}$ capitata (Pers.), 22-24 (tab. II, fig. 10-15).

* cinerea Tul. 16 (tab. I, fig. 11).

* coccigena Tul. 18 et 19 (tab. I, fig. 10).

Curculionum Tuz. 20.

* entomorrhiza (Diкs.), $11,{ }^{*} 14-16$ (tab. 1, fig. 12-18).

- Humberti (Rов.), 18.

Melolonthæ TuL. 5, 12.

memorabilis (CES.), 14 .

${ }^{*}$ militaris (VAlLL.), 5, * 6-9 (tab. I, fig. 19-31), 13.

— Miquelii Tur. 11.

myrmecophila (CEs.), 17, 19 .

*ophioglossoides (Енвн.), 11, * 20-22 (tab. II fig. 1-9), 23,147 .

-— Robertsii (Векк.) Ноок. $13,14$.

sinensis (ВеRк.), 13 et 14.

- ${ }^{*}$ sobolifera (HıLl. et WaTs.), 10-12 (tab. I, fig. 32 et 33$), 19$.

* sphecocephala (Kцотzsch), Tul. * ${ }^{16-18}$ (tab. I, fig. 5-9), 19 .

${ }^{*}$ Sphingum (Schw.); xv, ${ }^{*} 12-14$ (tab. I, fig. 1 et 2 ).

Tayloris (ВеRк.), 14.

* unilateralis Tul. 18 et 19 (tab. I, fig. 3 et 4).

Torulæ PERs. 201, in nota 1.

Tremella amethystea Bubl. (Coryne sarcoides Fr.), ${ }^{*} 190$.

-__ cinereo-viridis Schum. (Coryne nostra virescens nudispora), ${ }^{*} 193$.

dubia Pers. (Coryne sarcoides Fr.), ${ }^{*} 19^{\text {o) }}$

nigricans BuLL. ${ }^{*} 79$.

purpurea Lins. (Tubercularia vulgaris ToDE), 65 , in nota, ${ }^{*} 79,80$.

saligna Alb. et Schw. (Stictis cinerascens Pers.), ${ }^{*}{ }_{12} 5$.

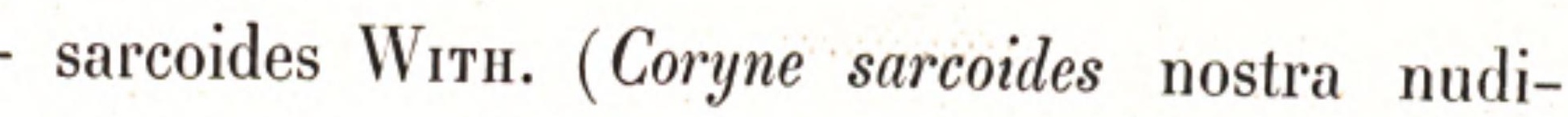
spora), xv, *19o.

Urticæ Pers. (Calloria fusarioides $\mathrm{F}_{\mathrm{r}}$.), ${ }^{*} 195$.

virescens Schum. (Corynes sp. nob.), ${ }^{*} 193$.

Tremellæ Dıll. Bull. Pers. cæt. 66, 19o, 192, in nota, 196.

Tremellinei Fr. 66.

Trichoderma æruginosum Pers. (Hypocrea rufa PERs. pars $),{ }^{*} 30$.

—— mycophilum aut parasilicum Alb. et Schw. (Hypomyces chrysospermus Tul. conidiophorus), * 49.

_ viride Pers. (Hypocrece rufae Fr. primordia), ${ }^{*} 30,32$.

Trichodermata Fr. 29, 38.

Trichothecium agaricinum Bonond. (Hypomycetis roselli nostri forma gemmifera), ${ }^{*} 45$. 
INDEX.

Trichothecium candidum Bovord. * 45 .

* Trochila Fr. 179 et seq.

— Craterium Fr. 180-181.

___ Laurocerasi (MAz.), 181.

ligni (Desm.) DNtrs. ${ }^{*} 169$.

Populorum Maz. 142 , in nota 4.

*Salicis nob. 181-182.

Trifolii DNtrs. (Ascobolus Biv.), 142.

Trochilæ Fr. 142, 168, 183.

Tryblidium difforme Pers. (Cenangium fuliginosum $\mathrm{F}_{\mathrm{r} .}$ ), ${ }^{*} 166$.

— Pinastri Fr. (Tymipanis nob.), ${ }^{*}{ }_{151}$

__ pineum Pers. (Cenangium ferruginosum Fr. ), ${ }^{*} 168$. quercinum Pers. Fr. 112.

Tubera Мıсн. 26.

Tubercularia Tod. Pers. Fr. cæt. (fungi nondum perfecti et maxime Nectriarum subicula gemmipara), 65 , 66,67 .

- Buxi DC. (Nectria Russeliana Mrtgn. gemmifera), ${ }^{*} 97$.

Castaneæ Pers. DC. 80

- Cerasi Schum. (Dermatea Cerasi Fr.), ${ }^{*} 157$.

___ coccophila Bovond. (Sphcerostilbes sp. gemmipara nob.), ${ }^{*} 105$.

confluens Pers. Fr. cæt. 80.

- discoidea Pers. Fr. 79 .

expallens Fr. Maz. 60.

- fasciculata Tode (Peziza carpinea Pers.), 183, in nota 2.

granulata Pers. DC. MAz. cæt. 79 .

Menispermi Fr. 80.

minor LK. $79,{ }^{*} 80$.

minor nonnullis aliis scriptorib. (Nectrice ditissime nostræ forma conidiophora), ${ }^{*} 73$.

mutabilis NeEsio, 80 .

- nigra Schun. (Dermatea Frangula nob.), ${ }^{*} 161$.

nigricans Lk. 79 .

- persicina Dıтм. 99 .

- (Agyrium) rufa Cords (minime Agyrium rufum Fr.), 150 .

sarmentorum Fr. ${ }^{*} 80,{ }^{*} 89$.

vulgaris Tode, Fr. cæl. (Nectrice cinnabarince et congenerum stroma conidiophorum), 66, in nota, $67,{ }^{*} 79,91,101$.

- vulgaris, cava, Corve, 80.

vulgaris, purpurata, Corde, 80 .

Tubiporus sulphuratus Padetio (Boletus subtomentosus Bull. Hypomycete nostro chrysospermo laborans), $* 49$.

Tympanides Fr. $155,163,173$.

*Tympanis Fr. DNTrs. 150 el seq. (tab. xix). alnea Fr. 153 , in nota 2.
Tympanis Ariæ Fr. ${ }^{*} 160$.

conspersa Fr. $127,{ }^{*} 153$.

Frangulæ Fr. (Dermatea nob.), ${ }^{*} 161$.

Fraxini Fr. 162.

* Ligustri T'ul. 154.

Patella Wallr. Rabenh. (Heterospharia Grev.), ${ }^{*} 175$.

*Pinastri nob. 151-153 (tab. xix, fig. 10-12).

Ribis Wallr. (Cenangium Ribis Fr.), ${ }^{*} 164$.

saligna Berk. et Br. (Tympanis Ligustri nob.), ${ }^{*} 176$. saligna (Tode) nob. 152 .

Typhodium Lk. 24 .
graminis Lk. (Epichloe typhina Fr.),${ }^{*} 5$.

Uredinei recentiorum, 66 .

Uredines Pers. Fr. cæt. 38.

Uredo CoRde, 40.

- mycophila Pers. (Hypomyces chrysospermus noster gemmiferus), ${ }^{*} 49$.

Ustilago Lк. 27.

Valsa Abietis Fr. $9^{2}$.

ambiens (Pers.), 80.

${ }^{*}$ chrysoides nob. 3 , in nota, ${ }^{*} 107$ (tab. 11I, fig. 15 et 16$)$.

_- leucostoma (P Prs. $), 127,156$.

- L liphæma Fr. 31.

nivea (Hofrm. Pers.), 127.

vestita Fr. 107.

Valsæ Fr. 4, 67, 107 .

Valsei (Pyrenomycetes), 107.

Verpa dubia Lev. (Morchella bohemica Квомвн.), 201 , in nota 2.

Verticillia Neesio, Conde, cæt. 4, 38, 40.

Verticillium affine Cords, 40.

- agaricinum Conde:(Hypomyces ochraceus nob.), * 41 .

corymbosum Leb. 6.

cylindrosporum CoRde (Hypomyces Linkii nob.), $40, * 44$.

Volutella Buxi Berк. et Вr. (pars Nectrice Russeliance Mntgi.), , 97 .

Xylaria aristata Mntgn. 18.

— gracilis Grev. (Torrubia entomorrhiza Dicks.), 15 , ${ }^{*} 16$.

—_ vaporaria Bевк. (forma, ut videtur, Xylarice pedunculate Dicks. vel pusille nostræ), 136 , in nota 1.

Xylariæ HiLt. 4.

Xylogramma versicolor Waldr. (Stictis cinerascens PERs.). ${ }^{*}{ }_{12} 6$. 
Xylographa parallela $F_{R} .149$, in nota. Schizoxylum DNtrs. 148.

Xyloma acerinum Pers. Alb. et Scrw. * 117 . Aquifolii DC. 138,140 , in nota 2.

Cicatrix Wallr. (Rhytisma maximum Fr.), ${ }^{*} 122$. concavum Grev. (Eustegoia Ilicis Fr.), 140, in nota 3.

leucocreas DC. (Rhytisma salicinum Fr.), ${ }^{*} 11$ q .

lichenoides Lasк. et DG. (Phacidium dentatum Sснм. et Kze.), ${ }^{*}{ }_{1} 3_{2}$.
Xyloma pezizoides Pers. (Phacidium coronatum Fr.), 111, $* 134$.

— Pini Arb. et Schw. (Phacidium Pini Schм.), * 136.

punctatum Pers. (Rhytisma acerinum Fr.), ${ }^{*} 116$.

Pseudoplatani DC. (Rhytisma acerinum Fr.), ${ }^{*} 117$.

— salicinum Pers. (Rhytisma Fr.), * $119,121$. umbonatum ScHw. ${ }^{*} 119$.

Xylomata Pers. DC. ${ }^{*} 115$ et seq. 131 . Rhytismatum Fr. ${ }^{*} 116$.

EXPLICIT

SELECTA FUNGORUM CARPOLOGIA. 


\section{TABULE.}

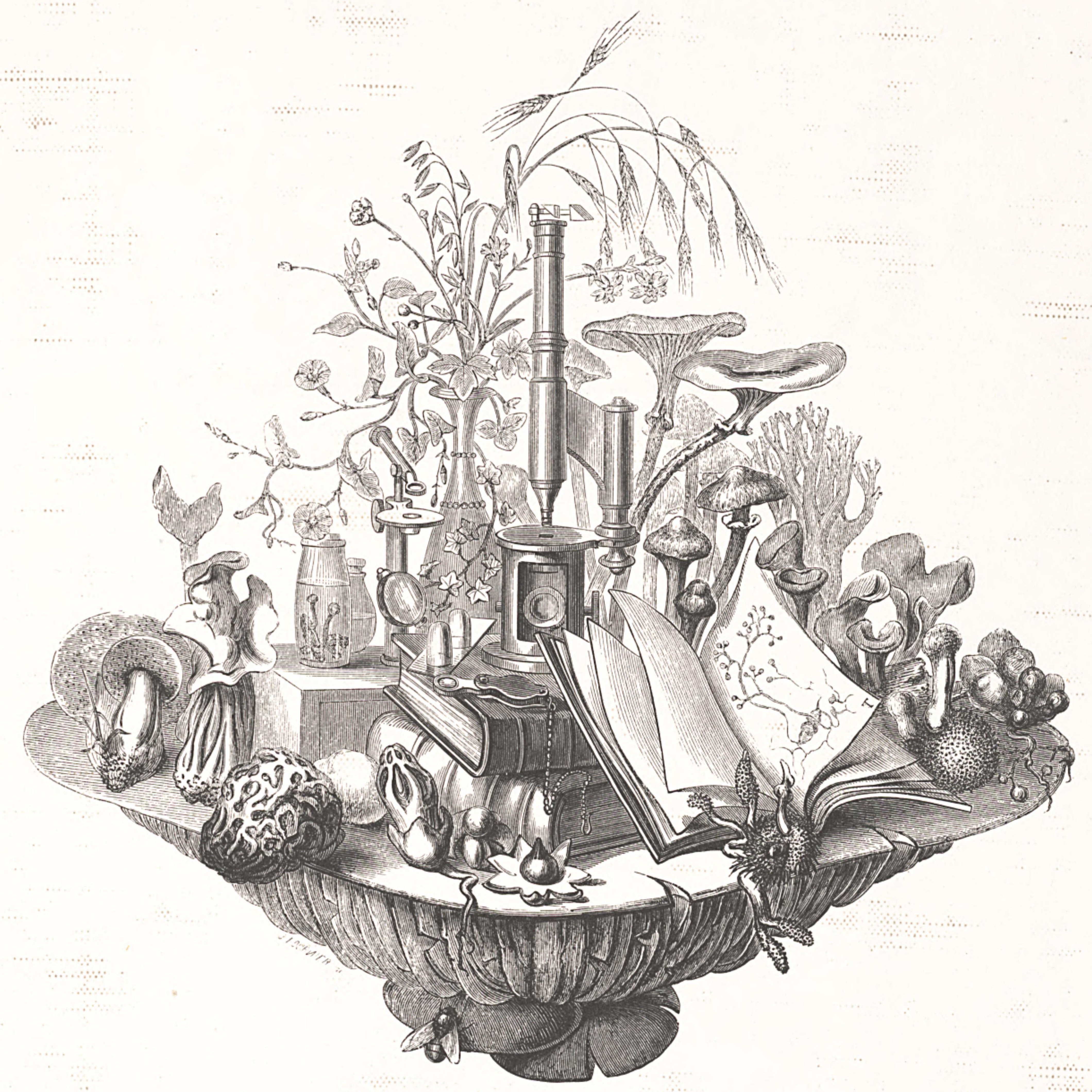

"I progressi della Botanica crittogamica si ripetono in principal modo dalle osservazioni microscopiche.

(DNtrs. in Parlatoris Giorn. Bot. Italo, anno I, tomo I (1844), p. 324.) 


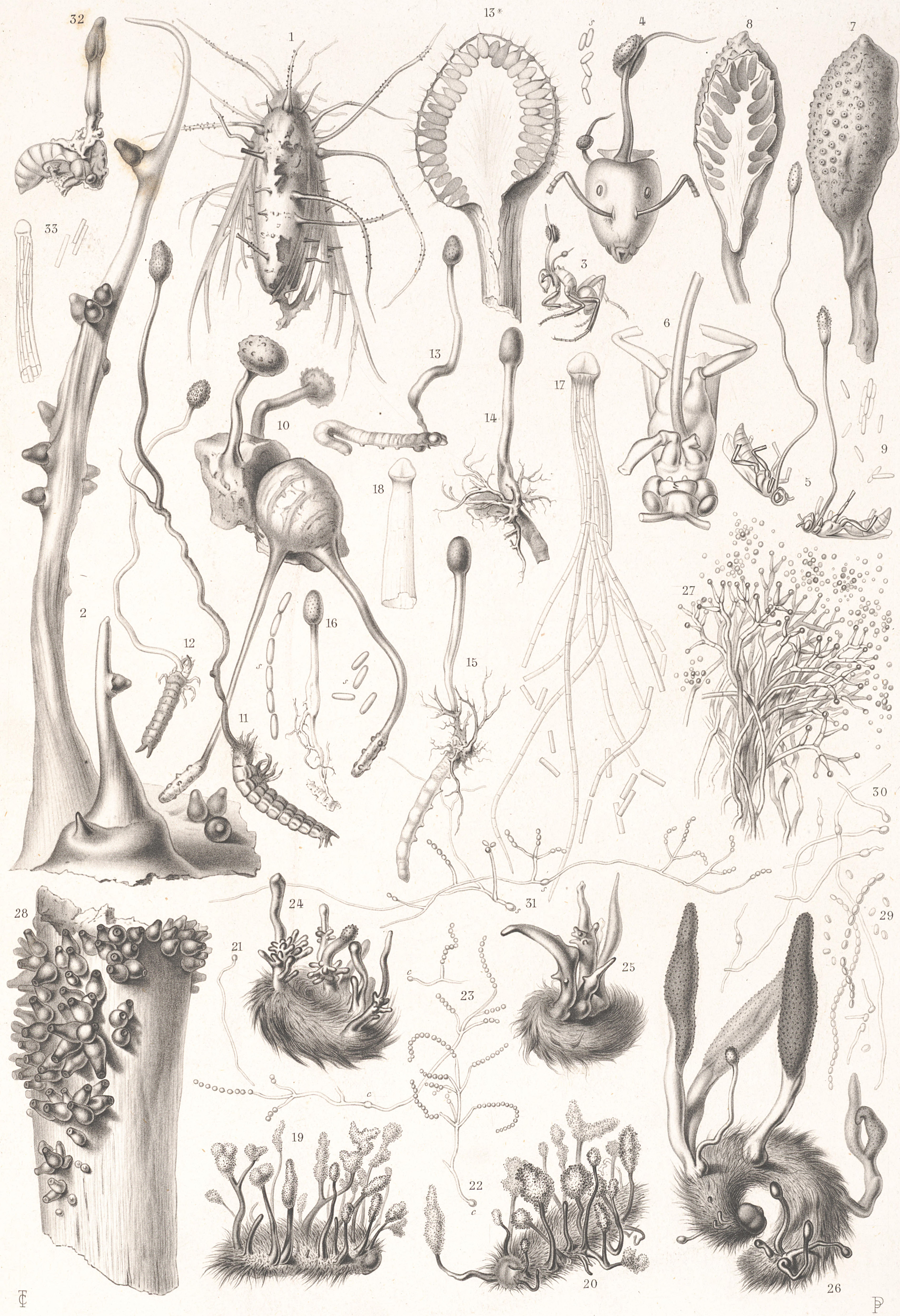

1 et 2. Torrubia Sphingum ( $\mathrm{Schw}_{\mathrm{c}}$ ) 3 et 4 .T. unilateralis Tul. $5-9$. T. sphecocephala (KL.)

10. T. coccigena TUL. 11. T. cinerea TUL. 12-18. T. entomorrhiza (Dicks)

$19-31$.T. militaris (VAILL) 32 et 33 . T. sobolifera (HILL) 


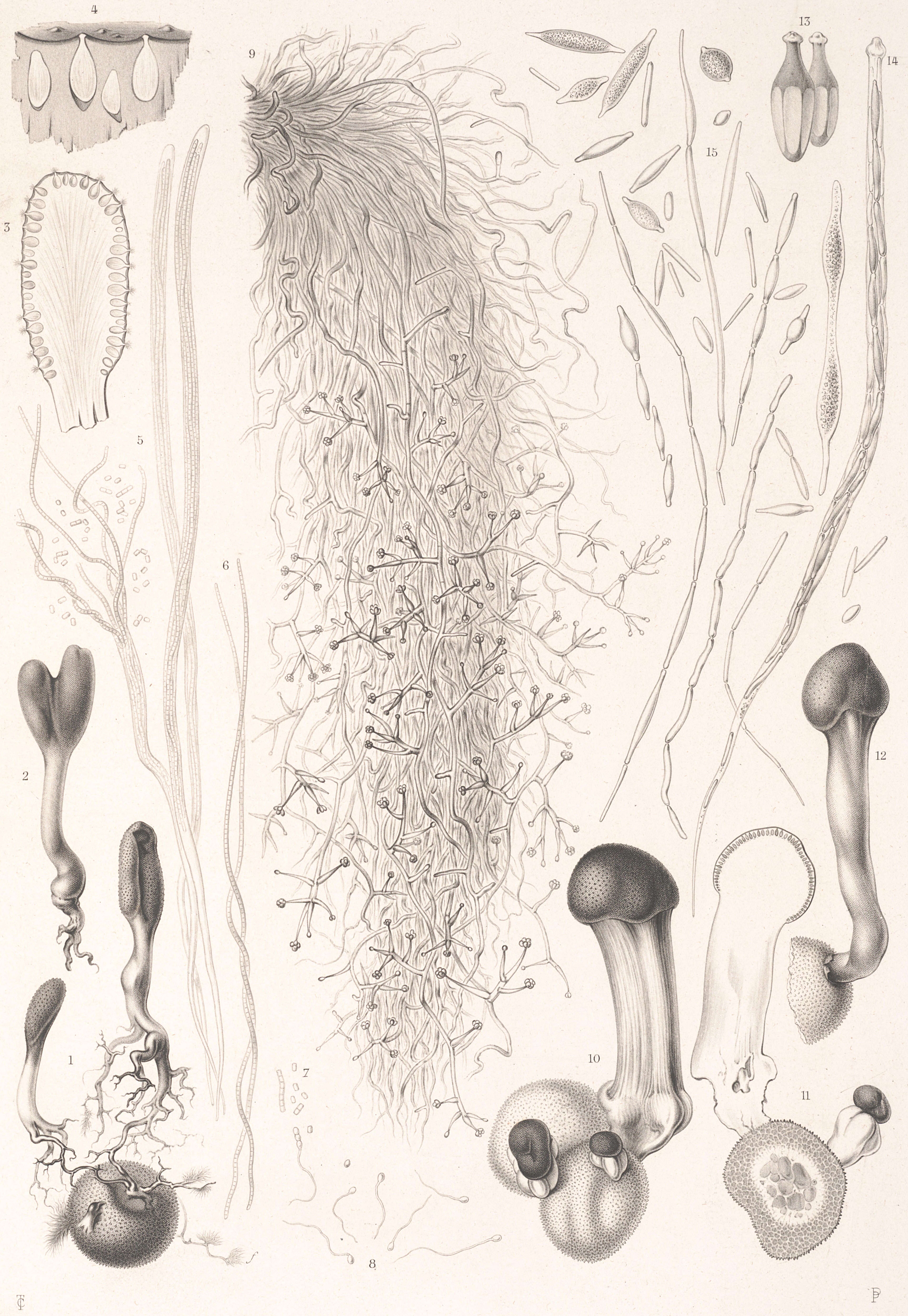



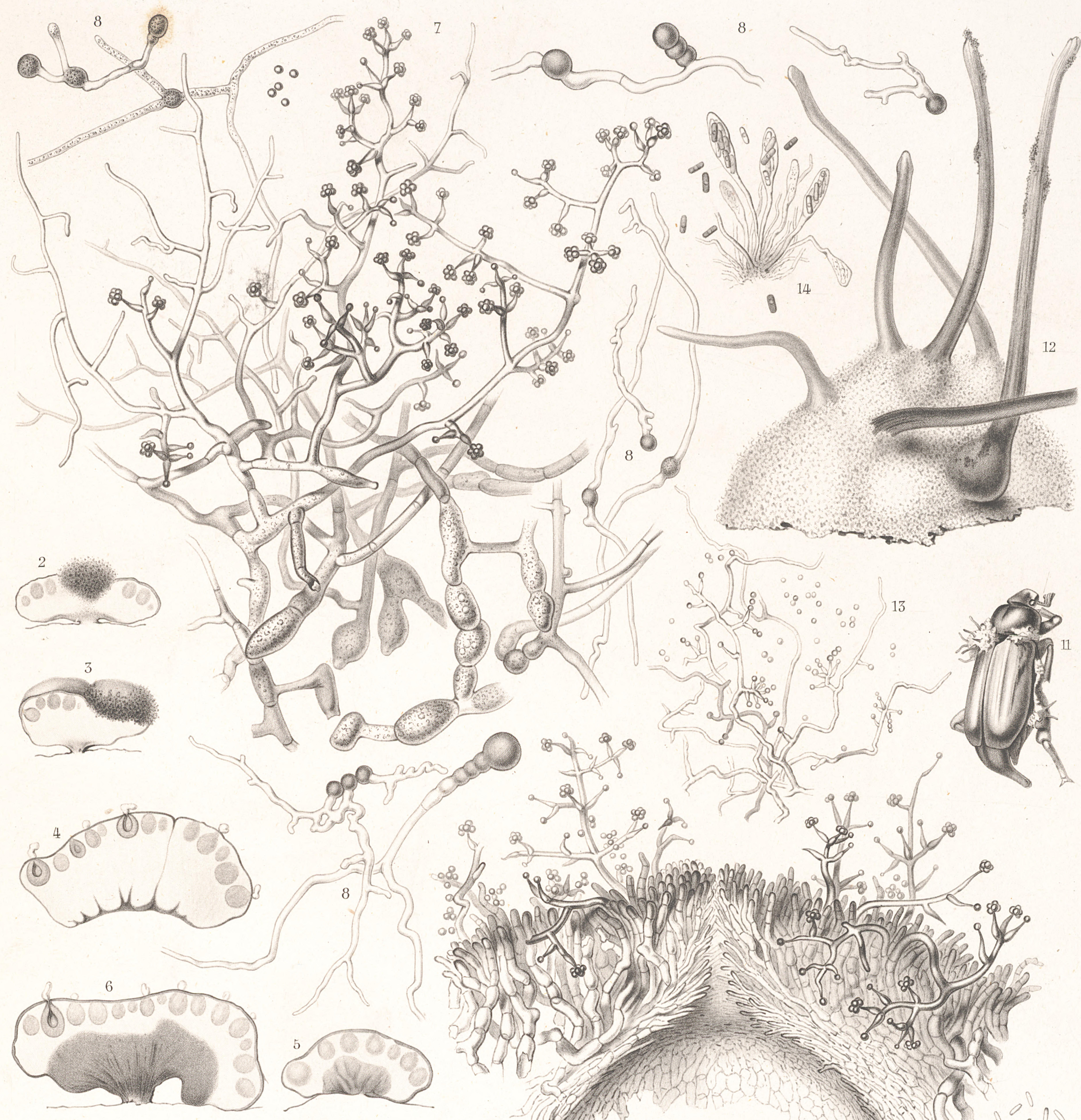

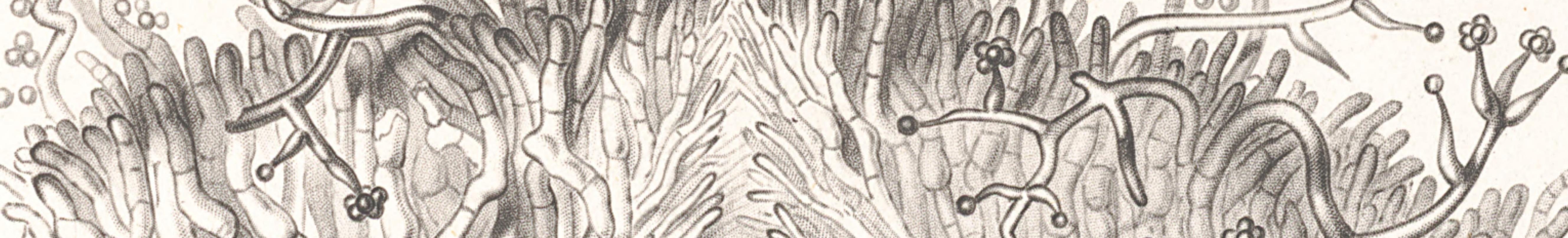

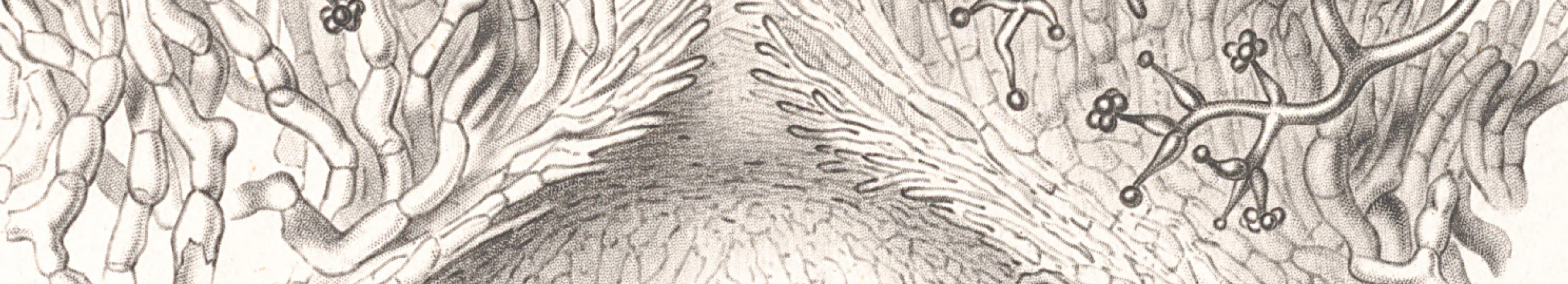
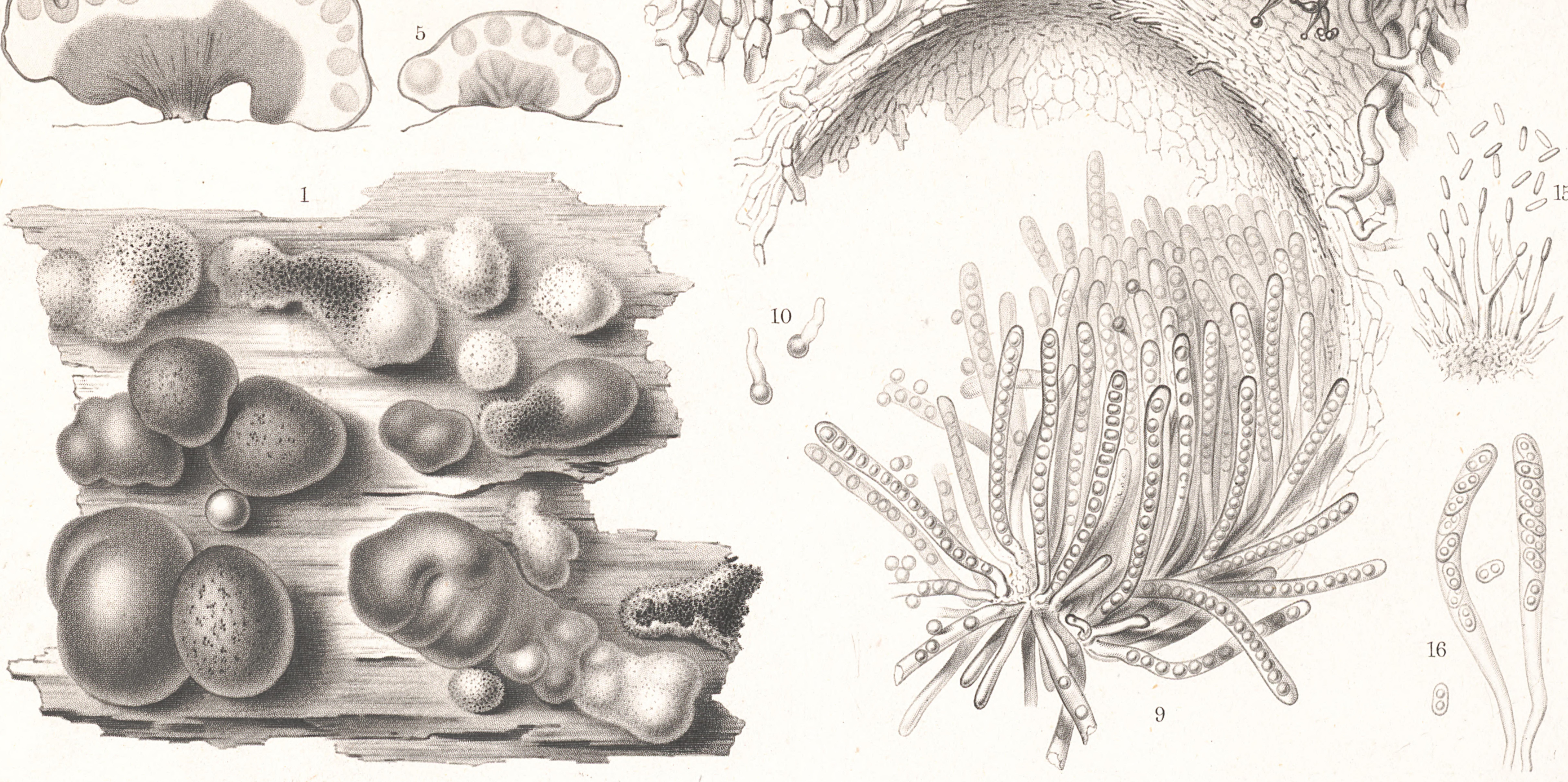

1-10. Hypocrea rufa (Pers.) 11-14. Melanospora parasitica Tul. 


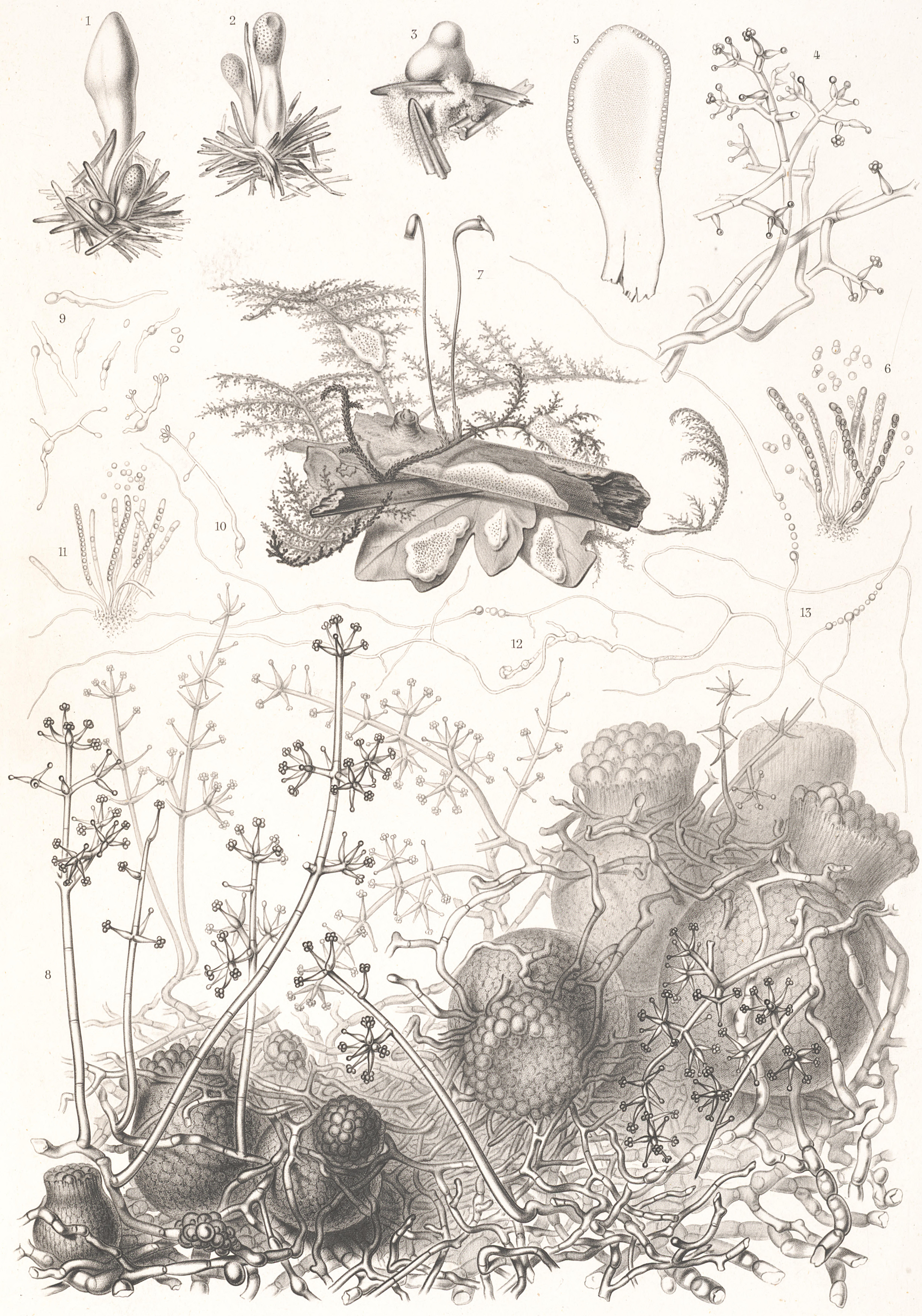




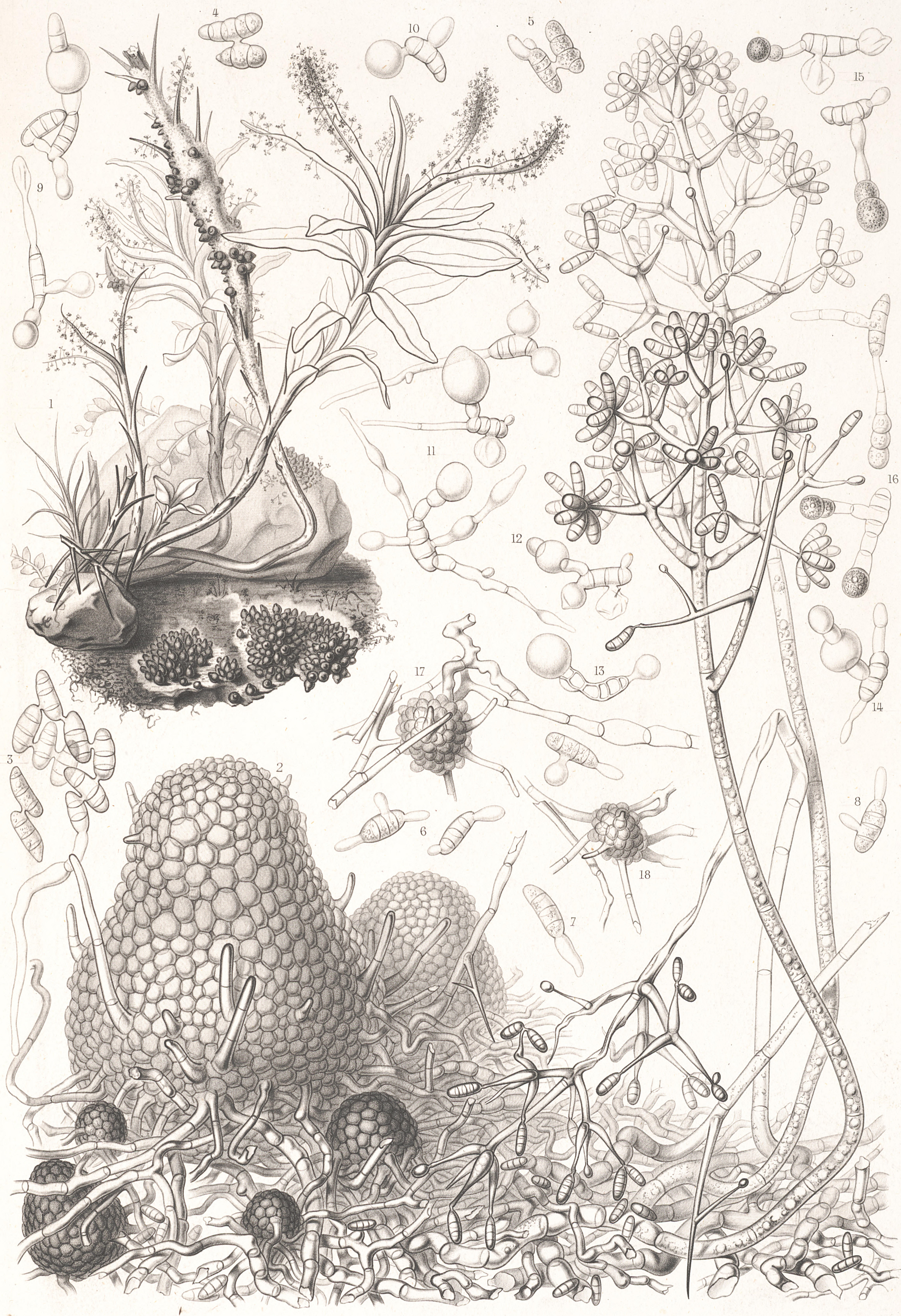




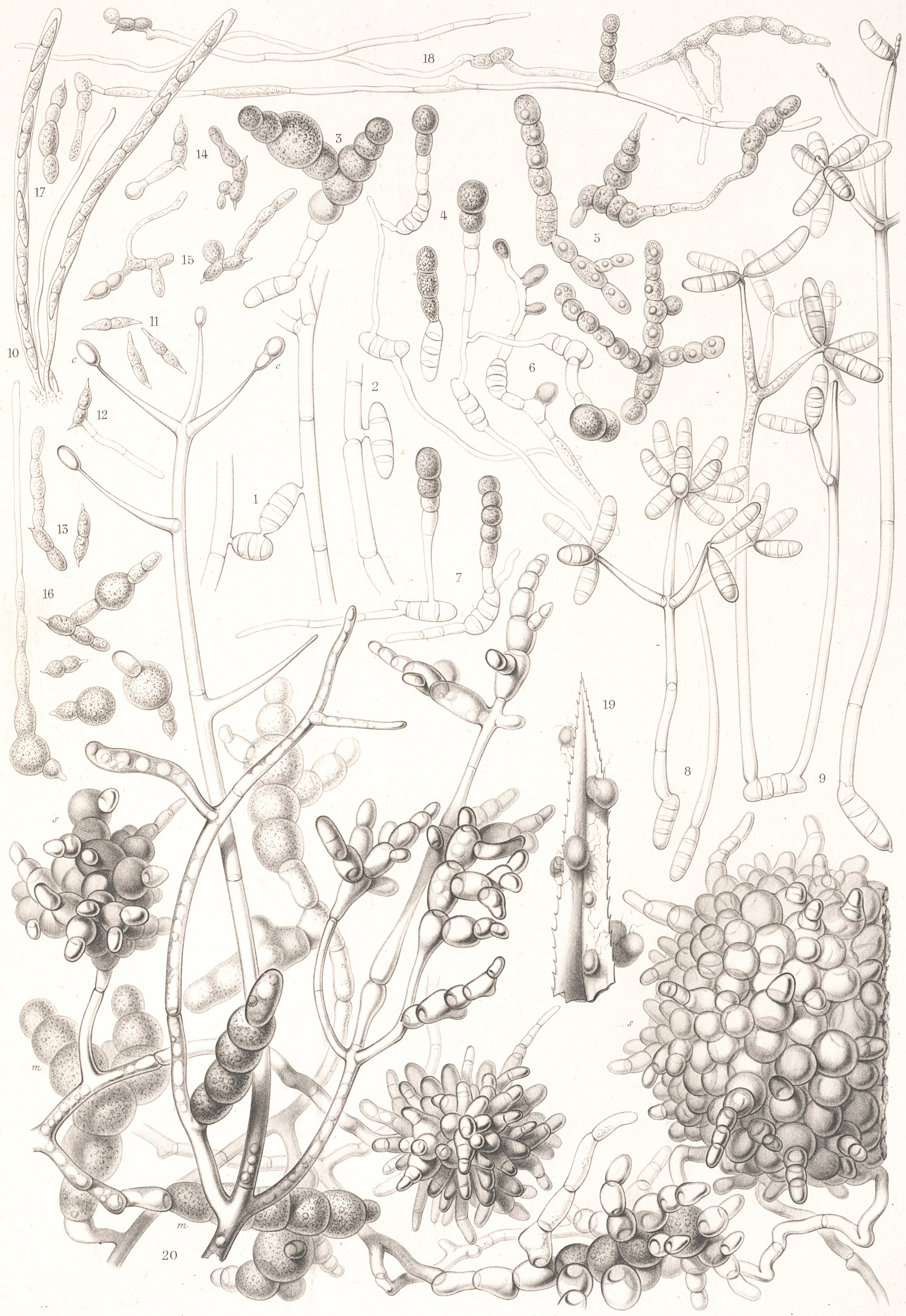




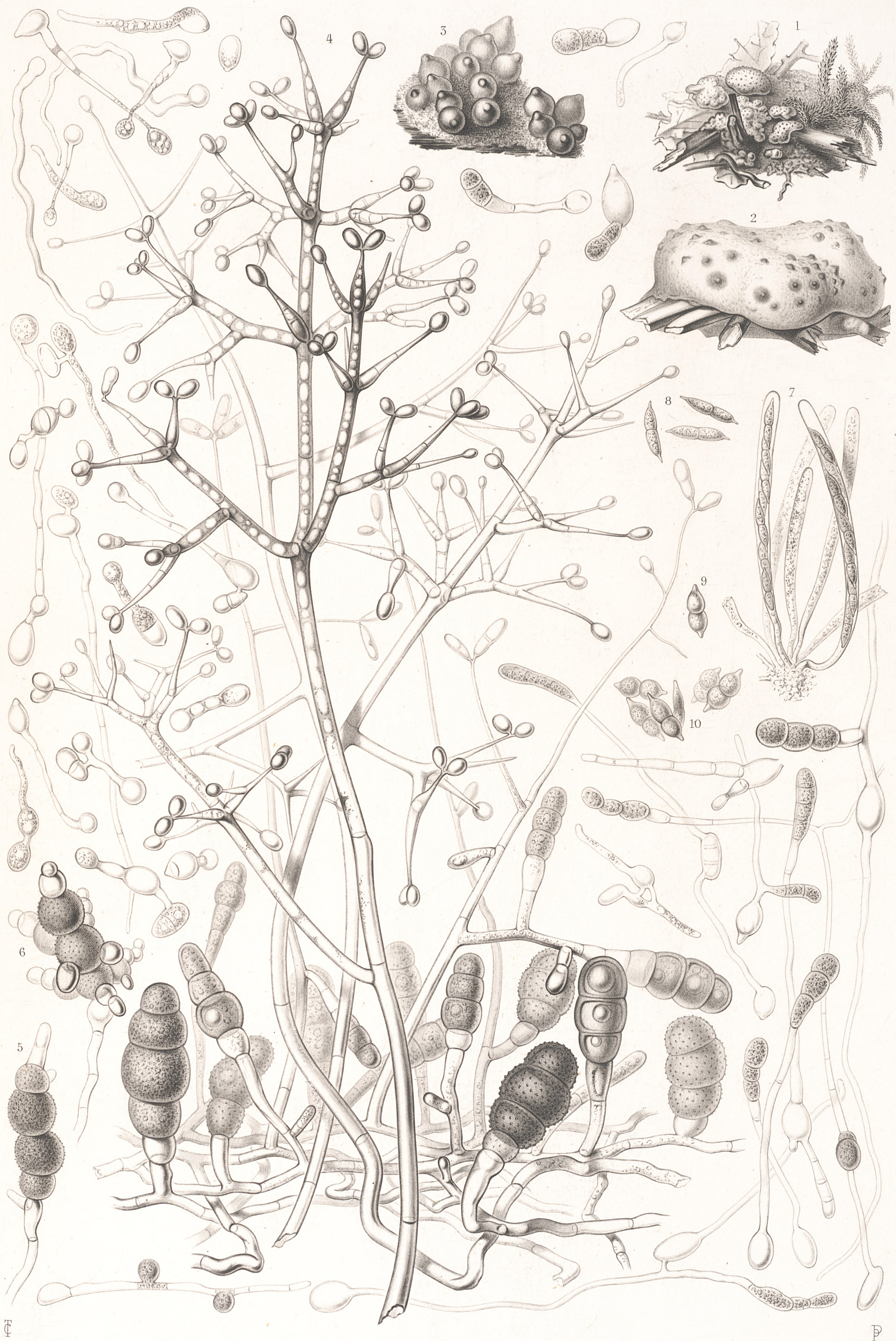



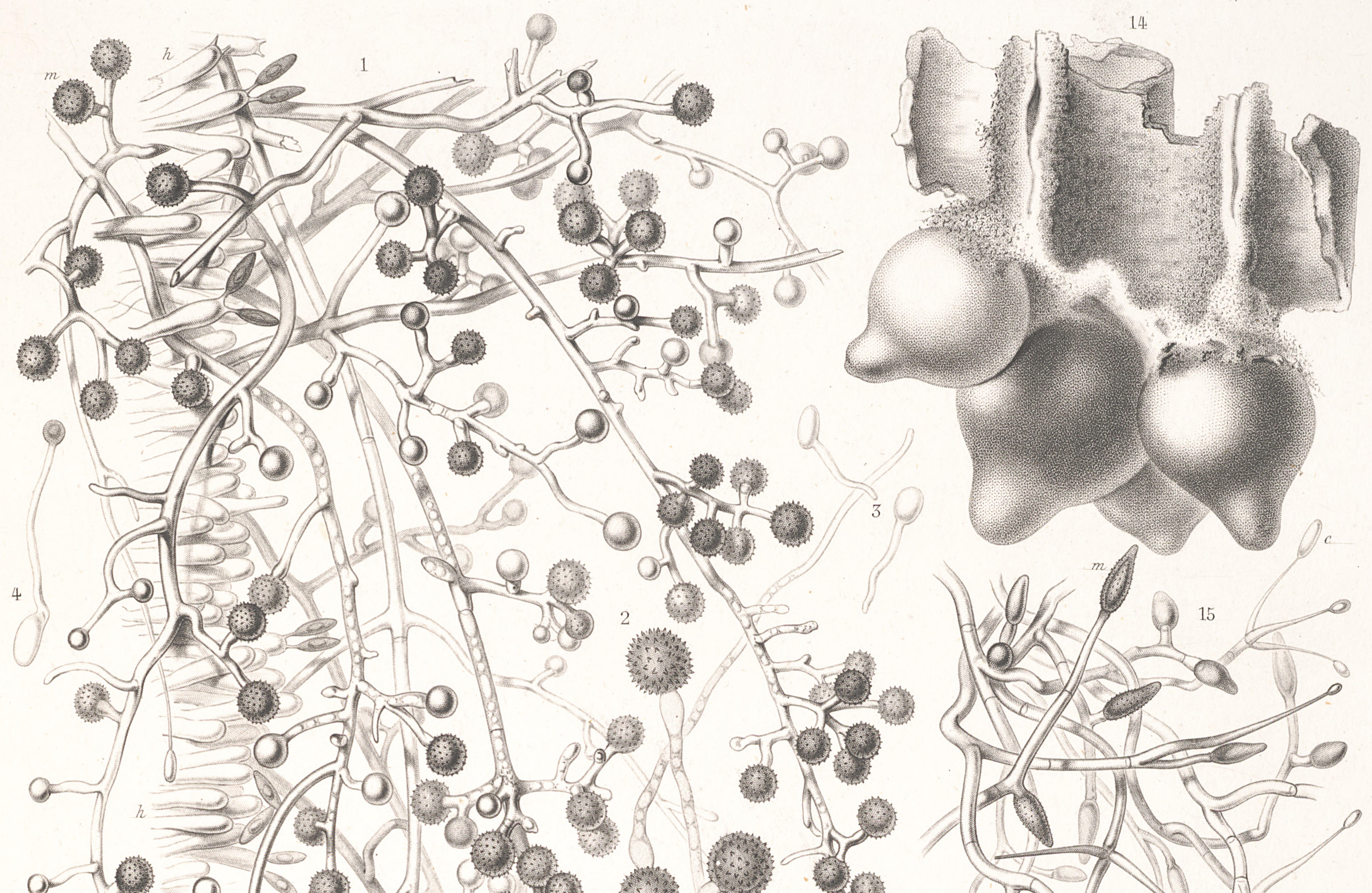

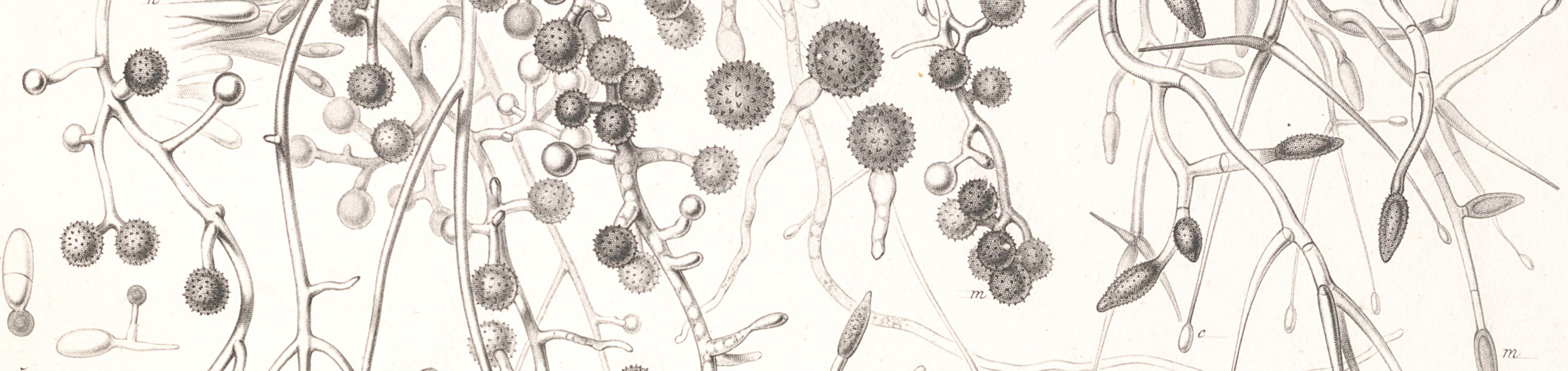

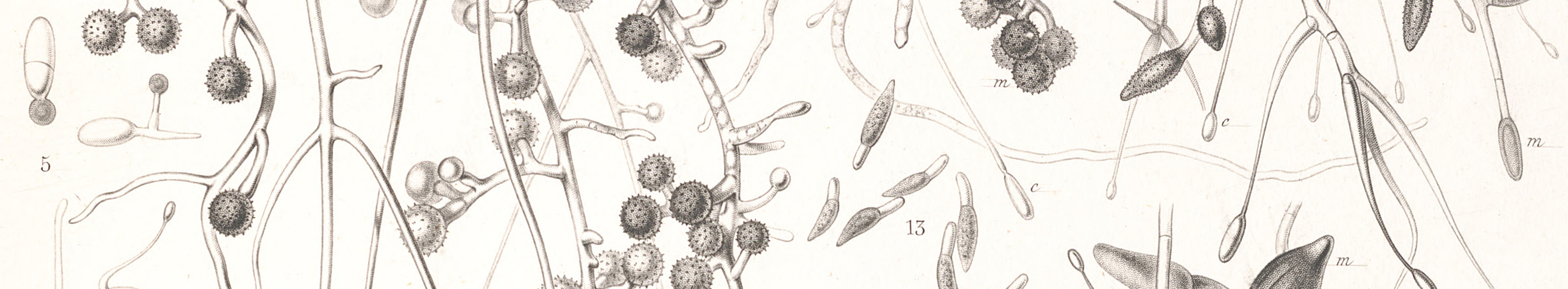

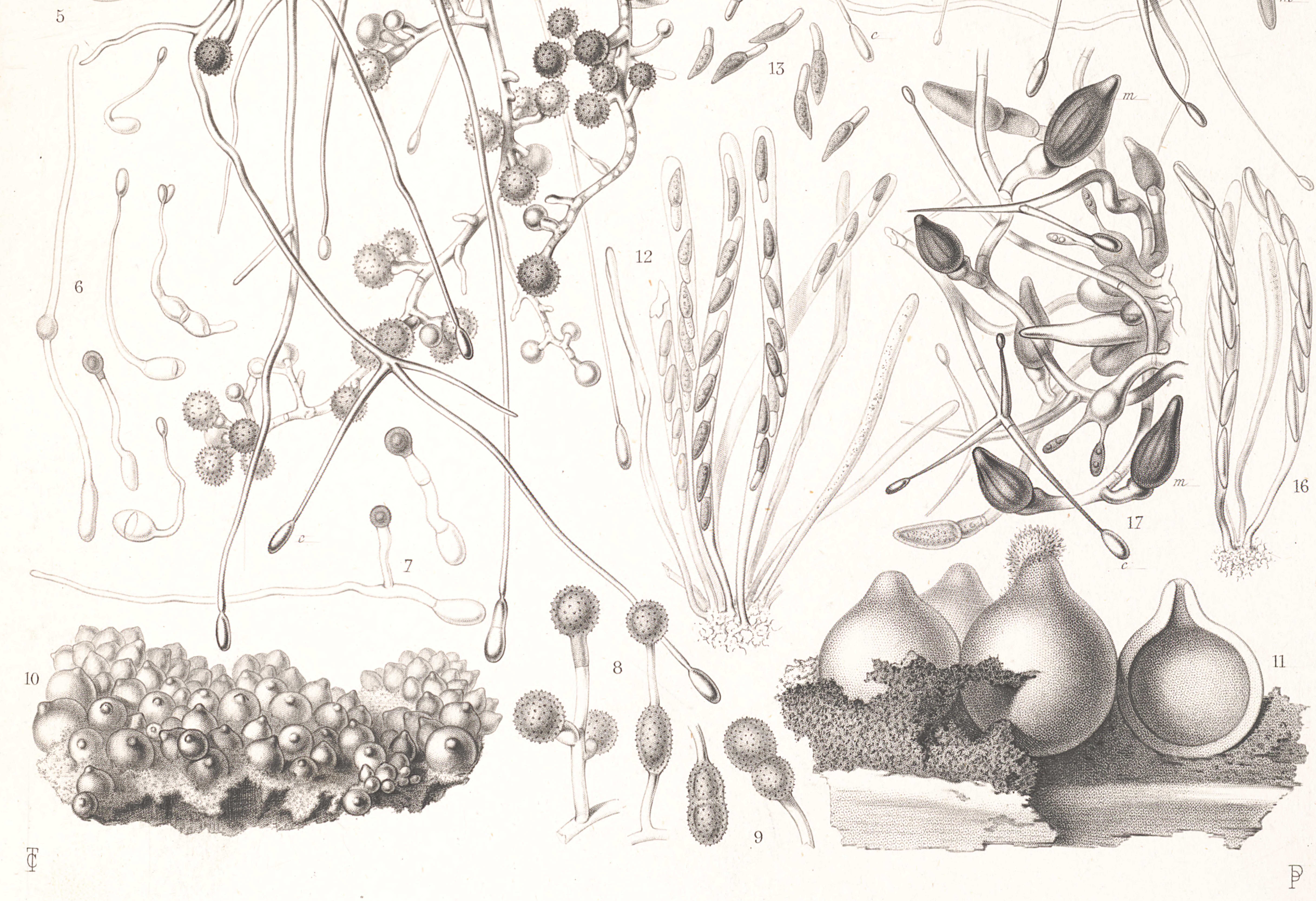




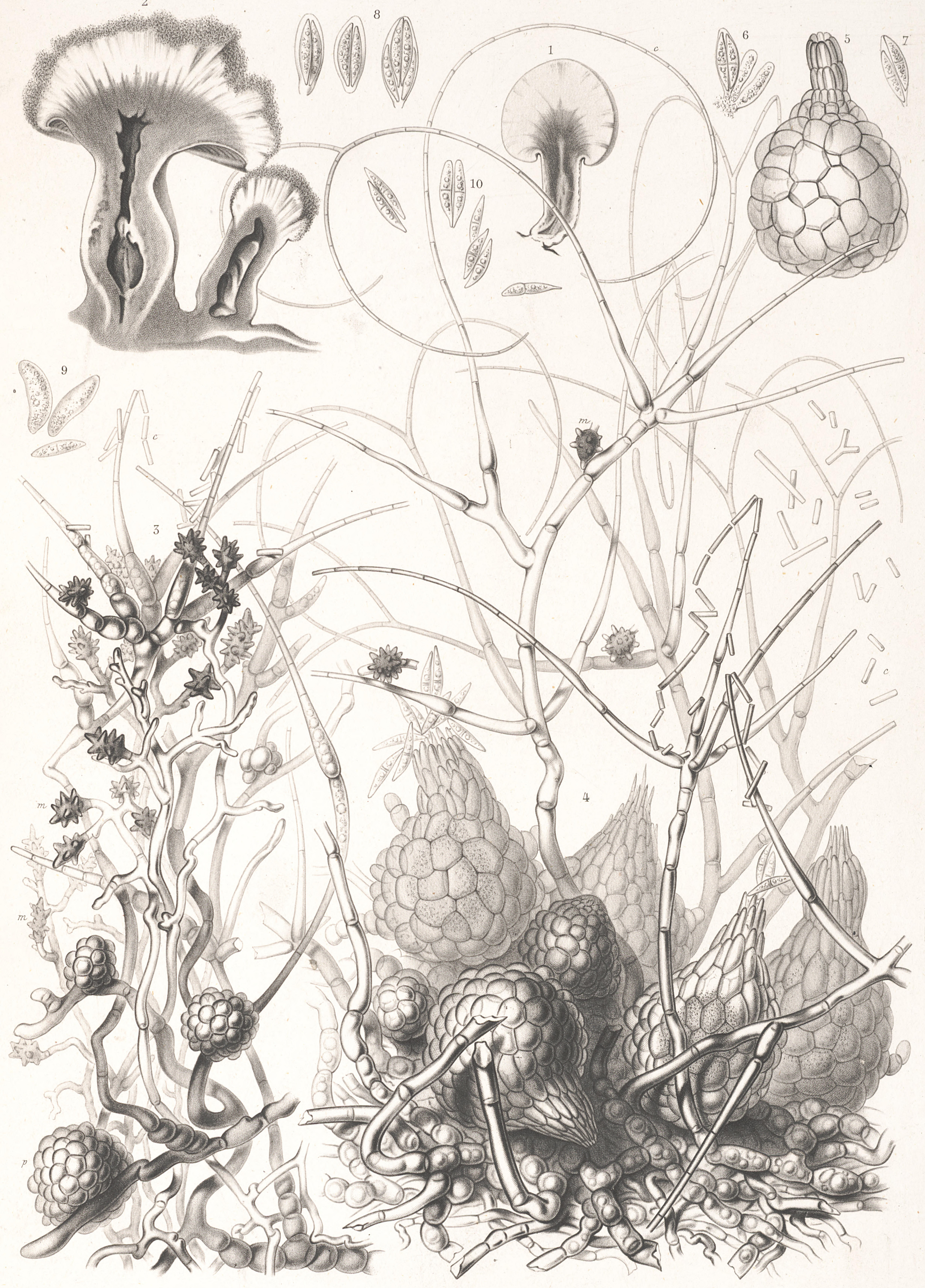




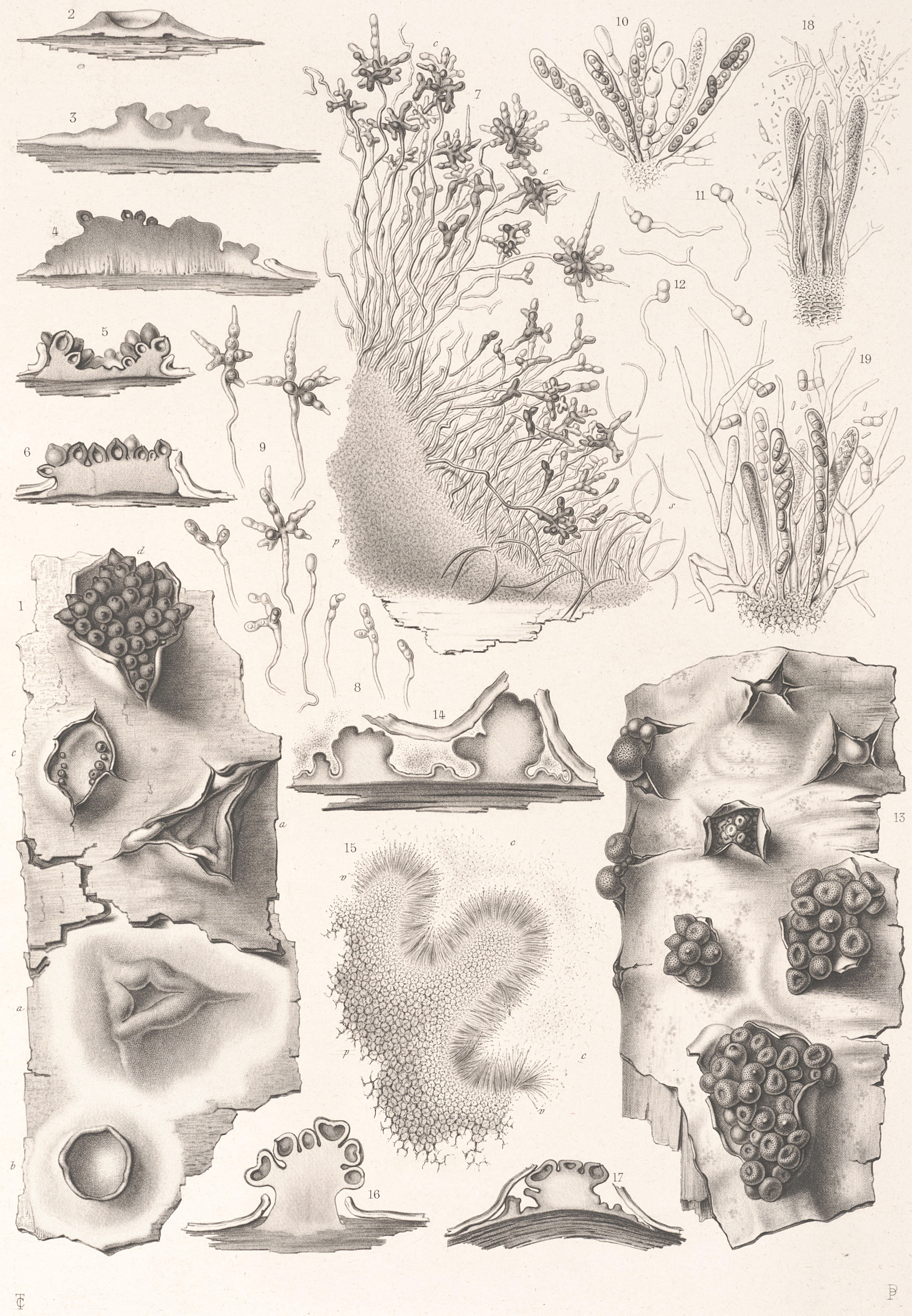



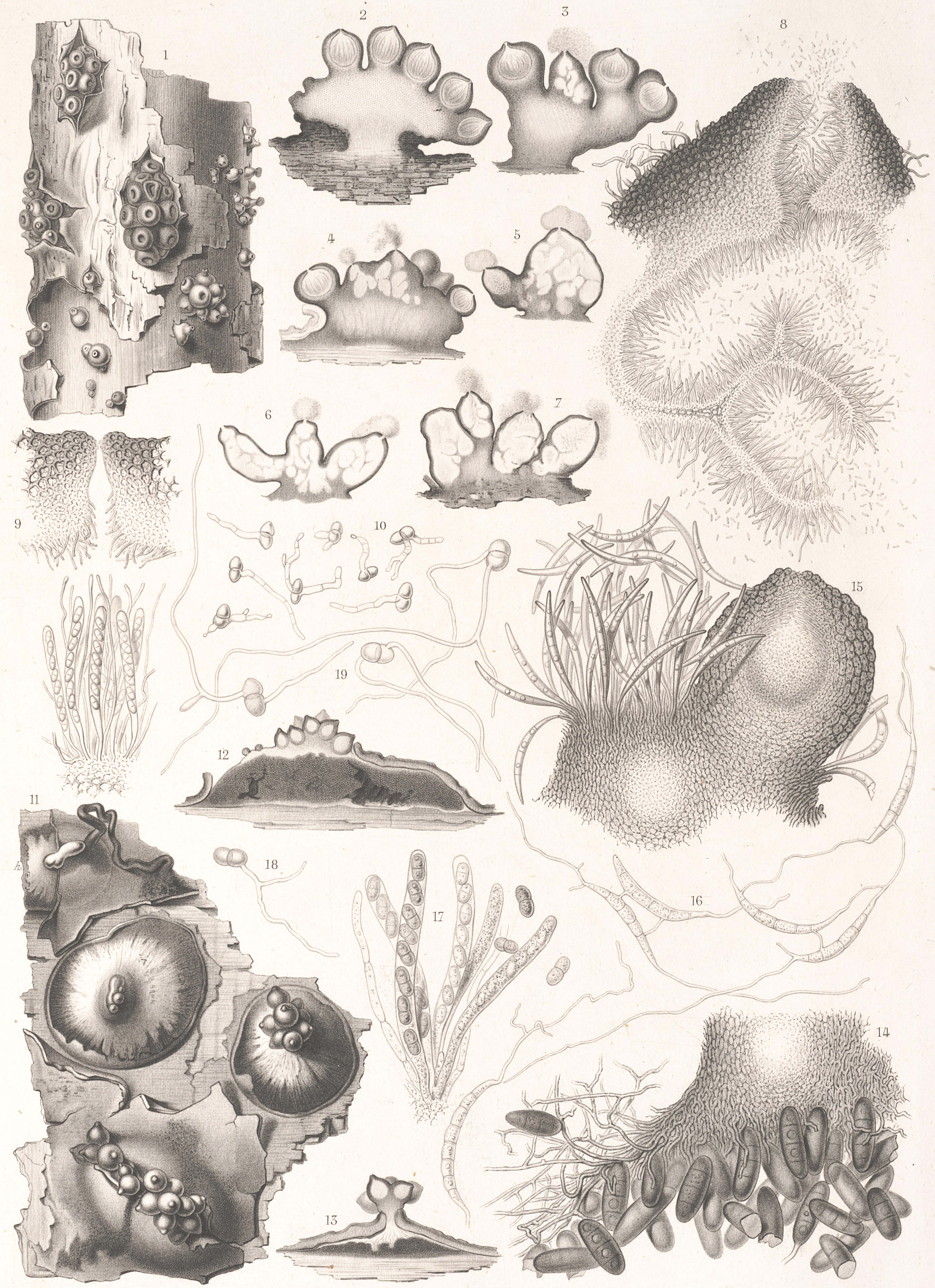

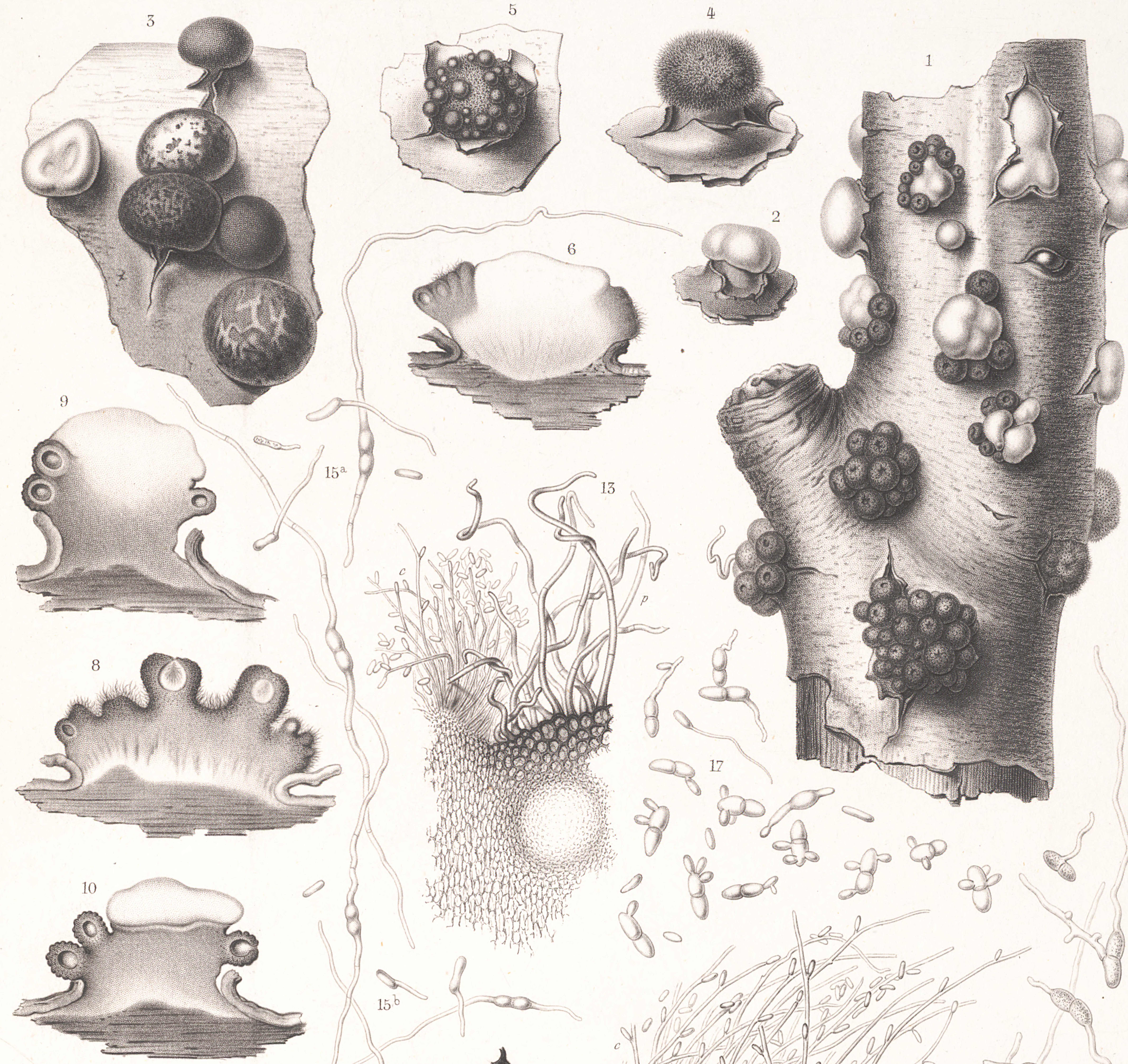

8) 000

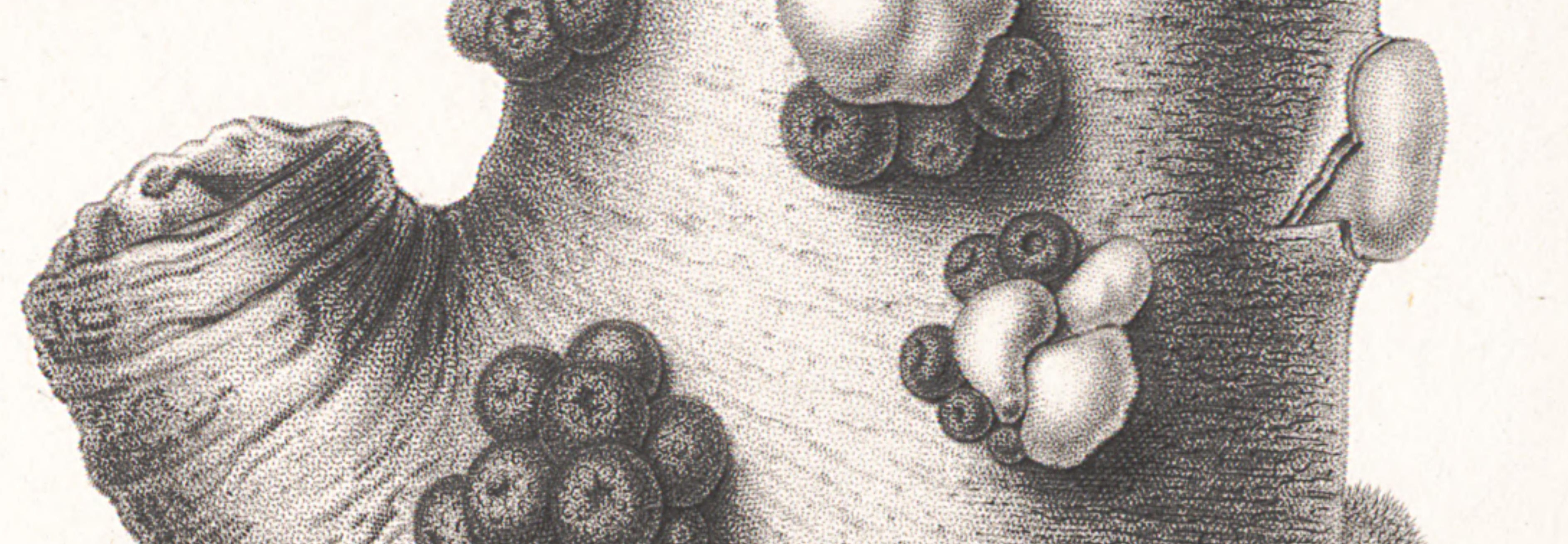

(2)
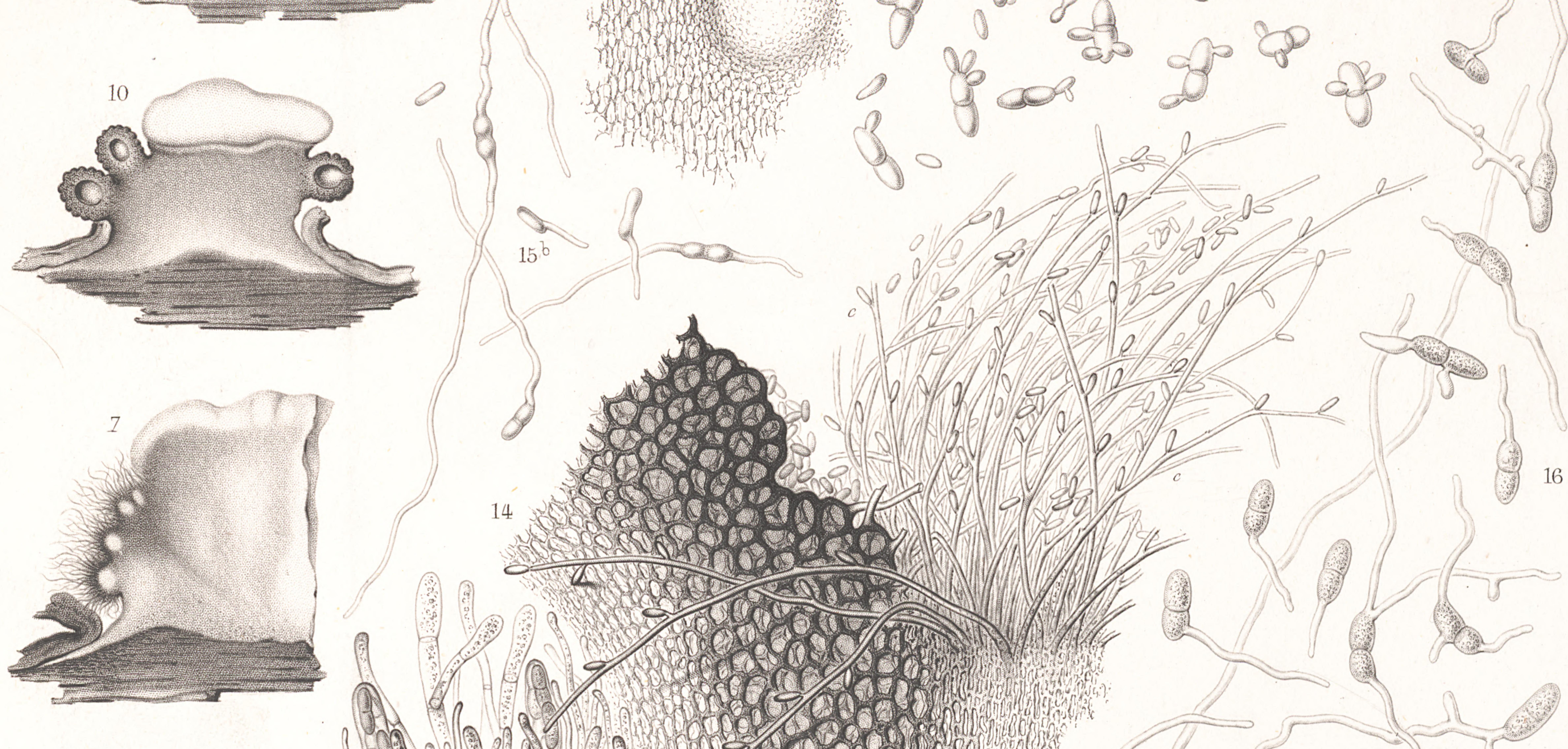

$\beta$
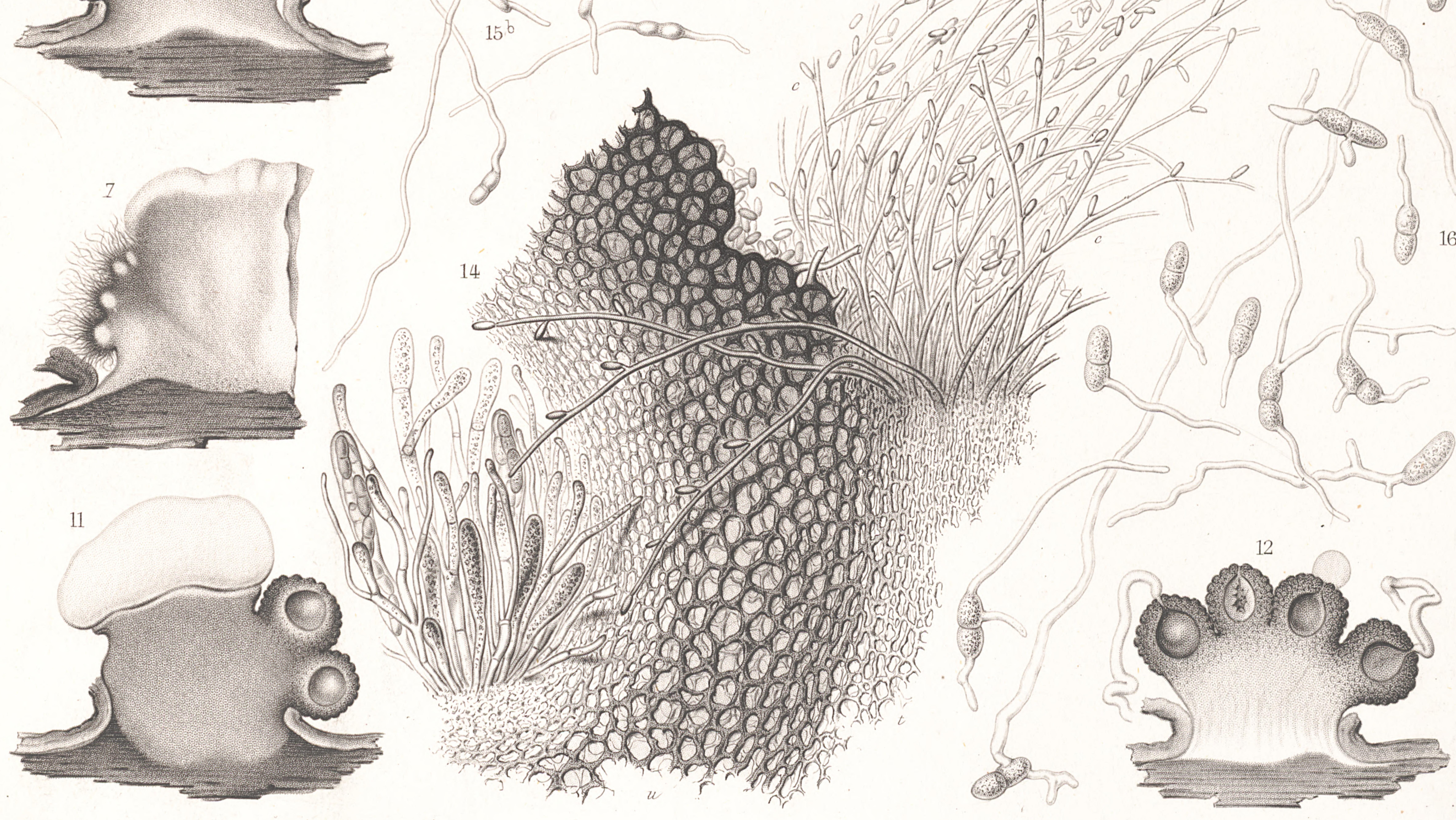


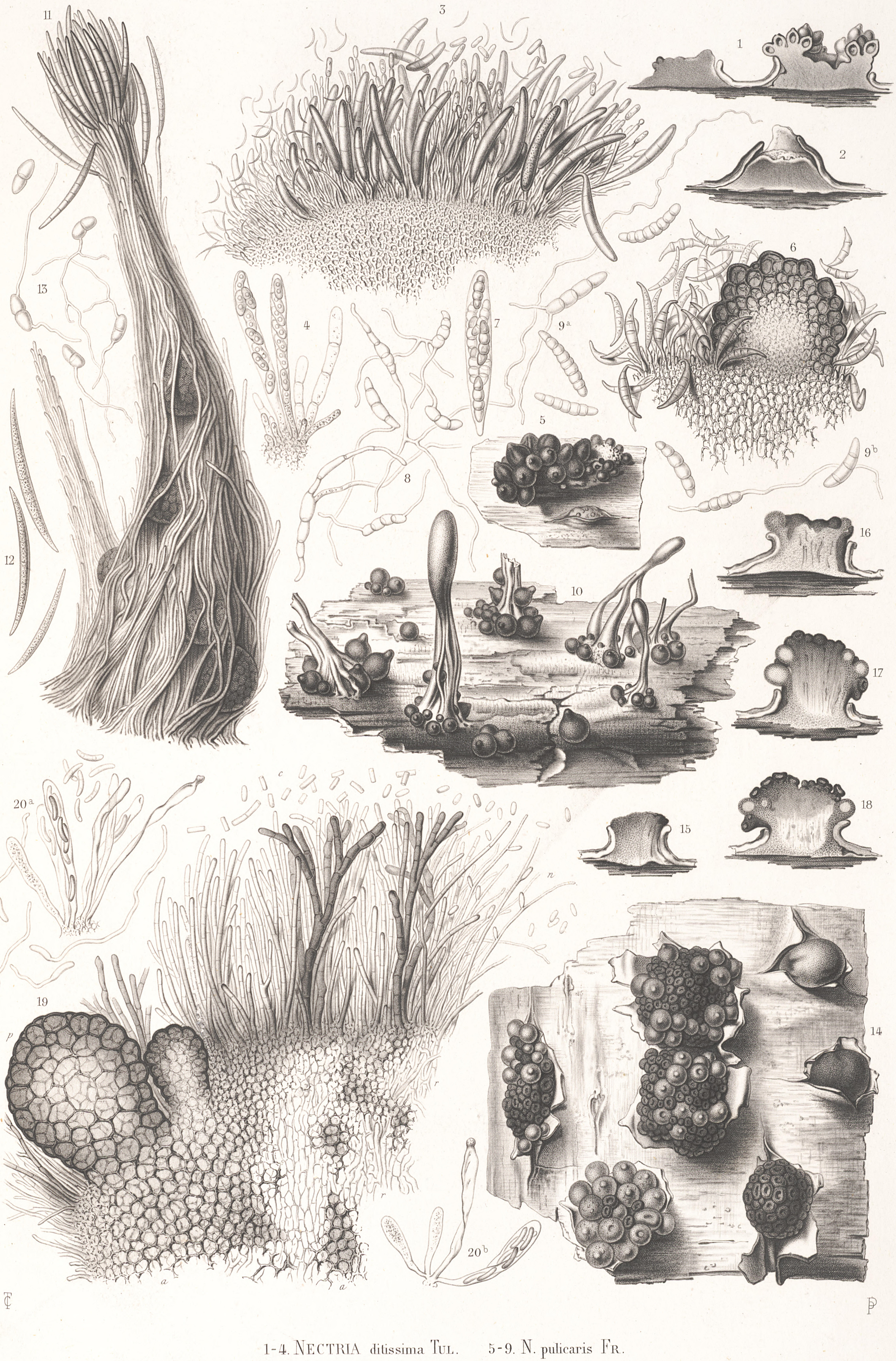

10-13. Spherostilbe flammea Tul. 14-21. Spheria cupularis Pers 


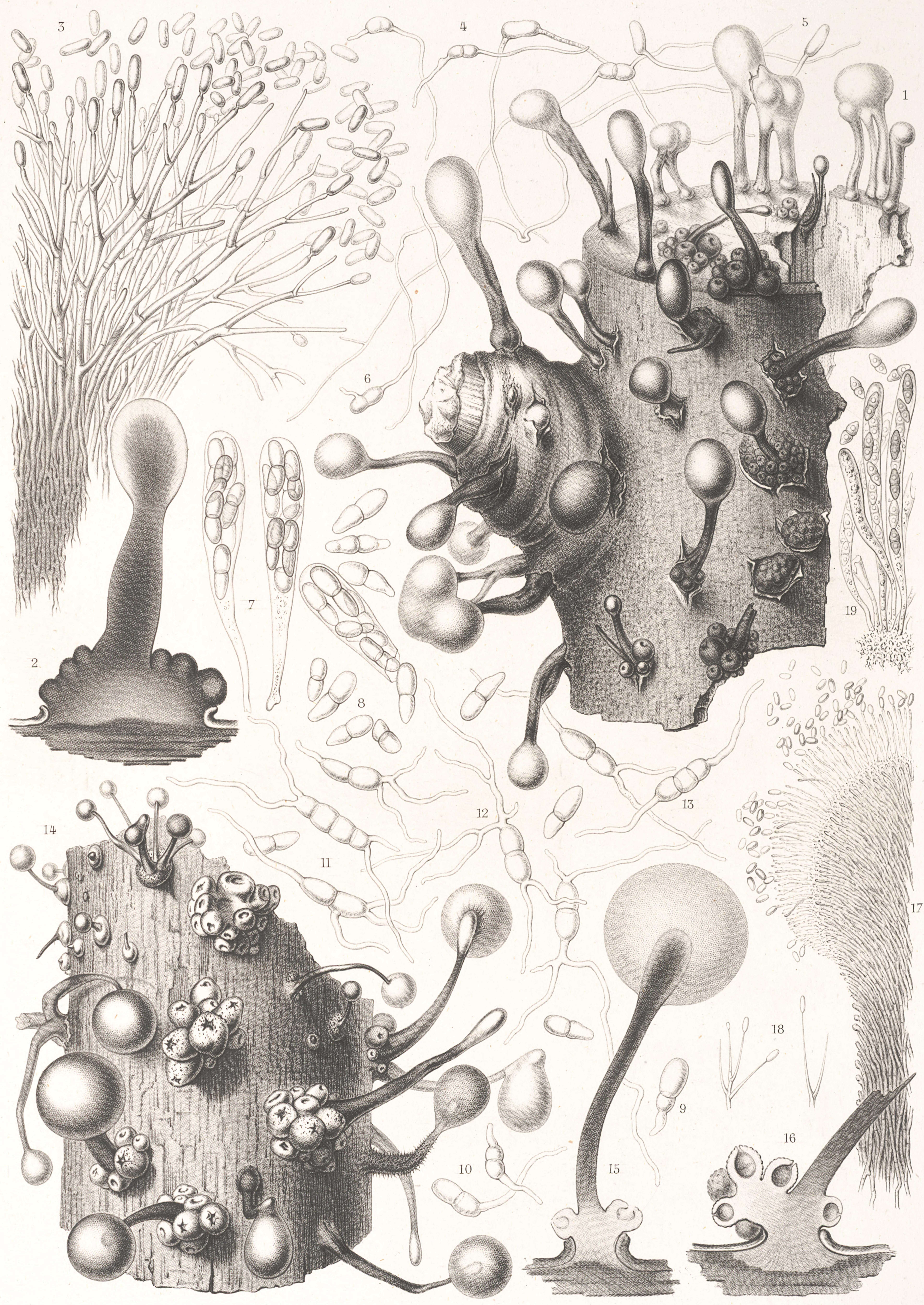



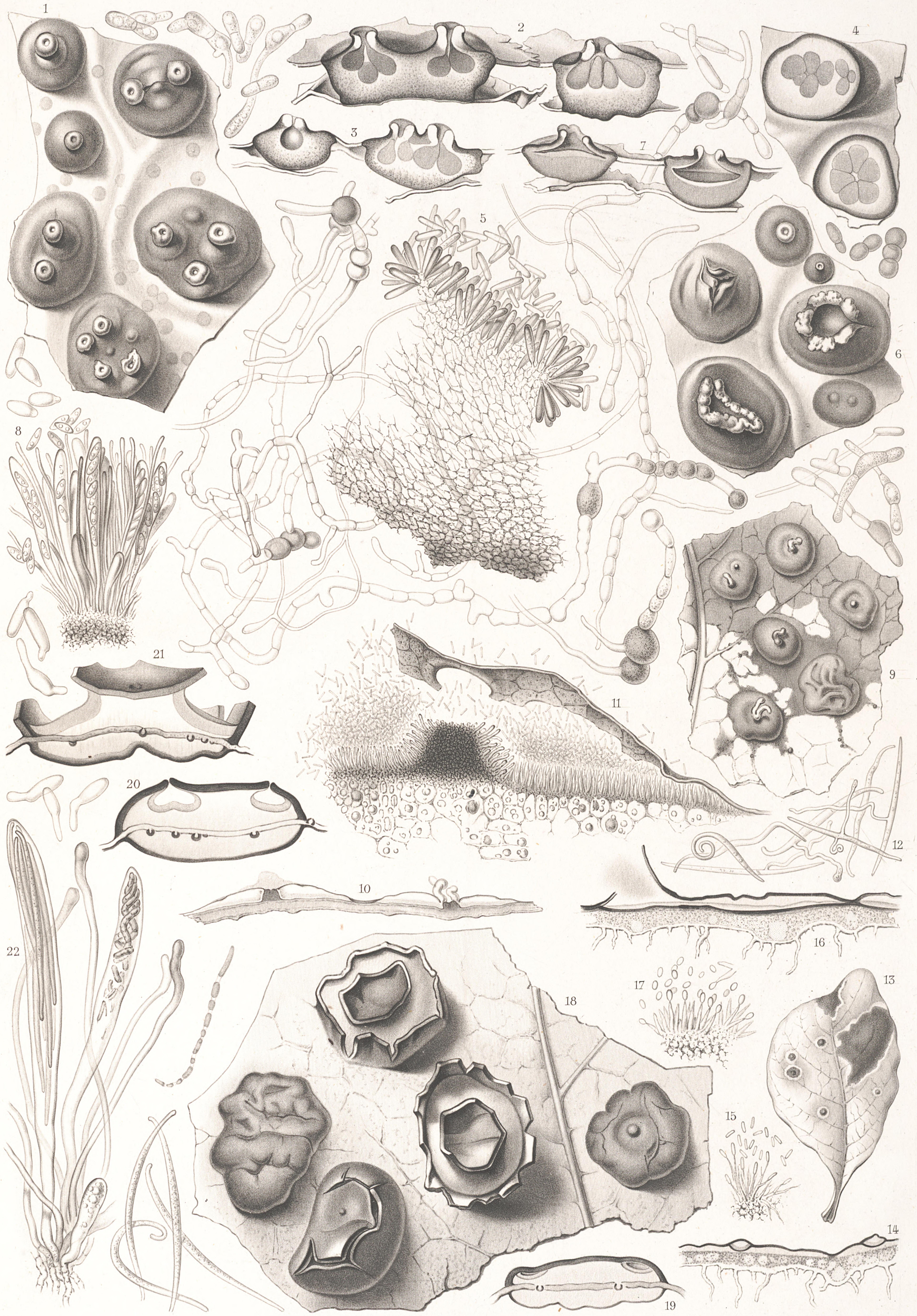


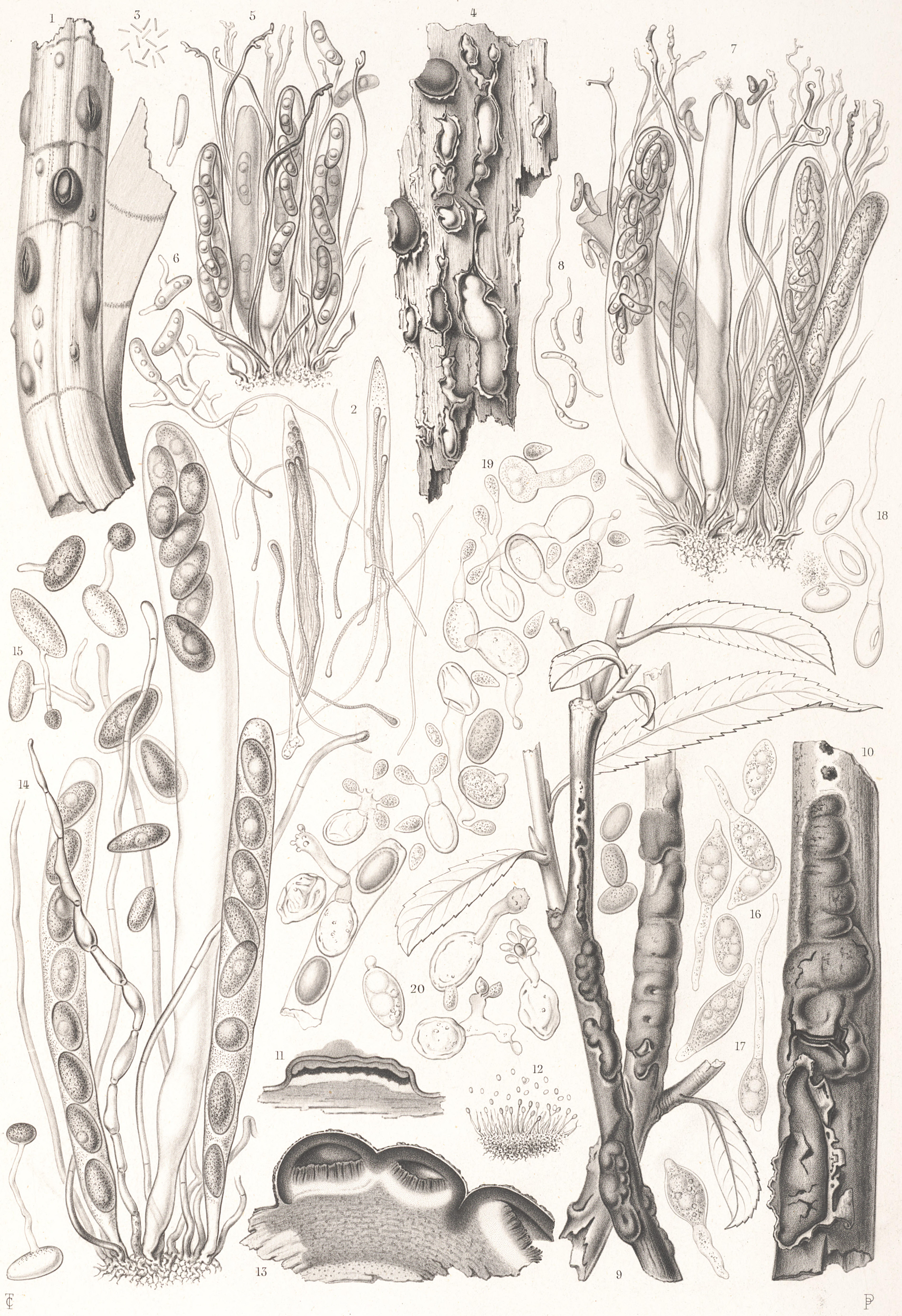

1-3. Hysterium Pinastri Schrad. 4-8. Stictis cinerascens Pers.

9-15. RHYTisma maximum FR. 16-18. MorcheLLA semilibera D C.

19 et 20 . Peziza vesiculosą Buld. 


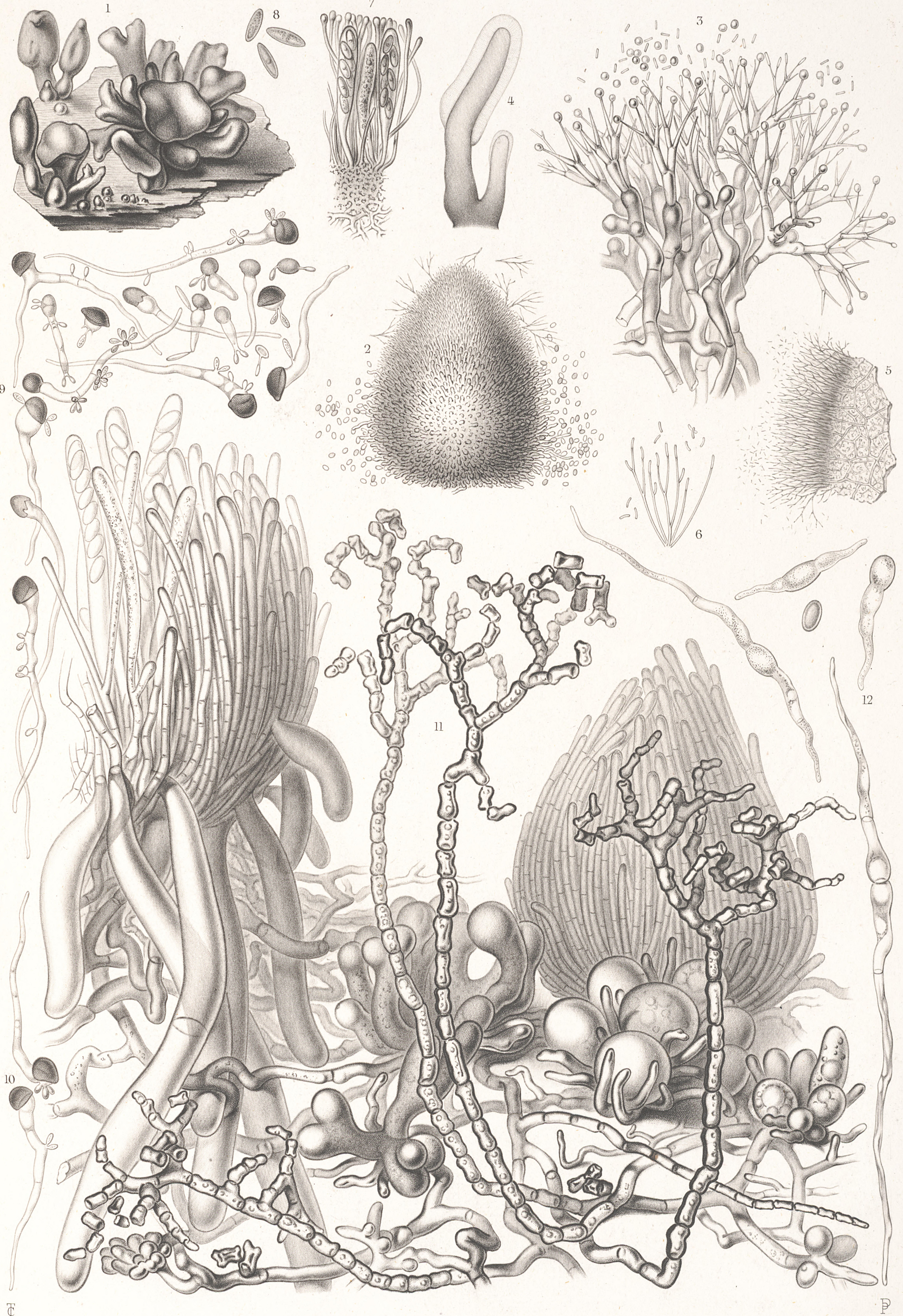




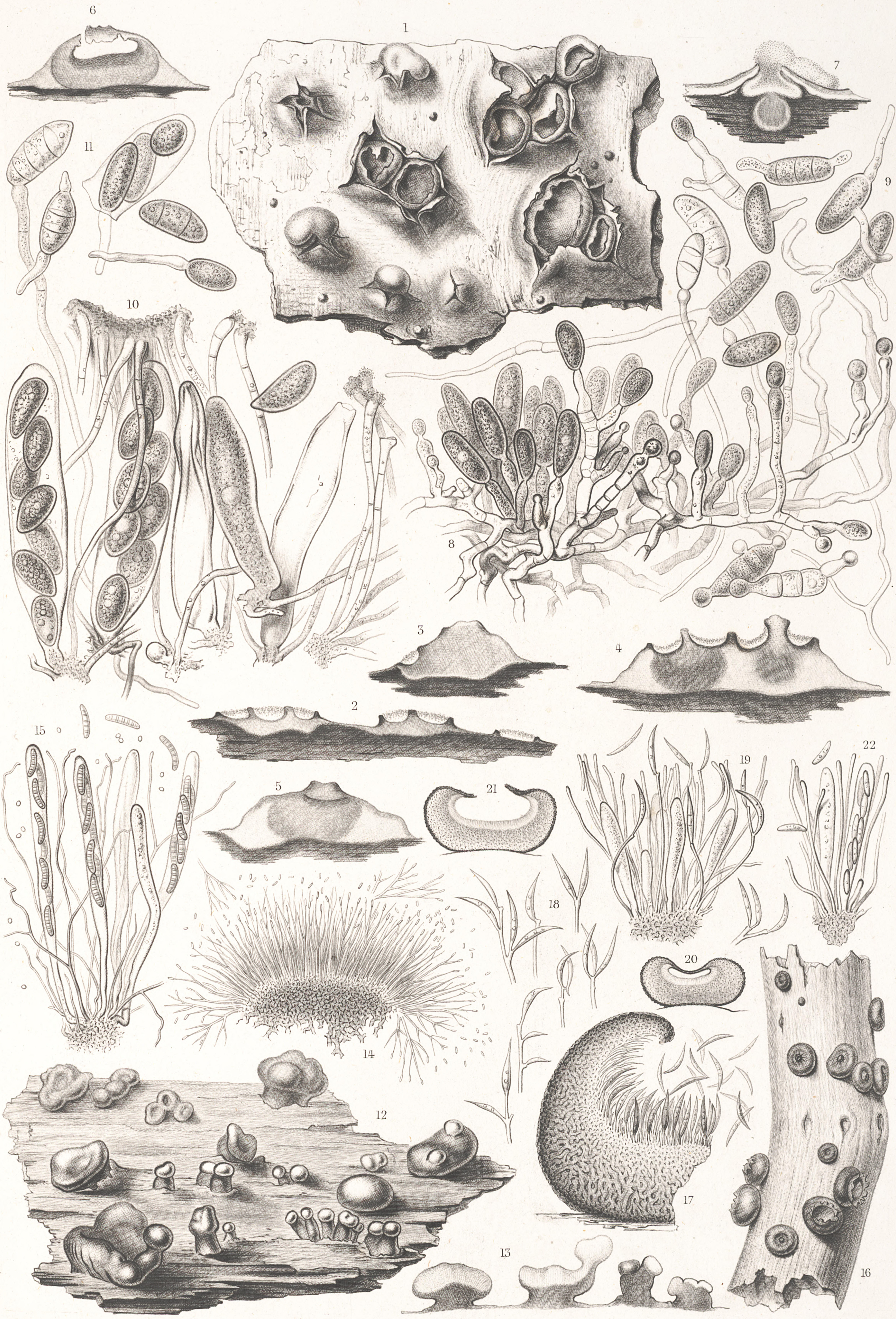




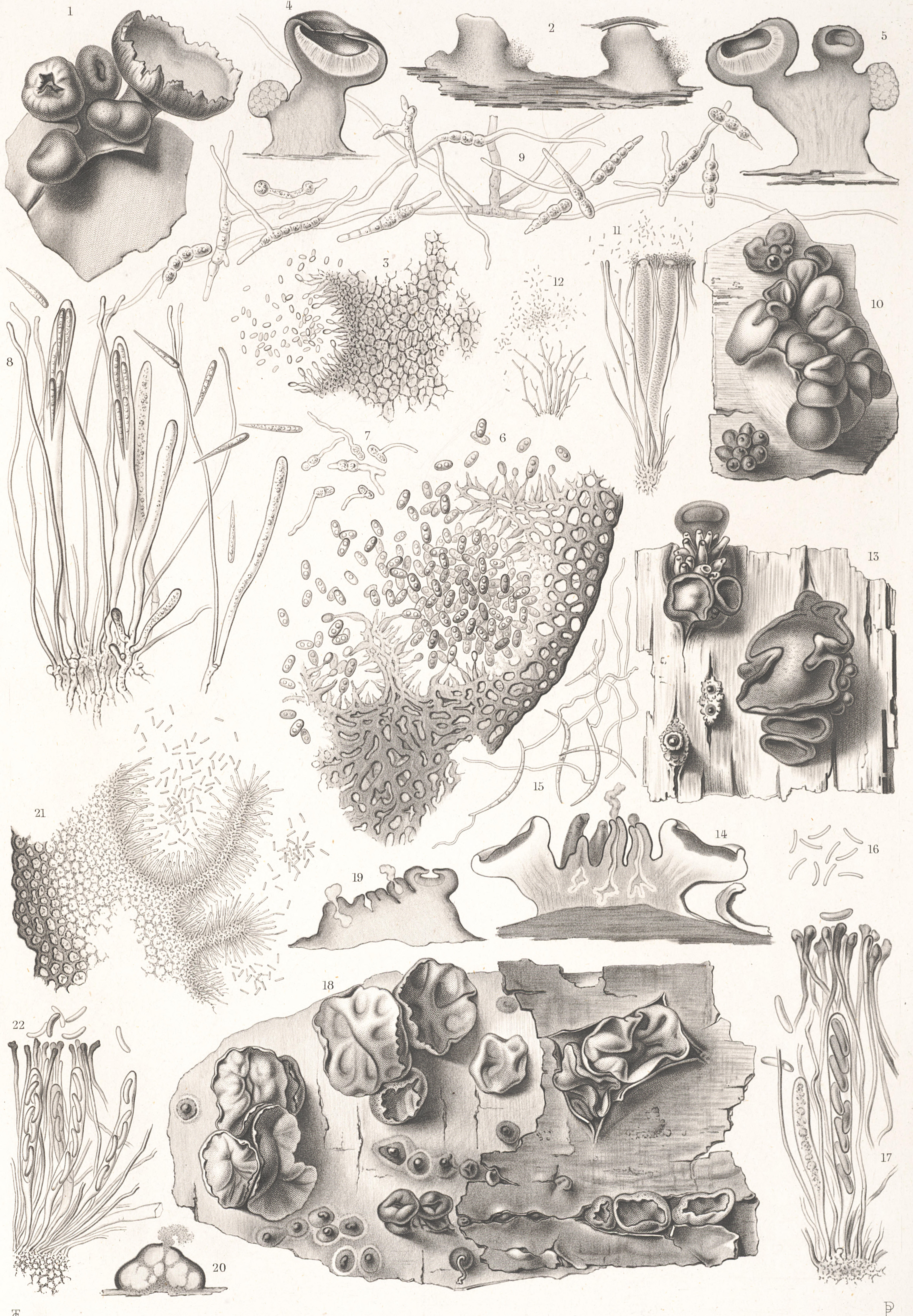

1-9. Chanangum Ribis Fr. 10-12. Tympanis Pinastri (Pers.)

13-17. Dermatea Cerasi Fir. 18-22. Cenangium umi Tur. 

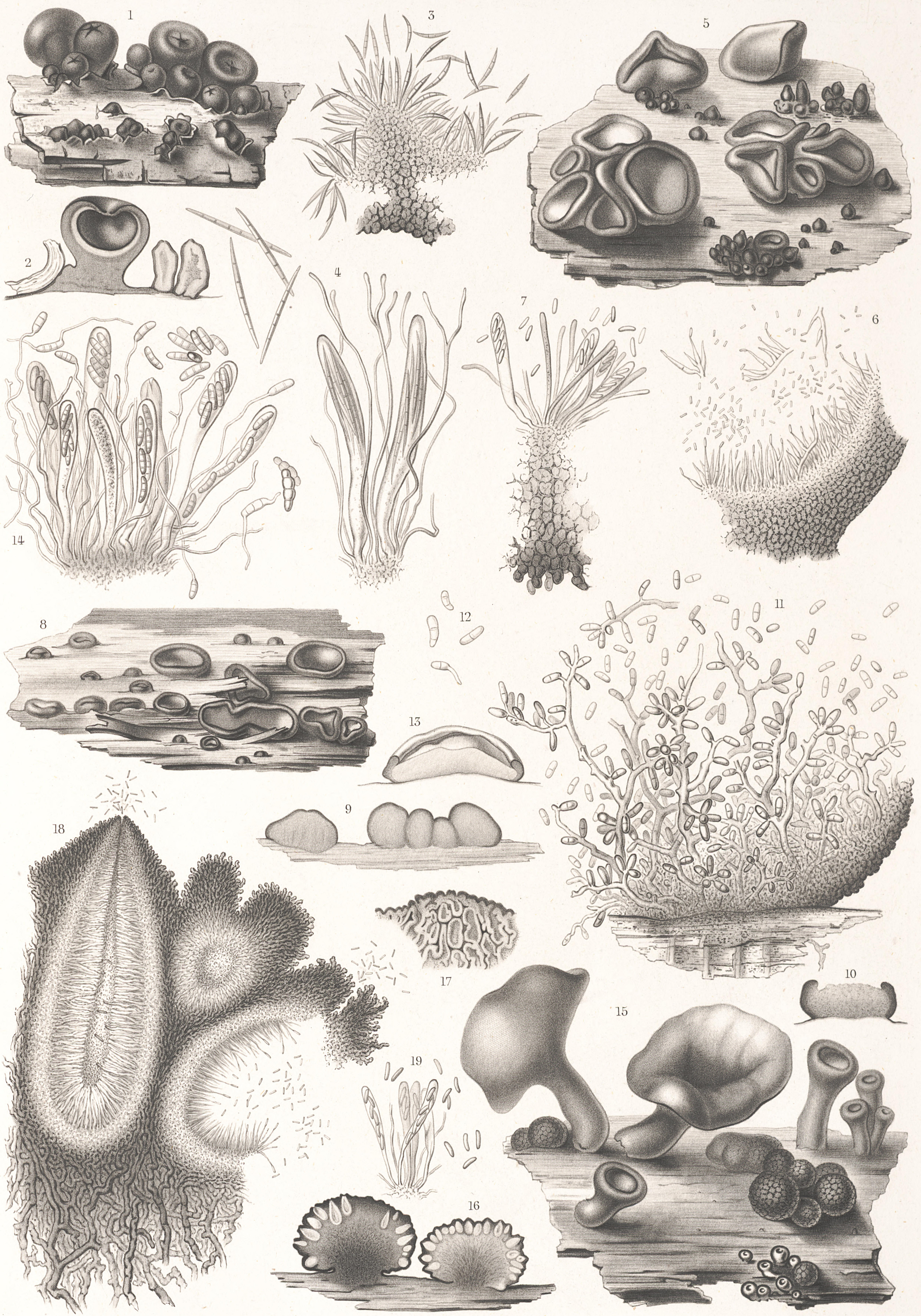

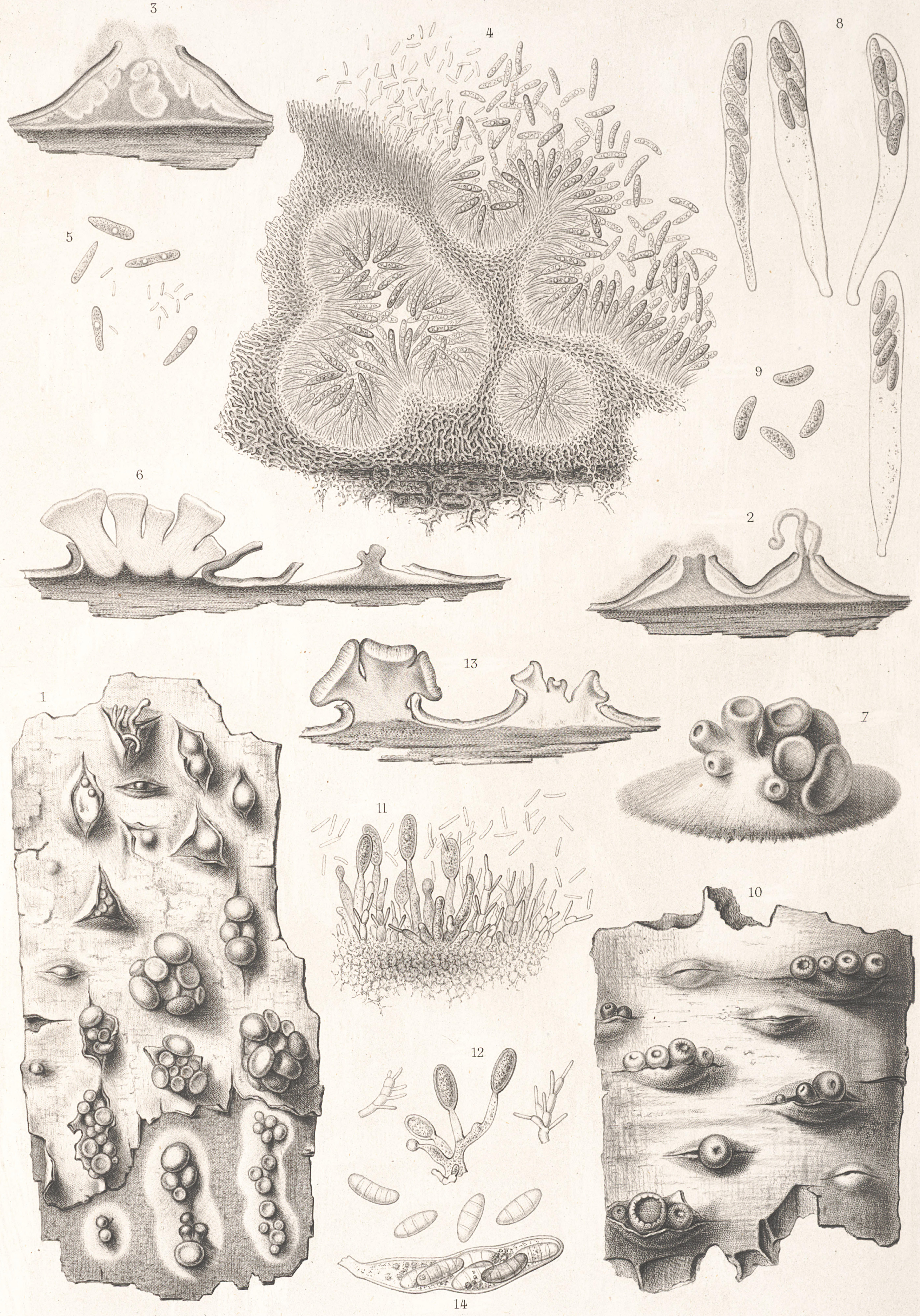


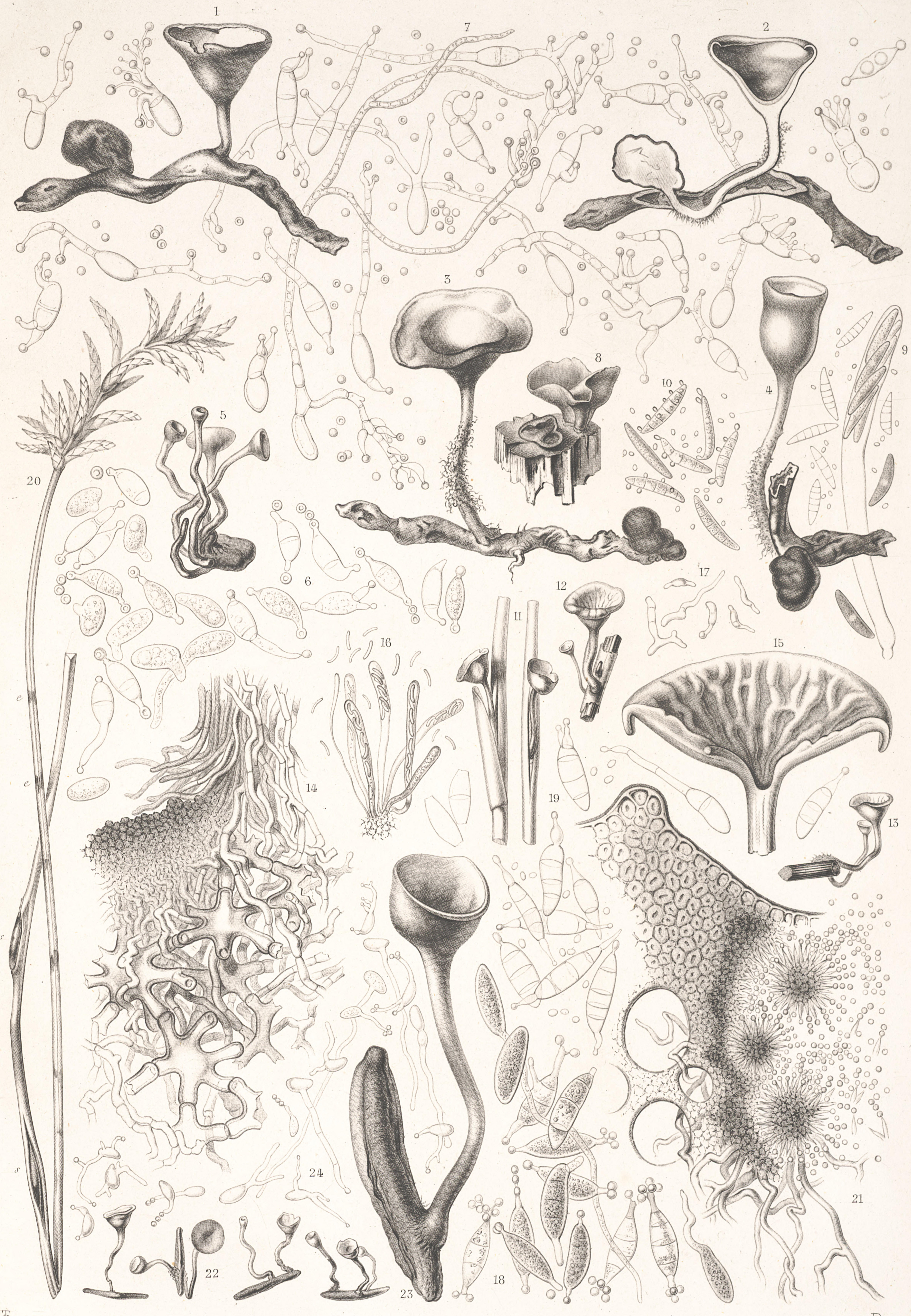

1-7. Peziza tuberosa Dicks. 8-10. P. Cylichnium Tul. 11-17. P. Curreiana Berk 